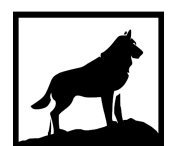

\begin{tabular}{llll|}
1 & 8 & 8 & 5 \\
\hline
\end{tabular}

\title{
A NOCSAE DROP TEST/ 3D-FEM STUDY ON THE RELATIONSHIP BETWEEN KINEMATIC RESPONSE OF THE HEAD, HEAD IMPACT CONTACT PRESSURE (HICP) AND KINETIC RESPONSE OF THE BRAIN TO DELINEATE THE RISK OF TRAUMATIC BRAIN INJURIES (TBI).
}

Raghavendra Krishna Tej Bhamidipati

Michigan Technological University, rbhamidi@mtu.edu

Copyright 2016 Raghavendra Krishna Tej Bhamidipati

\section{Recommended Citation}

Bhamidipati, Raghavendra Krishna Tej, "A NOCSAE DROP TEST/ 3D-FEM STUDY ON THE RELATIONSHIP BETWEEN KINEMATIC RESPONSE OF THE HEAD, HEAD IMPACT CONTACT PRESSURE (HICP) AND KINETIC RESPONSE OF THE BRAIN TO DELINEATE THE RISK OF TRAUMATIC BRAIN INJURIES (TBI).", Open Access Master's Thesis, Michigan Technological University, 2016.

https://doi.org/10.37099/mtu.dc.etdr/73

Follow this and additional works at: https://digitalcommons.mtu.edu/etdr

Part of the Biomechanical Engineering Commons, and the Computer-Aided Engineering and Design Commons 


\begin{abstract}
A NOCSAE DROP TEST/ 3D-FEM STUDY ON THE RELATIONSHIP BETWEEN KINEMATIC RESPONSE OF THE HEAD, HEAD IMPACT CONTACT PRESSURE (HICP) AND KINETIC RESPONSE OF THE BRAIN TO DELINEATE THE RISK OF TRAUMATIC BRAIN INJURIES (TBI).
\end{abstract}

\author{
By \\ Raghavendra Krishna Tej Bhamidipati
}

\begin{abstract}
A THESIS
Submitted in partial fulfillment of the requirements for the degree of MASTER OF SCIENCE

In Mechanical Engineering
\end{abstract}

MICHIGAN TECHNOLOGICAL UNIVERSITY

2016

(C) 2016 Raghavendra KrishnaTej Bhamidipati 
This thesis has been approved in partial fulfillment of the requirements for the Degree of MASTER OF SCIENCE in Mechanical Engineering

Department of Mechanical Engineering - Engineering Mechanics

Thesis Advisor: Dr.Gopal Jayaraman

Committee Member: Dr. V.C. Rao Komaravolu

Committee Member: Dr. Ibrahim Miskioglu

Committee Member: Dr. Allan A. Struthers

Department Chair: $\quad$ Dr. William Predebon 
People say that God can't be everywhere,

So

He created "Mother" ..........

To

My Mother ....... 


\section{Table of Contents}

List of Figures................................................................................................................................. $\mathrm{x}$

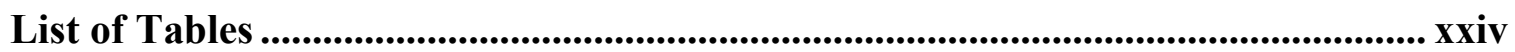

Abbreviations Used ................................................................................................................ xxvi

Acknowledgements ................................................................................................................. xxvii

Abstract................................................................................................................................. xxviii

Chapter 1 INTRODUCTION ....................................................................................... 1

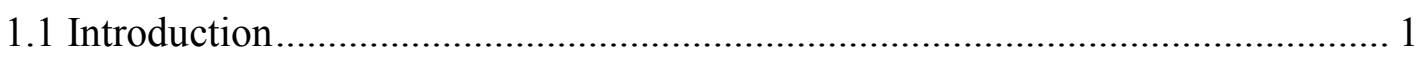

1.2 Demography of Head Injuries...................................................................... 3

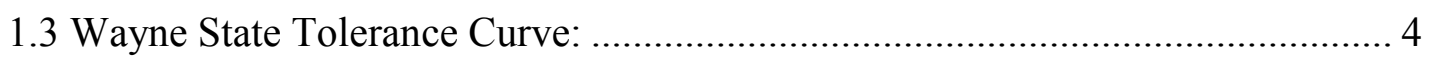

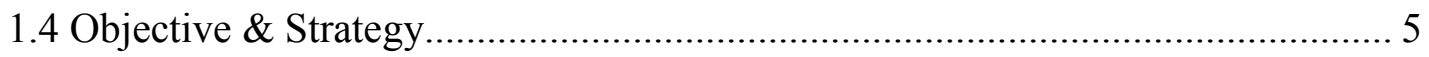

Chapter 2 BRAIN INJURIES................................................................................................. 7

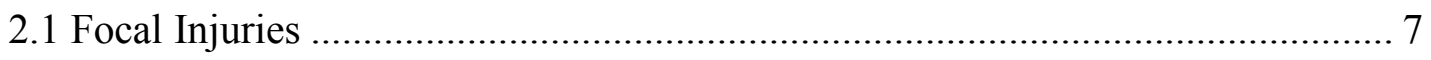

2.1.1 Contusion ......................................................................................................... 8

2.1.2 Epidural Hematoma .............................................................................................. 8

2.1.3 Subdural Hematoma................................................................................................. 8

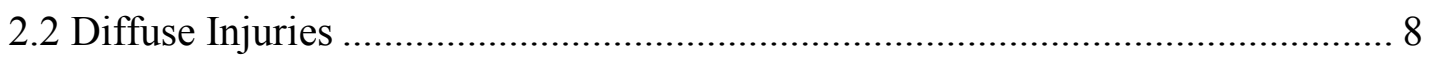

2.2.1 Concussion ....................................................................................................................... 8

2.2.2 Diffuse Axonal Injury ........................................................................................ 9

Chapter 3 EXPERIMENTS, RESULTS \& DISCUSSIONS........................................... 10

3.1 Experimental Procedure:_........................................................................... 10

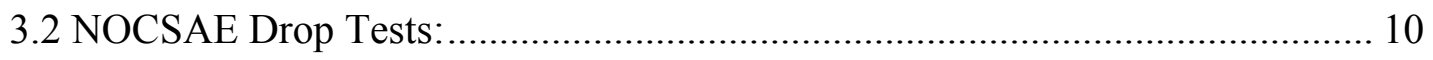




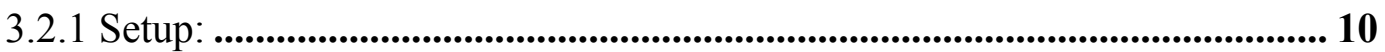

3.2.2 Head Linear Acceleration Curve ............................................................................ 11

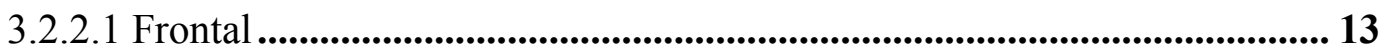

3.2.2.2 $45^{\circ}$ to Frontal: ............................................................................................ 15

3.2.2.3 Lateral: ............................................................................................................. 16

3.2.2.4 Posterior ............................................................................................................ 17

3.2.3 Measurement of Area of Impact ....................................................................... 20

3.2.4 Calculation of Impact Force and HICP............................................................ 22

3.2.5 Discussion ......................................................................................................... 24

3.3 Pressure Film and Topaq Analyzer.............................................................. 25

3.3.1 Pressure Films ................................................................................................. 25

3.3.2 Selection of Pressure Films................................................................................... 26

3.3.3 Topaq Analyzer........................................................................................... 26

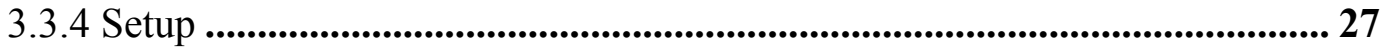

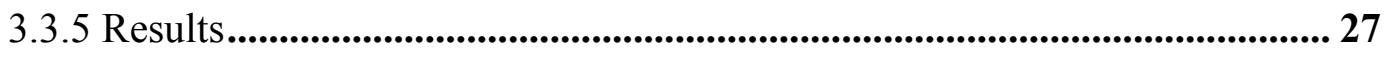

3.3.6 Discussions ........................................................................................................... 27

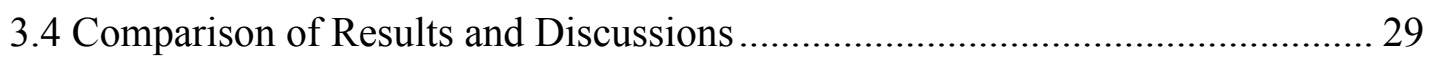

3.4.1 Comparison of HICP between Pressure films and Accelerometers.............. 29

3.4.2 HICP Plots ....................................................................................................... 32

3.4.2.1 Drop Height Vs. Maximum Linear Acceleration ............................. 32

3.4.2.2 Drop Heights Vs. Maximum HICP ………………........................... 33

3.4.2.3 Drop Height Vs. Maximum HICP Vs Maximum Linear Acceleration 


\section{Chapter 4 HICP VS STRESS DISTRIBUITION IN BRAIN BY FINITE}

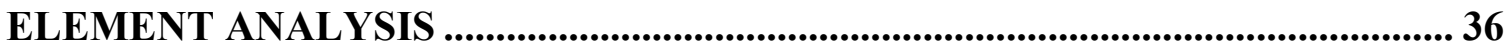

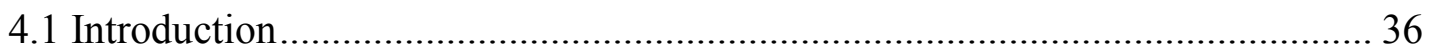

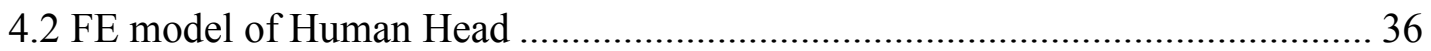

4.2.1 Material Properties.................................................................................................... 37

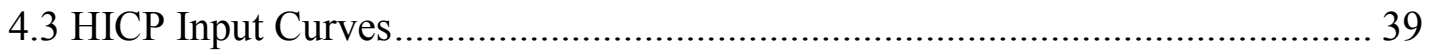

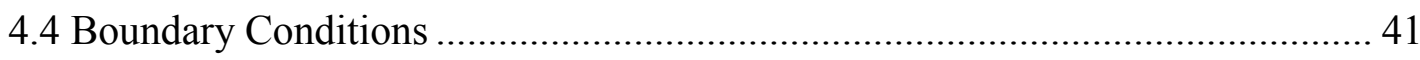

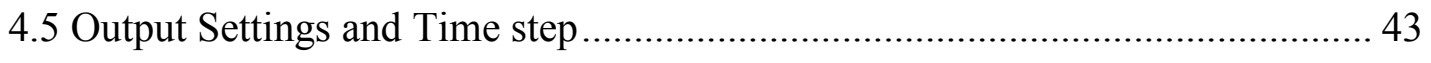

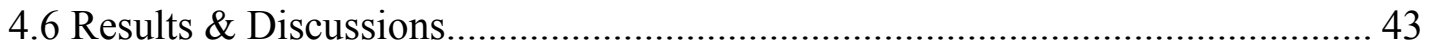

4.6.1 Frontal ............................................................................................................. 44

4.6.1.1 Drop Height of 2 feet ..................................................................... 44

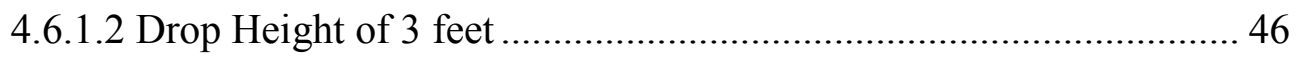

4.6.1.3 Drop Height of 4 feet ....................................................................... 48

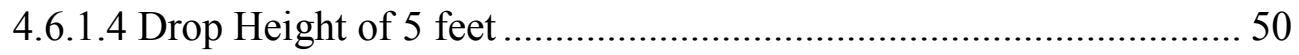

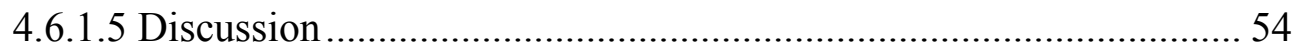

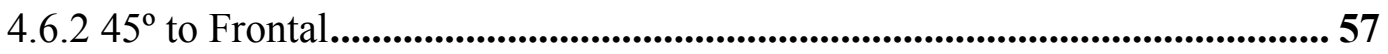

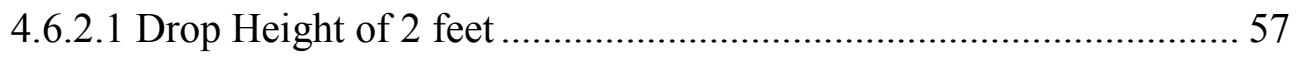

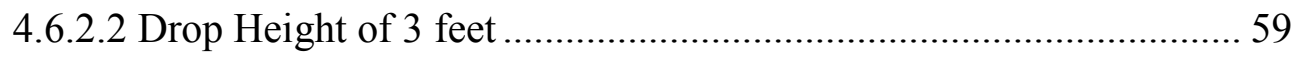

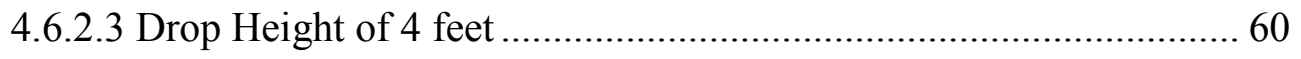

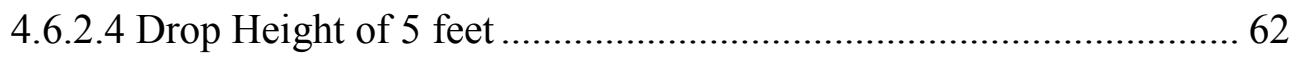

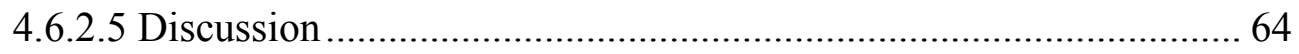

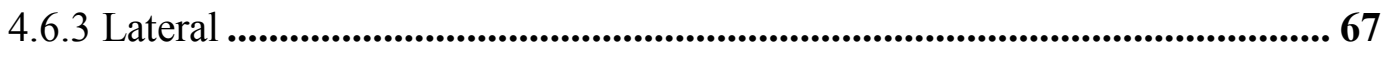

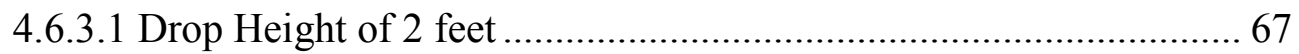


4.6.3.2 Drop Height of 3 feet ................................................................... 70

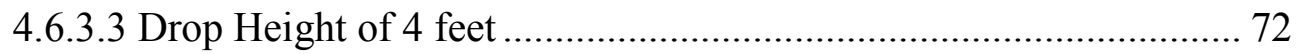

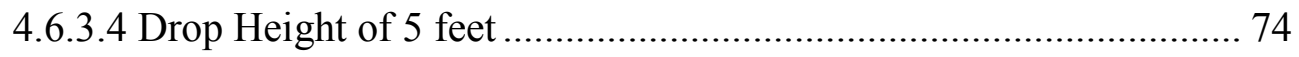

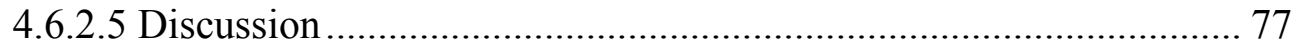

4.6.4 Posterior ....................................................................................................................... 80

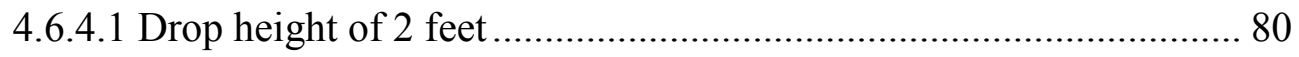

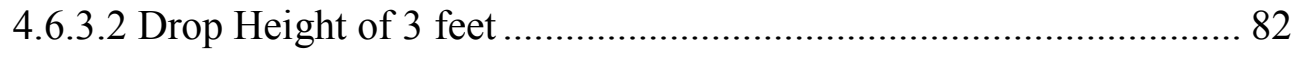

4.6.4.3 Drop Height of 4 feet ……………………………………….... 84

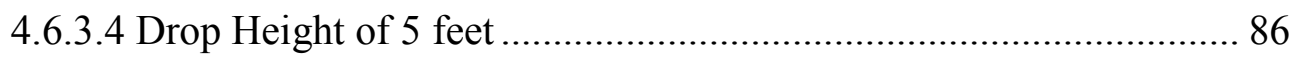

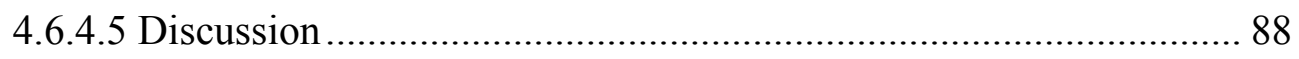

4.6.5 Overall Results Discussion ............................................................................. 91

\section{Chapter 5 CORRELATION BETWEEN HEAD ACCELERATION AND BRAIN}

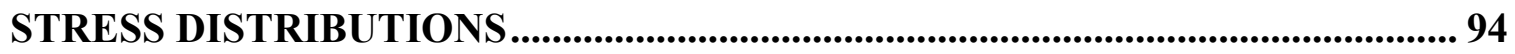

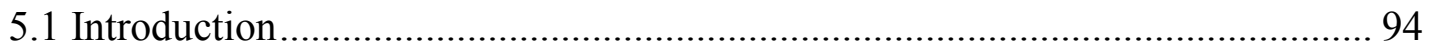

5.2 Determination of TBI Tolerance drop height using Maximum Shear stress ...... 94

5.3 Determination of TBI Tolerance drop height using Linear Accelerations .......... 98

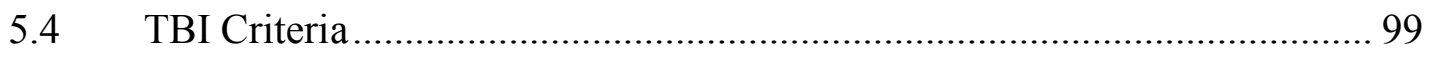

5.4.1 Frontal region of Impact .............................................................................. 100

5.4.2 $45^{\circ}$ to Frontal region of impact .......................................................................... 102

5.4.3 Lateral region of impact........................................................................... 104

5.4.4 Posterior region of impact............................................................................. 106

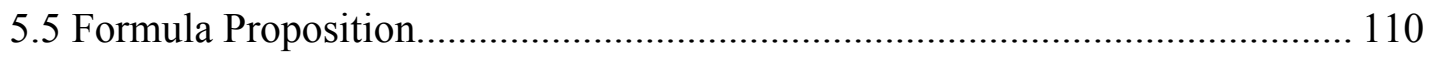

Chapter 6 CONCLUSIONS AND RECOMMENDATIONS ...................................... 113 


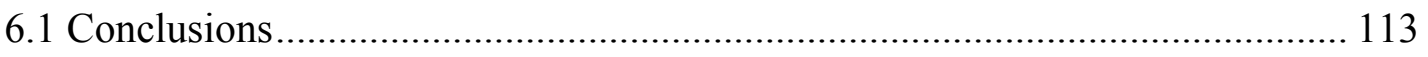

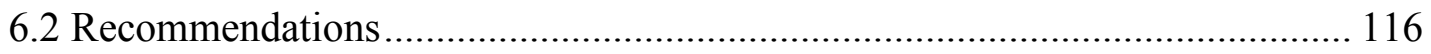

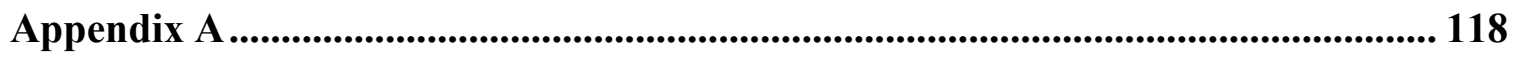

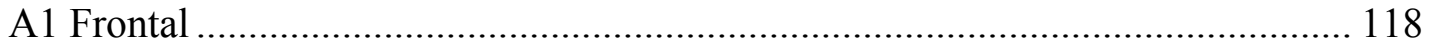

A1.1 Pressure film deformations .............................................................................. 118

A1.2 Topaq analyzer Outputs ....................................................................................... 119

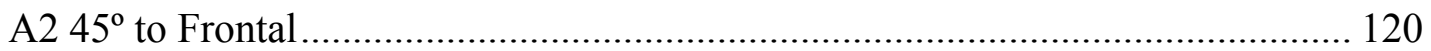

A2.1 Pressure film deformations ............................................................................. 120

A2.2 Topaq analyzer Outputs ................................................................................... 121

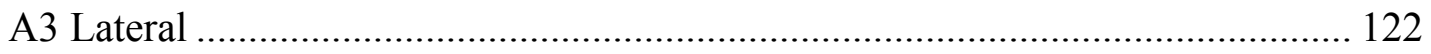

A3.1 Pressure film deformations ............................................................................ 122

A3.2 Topaq analyzer Outputs ........................................................................................ 123

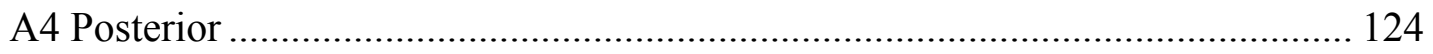

A4.1 Pressure film deformations .............................................................................. 124

A4.2 Topaq analyzer Outputs .................................................................................... 125

Appendix B ..................................................................................................................... 127

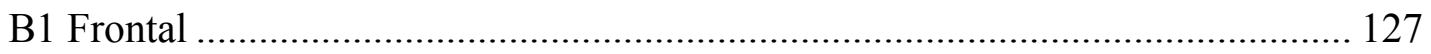

B1.1 Drop Height of 2 feet ......................................................................................... 127

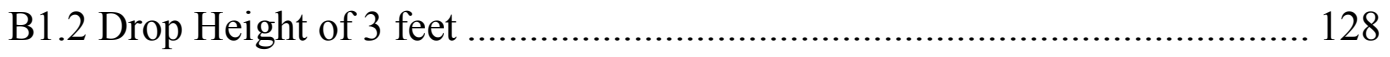

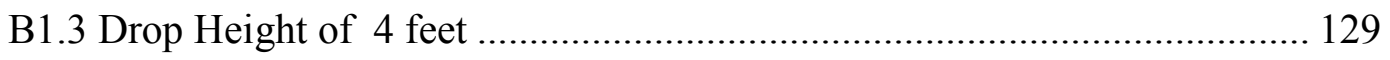

B1.4 Drop Height of 5 feet ...................................................................... 130

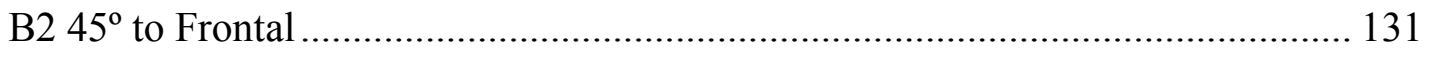

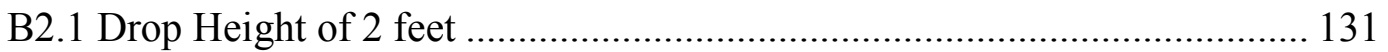

viii 


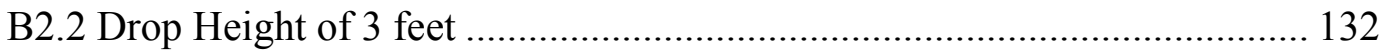

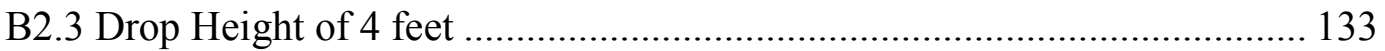

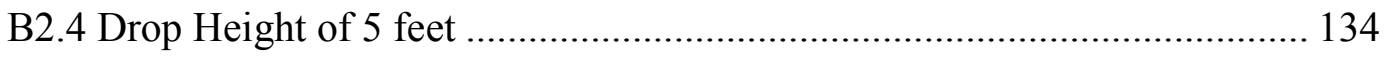

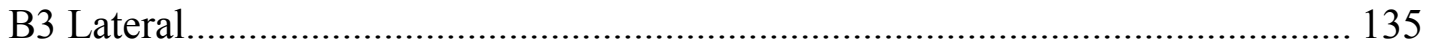

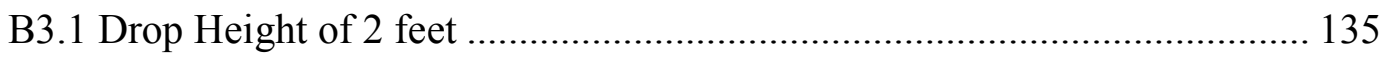

B3.2 Drop Height of 3 feet ...................................................................... 136

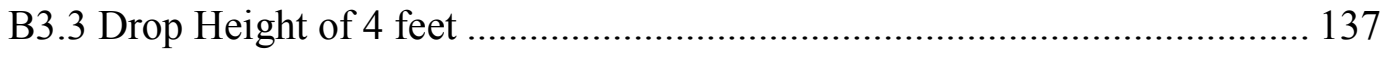

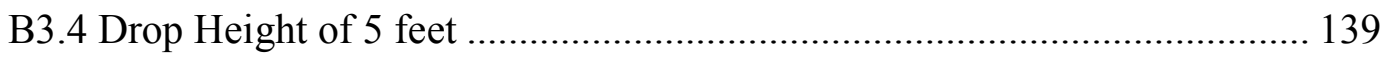

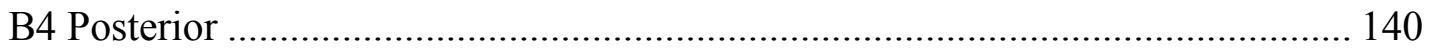

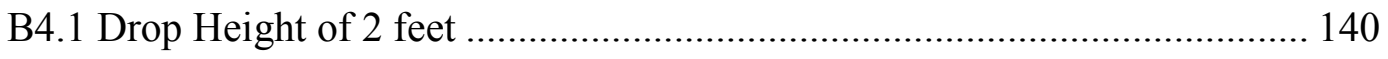

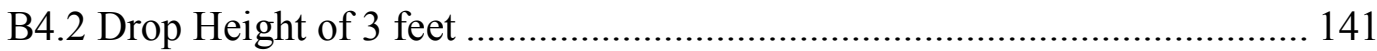

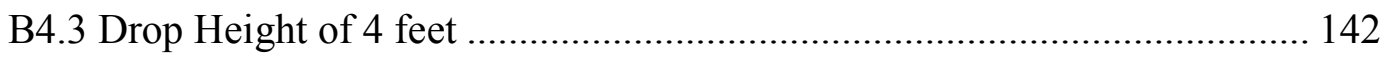

B4.4 Drop Height of 5 feet ................................................................... 143

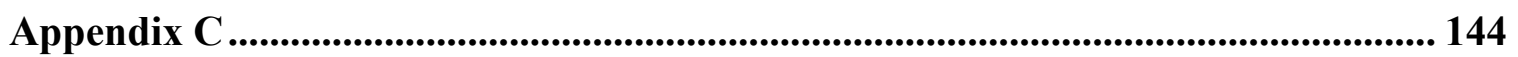

Appendix D ................................................................................................................. 155

References................................................................................................................................. 158 


\section{List of Figures}

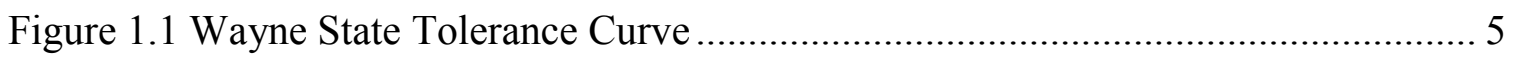

Figure 3.1 NOCSAE Drop Test Instrumentation at Michigan Tech ............................... 11

Figure 3.2 Linear Acceleration Plot obtained from the Siglab Unit .................................. 12

Figure 3.3 Headform with its X,Y,Z Axes................................................................. 13

Figure 3.4 Linear Acceleration curve for Frontal 2 feet drop......................................... 13

Figure 3.5 Linear Acceleration curve for Frontal 3 feet drop......................................... 14

Figure 3.6 Linear Acceleration curve for Frontal 4 feet drop........................................... 14

Figure 3.7 Linear Acceleration curve for Frontal 5 feet drop......................................... 14

Figure 3.8 Linear Acceleration curve for $45^{\circ}$ to Frontal 2 feet drop .............................. 15

Figure 3.9 Linear Acceleration curve for $45^{\circ}$ to Frontal 3 feet drop .............................. 15

Figure 3.10 Linear Acceleration curve for $45^{\circ}$ to Frontal 4 feet drop .............................. 15

Figure 3.11 Linear Acceleration curve for $45^{\circ}$ to Frontal 5 feet drop ............................ 16

Figure 3.12 Linear Acceleration curve for Lateral 2 feet drop ....................................... 16

Figure 3.13 Linear Acceleration curve for Lateral 3 feet drop ......................................... 16

Figure 3.14 Linear Acceleration curve for Lateral 4 feet drop ......................................... 17

Figure 3.15 Linear Acceleration curve for Lateral 5 feet drop ....................................... 17

Figure 3.16 Linear Acceleration curve for Posterior 2 feet drop ...................................... 17

Figure 3.17 Linear Acceleration curve for Posterior 3 feet drop ...................................... 18

Figure 3.18 Linear Acceleration curve for Posterior 4 feet drop ..................................... 18

Figure 3.19 Linear Acceleration curve for Posterior 5 feet drop ...................................... 18

Figure 3.20 Head form with chalk applied for Area measurement................................. 20

Figure 3.21 Projected Area of Impact on the Anvil................................................... 21

Figure 3.22 Explanation of working of a Pressure Film and C.S View of a Film........... 25

Figure 3.23 Maximum Linear Acceleration Vs Drop Height ........................................... 32

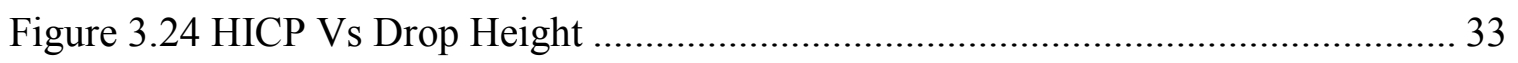

Figure 3.25 Plot of Drop height Vs HICP Vs Linear Acceleration for Frontal region of

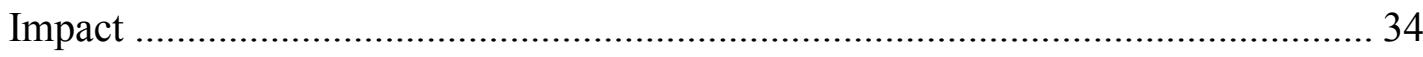


Figure 3.26 Plot of Drop height Vs HICP Vs Linear Acceleration for 45 to Frontal region of Impact 34

Figure 3.27 Plot of Drop Height Vs HICP Vs Linear Acceleration for Lateral region of Impact 35

Figure 3.28 Plot of Drop Height Vs HICP Vs Linear Acceleration for Lateral region of Impact 35

Figure 4.1 Meshed 3D form Model with Impact Areas Marked on it ............................ 37

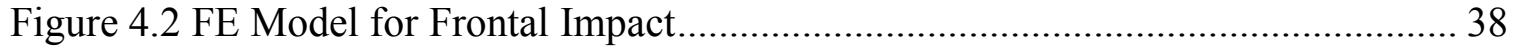

Figure 4.3 FE Model for 45 to Frontal Impact.......................................................... 38

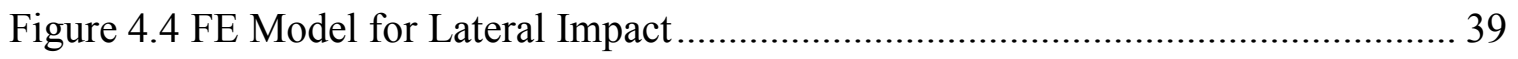

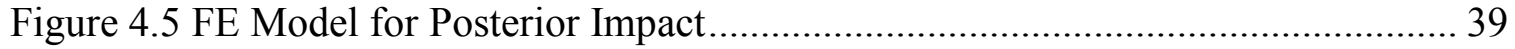

Figure 4.6 Impact Pressure Curves for Impact in Frontal Region ................................ 40

Figure 4.7 Impact Pressure Curves for Impact in 45 to Frontal Region ......................... 40

Figure 4.8 Impact Pressure Curves for Impact in Lateral Region ................................ 41

Figure 4.9 Impact Pressure Curves for Impact in Posterior Region .............................. 41

Figure 4.10 Unit Spring elements connecting skull to the Ground point ....................... 42

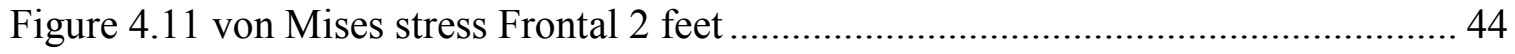

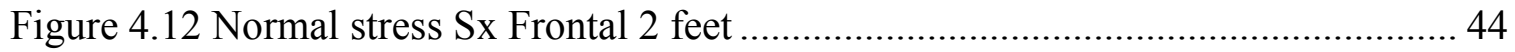

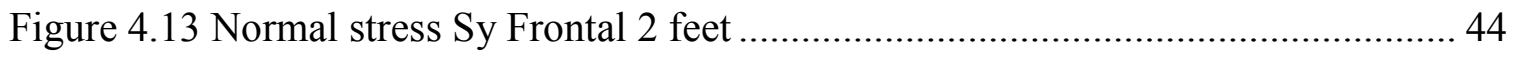

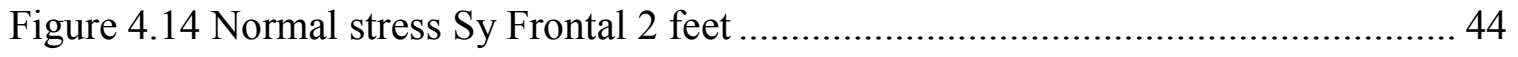

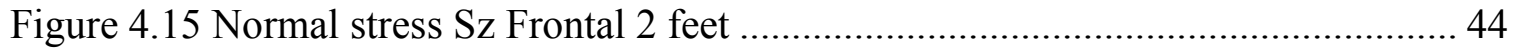

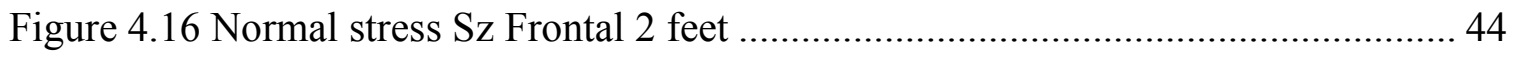

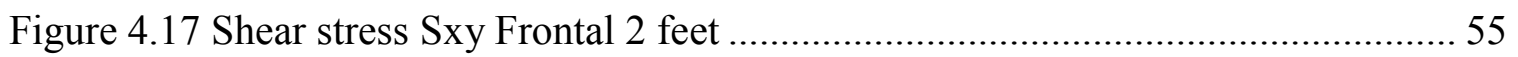

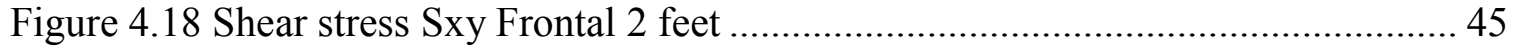

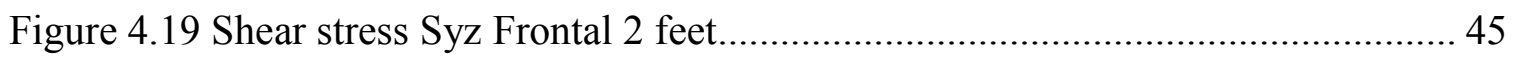

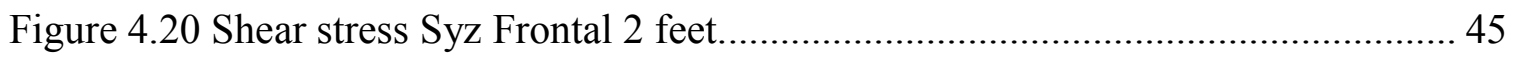

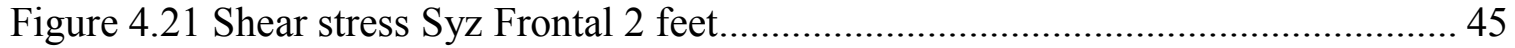

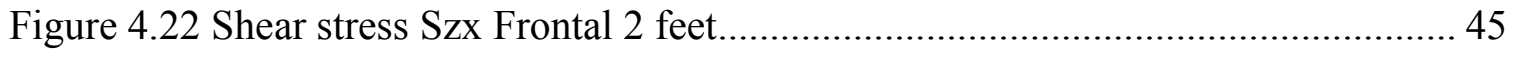

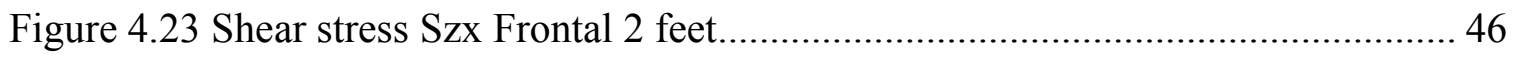

Figure 4.24 Shear stress Szx Frontal 2 feet............................................................. 46 
Figure 4.25 Normal stress Sx Frontal 3 feet ............................................................. 46

Figure 4.26 Normal stress Sx Frontal 3 feet ................................................................. 46

Figure 4.27 Normal stress Sy Frontal 3 feet ............................................................... 46

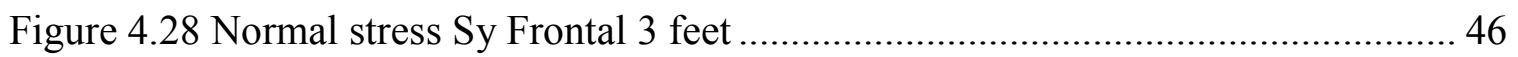

Figure 4.29 Normal stress Sz Frontal 3 feet ………….............................................. 47

Figure 4.30 von Mises stress Frontal 3 feet ............................................................. 47

Figure 4.31 Shear stress Sxy Frontal 3 feet ............................................................. 57

Figure 4.32 Shear stress Sxy Frontal 3 feet .................................................................. 47

Figure 4.33 Shear stress Syz Frontal 3 feet................................................................ 47

Figure 4.34 Shear stress Syz Frontal 3 feet............................................................... 47

Figure 4.35 Shear stress Szx Frontal 3 feet............................................................... 48

Figure 4.36 Shear stress Szx Frontal 3 feet................................................................. 48

Figure 4.37 von Mises stress Frontal 4 feet .............................................................. 48

Figure 4.38 Normal stress Sx Frontal 4 feet ............................................................. 48

Figure 4.39 Normal stress Sx Frontal 4 feet ............................................................ 48

Figure 4.40 Normal stress Sx Frontal 4 feet ............................................................. 48

Figure 4.41 Normal stress Sy Frontal 4 feet ............................................................... 49

Figure 4.42 Normal stress Sy Frontal 4 feet ............................................................. 49

Figure 4.43 Normal stress Sz Frontal 4 feet ............................................................... 49

Figure 4.44 Shear stress Sxy Frontal 4 feet ........................................................... 59

Figure 4.45 Shear stress Sxy Frontal 4 feet ................................................................. 49

Figure 4.46 Shear stress Sxy Frontal 4 feet ................................................................ 49

Figure 4.47 Shear stress Syz Frontal 4 feet............................................................. 50

Figure 4.48 Shear stress Syz Frontal 4 feet............................................................. 50

Figure 4.49 Shear stress Szx Frontal 4 feet................................................................. 50

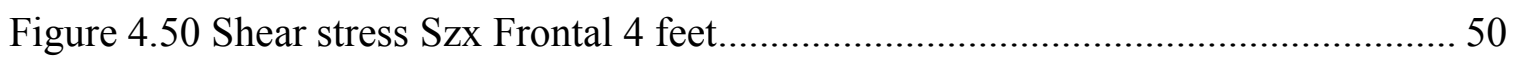

Figure 4.51 von Mises stress Frontal 5 feet .............................................................. 50

Figure 4.52 Normal stress Sx Frontal 5 feet .......................................................... 50

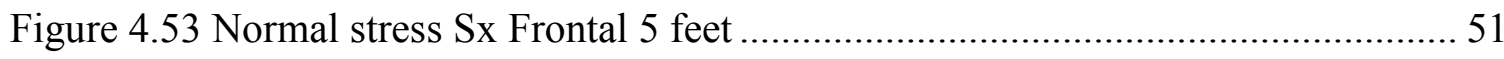

Figure 4.54 Normal stress Sx Frontal 5 feet ................................................................. 51 


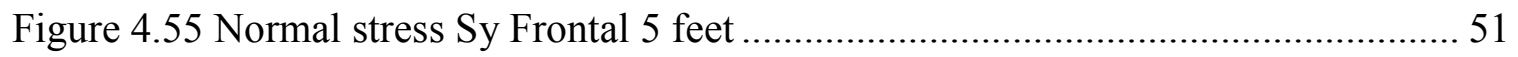

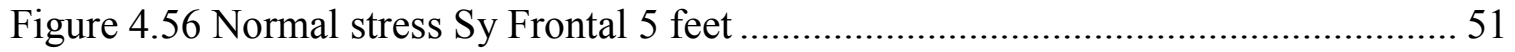

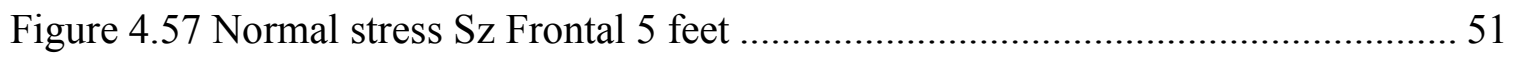

Figure 4.58 Shear stress Sxy Frontal 5 feet ............................................................... 51

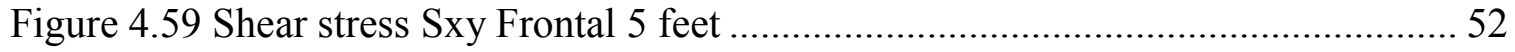

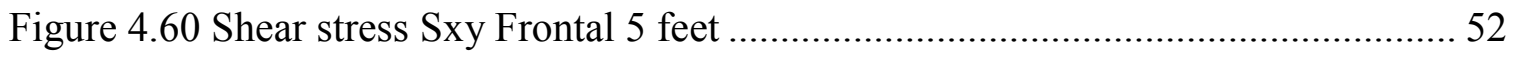

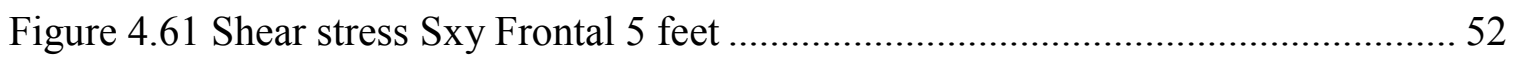

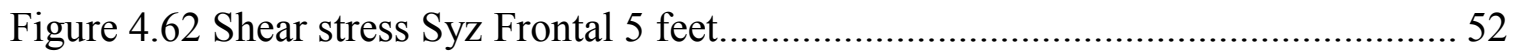

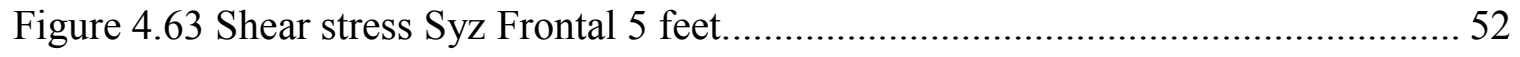

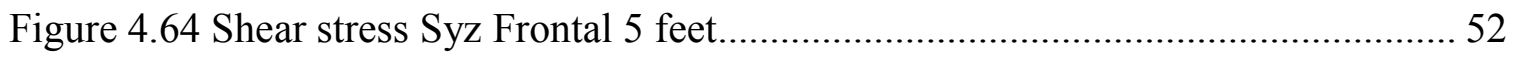

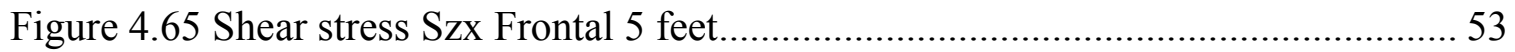

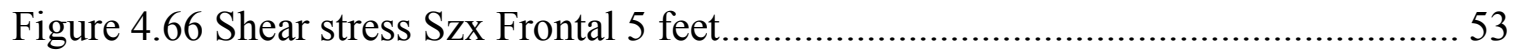

Figure 4.67 Comparison of Pressure on brain and HICP during Frontal Impact ............ 55

Figure 4.68 Maximum Principal stress (Tension) and von Mises Stress on brain obtained from FE Simulation of Frontal Impacts ........................................................... 55

Figure 4.69 Stress Variation on brain with respect to drop height during Frontal Impact 56

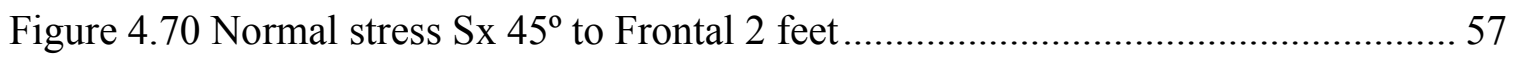

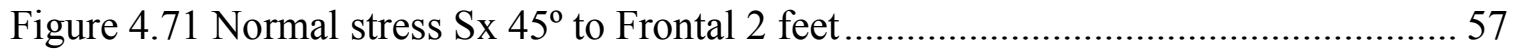

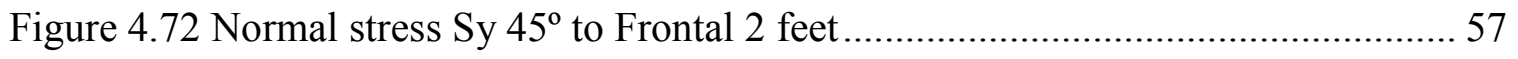

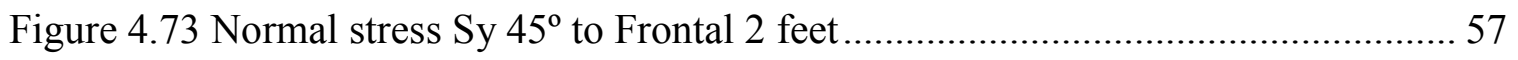

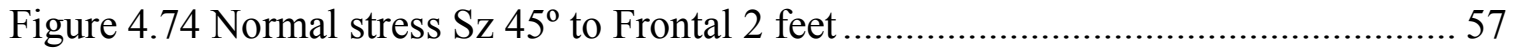

Figure 4.75 von Mises stress $45^{\circ}$ to Frontal 2 feet ................................................... 57

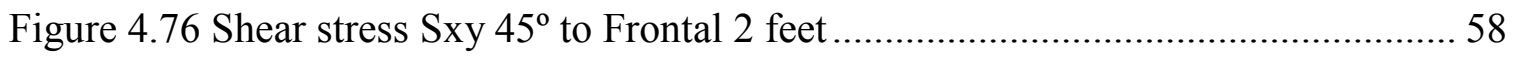

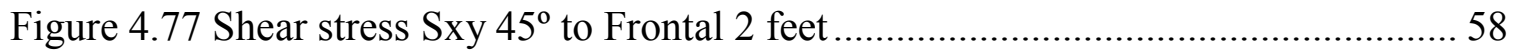

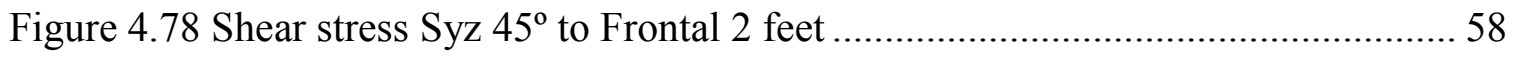

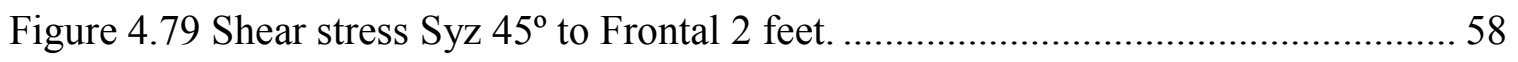

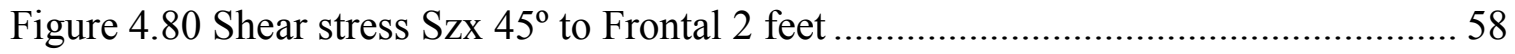

Figure 4.81 Shear stress Szx $45^{\circ}$ to Frontal 2 feet .................................................. 58

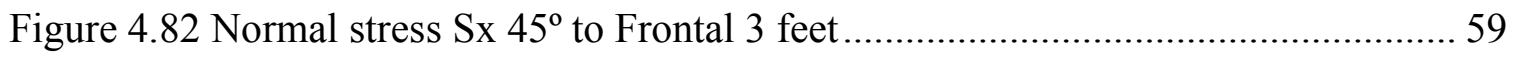

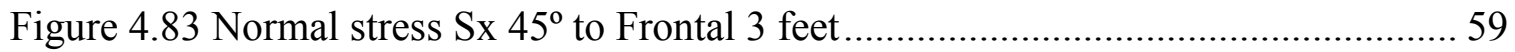




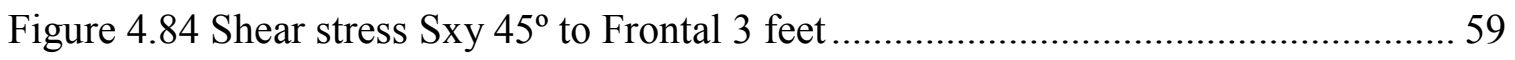

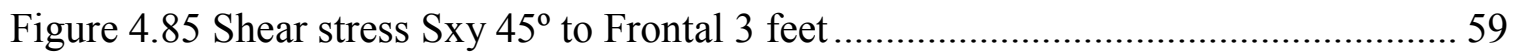

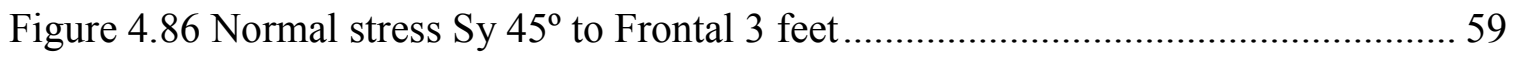

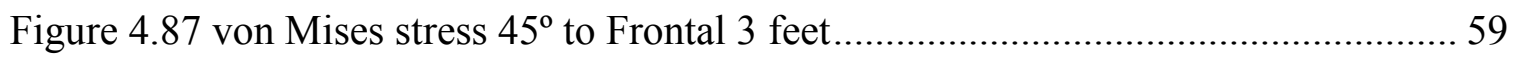

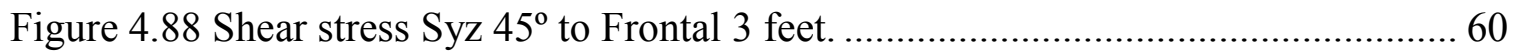

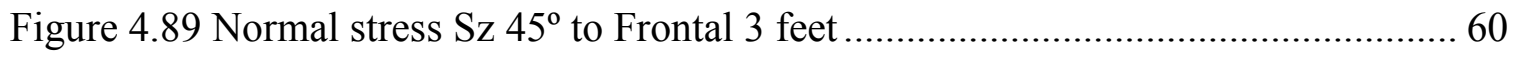

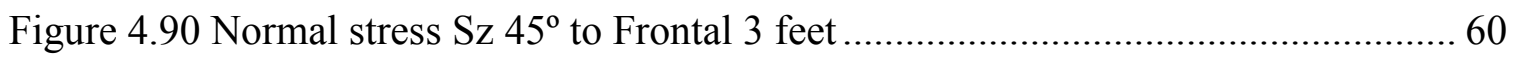

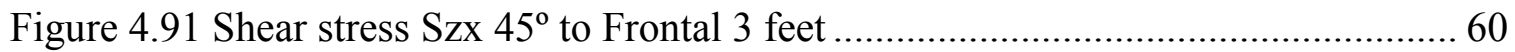

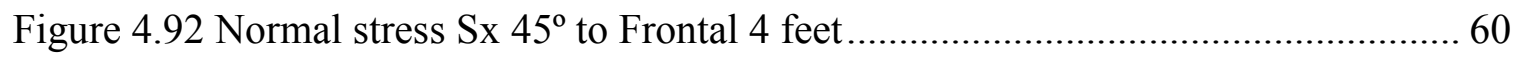

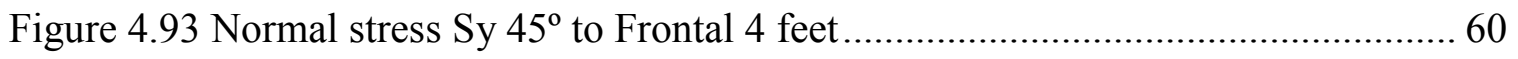

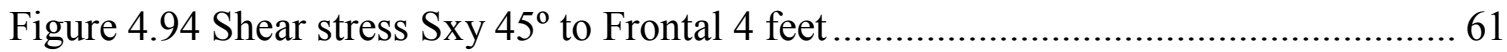

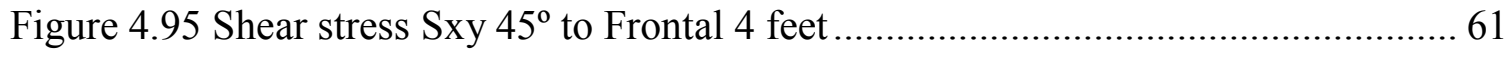

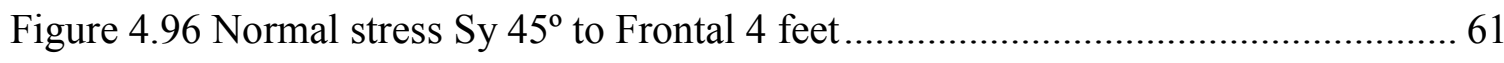

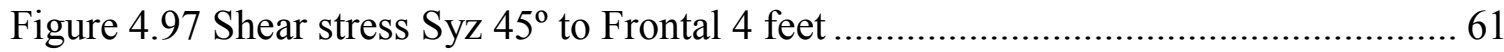

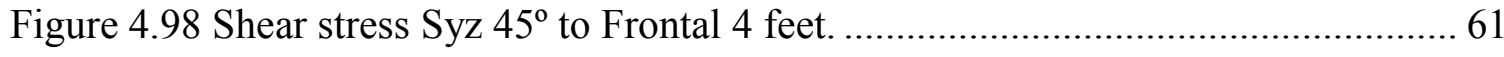

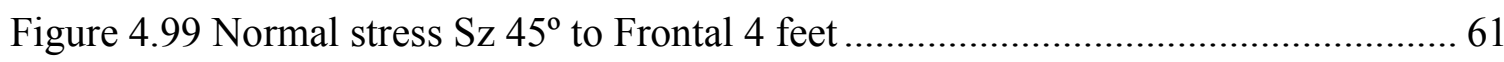

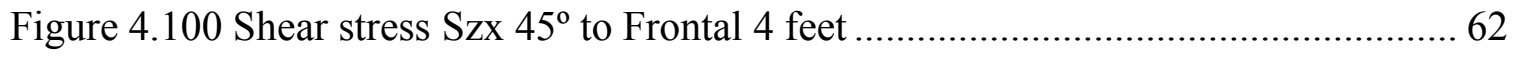

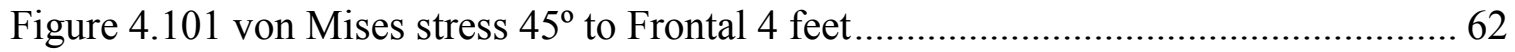

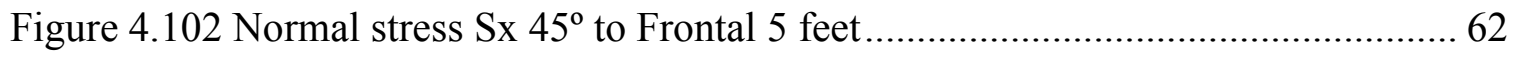

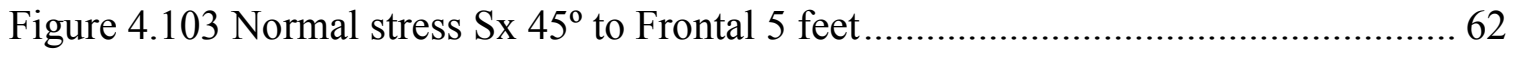

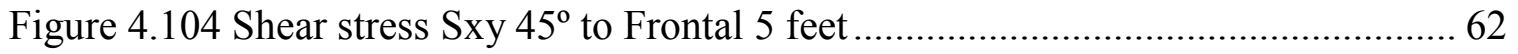

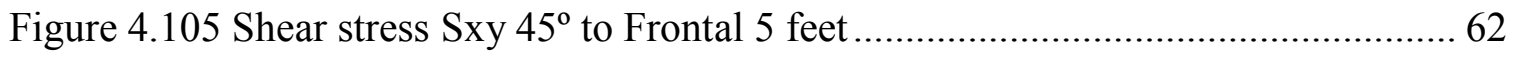

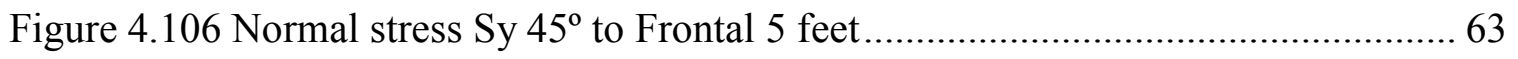

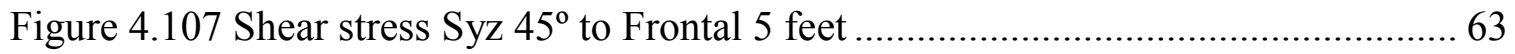

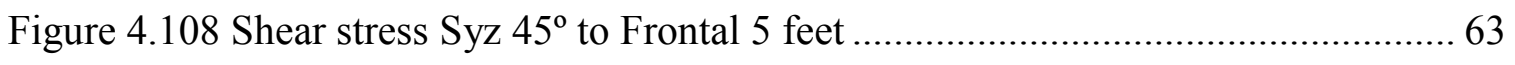

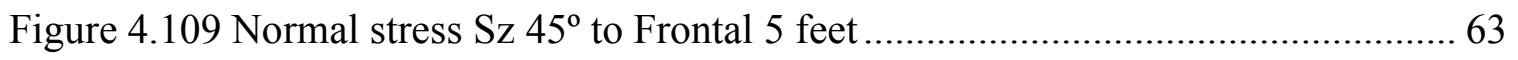

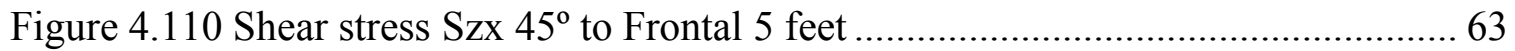

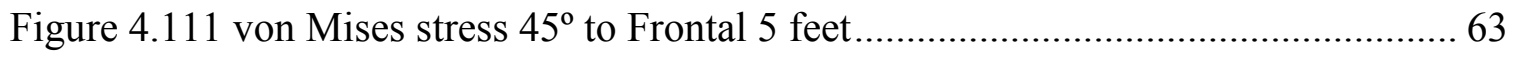

Figure 4.112 Comparison of Pressure on brain and HICP during $45^{\circ}$ to Frontal Impact . 65 
Figure 4.113 Maximum Principal stress (Tension) and von Mises Stress on brain obtained from FE Simulation of $45^{\circ}$ to Frontal Impacts 65

Figure 4.114 Stress Variation on brain with respect to drop height during $45^{\circ}$ to Frontal

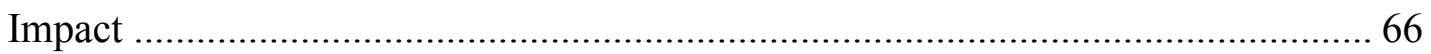

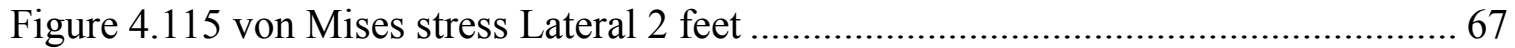

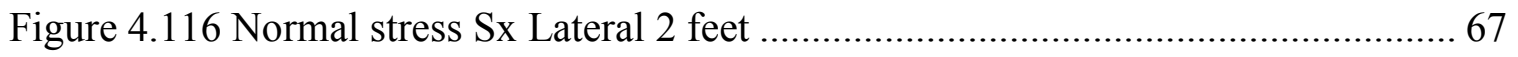

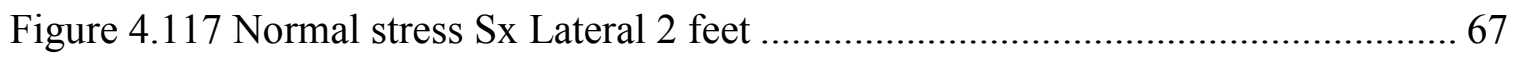

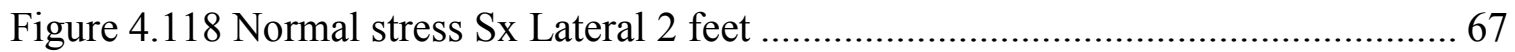

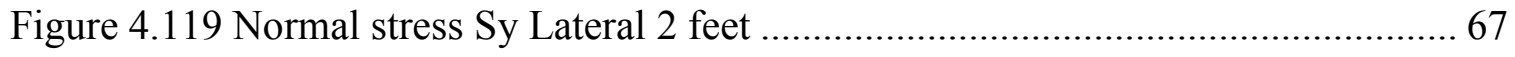

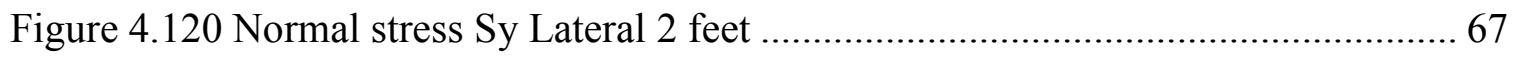

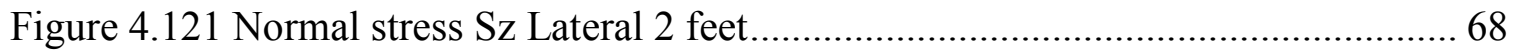

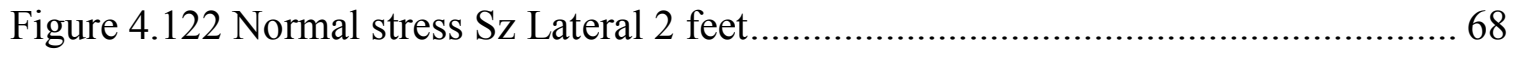

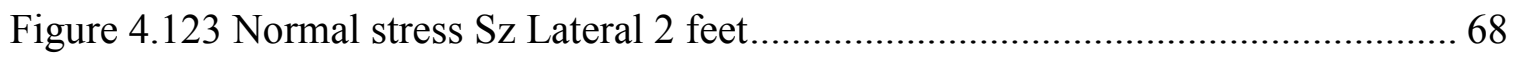

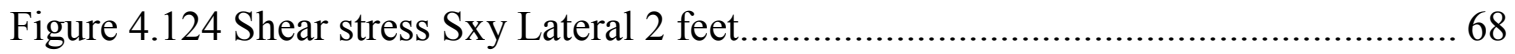

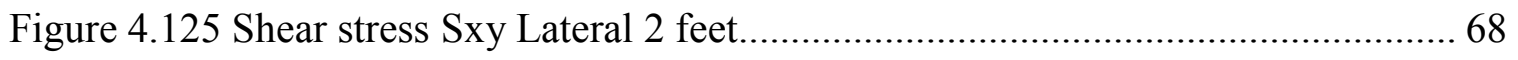

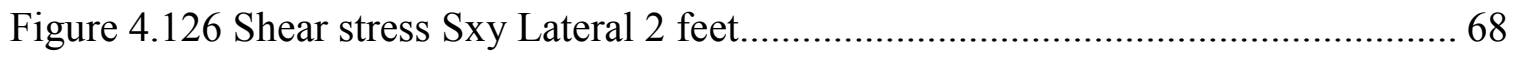

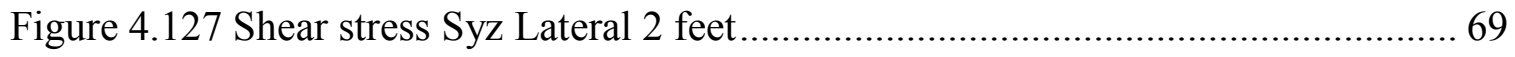

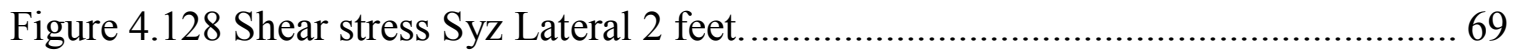

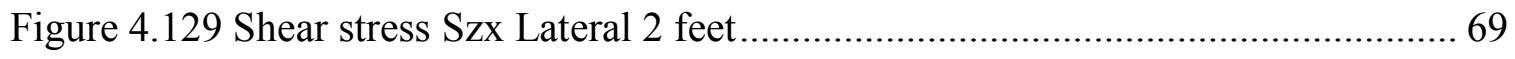

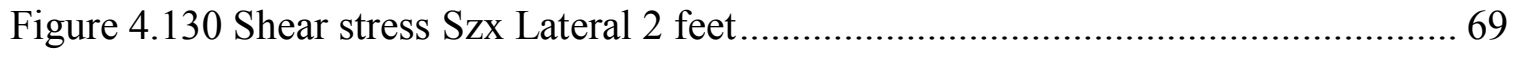

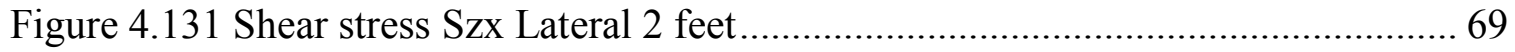

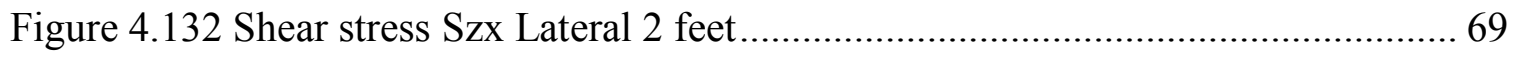

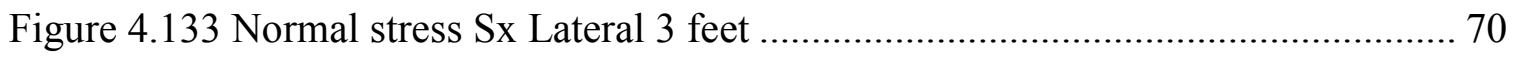

Figure 4.134 Normal stress Sx Lateral 3 feet ............................................................. 70

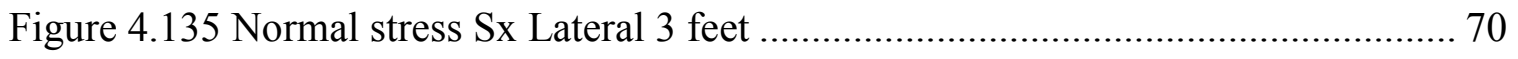

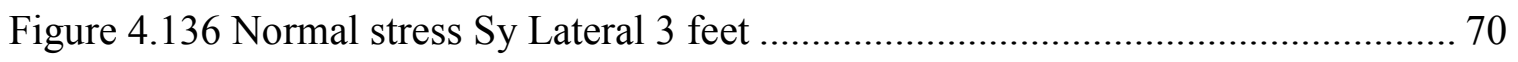

Figure 4.137 Normal stress Sz Lateral 3 feet........................................................... 70

Figure 4.138 Normal stress Sz Lateral 3 feet..................................................... 70

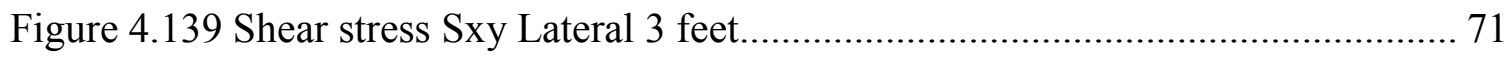

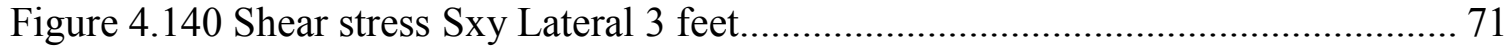




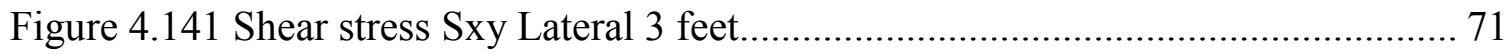

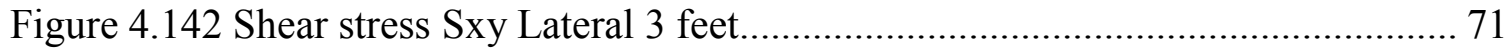

Figure 4.143 Shear stress Syz Lateral 3 feet........................................................... 71

Figure 4.144 Shear stress Syz Lateral 3 feet.......................................................... 71

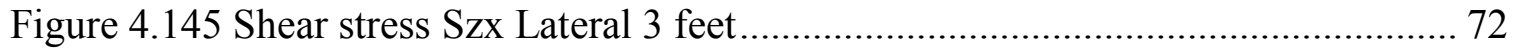

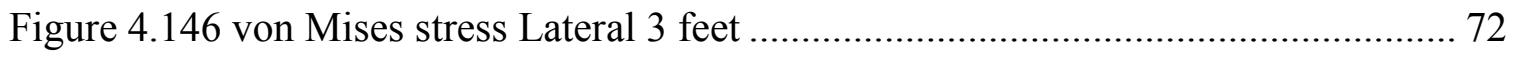

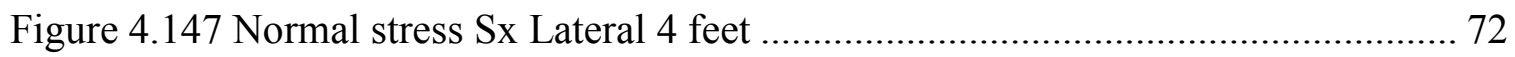

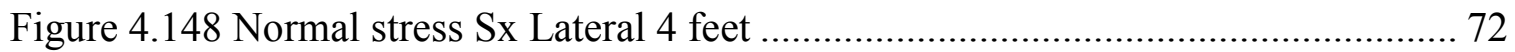

Figure 4.149 Normal stress Sx Lateral 4 feet .......................................................... 72

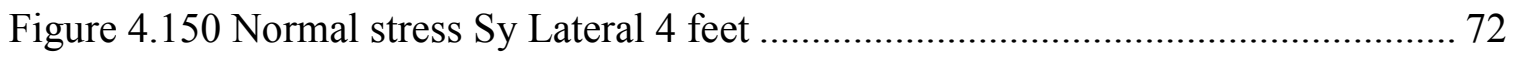

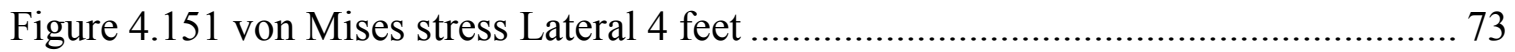

Figure 4.152 Normal stress Sz Lateral 4 feet........................................................... 73

Figure 4.153 Shear stress Sxy Lateral 4 feet......................................................... 73

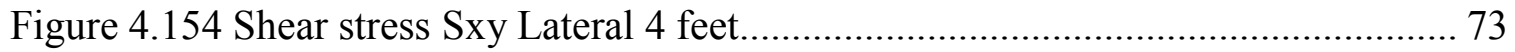

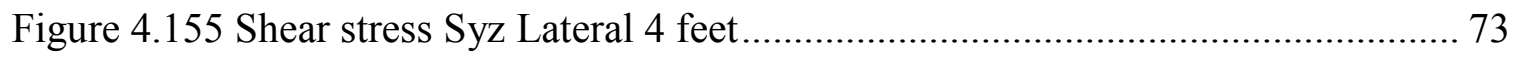

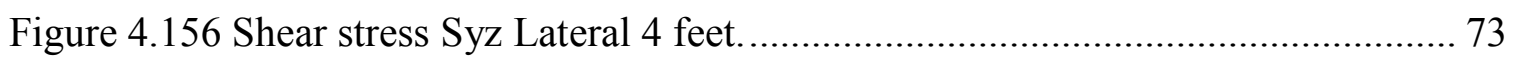

Figure 4.157 Shear stress Szx Lateral 4 feet ........................................................ 74

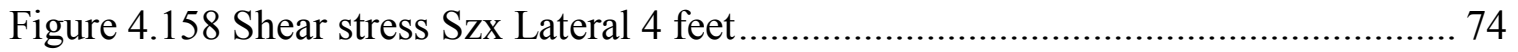

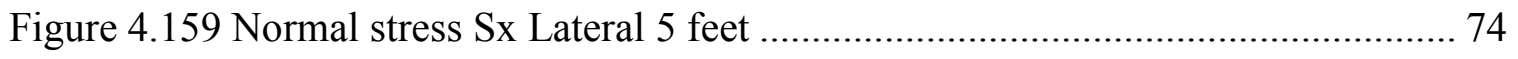

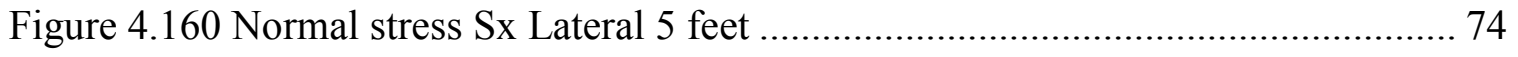

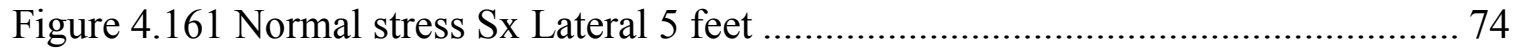

Figure 4.162 Normal stress Sy Lateral 5 feet ...................................................... 74

Figure 4.163 Normal stress Sy Lateral 5 feet ........................................................ 75

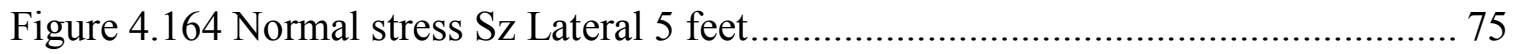

Figure 4.165 Normal stress Sz Lateral 5 feet..................................................... 75

Figure 4.166 Shear stress Sxy Lateral 5 feet.......................................................... 75

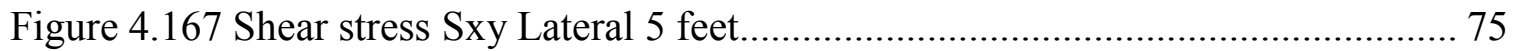

Figure 4.168 Shear stress Syz Lateral 5 feet ...................................................... 75

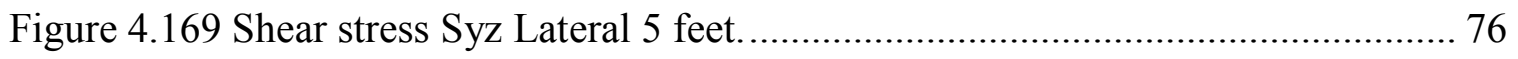

Figure 4.170 Shear stress Szx Lateral 5 feet......................................................... 76 


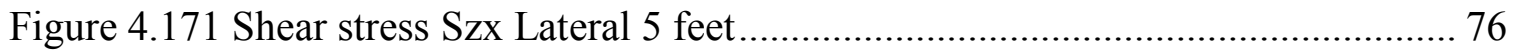

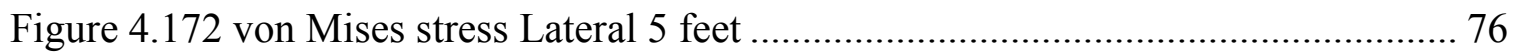

Figure 4.173 Comparison of Pressure on brain and HICP during Lateral Impact........... 78

Figure 4.174 Maximum Principal stress (Tension) and von Mises Stress on brain obtained from FE Simulation of Lateral Impacts …..................................................... 78

Figure 4.175 Stress Variation on brain with respect to drop height during Lateral Impact

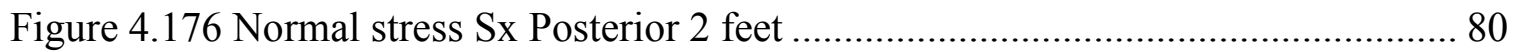

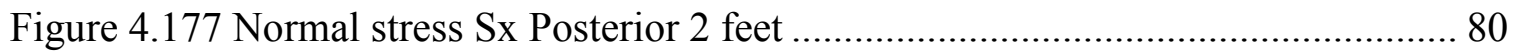

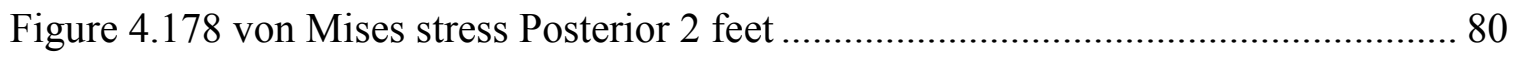

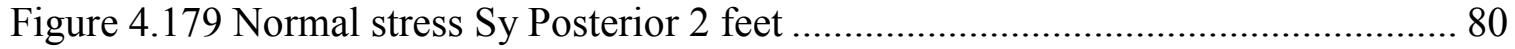

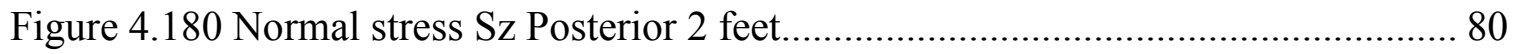

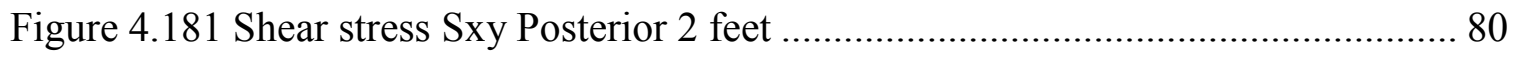

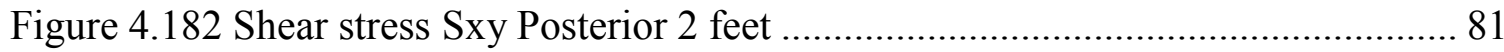

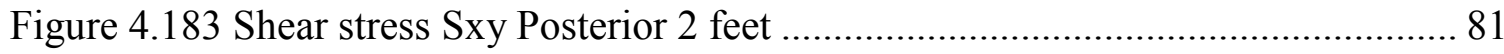

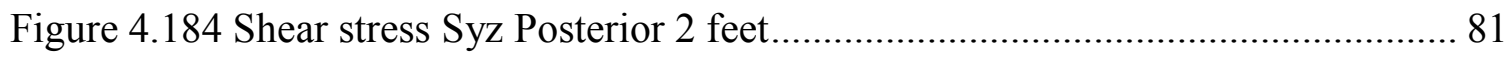

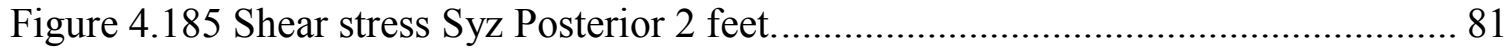

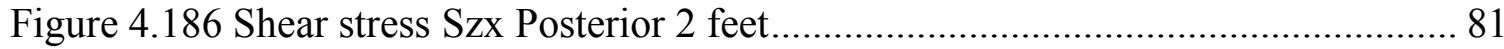

Figure 4.187 Shear stress Szx Posterior 2 feet.......................................................... 81

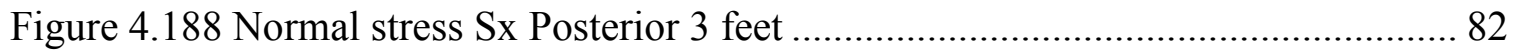

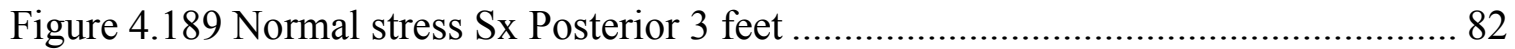

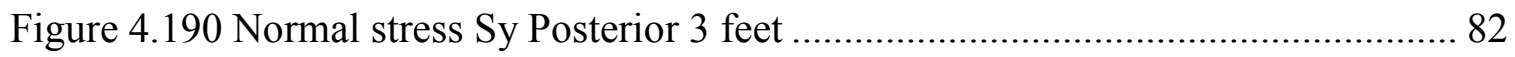

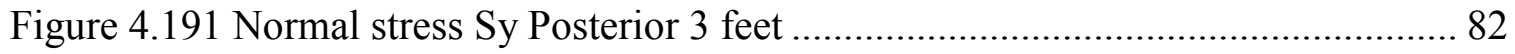

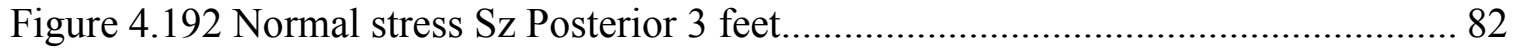

Figure 4.193 von Mises stress Posterior 3 feet .................................................... 82

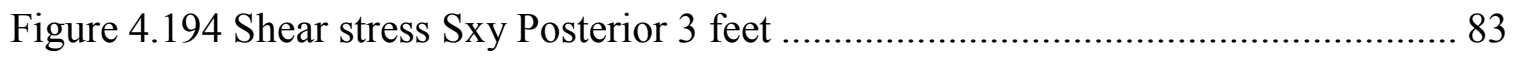

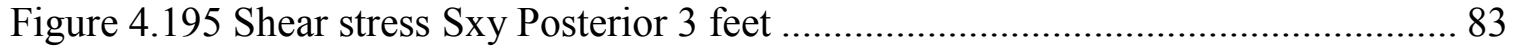

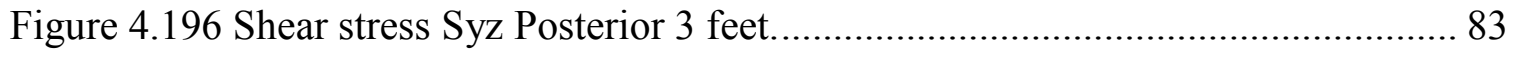

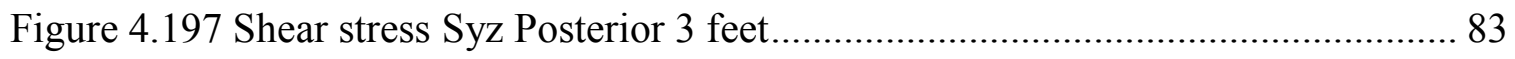

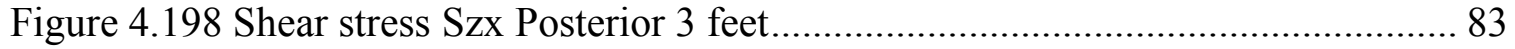




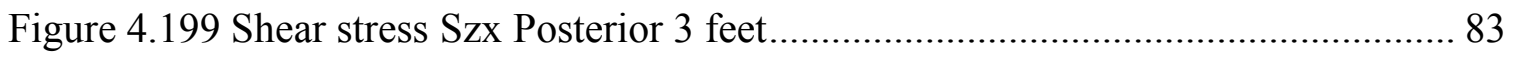

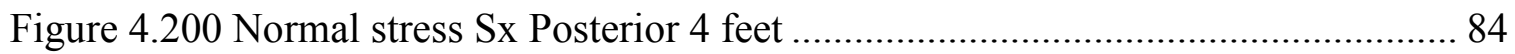

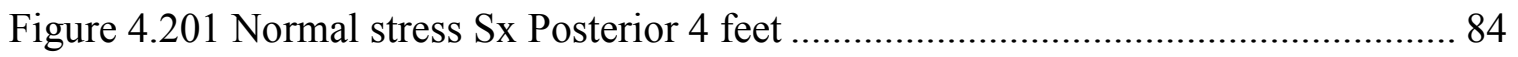

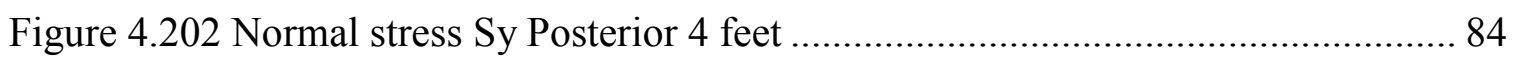

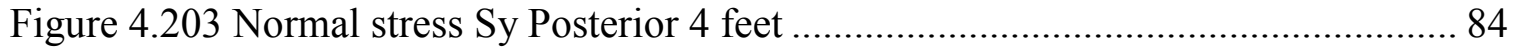

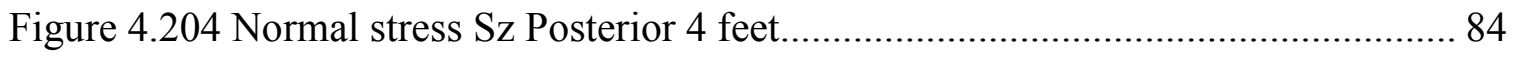

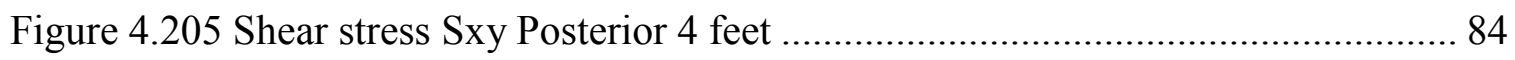

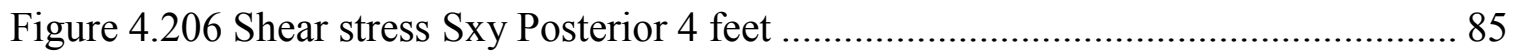

Figure 4.207 von Mises stress Posterior 4 feet ........................................................ 85

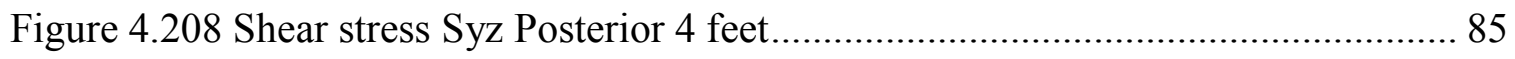

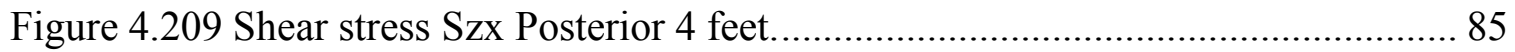

Figure 4.210 Shear stress Szx Posterior 4 feet........................................................ 85

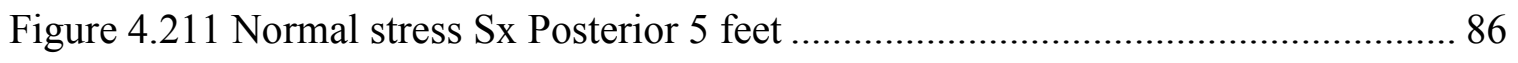

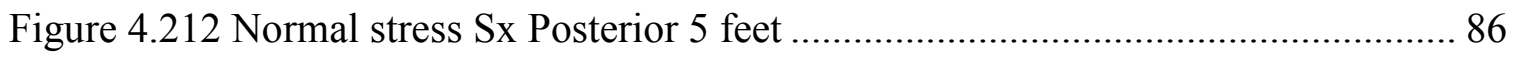

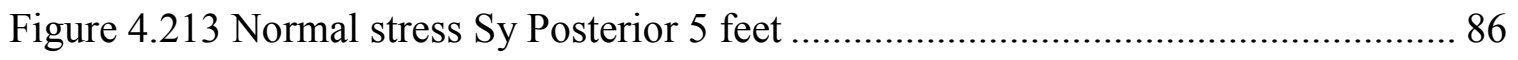

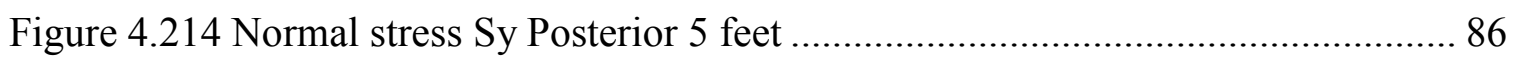

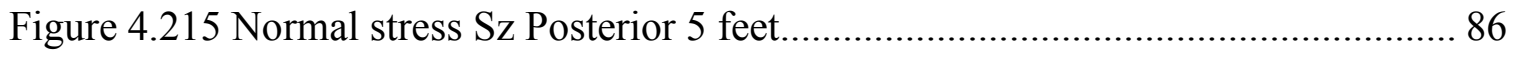

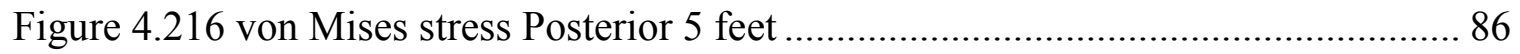

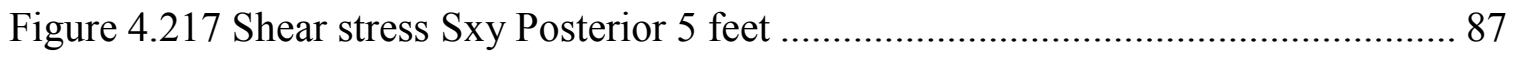

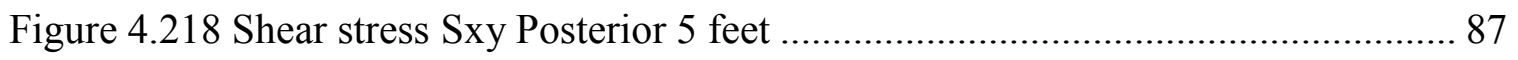

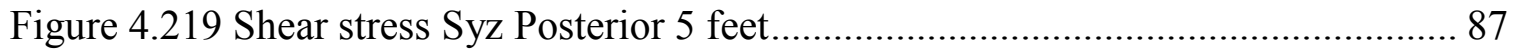

Figure 4.220 Shear stress Syz Posterior 5 feet...................................................... 87

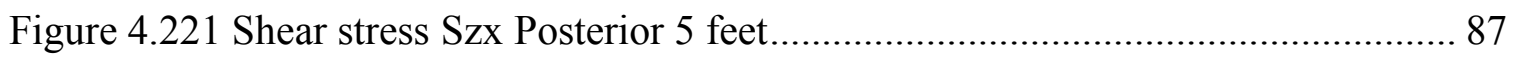

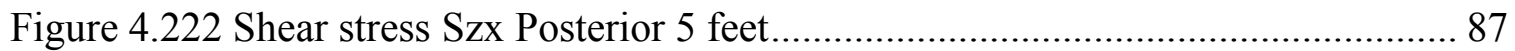

Figure 4.223 Comparison of Pressure on brain and HICP during Posterior Impact........ 89

Figure 4.224 Maximum Principal stress (Tension) and von Mises Stress on brain obtained

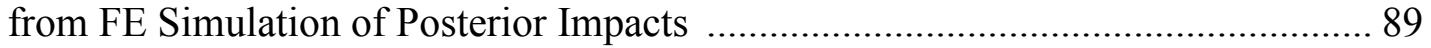

Figure 4.225 Stress Variation on brain with respect to drop height during Posterior Impact

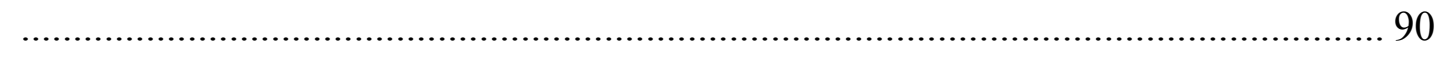

Figure 4.226 von Mises stress Vs Drop height for different regions of impact............... 91 
Figure 4.227 Maximum Principal stress Vs Drop height for different regions of impact 91

Figure 5.1 Maximum Shear Stress Vs Drop Height for the Frontal Region Impact ........ 95

Figure 5.2 Maximum Shear Stress Vs Drop Height for the 45 to Frontal Region Impact 95

Figure 5.3 Maximum Shear Stress Vs Drop Height for the Lateral Region Impact......... 96

Figure 5.4 Maximum Shear Stress Vs Drop Height for the Posterior Region Impact...... 96

Figure 5.5 Linear TBI tolerance for HICP and Pressure on Brain Located on plot of Comparison of Pressure on Brain and HICP during Frontal Impact ..................... 100

Figure 5.6 Linear TBI tolerance for Maximum Principal Stress and von Mises stress located on plot of Comparison of Maximum Principal stress and von Mises stress during Frontal Impact

Figure 5.7 Plot for Variation of Max. Linear Acceleration \& Shear stress Vs height for frontal impact 101

Figure 5.8 Plot for Variation of Max. Linear Acceleration \& Normal stress Vs height for frontal impact 101

Figure 5.9 Linear TBI tolerance for HICP and Pressure on Brain Located on plot of Comparison of Pressure on Brain and HICP during 45 to Frontal Impact 102

Figure 5.10 Linear TBI tolerance for Maximum Principal Stress and von Mises stress located on plot of Comparison of Maximum Principal stress and von Mises stress during 45 to Frontal Impact 102

Figure 5.11 Plot for Variation of Max. Linear Acceleration \& Shear stress Vs height for 45 to frontal impact 103

Figure 5.12 Plot for Variation of Max. Linear Acceleration \& Normal stress Vs height for 45 to frontal impact 103

Figure 5.13 Linear TBI tolerance for HICP and Pressure on Brain Located on plot of Comparison of Pressure on Brain and HICP during Lateral Impact 104

Figure 5.14 Linear TBI tolerance for Maximum Principal Stress and von Mises stress located on plot of Comparison of Maximum Principal stress and von Mises stress during Lateral Impact. 104

Figure 5.15 Plot for Variation of Max. Linear Acceleration \& Shear stress Vs height for Lateral impact 105 
Figure 5.16 Plot for Variation of Max. Linear Acceleration \& Normal stress Vs height for Lateral impact 105

Figure 5.17 Linear TBI tolerance for HICP and Pressure on Brain Located on plot of Comparison of Pressure on Brain and HICP during Frontal Impact .... 106

Figure 5.18 Linear TBI tolerance for Maximum Principal Stress and von Mises stress located on plot of Comparison of Maximum Principal stress and von Mises stress during Frontal Impact 106

Figure 5.19 Plot for Variation of Max. Linear Acceleration \& Shear stress Vs height for frontal impact 107

Figure 5.20 Plot for Variation of Max. Linear Acceleration \& Normal stress Vs height for frontal impact 107

Figure A1 Pressure Film Deformation for Frontal 2 feet Impact ............................... 118

Figure A2 Pressure Film Deformation for Frontal 3 feet Impact ................................ 118

Figure A3 Pressure Film Deformation for Frontal 4 feet Impact ............................... 118

Figure A4 Pressure Film Deformation for Frontal 5 feet Impact ............................... 118

Figure A5 Topaq Analyzer output for Frontal 2 feet Impact....................................... 119

Figure A6 Topaq Analyzer output for Frontal 3 feet Impact ...................................... 119

Figure A7 Topaq Analyzer output for Frontal 4 feet Impact..................................... 119

Figure A8 Topaq Analyzer output for Frontal 5 feet Impact ..................................... 120

Figure A9 Pressure Film Deformation for $45^{\circ}$ to Frontal 2 feet Impact ....................... 120

Figure A10 Pressure Film Deformation for $45^{\circ}$ to Frontal 3 feet Impact ..................... 120

Figure A11 Pressure Film Deformation for $45^{\circ}$ to Frontal 4 feet Impact ..................... 120

Figure A12 Pressure Film Deformation for $45^{\circ}$ to Frontal 5 feet Impact ...................... 120

Figure A13 Topaq Analyzer output for $45^{\circ}$ to Frontal 2 feet Impact .......................... 121

Figure A14 Topaq Analyzer output for $45^{\circ}$ to Frontal 3 feet Impact .......................... 121

Figure A15 Topaq Analyzer output for $45^{\circ}$ to Frontal 4 feet Impact .......................... 121

Figure A16 Topaq Analyzer output for $45^{\circ}$ to Frontal 5 feet Impact ......................... 122

Figure A17 Pressure Film Deformation for Lateral 2 feet Impact............................... 122

Figure A18 Pressure Film Deformation for Lateral 3 feet Impact.............................. 122 
Figure A19 Pressure Film Deformation for Lateral 4 feet Impact............................... 122

Figure A20 Pressure Film Deformation for Lateral 5 feet Impact.............................. 122

Figure A21 Topaq Analyzer output for Lateral 2 feet Impact .................................... 123

Figure A22 Topaq Analyzer output for Lateral 3 feet Impact .................................... 123

Figure A23 Topaq Analyzer output for Lateral 4 feet Impact .................................... 123

Figure A24 Topaq Analyzer output for Lateral 5 feet Impact .................................... 124

Figure A25 Pressure Film Deformation for Posterior 2 feet Impact ............................ 124

Figure A26 Pressure Film Deformation for Posterior 3 feet Impact ............................ 124

Figure A27 Pressure Film Deformation for Posterior 4 feet Impact ........................... 124

Figure A28 Pressure Film Deformation for Posterior 5 feet Impact ........................... 124

Figure A29 Topaq Analyzer output for Posterior 2 feet Impact ................................. 125

Figure A30 Topaq Analyzer output for Posterior 3 feet Impact ................................. 125

Figure A31 Topaq Analyzer output for Posterior 4 feet Impact .................................. 125

Figure A32 Topaq Analyzer output for Posterior 5 feet Impact ................................. 126

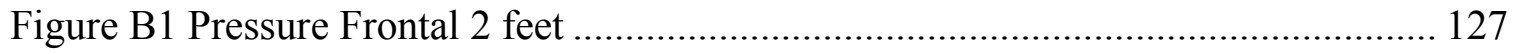

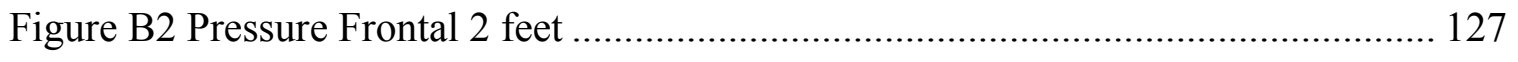

Figure B3 Mohr Circle for Frontal 2 Impact ...................................................... 127

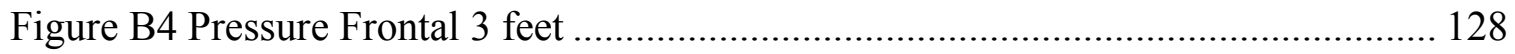

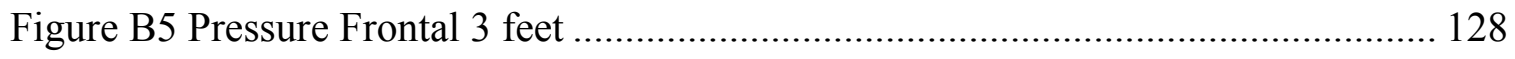

Figure B6 Mohr Circle for Frontal 3 Impact ...................................................... 128

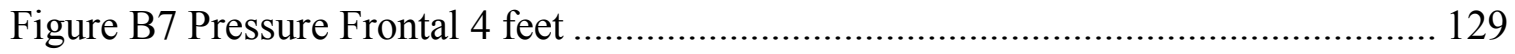

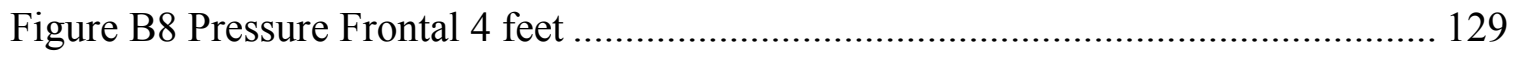

Figure B9 Mohr Circle for Frontal 4 Impact ...................................................... 129

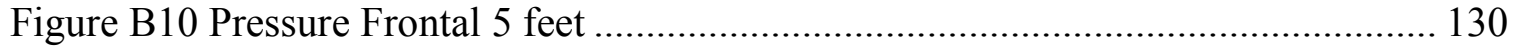

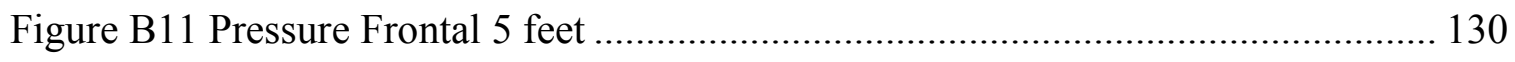

Figure B12 Mohr Circle for Frontal 5 Impact ....................................................... 130

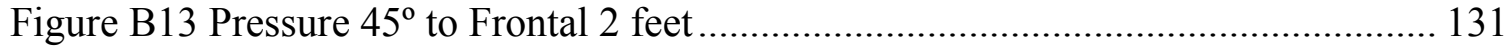

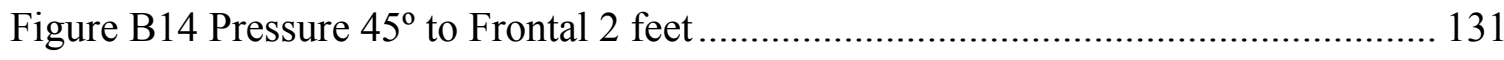

Figure B15 Mohr Circle for $45^{\circ}$ to Frontal 2 Impact ............................................... 131

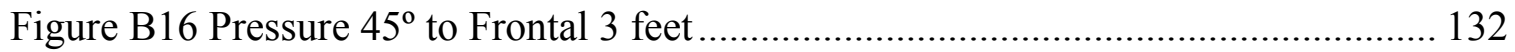


Figure B17 Pressure 45 to Frontal 3 feet............................................................... 132

Figure B18 Mohr Circle for 45 to Frontal 3 Impact ................................................ 132

Figure B19 Pressure 45 to Frontal 4 feet.................................................................. 133

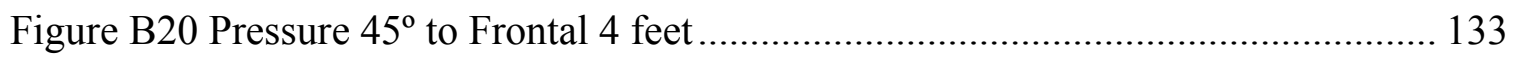

Figure B21 Mohr Circle for 45 to Frontal 4 Impact ..................................................... 133

Figure B22 Pressure $45^{\circ}$ to Frontal 5 feet............................................................ 134

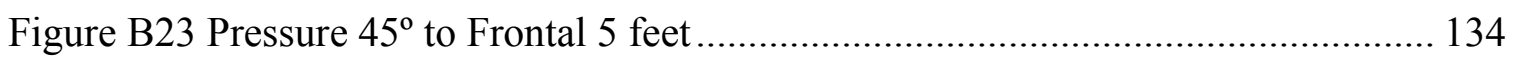

Figure B24 Mohr Circle for 45 to Frontal 5 Impact ................................................... 134

Figure B25 Pressure Lateral 2 feet....................................................................... 135

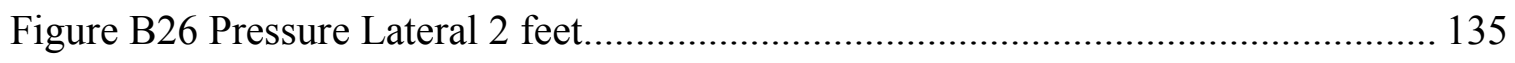

Figure B27 Mohr Circle for Lateral 2 Impact............................................................ 135

Figure B28 Pressure Lateral 3 feet....................................................................... 136

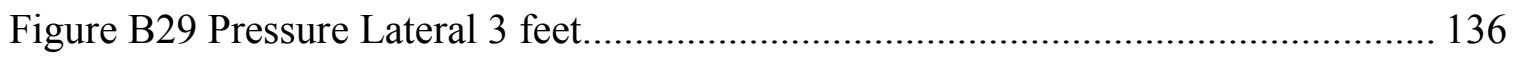

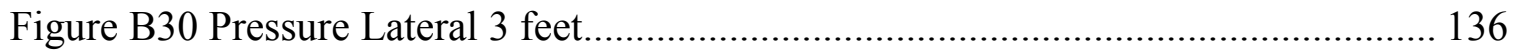

Figure B31 Pressure Lateral 3 feet........................................................................... 136

Figure B32 Mohr Circle for Lateral 3 Impact........................................................... 137

Figure B33 Pressure Lateral 4 feet...................................................................... 137

Figure B34 Pressure Lateral 4 feet....................................................................... 137

Figure B35 Pressure Lateral 4 feet....................................................................... 138

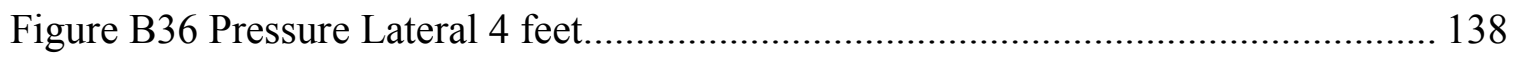

Figure B37 Mohr Circle for Lateral 4 Impact............................................................ 138

Figure B38 Pressure Lateral 5 feet....................................................................... 139

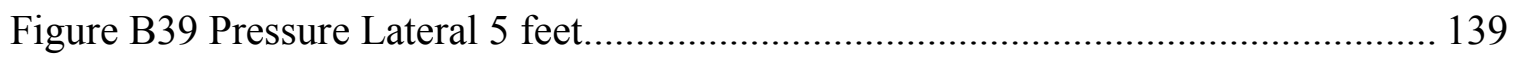

Figure B40 Mohr Circle for Lateral 5 Impact.............................................................. 139

Figure B41 Pressure Posterior 2 feet ........................................................................ 140

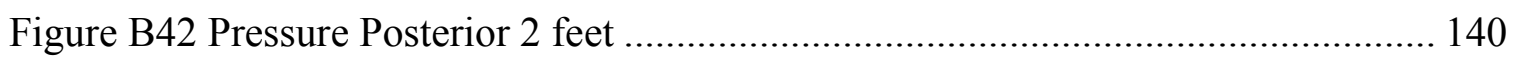

Figure B43 Mohr Circle for Posterior 2 Impact.............................................................. 140

Figure B44 Pressure Posterior 3 feet ......................................................................... 141

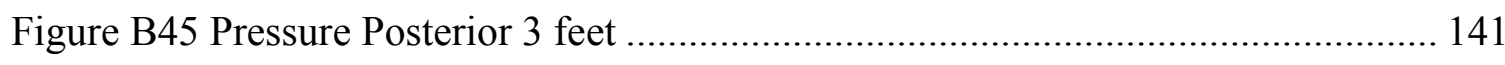

Figure B46 Mohr Circle for Posterior 3 Impact.............................................................. 141 
Figure B47 Pressure Posterior 4 feet ……………………..................................... 142

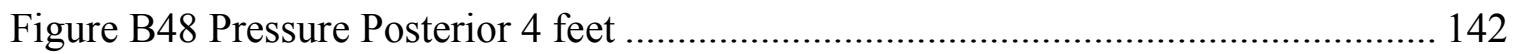

Figure B49 Mohr Circle for Posterior 4 Impact......................................................... 142

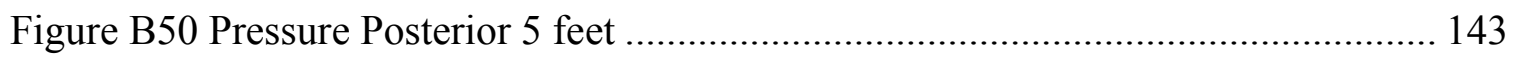

Figure B51 Pressure Posterior 5 feet ...................................................................... 143

Figure B52 Mohr Circle for Posterior 5 Impact......................................................... 143

Figure C1 Selecting the User profile in Hyperworks environment ............................... 144

Figure C2 Importing FE Model from other environment ............................................. 145

Figure C3 Creation of Mesh .................................................................................. 145

Figure C4 Mesh Properties .............................................................................. 146

Figure C5 Material assignment Tab...................................................................... 146

Figure C6 Component assignment Tab..................................................................... 147

Figure C7 Property Assignment Tab ...................................................................... 147

Figure C8 Mechanical Property Assignment to the FE model …………...................... 148

Figure C9 Creation of Spring Element ……………….......................................... 148

Figure C10 Creation of Contact Surfaces ………………......................................... 149

Figure C11 Creation of Input plots ..................................................................... 149

Figure C12 Creation of Load Collector ............................................................... 150

Figure C13 Boundary Condition manager.............................................................. 151

Figure C14 Engine File 1 showing output time step settings ........................................ 152

Figure C15 Enginefile ……………………………….................................. 152

Figure C16 Creation of Altair ${ }^{\circledR}$ RADIOSS ${ }^{\circledR}$ file ………………………................... 153

Figure C17 Importing results into Hyperview ........................................................ 154

Figure C18 Output Property manager in HyperView ……………................................. 154

Figure C19 Editing output scale in the Analysis Viewer............................................... 154

Figure D1 Different Layers of human Head .......................................................... 155

Figure D2 Cross Section of Brain showing different lobes .......................................... 156

Figure D3 Different regions of brain and their respective functions ............................ 157 


\section{List of Tables}

Table 3.1 Maximum Linear accelerations of different drop heights with their respective

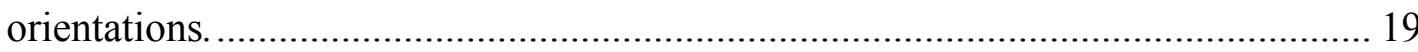

Table 3.2 Area of impact for different drops ......................................................... 21

Table 3.3 HICP for different drop heights and respective orientations. ........................ 24

Table 3.4 Pressure Film Types and their ranges of pressures...................................... 26

Table 3.5 HICP for different drops and their respective orientations from Pressure Films 28

Table 3.6 HICP Comparison between Siglab and Pressure Films ................................... 29

Table 3.7 Maximum Linear Acceleration Vs Drop Heights for different regions............ 32

Table 3.8 Drop Heights Vs Max HICP for different Drops.......................................... 33

Table 4.1 Material Properties of FE Model ….............................................................. 38

Table 4.2 Normal Stress Values on brain from FE Simulation of Frontal Impact .......... 54

Table 4.3 Shear Stress values on brain from the FE Simulation of Frontal Impact ......... 54

Table 4.4 Results Obtained from Mohr Circle Analysis for Frontal Impacts.................. 54

Table 4.5 Pressures on the Brain due to Frontal Impact from different heights............... 55

Table 4.6 Normal Stress Values on brain from FE Simulation of $45^{\circ}$ to Frontal Impact. 64

Table 4.7 Shear Stress values on brain from the FE Simulation of $45^{\circ}$ to Frontal Impact

Table 4.8 Results Obtained from Mohr Circle Analysis for $45^{\circ}$ to Frontal Impacts ........ 64

Table 4.9 Pressures on the Brain due to $45^{\circ}$ to Frontal Impact from different heights ... 65

Table 4.10 Normal Stress Values on brain from FE Simulation of Lateral Impact......... 77

Table 4.11 Shear Stress values on brain from the FE Simulation of Lateral Impact........ 77

Table 4.12 Results Obtained from Mohr Circle Analysis for Lateral Impacts ................ 77

Table 4.13 Pressures on the Brain due to Lateral Impact from different heights ............ 78

Table 4.14 Normal Stress Values on brain from FE Simulation of Posterior Impact ...... 88

Table 4.15 Shear Stress values on brain from the FE Simulation of Posterior Impact..... 88

Table 4.16 Results Obtained from Mohr Circle Analysis for Posterior Impacts ............. 88

Table 4.17 Pressures on the Brain due to Posterior Impact from different heights ......... 89 
Table 5.1 Maximum Shear Stress on Brain and TBI Tolerance Drop Heights for the

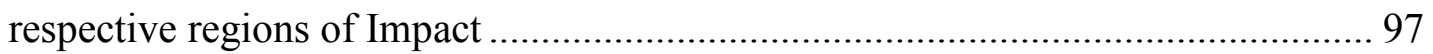

Table 5.2 Drop Height tolerance for TBI caused by Linear Acceleration....................... 98

Table 5.3 Drop Height tolerance for TBI for respective regions of Impact ................... 99

Table 5.4 TBI Tolerance Limits for different regions of Impact ................................ 108

Table 5.5 Safety criteria for drops in respective region using the TBI Tolerance values from

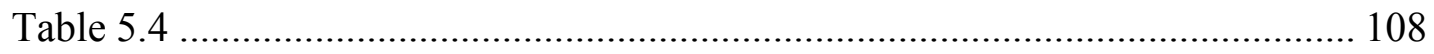

Table 5.6 TBI Stress criterion for Frontal Impact using Eq. 5.1 ................................. 111

Table 5.7 TBI Stress criterion for $45^{\circ}$ to Frontal Impact using Eq. 5.1 ........................ 111

Table 5.8 TBI Stress criterion for Lateral Impact using Eq. 5.1 ................................ 111

Table 5.9 TBI Stress criterion for Posterior Impact using Eq. 5.1 .............................. 112

Table 6.1 TBI Tolerance Limits for different regions of Impact................................. 115 


\section{Abbreviations Used}

1. NOCSAE-National Operating Committee on Standards for Athletic Equipment

2. FE - Finite Element

3. Pressure Film - Fuji Film Prescale

4. Head Form - Hybrid-III Dummy Head form

5. Max - Maximum

6. MPa-Mega Pascal

7. $\mathrm{KPa}-\mathrm{Kilo}$ Pascal

8. Acc-Acceleration

9. TBI - Traumatic Brain injury

10. HICP - Head Impact Contact Pressure 


\section{Acknowledgements}

On the first note, I would like to thank my mother, Maha Lakshmi Bhamidipati, for everything, giving everything she had, in fact going an extra mile to help me achieve my goal, to do my Masters. Without you I am nothing, you are my Super hero, Friend, guide and everything. Thank you god, for giving me such a great Mother. I owe you one.

Secondly, Rama Devi Rachakonda, my life partner, without your moral boost it would have taken me a lot of effort to go through every problem I had, Thank you for believing me that I can achieve my goal and for being always available anytime I need you. I am lucky to have you in my life.

A person, without whom this work would not have been possible, my advisor Dr. Gopal Jayaraman for believing me that I could do this work and without your kind guidance I wouldn't have completed my Masters and I should not forget another important person, Mr. David Labyak, for guiding me through my entire research work and always being available for every question I had. Thanks to my defense committee Dr. KVC Rao, Dr. Ibrahim Miskioglu and Dr.Allan Struthers for taking out time from your busy schedule in going through my work.

Last but not the least, my family away from my home, my friends, Deepika JayaPrakash, Jaswanth Kalavagadda, Prathik Meruva, Pruthvi Raviraj Bachu and Raviteja Zakkam at Michigan Tech, for everything, for believing me that I could do this, supporting me when I am down, guiding me when I am struck. You guys made my masters life a sweet journey, And Sandhya Nadipalli and Shanmukha Modugula for supporting me and helping me resume my work and concentrate on it even in a hectic schedule. Without you all I am nowhere, Thank you god for giving me such a good friends.

Finally, Thank you Michigan Tech for shaping me into a better person 


\section{Abstract}

How many times have you seen a person slip and fall down and had a good laugh about it? How many times we slip and fall down on the floor, got up and walked away thinking everything is normal? Probably we might wonder "Are drops which occur at such a small height dangerous?" Yes, they can be. Brain injuries are main reason for the fatality in youth [1], and low level falls are one of the most neglected and understated injuries.

The main objective of this study is to study the response of the brain for low level falls from a drop height of 2-5 feet. Earlier studies have related the brain kinematics to injuries, while fewer data is available regarding the relation of brain kinetics to a Traumatic Brain Injury (TBI). The main purpose of this work is to study the effect of an impact due to free fall on the head. The Linear acceleration of the head is measured using accelerometers and Siglab unit by performing drop tests as per NOCSAE standards in Frontal, $45^{\circ}$ to Frontal, Lateral and Posterior regions from a height of 2 feet, 3 feet, 4 feet and 5 feet. The corresponding pressure on head called Head Impact Contact Pressure (HICP), has been measured using Fujifilm Prescale and validated by the HICP values calculated from the linear head accelerations. The corresponding Impact pressure curves has been used as an input for finite element (FE) analysis in Altair ${ }^{\circledR}$ RADIOSS $®$ module from Hypermesh, using a 3-D FE model of a $50^{\text {th }}$ percentile human male from the National Library of Medicine (NLM) Visible Human Project (VHP), to study the response of brain during these impacts. Various entities like resultant pressure on the brain, Normal and Shear stresses on the brain, Maximum principal stresses and von Mises Stresses were extracted from the FE analysis. These values are used in conjunction with the Kang and Ward's [24] criteria and 
Anna's [25] criteria for Traumatic Brain Injury (TBI) to determine the tolerance values of drop height, linear head acceleration, Maximum Principal Stresses and von Mises stresses for a chance of risk of TBI. It is been observed that a TBI can be caused either by linear acceleration component or angular acceleration component or both. Hence, a new formula has been proposed to determine the chance of TBI due to impact in particular region.

It is been observed that the lateral region of the brain is more susceptible to injury followed by the Posterior region, a mere drop height of 2.52 feet produces a HICP of $1.21 \mathrm{MPa}$, an acceleration of $138.67 \mathrm{G}$, a von Mises stresses of $30.1 \mathrm{KPa}$ and a maximum Principal stress of $0.154 \mathrm{MPa}$. These values are the tolerance limits for TBI in lateral region and a value higher than those might cause a TBI although any external damage is not observed on the head. 


\section{Chapter 1}

\section{Introduction}

\subsection{Introduction}

How many times have you seen a person fall on a floor by slipping or tripping and had a good laugh about it? How many times we had some fall on the floor and immediately got up and thought nothing was wrong. Well, is a fall from such a small height can be dangerous? The research says "yes, it could be".

The brain is one of the complex organs in the human body. In spite of stellar research in fields of science, there are still many areas which are still in dark. Brain in one among them. Because of its complexity very little data is available for its response under injury. The data which is available has been acquired through the studies on the cadaver subjects, data from accidents and research on animals. Although the research on animals gave some idea about the functionality and response of brain the same cannot be completely relied on as their response is different from human brain in many aspects. [1] Head Injury is major cause of fatality in young (age group of 15-24), especially due to highway accidents and sport related injuries [2] [3]. This is really a tragic loss because there is a huge life ahead of them and they have a lot to lose. There are many fatalities in all age groups due to head injuries.

"You don't have to see external injury to have injury to the brain, to evaluate a person's response after a minor trauma, it is recommended checking the size of their pupils and asking questions such as the person's name and what year it is. In the hours following, it is recommended monitoring the person's cognitive skills and to bring them in to get a 
CAT scan if there is a change in behavior", said Dr. Philip Stieg, chair of neurosurgery at NYP/Weill Cornell [4].

It's a common knowledge that drops from heights more than 20 feet can be fatal, but what about the drops from a height lesser than that, what about slips which are quite common amongst all age groups? [4][5]. "A patient can appear so deceivingly normal at first, but they actually have a brain bleed and as the pressure builds up, they'll experience classic symptoms of a traumatic brain injury." said Graffagnino, director of Duke University Medical Center's Neurosciences Critical Care Unit [4].

According to the 2006 Liberty Mutual Workplace Safety Index, "the annual direct cost of disabling occupational injuries due to slips, trips and falls is estimated to exceed $\$ 11$ billion. The Index reports that falls on the same level are the second most costly occupational injury (estimated annual cost of $\$ 6.7$ billion), just behind overexertion. It also shows that injuries from slipping or tripping, is the third highest injury category, followed by falls to a lower level (4.6 billion).[6] What is the difference between a slip and a fall? "When you slip, you slip on a floor, and lose your balance, a fall is when you move from one level to another."[6]. Hence it can be considered that slips are one of the understated injuries, and it is important to study the effects and types of injuries on brain for falls between 2-5 feet. This work concentrates on effects of the slips and their response on the brain by determining the tolerances for an injury on the brain due to free fall. 


\subsection{Demography of Head Injuries.}

- In North America, Nearly 0.54 Million injuries which require hospital care occur due to slip fall every year. Out of which 300,000 results in disabilities, while over 20,000 are fatalities i.e. 55 people per day are dying because of slip falls. [6]

- It is the second leading cause of accidental death and disability after automobile accidents. [6]

- Slips and falls are the primary cause of accidents in the home and workplace. [6]

- Slip-Falls kill more workers than all other combined forms of workplace accidents. [6]

- Slip-Falls are the number one cause of accidents in Hotels, Restaurants and Public Buildings; 70\% occur in flat and level surfaces. [6]

- Slip-Fall accidents account for 30\% of all reported injuries. [6]

- The total expense resulting from slip-fall injuries alone is a $\$ 100$ million per day problem. [6]

The demographics of slip falls with respective age groups has been explained below

\section{Demographics of fall in Children}

- The slips and fall among children and adolescents account for more than 3 million emergency department visits each year, and more than 40 percent occur among infants, toddlers, and preschoolers.[7]

- Accounting for 5.9 percent of childhood deaths due to trauma, falls represent the third leading cause of death in children [7][8]. Death due to falls is generally from a head injury [9]. 
- Falls in children are mostly common, they can be from balconies, windows, and trees, and playgrounds. Approximately $75 \%$ of the falls in children are unintentional.[7][10]

\section{Demographics of Falls in Adults}

- More than $50 \%$ of the of non-occupational falls in adults and 17 percent of occupational falls are because of the use of alcohol [11].

\section{Demographics of Falls in the Elderly}

- Falls in the elderly are likely to occur with daily activities.

- They account for 29 percent of injury deaths among adults aged 65 and older.[8]

- Older adults are five times more likely to be hospitalized due to falls than any other injuries [7][12].

\subsection{Wayne State Tolerance Curve:}

The Wayne State Tolerance (WST) curve was presented in 1960, it was the basis for all injury curves. It was the first attempt to relate head linear acceleration in terms of G's with the impact time to study the injuries on the head. [13] It shows that the effect of acceleration on impact decreases with an increase in time. 


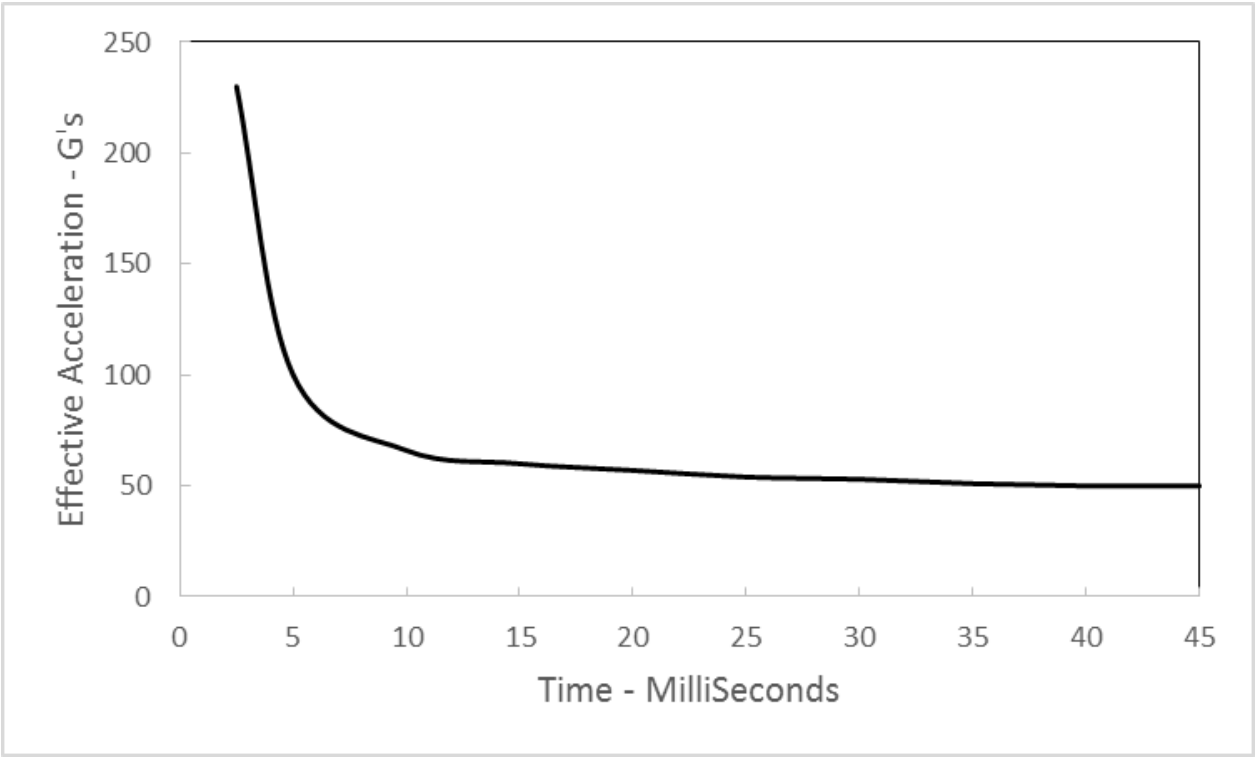

Figure 1.1 Wayne State Tolerance Curve

\subsection{Objective \& Strategy}

After looking at the above figures, one can realize how serious low level falls could get and proper safety equipment should be designed at least to reduce the effects of the brain injuries. In order to design proper safety equipment, one must have a proper idea about the tolerance levels on the brain for an injury and the response of the brain under an impact. The main objective of this study is

- To determine the effect of drop height on a brain injury.

- To determine the amount of pressure transferred from the head to brain during injury.

- To propose a proper tolerance criteria to determine the chance of a brain injury.

- To study the effect of region of impact on the brain injury.

- To study whether the injury restricts itself to the region of impact. 
In order to study the above objectives the following approach have been followed in this study:

- Conduct experimental drop tests according to NOCSAE standards to determine the linear accelerations during impact.

- Study the impact pressures by using experimental methods

- Measure the area of impacts using means available.

- Apply the impact curves derived from the experimental methods as an input to the Finite element analysis.

- Study the response of brain to the given pressure

- Propose a tolerance level of stresses on brain, corresponding linear accelerations and drop height from the previously available data for determining brain injuries 


\section{Chapter 2}

\section{Brain Injuries}

As mentioned earlier brain being one of the most complex organs in the human body there is a little data available about brain injuries which was obtained from the cadaver subjects, volunteers and anesthetized animals. The Centers for Disease Control (CDC) has defined a Traumatic Brain Injury (TBI) as "an occurrence of injury to the head arising from blunt or penetrating trauma or from acceleration-deceleration forces that is associated with any of the following symptoms or signs attributed to injury: decreased levels of consciousness, amnesia, other neurologic or neuropsychological abnormalities, skull fracture, diagnosed intracranial lesions, or death" [14]. The general Consequences of a TBI are temporary memory loss, and problems with judgement, mood, strength, coordination, balance and vision. Mild injuries when occur in repeated manner can sometimes be fatal [2]. The injuries which are caused due to external impact can be majorly classified into two types.

\subsection{Focal Injuries}

If an injury occurs as a result of the direct blow to the cranial vault or penetration through the skull then it is known as a focal brain injury [15]. Focal brain injury usually results in localized area of bleeding at the site of impact, which is generally known as hematoma. Contusions, epidural hematoma, subdural hematoma are general kind of focal injuries [16]. 


\subsubsection{Contusion}

The bruising of brain generally called as contusion occurs due to the inwards deformation of the skull under applied impact, which causes rupture of blood vessels. This causes the compression of brain against skull. Coup and Contre coup injury are general forms of contusions [15]. The injury which generally occurs at the site of injury is called Coup injury and the brain bounces off from the opposite wall of the skull causing Contre Coup injury [17].

\subsubsection{Epidural Hematoma}

It is an injury in which blood is collected between duramater and interior of Skull [15].

\subsubsection{Subdural Hematoma}

It is an injury in which the bleeding occurs in the subdural space as a result of breakage of veins in that area. These veins drain the blood from the surface of the brain and force them to the sinuses. The blood accumulates between dura and brain increasing the compression on brain which results in a higher compressive stresses than those of the epidural hematoma [15].

\subsection{Diffuse Injuries}

These injuries occurs as a result of global disruption of neurological functions. Cerebral concussions and diffuse axonal injuries are general kinds of diffuse injuries [15].

\subsubsection{Concussion}

Concussions are generally defined as "A post traumatic stage that results in loss of consciousness" [16]. Cerebral functions such as loss of consciousness, equilibrium problems and disturbance of vision are generally effected. The severity of concussion is 
generally determined based upon the level of confusion and the state of consciousness [16]. Concussions are most common type of head injuries in athletic injuries. [16] The concussions can be classified into 3 grades Grade 1 or mild concussion which involves no loss of consciousness, but involve confusion without amnesia which lasts for less than 30 minutes. [16]

Grade 2 or moderate concussion involves loss of consciousness for less than 5 minutes and confusion associated with amnesia which lasts from 30 minutes to 24 hours. [16] Grade 3 or severe concussion involves loss of consciousness for more than 5 minutes with amnesia which lasts for more than 24 hours. [16]

\subsubsection{Diffuse Axonal Injury}

It is one of the most severe brain injuries which have high chances to be fatal. It is generally a shearing injury in which the white mater fiber which runs from cortex to the mid brain, and from the brain stem to spinal cord, disrupts throughout the cerebral hemispheres. The results will be immediate loss of consciousness for more than a day which could last up to weeks. In some cases patient will be under coma with permanent memory loss or other disabilities [16]. 


\section{Chapter 3 \\ Experiments, Results and Discussions}

\section{Head Acceleration \& HICP Vs Drop Height}

\subsection{Experimental Procedure:}

In this chapter the real time head injuries due to impact are simulated in the lab by

conducting drop tests as per NOCSAE standards. The HICP developed on the head due to free fall head form on the anvil is measured by two different approaches;

1) NOCSAE Drop Tests

2) Pressure Films and Topaq Pressure Analyzer

By observing the HICP developed on the head-form due to the free fall, the following comparisons were drawn in this chapter.

a. Comparison of HICP obtained from Topaq Analyzer and NOCSAE Drop Tests.

b. Linear Acceleration of the Head Vs Drop Heights

c. HICP from NOCSAE Tests Vs Drop Heights.

\subsection{NOCSAE Drop Tests:}

\subsubsection{Setup:}

NOCSAE [18] has defined some standards for testing the protective head gear equipment and the head form which should be used for testing purposes. A NOCSAE standard Drop Instrumentation has been set up at Michigan Technological University which is shown in Fig 3.1. 


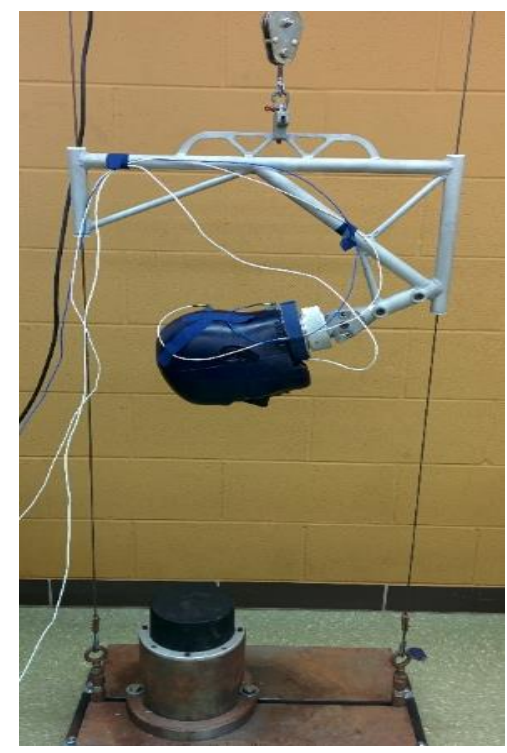

Fig. 3.1 NOCSAE Drop Test Instrumentation at Michigan Tech.

Drop tests were performed with a NOCSAE Hybrid III dummy head (Here after referred as head form) on a polyurethane elastomer based anvil with a steel base. The Head form is equipped with uniaxial accelerometers to study the impact acceleration in G's during the drop. The head form was allowed to fall freely from 2 feet, 3 feet, 4 feet and 5 feet oriented in Frontal (along positive Z-axis), $45^{\circ}$ to Frontal (along XY-axis), Lateral (along negative $\mathrm{X}$-axis) and Posterior (along negative Z-axis) to anvil.

The accelerometers relay the readings during the drops to the Siglab unit which will calculate the Linear Acceleration in terms of G's and Severity Index and thus calculates a linear acceleration curve from the moment the head form comes in contact with the anvil.

\subsubsection{Head Linear Acceleration Curve}

The data which is imported from the Siglab unit is in the form of large text file, which can be exported to excel format for further processing. The head linear acceleration (here after referred to as Linear Acceleration) curve can be plotted from the same. 


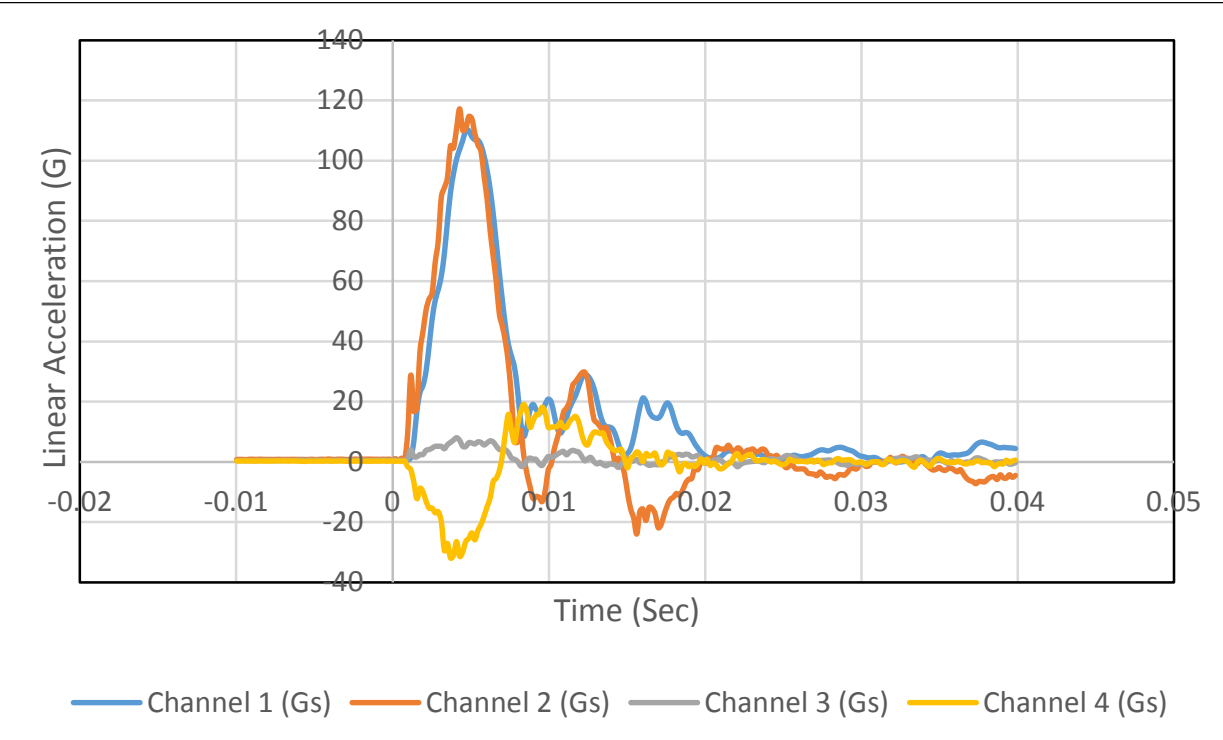

Fig. 3.2 Linear Acceleration Plot obtained from the Siglab Unit.

In the above figure we can find a linear acceleration plot obtained from the Siglab unit. Channels 2, 3 and 4 corresponds to linear acceleration in $\mathrm{X}, \mathrm{Y}$ and $\mathrm{Z}$ axes respectively while Channel 1 is the Resultant Linear acceleration. By observing the above plot (Fig 3.2) one can observe that the curve has started from the negative time, it is because the Siglab will start recording the readings from the instant the head form touches the anvil (which is considered as $t=0$ ) and the values earlier to that are the disturbances during the drop.

The $\mathrm{X}, \mathrm{Y}, \mathrm{Z}$ axes of the head-form are shown in fig. below. 


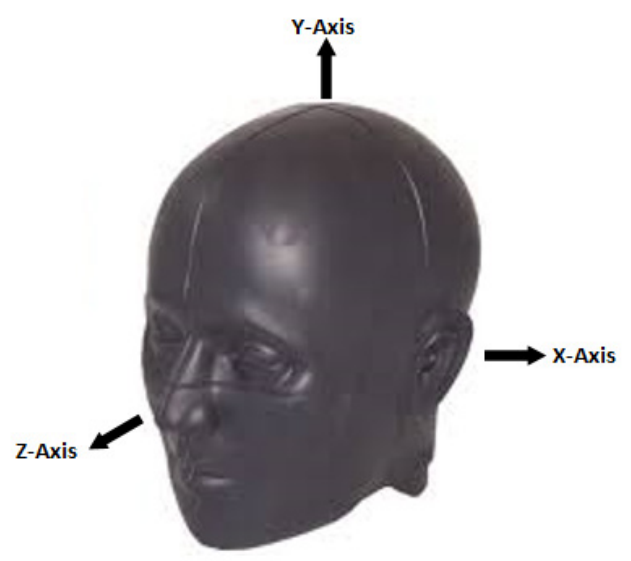

Fig 3.3 Headform with its X,Y,Z Axes

The Linear acceleration curves for different heights and different orientations are shown below

\subsubsection{Frontal}

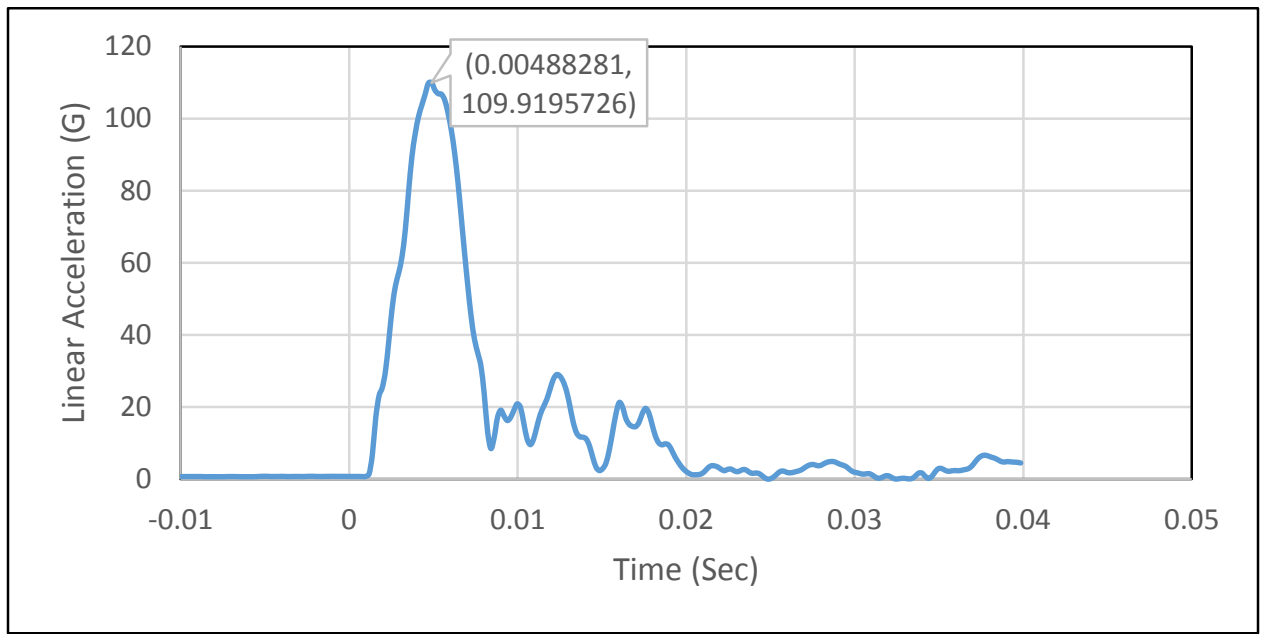

Fig 3.4 Linear Acceleration curve for Frontal 2 feet drop 


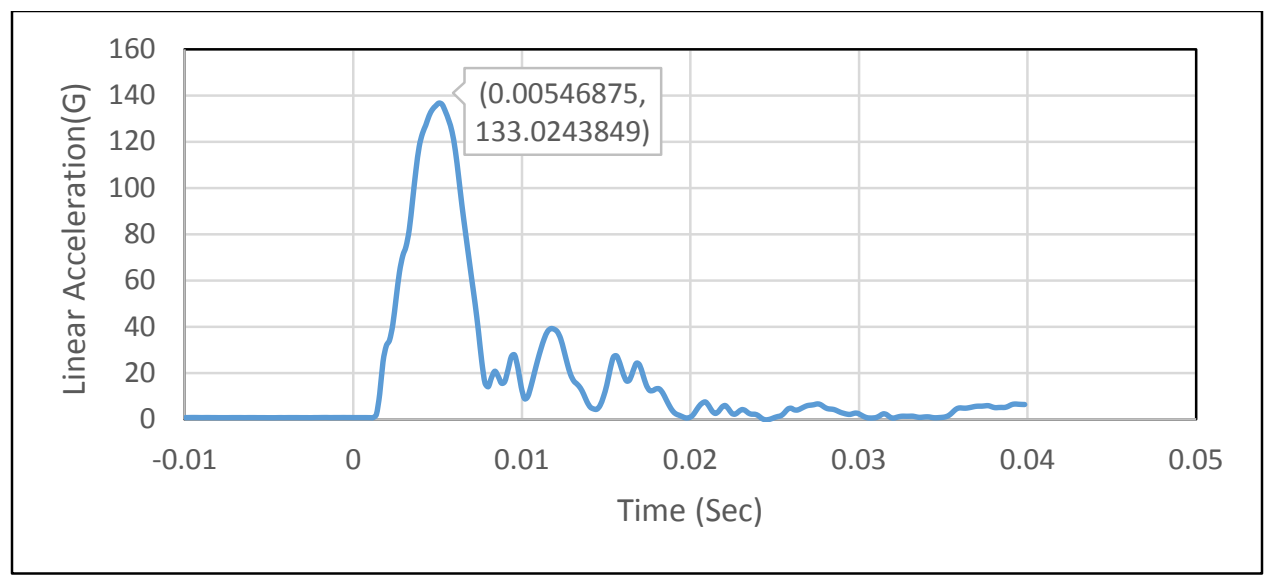

Fig 3.5 Linear Acceleration curve for Frontal 3 feet drop

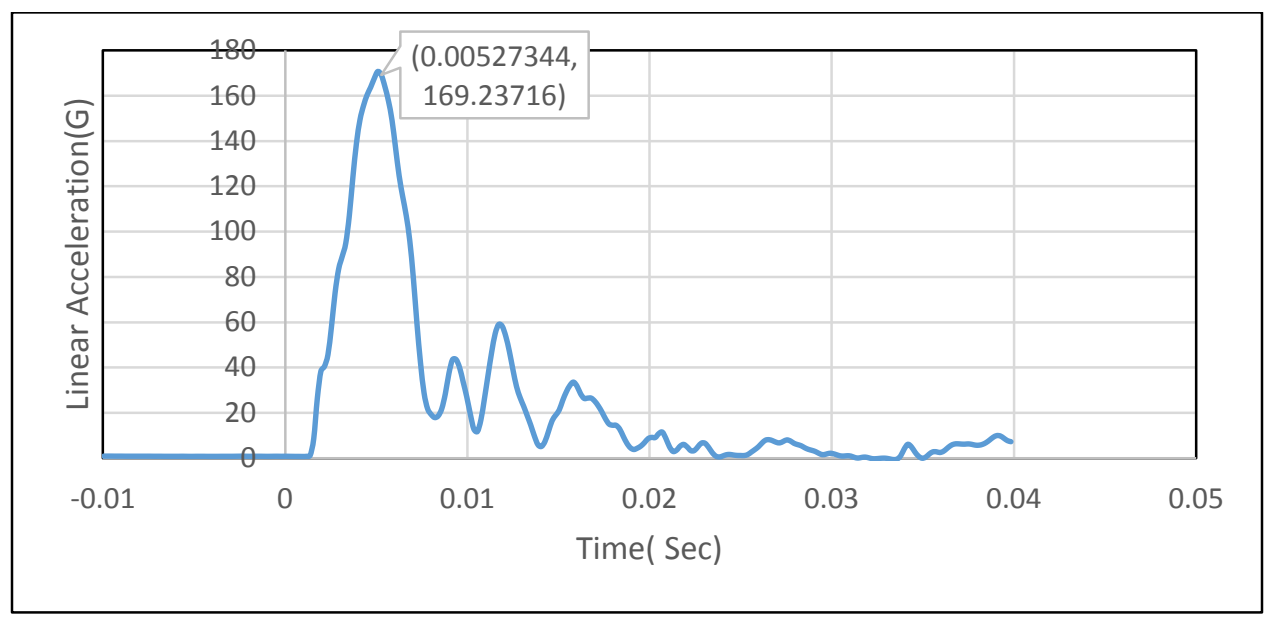

Fig 3.6 Linear Acceleration curve for Frontal 4 feet drop

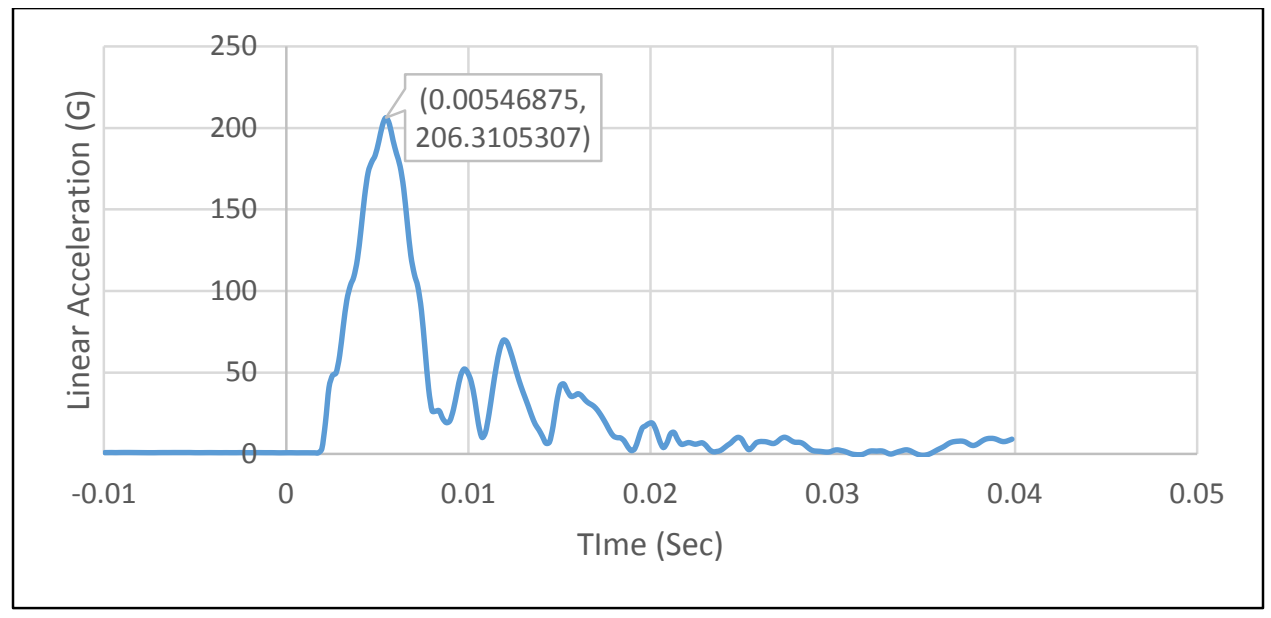

Fig 3.7 Linear Acceleration curve for Frontal 5 feet drop 


\subsubsection{2 $45^{\circ}$ to Frontal:}

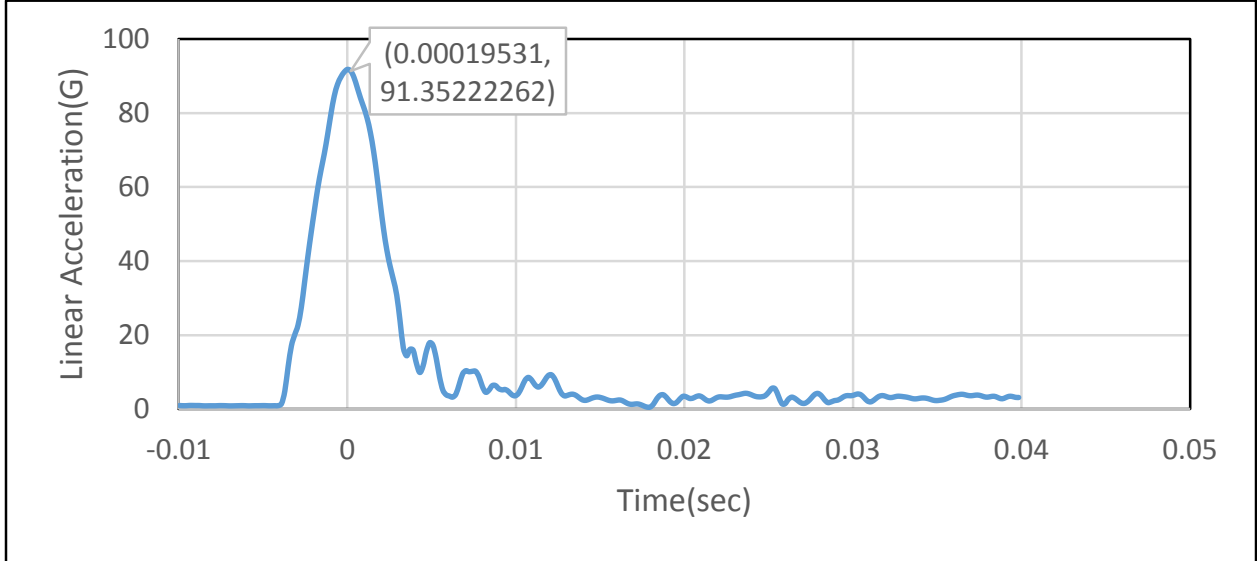

Fig 3.8 Linear Acceleration curve for $45^{\circ}$ to Frontal 2 feet drop

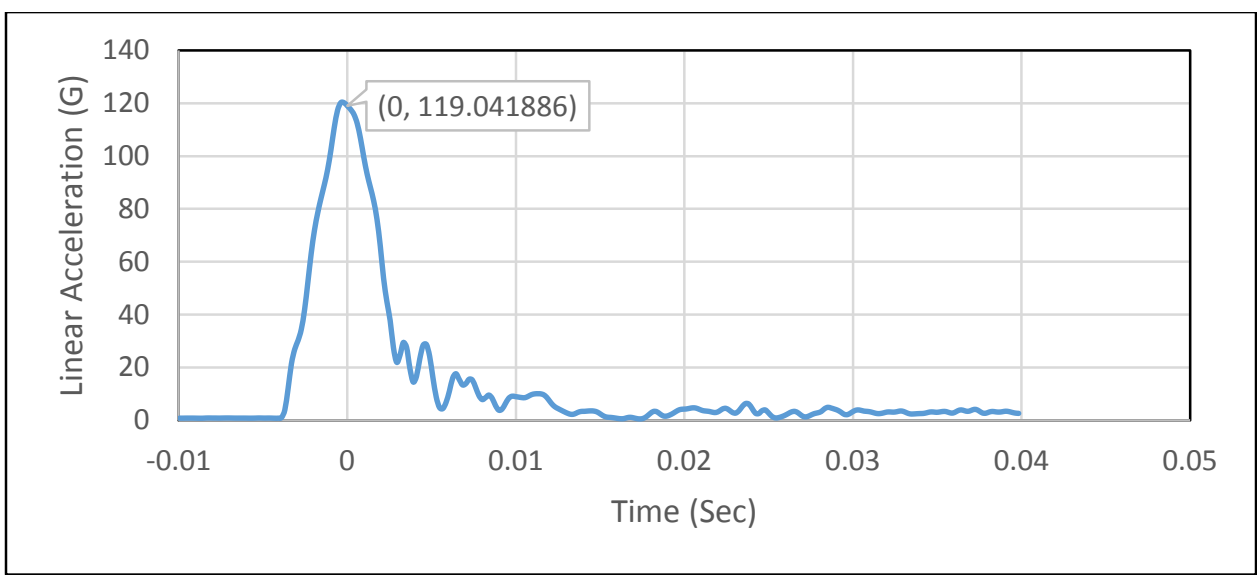

Fig 3.9 Linear Acceleration curve for $45^{\circ}$ to Frontal 3 feet drop

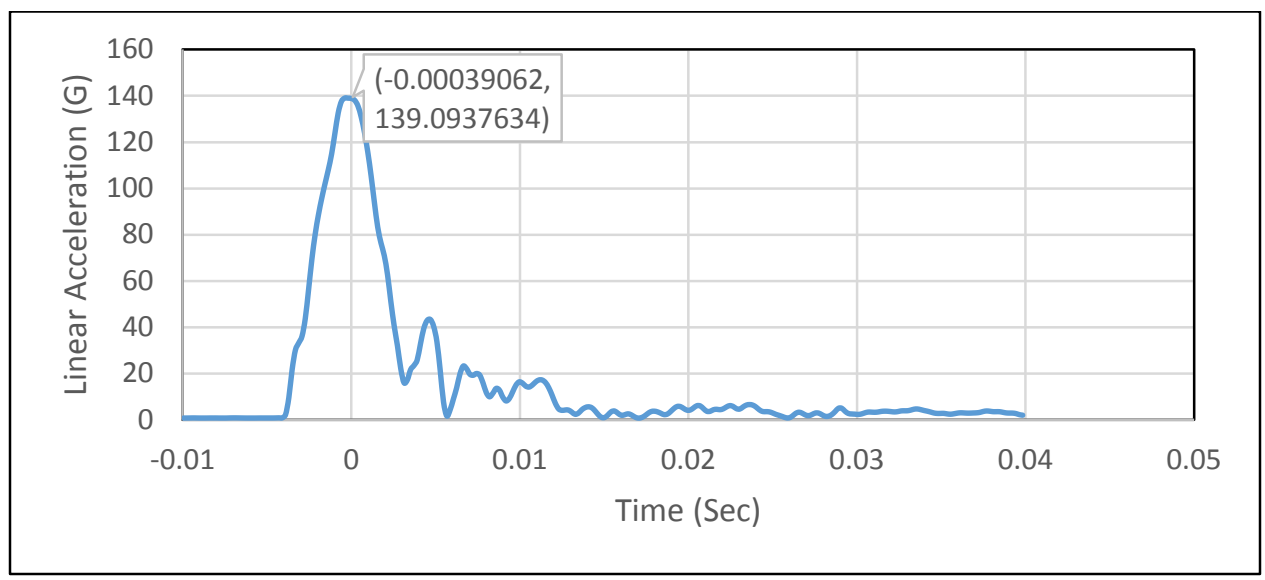

Fig 3.10 Linear Acceleration curve for $45^{\circ}$ to Frontal 4 feet drop 


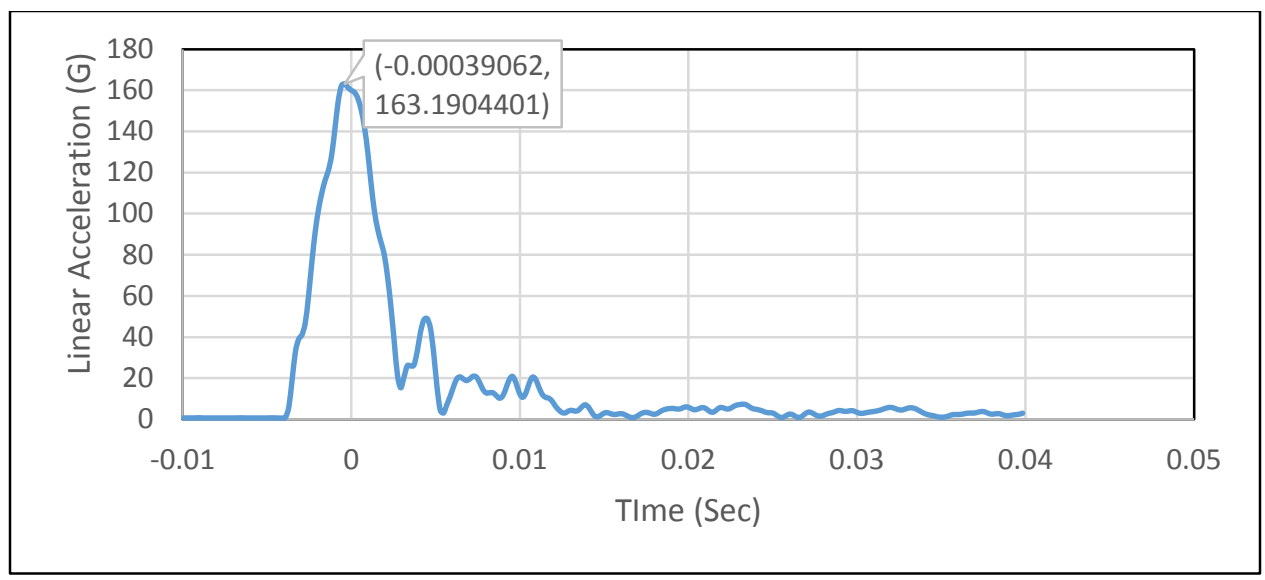

Fig 3.11 Linear Acceleration curve for $45^{\circ}$ to Frontal 5 feet drop

\subsubsection{Lateral:}

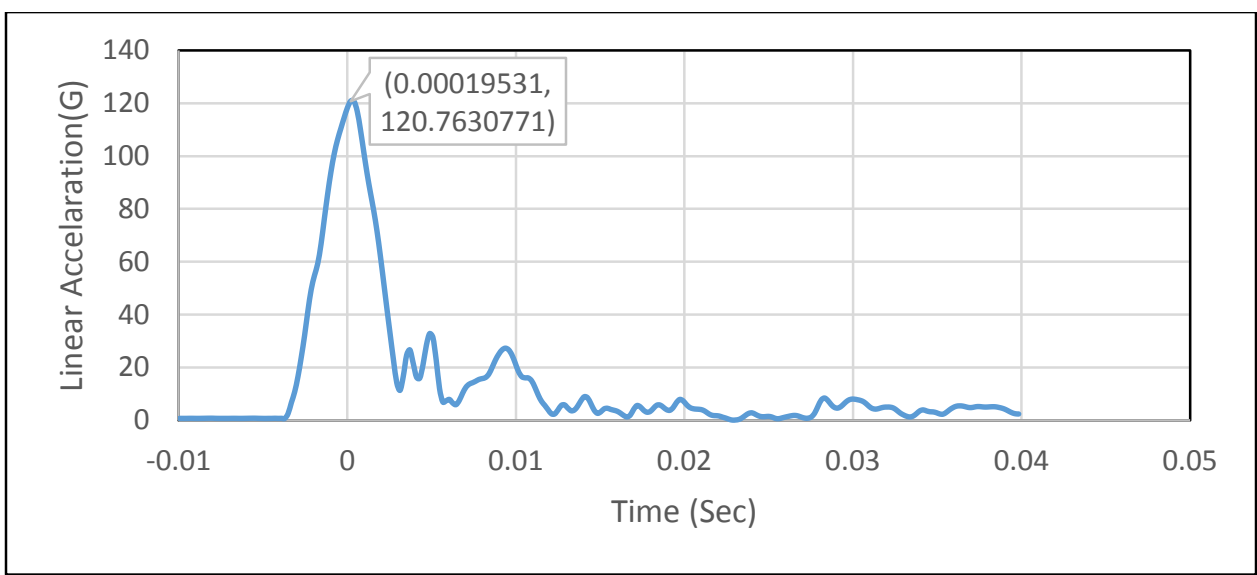

Fig 3.12 Linear Acceleration curve for Lateral 2 feet drop

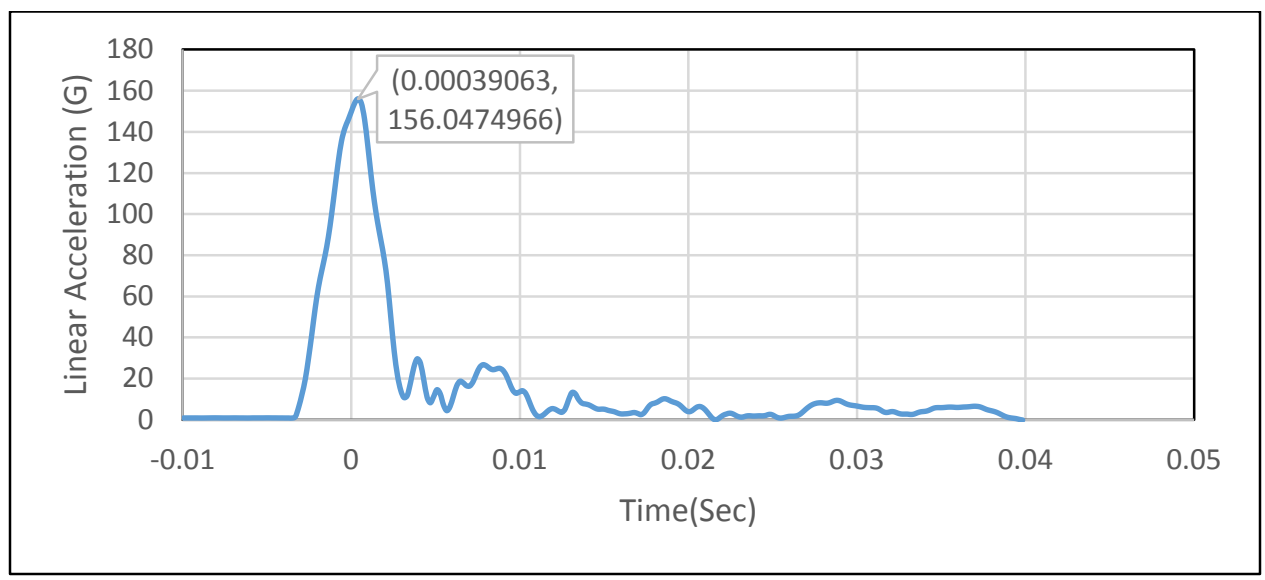

Fig 3.13 Linear Acceleration curve for Lateral 3 feet drop 


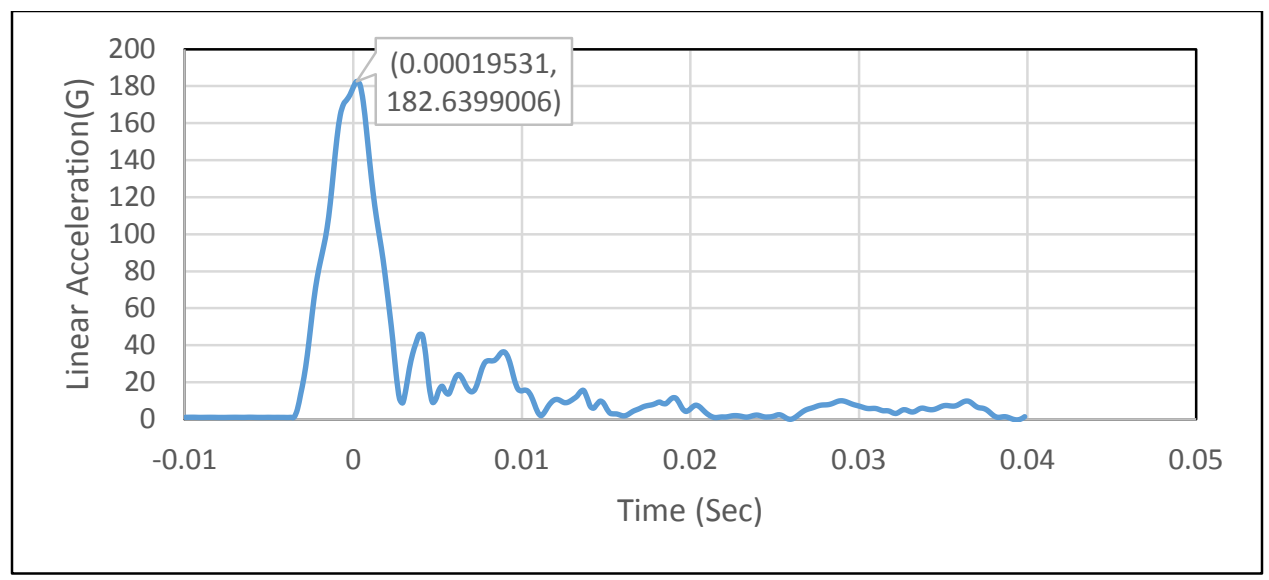

Fig 3.14 Linear Acceleration curve for Lateral 4 feet drop

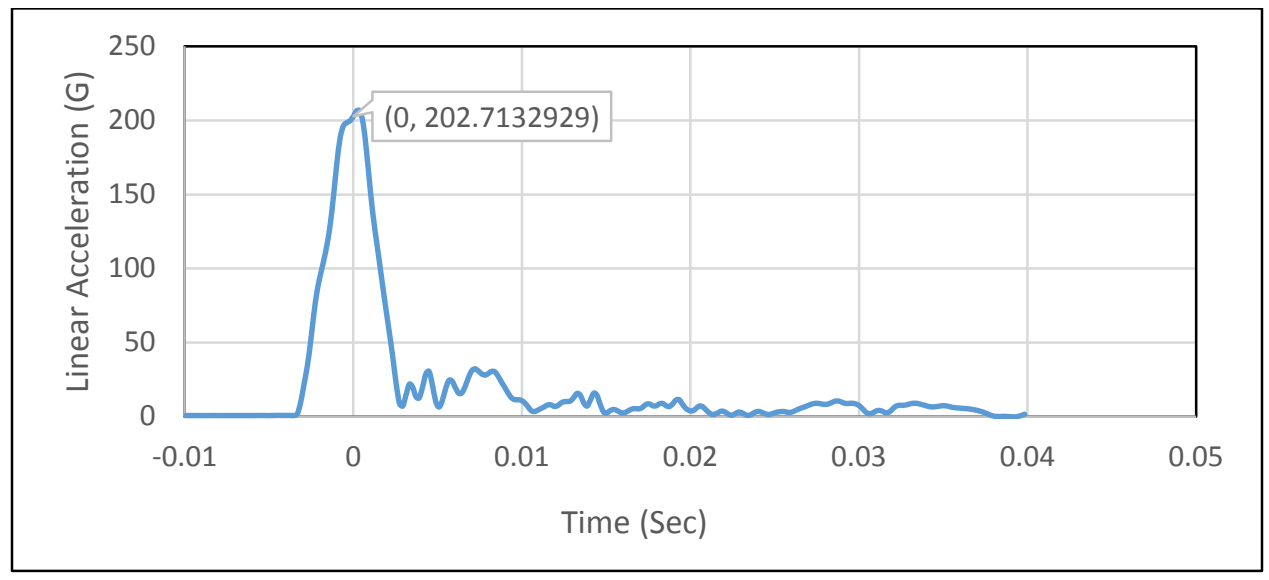

Fig 3.15 Linear Acceleration curve for Lateral 5 feet drop

\subsubsection{Posterior}

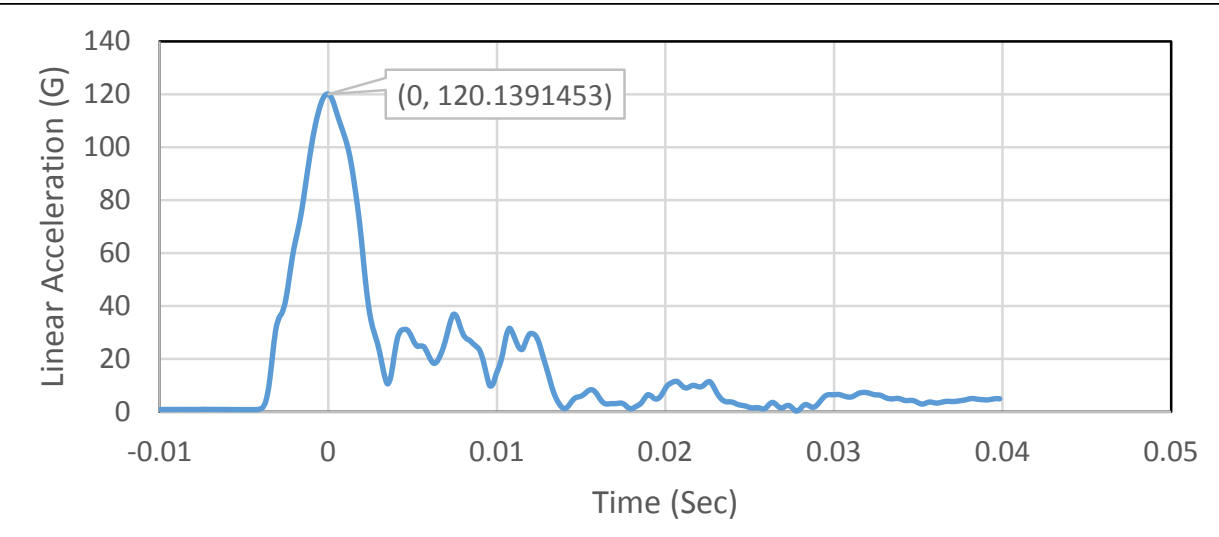

Fig 3.16 Linear Acceleration curve for Posterior 2 feet drop 


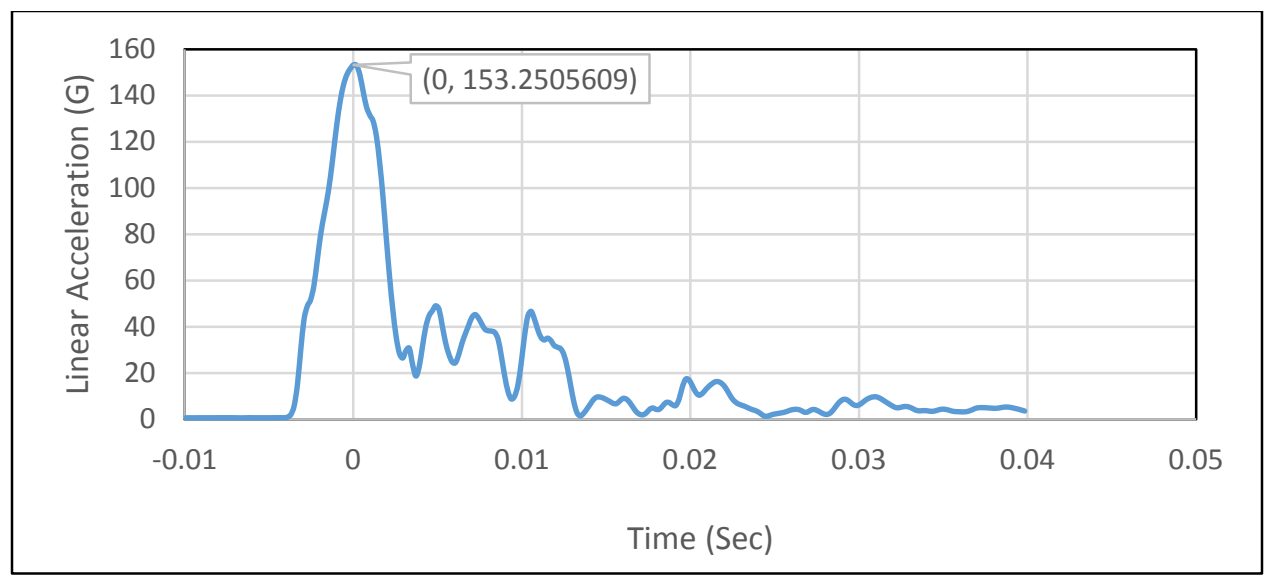

Fig 3.17 Linear Acceleration curve for Posterior 3 feet drop

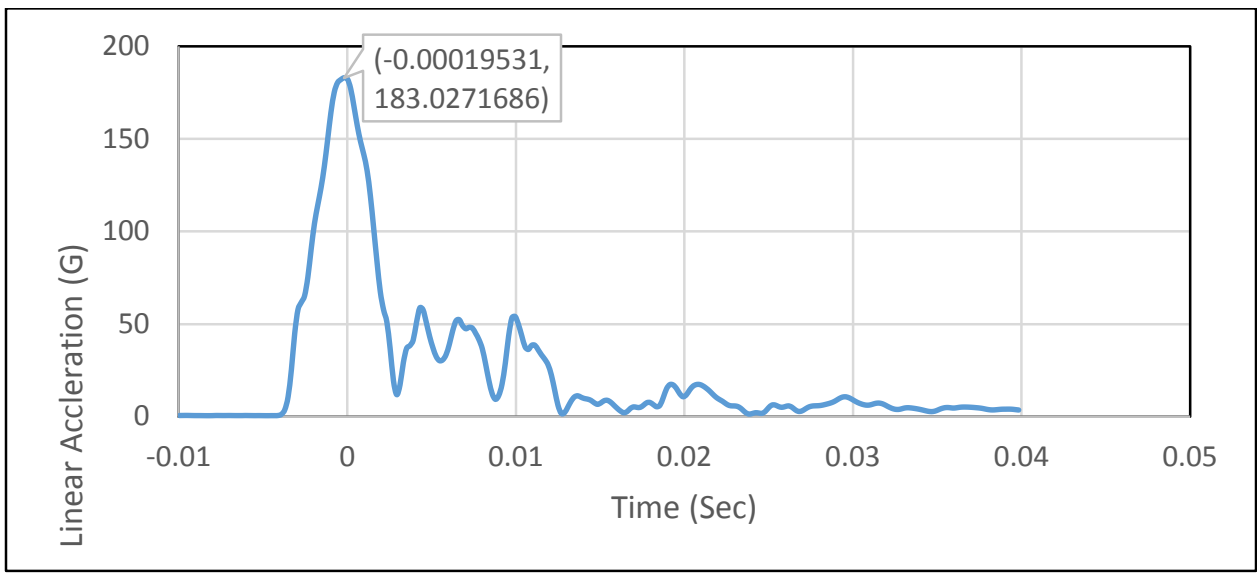

Fig 3.18 Linear Acceleration curve for Posterior 4 feet drop

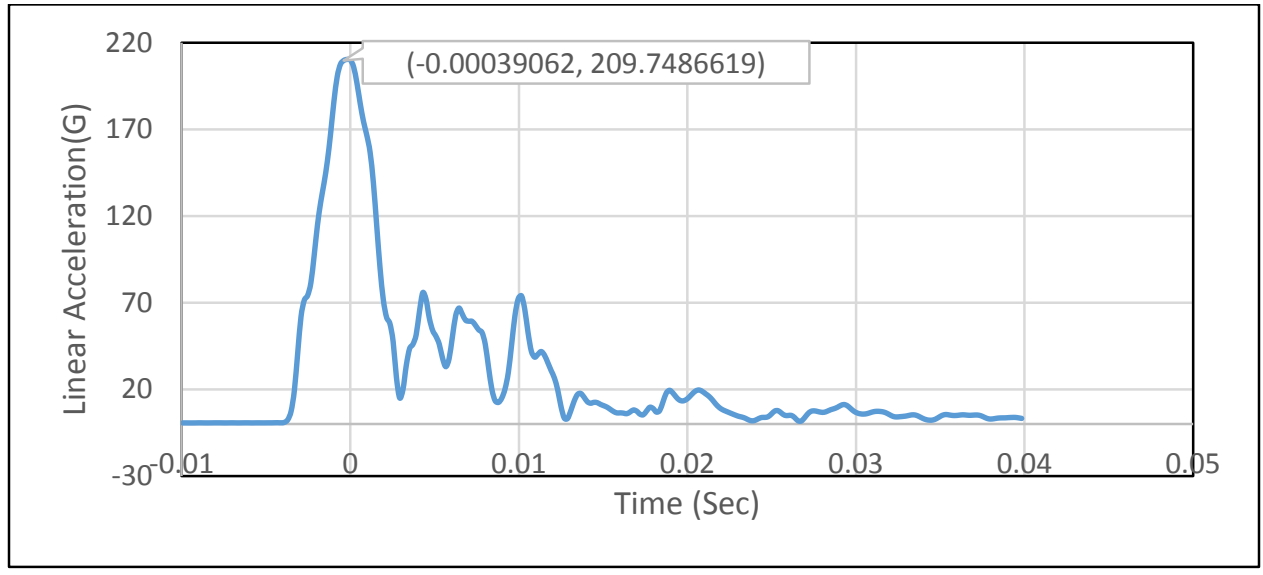

Fig 3.19 Linear Acceleration curve for Posterior 5 feet drop 
The maximum Linear Accelerations measured from the Siglab unit and extracted from the acceleration curves has been tabulated below.

Table 3.1 Maximum Linear accelerations of different drop heights with their respective orientations.

\begin{tabular}{|c|c|c|c|c|c|c|}
\hline $\begin{array}{l}\text { Orientati } \\
\text { on }\end{array}$ & $\begin{array}{l}\text { Drop } \\
\text { Heig } \\
\text { ht } \\
\text { (feet) }\end{array}$ & $\begin{array}{l}\text { Severity } \\
\text { Index }\end{array}$ & $\begin{array}{l}\text { Max Linear } \\
\text { Acceleration } \\
\text { (G) }\end{array}$ & $\begin{array}{l}\text { Max. } \\
\text { Linear } \\
\text { Acceleratio } \\
\text { n From } \\
\text { Siglab Unit } \\
\text { (G) } \\
\end{array}$ & $\begin{array}{l}\text { Percent } \\
\text { age } \\
\text { Differe } \\
\text { nce }^{1}\end{array}$ & $\begin{array}{c}\text { Time of } \\
\text { Peak } \\
\text { Accelera } \\
\text { tion } \\
\text { (Sec) }\end{array}$ \\
\hline \multirow{4}{*}{ Frontal } & 2 & 385 & 109.92 & 107 & $2.69 \%$ & $3.52 \mathrm{E}-03$ \\
\hline & 3 & 652 & 136.77 & 135 & $1.30 \%$ & $3.52 \mathrm{E}-03$ \\
\hline & 4 & 1047 & 170.80 & 170 & $0.47 \%$ & $3.52 \mathrm{E}-03$ \\
\hline & 5 & 1493 & 206.31 & 205 & $0.64 \%$ & $3.32 \mathrm{E}-03$ \\
\hline \multirow{4}{*}{$\begin{array}{l}45^{\circ} \text { to } \\
\text { Frontal }\end{array}$} & 2 & 336 & 101.14 & 98 & $3.16 \%$ & $3.91 \mathrm{E}-03$ \\
\hline & 3 & 545 & 130.36 & 128 & $1.83 \%$ & $3.71 \mathrm{E}-03$ \\
\hline & 4 & 875 & 153.75 & 152 & $1.14 \%$ & $3.52 \mathrm{E}-03$ \\
\hline & 5 & 1107 & 169.58 & 173 & $-2.00 \%$ & $3.52 \mathrm{E}-03$ \\
\hline \multirow{4}{*}{ Lateral } & 2 & 405 & 124.55 & 120 & $3.72 \%$ & $3.91 \mathrm{E}-03$ \\
\hline & 3 & 704 & 154.54 & 153 & $1.00 \%$ & $3.71 \mathrm{E}-03$ \\
\hline & 4 & 1107 & 185.11 & 182 & $1.70 \%$ & $3.91 \mathrm{E}-03$ \\
\hline & 5 & 1482 & 212.12 & 209 & $1.48 \%$ & $3.71 \mathrm{E}-03$ \\
\hline \multirow{4}{*}{ Posterior } & 2 & 484 & 122.05 & 119 & $2.53 \%$ & 4.10E-03 \\
\hline & 3 & 848 & 156.71 & 155 & $1.10 \%$ & $3.91 \mathrm{E}-03$ \\
\hline & 4 & 1316 & 191.96 & 191 & $0.50 \%$ & $3.71 \mathrm{E}-03$ \\
\hline & 5 & 1700 & 213.36 & 213 & $0.17 \%$ & $3.71 \mathrm{E}-03$ \\
\hline
\end{tabular}

The variations in the values of acceleration is due to the voltage fluctuations and other errors in the Siglab equipment. We see that the Percentage difference in the acceleration values is low $(<5 \%)$. Hence we can go ahead and use these values in the analysis. The

\footnotetext{
${ }^{1}$ Percentage Difference $=\left(\frac{\left(A_{1}-A_{2}\right)}{\left(A_{1}+A_{2}\right) / 2}\right) * 100$
} 
peak value of the Impact occurs almost at the same time interval $(3.5-4 \mathrm{msec})$, with frontal being the lower $(3.5 \mathrm{msec})$ and Posterior being the highest $(4.1 \mathrm{msec})$.

\subsubsection{Measurement of Area of Impact}

Area of Impact plays an important role in the measurement of Head Impact Contact Pressure (HICP) and Impact Force. The measurement of area of impact is a bit tedious because of the complicated shape of the Head Form and it would be really difficult to measure the actual surface which is in contact with the anvil during Impact, also the minute time of contact and the Area of contact which is in 3D makes the task much herculean.

After considering various methods, chalk measuring technique was proved to be appropriate for the measurement of Area of Impact with minute errors. In this process wet chalk powder is applied to the head form and allowed to dry.

After the drop we can find the imprint of the Area of Impact which is a 2D projection of the Area of Impact.

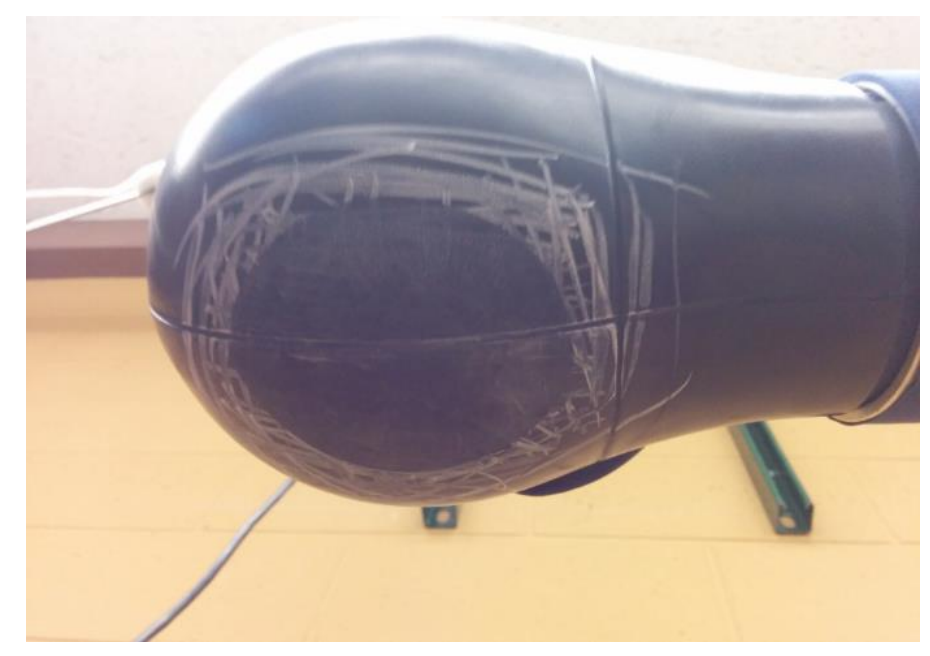

Fig 3.20 Head form with chalk applied for Area measurement 


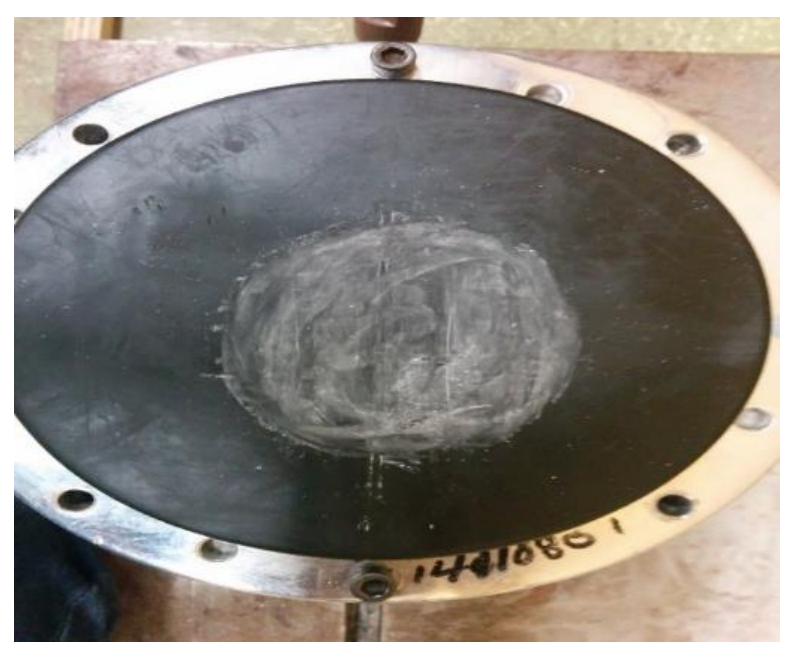

Fig 3.21 Projected Area of Impact on the Anvil

The Area of Impact for Different Falls in different orientations is shown below.

Table 3.2 Area of Impact for different drops

\begin{tabular}{|c|c|c|c|c|}
\hline Orientation & $\begin{array}{l}\text { Drop } \\
\text { Height } \\
\text { (feet) }\end{array}$ & $\begin{array}{c}\text { Major } \\
\text { Axis } \\
(2 a) \\
(\mathbf{m m}) \\
\end{array}$ & $\begin{array}{l}\text { Minor } \\
\text { Axis } \\
(2 b) \\
(\mathbf{m m}) \\
\end{array}$ & $\begin{array}{l}\text { Impact } \\
\text { Area } \pi \text { ab } \\
(\mathrm{m} 2)\end{array}$ \\
\hline \multirow{4}{*}{$\begin{array}{c}\text { Frontal } \\
(\text { Semi- } \\
\text { Elliptical }= \\
\pi a b / 2)\end{array}$} & 2 & 65 & 55 & 0.0056 \\
\hline & 3 & 65 & 60 & 0.0061 \\
\hline & 4 & 68 & 62 & 0.0066 \\
\hline & 5 & 70 & 65 & 0.0071 \\
\hline \multirow{4}{*}{$\begin{array}{l}45^{\circ} \text { to } \\
\text { Frontal }\end{array}$} & 2 & 70 & 55 & 0.0030 \\
\hline & 3 & 72 & 57 & 0.0032 \\
\hline & 4 & 74 & 60 & 0.0035 \\
\hline & 5 & 77 & 60 & 0.0036 \\
\hline \multirow{4}{*}{ Lateral } & 2 & 95 & 70 & 0.0052 \\
\hline & 3 & 98 & 75 & 0.0058 \\
\hline & 4 & 100 & 77 & 0.0060 \\
\hline & 5 & 102 & 80 & 0.0064 \\
\hline & & & & \\
\hline \multirow{4}{*}{ Posterior } & 2 & 70 & 62 & 0.0034 \\
\hline & 3 & 74 & 67 & 0.0039 \\
\hline & 4 & 76 & 68 & 0.0041 \\
\hline & 5 & 78 & 68 & 0.0042 \\
\hline
\end{tabular}


The projected area is approximated to be an ellipse for easy calculation purposes. It can be observed that the Area of Impact is higher for Frontal followed be Lateral, Posterior and $45^{\circ}$ to Frontal.

\subsubsection{Calculation of Impact Force and HICP}

The Impact Force and the HICP can be calculated from the Newton's Second Law of Motion.

It states that, "The rate of change of momentum of a body is proportional to to the impulse impressed on the body, and happens along the straight line on which that impulse is impressed." In common terms it can be expressed as that the resultant net force on a body is equal to the rate of change of linear momentum.

It can be mathematically expressed as:

$$
\vec{F}=\frac{d(\rho)}{d t}
$$

The linear momentum $(\rho)$ can be expressed as the product of the mass and resultant velocity of the body. Thus the above equation can be rewritten as:

$$
\vec{F}=\frac{d(m \vec{v})}{d t}
$$

Where $\vec{F}$ is the resultant force acting on the body,

$\mathrm{m}$ is the mass of the body and

$\vec{v}$ is the resultant velocity

As the mass of the body is constant, the resultant equation would be

$$
\vec{F}=m \frac{d(\vec{v})}{d t}
$$

We know that the rate of change of velocity is acceleration $(\vec{a})$ 


$$
\vec{F}=m \vec{a}
$$

The above relation can be used to calculate the Impact Pressure due to free fall.

As we know,

$\mathrm{m}=\mathrm{m}_{\mathrm{h}}=$ Mass of the Head form $=4.716 \mathrm{~kg}$.

$(\vec{a})=\overrightarrow{a_{l g}}=$ Linear Acceleration expressed in $\mathrm{m} / \mathrm{s}^{2}$.

The linear acceleration values obtained from the drop test are in terms of 'Gs'. It can be converted into $\mathrm{m} / \mathrm{s}^{2}$ by multiplying acceleration due to gravity (g).

Thus the above Eq. 1 can be modified as

$$
\text { Impact Force }=\vec{F}_{l}=\mathrm{m}_{\mathrm{h}} \cdot \overrightarrow{a_{l g}}
$$

\section{Pressure Calculation:}

Pressure $(\mathrm{P})$ can be defined as the Force per unit Area acting on the body.

$$
\begin{aligned}
& \mathrm{P}=\frac{\vec{F}}{A} \\
& \vec{F}=P . A
\end{aligned}
$$

Applying the above Eq. to our criteria,

Impact Force $=\overrightarrow{F_{l}}=\mathrm{m}_{\mathrm{h}} \cdot \overrightarrow{a_{l g}}=\mathrm{P}_{\mathrm{i}} \cdot \mathrm{A}_{\mathrm{i}}$

Where,

$\mathrm{P}_{\mathrm{i}}=$ Head Impact Contact Pressure (HICP)

$A_{i}=$ Area of Impact

The Area of Impact is assumed to be constant during the drop.

The HICP $\left(\mathrm{P}_{\mathrm{i}}\right)$ can be redefined as:

$$
P_{i}=\frac{m_{h} \times \overrightarrow{a_{l g}}}{A_{i}}
$$




\subsubsection{Discussion}

The HICP values for different drops in their respective orientations has been calculated and tabulated below.

It should be noted that the Impact Pressure and Impact forces follow the similar profile as the acceleration curves as the mass of the head form and Area of impact were assumed to be constant.

Table 3.3 HICP for different drop heights and respective orientations

\begin{tabular}{|c|c|c|c|c|}
\hline Orientation & $\begin{array}{l}\text { Drop } \\
\text { Height } \\
\text { (feet) }\end{array}$ & $\begin{array}{l}\text { Linear } \\
\text { Acceleration } \\
\text { (G) (From } \\
\text { Graph) } \\
\end{array}$ & $\begin{array}{l}\text { Impact Force }= \\
\left(m^{*} g^{*} G\right)(N)\end{array}$ & HICP (MPa) \\
\hline \multirow{4}{*}{ Frontal } & 2 & 109.92 & 5305.298071 & 0.94 \\
\hline & 3 & 136.77 & 6601.301863 & 1.08 \\
\hline & 4 & 170.80 & 8243.737613 & 1.24 \\
\hline & 5 & 206.31 & 9957.633879 & 1.39 \\
\hline \multirow{4}{*}{$45^{\circ}$ to frontal } & 2 & 91.74 & 4427.831469 & 1.46 \\
\hline & 3 & 120.25 & 5803.740637 & 1.80 \\
\hline & 4 & 139.09 & 6713.398322 & 1.93 \\
\hline & 5 & 163.19 & 7876.430978 & 2.17 \\
\hline \multirow{4}{*}{ Lateral } & 2 & 120.76 & 5828.662766 & 1.12 \\
\hline & 3 & 156.05 & 7531.674869 & 1.30 \\
\hline & 4 & 182.64 & 8815.164479 & 1.46 \\
\hline & 5 & 206.41 & 9962.620804 & 1.55 \\
\hline \multirow{4}{*}{ Posterior } & 2 & 120.14 & 5798.548527 & 1.70 \\
\hline & 3 & 153.25 & 7396.680007 & 1.90 \\
\hline & 4 & 183.03 & 8833.856075 & 2.18 \\
\hline & 5 & 210.35 & 10152.65203 & 2.44 \\
\hline
\end{tabular}




\subsection{Pressure Film and Topaq Analyzer.}

\subsubsection{Pressure Films [19]}

A Fujifilm Prescale (Here after referred as a pressure film) is a tool which is used to study the distribution and magnitude of Pressure between two surfaces in contact. It is an extremely thin mylar based film (Thickness is approximately 1-2 $\mu \mathrm{m}$ ). It contains of layer of microcapsules which rupture upon application of force revealing a pressure distribution profile between the two contacting surfaces similar to litmus paper. Higher the color intensity (Dark red), higher the pressure between the surfaces.

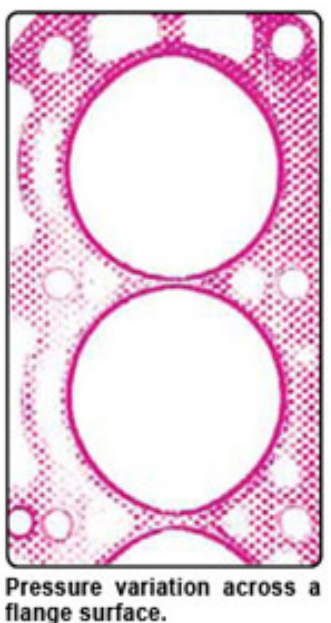

\section{CROSS SECTIONAL VIEW OF SENSOR FILM}

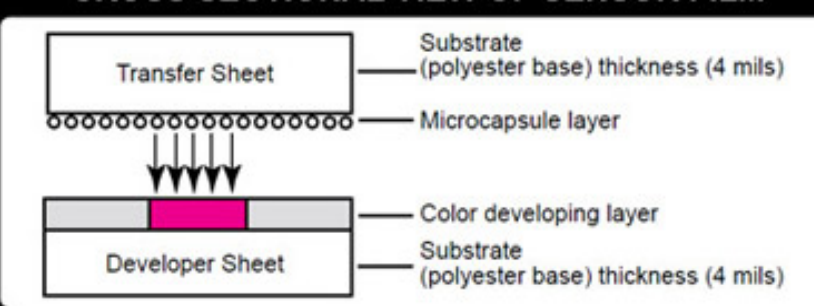

Figure 3.22 Explanation of working of a Pressure Film and C.S View of a Film from Sensor Prod. Inc [25] Image Courtesy: Sensor Products Inc. website [20] 


\subsubsection{Selection of Pressure Films}

There are different kinds of Pressure films available with their respective ranges of pressures which they can measure.

Table 3.4 Pressure Film Types and their ranges of pressures

\begin{tabular}{|l|l|l|}
\hline S.No & Pressure Film Type & Pressure Range \\
\hline 1 & Extreme Low & $7.2-28$ PSI $\left(0.5-2 \mathrm{~kg} / \mathrm{cm}^{2}\right)$ \\
\hline 2 & Ultra Low & $28-85$ PSI $\left(2-6 \mathrm{~kg} / \mathrm{cm}^{2}\right)$ \\
\hline 3 & Super Low & $70-350$ PSI $\left(5-25 \mathrm{~kg} / \mathrm{cm}^{2}\right)$ \\
\hline 4 & Low & $350-1400$ PSI $\left(25-100 \mathrm{~kg} / \mathrm{cm}^{2}\right)$ \\
\hline 5 & Medium & $1400-7100$ PSI $\left(100-500 \mathrm{~kg} / \mathrm{cm}^{2}\right)$ \\
\hline 6 & High & $7100-18,500$ PSI $\left(500-1300 \mathrm{~kg} / \mathrm{cm}^{2}\right)$ \\
\hline 7 & Super High & $18,500-43,200$ PSI $\left(1300-3000 \mathrm{~kg} / \mathrm{cm}^{2}\right)$ \\
\hline
\end{tabular}

Upon observing the readings from the Siglab unit during the drop tests it hass been observed that the pressure range of the entire experiments falls in the range of 350-7100 PSI. Hence Medium and Low pressure films were selected depending upon the drop height and orientation.

Temperature and Relative humidity also plays a major role in the operation of the pressure films.

\subsubsection{Topaq Analyzer}

A Topaq Analyzer is a system which looks similar to a normal scanner but when used with the Pressure film produce a high resolution, color calibrated description of distribution of pressure on the film. It consists of a specially calibrated densitimetric scanner which 
interprets the stress marks on the films and produce results such as Area, Impact force, Average pressure and also Pressure histograms.

\subsubsection{Setup}

A Pressure film set consists of the two different sheets as explained in the figure above (3.22), A Donor sheet (Transfer sheet) and a Receiver sheet (Developer sheet). Both the sheets have a textured matte side. While performing the operation both the sheets are to be placed in such a manner that the textured surfaces must be in contact with one another. Care should be taken while handling the films as a set because minute pressures are sufficient to rupture the bubbles leaving a permanent color in the film causing discrepancies in the reading. A Donor sheet is not required when using the Low pressure films as the sensitivity of these films is really high.

The Pressure film set is to be placed on the anvil in such manner that the receiver film is on the bottom and the Donor sheet is on the top. It is to be tightly attached to the anvil restricting any moment of the film.

\subsubsection{Results}

Drop Tests were performed from 2 feet, 3 feet, 4 feet and 5 feet in Frontal, $45^{\circ}$ to Frontal, Lateral and Posterior orientations as per NOCSAE standards, and the Deformations on the Pressure films, Results and the Pseudo image obtained from the Topaq scanner and the results have been shown in Appendix-A.

\subsection{Discussions}

The results obtained from the analyzer are congregated in the tabular form below 
Table 3.5 HICP for different drops and their respective orientations from Pressure Films

\begin{tabular}{|c|c|c|}
\hline \multirow{4}{*}{ Orientation } & $\begin{array}{c}\text { Height } \\
\text { (feet) }\end{array}$ & $\begin{array}{c}\text { HICP } \\
\text { (MPa) }\end{array}$ \\
\hline \multirow{4}{*}{ Frontal } & $\mathbf{2}$ & 2.79 \\
\cline { 2 - 3 } & $\mathbf{3}$ & 2.84 \\
\cline { 2 - 3 } & $\mathbf{4}$ & 3.25 \\
\cline { 2 - 3 } & $\mathbf{5}$ & 3.42 \\
\hline \multirow{4}{*}{$\mathbf{4 5}^{\circ}$ to Frontal } & $\mathbf{2}$ & 3.85 \\
\cline { 2 - 3 } & $\mathbf{3}$ & 4.04 \\
\cline { 2 - 3 } & $\mathbf{4}$ & 4.26 \\
\cline { 2 - 3 } & $\mathbf{5}$ & 4.63 \\
\hline \multirow{4}{*}{ Lateral } & $\mathbf{2}$ & 3.32 \\
\hline & $\mathbf{3}$ & 3.49 \\
\cline { 2 - 3 } & $\mathbf{4}$ & 3.55 \\
\cline { 2 - 3 } & $\mathbf{5}$ & 3.64 \\
\hline \multirow{3}{*}{ Posterior } & & \\
\hline & $\mathbf{2}$ & 2.77 \\
\hline & $\mathbf{3}$ & 3.9 \\
\hline & $\mathbf{4}$ & 4.01 \\
\hline \multirow{4}{*}{$\mathbf{5}$} & 4.2 \\
\hline & & \\
\hline
\end{tabular}

We observe that the HICP increases with the increase in height. The peak values of HICP of 4.63 MPa, is observed in the 5 feet drop of $45^{\circ}$ to Frontal Region. While the lowest value of 2.79 $\mathrm{MPa}$ is observed in the 2 feet drop of Frontal Region.

One can observe that we can only get the average pressure values from the analyzer. There is also a lot of discrepancies in the Area of Impacts and the Impact forces which will be explained further. ${ }^{2}$

\footnotetext{
${ }^{2}$ Mail conversation with SensorProd explaining the reasons is attached
} 


\subsection{Comparison of Results and Discussions}

In this chapter we will compare the HICP values obtained from both the experimental methods.

\subsubsection{Comparison of HICP between Pressure films and Accelerometers}

Table 3.6 HICP Comparison between Siglab and Pressure Films

\begin{tabular}{|c|c|c|c|c|}
\hline Orientation & $\begin{array}{l}\text { Drop } \\
\text { Height } \\
\text { (feet) }\end{array}$ & $\begin{array}{l}\text { HICP (MPa) - } \\
\text { Accelerometers }\end{array}$ & $\begin{array}{l}\text { HICP } \\
\text { (MPa) - } \\
\text { Pressure } \\
\text { Films }\end{array}$ & $\begin{array}{l}\text { Percentage } \\
\text { Difference }\end{array}$ \\
\hline \multirow{4}{*}{ Frontal } & 2 & 0.94 & 2.79 & $99.20 \%$ \\
\hline & 3 & 1.08 & 2.84 & $89.80 \%$ \\
\hline & 4 & 1.24 & 3.25 & $89.53 \%$ \\
\hline & 5 & 1.39 & 3.42 & $84.41 \%$ \\
\hline & & & & \\
\hline \multirow{4}{*}{$\begin{array}{l}45^{\circ} \text { to } \\
\text { Frontal }\end{array}$} & 2 & 1.46 & 3.85 & $90.02 \%$ \\
\hline & 3 & 1.8 & 4.04 & $76.71 \%$ \\
\hline & 4 & 1.93 & 4.26 & $75.28 \%$ \\
\hline & 5 & 2.17 & 4.63 & $72.35 \%$ \\
\hline \multirow{5}{*}{ Lateral } & & & & 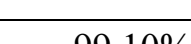 \\
\hline & 2 & 1.12 & 3.32 & $99.10 \%$ \\
\hline & 3 & 1.3 & 3.49 & $91.44 \%$ \\
\hline & 4 & 1.46 & 3.55 & $83.43 \%$ \\
\hline & 5 & 1.55 & 3.64 & $80.54 \%$ \\
\hline & & & & \\
\hline \multirow{4}{*}{ Posterior } & 2 & 1.7 & 2.77 & $47.87 \%$ \\
\hline & 3 & 1.9 & 3.9 & $68.97 \%$ \\
\hline & 4 & 2.18 & 4.01 & $59.13 \%$ \\
\hline & 5 & 2.44 & 4.2 & $53.01 \%$ \\
\hline
\end{tabular}

The HICP values obtained from the Siglab Unit and the Pressure films have been compared in the Table 3.6 and the following observations can be inferred.

The difference in the HICP values from the experiments can be due to the following reasons. 
1) The Analyzer is generally used for the static analysis and rarely used for the Impact testing.

2) The source of error can be due to the multiple impacts of Head form with the film. The Analyzer works perfect for the single Impact conditions. As we can't control the minor re-bouncing of the head form, we are prone to get some errors.

3) Out of many outputs only the Pressure and Contact area are reliable as the Analyzer is not designed for the Impact force measurement.

4) The Pressure films are designed for the Flat surfaces, as our head form has a curved profile, the center region of the Impact area is prone to have more pressure concentration than the other regions, which in turn varies the average pressure.

5) The Eye brow region of the head form is involved in impact which modifies the area and the pressure acting on the film.

6) The approximation with the area of impact might lead to some discrepancies in the HICP measurement.

Considering the above conditions the head form has been torqued to $180 \mathrm{lb}$.-in as per NOCSAE standards, for every drop and care was taken to tighten the equipment to minimize the rebound effect.

The following observations can be made from the Table-3.6

1. Both the methods show similar profile in the HICP increase with increase in height.

2. It can be observed that the Frontal region has the lowest range of HICP in both the methods. 
3. $45^{\circ}$ to Frontal region has the highest range of HICP values than the other regions as per the pressure films, although it has lower linear acceleration values when compared to the other regions. It might be because of the lower surface areas. We can also observe that the discrepancies between both the methods is higher in this region because of the lower surface area leads to maximum rebound resulting in multiple impacts on the film.

4. The highest range of HICP values is found the posterior region which is verified by both the methods and the highest HICP values can be observed for 5 feet drop of the posterior region which implies that there is a higher chance of HICP if the impact happens in this region.

5. Although lateral and posterior region has similar range of linear accelerations, the difference in the range of HICP values can be because of the variance in impact area which proves the importance of impact area in HICP measurement.

While with the siglab unit the approximations might also lead to some discrepancies in the calculations too, but as we cannot get the acceleration profiles from the Pressure films and by comparing the HICP values to the previous experiments the readings obtained from the Siglab unit were considered for the Finite Element Analysis which will be explained in the further chapters. 


\subsubsection{HICP Plots}

\subsubsection{Drop Height Vs. Maximum Linear Acceleration}

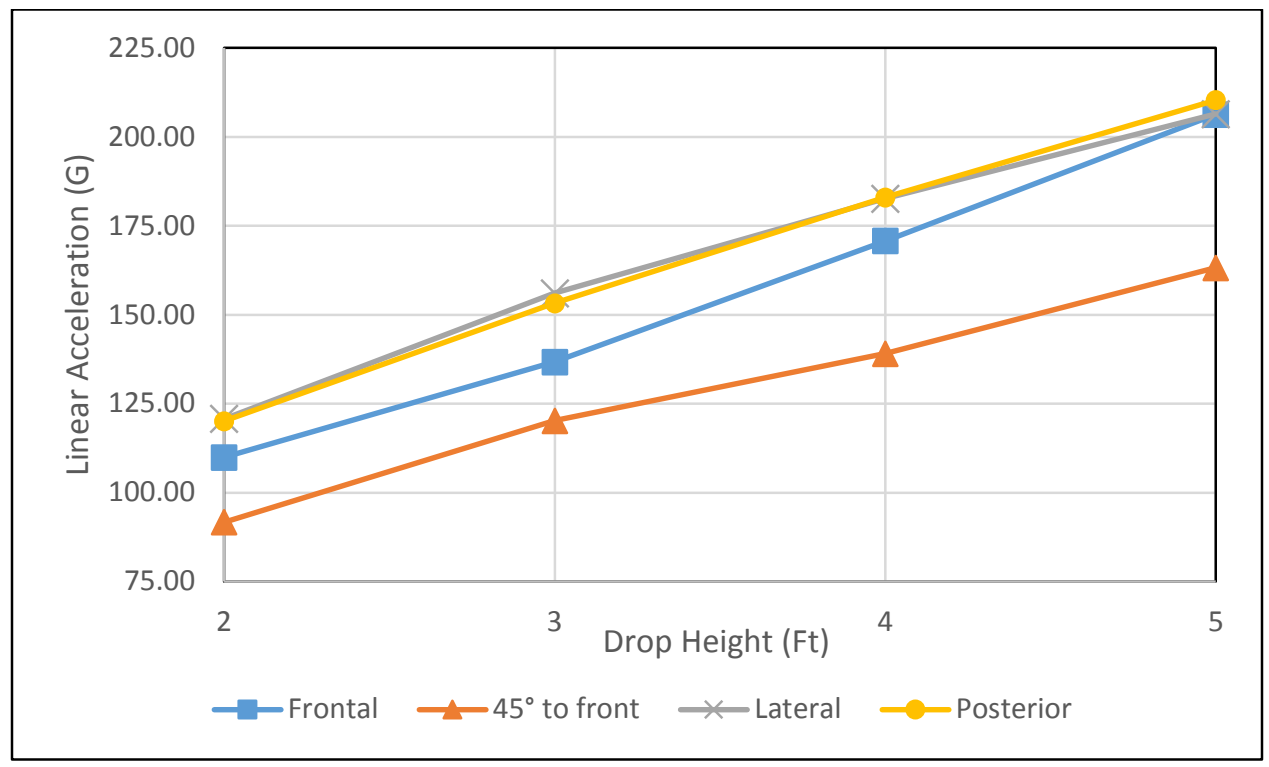

Figure 3.23 Maximum Linear Acceleration Vs Drop Height

From the above plot it can be observed that the Linear acceleration is lower $(91-164 \mathrm{G})$ for $45^{\circ}$ to frontal region for any given height while posterior region is on the higher end $(120-210 \mathrm{G})$.

It can also be observed that the Posterior and Lateral regions have their linear accelerations distributed in the same range.

Table 3.7 Maximum Linear Acceleration Vs Drop Heights for different regions

\begin{tabular}{|c|c|c|c|c|c|}
\hline & & \multicolumn{4}{|c|}{ Maximum Linear Acceleration (G's) } \\
\hline \multicolumn{2}{|c|}{ Orientation } & Frontal & $45^{\circ}$ to Frontal & Lateral & Posterior \\
\hline \multirow{4}{*}{ 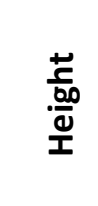 } & 2 & 109.92 & 91.74 & 120.76 & 120.14 \\
\hline & 3 & 136.77 & 120.25 & 156.05 & 153.25 \\
\hline & 4 & 170.80 & 139.09 & 182.64 & 183.03 \\
\hline & 5 & 206.31 & 163.19 & 206.41 & 210.35 \\
\hline
\end{tabular}




\subsubsection{Drop Heights Vs. Maximum HICP}

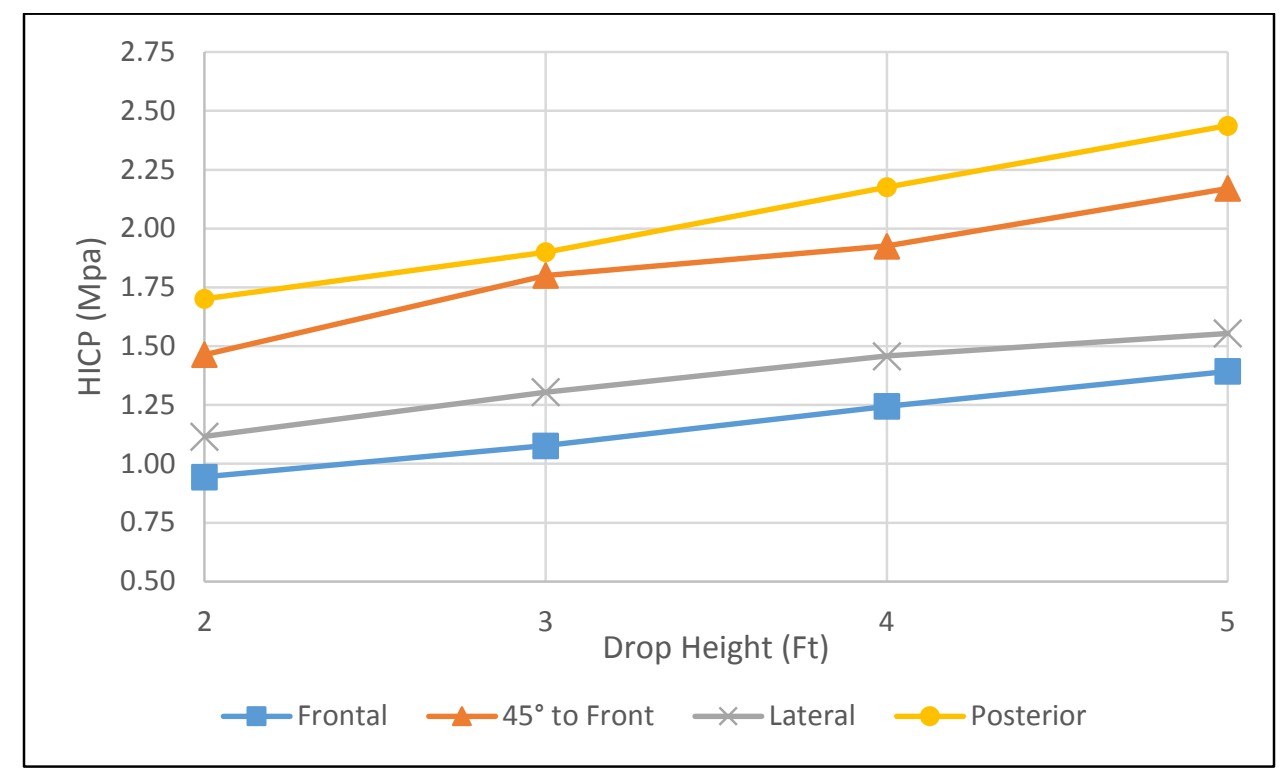

Figure 3.24 HICP Vs Drop Heights

From the above plot it can be inferred that the Posterior range have higher range of HICP with the highest value being $2.44 \mathrm{MPa}$ for 5 feet drop which occurs at $3.71 \mathrm{~ms}$. The Frontal region has the lowest values of HICP for any given height with the lowest being $0.94 \mathrm{MPa}$ for 2 feet drop which occurs at $3.52 \mathrm{msec}$.

Table 3.8 Drop Heights Vs Max HICP for different Drops

\begin{tabular}{|c|c|c|c|c|c|}
\hline & & \multicolumn{4}{|c|}{ Maximum HICP (MPa) } \\
\hline \multicolumn{2}{|c|}{ Orientation } & Frontal & $\begin{array}{l}45^{\circ} \text { to } \\
\text { Front }\end{array}$ & Lateral & Posterior \\
\hline \multirow{4}{*}{ 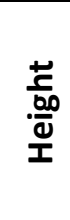 } & 2 & 0.94 & 1.46 & 1.12 & 1.70 \\
\hline & 3 & 1.08 & 1.80 & 1.30 & 1.90 \\
\hline & 4 & 1.24 & 1.93 & 1.46 & 2.18 \\
\hline & 5 & 1.39 & 2.17 & 1.55 & 2.44 \\
\hline
\end{tabular}




\subsubsection{Drop Height Vs. Maximum HICP Vs Maximum Linear Acceleration}

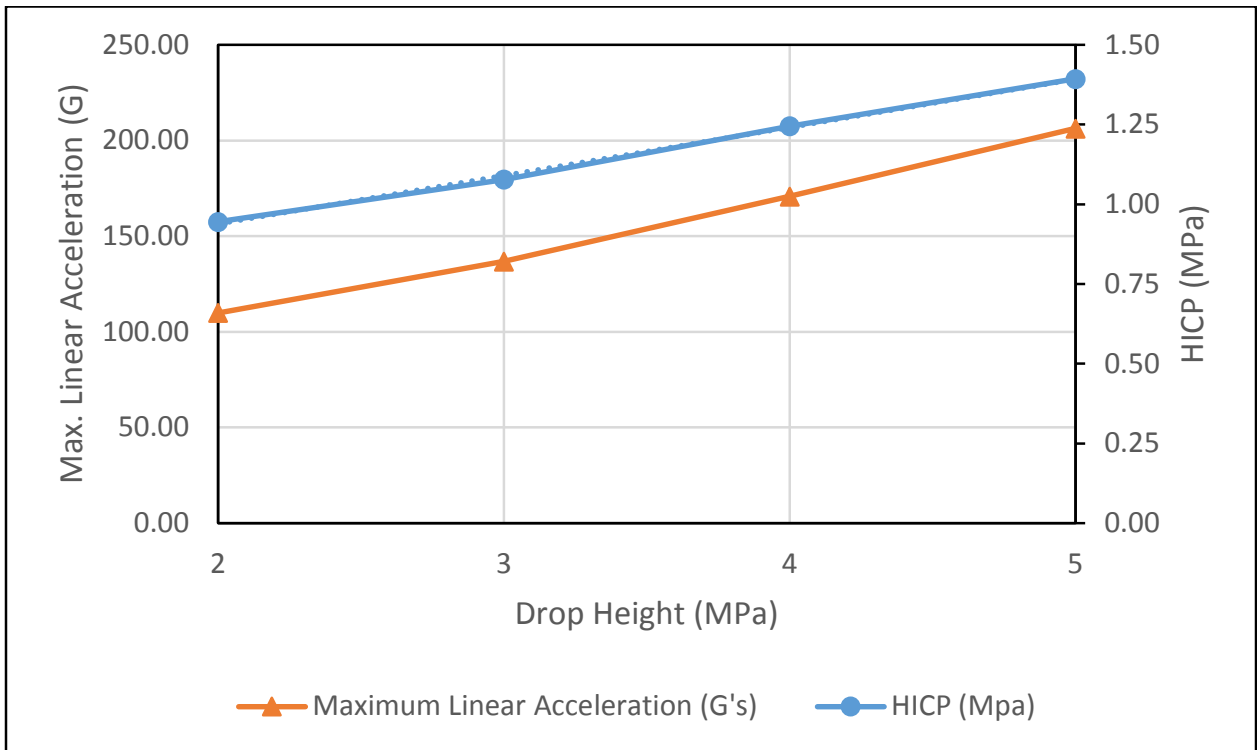

Figure 3.25 Plot of Drop Height Vs HICP Vs Linear Acceleration for Frontal region of Impact

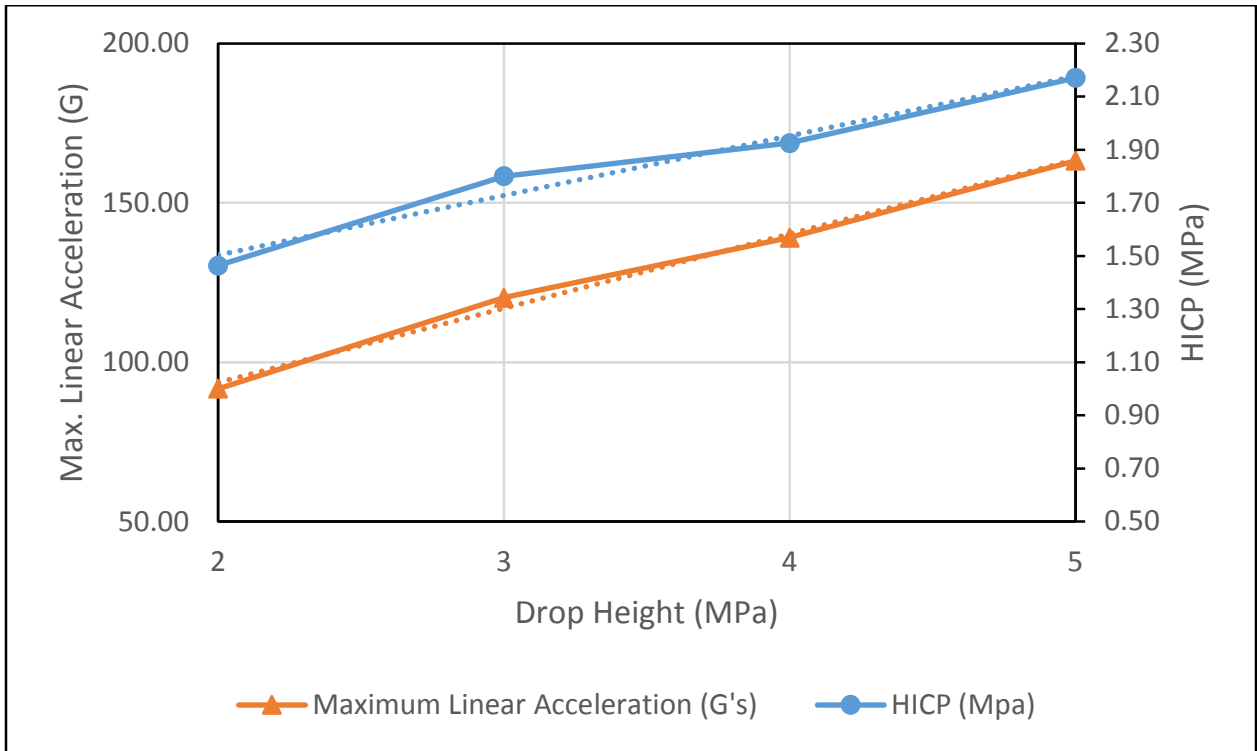

Figure 3.26 Plot of Drop height Vs HICP Vs Linear Acceleration for 45 to Frontal region of Impact 


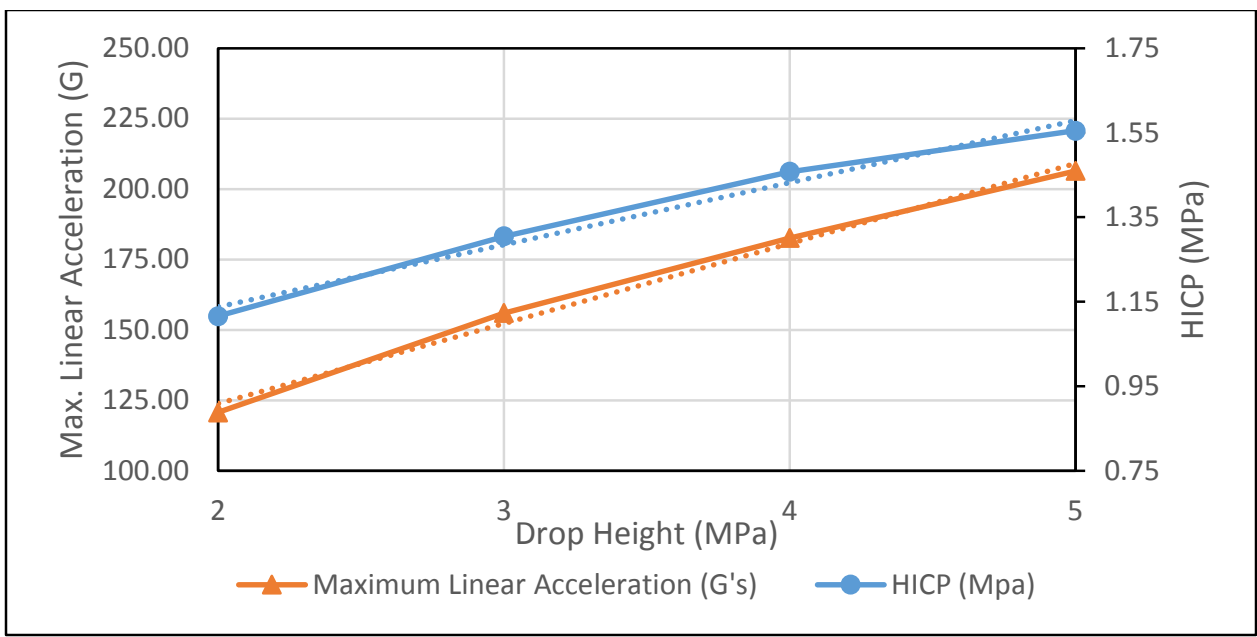

Figure 3.27 Plot of Drop Height Vs HICP Vs Linear Acceleration for Lateral region of Impact

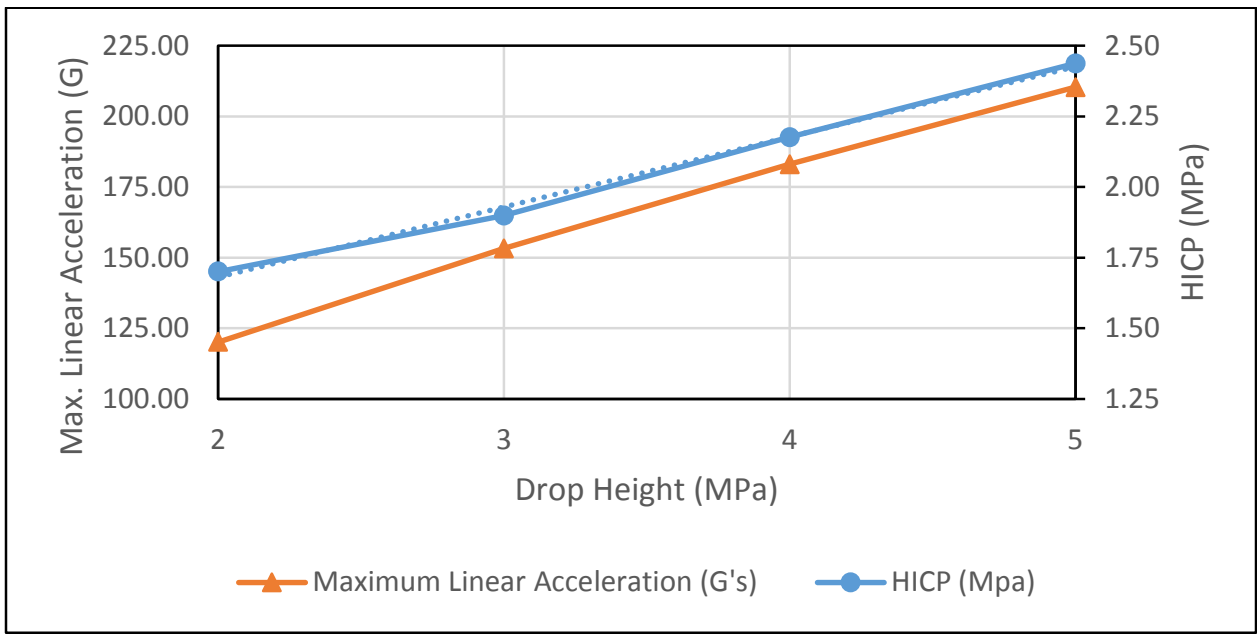

Figure 3.28 Plot of Drop Height Vs HICP Vs Linear Acceleration for Posterior region of Impact

We can observe that the both the manually calculated HICP and the Linear acceleration follow the similar profile with increase in height. Hence we can go ahead and use these values in the Finite Element Simulation. 


\section{Chapter 4 \\ HICP Vs Stress Distribution in Brain by Finite Element Analysis}

\subsection{Introduction}

In chapter-3 kinetic response of head namely linear accelerations Vs drop heights and HICP Vs drop heights were studied. In this chapter kinetic response of brain namely stress distribution in brain Vs HICP are studied by Finite Element Analysis.

As discussed earlier majority of the TBI occurs when HICP is transferred to the brain through the outer layer (scalp) and through the interior layers as Skull, Dura Mater, and Cerebral Spinal Fluid. If one can measure the kinetic response of the brain due to a given HICP, then one can quantify brain injuries such as concussion, and contusion, and other TBIs. The best way to quantify the kinetic response of the brain due to HICP is either by medical imagining like CT scan or through Finite Element Method (FEM) of Stress analysis. Although the former method is accurate clinically readily acceptable solution, the later provides quantitative measure of the kinetic response of the brain in terms of pressure and shear stress distribution in the brain corresponding to a given mechanics of HICP.

Also using FEM of stress analysis one can correlate kinematic response of the head (discussed in chapter 3) with kinetic response of the brain for the same HICP to elicit the connection between the cause and effect for the brain concussion.

\subsection{FE model of Human Head}

An accurate FE model is a primary requirement for any analysis. The FE model for this study has been generated by using Geometric surface scanning. The Generation and 
validation of the model has been explained in detail in thesis work of Mr. David M Labyak[20].

The validated model was meshed in Abaqus, and stored as an .inp* format. Hypermesh was selected for the analysis depending upon the availability of the licenses in the university and the efficiency of Altair ${ }^{\circledR}$ RADIOSS $₫$ in impact analysis. Although the model has been set up correctly in Abaqus there were some errors with the mesh when the model was imported into Hypermesh. The imported model has an impactor and anvil in the model which were deleted. The model was re-meshed with tetra element maintaining a consistent aspect ratio and a proper element size.

The model consists of Scalp, Skull, Dura mater and the Brain.

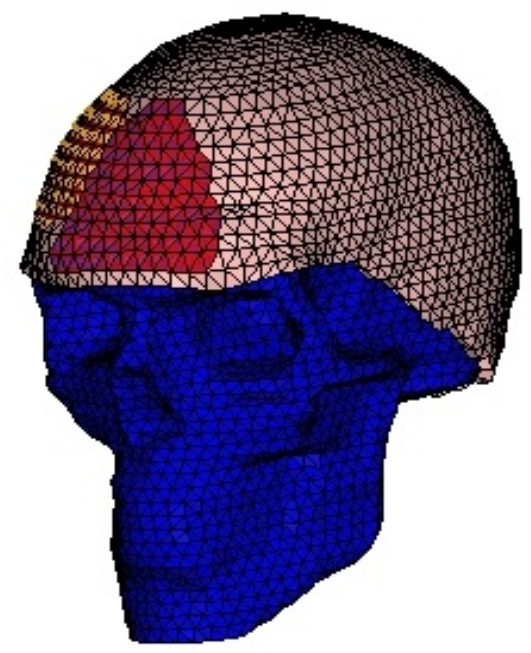

Figure 4.1 Meshed 3D form Model with Impact Areas Marked on it

\subsubsection{Material Properties}

Element properties plays an important role in a Finite Element (Here after referred to as FE) study. The element type was assumed to be elastic and the properties of different 
layers were considered from Mr. David M Labyak's thesis[21], which were shown below.

Table 4.1 Material Properties for the FE Model [21]

\begin{tabular}{|c|c|c|c|c|}
\hline Layer & $\begin{array}{l}\text { Density } \\
\mathbf{( K g / m 3 )}\end{array}$ & $\begin{array}{l}\text { Young's } \\
\text { Modulus (MPa) }\end{array}$ & $\begin{array}{l}\text { Poisson's } \\
\text { Ratio }\end{array}$ & $\begin{array}{l}\text { Number of } \\
\text { elements }\end{array}$ \\
\hline Scalp & $1.41 \mathrm{E}-09$ & 8.05 & 0.49 & 3665 \\
\hline Skull & $2.70 \mathrm{E}-09$ & 6500 & 0.22 & 22930 \\
\hline Dura mater & $1.04 \mathrm{E}-09$ & 0.148 & 0.4996 & 4154 \\
\hline Brain Tissue & $1.04 \mathrm{E}-09$ & 0.533 & 0.4996 & 17088 \\
\hline
\end{tabular}

The material properties have been applied to the respective layers in the model are

explained in detail in Appendix-C.

The different areas of impact applied on the model are shown below.

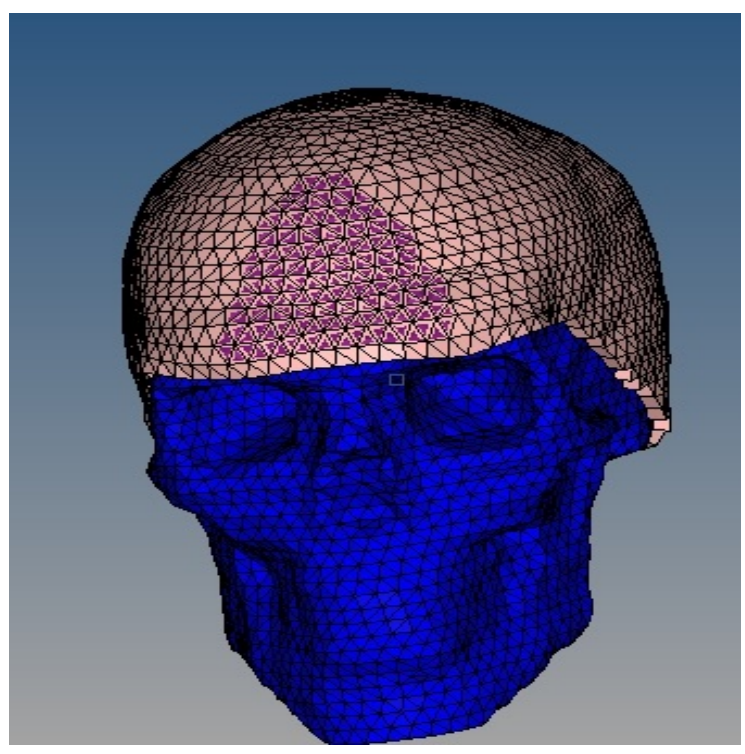

Figure 4.2 FE Model for Frontal Impact

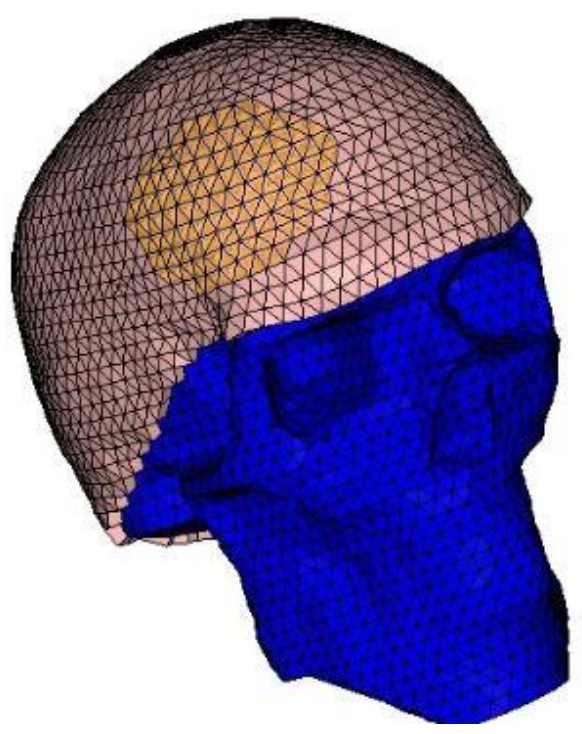

Figure $4.3 \mathrm{FE}$ Model for $45^{\circ}$ to Frontal Impact 


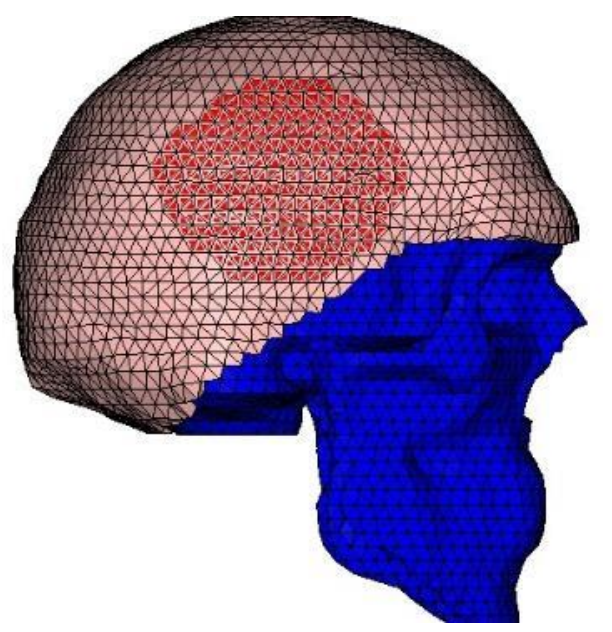

Figure 4.4 FE Model for Lateral Impact

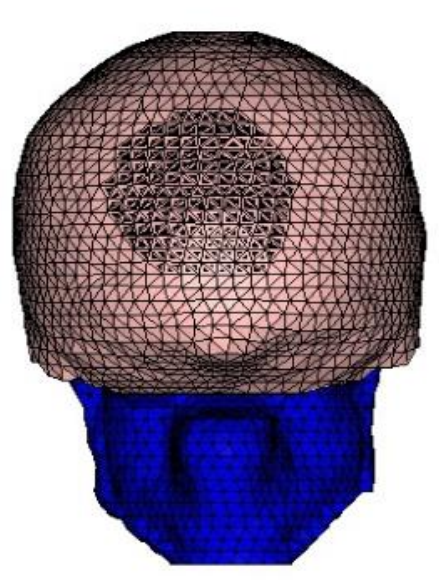

Figure 4.5 FE Model for posterior Impact

As observed in the Table-3.2 we see that the area of Impact is different for different orientations and heights, the locations of the area of impact is measured from the drop tests and the average area for respective orientations has been calculated and applied on the model following the contour of the area of Impact. The area of Impacts were imposed on the model assuming that the center of mass of head form coincides with center of mass of the FE Model.

\subsection{HICP Input Curves}

A general acceleration curve developed from the Siglab unit during drop test has been shown in the earlier sections. However for the FEA only the peak curve of the Impact (the curve which has the peak Linear Acceleration) was considered assuming that the majority of the injury is caused by the maximum acceleration of the peak curve.

The maximum acceleration peak curve has been scaled to start from $\mathrm{t}=0 \mathrm{sec}$, and the corresponding acceleration values has been scaled accordingly which in turn effects the Impact pressure values. 
The load is assumed to be uniformly distributed and is applied in terms of the pressure Vs time (Transient loading), to the model.

Different Pressure curves used for the analysis were shown below.

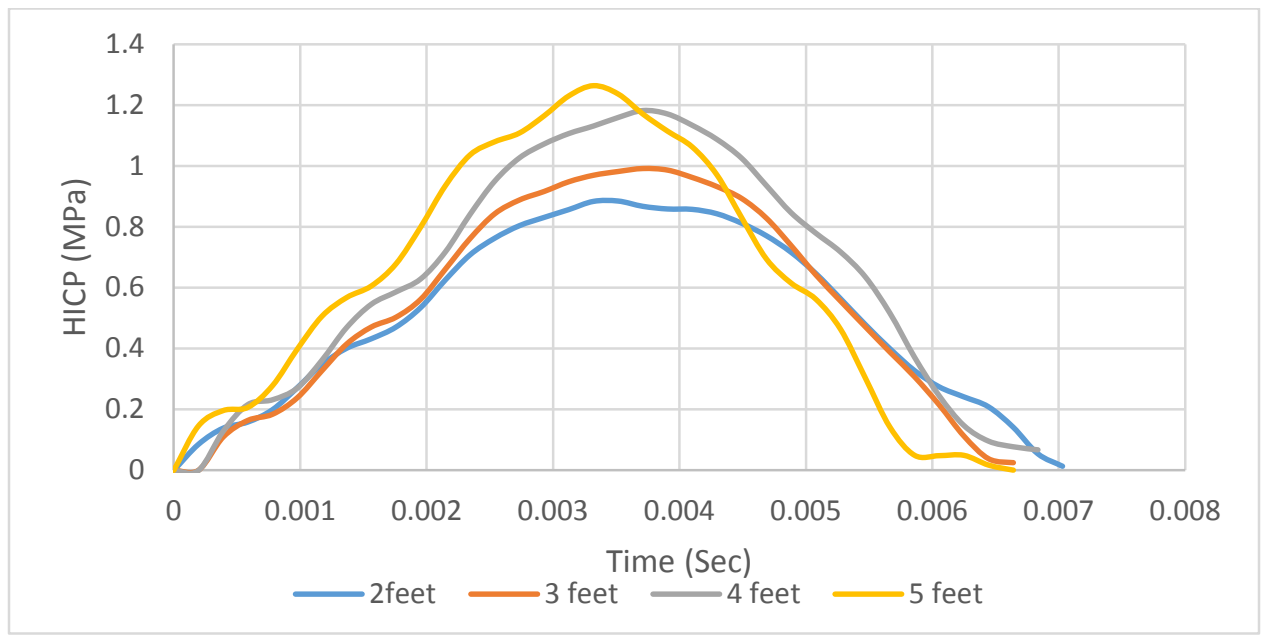

Figure 4.6 Impact Pressure Curves for Impact in Frontal Region

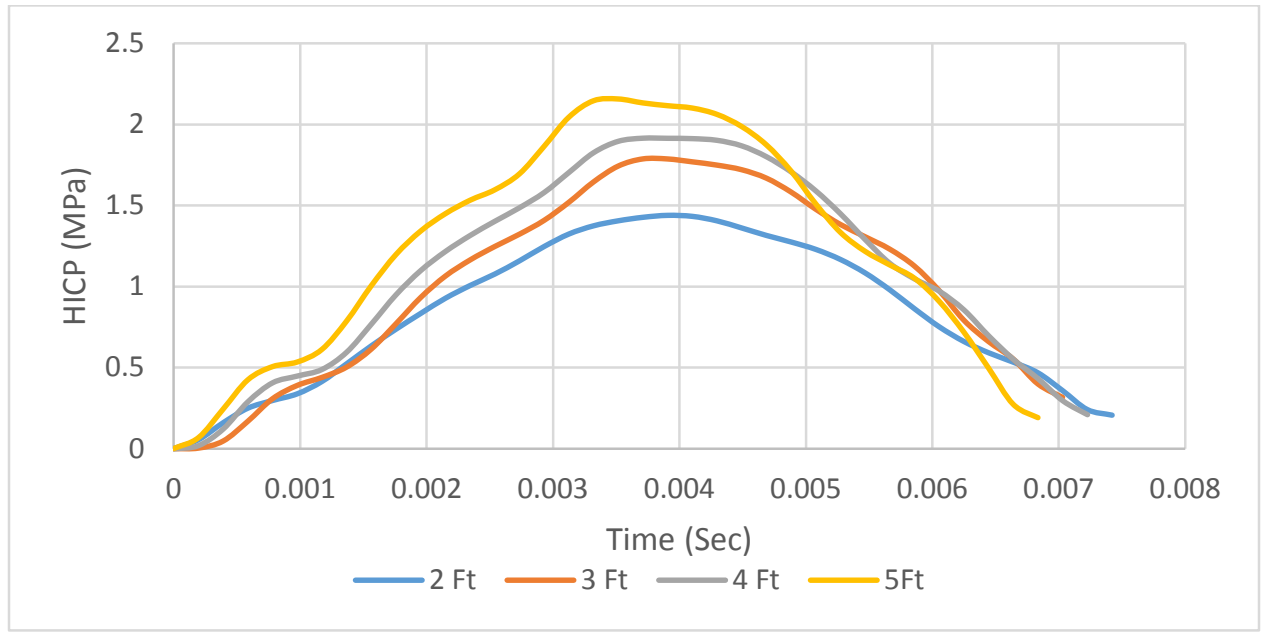

Figure 4.7 Impact Pressure curves for impact in 45 to Frontal region 


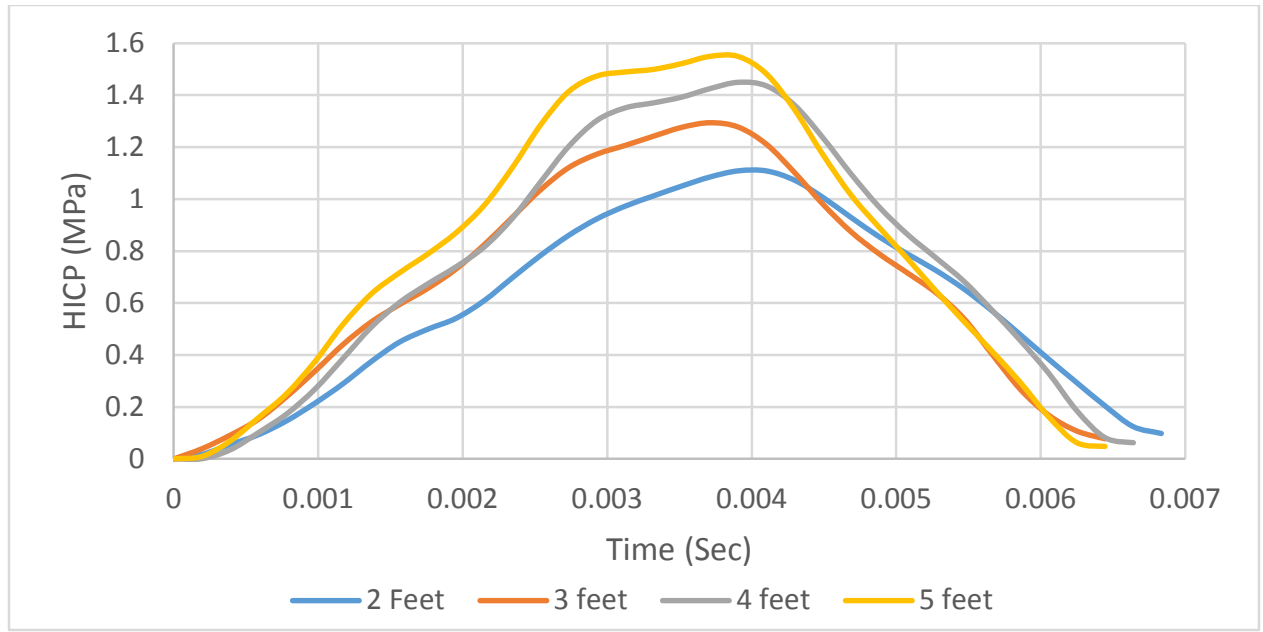

Figure 4.8 Impact pressure curve for Impact in Lateral region

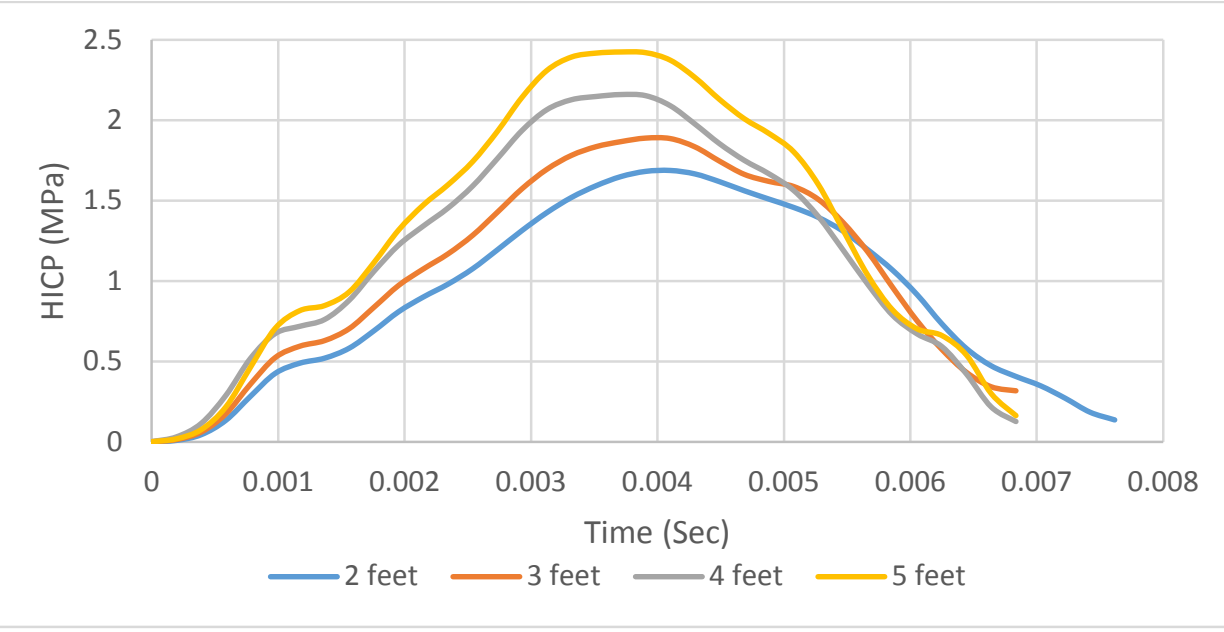

Figure 4.9 Impact pressure curves for Impact in Posterior region

It can be observed that the Impact time is different for different heights in the same region. It can be because of the approximation considered in the curve fitting. The Impact pressure is considered as a positive entity in this work hence all the tensile stresses would be in negative magnitude.

\subsection{Boundary Conditions}

Constraining the model is another important step in a FE analysis. The constraints have been applied to the model in order to replicate the testing conditions and the actual 
scenario. The model was constrained at the brainstem and the stem junction at skull similar to the head form.

When the fixed constraints were applied at the above locations the deformation were being produced at these locations as they were constrained to move under pressure causing discrepancies in the results obtained.

Hence a ground fixed node was created at a unit distance from the stem junction and all the nodes on the model which are supposed to be constrained were attached to the fixed node with spring elements giving them the a proper flexibility to deform under applied pressure.

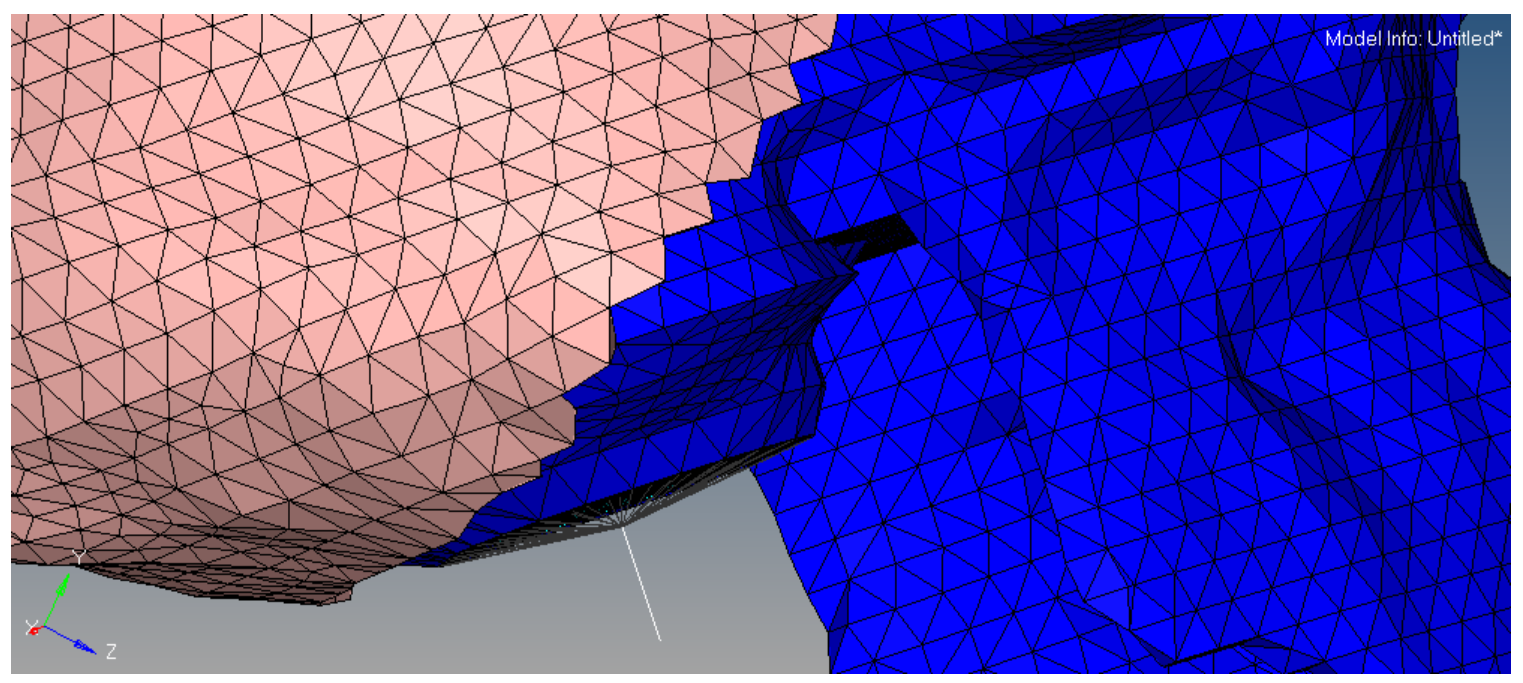

Figure 4.10 Unit Spring elements connecting skull to the Ground point

Different spring constants were applied for the spring element to study the behavior of elements under applied load. The element shouldn't be too rigid as too much rigidity effects the results while on the other if it's flexible the effect of the pressure causes the material to oscillate more. Hence after many trials and comparing the values to those from the previous research performed by Chandrika Abhang and David Labyak, the 
spring constant value is assumed to $10000 \mathrm{~N} / \mathrm{m}$ making it stronger than skull but not too rigid to completely defy its purpose.

\subsection{Output Settings and Time step}

Time steps plays an important role in the measurement of output in transient analysis. It refers to the time interval at which the system should record the output. One must make sure that the time interval should not be too small as it increases the processing time while a bigger interval leads to improper measurement of output as bigger interval might miss the sudden changes in the output profiles.

The time step details used in the Altair ${ }^{\circledR}$ RADIOSS $®$ analysis will be explained along with the detail description of entire procedure in Appendix-C.

\subsection{Results \& Discussions}

The model has been converted into Altair ${ }^{\circledR}$ RADIOSS ${ }^{\circledR}$ file (*.Rad) and analyzed in the Altair ${ }^{\circledR}$ RADIOSS ${ }^{\circledR}$ solver. The engine file has been set to give an output of pressure and maximum shear and principal stresses. The result file has been analyzed in Hyperview and the maximum value of the pressures and stresses has been found out from them. But due to the limitations of the software version available at the university, in order to calculate the maximum principal and shear stresses, the stresses in the directions of X, Y, Z, XY, YZ and XZ were calculated and 3 dimensional Mohr's circle approach [21] was used to get the required outputs which would be maximum von Mises stresses, maximum Shear stresses and maximum tensile stresses from the available values. The results obtained along with their input pressure curves are shown below 


\subsubsection{Frontal}

\subsubsection{Drop Height of 2 feet}
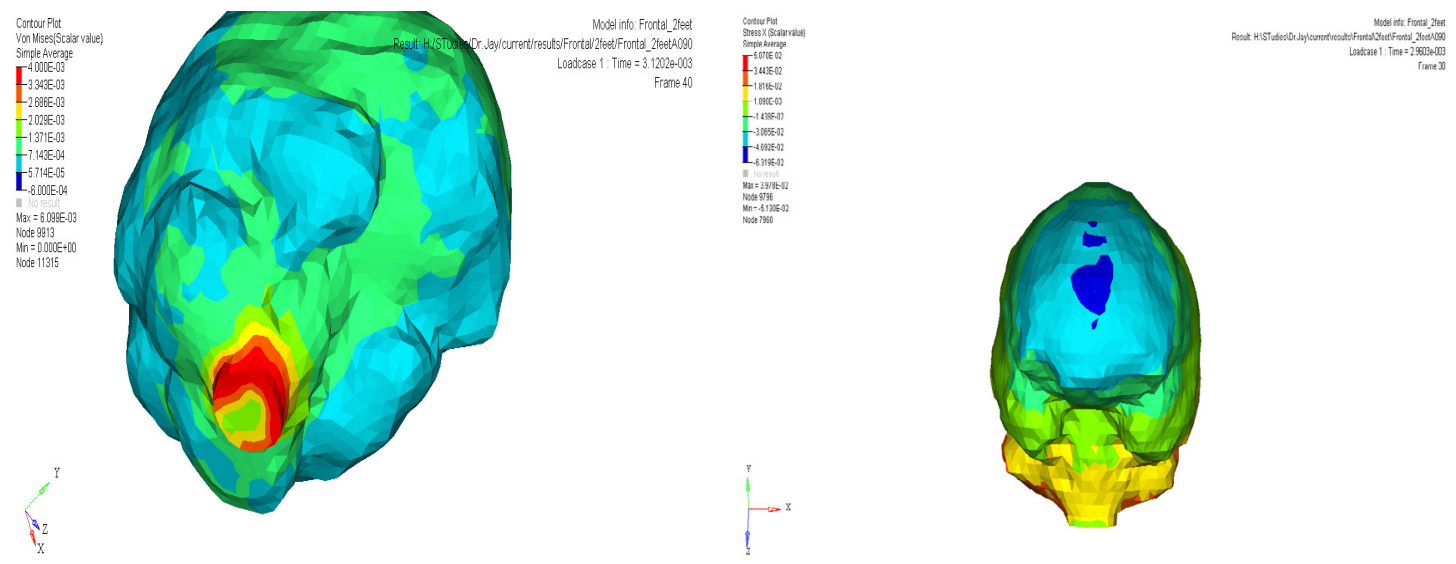

Figure 4.11 von Mises stress Frontal 2 feet

Figure 4.12 Normal stress $S_{x}$ Frontal 2 feet
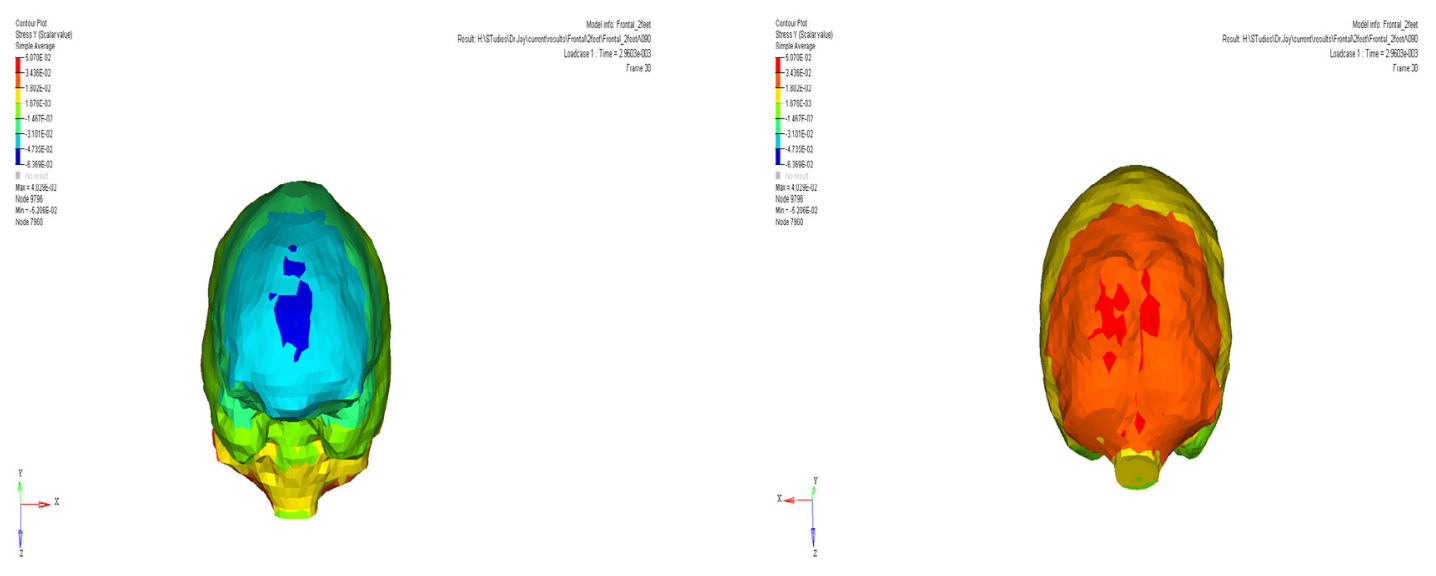

Figure 4.13 Normal stress $S_{y}$ Frontal 2 feet
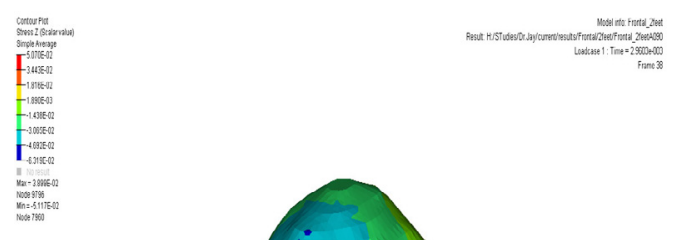

Figure 4.14 Normal stress $S_{y}$ Frontal 2 feet
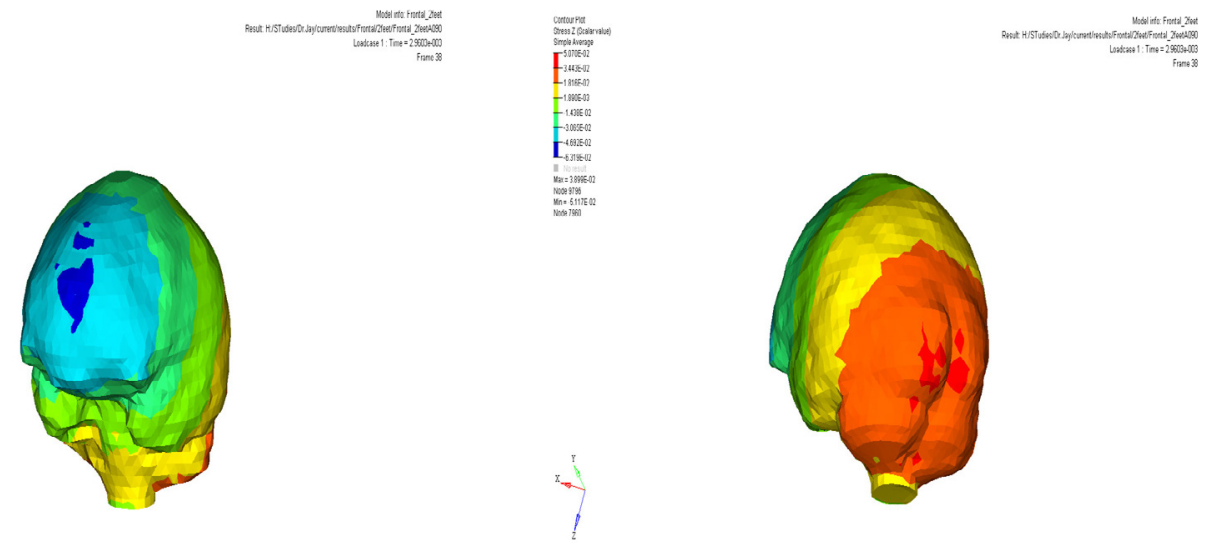

Figure 4.16 Normal stress $S_{z}$ Frontal 2 feet

Figure 4.15 Normal stress $S_{z}$ Frontal 2 feet 

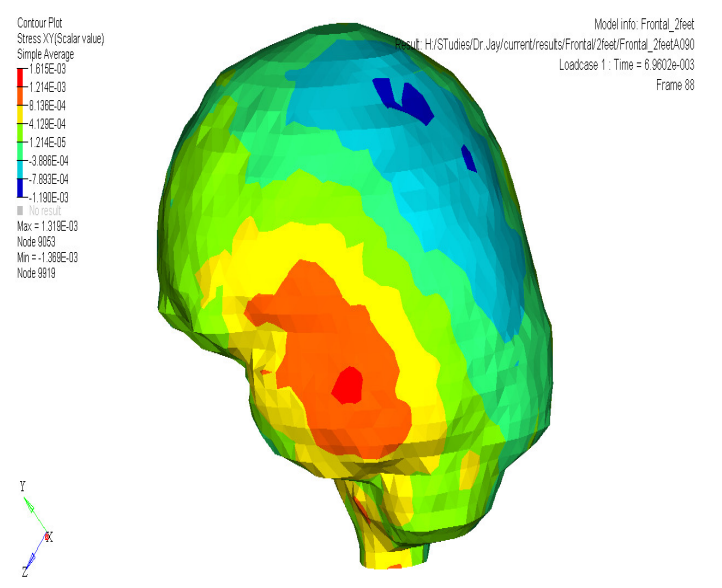

Figure 4.17 Shear stress $S_{x y}$ Frontal 2 feet
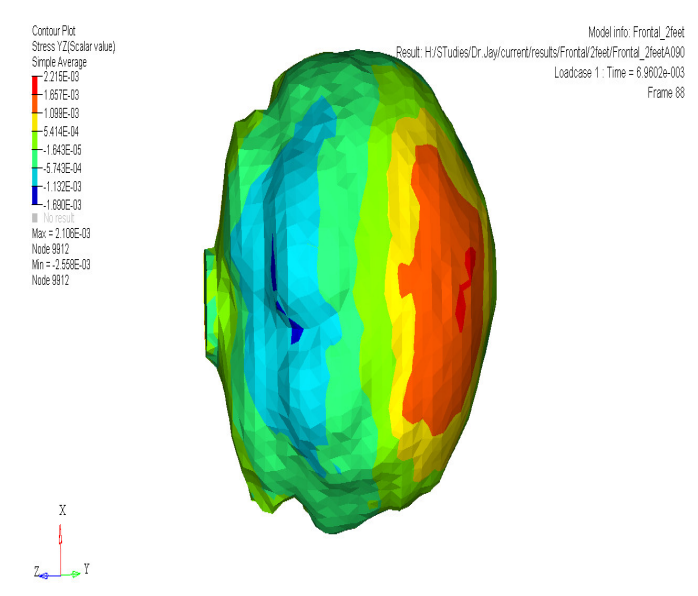

Figure 4.19 Shear stress $S_{y z}$ Frontal 2 feet

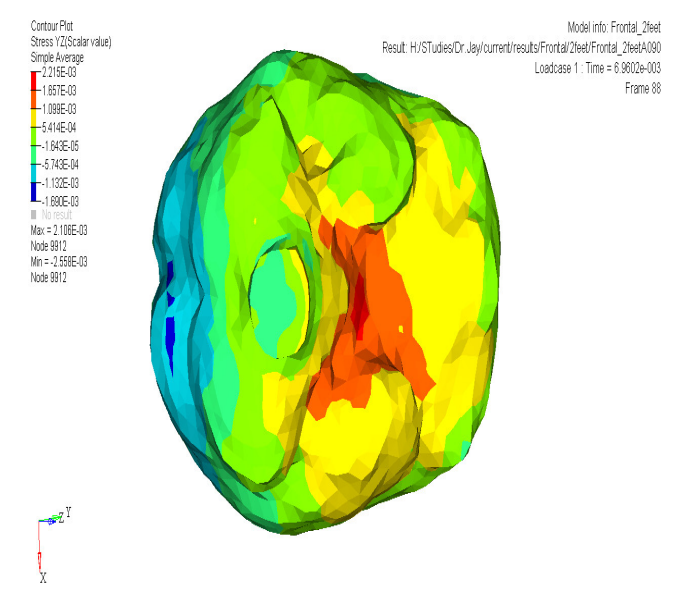

Figure 4.21 Shear stress $S_{y z}$ Frontal 2 feet

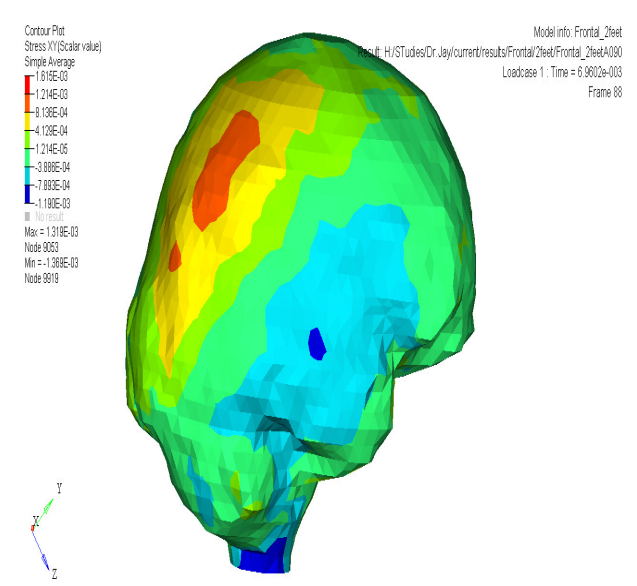

Figure 4.18 Shear stress $S_{x y}$ Frontal 2 feet
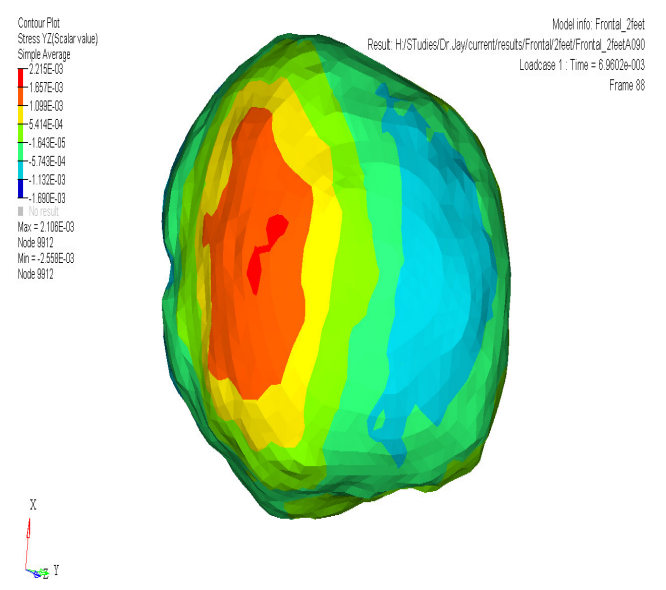

Figure 4.20 Shear stress $S_{y z}$ Frontal 2 feet
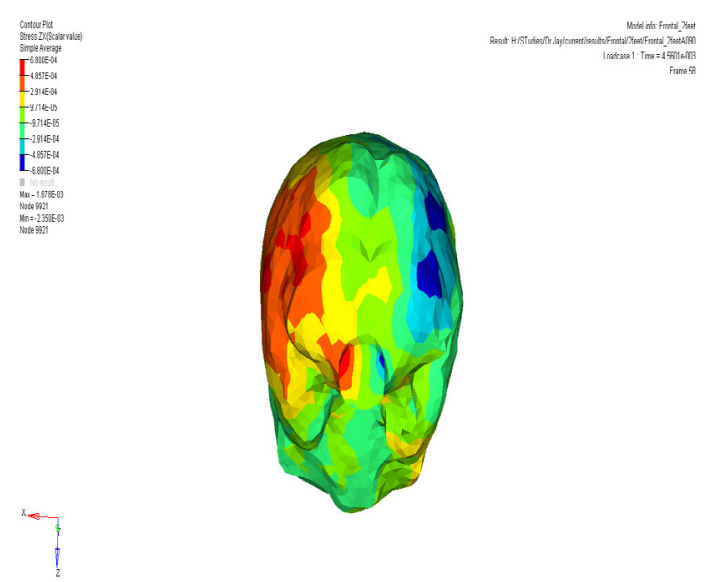

Figure 4.22 Shear stress $S_{z x}$ Frontal 2 feet 

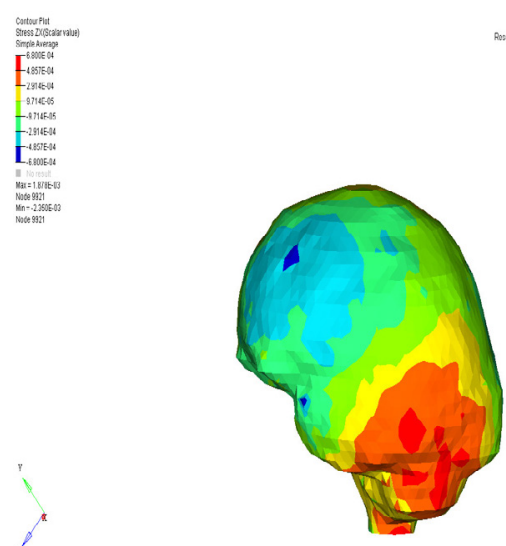

Figure 4.23 Shear stress $S_{z x}$ Frontal 2 feet

\subsubsection{Drop Height of 3 feet}
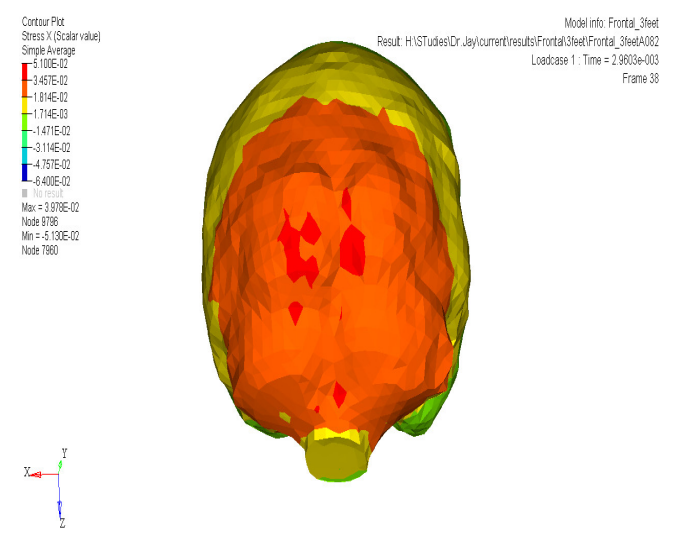

Figure 4.25 Normal stress $S_{x}$ Frontal 3 feet
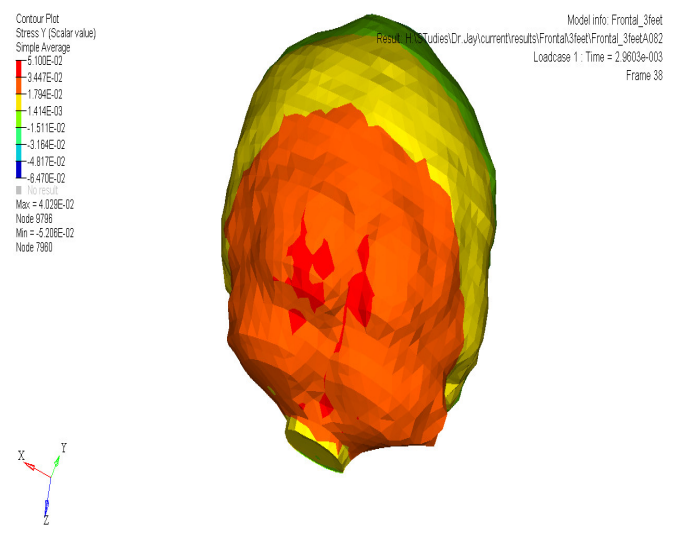

Figure 4.27 Normal stress $S_{y}$ Frontal 3 feet
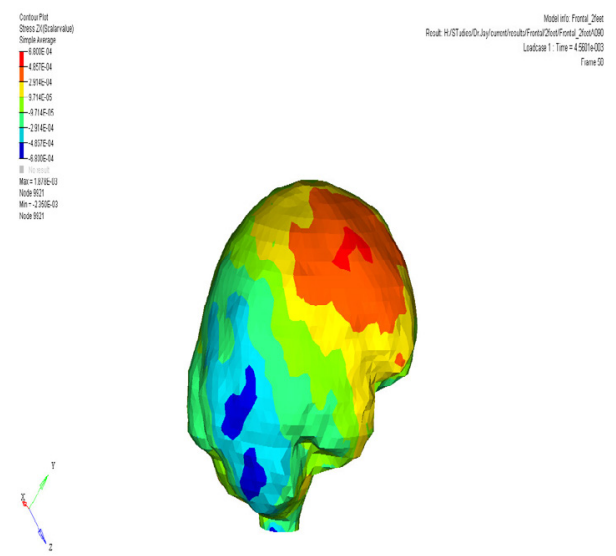

Figure 4.24 Shear stress $S_{z x}$ Frontal 2 feet
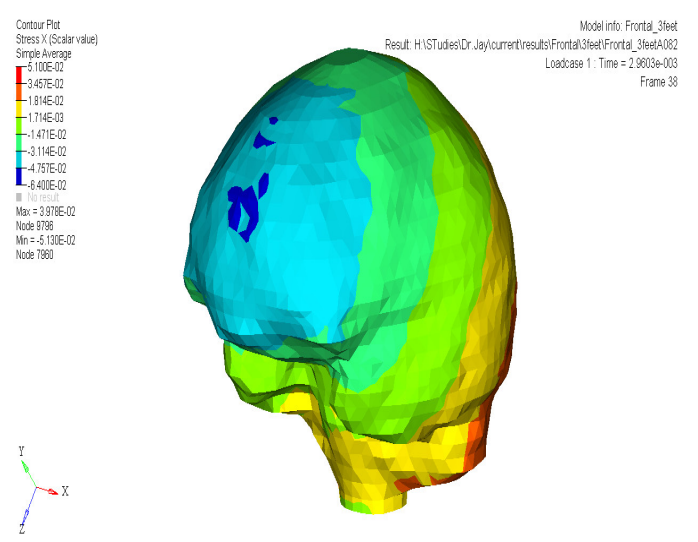

Figure 4.26 Normal stress $S_{x}$ Frontal 3 feet
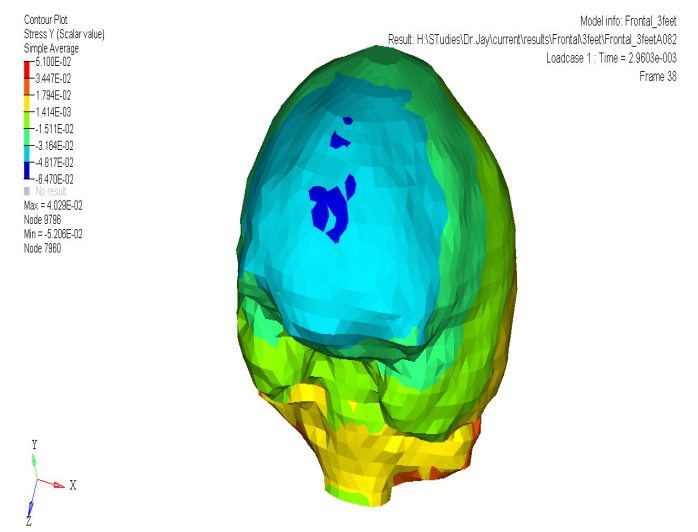

Figure 4.28 Normal stress $S_{y}$ Frontal 3 feet 


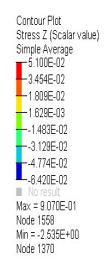

$\operatorname{lox}_{2}$

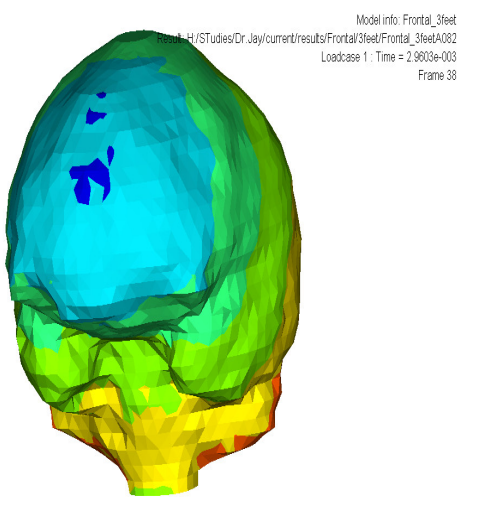

Figure 4.29 Normal stress $S_{z}$ Frontal 3 feet
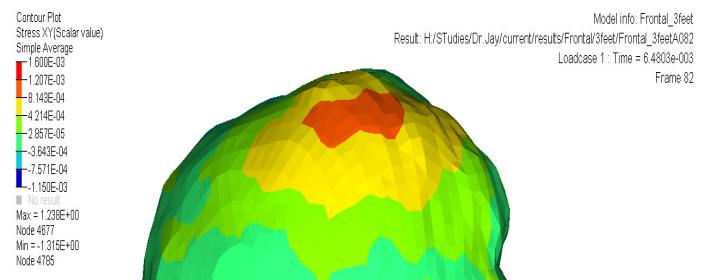

$r^{r_{4}}$

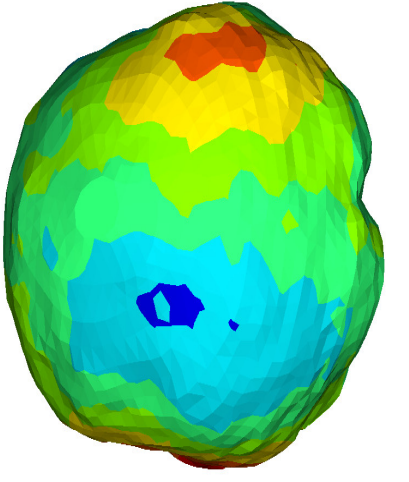

Figure 4.31 Shear stress $S_{x y}$ Frontal 3 feet
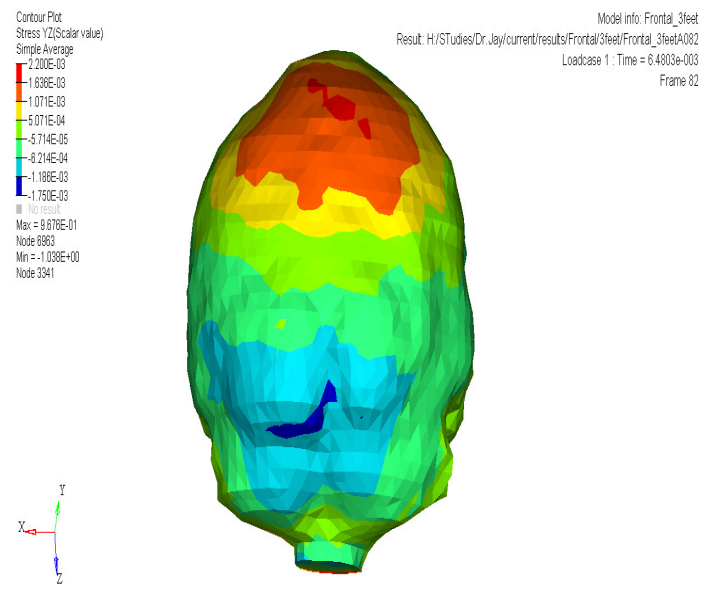

Figure 4.33 Shear stress $S_{y z}$ Frontal 3 feet

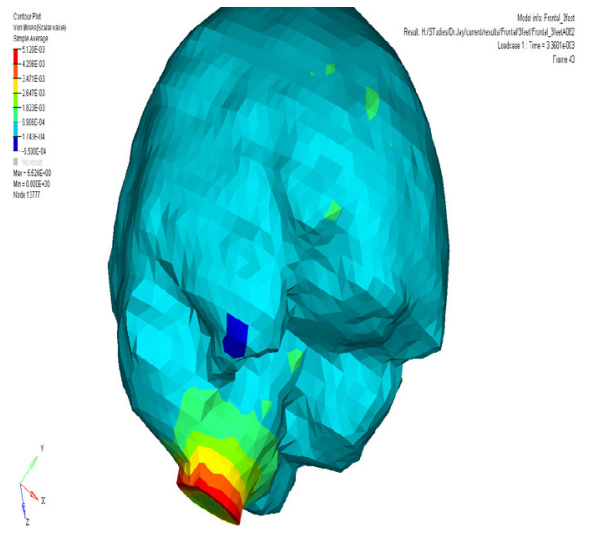

Figure 4.30 von Mises stress Frontal 3 feet
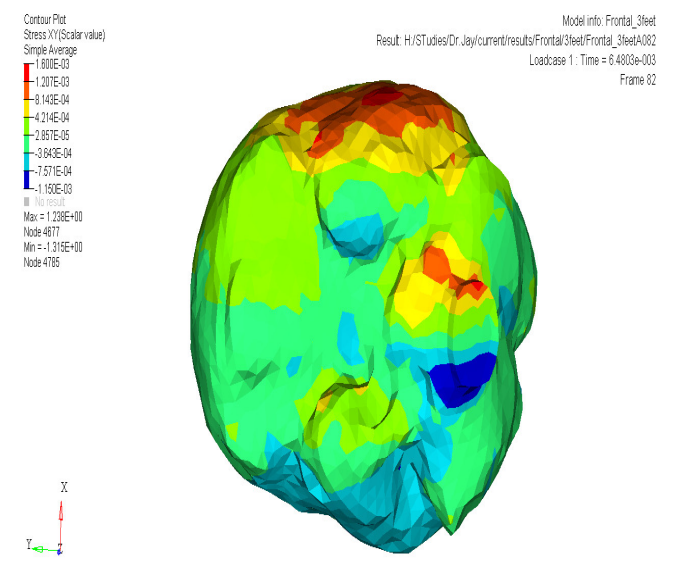

Figure 4.32 Shear stress $S_{x y}$ Frontal 3 feet
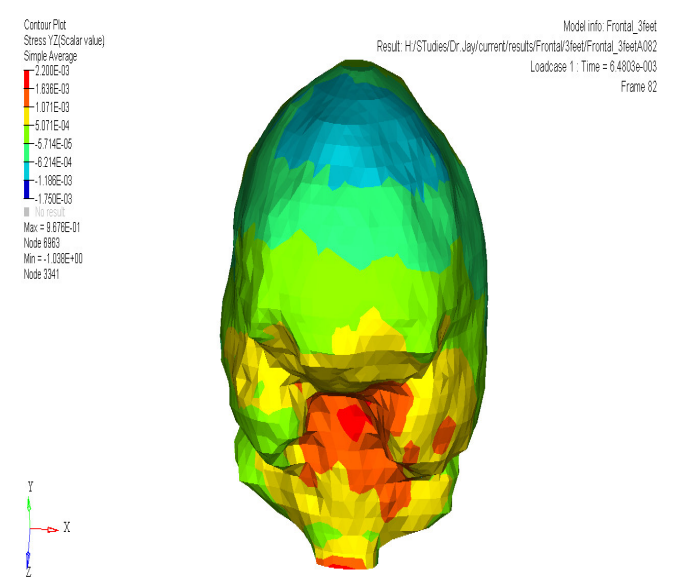

Figure 4.34 Shear stress $S_{y z}$ Frontal 3 feet 


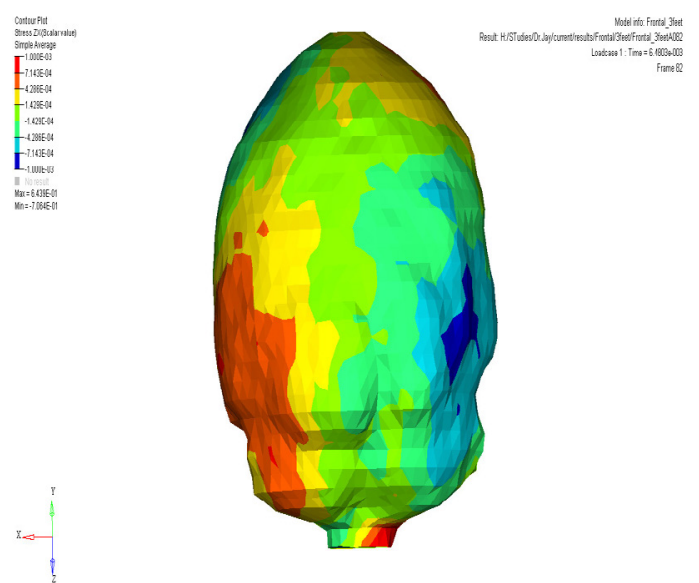

Figure 4.35 Shear stress $S_{z x}$ Frontal 3 feet

\subsubsection{Drop Height of 4 feet}

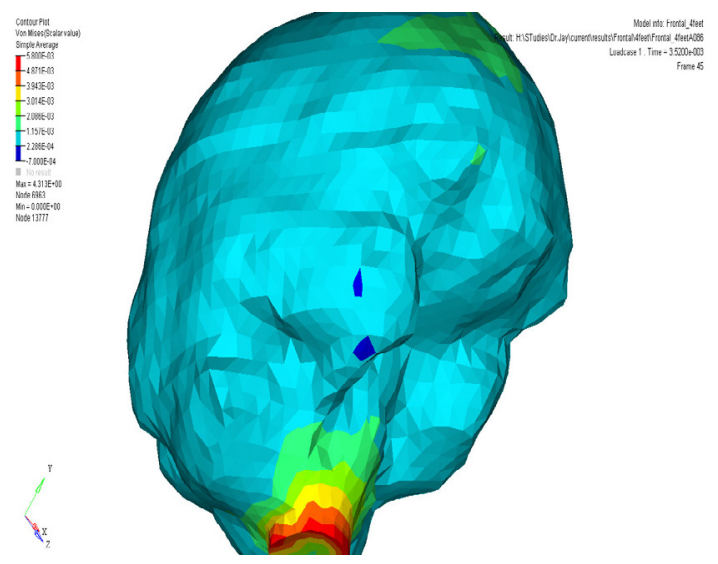

Figure 4.37 von Mises stress Frontal 4 feet
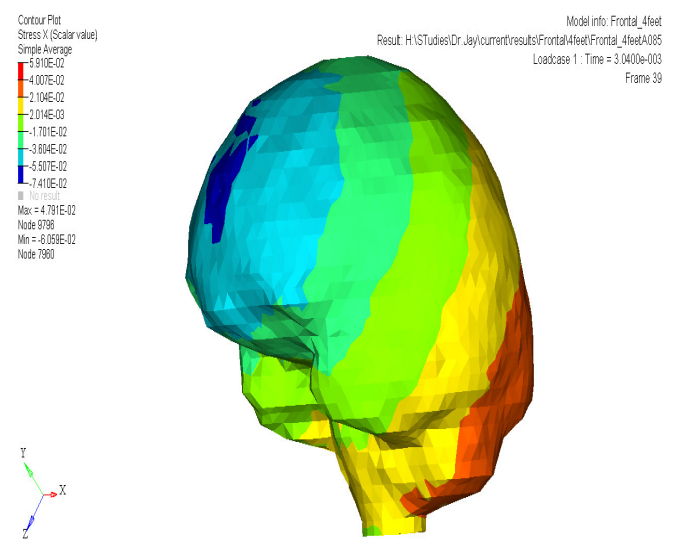

Figure 4.39 Normal stress $S_{x}$ Frontal 4 feet
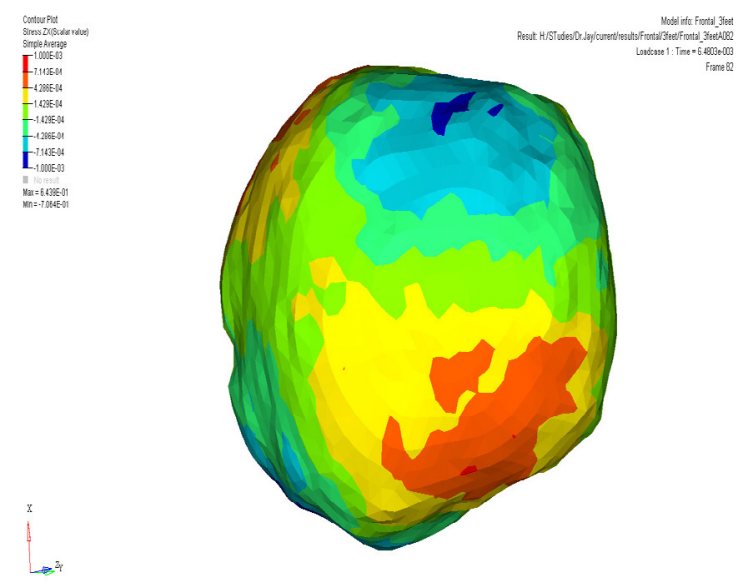

Figure 4.36 Shear stress $S_{z x}$ Frontal 3 feet
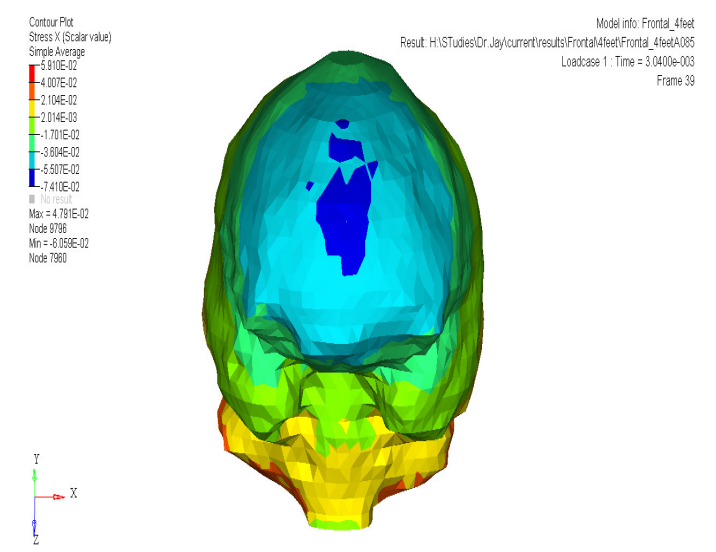

Figure 4.38 Normal stress $S_{x}$ Frontal 4 feet
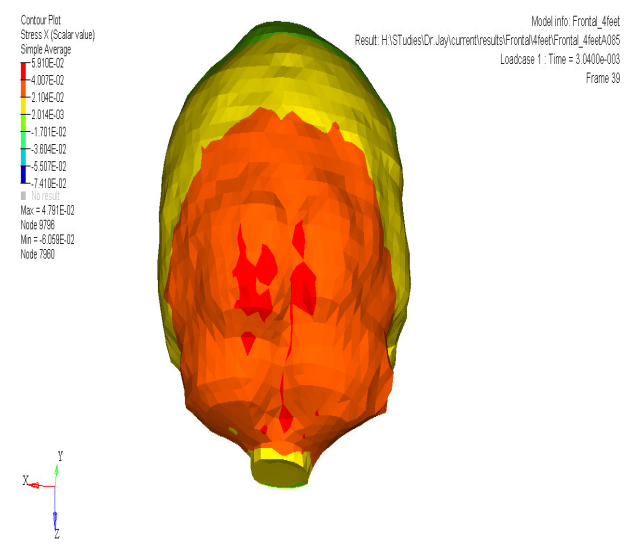

Figure 4.40 Normal stress $S_{x}$ Frontal 4 feet 

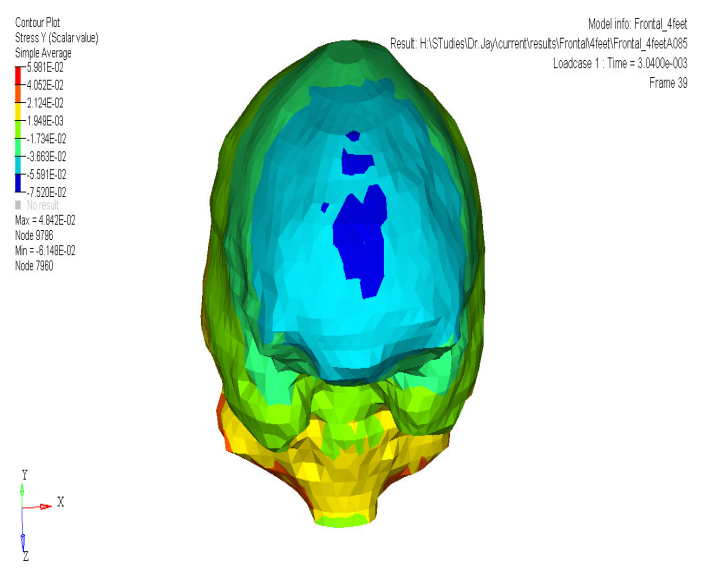

Figure 4.41 Normal stress $S_{y}$ Frontal 4 feet
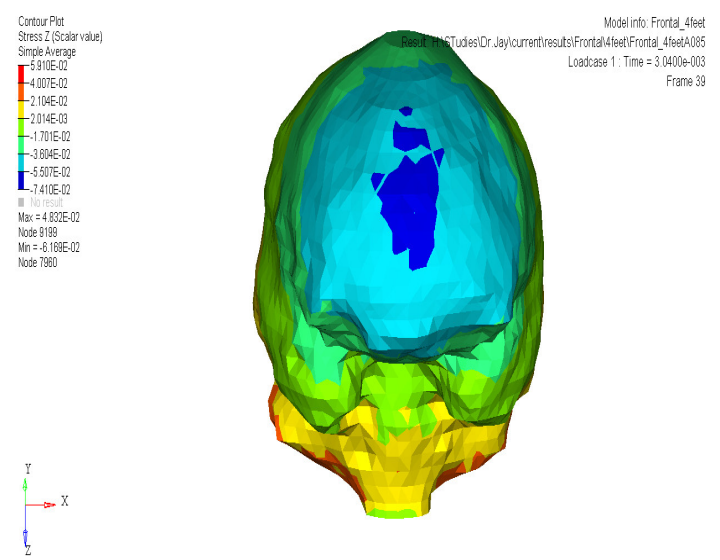

Figure 4.43 Normal stress $S_{z}$ Frontal 4 feet
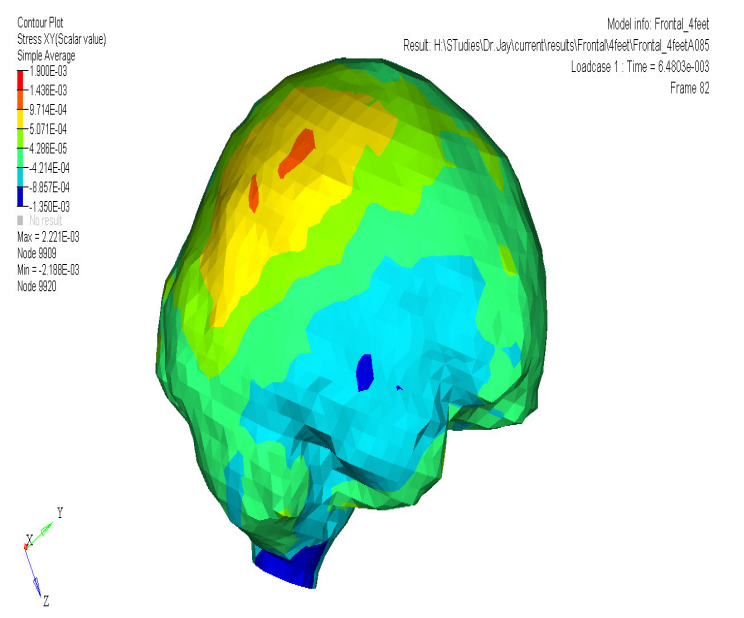

Figure 4.45 Shear stress $S_{x y}$ Frontal 4 feet
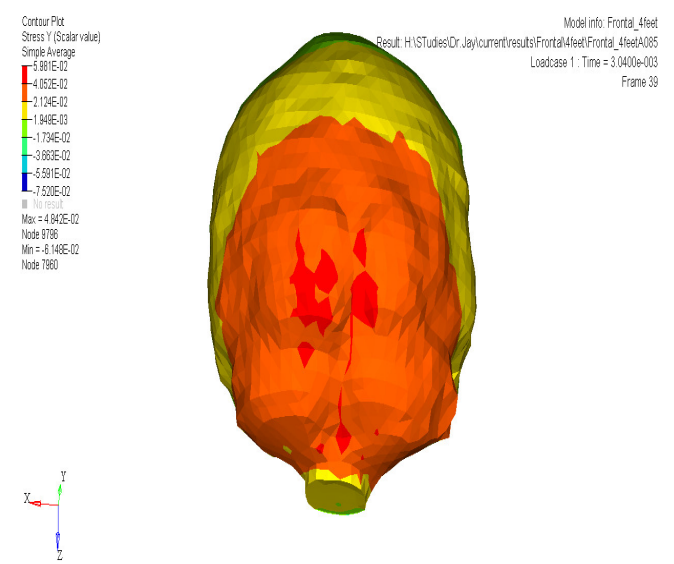

Figure 4.42 Normal stress $S_{y}$ Frontal 4 feet
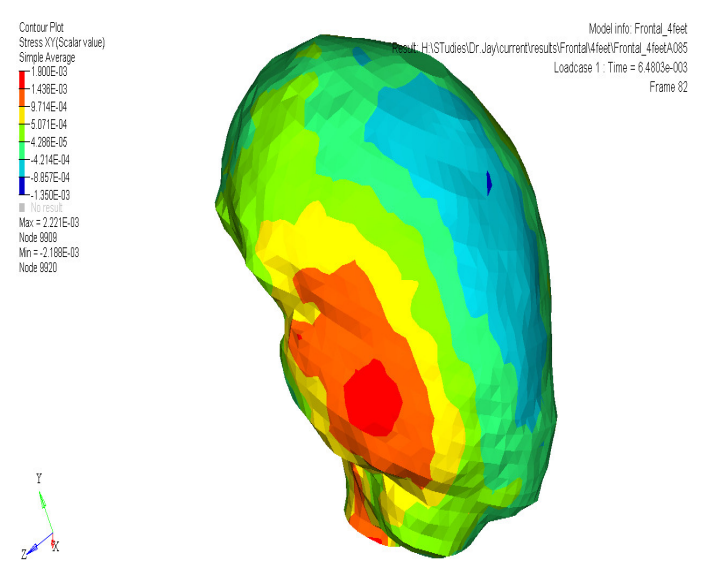

Figure 4.44 Shear stress $S_{x y}$ Frontal 4 feet
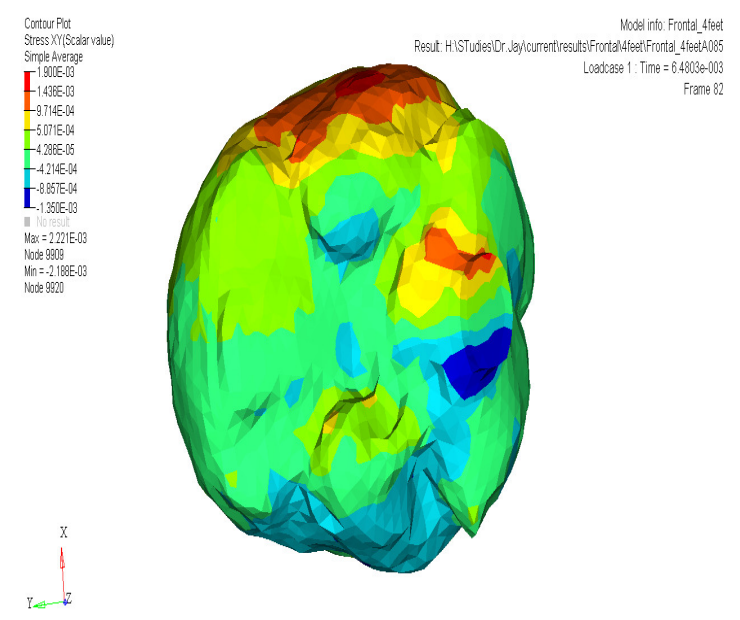

Figure 4.46 Shear stress $S_{x y}$ Frontal 4 feet 

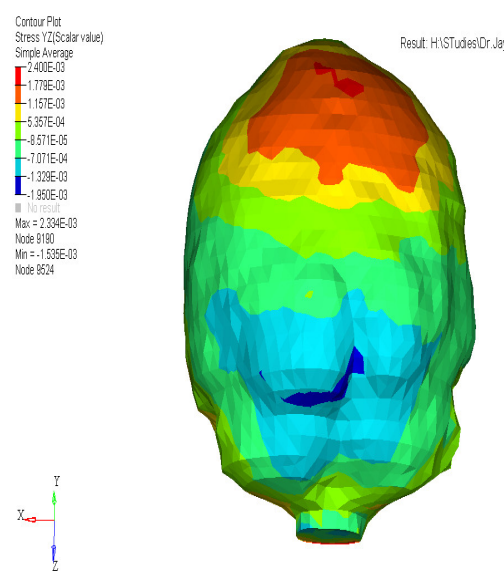

Figure 4.47 Shear stress $S_{y z}$ Frontal 4 feet
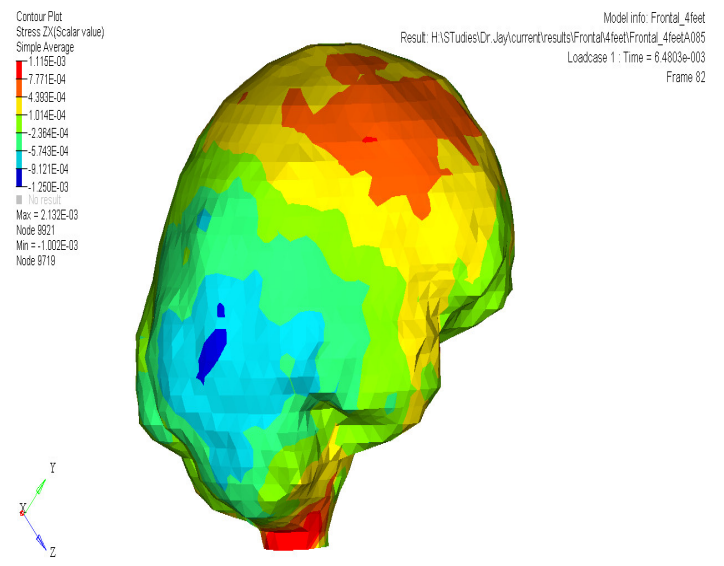

Figure 4.49 Shear stress $S_{z x}$ Frontal 4 feet

\subsubsection{Drop Height of 5 feet}
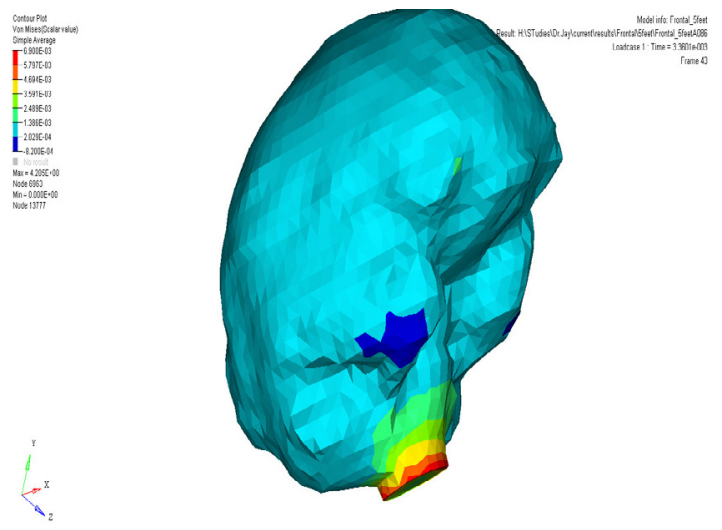

Figure 4.51 von Mises stress Frontal 5 feet
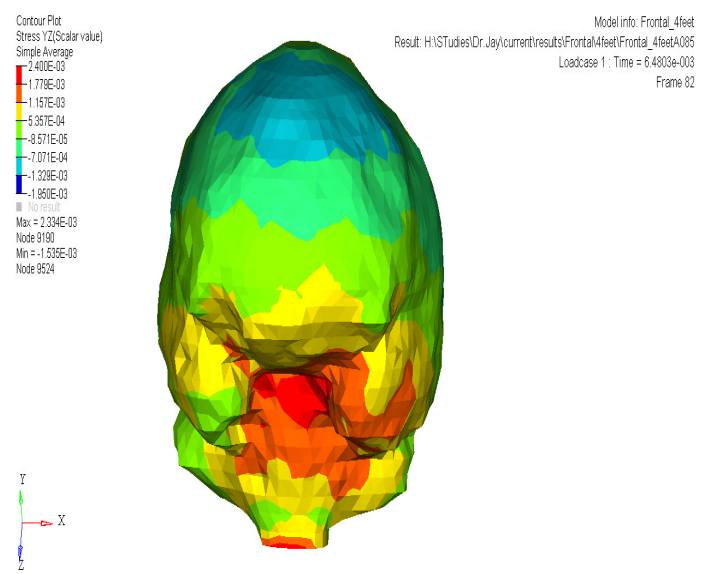

Figure 4.48 Shear stress $S_{y z}$ Frontal 4 feet
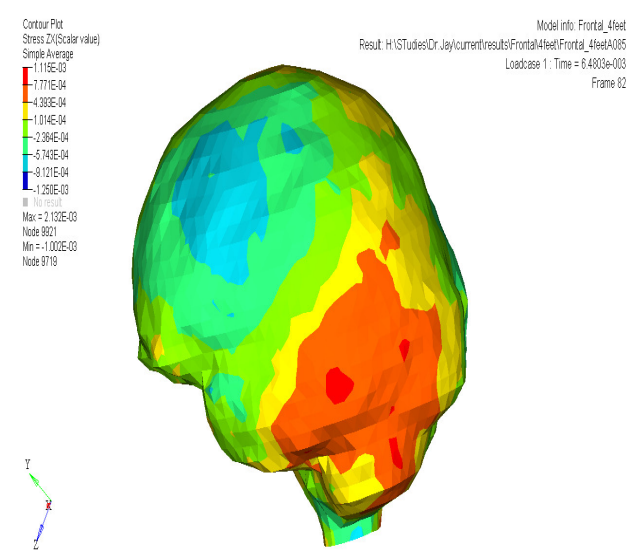

Figure 4.50 Shear stress $S_{z x}$ Frontal 4 feet
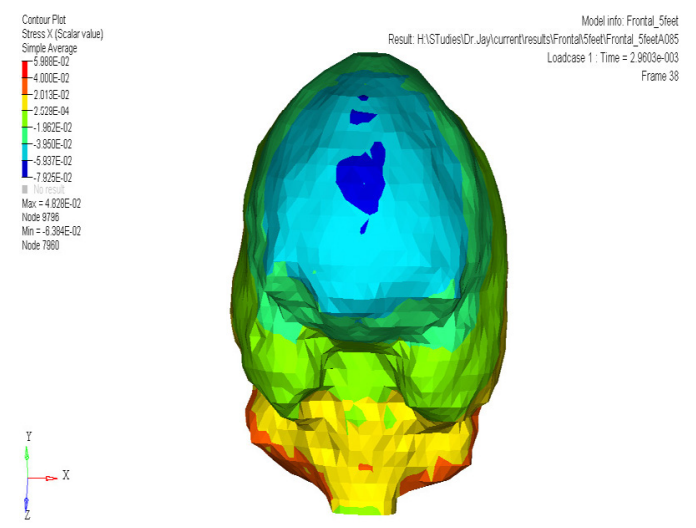

Figure 4.52 Normal Stress $S_{x}$ Frontal 5feet 

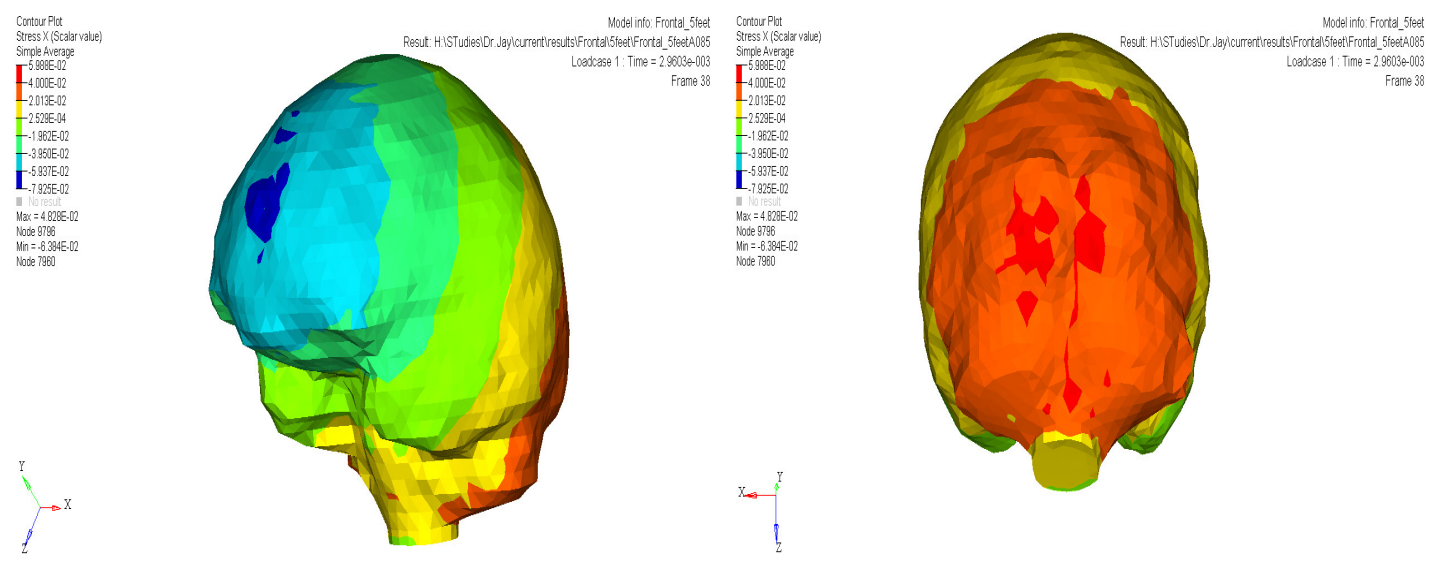

Figure 4.53 Normal stress $S_{x}$ Frontal 5 feet
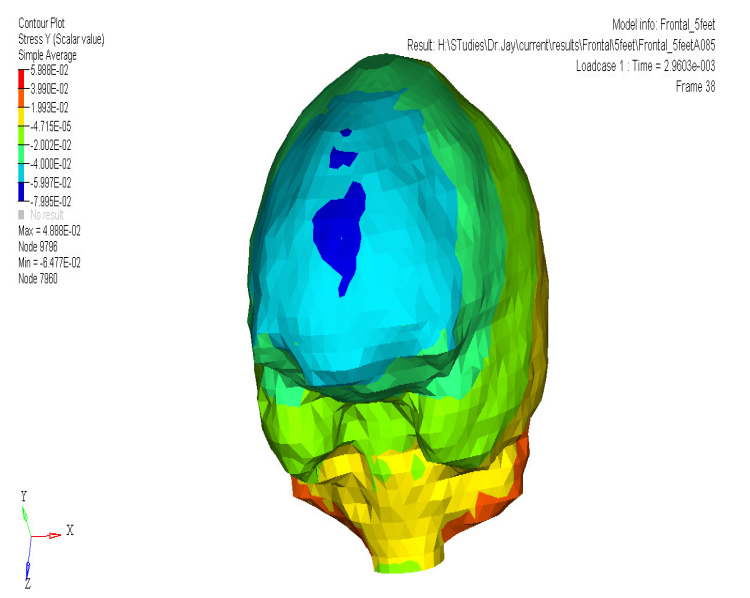

Figure 4.54 Normal stress $S_{x}$ Frontal 5 feet
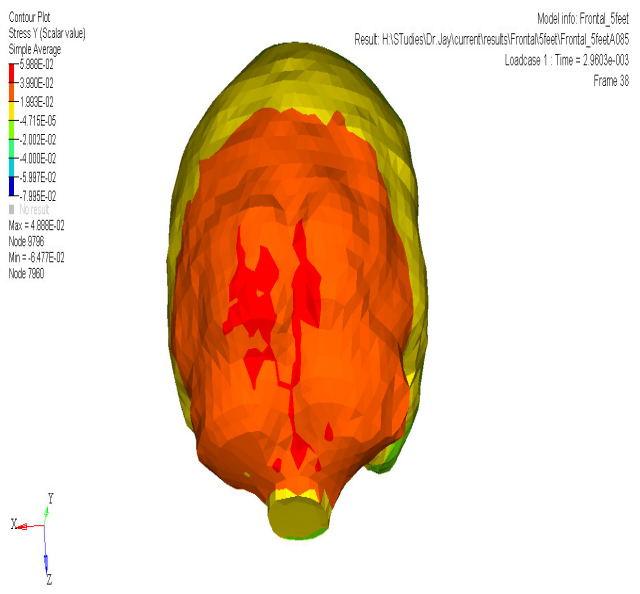

Figure 4.55 Normal stress $S_{y}$ Frontal 5 feet

Figure 4.56 Normal stress $S_{y}$ Frontal 5 feet
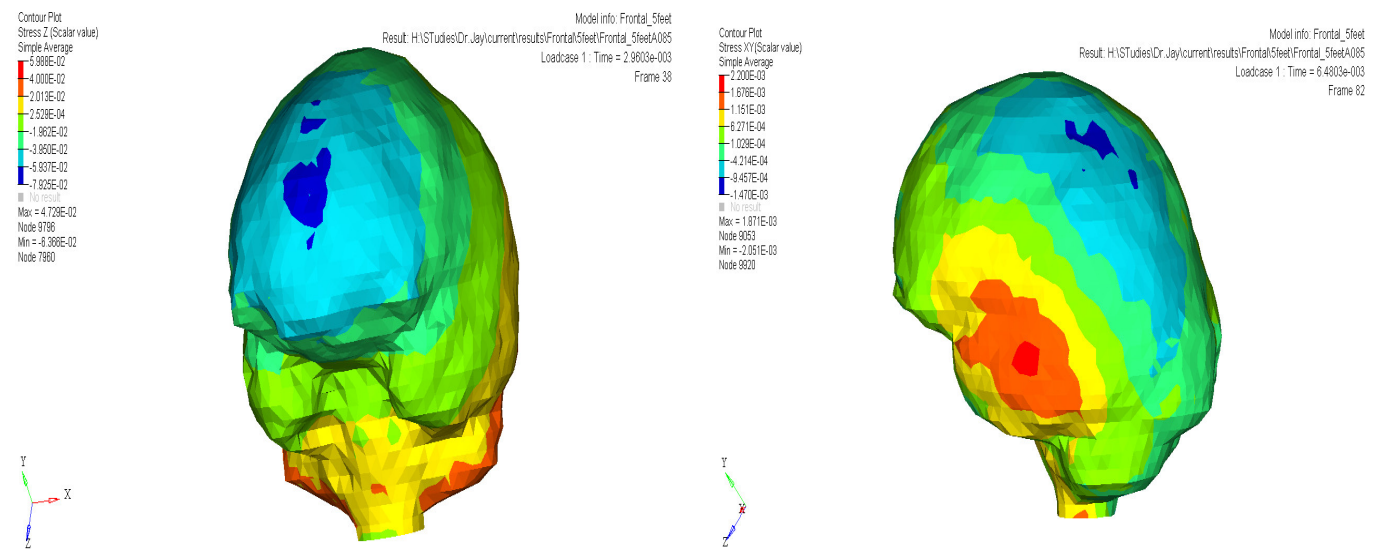

Figure 4.57 Normal stress $S_{z}$ Frontal 5 feet

Figure 4.58 Shear stress $S_{x y}$ Frontal 5 feet 

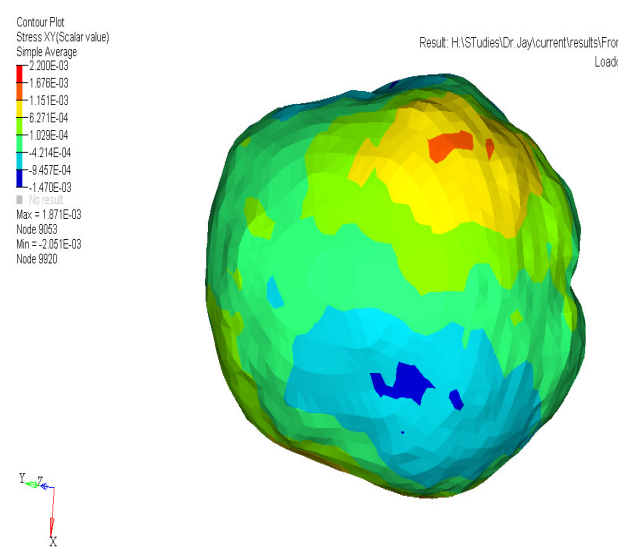

Figure 4.59 Shear stress $S_{x y}$ Frontal 5 feet
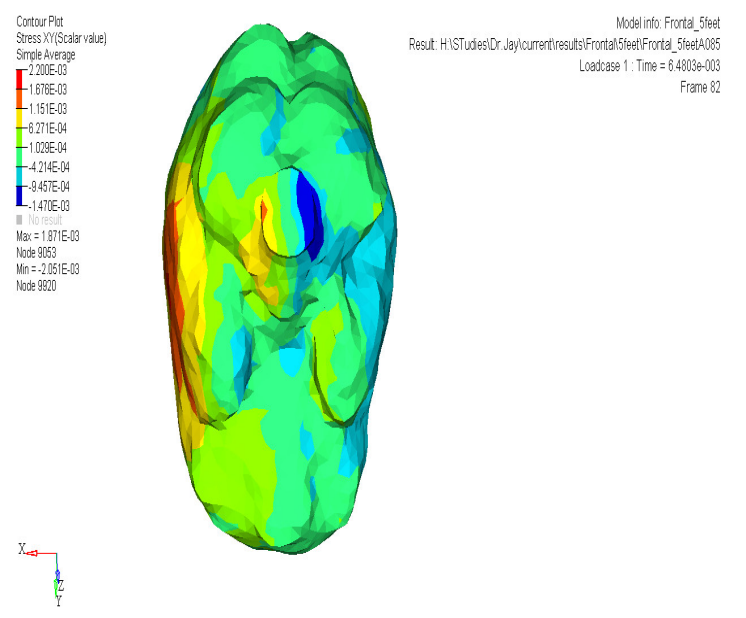

Figure 4.61 Shear stress $S_{x y}$ Frontal 5 feet
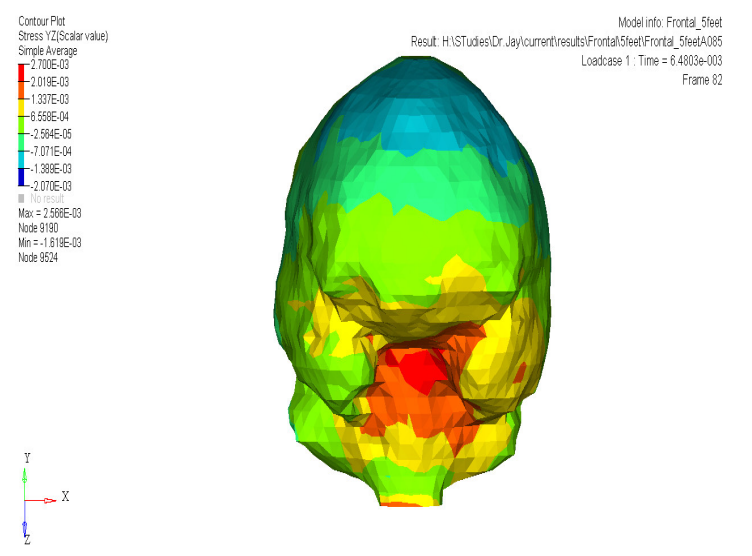

Figure 4.63 Shear stress $S_{y z}$ Frontal 5 feet
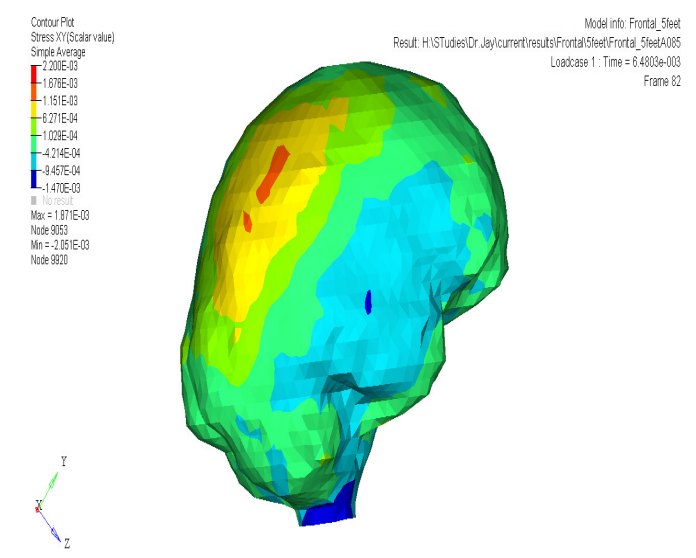

Figure 4.60 Shear stress $S_{x y}$ Frontal 5 feet
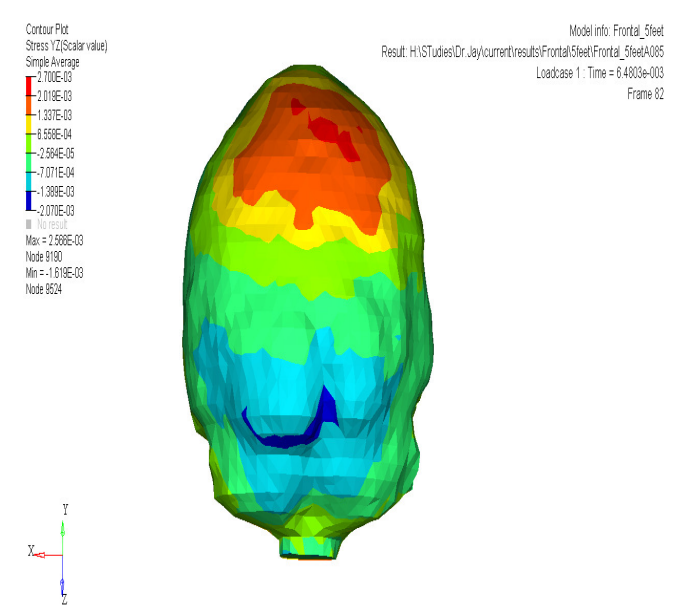

Figure 4.62 Shear stress $S_{y z}$ Frontal 5 feet
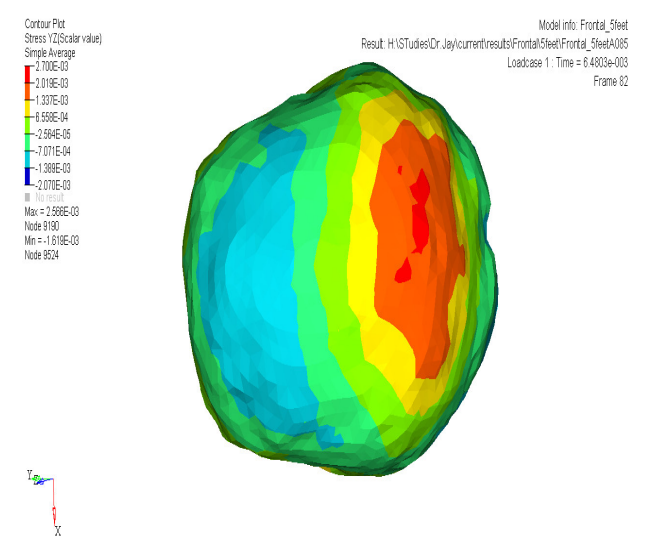

Figure 4.64 Shear stress $S_{y z}$ Frontal 5 feet 

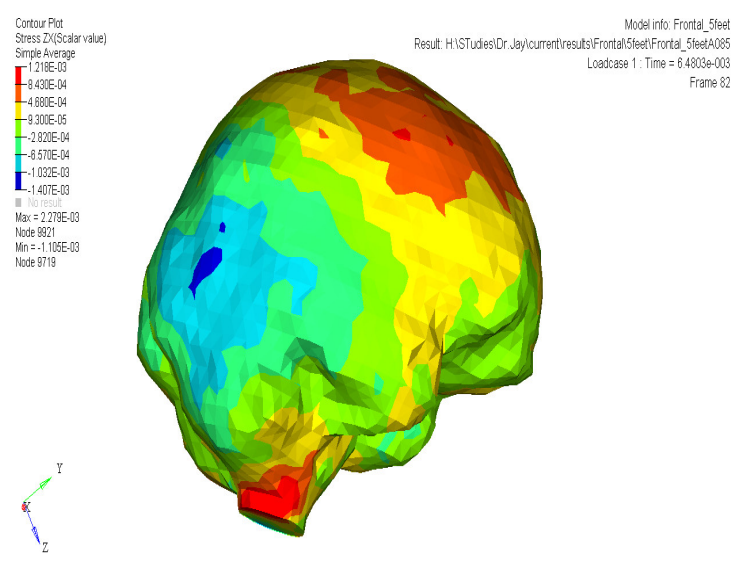

Figure 4.65 Shear stress $S_{z x}$ Frontal 5 feet
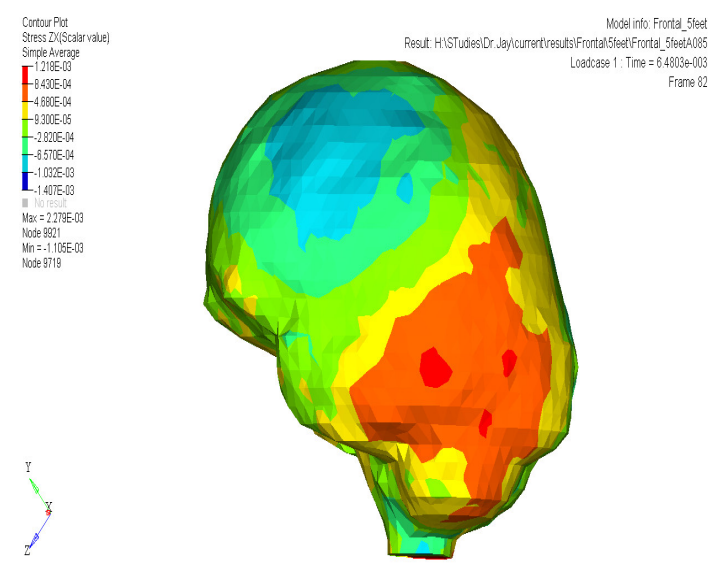

Figure 4.66 Shear stress $S_{z x}$ Frontal 5 feet 


\subsubsection{Discussion}

The normal stresses values obtained from the Finite element simulation are listed below.

It should be remembered that as the input pressure is considered as positive the resultant tensile stress on the brain would be negative.

Table 4.2 Normal Stress Values on brain from FE Simulation of Frontal Impact

\begin{tabular}{|c|c|c|c|c|c|c|}
\hline \multirow{2}{*}{$\begin{array}{c}\text { Height } \\
\text { (feet) }\end{array}$} & \multicolumn{2}{|c|}{ Stress X (MPa) } & \multicolumn{2}{c|}{ Stress Y (MPa) } & \multicolumn{2}{c|}{ Stress Z (MPa) } \\
\cline { 2 - 7 } & Tension & Compression & Tension & Compression & Tension & Compression \\
\hline $\mathbf{2}$ & $\mathbf{- 6 . 3 2 E - 0 2}$ & $5.07 \mathrm{E}-02$ & $\mathbf{- 6 . 3 7 E - 0 2}$ & $5.07 \mathrm{E}-02$ & $\mathbf{- 6 . 3 2 E - 0 2}$ & $5.07 \mathrm{E}-02$ \\
\hline $\mathbf{3}$ & $\mathbf{- 6 . 4 0 E - 0 2}$ & $5.10 \mathrm{E}-02$ & $\mathbf{- 6 . 4 7 E - 0 2}$ & $5.10 \mathrm{E}-02$ & $\mathbf{- 6 . 4 2 E - 0 2}$ & $5.10 \mathrm{E}-02$ \\
\hline $\mathbf{4}$ & $\mathbf{- 7 . 4 1 E - 0 2}$ & $5.91 \mathrm{E}-02$ & $\mathbf{- 7 . 5 2 E - 0 2}$ & $5.98 \mathrm{E}-02$ & $\mathbf{- 7 . 4 1 E - 0 2}$ & $5.91 \mathrm{E}-02$ \\
\hline $\mathbf{5}$ & $\mathbf{- 7 . 9 3 E - 0 2}$ & $5.99 \mathrm{E}-02$ & $\mathbf{- 8 . 0 0 E - 0 2}$ & $5.99 \mathrm{E}-02$ & $\mathbf{- 7 . 9 3 E - 0 2}$ & $5.99 \mathrm{E}-02$ \\
\hline
\end{tabular}

The Shear stress values obtained for different drops from the finite element simulation are listed below

Table 4.3 Shear Stress values on brain from the FE Simulation of Frontal Impact

\begin{tabular}{|c|c|c|c|}
\hline $\begin{array}{c}\text { Height } \\
\text { (feet) }\end{array}$ & Stress XY (MPa) & Stress YZ (MPa) & Stress ZX (MPa) \\
\hline $\mathbf{2}$ & $1.62 \mathrm{E}-03$ & $2.22 \mathrm{E}-03$ & $-6.80 \mathrm{E}-04$ \\
\hline $\mathbf{3}$ & $1.60 \mathrm{E}-03$ & $2.20 \mathrm{E}-03$ & $-1.00 \mathrm{E}-03$ \\
\hline $\mathbf{4}$ & $1.90 \mathrm{E}-03$ & $2.40 \mathrm{E}-03$ & $-1.25 \mathrm{E}-03$ \\
\hline $\mathbf{5}$ & $2.20 \mathrm{E}-03$ & $2.70 \mathrm{E}-03$ & $-1.41 \mathrm{E}-03$ \\
\hline
\end{tabular}

The Values when used in the Mohr Circle calculation, yielded the following results

Table 4.4 Results Obtained from Mohr Circle Analysis for Frontal Impacts

\begin{tabular}{|r|c|c|c|c|c|}
\hline \multirow{2}{*}{$\begin{array}{c}\text { Height } \\
\text { (feet) }\end{array}$} & \multicolumn{2}{|c|}{ Principal Stresses (MPa) } & \multirow{2}{*}{$\begin{array}{c}\text { Max Shear } \\
\text { Stress (MPa) }\end{array}$} & $\begin{array}{c}\text { von Mises } \\
\text { (MPa) }\end{array}$ \\
\cline { 2 - 6 } & $\mathbf{P - 2}$ & $\mathbf{P - 3}$ & & \\
\hline $\mathbf{2}$ & $-6.10 \mathrm{E}-02$ & $-6.26 \mathrm{E}-02$ & $\mathbf{- 6 . 6 5 E - 0 2}$ & $2.76 \mathrm{E}-03$ & $4.93 \mathrm{E}-03$ \\
\hline $\mathbf{3}$ & $-6.16 \mathrm{E}-02$ & $-6.31 \mathrm{E}-02$ & $\mathbf{- 6 . 7 2 E - 0 2}$ & $2.83 \mathrm{E}-03$ & $5.06 \mathrm{E}-03$ \\
\hline $\mathbf{4}$ & $-7.21 \mathrm{E}-02$ & $-7.29 \mathrm{E}-02$ & $\mathbf{- 7 . 8 3 E - 0 2}$ & $3.09 \mathrm{E}-03$ & $5.83 \mathrm{E}-03$ \\
\hline $\mathbf{5}$ & $-7.68 \mathrm{E}-02$ & $-7.79 \mathrm{E}-02$ & $\mathbf{- 8 . 3 8 E - 0 2}$ & $3.52 \mathrm{E}-03$ & $6.55 \mathrm{E}-03$ \\
\hline
\end{tabular}

\footnotetext{
${ }^{3}$ Values in bold are maximum values which are used in FE Simulation
} 
The Maximum Pressure values observed on the brain obtained from the simulation are tabulated below.

Table 4.5 Pressures on the Brain due to Frontal Impact from different heights

\begin{tabular}{|c|c|c|c|}
\hline $\begin{array}{c}\text { Height } \\
\text { (feet) }\end{array}$ & $\begin{array}{c}\text { HICP } \\
\text { (MPa) }\end{array}$ & $\begin{array}{c}\text { Velocity of Fall } \\
(\mathbf{2 g h})^{\wedge} \mathbf{0 . 5} \mathbf{~ m} / \mathbf{s}\end{array}$ & $\begin{array}{c}\text { Pressure on Brain - } \\
\text { Tension } \\
\text { (MPa) }\end{array}$ \\
\hline $\mathbf{2}$ & 0.94 & 3.46 & $6.20 \mathrm{E}-02$ \\
\hline $\mathbf{3}$ & 1.08 & 4.24 & $6.29 \mathrm{E}-02$ \\
\hline $\mathbf{4}$ & 1.24 & 4.89 & $7.35 \mathrm{E}-02$ \\
\hline $\mathbf{5}$ & 1.39 & 5.47 & $7.89 \mathrm{E}-02$ \\
\hline
\end{tabular}

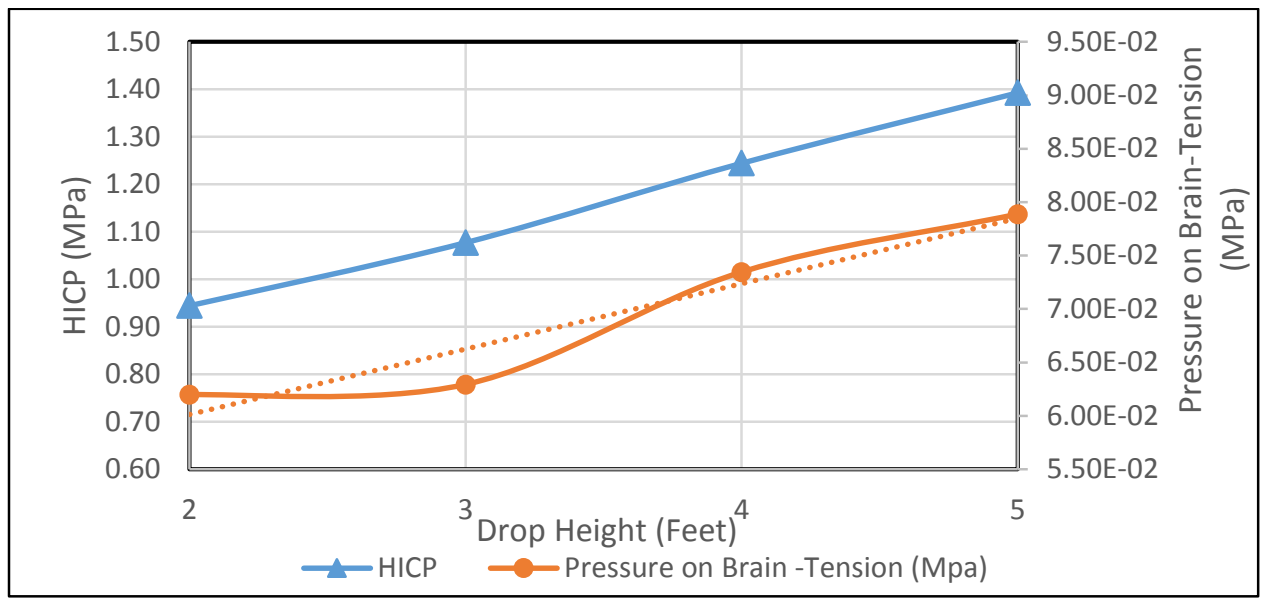

Figure 4.67 Comparison of Pressure on Brain and HICP during Frontal Impact

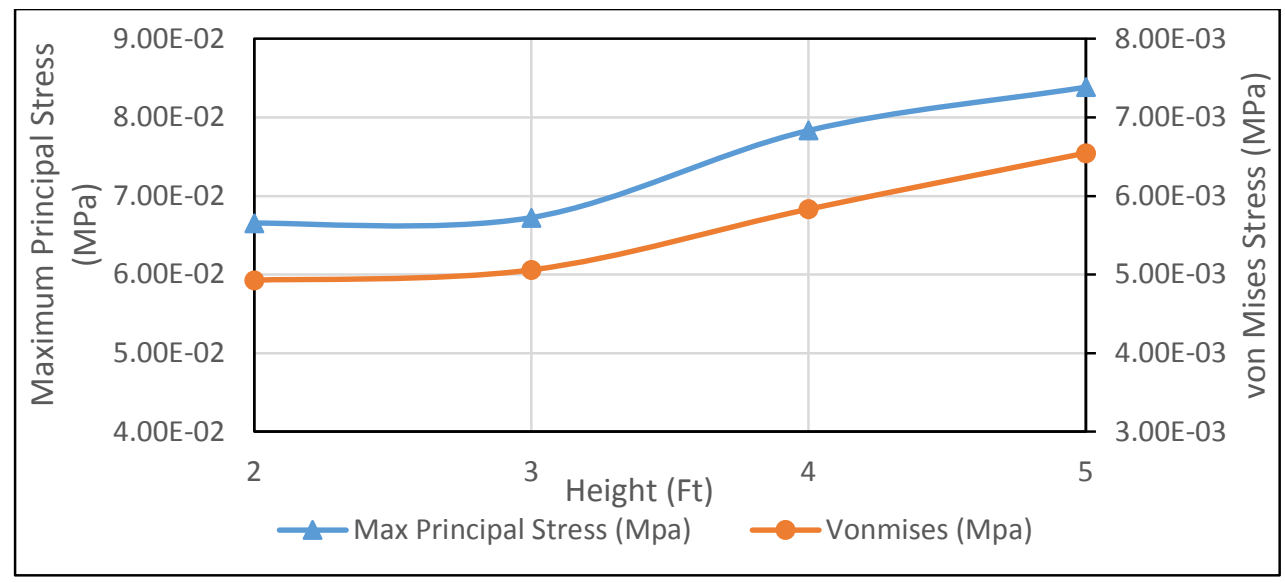

Figure 4.68 Maximum Principal Stress and von Mises Stress on Brain obtained from FE Simulation for Frontal Impacts 


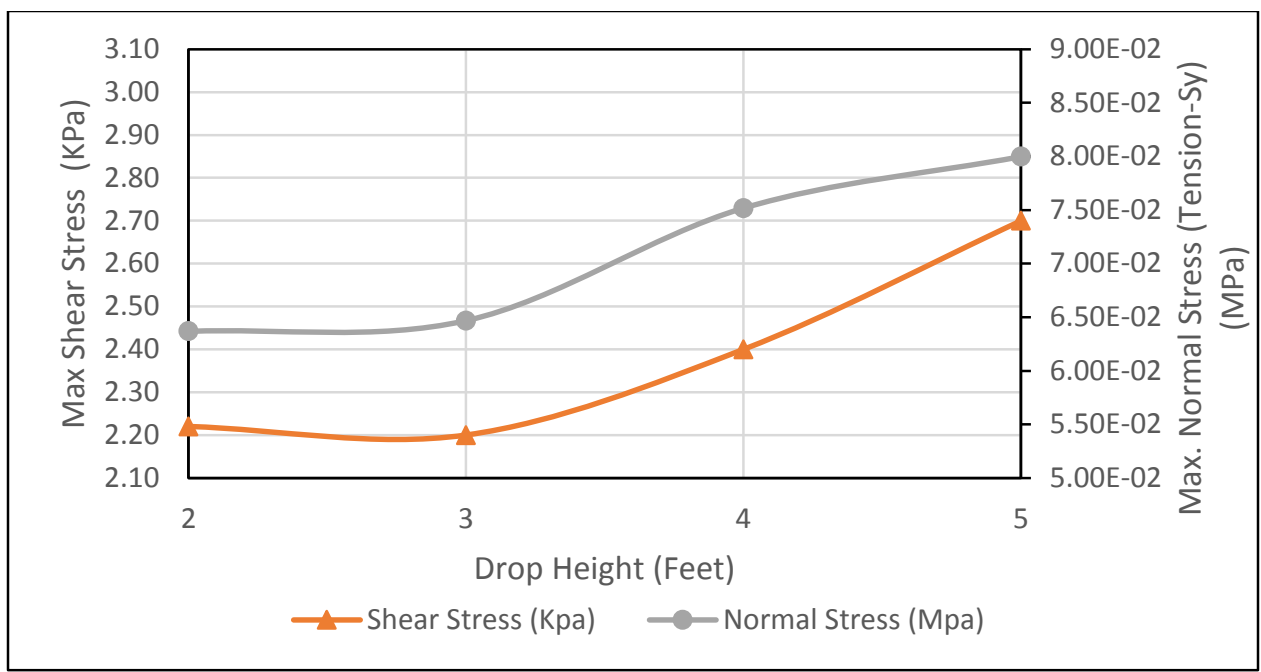

Figure 4.69 Stress variation on brain with respect to drop height in Frontal Impact

Upon observing the results of the simulation the following information can be inferred.

- One can see that the pressure wave travels from the frontal lobe (site of impact) to parietal lobe and thus to occipital lobe and gets reflected back in the opposite direction as a tensile stress wave surfacing upon the frontal lobe towards the site of Injury, thus explaining the concept of Coup and Contre Coup Injury. Consider the Fig.4.53 which shows the frontal lobe under compression and the change in the magnitude of stress towards occipital lobe which in tension as observed in Fig 4.54. The maximum pressure is observed around the peak value of the acceleration.

- The maximum Shear stress values are obtained in the regions of frontal lobe and occipital lobe which are under compression, while parietal and temporal lobes are under tension.

- The maximum von Mises stress values are obtained in the regions around the brain stem. The concussions which happen in this region are due to shear stress as location of maximum von Mises stress is not on the brain. 


\subsection{2 $45^{\circ}$ to Frontal}

\subsubsection{Drop Height of 2 feet}

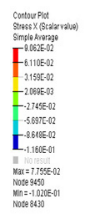

$\sum_{2}^{x}$

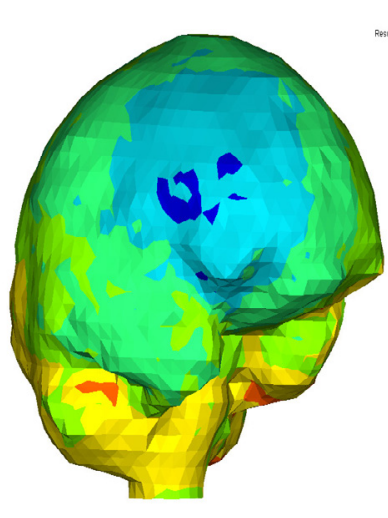

Figure 4.70 Normal stress $S_{x} 45^{\circ}$ to Frontal 2 feet
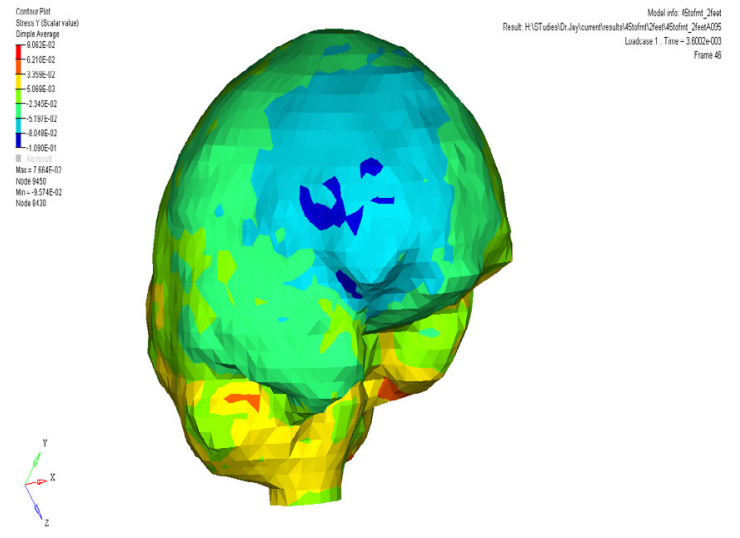

Figure 4.72 Normal stress $S_{y} 45^{\circ}$ to Frontal 2 feet
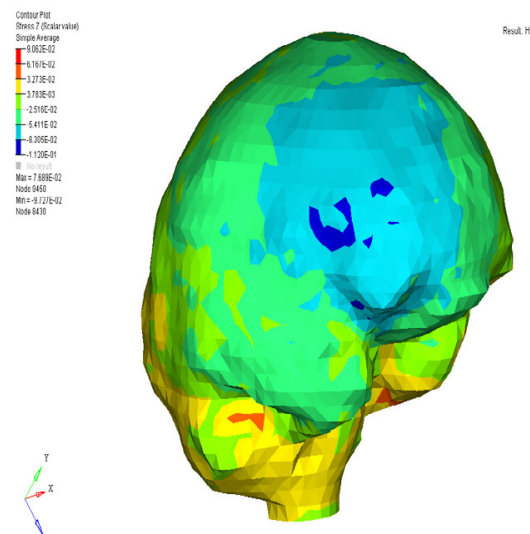

Figure 4.74 Normal stress $S_{z} 45^{\circ}$ to Frontal 2 feet
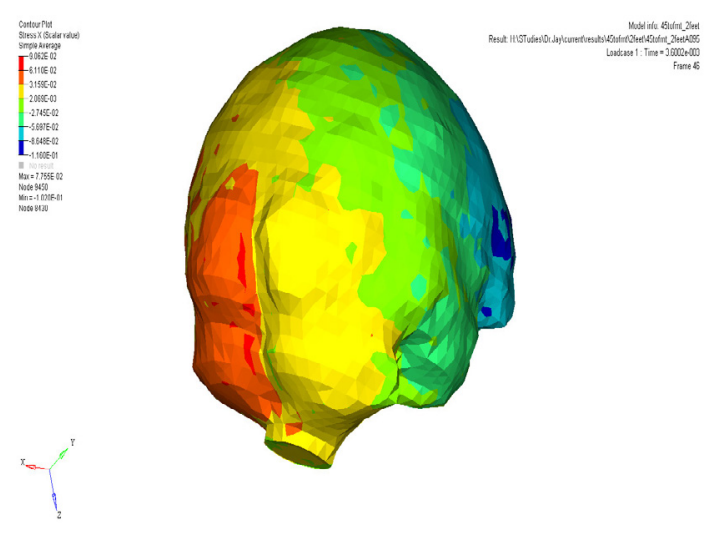

Figure 4.71 Normal stress $S_{x} 45^{\circ}$ to Frontal 2 feet
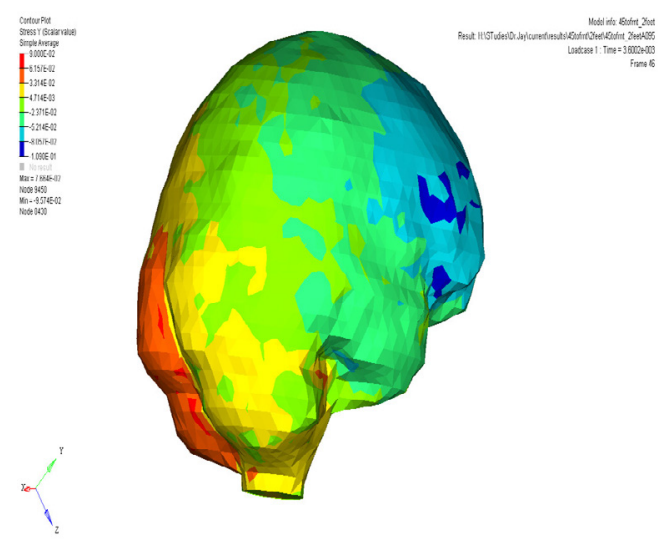

Figure 4.73 Normal stress $S_{y} 45^{\circ}$ to Frontal 2 feet
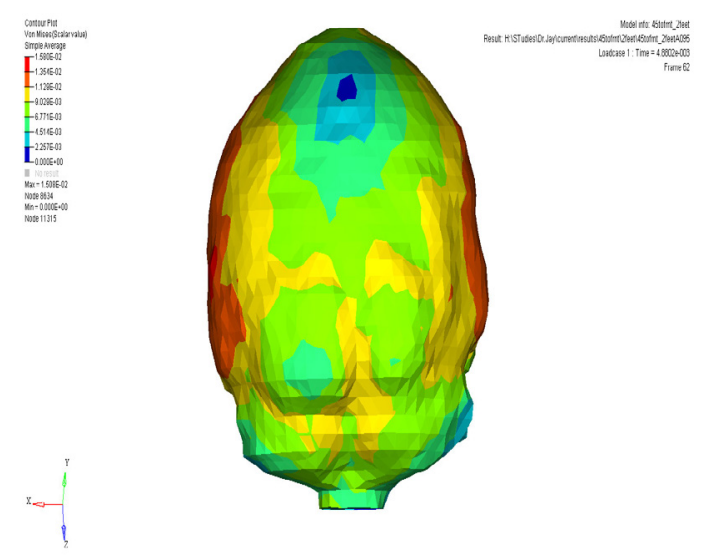

Figure 4.75 von Mises $45^{\circ}$ to Frontal 2 feet 

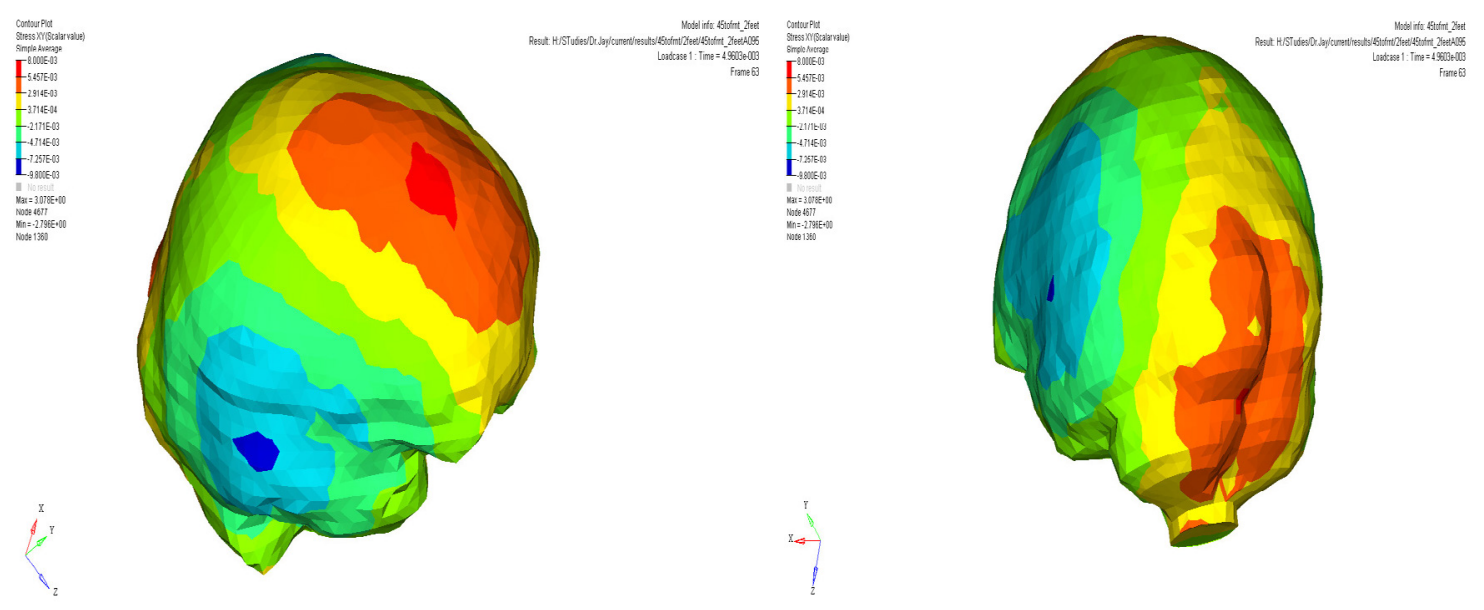

Figure 4.76 Shear stress $S_{x y} 45^{\circ}$ to Frontal 2 feet

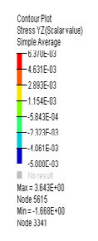

$\sum_{i}$

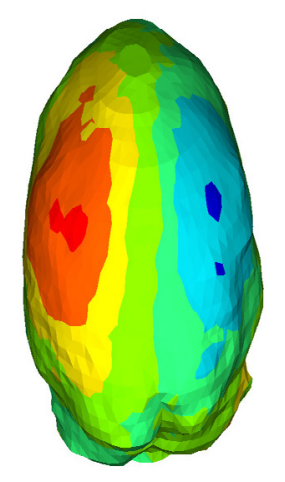

Figure 4.78 Shear stress $S_{y z} 45^{\circ}$ to Frontal 2 feet
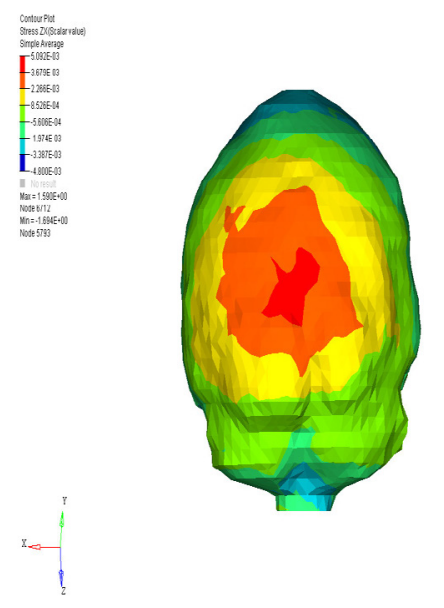

Figure 4.80 Shear stress $S_{z x} 45^{\circ}$ to Frontal 2 feet
Figure 4.77 Shear stress $S_{x y} 45^{\circ}$ to Frontal 2 feet
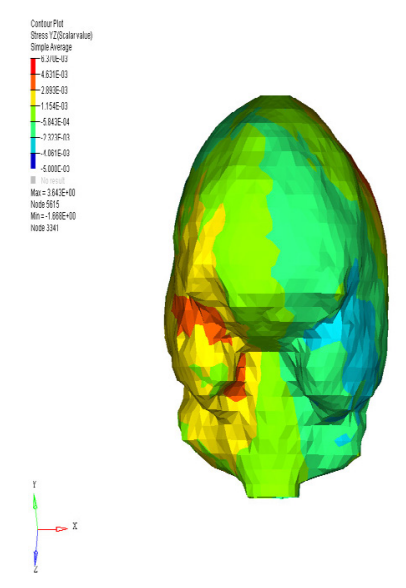

Figure 4.79 Shear stress $S_{y z} 45^{\circ}$ to Frontal 2 feet
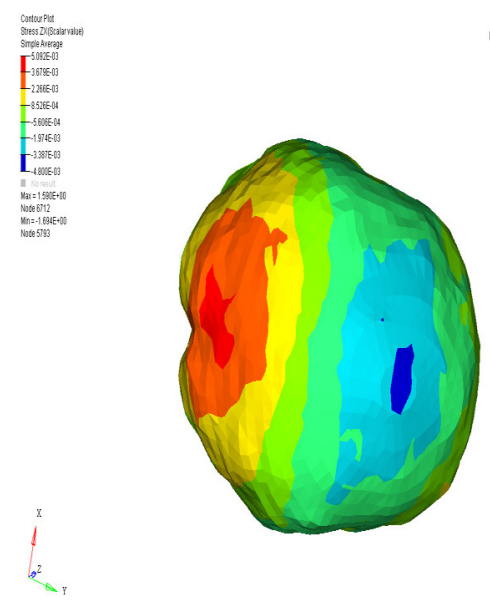

Figure 4.81 Shear stress $S_{z x} 45^{\circ}$ to Frontal 2 feet 


\subsubsection{Drop Height of 3 feet}
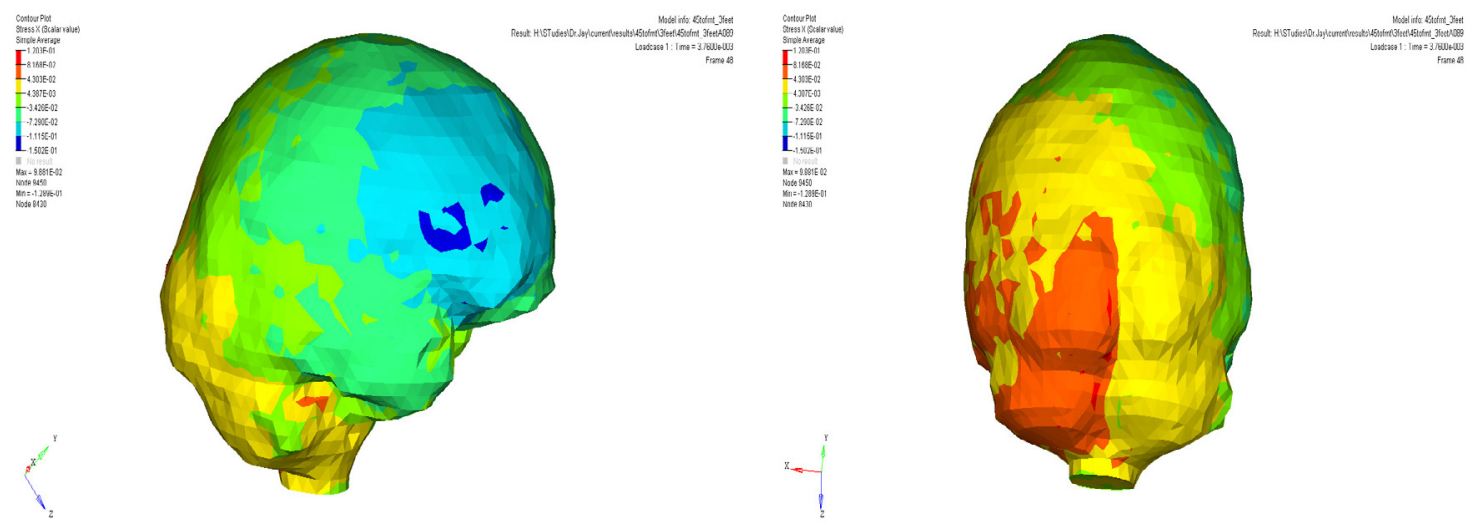

Figure 4.82 Normal Stress $S_{x} 45^{\circ}$ to Frontal 3 feet

Figure 4.83 Normal Stress $S_{x} 45^{\circ}$ to Frontal 3 feet
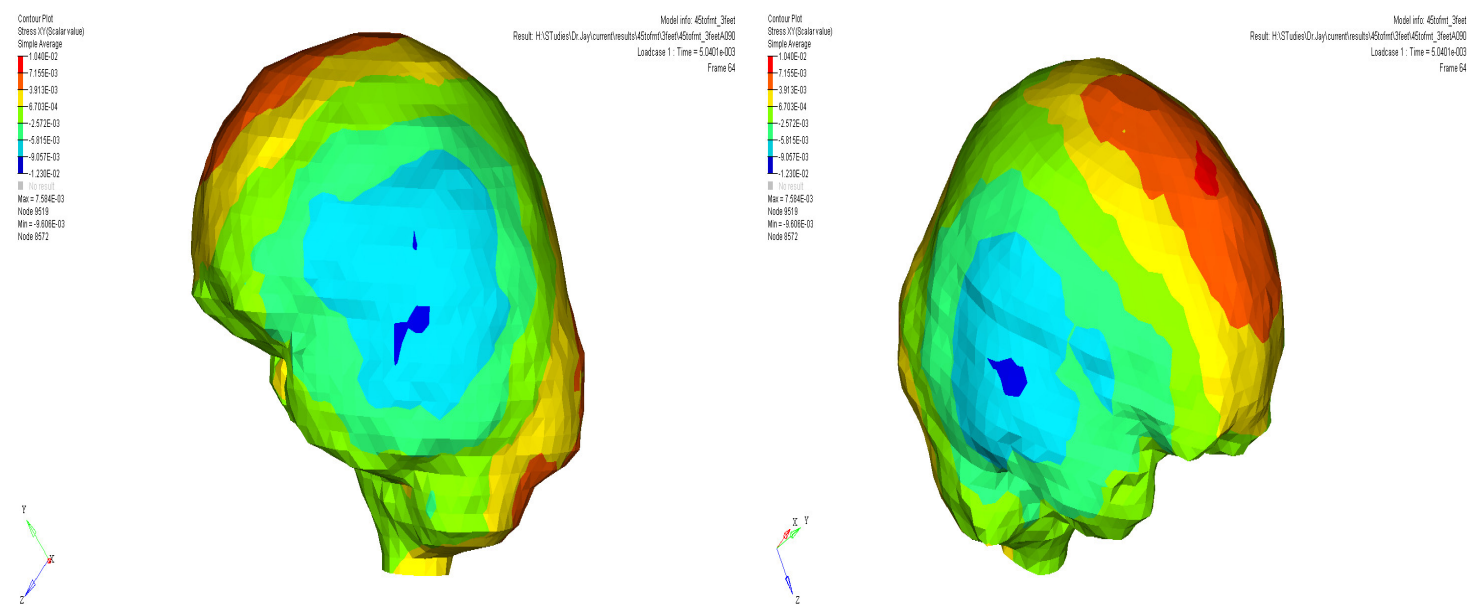

Figure 4.84 Shear stress $S_{x y} 45^{\circ}$ to Frontal 3 feet

Figure 4.85 Shear stress $S_{x y} 45^{\circ}$ to Frontal 3 feet
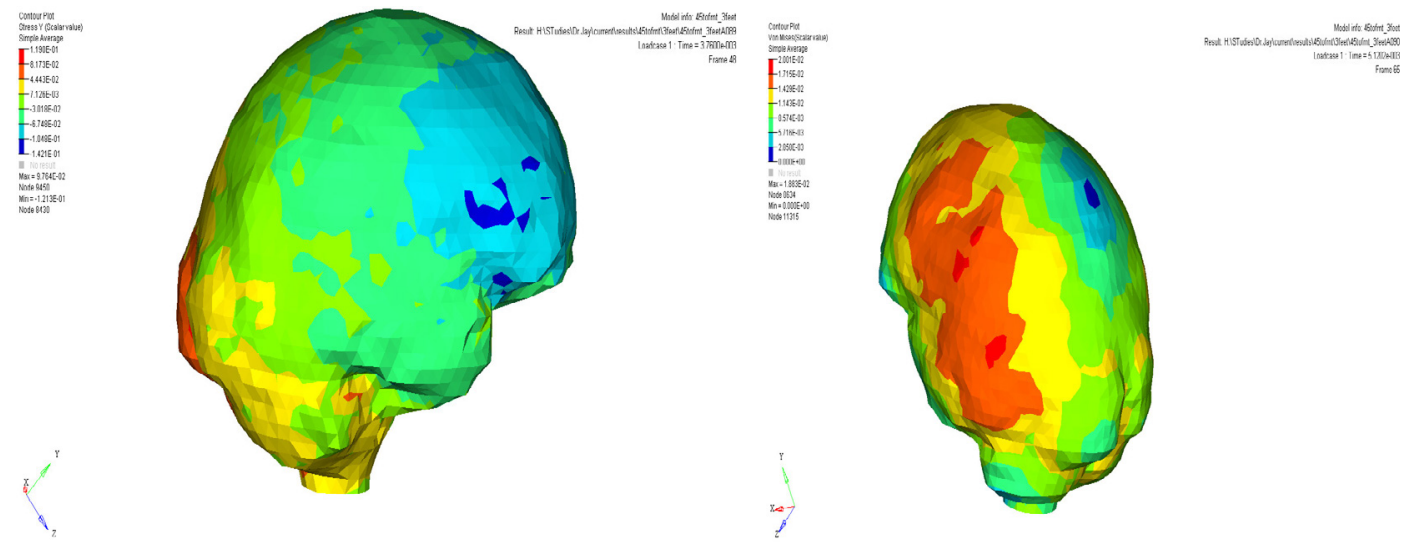

Figure 4.86 Normal stress $S_{y} 45^{\circ}$ to Frontal 3 feet

Figure 4.87 von Mises stress $45^{\circ}$ to Frontal 3 feet 

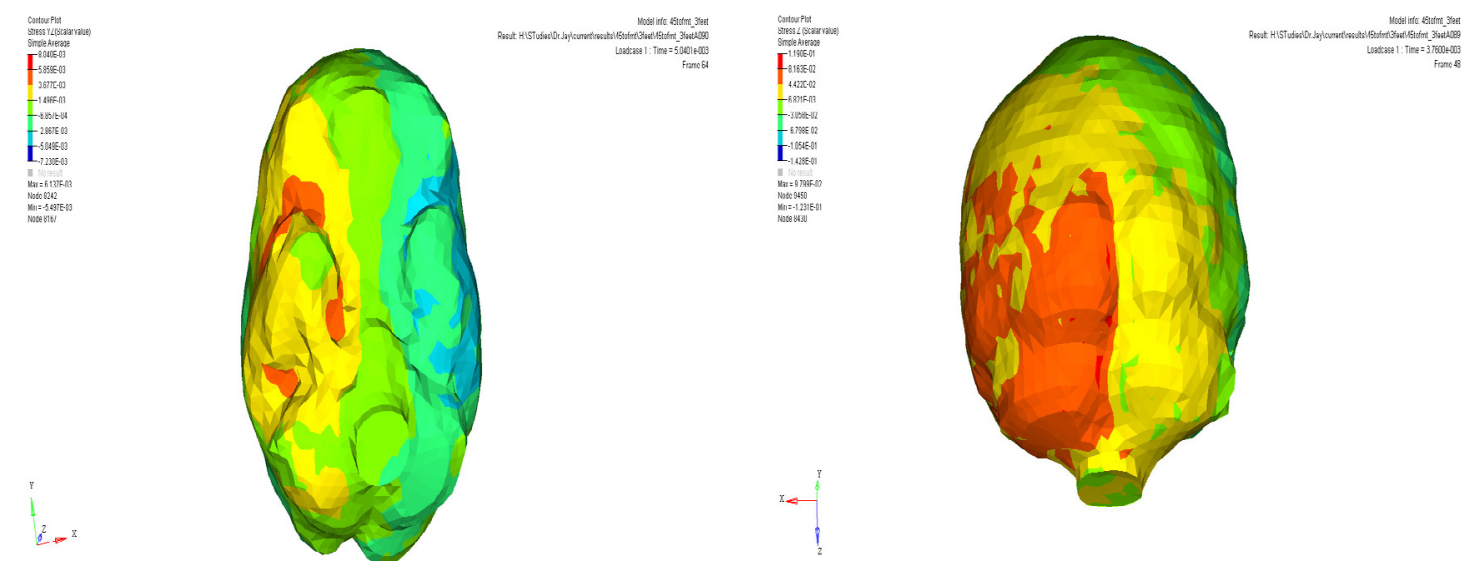

Figure4.88 Shear stress $S_{y z} 45^{\circ}$ to Frontal 3 feet

Figure 4.89 Normal stress $S_{z} 45^{\circ}$ to Frontal 3 feet

$$
\text { 를 }
$$
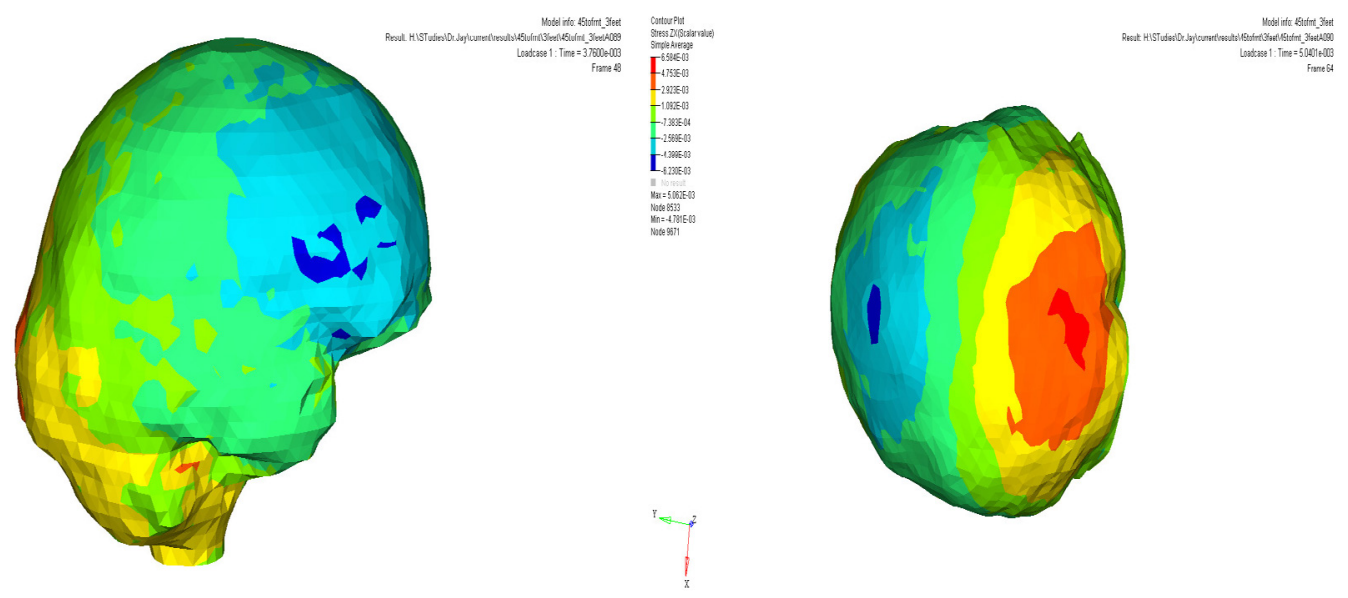

Figure 4.90 Normal stress $S_{z} 45^{\circ}$ to Frontal 3 feet

Figure 4.91 Shear stress $S_{z x} 45^{\circ}$ to Frontal 3 feet

\subsubsection{Drop Height of 4 feet}
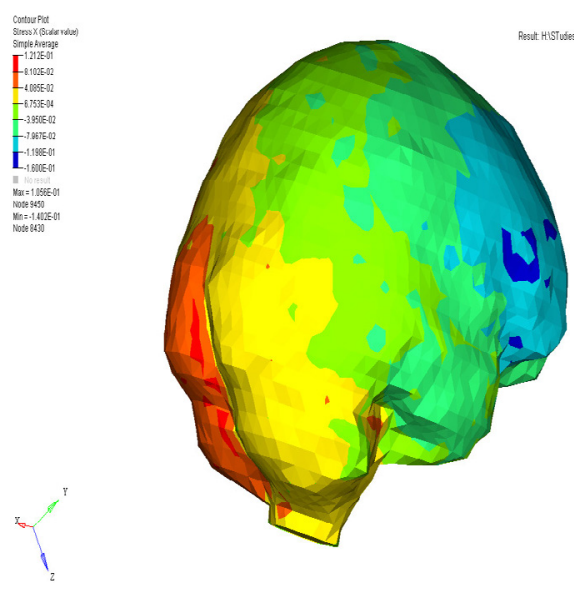

Figure 4.92 Normal Stress $S_{x} 45^{\circ}$ to Frontal 4 feet
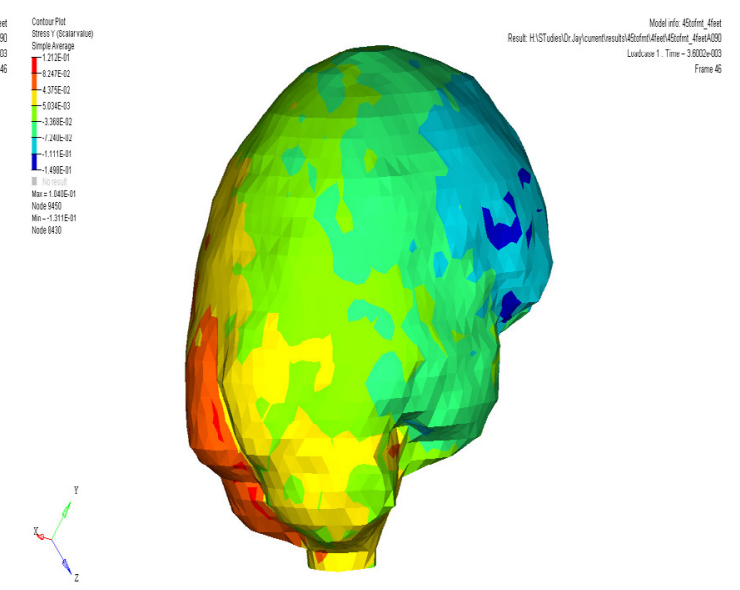

Figure 4.93 Normal Stress $S_{y} 45^{\circ}$ to Frontal 4 feet 

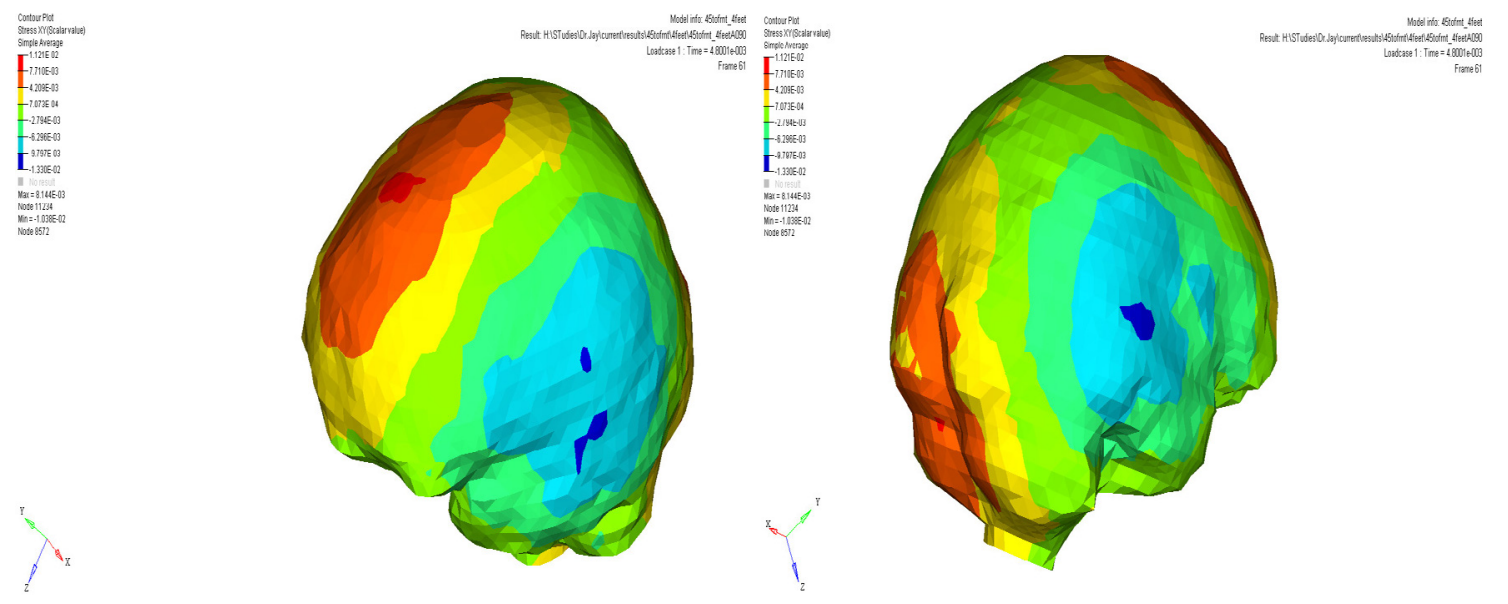

Figure 4.94 Shear stress $S_{x y} 45^{\circ}$ to Frontal 4 feet

Figure 4.95 Shear stress $S_{x y} 45^{\circ}$ to Frontal 4 feet

$$
\text { 壾 }
$$
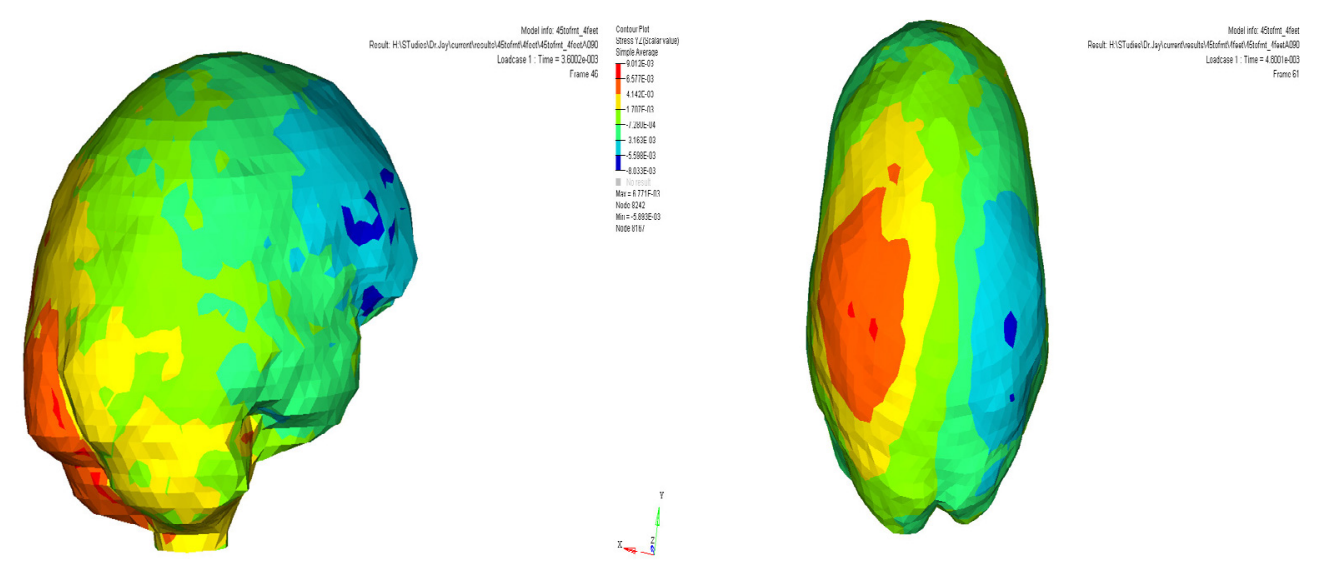

Figure 4.96 Normal Stress $S_{y} 45^{\circ}$ to Frontal 4 feet $\quad$ Figure 4.97 Shear stress $S_{y z} 45^{\circ}$ to Frontal 4 feet

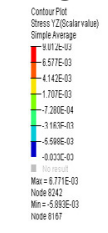

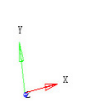

Figure 4.98 Shear stress $S_{y z} 45^{\circ}$ to Frontal 4 feet
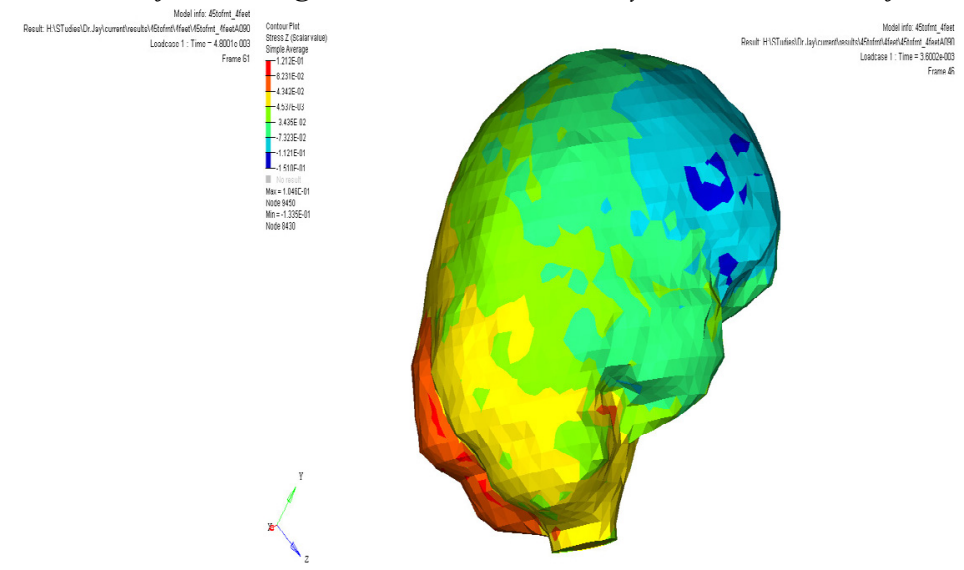

Figure 4.99 Normal stress $S_{z} 45^{\circ}$ to Frontal 4 feet 

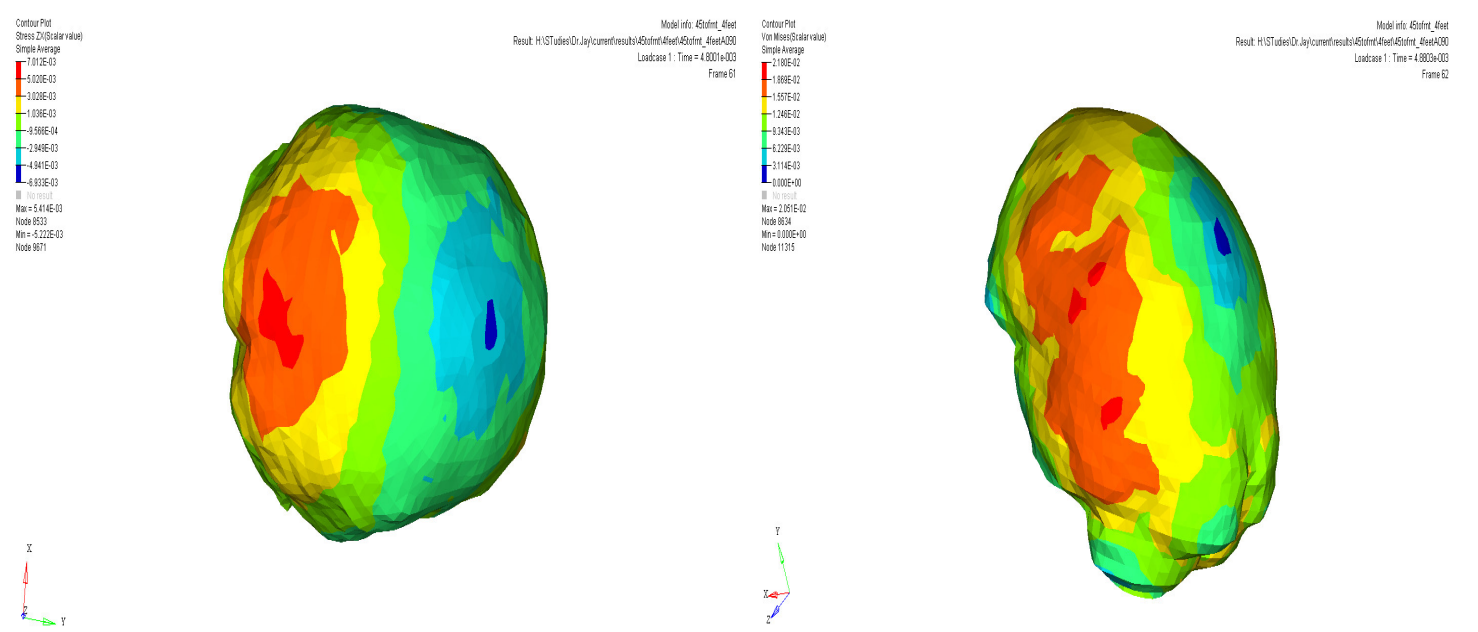

Figure 4.100 Shear stress $S_{z x} 45^{\circ}$ to Frontal 4 feet

Figure 4.101 von Mises $45^{\circ}$ to Frontal 4 feet

\subsubsection{Drop Height of 5 feet}
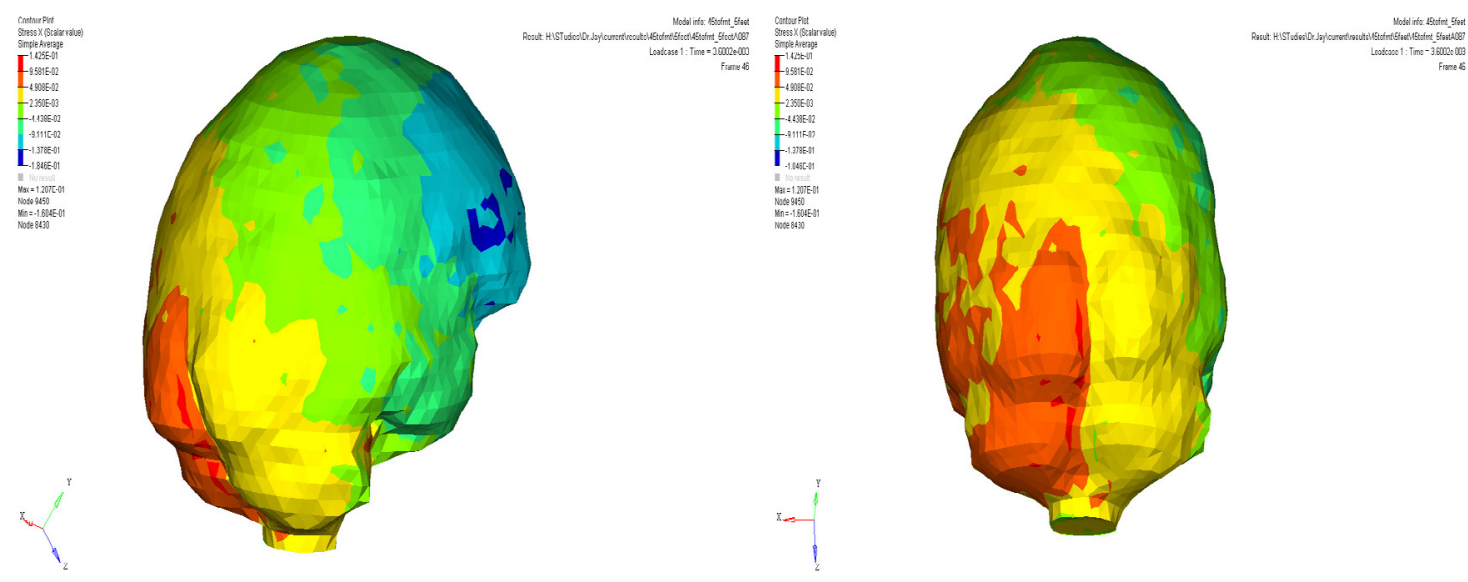

Figure 4.102 Normal Stress $S_{x} 45^{\circ}$ to Frontal 5 feet

Figure 4.103 Normal Stress $S_{x} 45^{\circ}$ to Frontal 5 feet
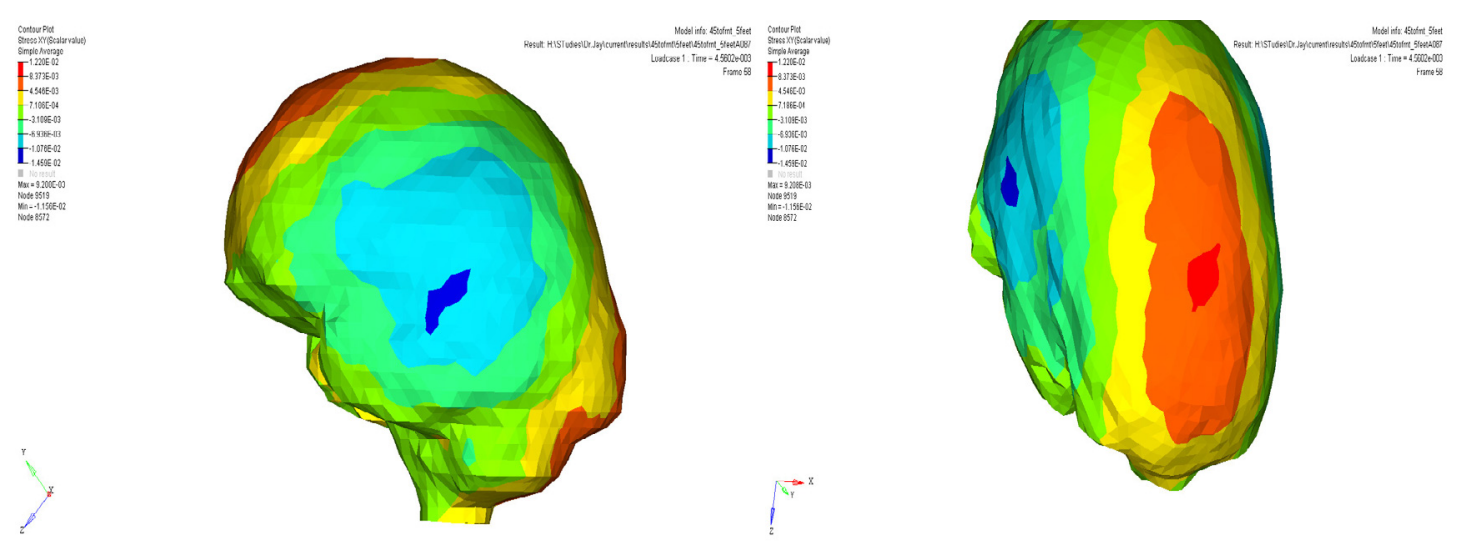

Figure 4.104 Shear stress $S_{x y} 45^{\circ}$ to Frontal 5 feet

Figure 4.105 Shear stress $S_{x y} 45^{\circ}$ to Frontal 5 feet 

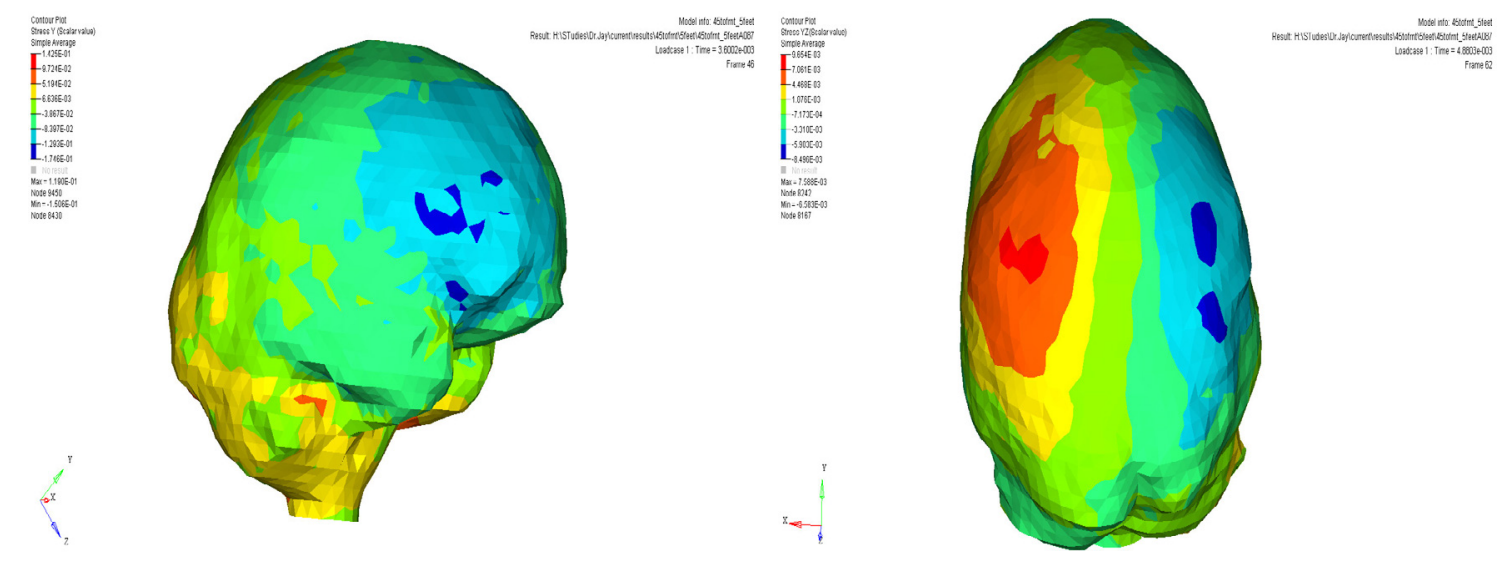

Figure 4.106 Normal Stress $S_{y} 45^{\circ}$ to Frontal 5 feet

Figure 4.107 Shear stress Syz $45^{\circ}$ to Frontal 5 feet
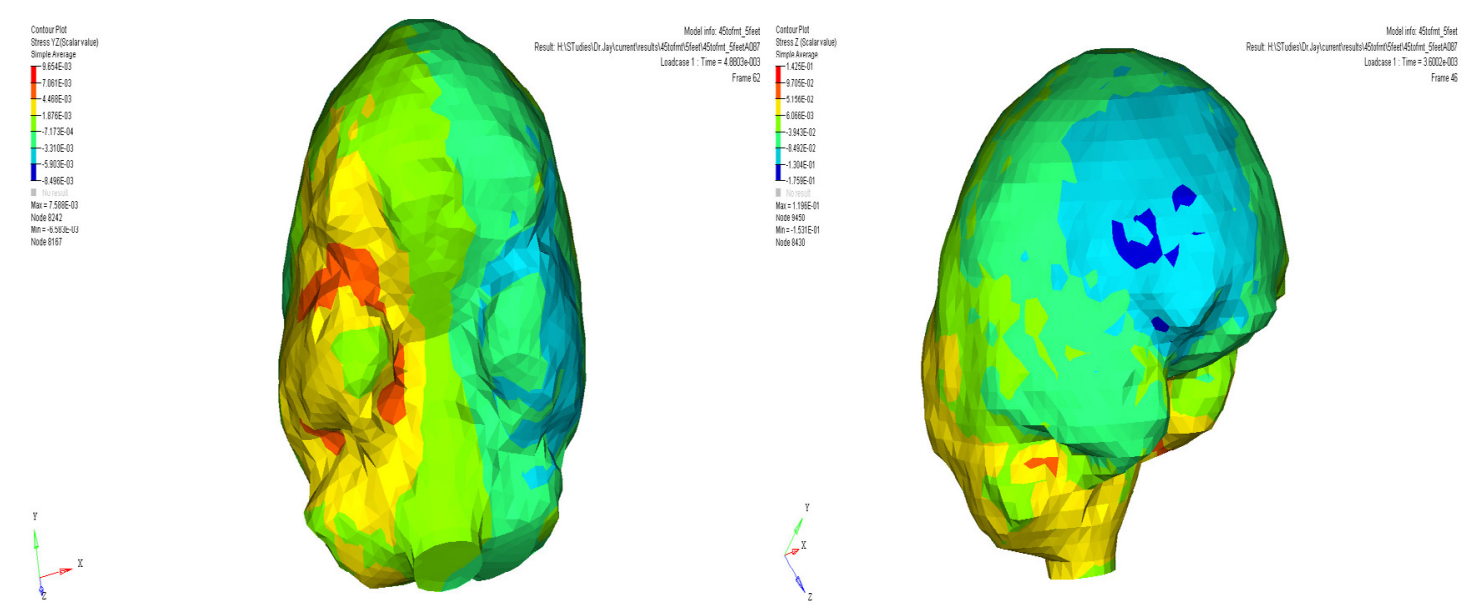

Figure 4.108 Shear stress $S_{y z} 45^{\circ}$ to Frontal 5 feet
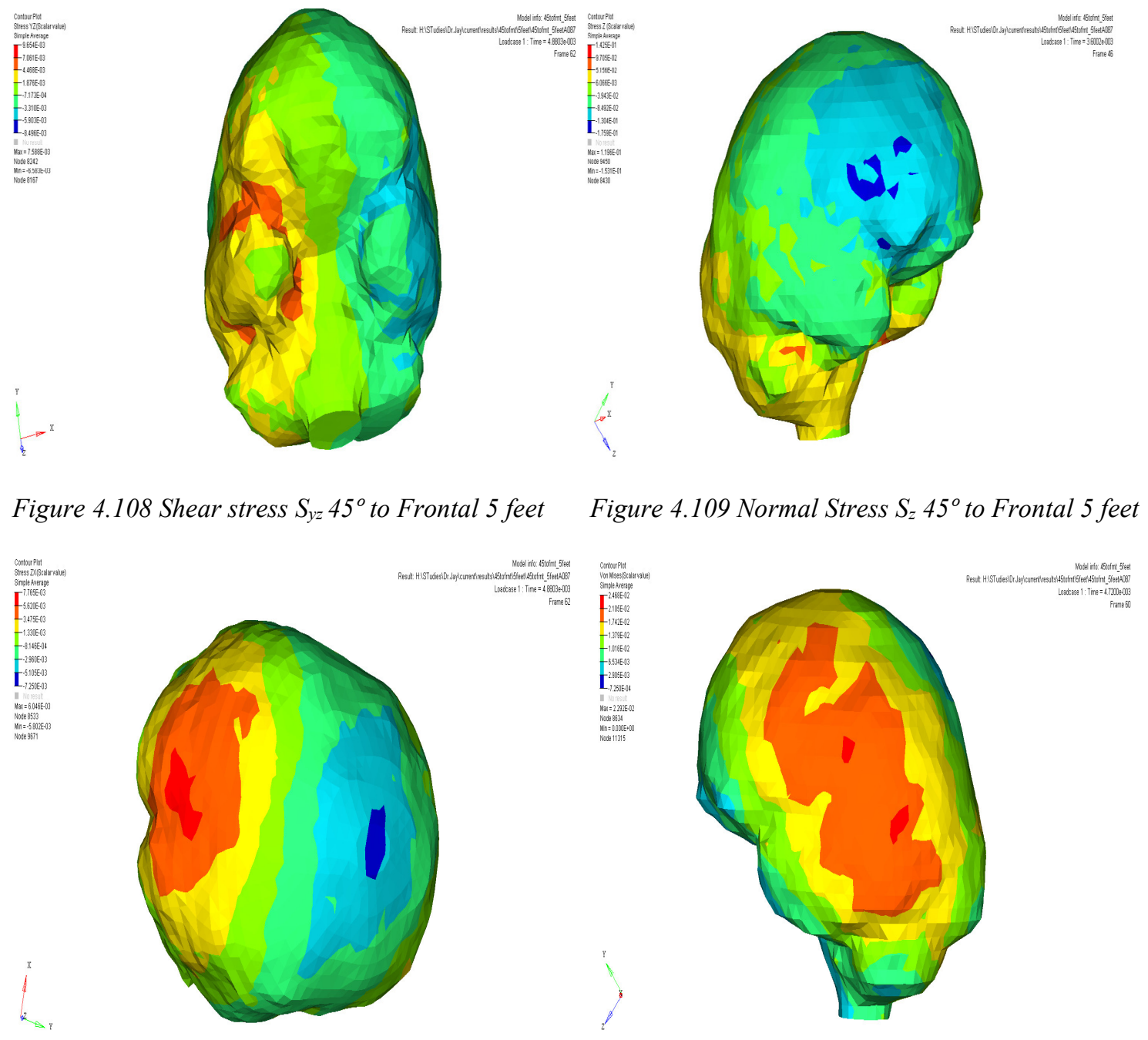

Figure 4.110 Shear stress $S_{z x} 45^{\circ}$ to Frontal 5 feet

Figure 4.111 von Mises stresses $45^{\circ}$ to Frontal 5 feet 


\subsubsection{Discussion}

The normal stresses values obtained from the Finite element simulation are listed below.

Table 4.6 Normal Stress values on brain from FE Simulation of $45^{\circ}$ to Frontal Impact

\begin{tabular}{|r|c|r|c|r|r|r|}
\hline \multirow{2}{*}{$\begin{array}{c}\text { Height } \\
\text { (feet) }\end{array}$} & \multicolumn{2}{|c|}{ Stress X (MPa) } & \multicolumn{2}{c|}{ Stress Y (MPa) } & \multicolumn{2}{c|}{ Stress Z (MPa) } \\
\cline { 2 - 7 } & \multicolumn{1}{c|}{ Tension } & \multicolumn{1}{c|}{ Compression } & \multicolumn{1}{c|}{ Tension } & \multicolumn{1}{c|}{ Compression } & \multicolumn{1}{c|}{ Tension } & Compression \\
\hline $\mathbf{2}$ & $\mathbf{- 1 . 1 6 E - 0 1}$ & $9.06 \mathrm{E}-02$ & $\mathbf{- 1 . 0 9 E - 0 1}$ & $9.06 \mathrm{E}-02$ & $\mathbf{- 1 . 1 2 E - 0 1}$ & $9.06 \mathrm{E}-02$ \\
\hline $\mathbf{3}$ & $\mathbf{- 1 . 5 0 E - 0 1}$ & $1.20 \mathrm{E}-01$ & $\mathbf{- 1 . 4 2 E - 0 1}$ & $1.19 \mathrm{E}-01$ & $\mathbf{- 1 . 4 3 E - 0 1}$ & $1.19 \mathrm{E}-01$ \\
\hline $\mathbf{4}$ & $\mathbf{- 1 . 6 0 E - 0 1}$ & $1.21 \mathrm{E}-01$ & $\mathbf{- 1 . 5 0 E - 0 1}$ & $1.21 \mathrm{E}-01$ & $\mathbf{- 1 . 5 1 E - 0 1}$ & $1.21 \mathrm{E}-01$ \\
\hline $\mathbf{5}$ & $\mathbf{- 1 . 8 5 E - 0 1}$ & $1.43 \mathrm{E}-01$ & $\mathbf{- 1 . 7 5 E - 0 1}$ & $1.43 \mathrm{E}-01$ & $\mathbf{- 1 . 7 6 E - 0 1}$ & $1.43 \mathrm{E}-01$ \\
\hline
\end{tabular}

The Shear stress values obtained for different drops from the finite element simulation are listed below

Table 4.7 Shear Stress values on brain from the FE Simulation of $45^{\circ}$ to Frontal Impact

\begin{tabular}{|r|r|r|r|}
\hline $\begin{array}{c}\text { Height } \\
\text { (feet) }\end{array}$ & Stress XY (MPa) & Stress YZ (MPa) & Stress ZX (MPa) \\
\hline $\mathbf{2}$ & $\mathbf{- 9 . 8 0 E - 0 3}$ & $6.37 \mathrm{E}-03$ & $5.09 \mathrm{E}-03$ \\
\hline $\mathbf{3}$ & $\mathbf{- 1 . 2 3 E - 0 2}$ & $8.04 \mathrm{E}-03$ & $6.58 \mathrm{E}-03$ \\
\hline $\mathbf{4}$ & $\mathbf{- 1 . 3 3 E - 0 2}$ & $9.01 \mathrm{E}-03$ & $7.01 \mathrm{E}-03$ \\
\hline $\mathbf{5}$ & $\mathbf{- 1 . 4 6 E - 0 2}$ & $9.65 \mathrm{E}-03$ & $7.77 \mathrm{E}-03$ \\
\hline
\end{tabular}

The Values when used in the Mohr Circle calculation, yielded the following results

Table 4.8 Results Obtained from Mohr Circle Analysis of $45^{\circ}$ to Frontal Impact

\begin{tabular}{|c|c|c|c|c|c|}
\hline \multirow{2}{*}{$\begin{array}{l}\text { Height } \\
\text { (feet) }\end{array}$} & \multicolumn{3}{|c|}{ Principal Stresses (MPa) } & \multirow{2}{*}{$\begin{array}{l}\text { Max Shear } \\
\text { Stress } \\
\text { (MPa) }\end{array}$} & \multirow{2}{*}{$\begin{array}{c}\text { von Mises } \\
\text { (MPa) }\end{array}$} \\
\hline & P-1 & P-2 & $\mathbf{P}-3$ & & \\
\hline 2 & $-1.01 \mathrm{E}-01$ & $-1.09 \mathrm{E}-01$ & $-1.27 E-01$ & & $2.29 \mathrm{E}-02$ \\
\hline 3 & $-1.32 \mathrm{E}-01$ & $-1.39 \mathrm{E}-01$ & $-1.64 \mathrm{E}-01$ & $1.59 \mathrm{E}-02$ & $2.89 \mathrm{E}-02$ \\
\hline 4 & $-1.39 \mathrm{E}-01$ & $-1.47 \mathrm{E}-01$ & $-1.74 E-01$ & $1.75 \mathrm{E}-02$ & $3.18 \mathrm{E}-02$ \\
\hline 5 & $-1.63 \mathrm{E}-01$ & $-1.72 \mathrm{E}-01$ & $-2.01 E-01$ & $1.90 \mathrm{E}-02$ & $3.45 \mathrm{E}-02$ \\
\hline
\end{tabular}

The Maximum Pressure values observed on the brain obtained from the simulation are tabulated below. 
Table 4.9 Pressures on the Brain due to $45^{\circ}$ to Frontal Impact from different heights

\begin{tabular}{|c|c|c|c|}
\hline $\begin{array}{c}\text { Height } \\
\text { (feet) }\end{array}$ & HICP & $\begin{array}{c}\text { Velocity of Fall } \\
\text { (2gh)^0.5 } \mathbf{~ m} / \mathbf{s}\end{array}$ & $\begin{array}{c}\text { Pressure on Brain } \\
\text {-Tension (MPa) }\end{array}$ \\
\hline $\mathbf{2}$ & 1.46 & 3.46 & $1.10 \mathrm{E}-01$ \\
\hline $\mathbf{3}$ & 1.80 & 4.24 & $1.42 \mathrm{E}-01$ \\
\hline $\mathbf{4}$ & 1.93 & 4.89 & $1.51 \mathrm{E}-01$ \\
\hline $\mathbf{5}$ & 2.17 & 5.47 & $1.75 \mathrm{E}-01$ \\
\hline
\end{tabular}

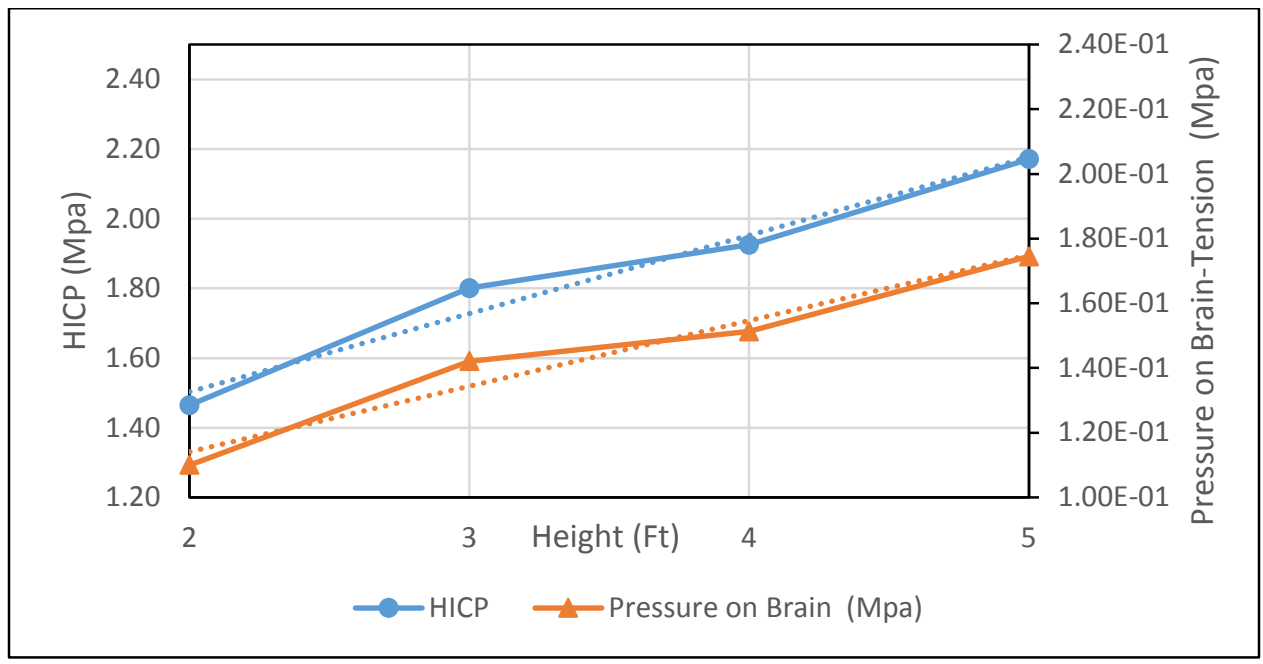

Figure 4.112 Comparison of Pressure on Brain and HICP during $45^{\circ}$ to Frontal Impact

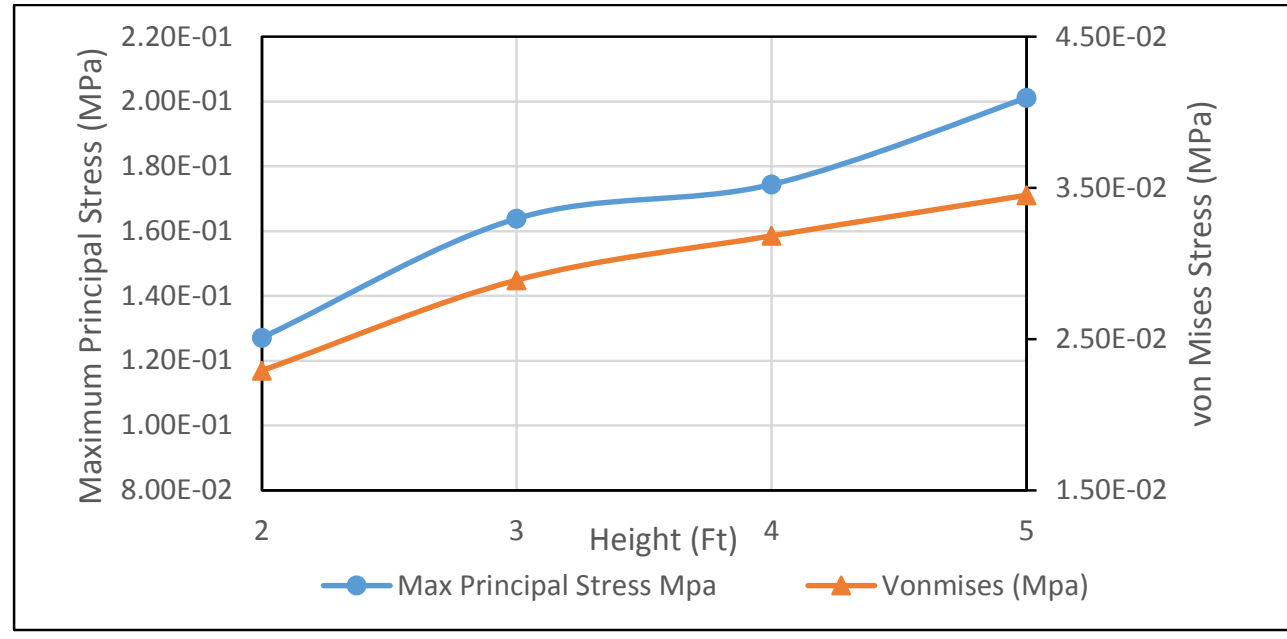

Figure 4.113 Maximum Principal Stress and von Mises Stress on Brain obtained from FE Simulation of $45^{\circ}$ to Frontal Impact 


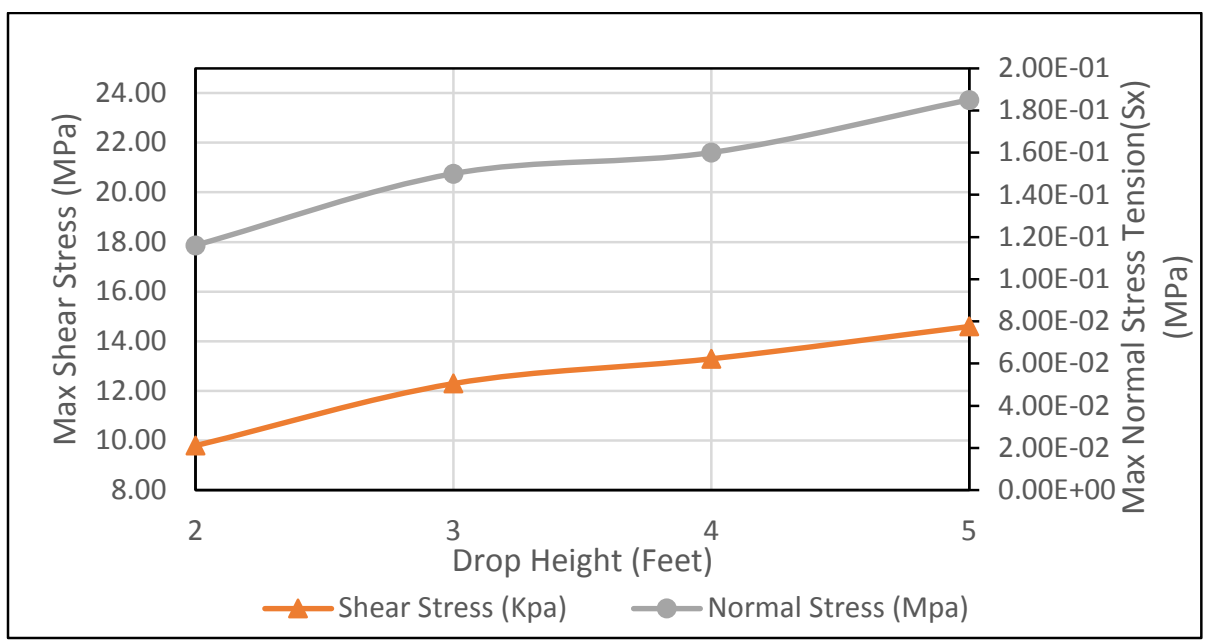

Figure 4.114 Stress variation on brain with respect to drop height in 45 to Frontal Impact

Upon observing the results of the simulation the following information can be inferred.

- One can see that the pressure wave travels from the frontal lobe (site of impact) to parietal lobe and then to occipital lobe and gets reflected back in the opposite direction as a tensile stress wave surfacing upon the frontal lobe towards the site of impact explaining the concept of Coup and Contre Coup Injury. One can observe that in Fig 4.70 the site of injury is in compression and in Fig 4.71 the change in magnitude of stress to tension in occipital lobe specifying the travel of wave. The maximum pressure is observed around the peak of the impact curve specifying the travel of the pressure wave during the impact. - The maximum shear stress values are obtained in the regions of parietal lobe (top of the head) and occipital lobe which are under tension, while brain is under compression from both sides along the ears.

- The maximum von Mises stress values are obtained in the regions around the brain stem and on the parietal lobe and occipital lobe along the line of impact. The rotation of the brain is predominant in this region when compared to frontal region implying the effect of angular acceleration along with the linear acceleration for an injury in this region. 


\subsubsection{Lateral}

\subsubsection{Drop Height of 2 feet}
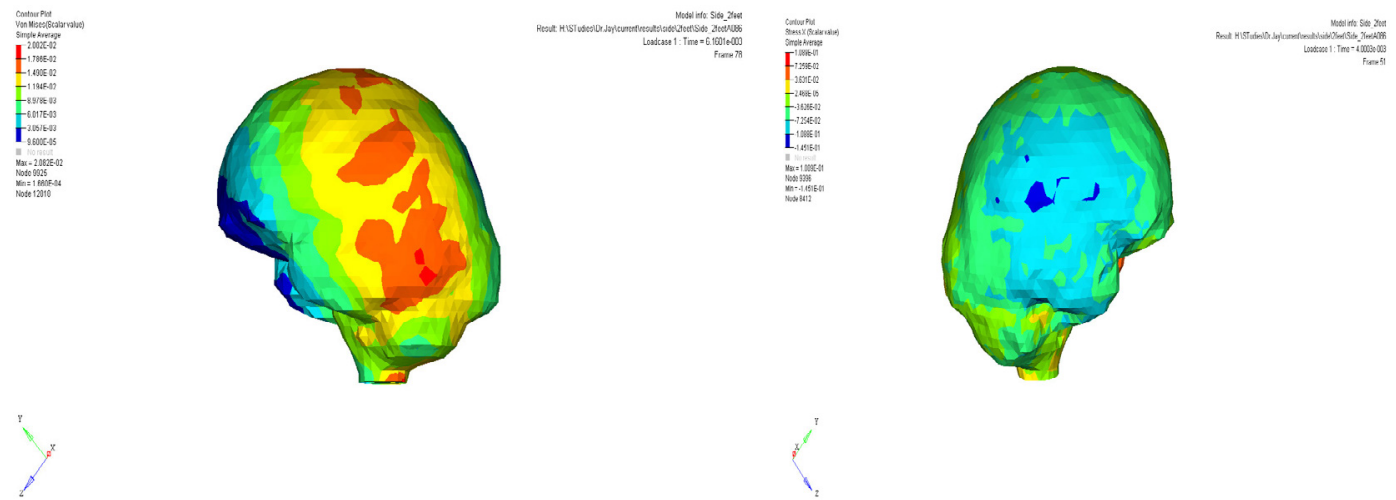

Figure 4.115 von Mises stress Lateral 2 feet

Figure 4.116 Normal stress $S_{x}$ Lateral 2 feet
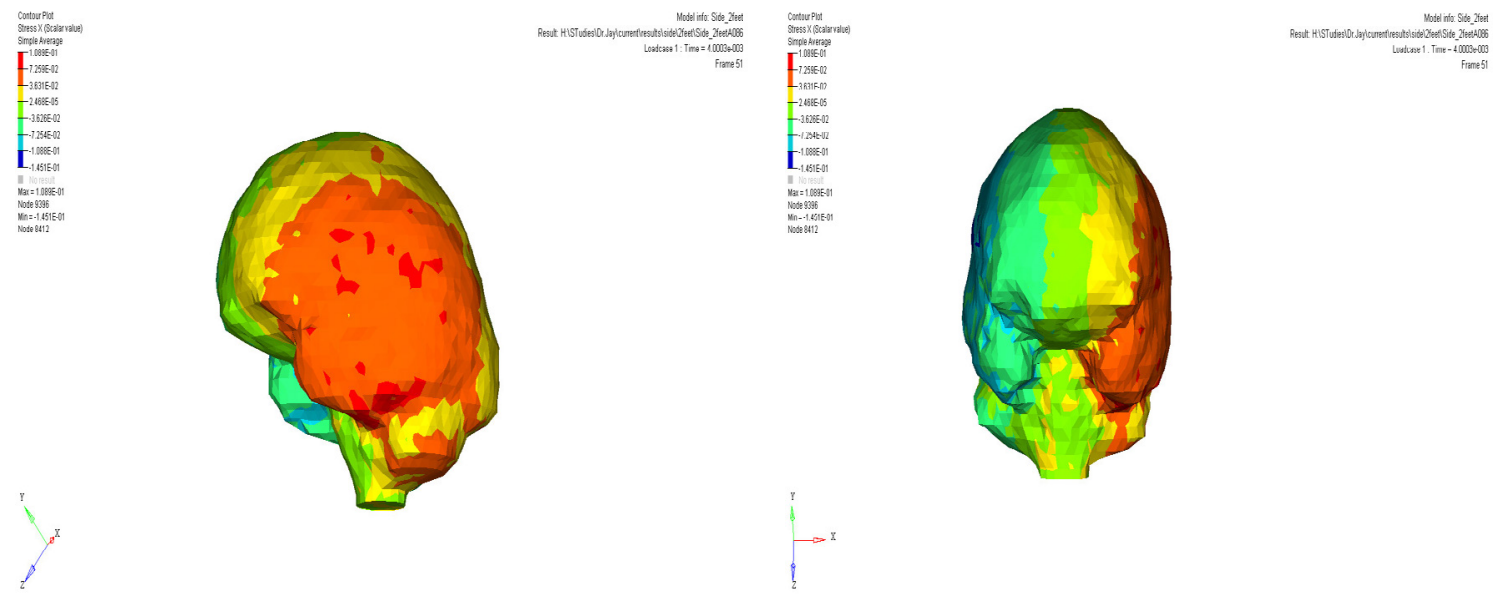

Figure 4.117 Normal stress $S_{x}$ Lateral 2 feet

Figure 4.118 Normal stress $S_{x}$ Lateral 2 feet
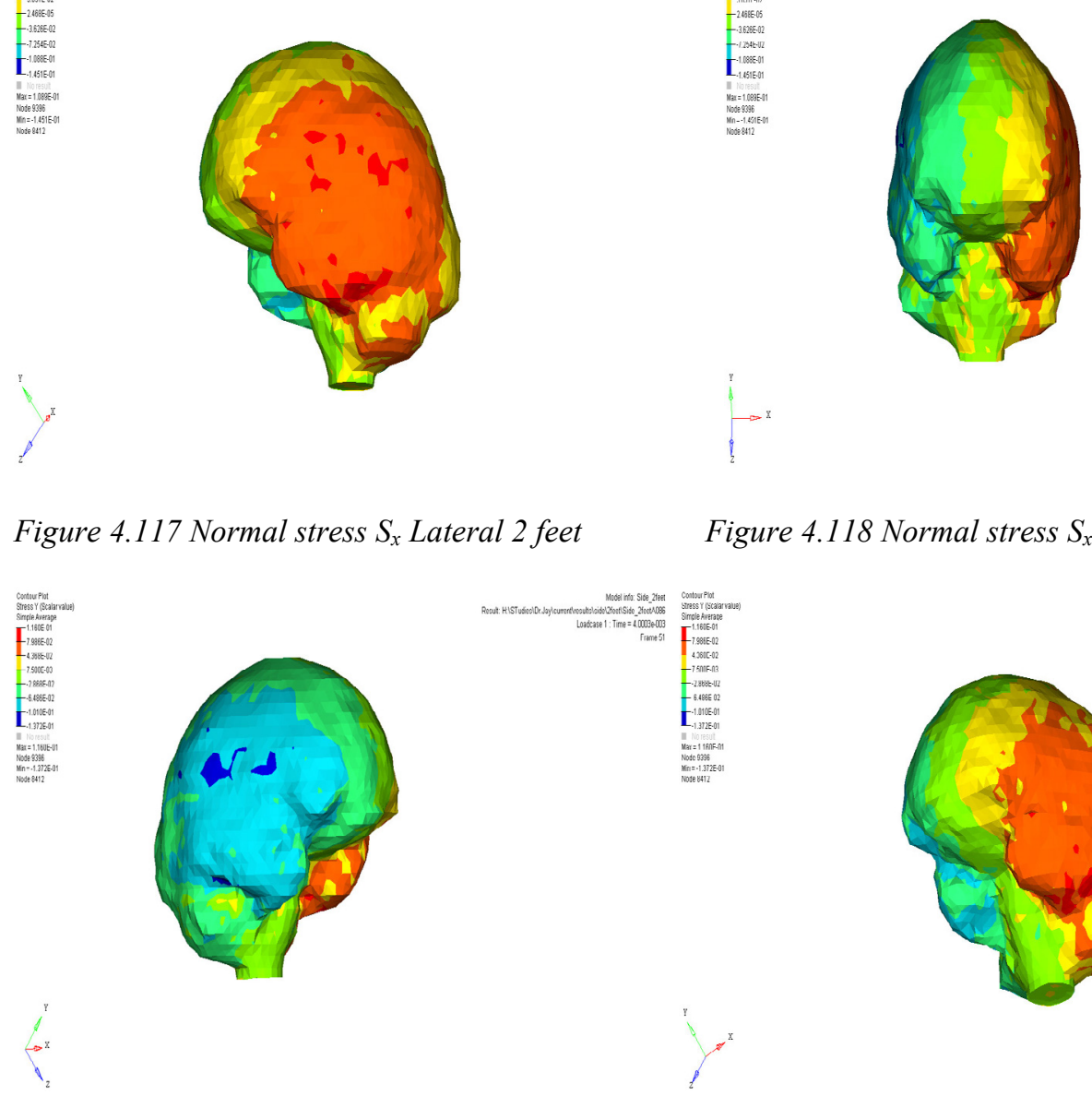

Figure 4.119 Normal stress $S_{y}$ Lateral 2 feet

Figure 4.120 Normal stress $S_{y}$ Lateral 2 feet 

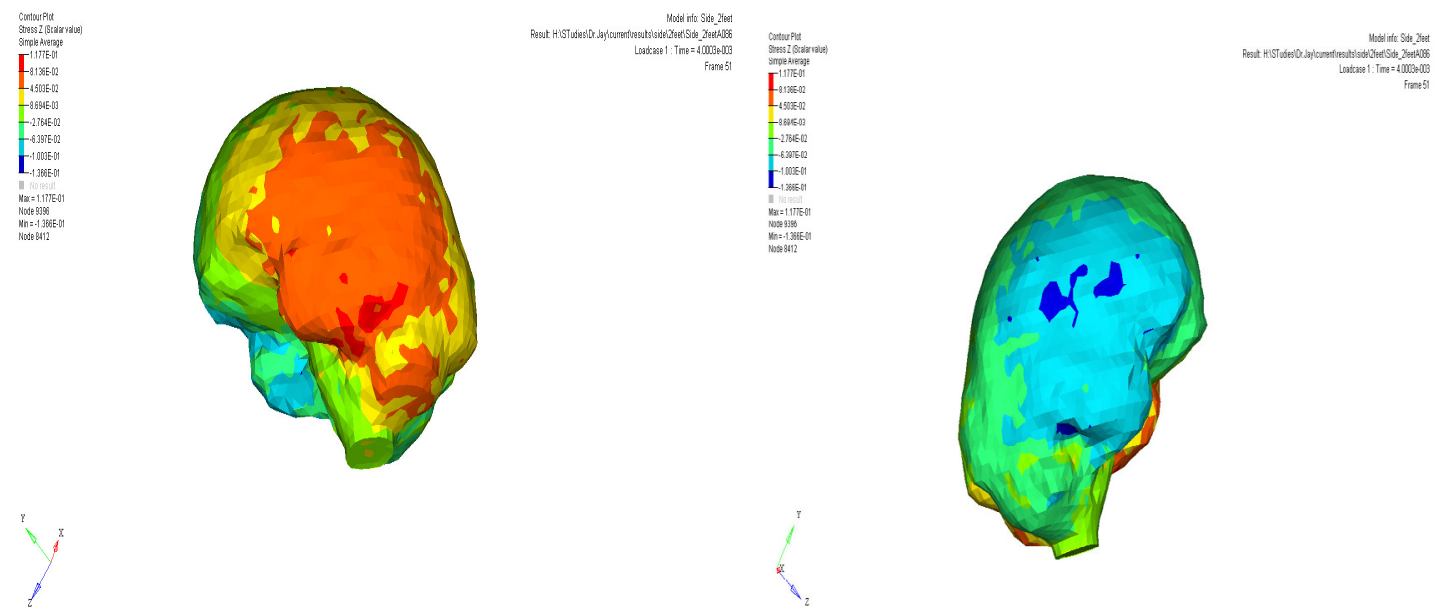

Figure 4.121 Normal stress $S_{z}$ Lateral 2 feet

Figure 4.122 Normal stress $S_{z}$ Lateral 2 feet
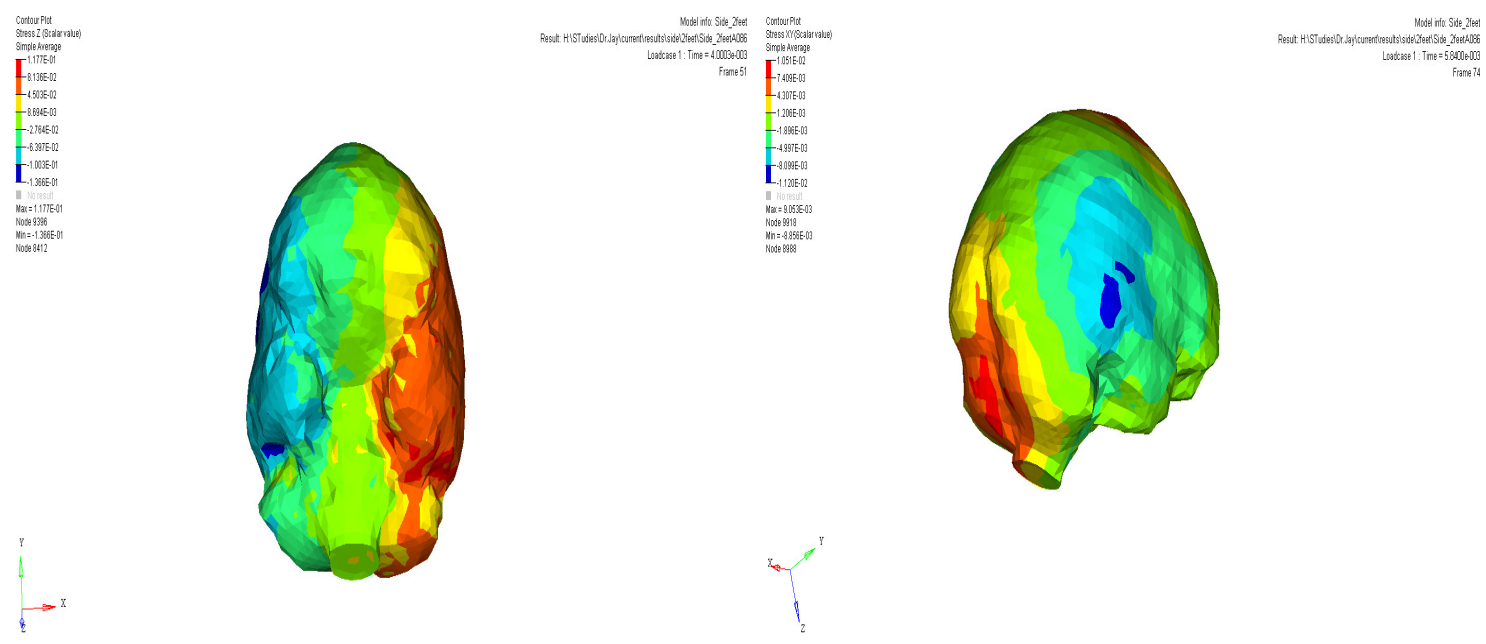

Figure 4.123 Normal stress $S_{z}$ Lateral 2 feet

Figure 4.124 Shear stress $S_{x y}$ Lateral 2 feet
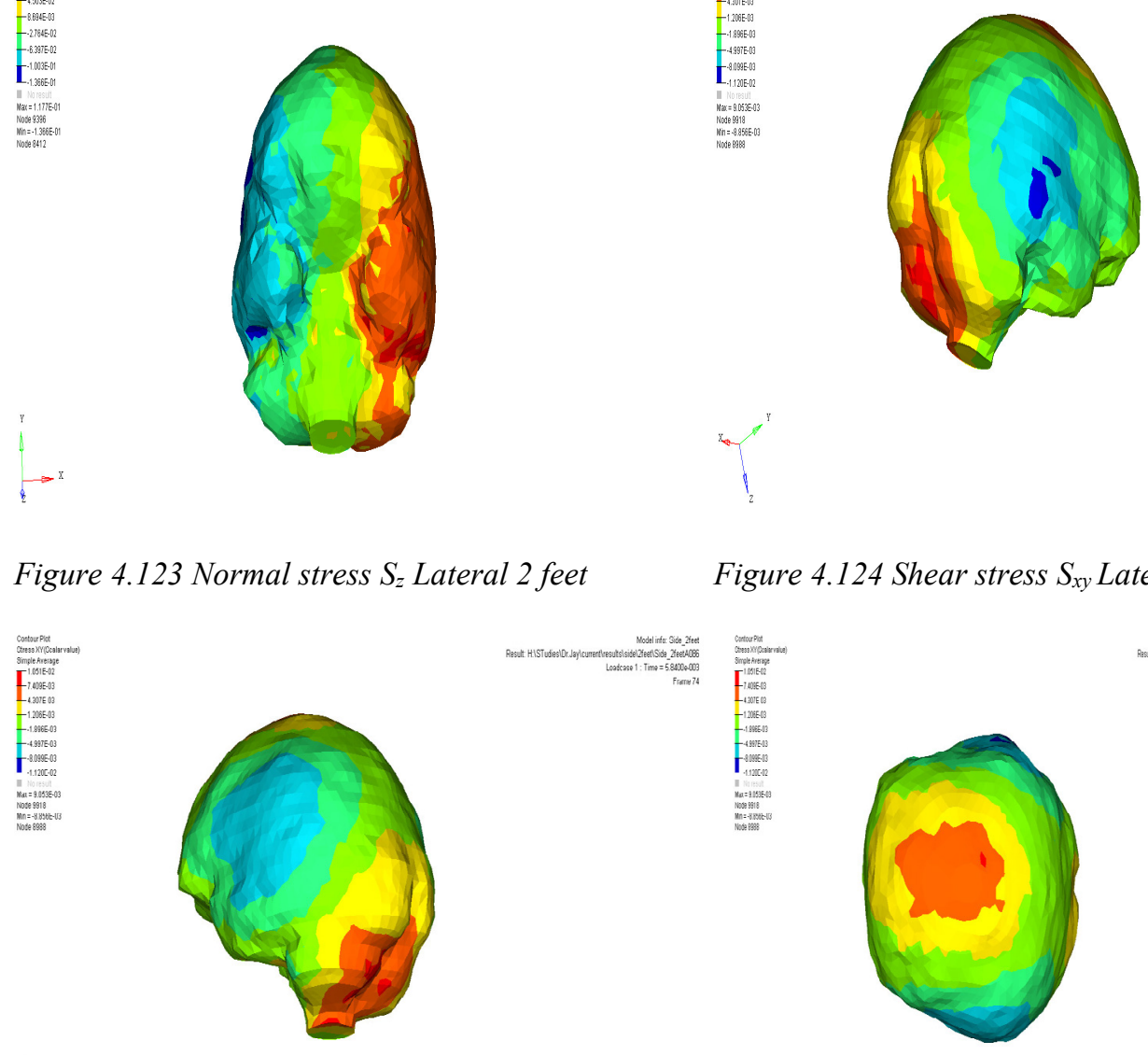

?
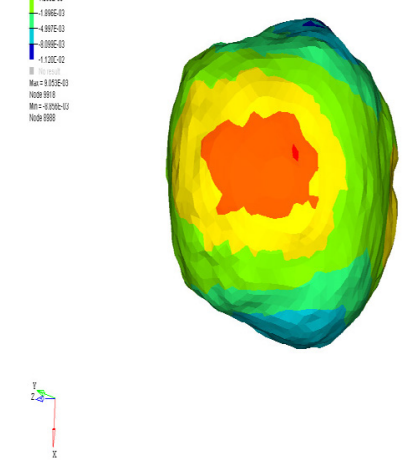

Figure 4.125 Shear stress $S_{x y}$ Lateral 2 feet

Figure 4.126 Shear stress $S_{x y}$ Lateral 2 feet 

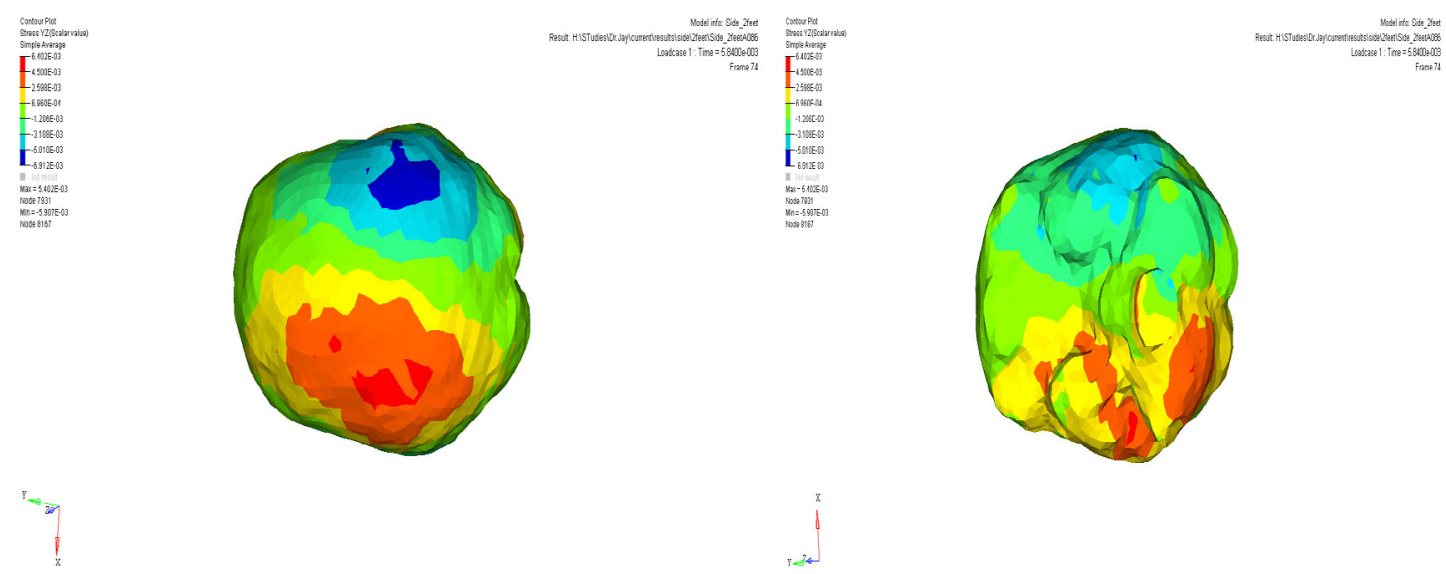

Figure 4.127 Shear stress $S_{y z}$ Lateral 2 feet

Figure 4.128 Shear stress $S_{y z}$ Lateral 2 feet
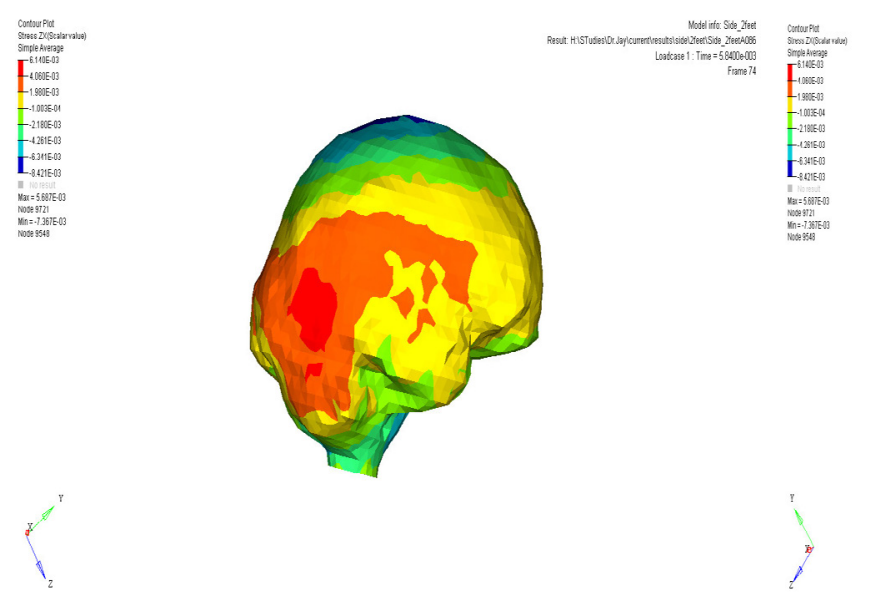

j

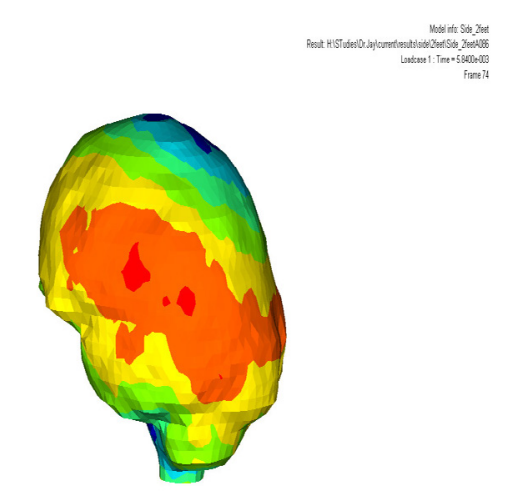

Figure 4.129 Shear stress $S_{z x}$ lateral 2 feet

Figure 4.130 Shear stress $S_{z x}$ lateral 2 feet

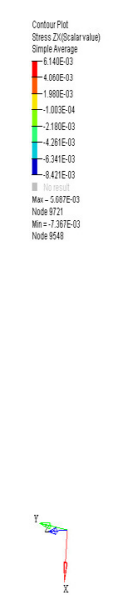

Figure 4.131 Shear stress $S_{z x}$ lateral 2 feet

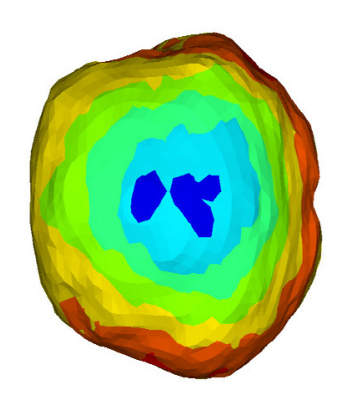

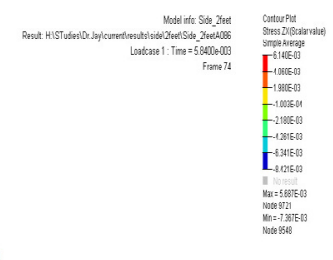

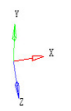

Figure 4.132 Shear stress $S_{z x}$ lateral 2 feet 


\subsubsection{Drop Height of 3 feet}
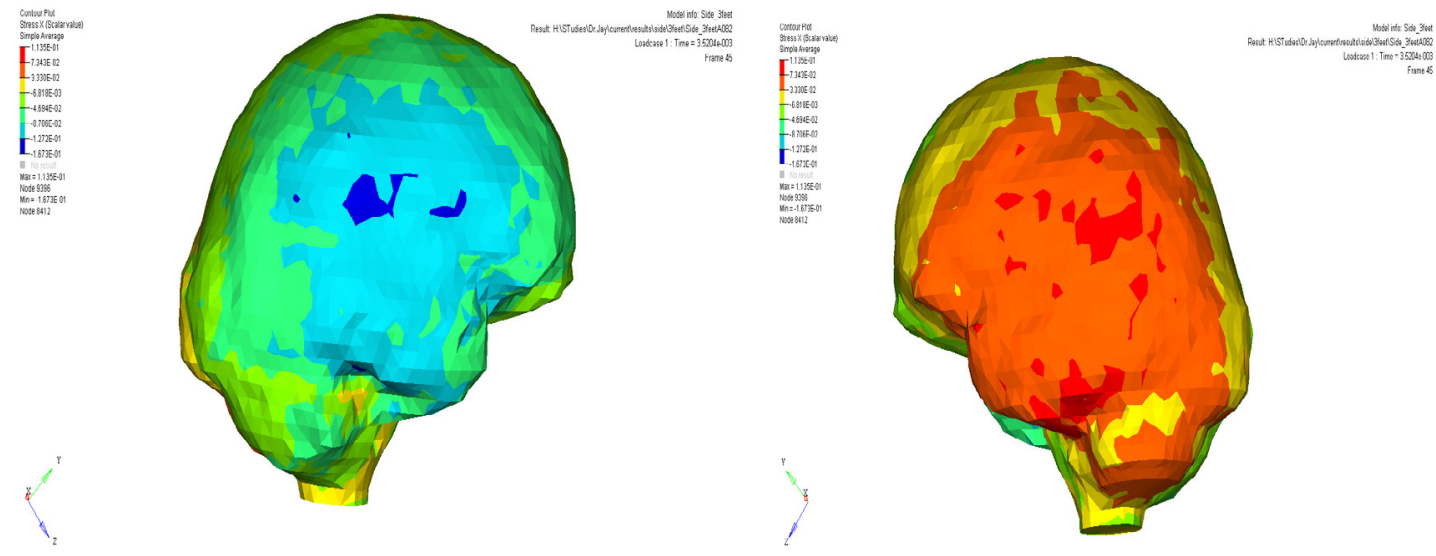

Figure 4.133 Normal stress $S_{x}$ Lateral 3 feet

Figure 4.134 Normal stress $S_{x}$ Lateral 3 feet

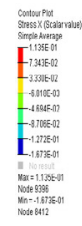

$t_{i}=$
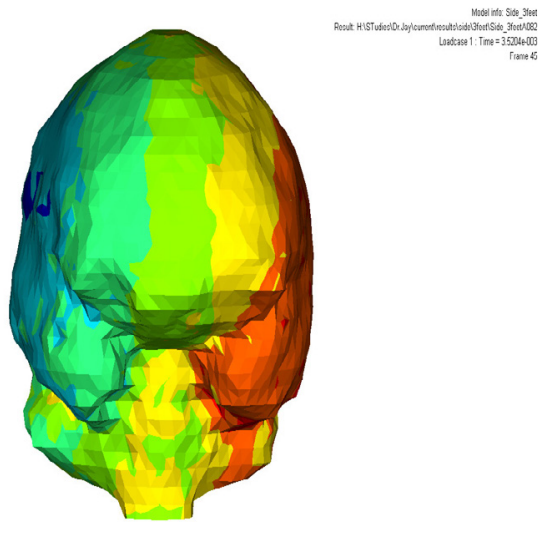

Figure 4.135 Normal stress $S_{x}$ Lateral 3 feet

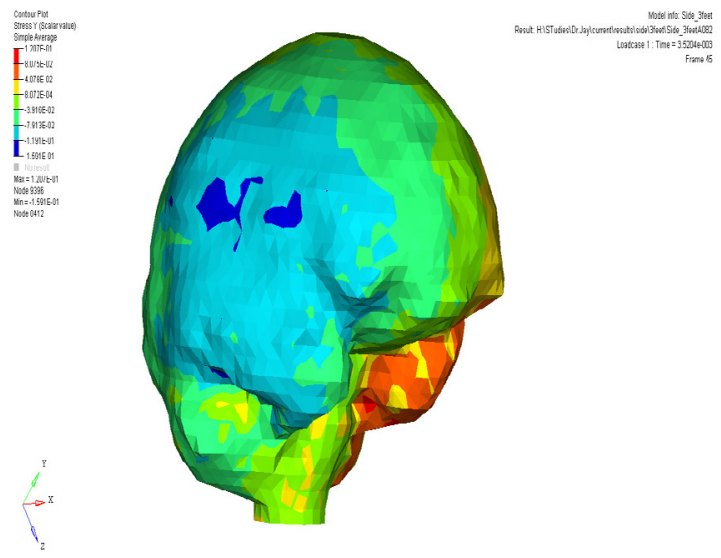

Figure 4.136 Normal stress $S_{y}$ Lateral 3 feet
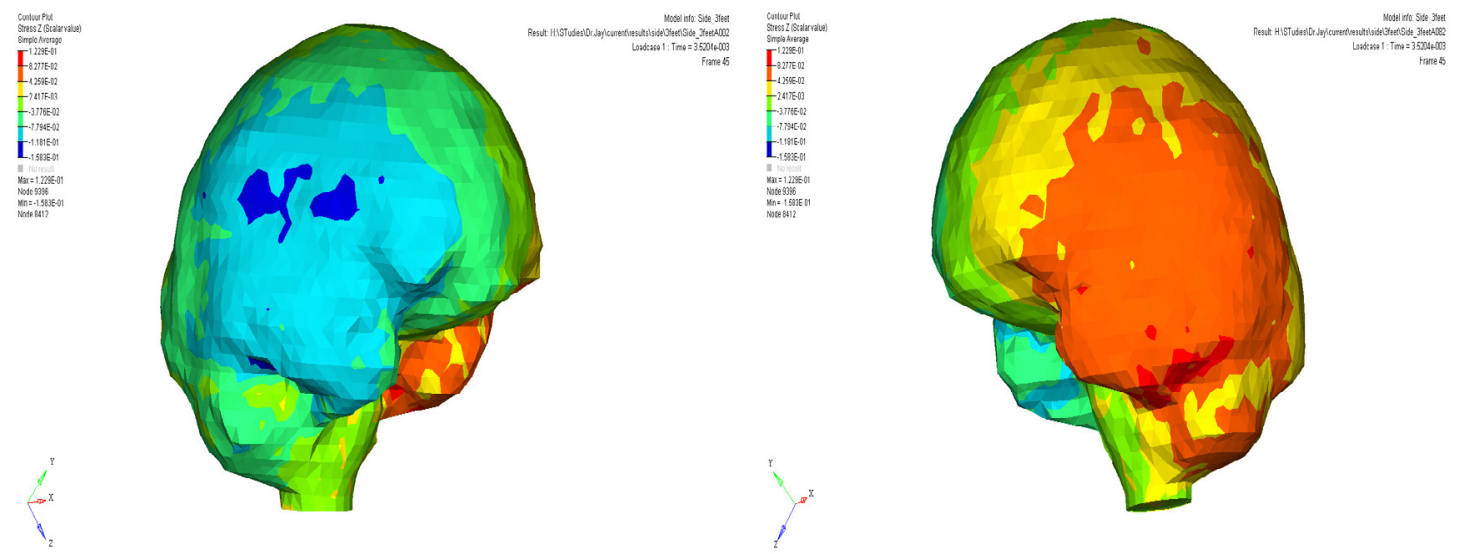

Figure 4.137 Normal stress $S_{z}$ Lateral 3 feet

Figure 4.138 Normal stress $S_{z}$ Lateral 3 feet 

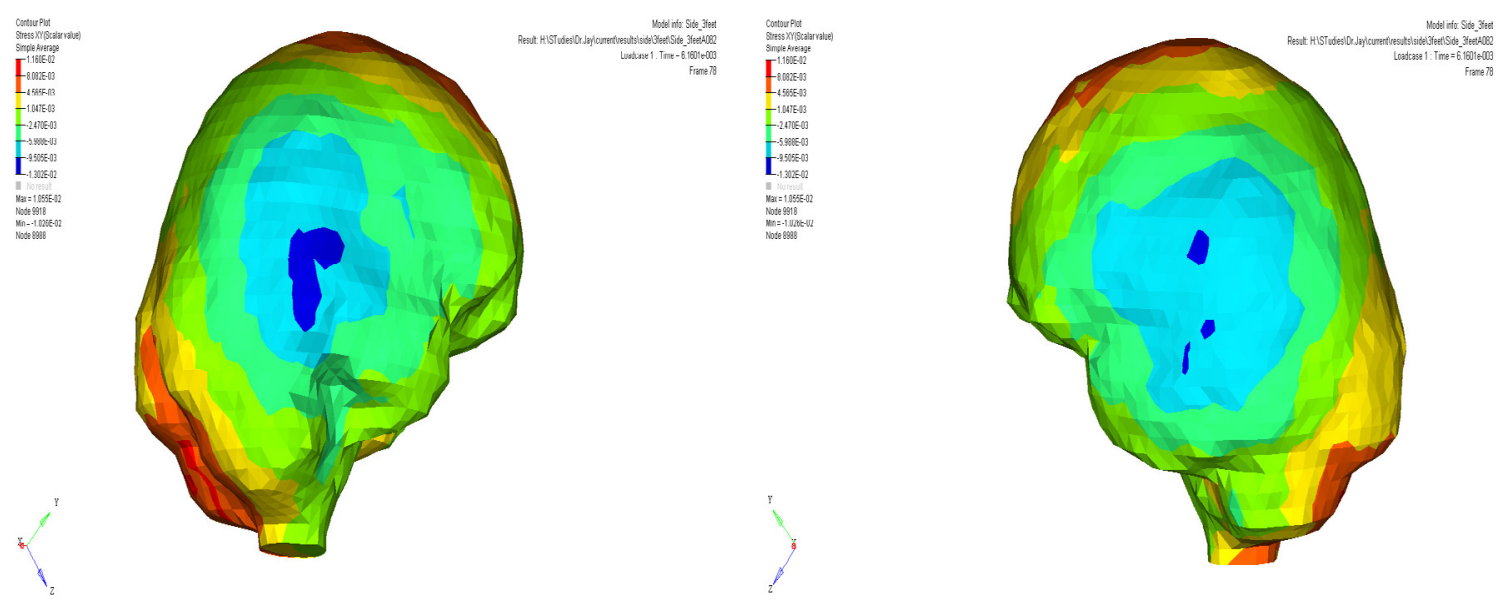

Figure 4.139 Shear stress $S_{x y}$ Lateral 3 feet

Figure 4.140 Shear stress $S_{x y}$ Lateral 3 feet

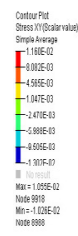

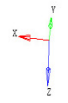
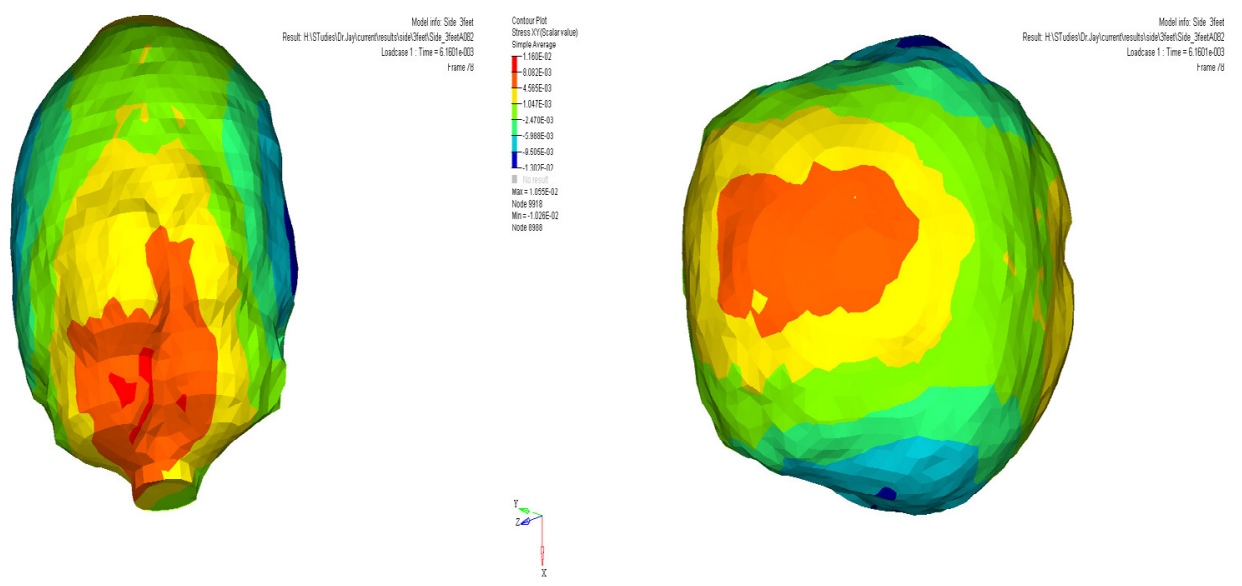

Figure 4.141 Shear stress $S_{x y}$ Lateral 3 feet

Figure 4.142 Shear stress $S_{x y}$ Lateral 3 feet
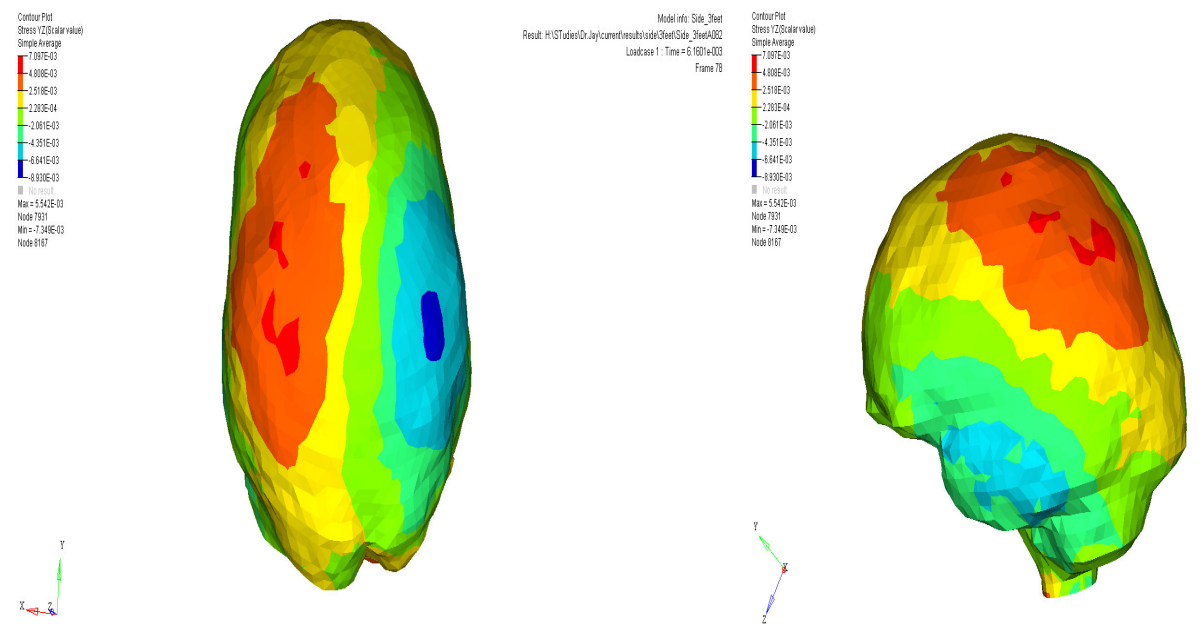

Figure 4.143 Shear stress $S_{y z}$ Lateral 3 feet

Figure 4.144 Shear stress $S_{y z}$ Lateral 3 feet 


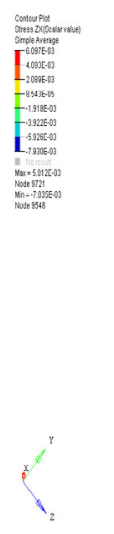

Figure 4.145 Shear stress $S_{z x}$ lateral 3 feet

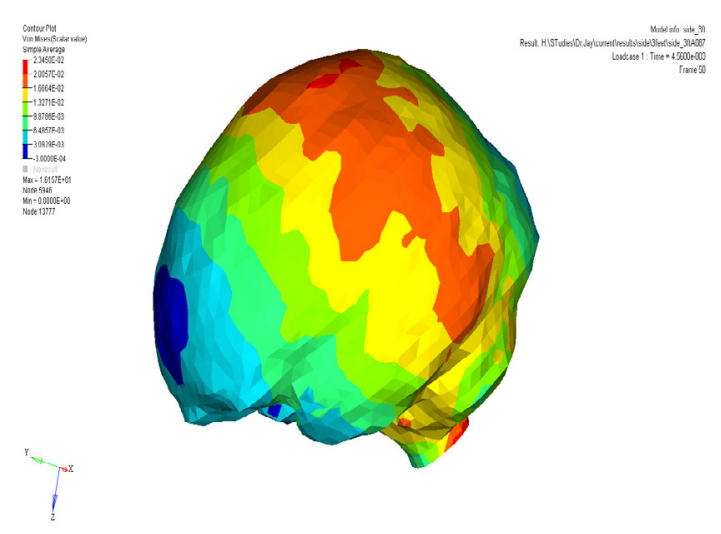

Figure 4.146 von Mises Stress lateral 3 feet

\subsubsection{Drop Height of 4 feet}
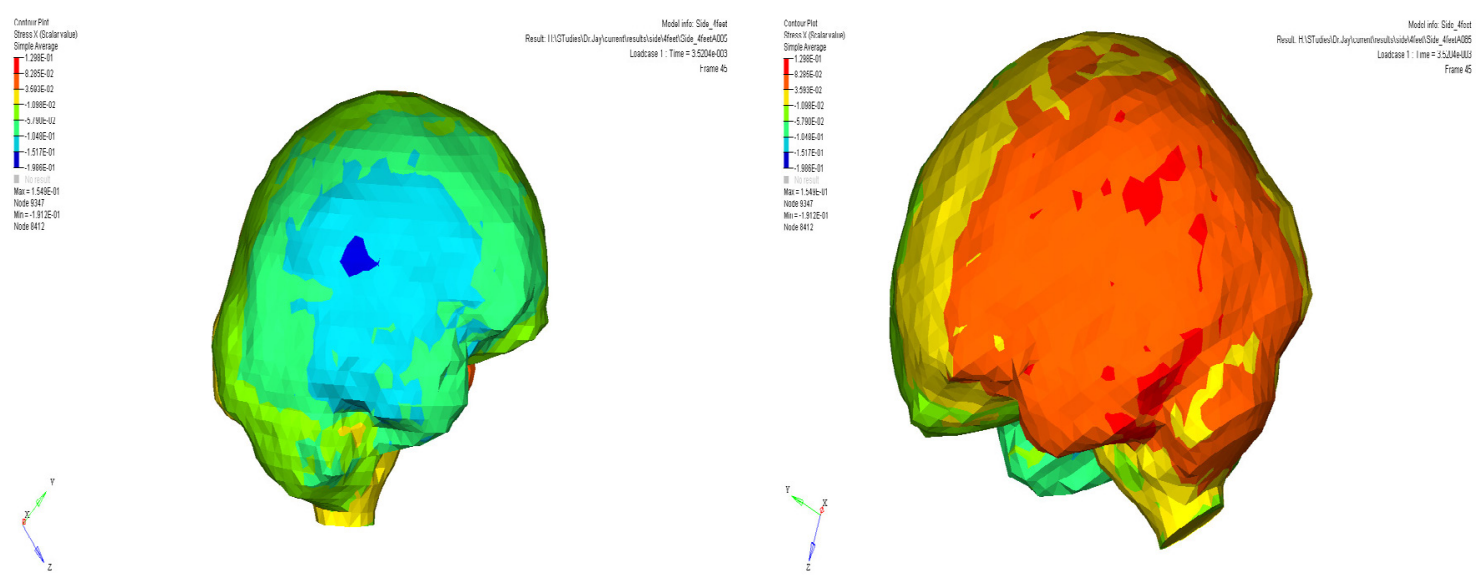

Figure 4.147 Normal stress $S_{x}$ Lateral 4 feet

Figure 4.148 Normal stress $S_{x}$ Lateral 4 feet

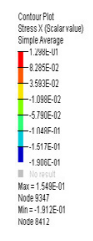

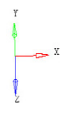

Figure 4.149 Normal stress $S_{x}$ Lateral 4 feet

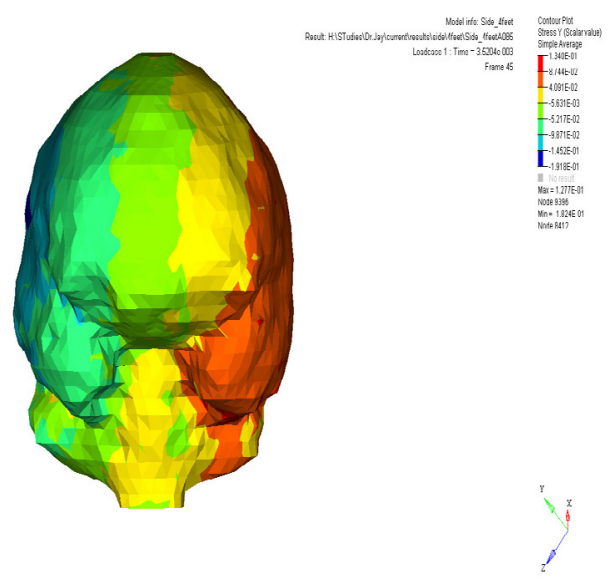

Figure 4.150 Normal stress $S_{y}$ Lateral 4 feet

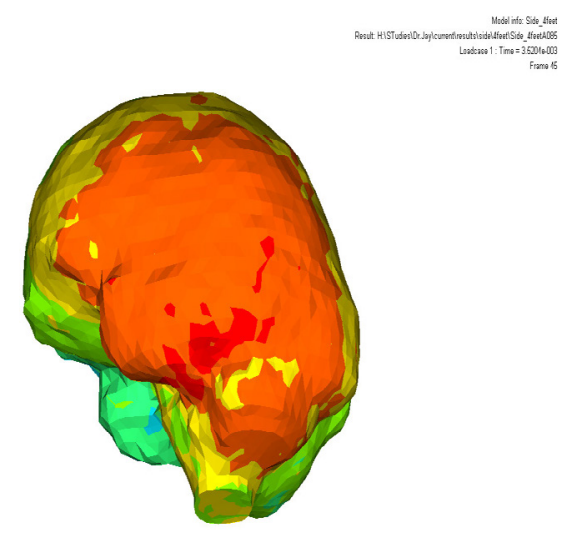

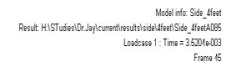



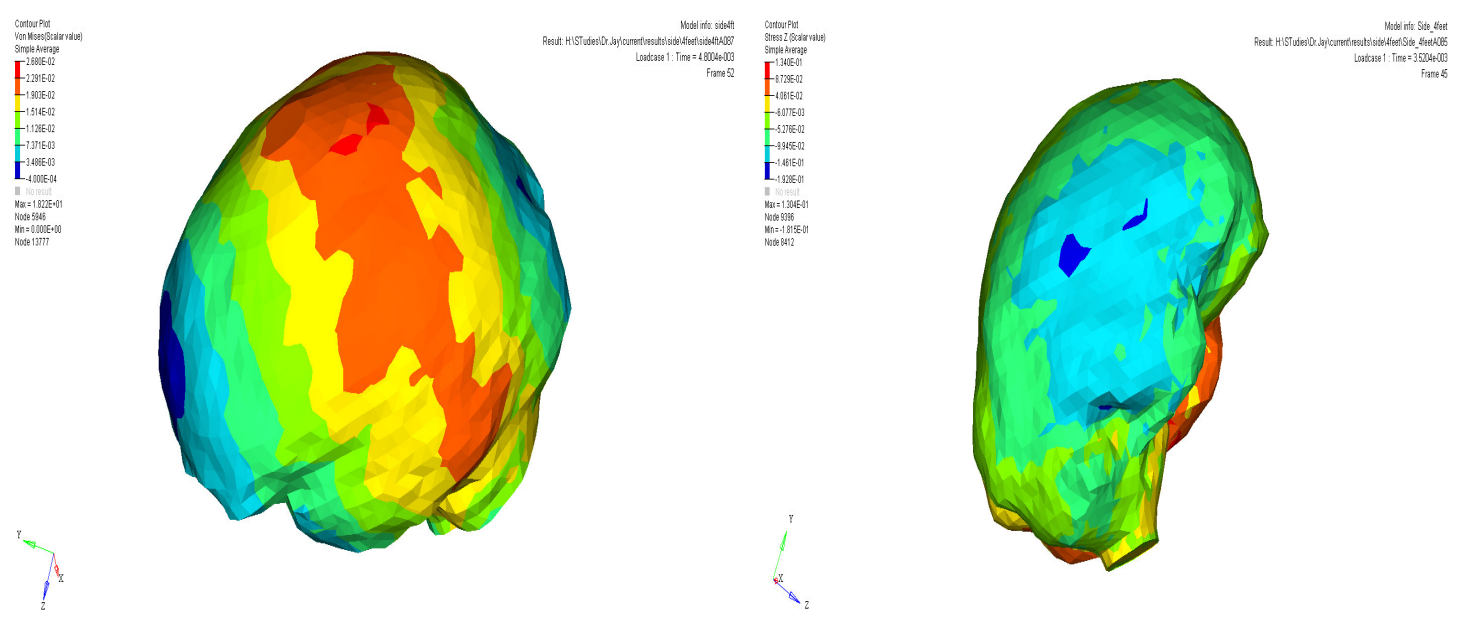

Figure 4.151 von Mises stress Lateral 4 feet

Figure 4.152 Normal stress $S_{z}$ Lateral 4 feet
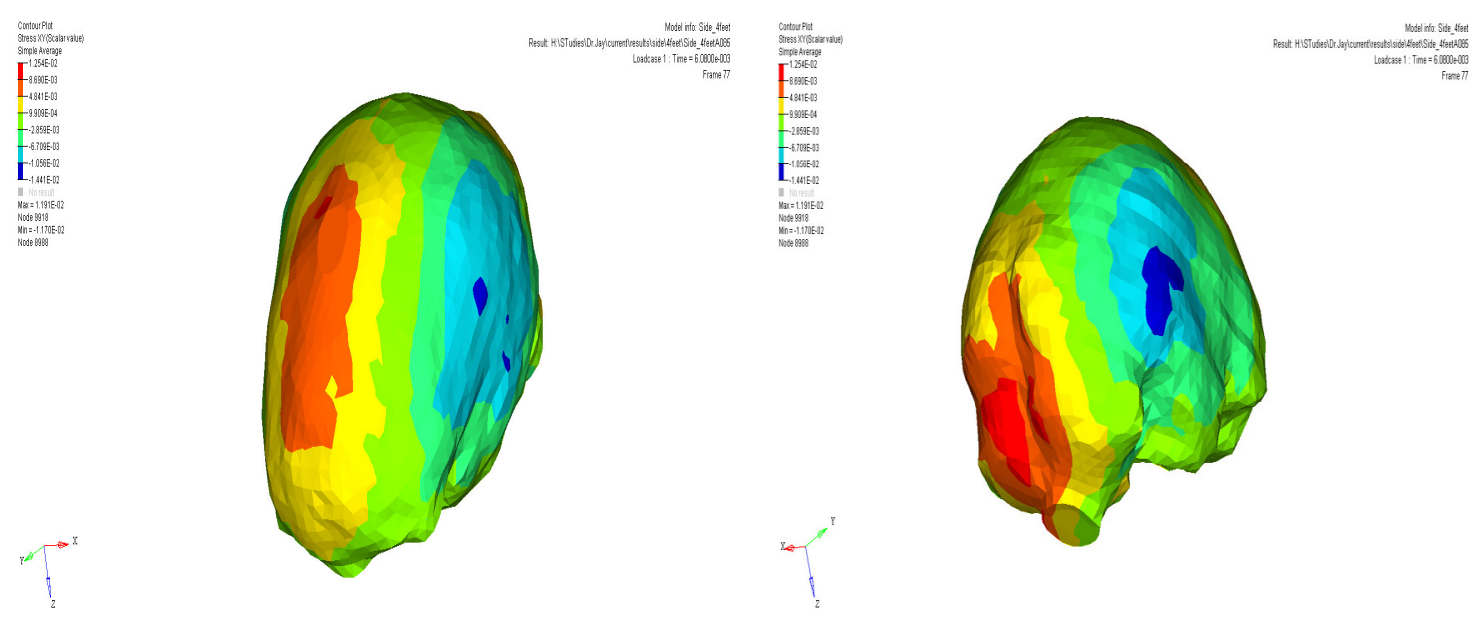

Figure 4.153 Shear stress $S_{x y}$ Lateral 4 feet

Figure 4.154 Shear stress $S_{x y}$ Lateral 4 feet

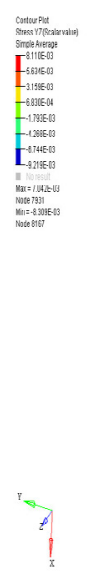

Figure 4.155 Shear stress $S_{y z}$ Lateral 4 feet
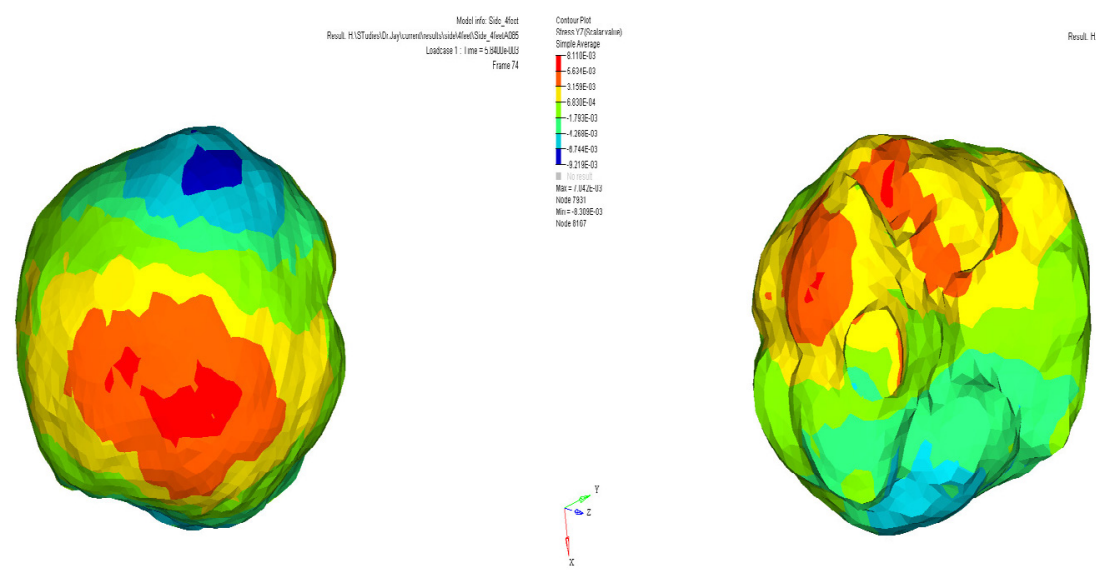

Figure 4.156 Shear stress $S_{y z}$ Lateral 4 feet 

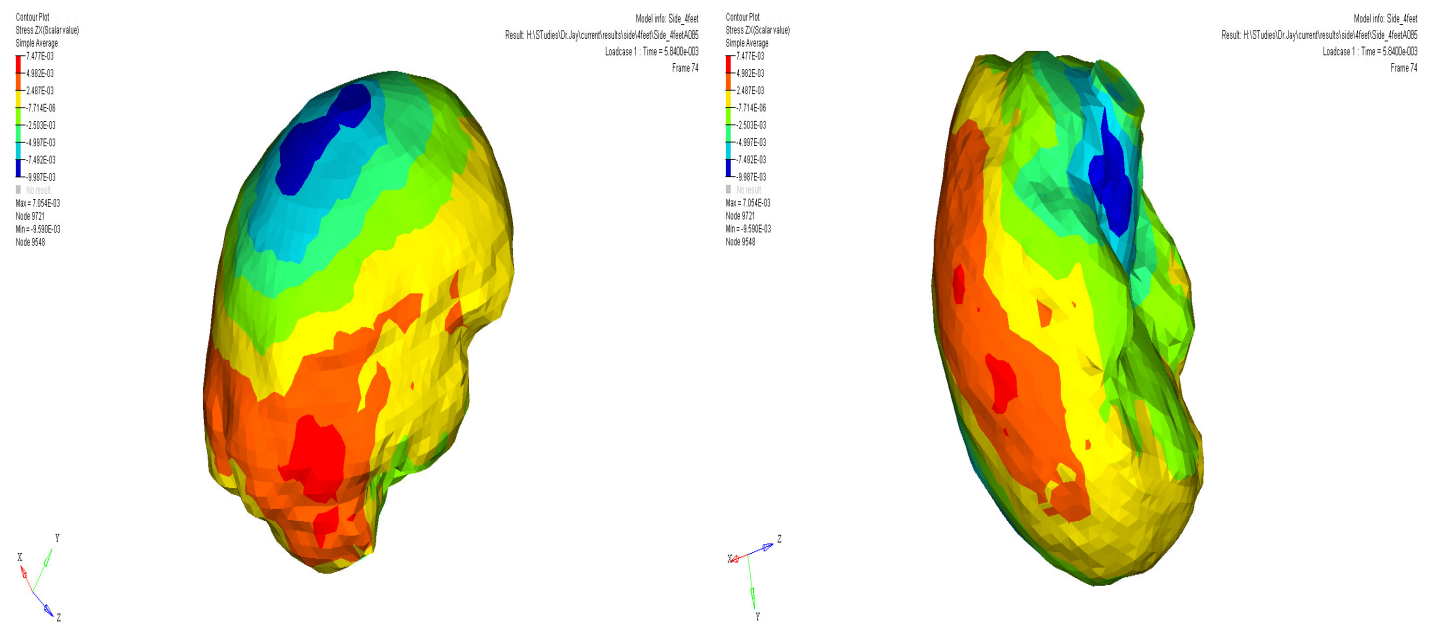

Figure 4.157 Shear stress $S_{z x}$ Lateral 4 feet

Figure 4.158 Shear stress $S_{z x}$ Lateral 4 feet

\subsubsection{Drop Height of 5 feet}
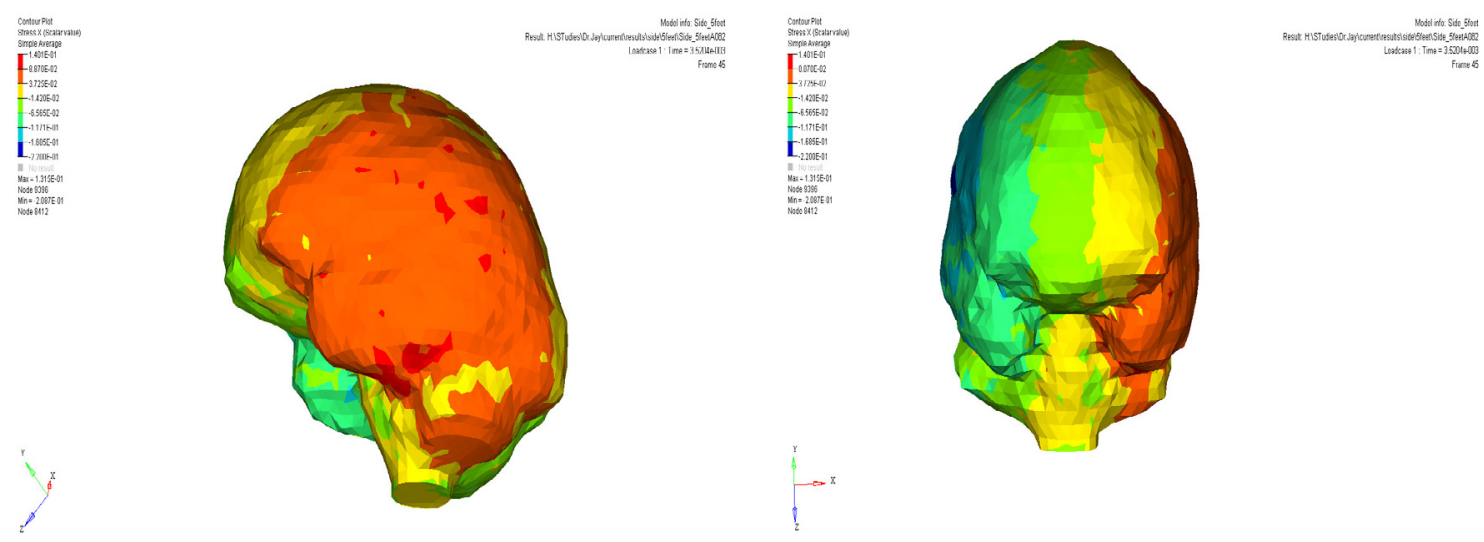

Figure 4.159 Normal stress $S_{x}$ Lateral 5 feet

Figure 4.160 Normal stress $S_{x}$ Lateral 5 feet
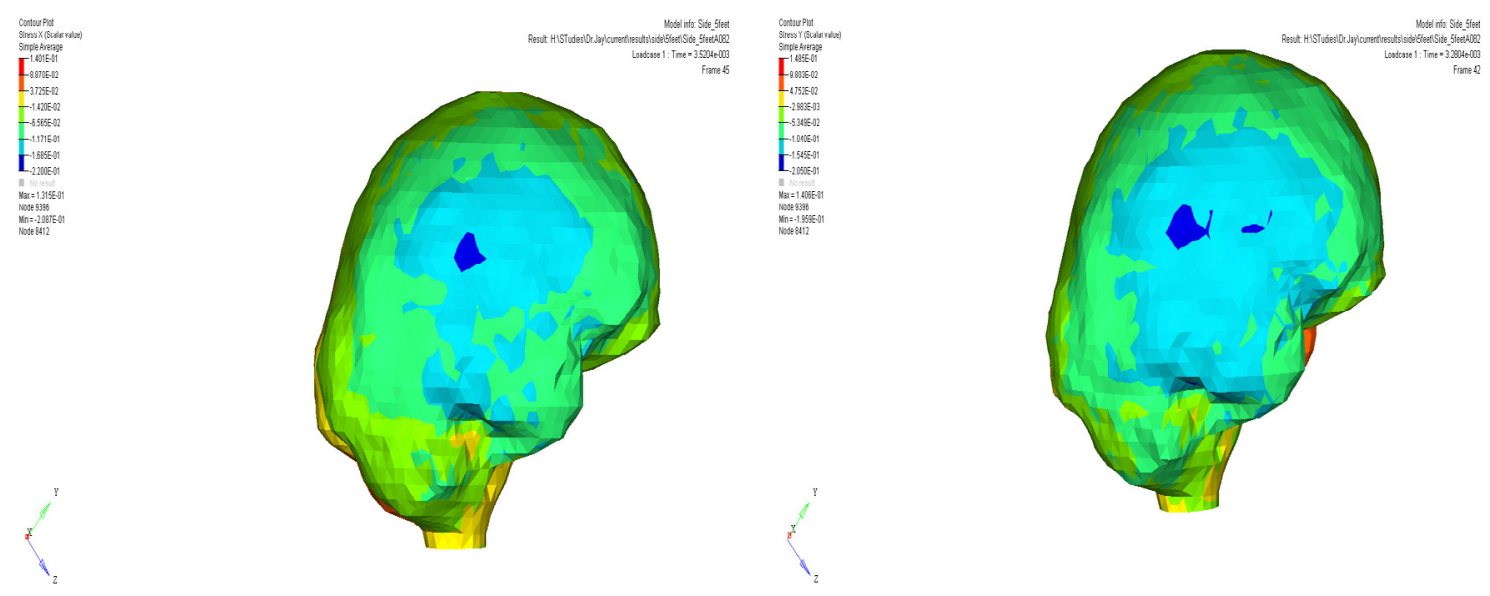

Figure 4.161 Normal stress $S_{x}$ Lateral 5 feet

Figure 4.162 Normal stress $S_{y}$ Lateral 5 feet 

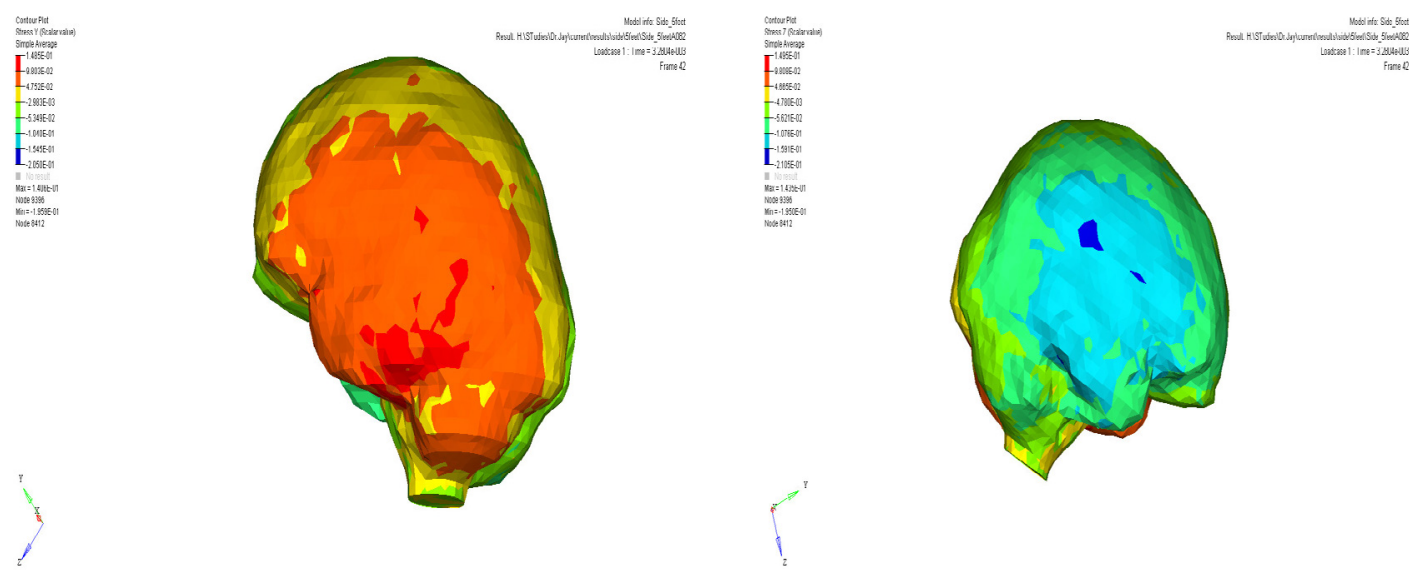

Figure 4.163 Normal stress $S_{y}$ Lateral 5 feet
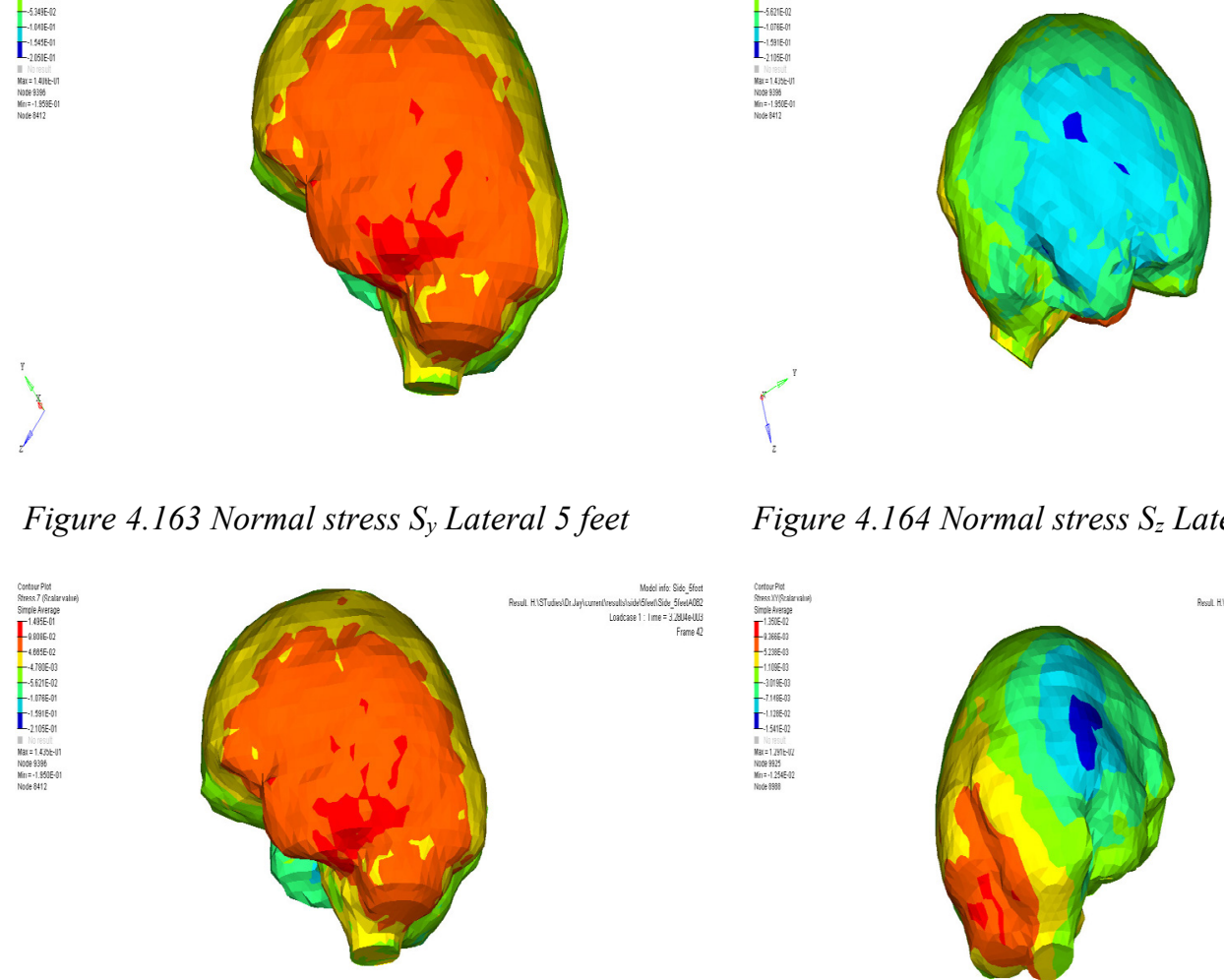

Figure 4.164 Normal stress $S_{z}$ Lateral 5 feet
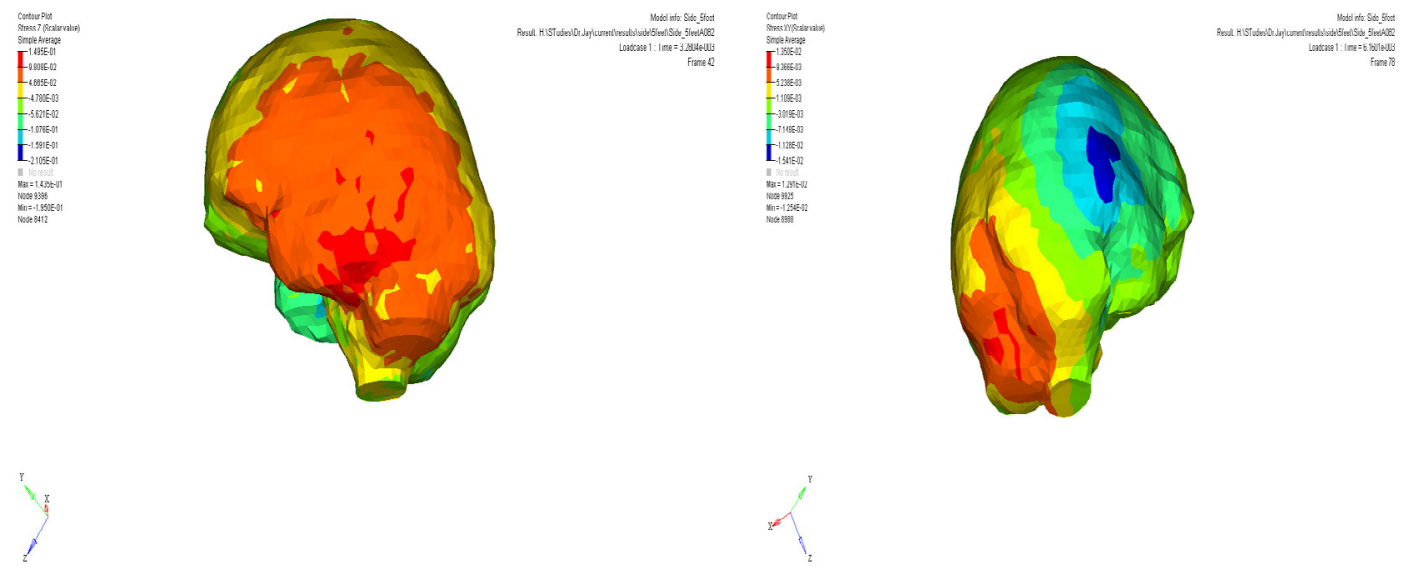

Figure 4.165 Normal stress $S_{z}$ Lateral 5 feet

Figure 4.166 Shear stress $S_{x y}$ Lateral 5 feet
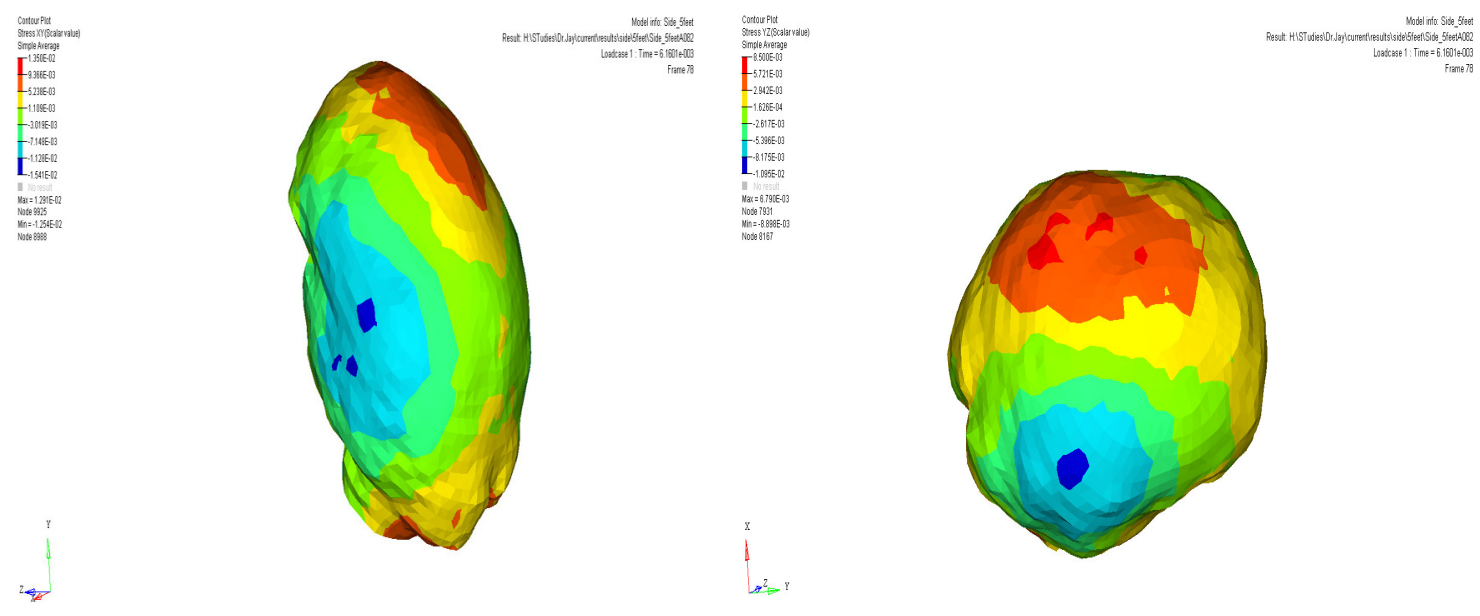

Figure 4.167 Shear stress $S_{x y}$ Lateral 5 feet

Figure 4.168 Shear stress $S_{y z}$ Lateral 5 feet 

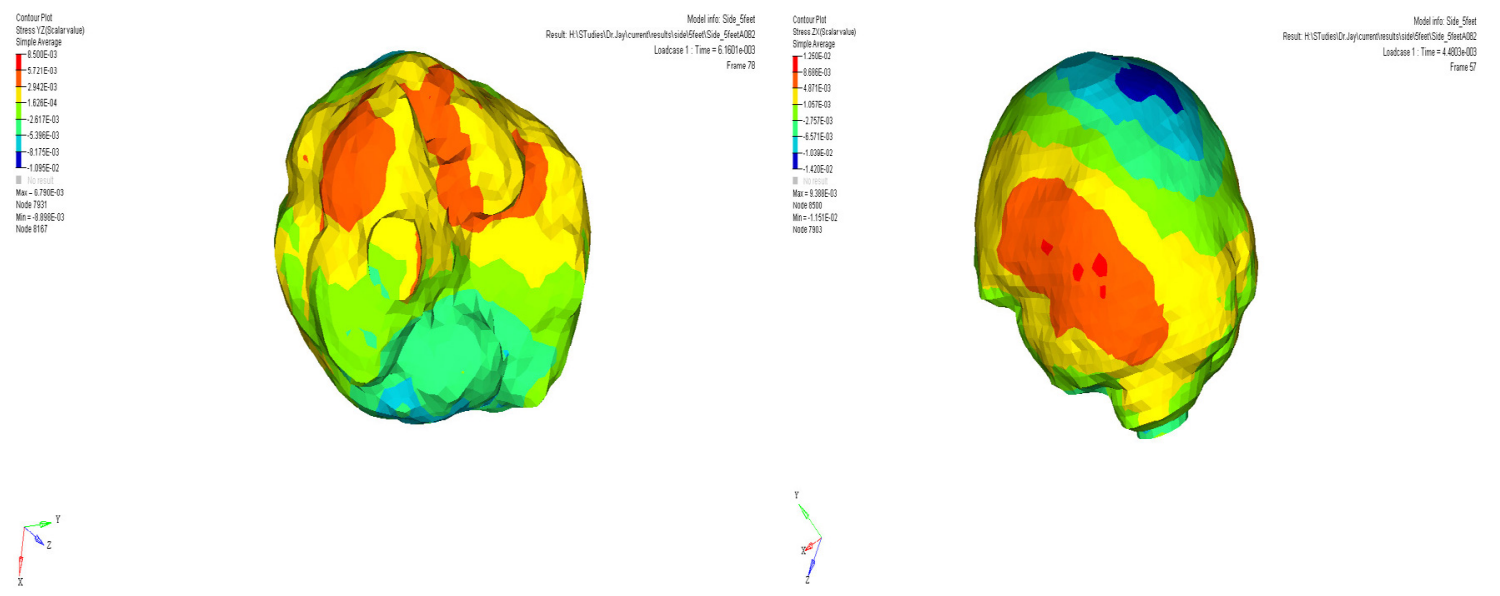

Figure 4.169 Shear stress $S_{y z}$ Lateral 4 feet

Figure 4.170 Shear stress $S_{z x}$ Lateral 5 feet
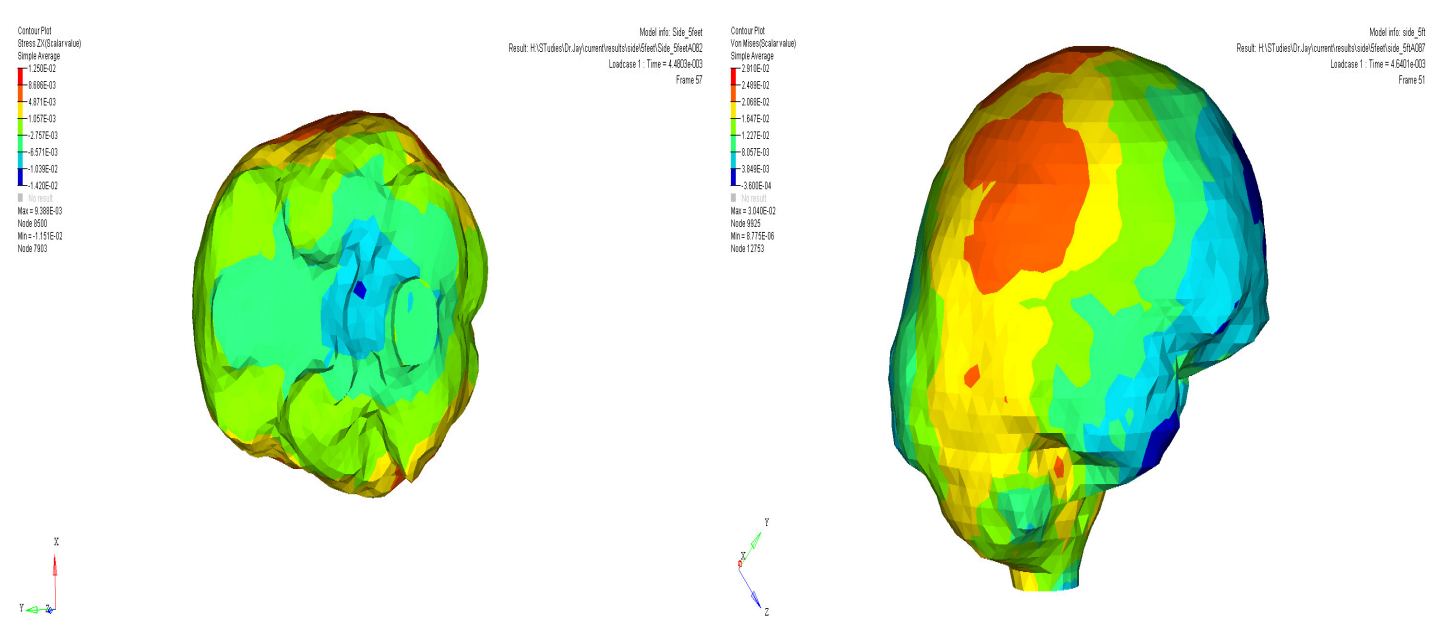

Figure 4.171 Shear stress $S_{z x}$ Lateral 5 feet

Figure 4.172 von Mises Lateral 5 feet 


\subsubsection{Discussion}

The normal stresses values obtained from the Finite element simulation are listed below.

Table 4.10 Normal Stress Values on brain from FE Simulation of Lateral Impact

\begin{tabular}{|r|c|r|r|r|r|r|}
\hline \multirow{2}{*}{$\begin{array}{c}\text { Height } \\
\text { (feet) }\end{array}$} & \multicolumn{2}{|c|}{ Stress X (MPa) } & \multicolumn{2}{c|}{ Stress Y (MPa) } & \multicolumn{2}{c|}{ Stress Z (MPa) } \\
\cline { 2 - 7 } & \multicolumn{1}{|c|}{ Tension } & Compression & \multicolumn{1}{c|}{ Tension } & Compression & \multicolumn{1}{c|}{ Tension } & Compression \\
\hline $\mathbf{2}$ & $\mathbf{- 1 . 4 5 E - 0 1}$ & $1.09 \mathrm{E}-01$ & $\mathbf{- 1 . 3 7 E - 0 1}$ & $1.16 \mathrm{E}-01$ & $\mathbf{- 1 . 4 4 E - 0 1}$ & $1.18 \mathrm{E}-01$ \\
\hline $\mathbf{3}$ & $\mathbf{- 1 . 7 2 E - 0 1}$ & $1.41 \mathrm{E}-01$ & $\mathbf{- 1 . 5 9 E - 0 1}$ & $1.21 \mathrm{E}-01$ & $\mathbf{- 1 . 5 8 E - 0 1}$ & $1.23 \mathrm{E}-01$ \\
\hline $\mathbf{4}$ & $\mathbf{- 1 . 9 9 E - 0 1}$ & $1.30 \mathrm{E}-01$ & $\mathbf{- 1 . 9 2 E - 0 1}$ & $1.34 \mathrm{E}-01$ & $\mathbf{- 1 . 9 3 E - 0 1}$ & $1.34 \mathrm{E}-01$ \\
\hline $\mathbf{5}$ & $\mathbf{- 2 . 2 0 E - 0 1}$ & $1.40 \mathrm{E}-01$ & $\mathbf{- 2 . 0 5 E - 0 1}$ & $1.49 \mathrm{E}-01$ & $\mathbf{- 2 . 1 1 E - 0 1}$ & $1.50 \mathrm{E}-01$ \\
\hline
\end{tabular}

The Shear stress values obtained for different drops from the finite element simulation are listed below

Table 4.11 Shear Stress values on brain from the FE Simulation of Lateral Impact

\begin{tabular}{|c|c|c|c|}
\hline $\begin{array}{c}\text { Height } \\
\text { (feet) }\end{array}$ & Stress XY (MPa) & Stress YZ (MPa) & Stress ZX (MPa) \\
\hline $\mathbf{2}$ & $\mathbf{- 1 . 1 2 E - 0 2}$ & $-6.91 \mathrm{E}-03$ & $-8.42 \mathrm{E}-03$ \\
\hline $\mathbf{3}$ & $\mathbf{- 1 . 3 0 E - 0 2}$ & $-8.93 \mathrm{E}-03$ & $-7.93 \mathrm{E}-03$ \\
\hline $\mathbf{4}$ & $\mathbf{- 1 . 4 4 E - 0 2}$ & $-9.22 \mathrm{E}-03$ & $-9.99 \mathrm{E}-03$ \\
\hline $\mathbf{5}$ & $\mathbf{- 1 . 5 4 E - 0 2}$ & $-1.10 \mathrm{E}-02$ & $-1.42 \mathrm{E}-02$ \\
\hline
\end{tabular}

The values when used in the Mohr Circle calculation, yielded the following results

Table 4.12 Results Obtained from Mohr Circle Analysis for lateral Impact

\begin{tabular}{|r|c|c|c|c|c|}
\hline \multirow{2}{*}{$\begin{array}{c}\text { Height } \\
\text { (feet) }\end{array}$} & \multicolumn{2}{|c|}{ Principal Stresses (MPa) } & \multirow{2}{*}{$\begin{array}{c}\text { Max Shear } \\
\text { Stress (MPa) }\end{array}$} & $\begin{array}{c}\text { von Mises } \\
\text { (MPa) }\end{array}$ \\
\hline $\mathbf{2}$ & $-1.29 \mathrm{E}-01$ & $-1.37 \mathrm{E}-01$ & $\mathbf{- 1 . 6 0 E - 0 1}$ & $1.56 \mathrm{E}-02$ & $2.81 \mathrm{E}-02$ \\
\hline $\mathbf{3}$ & $-1.49 \mathrm{E}-01$ & $-1.55 \mathrm{E}-01$ & $\mathbf{- 1 . 8 5 E - 0 1}$ & $1.81 \mathrm{E}-02$ & $3.34 \mathrm{E}-02$ \\
\hline $\mathbf{4}$ & $-1.80 \mathrm{E}-01$ & $-1.86 \mathrm{E}-01$ & $\mathbf{- 2 . 1 8 E - 0 1}$ & $1.86 \mathrm{E}-02$ & $3.49 \mathrm{E}-02$ \\
\hline $\mathbf{5}$ & $-1.95 \mathrm{E}-01$ & $-2.01 \mathrm{E}-01$ & $\mathbf{- 2 . 4 0 E - 0 1}$ & $2.28 \mathrm{E}-02$ & $4.31 \mathrm{E}-02$ \\
\hline
\end{tabular}

The Maximum Pressure values observed on the brain obtained from the simulation are tabulated below. 
Table 4.13 Pressures on the Brain due to Lateral Impact from different heights

\begin{tabular}{|r|c|c|r|}
\hline $\begin{array}{l}\text { Height } \\
\text { (feet) }\end{array}$ & $\begin{array}{l}\text { HICP } \\
\text { (MPa) }\end{array}$ & $\begin{array}{l}\text { Velocity of Fall } \\
(\mathbf{2 g h})\end{array}$ & $\begin{array}{c}\text { Pressure on Brain } \\
\text { Tension (MPa) }\end{array}$ \\
\hline $\mathbf{2}$ & 1.12 & 3.46 & $1.44 \mathrm{E}-01$ \\
\hline $\mathbf{3}$ & 1.30 & 4.24 & $1.62 \mathrm{E}-01$ \\
\hline $\mathbf{4}$ & 1.46 & 4.89 & $1.86 \mathrm{E}-01$ \\
\hline $\mathbf{5}$ & 1.55 & 5.47 & $2.00 \mathrm{E}-01$ \\
\hline
\end{tabular}

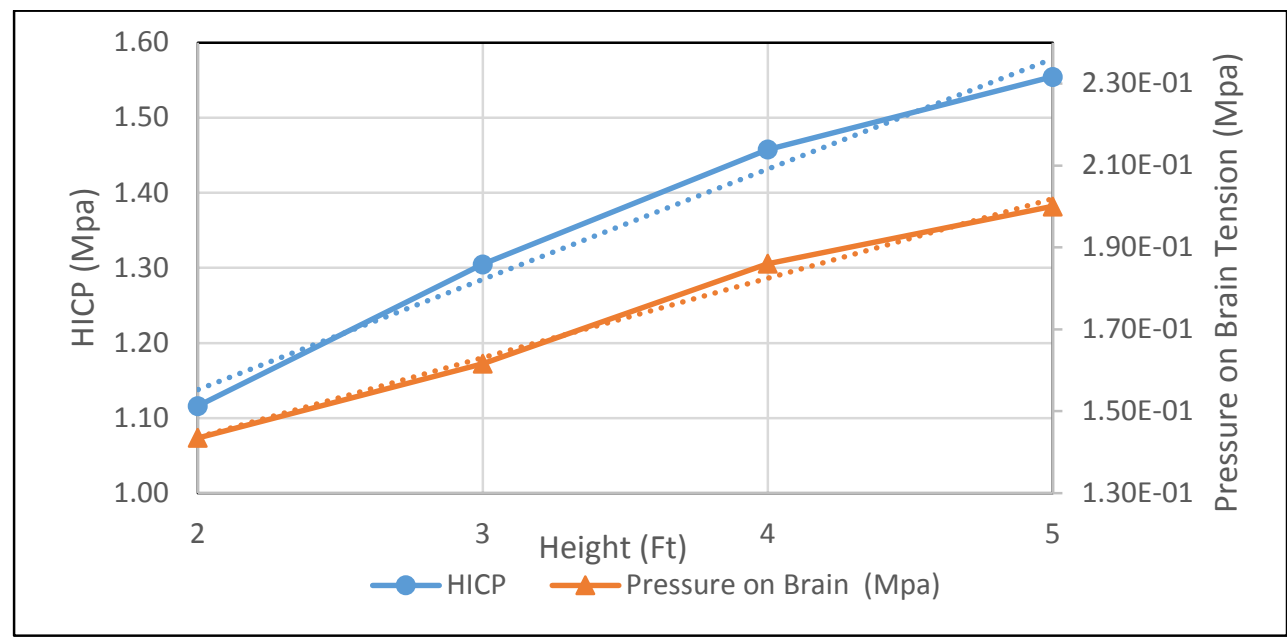

Figure 4.173 Comparison of Pressure on Brain and HICP during Lateral Impact

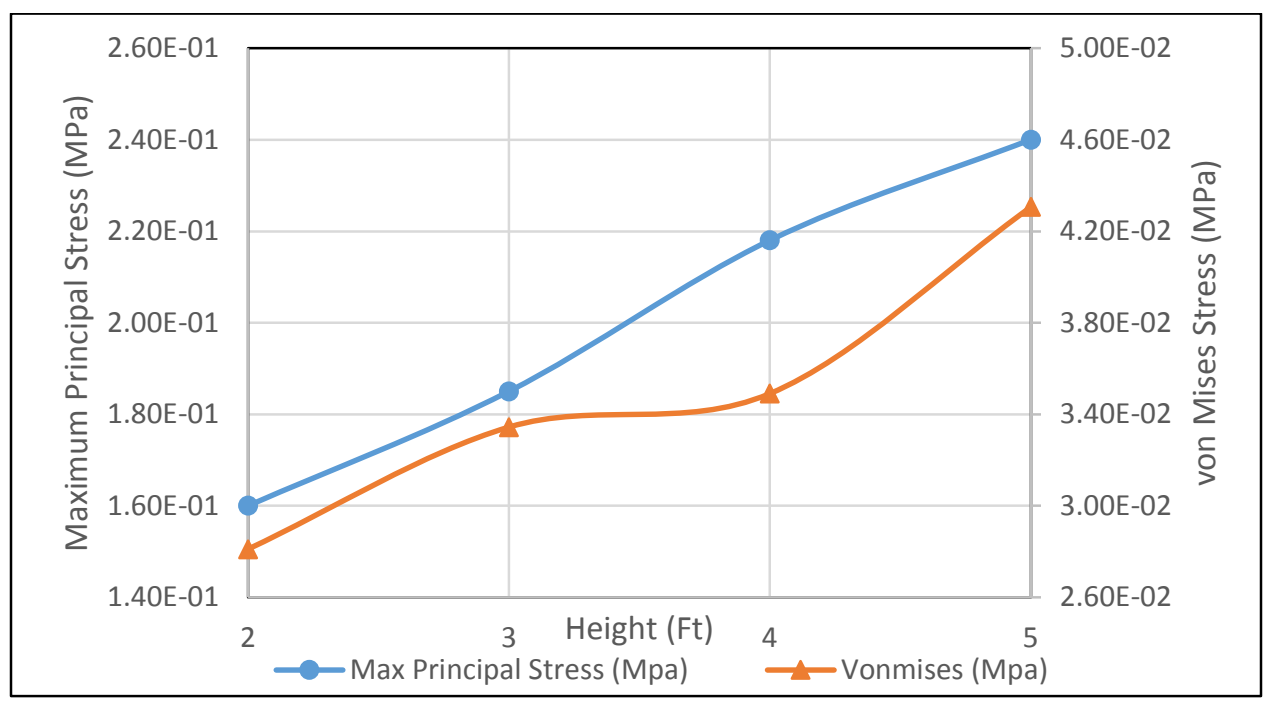

Figure 4.174 Maximum Principal Stress and von Mises Stress on Brain obtained from FE Simulation of Lateral Impact 


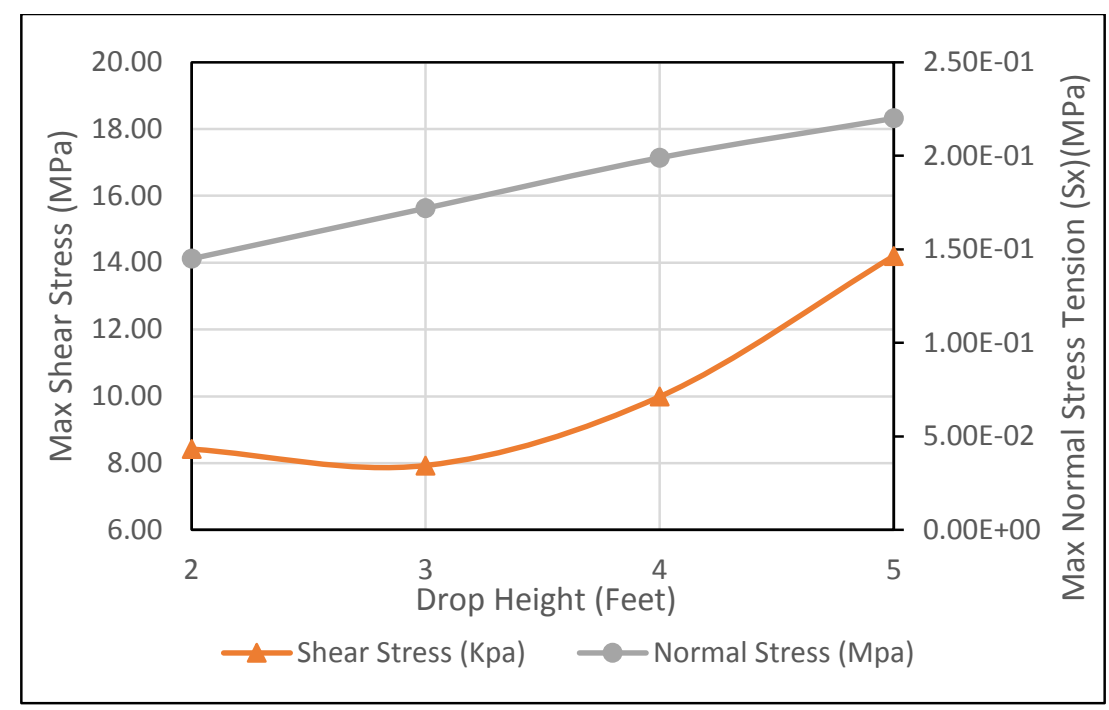

Figure 4.175 Stress variations on brain with respect to height for impacts in Lateral region

Upon observing the results of the simulation the following information can be inferred.

- One can see that the pressure wave travels from the ear side of the brain (site of impact on parietal lobe) to other side and gets reflected back in the opposite direction as a tensile stress wave surfacing upon the occipital lobe towards the site of impact explaining the concept of Coup and Contre Coup Injury (Refer to Fig B28-B41). The maximum pressure is observed around the peak acceleration of the impact curve.

- The maximum Shear stress values are obtained in the regions of parietal lobe (top of the head) near the impact region and temporal lobe which are under compression, while the parietal lobe and regions of temporal lobe near the impact regions are under tension.

- The maximum von Mises stress values are obtained in the regions around the brain stem and on the parietal lobe and occipital lobe along the line of impact.

- Shear stress distribution for the given HICP is predominant in this region when compared to other regions implying the presence of dominating angular acceleration compared with the linear acceleration in this region. 


\subsubsection{Posterior}

\subsubsection{Drop height of 2 feet}
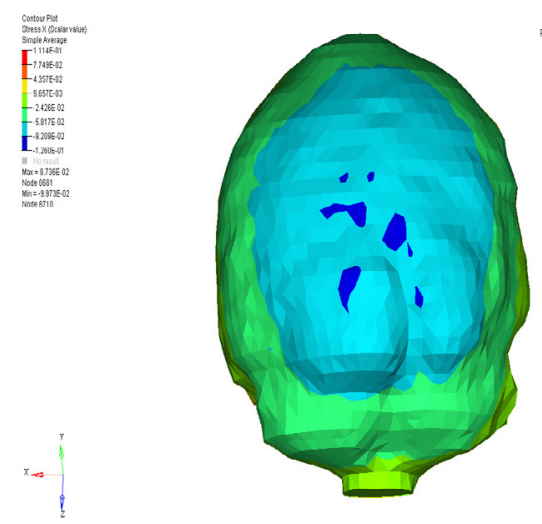

Figure 4.176 Normal stress $S_{x}$ Posterior 2 feet

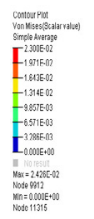

$\int_{a 2^{-1}}^{8}$

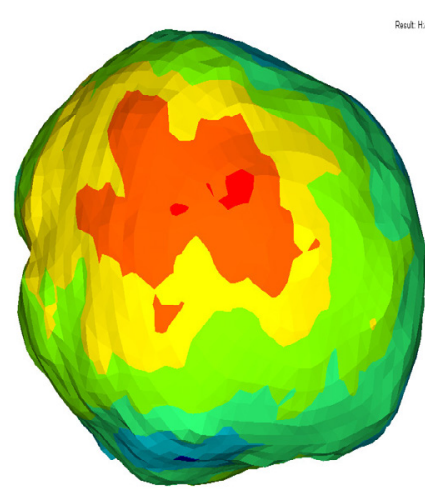

Figure 4.178 von Mises stress Posterior 2 feet
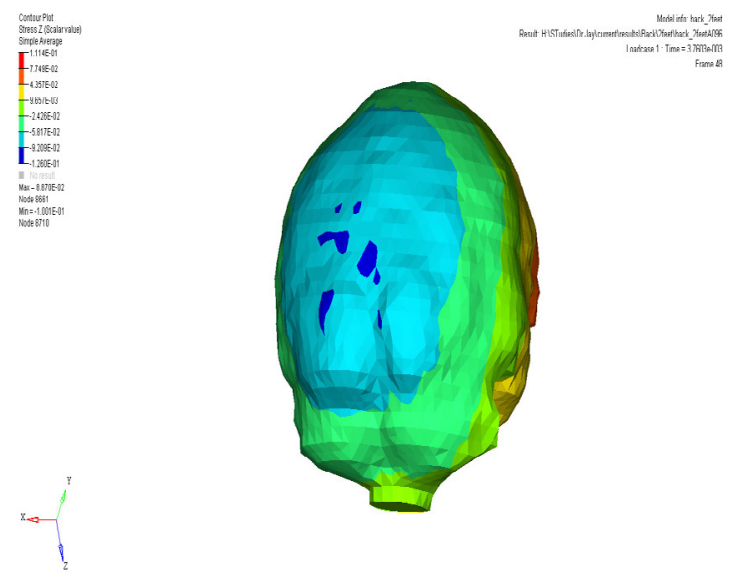

Figure 4.180 Normal stress $S_{z}$ Posterior 2 feet
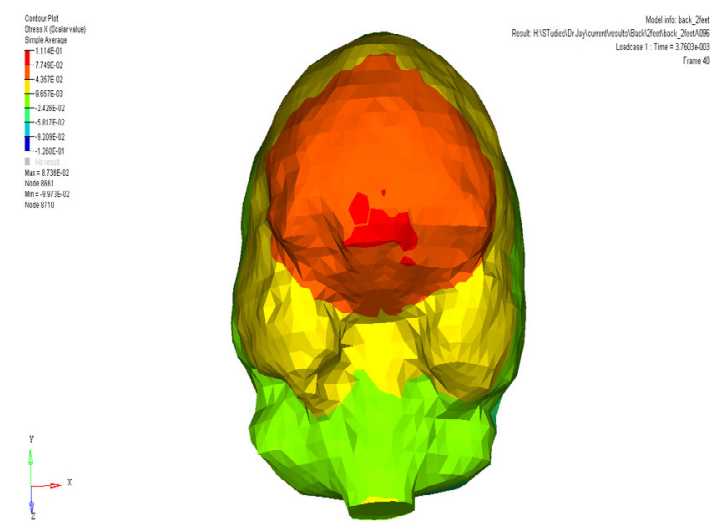

Figure 4.177 Normal stress $S_{x}$ Posterior 2 feet
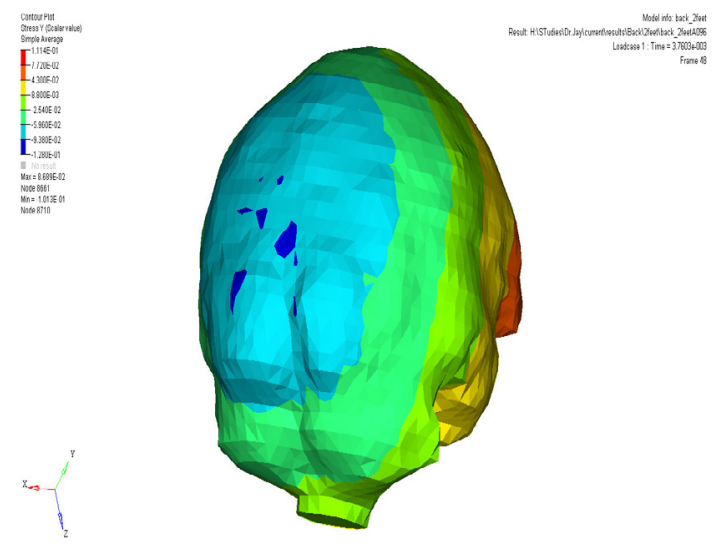

Figure 4.179 Normal stress $S_{y}$ Posterior 2 feet
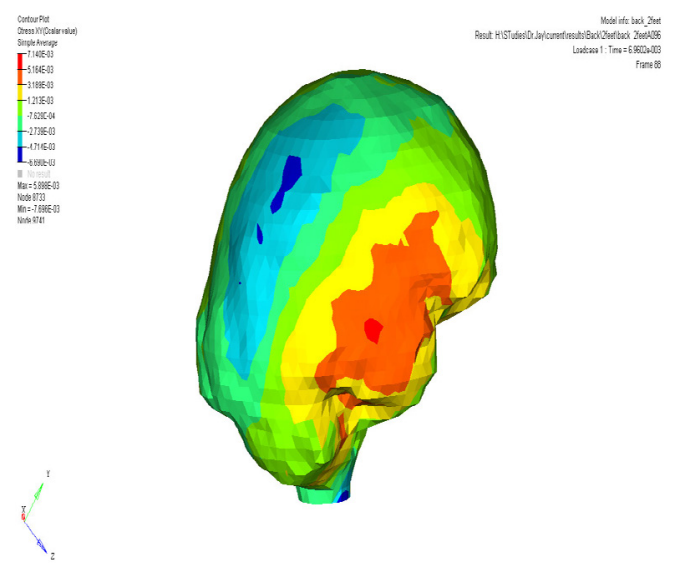

Figure 4.181 Shear stress $S_{x y}$ Posterior 2 feet 

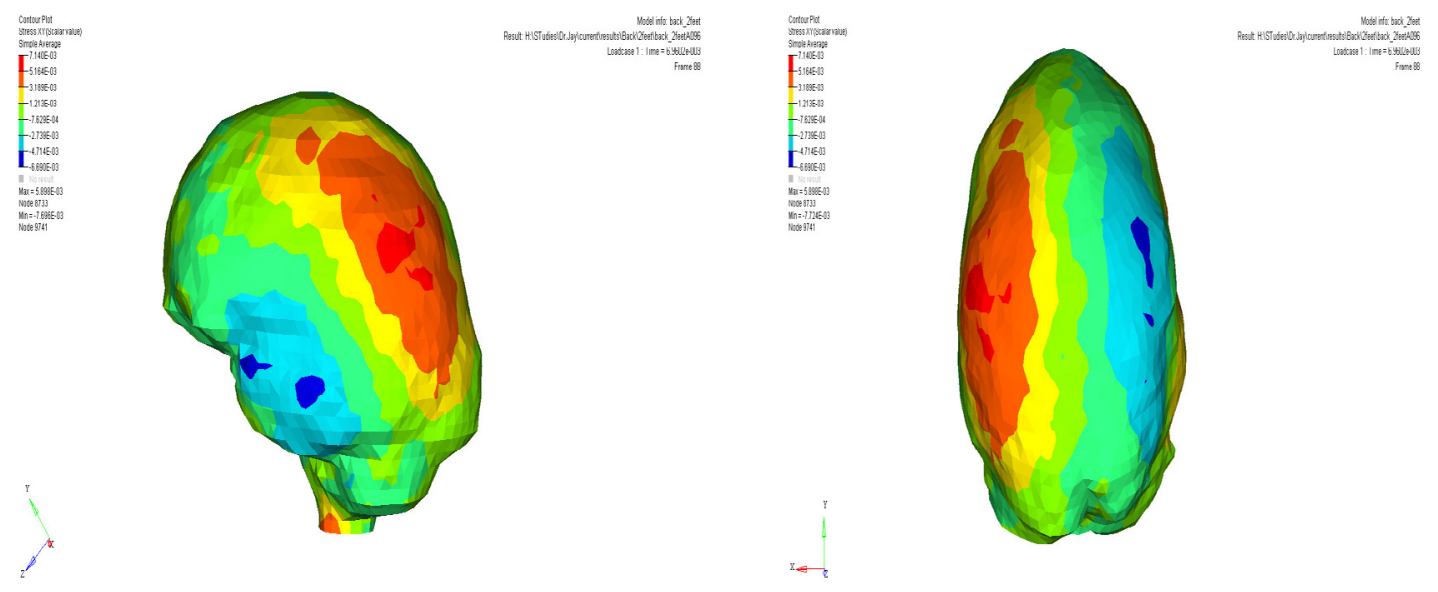

Figure 4.182 Shear stress $S_{x y}$ Posterior 2 feet

Figure 4.183 Shear stress $S_{x y}$ Posterior 2 feet

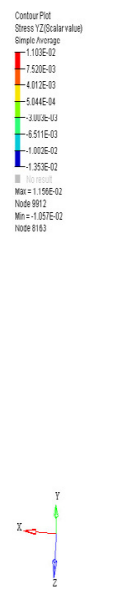

Figure 4.184 Shear stress $S_{y z}$ Posterior 2 feet

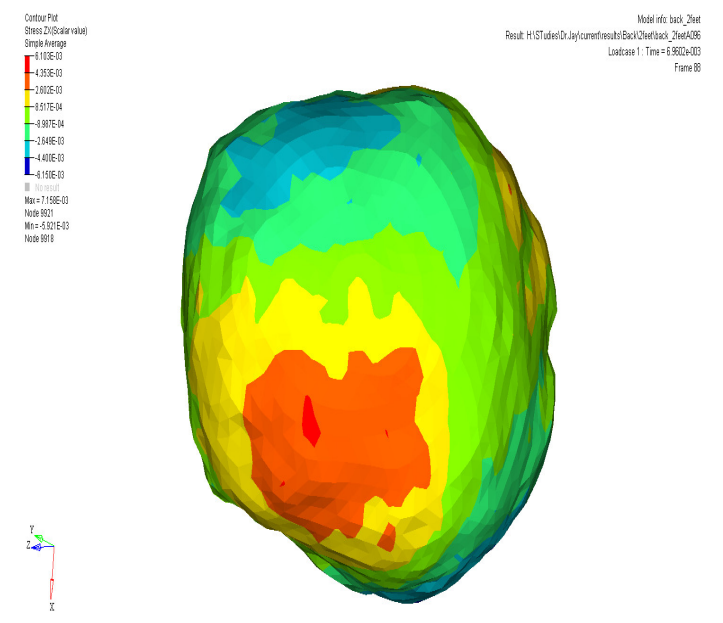

Figure 4.186 Shear stress $S_{z x}$ Posterior 2 feet

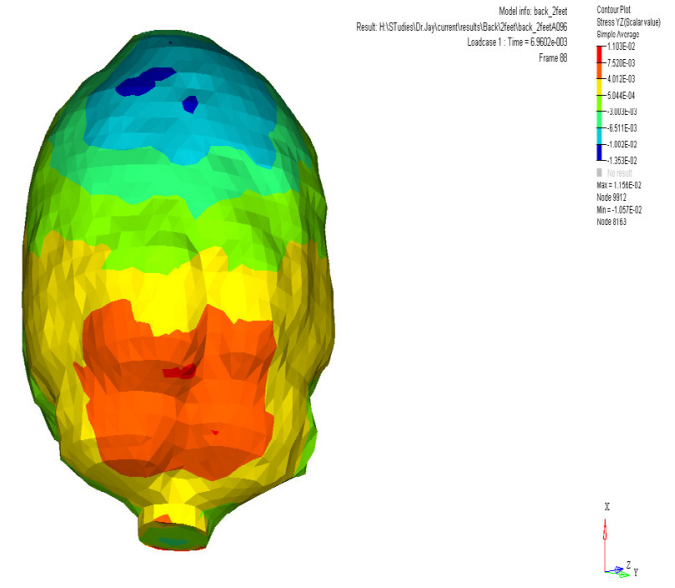

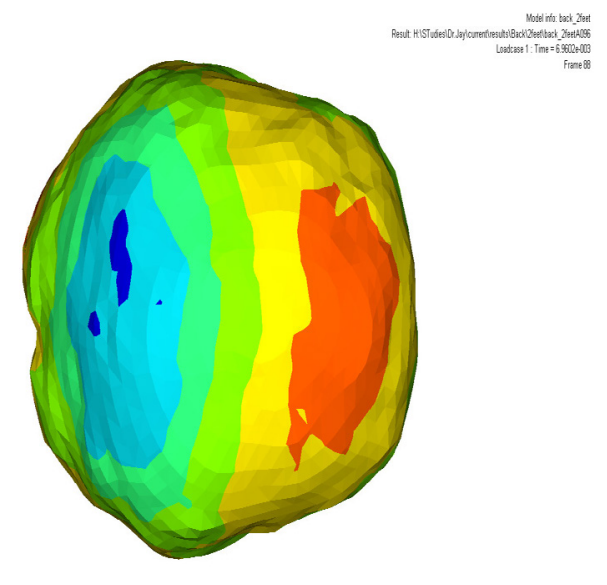

Figure 4.185 Shear stress $S_{y z}$ Posterior 2 feet
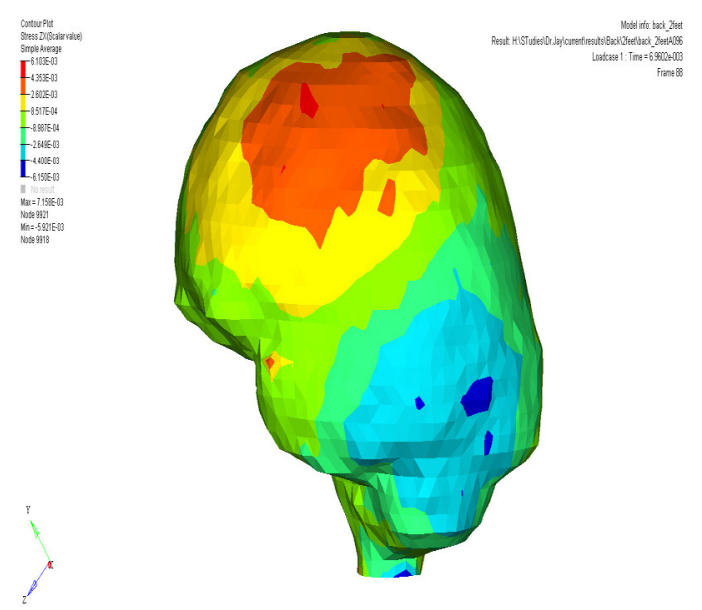

Figure 4.187 Shear stress $S_{z x}$ Posterior 2 feet 


\subsubsection{Drop Height of 3 feet}

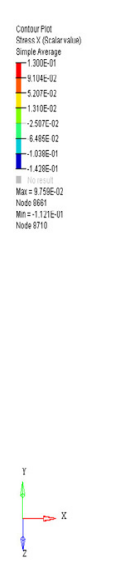

Figure 4.188 Normal stress $S_{x}$ Posterior 3 feet
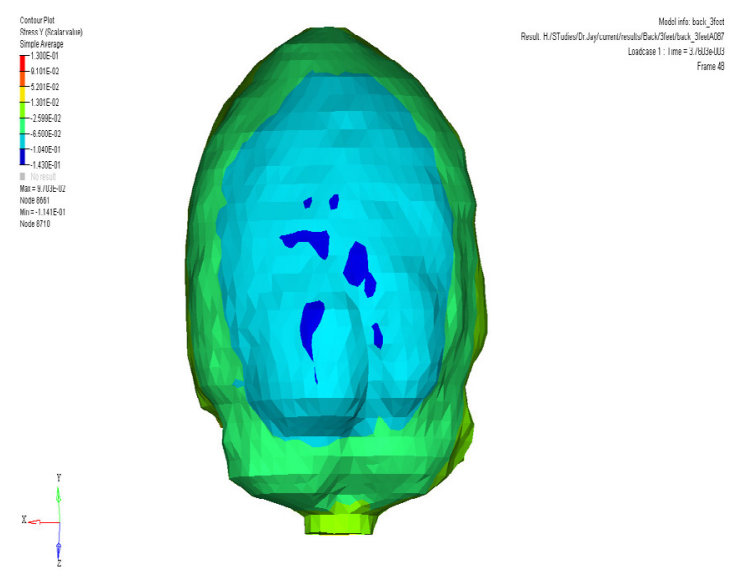

Figure 4.190 Normal stress $S_{y}$ Posterior 3 feet
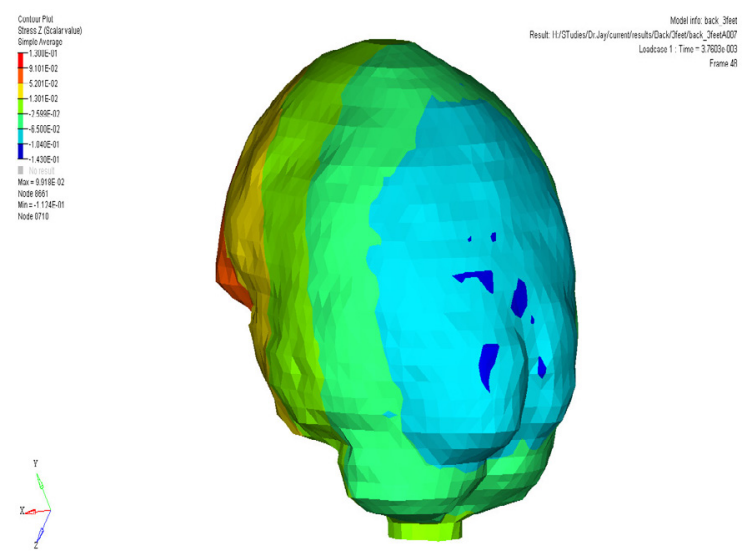

Figure 4.192 Normal stress $S_{z}$ Posterior 3 feet
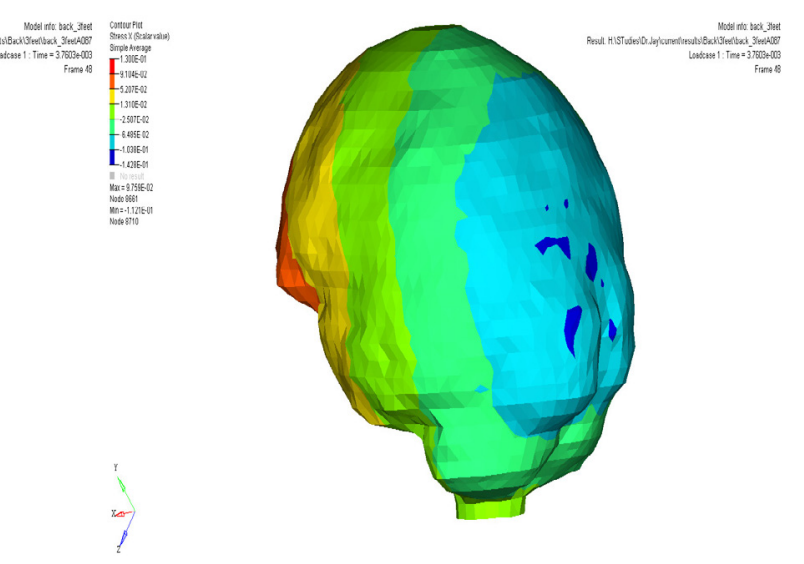

Figure 4.189 Normal stress $S_{x}$ Posterior 3 feet
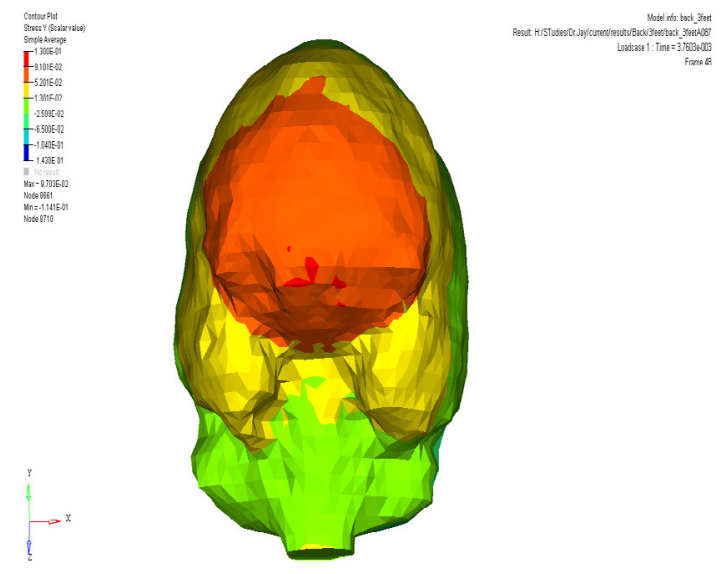

Figure 4.191 Normal stress $S_{y}$ Posterior 3 feet
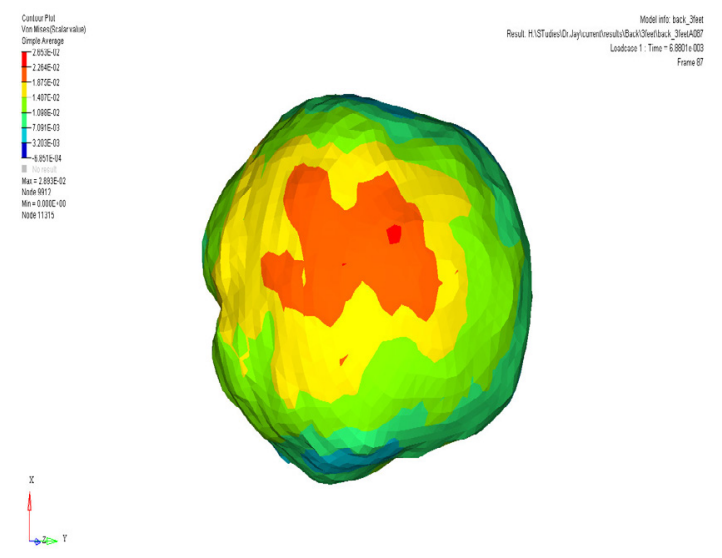

Figure 4.193 von Mises stress Posterior 3 feet 

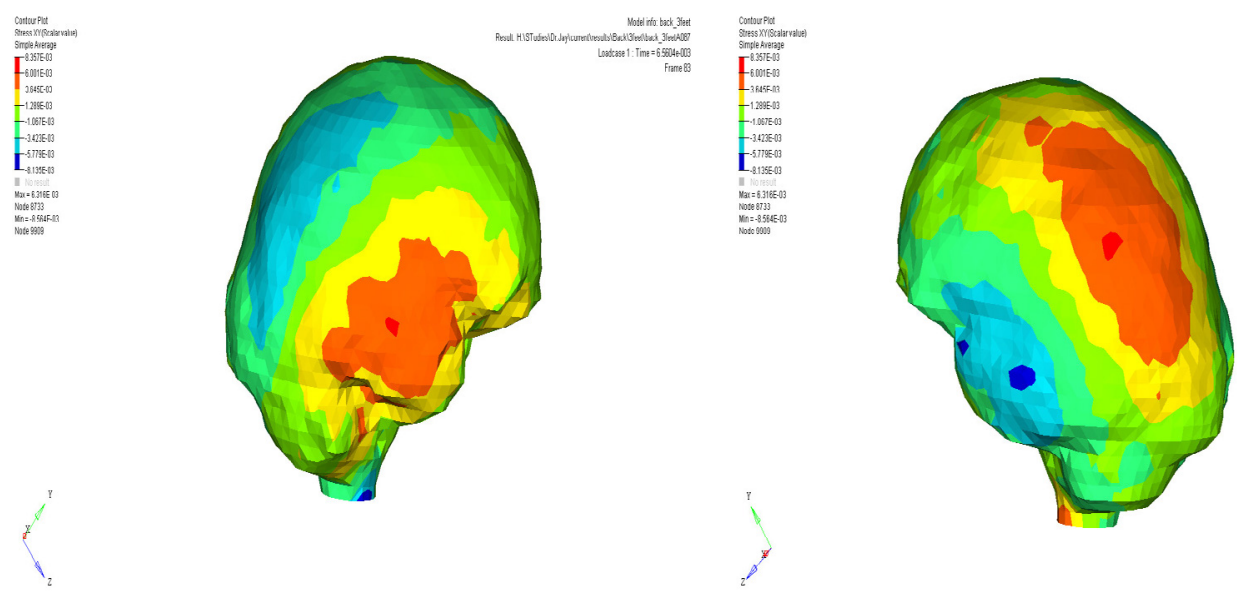

Figure 4.194 Shear stress $S_{x y}$ Posterior 3 feet

Figure 4.195 Shear stress $S_{x y}$ Posterior 3 feet
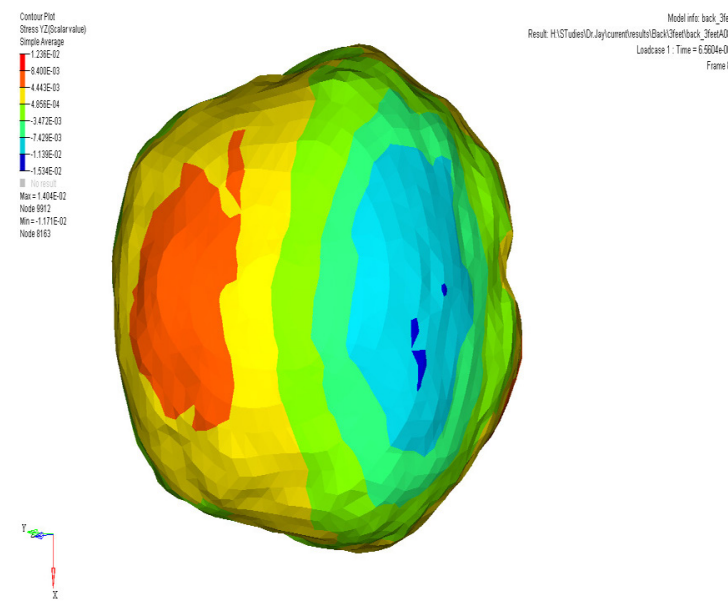

Figure 4.196 Shear stress $S_{y z}$ Posterior 3 feet
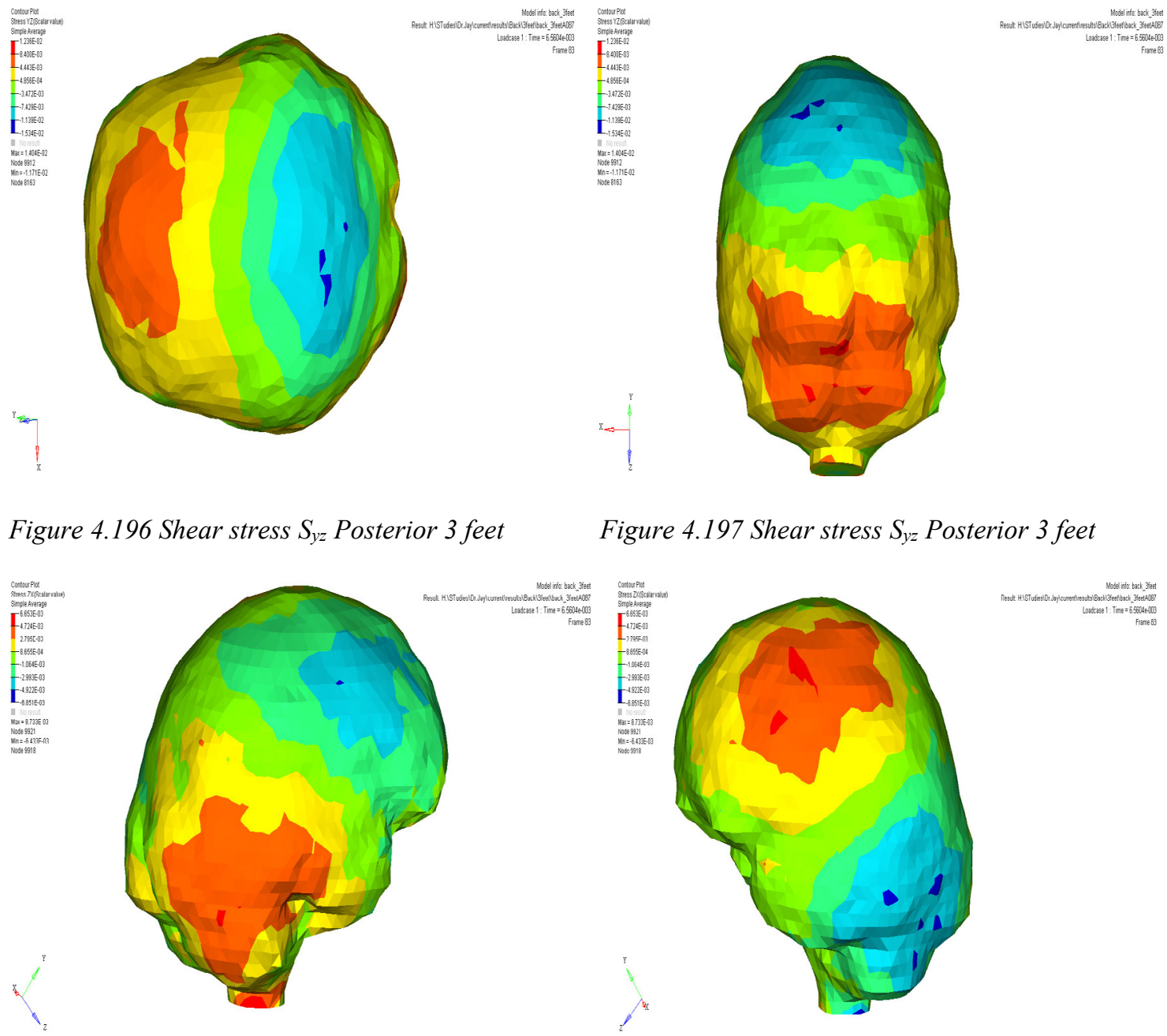

Figure 4.197 Shear stress $S_{y z}$ Posterior 3 feet

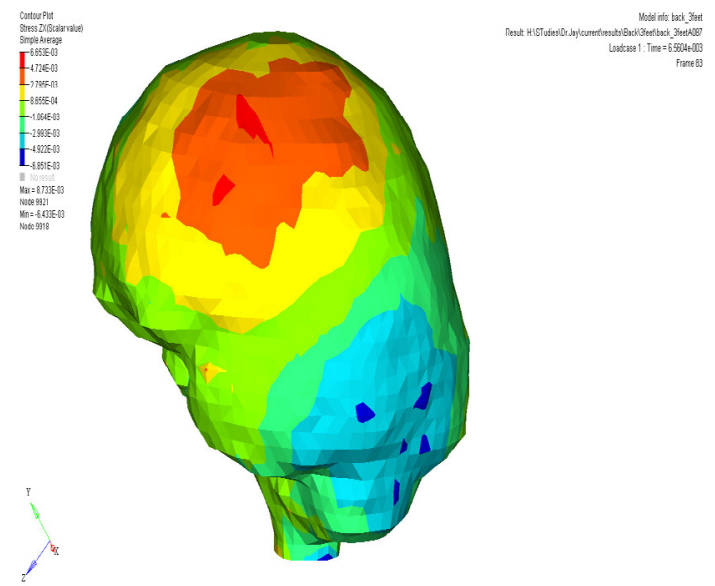

Figure 4.198 Shear stress $S_{z x}$ Posterior 3 feet

Figure 4.199 Shear stress $S_{z x}$ Posterior 3 feet 


\subsubsection{Drop Height of 4 feet}
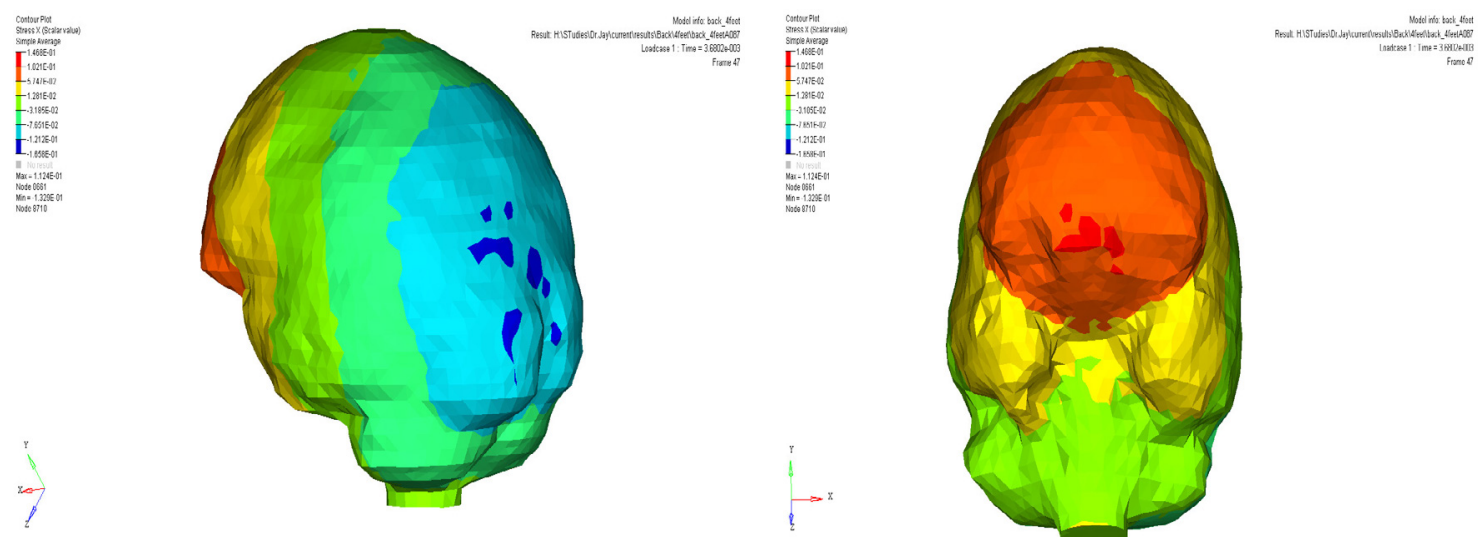

Figure 4.200 Normal Stress $S_{x}$ Posterior 4 feet

Figure 4.201 Normal Stress $S_{x}$ Posterior 4 feet
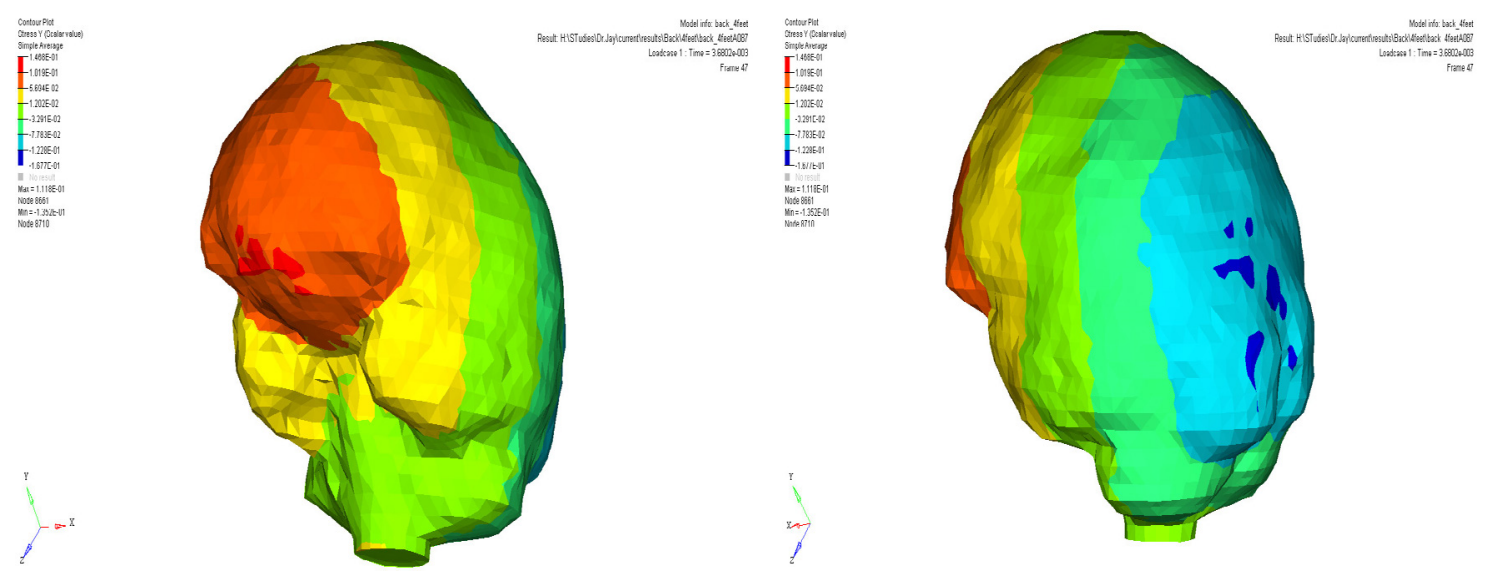

Figure 4.202 Normal stress $S_{y}$ Posterior 4 feet

Figure 4.203 Normal stress $S_{y}$ Posterior 4 feet
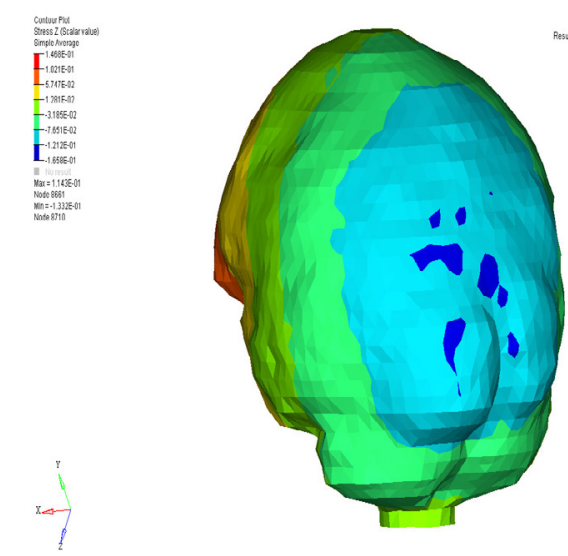

Figure 4.204 Normal stress $S_{z}$ Posterior 4 feet

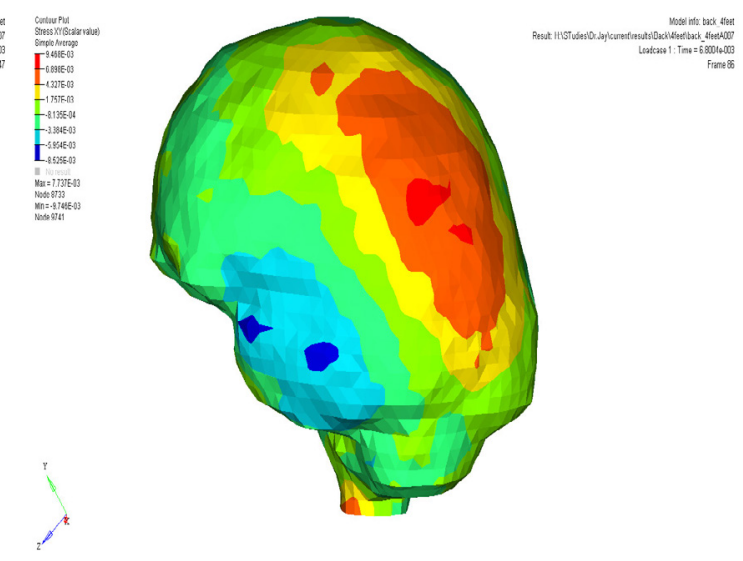

Figure 4.205 Shear stress $S_{x y}$ Posterior 4 feet 

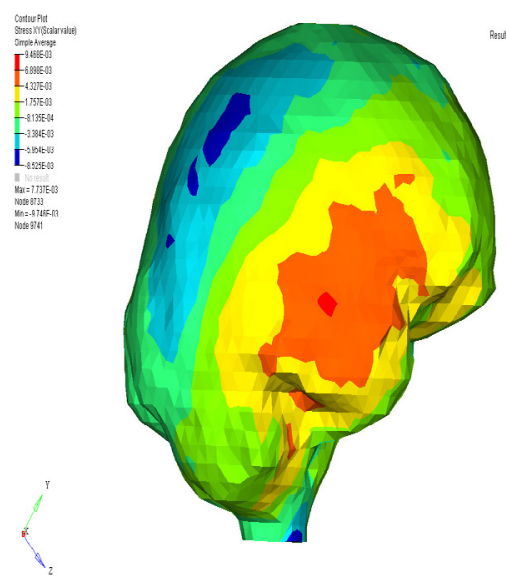

Figure 4.206 Shear stress $S_{x y}$ Posterior 4 feet

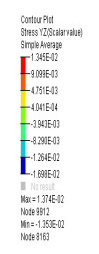

$y^{y}=x$

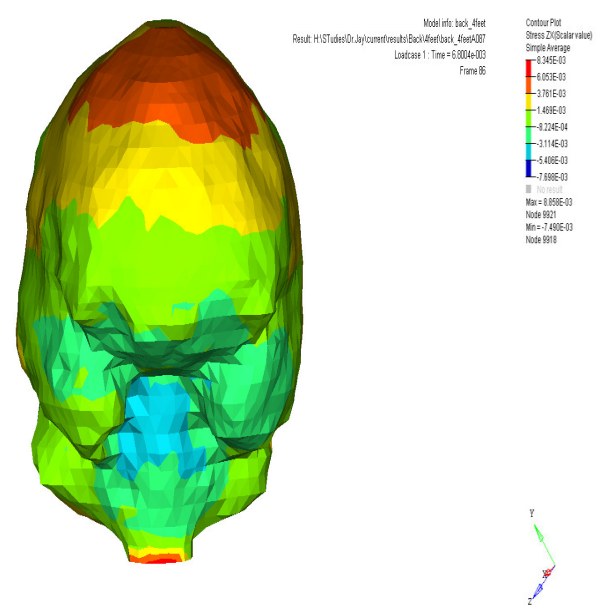

Figure 4.207 von Mises stress Posterior 4 feet

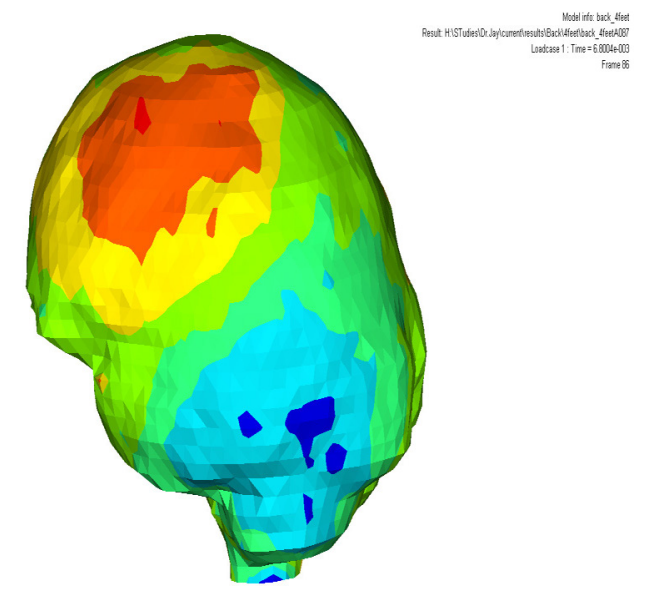

Figure 4.209 Shear stress $S_{z x}$ Posterior 4 feet

Figure 4.208 Shear stress $S_{y z}$ Posterior 4 feet
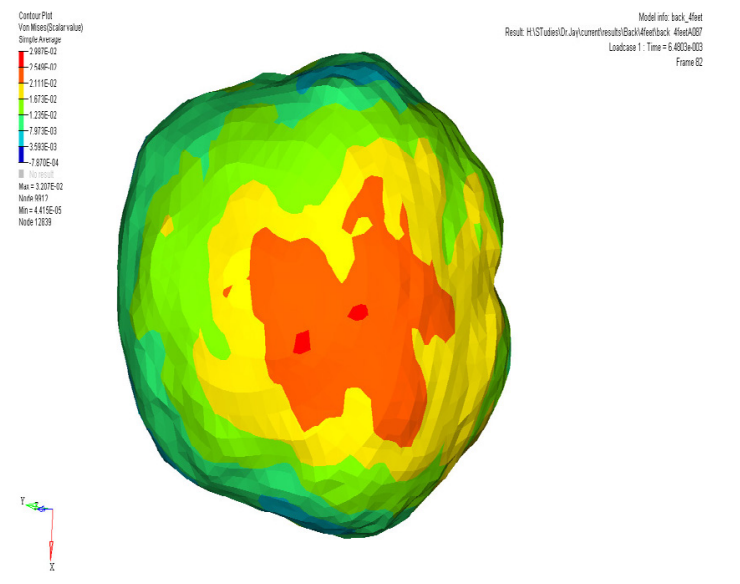
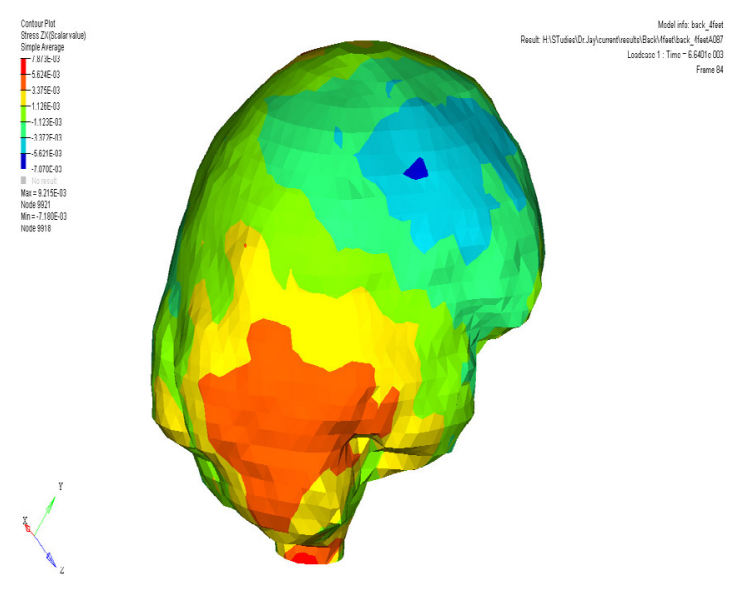

Figure 4.210 Shear stress $S_{z x}$ Posterior 4 feet 


\subsubsection{Drop Height of 5 feet}

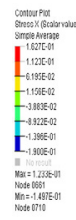

$?$

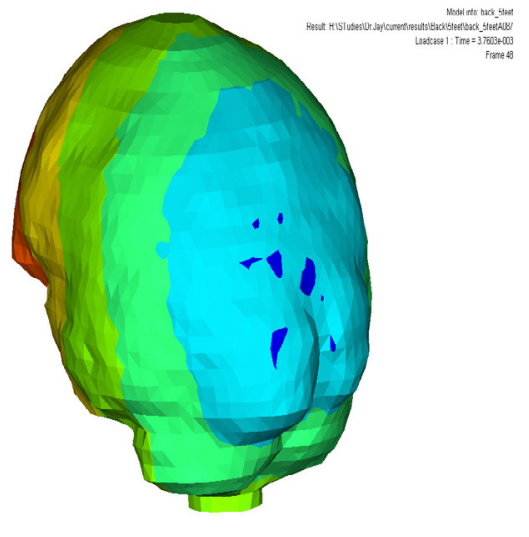

Figure 4.211 Normal stress $S_{x}$ Posterior 5 feet

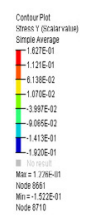

7

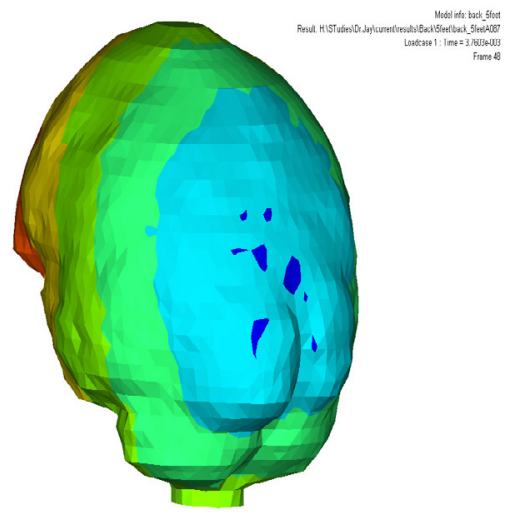

Figure 4.213 Normal stress $S_{y}$ Posterior 5 feet
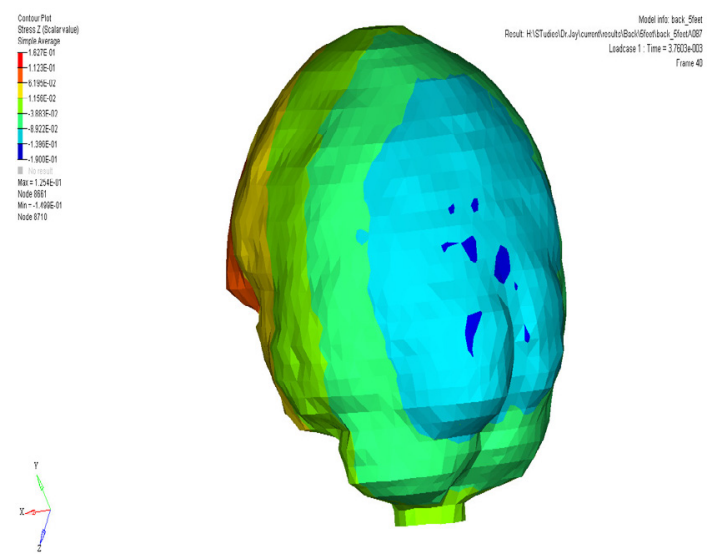

Figure 4.215 Normal stress $S_{z}$ Posterior 5 feet
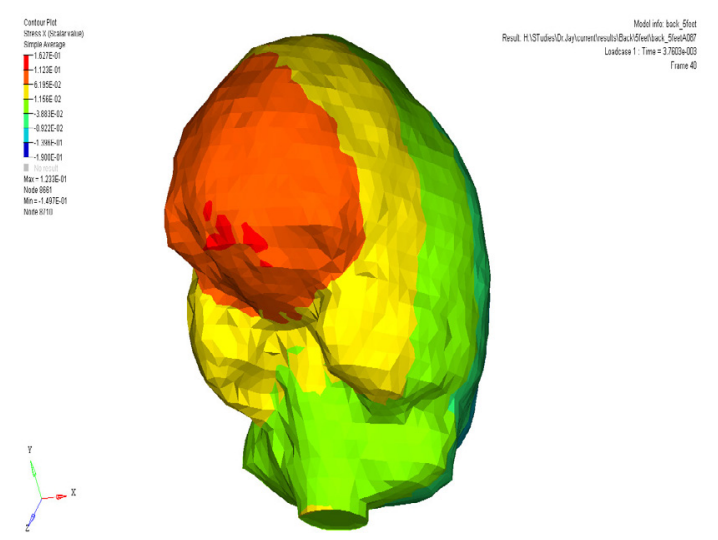

Figure 4.212 Normal stress $S_{x}$ Posterior 5 feet
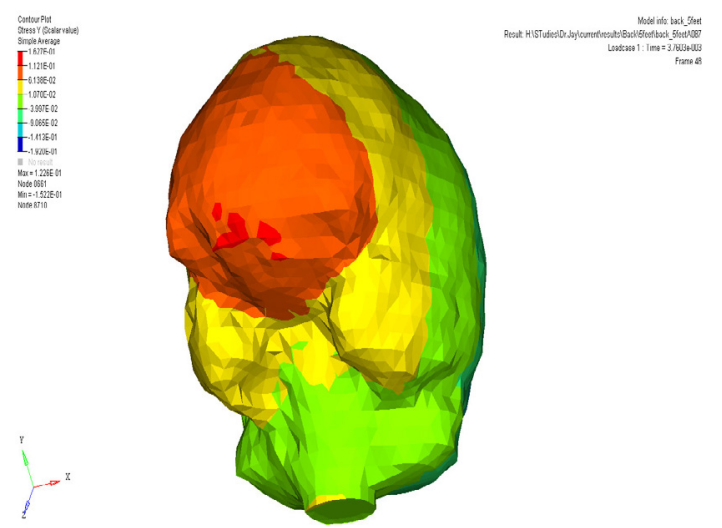

Figure 4.214 Normal stress $S_{y}$ Posterior 5 feet
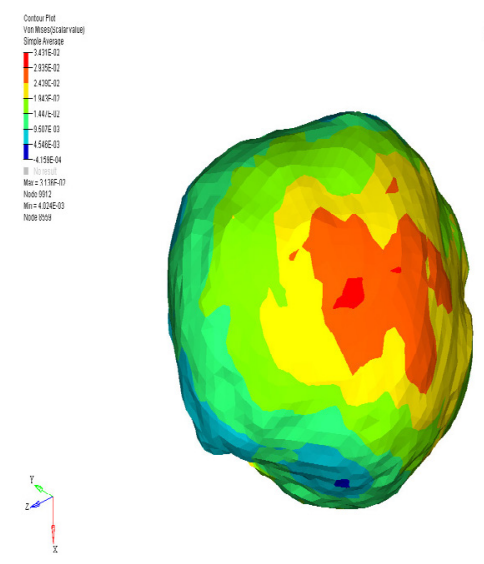

Figure 4.216 von Mises stress Posterior 5 feet 

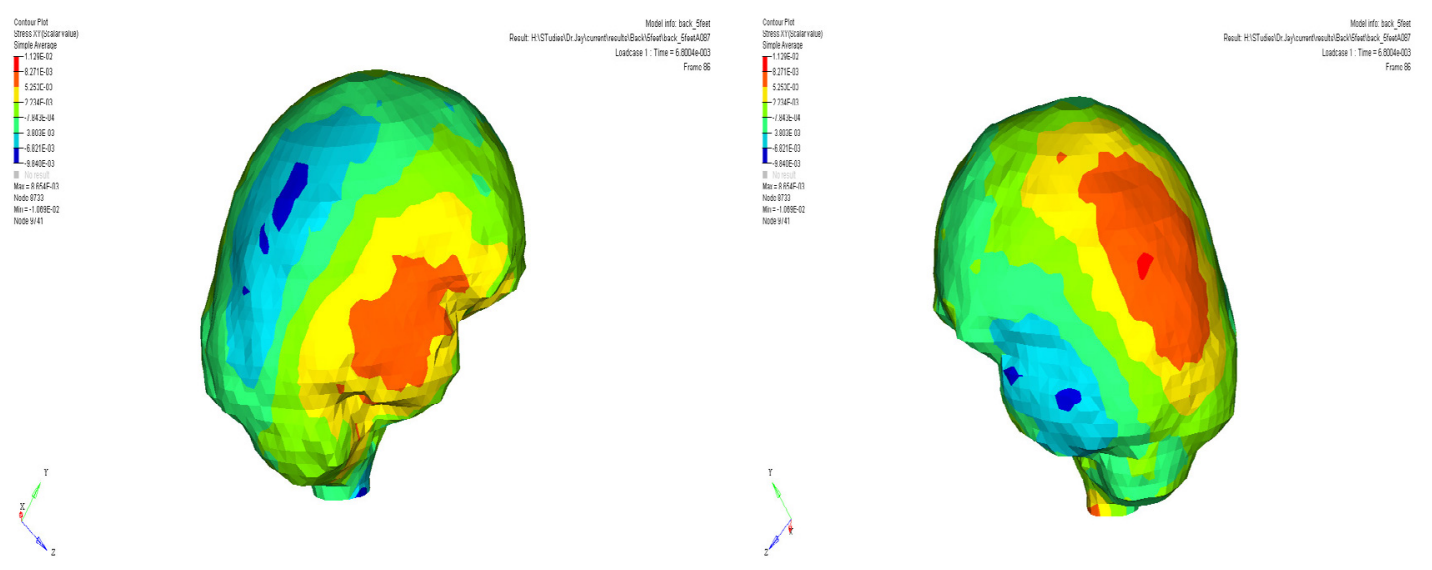

Figure 4.217 Shear stress $S_{x y}$ Posterior 5 feet

Figure 4.218 Shear stress $S_{x y}$ Posterior 5 feet
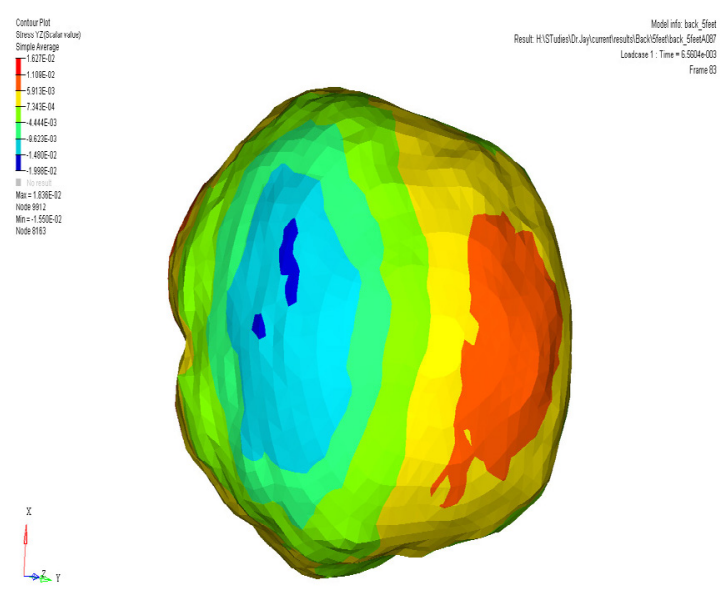

Figure 4.219 Shear stress $S_{y z}$ Posterior 5 feet
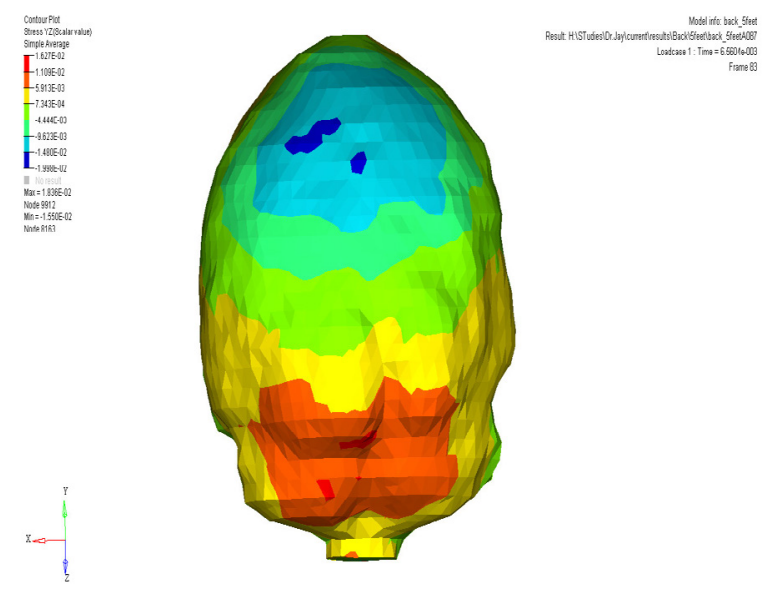

Figure 4.220 Shear stress $S_{y z}$ Posterior 5 feet

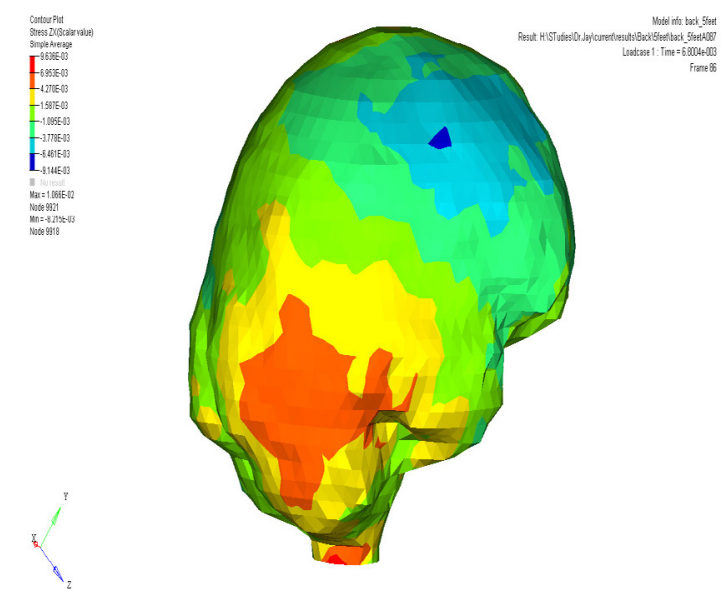

Figure 4.221 Shear stress $S_{z x}$ Posterior 4 feet

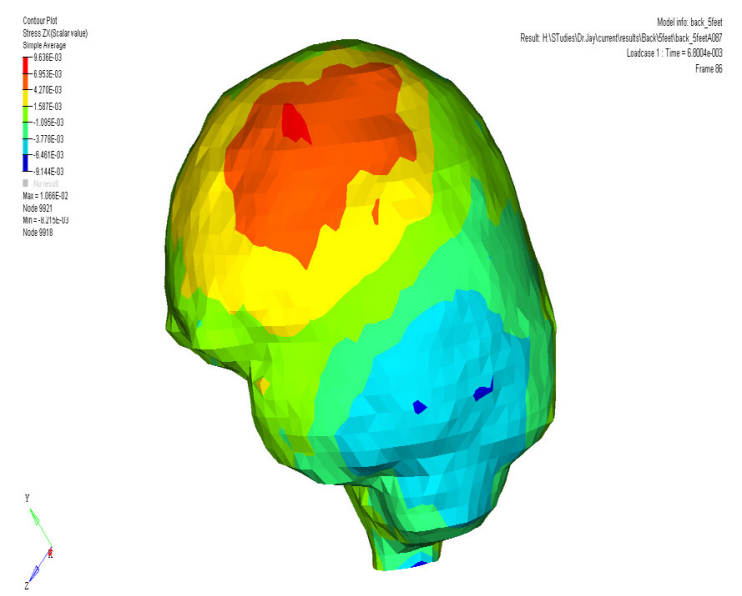

Figure 4.222 Shear stress $S_{z x}$ Posterior 5 feet 


\subsubsection{Discussion}

The normal stresses values obtained from the Finite element simulation are listed below.

Table 4.14 Normal Stress Values on brain from FE Simulation for Posterior Impact

\begin{tabular}{|r|c|c|c|c|c|c|}
\hline \multirow{2}{*}{$\begin{array}{c}\text { Height } \\
\text { (feet) }\end{array}$} & \multicolumn{2}{|c|}{ Stress X (MPa) } & \multicolumn{2}{c|}{ Stress Y (MPa) } & \multicolumn{2}{c|}{ Stress Z (MPa) } \\
\cline { 2 - 7 } & \multicolumn{1}{|c|}{ Tension } & Comp & \multicolumn{1}{c|}{ Tension } & Comp & \multicolumn{1}{c|}{ Tension } & \multicolumn{1}{c|}{ Comp } \\
\hline $\mathbf{2}$ & $\mathbf{- 1 . 2 6 E - 0 1}$ & $1.11 \mathrm{E}-01$ & $\mathbf{- 1 . 2 8 E - 0 1}$ & $1.11 \mathrm{E}-01$ & $\mathbf{- 1 . 2 6 E - 0 1}$ & $1.11 \mathrm{E}-01$ \\
\hline $\mathbf{3}$ & $\mathbf{- 1 . 4 3 E - 0 1}$ & $1.30 \mathrm{E}-01$ & $\mathbf{- 1 . 4 2 E - 0 1}$ & $1.30 \mathrm{E}-01$ & $\mathbf{- 1 . 4 3 E - 0 1}$ & $1.30 \mathrm{E}-01$ \\
\hline $\mathbf{4}$ & $\mathbf{- 1 . 6 6 E - 0 1}$ & $1.47 \mathrm{E}-01$ & $\mathbf{- 1 . 6 8 E - 0 1}$ & $1.47 \mathrm{E}-01$ & $\mathbf{- 1 . 6 6 E - 0 1}$ & $1.47 \mathrm{E}-01$ \\
\hline $\mathbf{5}$ & $\mathbf{- 1 . 9 0 E - 0 1}$ & $1.63 \mathrm{E}-01$ & $\mathbf{- 1 . 9 2 E - 0 1}$ & $1.63 \mathrm{E}-01$ & $\mathbf{- 1 . 9 0 E - 0 1}$ & $1.63 \mathrm{E}-01$ \\
\hline
\end{tabular}

The Shear stress values obtained for different drops from the finite element simulation are listed below

Table 4.15 Shear Stress values on brain from the FE Simulation for posterior impact

\begin{tabular}{|r|r|r|r|}
\hline $\begin{array}{c}\text { Height } \\
\text { (feet) }\end{array}$ & Stress XY (MPa) & Stress YZ (MPa) & Stress ZX (MPa) \\
\hline $\mathbf{2}$ & $7.14 \mathrm{E}-03$ & $\mathbf{- 1 . 3 5 E - 0 2}$ & $-6.15 \mathrm{E}-03$ \\
\hline $\mathbf{3}$ & $8.36 \mathrm{E}-03$ & $\mathbf{- 1 . 5 3 E - 0 2}$ & $-6.85 \mathrm{E}-03$ \\
\hline $\mathbf{4}$ & $9.47 \mathrm{E}-03$ & $\mathbf{- 1 . 7 0 E - 0 2}$ & $-7.87 \mathrm{E}-03$ \\
\hline $\mathbf{5}$ & $1.13 \mathrm{E}-02$ & $\mathbf{- 2 . 0 0 E - 0 2}$ & $-9.14 \mathrm{E}-03$ \\
\hline
\end{tabular}

The Values when used in the Mohr Circle calculation, yielded the following results

Table 4.16 Results Obtained from Mohr Circle Analysis for posterior impact.

\begin{tabular}{|r|c|c|c|c|c|}
\hline \multirow{2}{*}{$\begin{array}{c}\text { Height } \\
\text { (feet) }\end{array}$} & \multicolumn{2}{|c|}{ Principal Stresses (MPa) } & \multirow{2}{*}{$\begin{array}{c}\text { Max Shear } \\
\text { Stress } \\
\text { (MPa) }\end{array}$} & $\begin{array}{c}\text { von Mises } \\
\text { (MPa) }\end{array}$ \\
\hline 2 & $-1.08 \mathrm{E}-01$ & $-1.31 \mathrm{E}-01$ & $\mathbf{- 1 . 4 1 E - 0 1}$ & $1.61 \mathrm{E}-02$ & $2.86 \mathrm{E}-02$ \\
\hline 3 & $-1.22 \mathrm{E}-01$ & $-1.48 \mathrm{E}-01$ & $\mathbf{- 1 . 5 8 E - 0 1}$ & $1.81 \mathrm{E}-02$ & $3.25 \mathrm{E}-02$ \\
\hline 4 & $-1.43 \mathrm{E}-01$ & $-1.72 \mathrm{E}-01$ & $\mathbf{- 1 . 8 4 E - 0 1}$ & $2.04 \mathrm{E}-02$ & $3.64 \mathrm{E}-02$ \\
\hline 5 & $-1.63 \mathrm{E}-01$ & $-1.98 \mathrm{E}-01$ & $\mathbf{- 2 . 1 1 E - 0 1}$ & $2.41 \mathrm{E}-02$ & $4.32 \mathrm{E}-02$ \\
\hline
\end{tabular}

The Maximum Pressure values observed on the brain obtained from the simulation are tabulated below. 
Table 4.17 Pressures on the Brain due to posterior Impact from different heights

\begin{tabular}{|c|c|c|c|}
\hline $\begin{array}{l}\text { Height } \\
\text { (feet) }\end{array}$ & $\begin{array}{l}\text { HICP } \\
\text { (MPa) }\end{array}$ & $\begin{array}{l}\text { Velocity of Fall } \\
(2 \mathrm{gh})^{\wedge} 0.5 \mathrm{~m} / \mathrm{s}\end{array}$ & $\begin{array}{c}\text { Pressure on } \\
\text { Brain - } \\
\text { Tension(MPa) }\end{array}$ \\
\hline 2 & 1.12 & 3.46 & $1.44 \mathrm{E}-01$ \\
\hline 3 & 1.30 & 4.24 & $1.62 \mathrm{E}-01$ \\
\hline 4 & 1.46 & 4.89 & $1.86 \mathrm{E}-01$ \\
\hline 5 & 1.55 & 5.47 & $2.00 \mathrm{E}-01$ \\
\hline
\end{tabular}

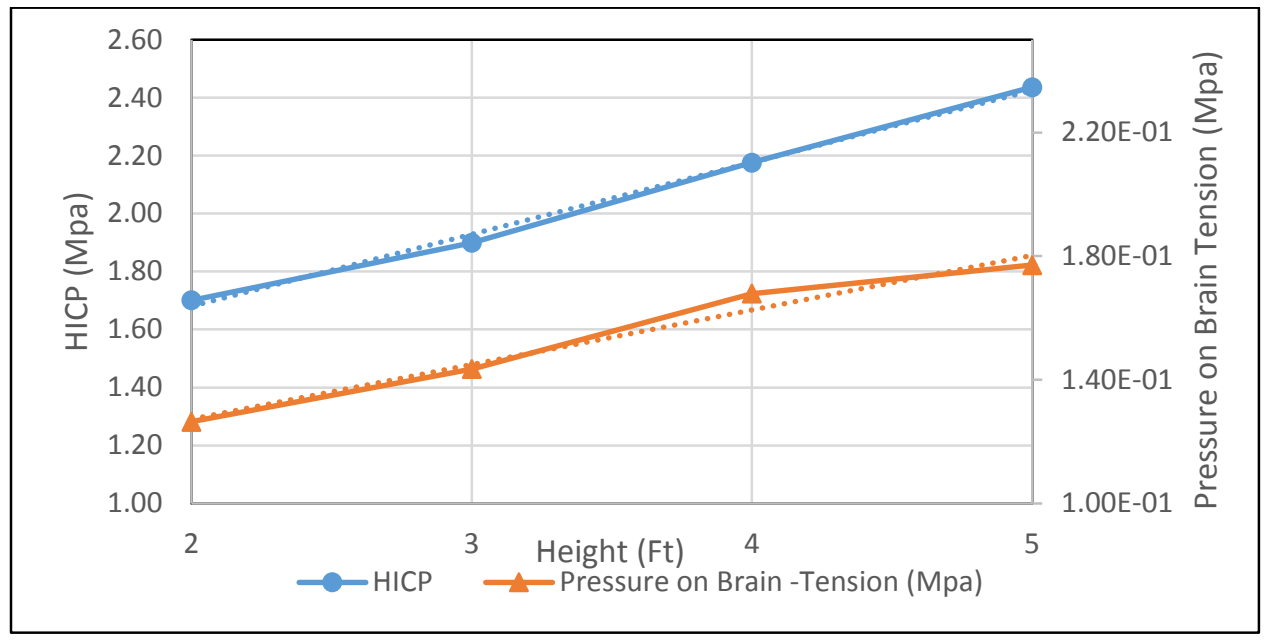

Figure 4.223 Comparison of Pressure on Brain and HICP during posterior Impact

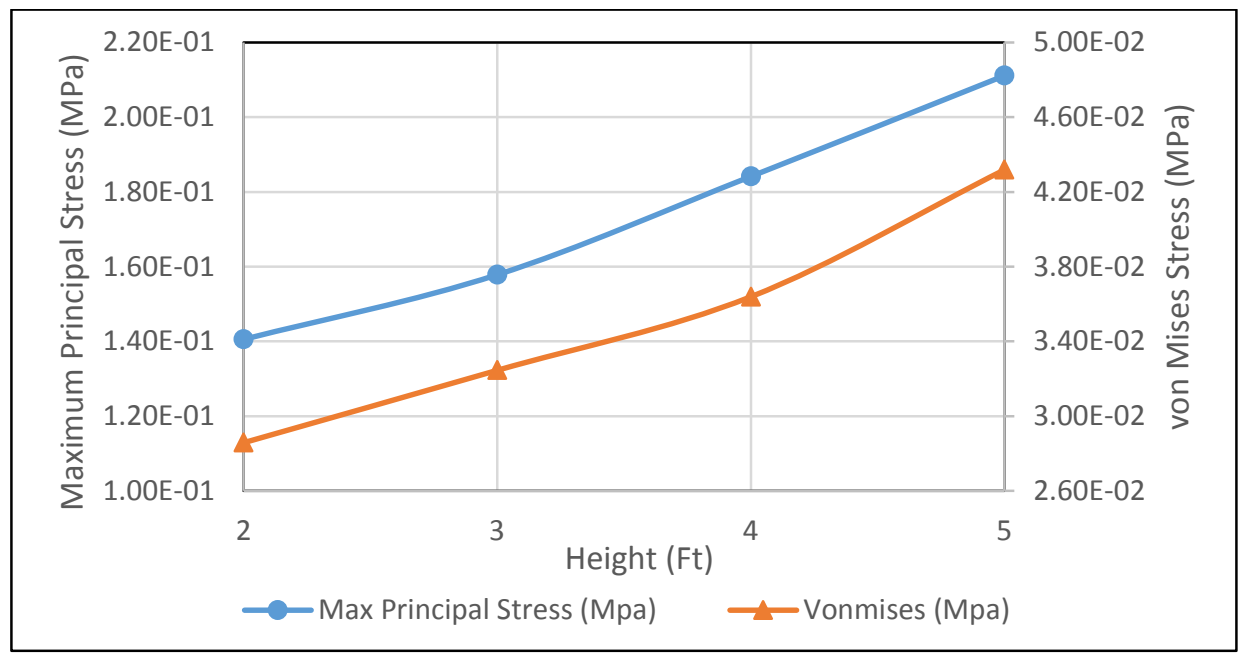

Figure 4.224 Maximum Principal Stress and von Mises Stress on Brain obtained from FE Simulation for posterior impact. 


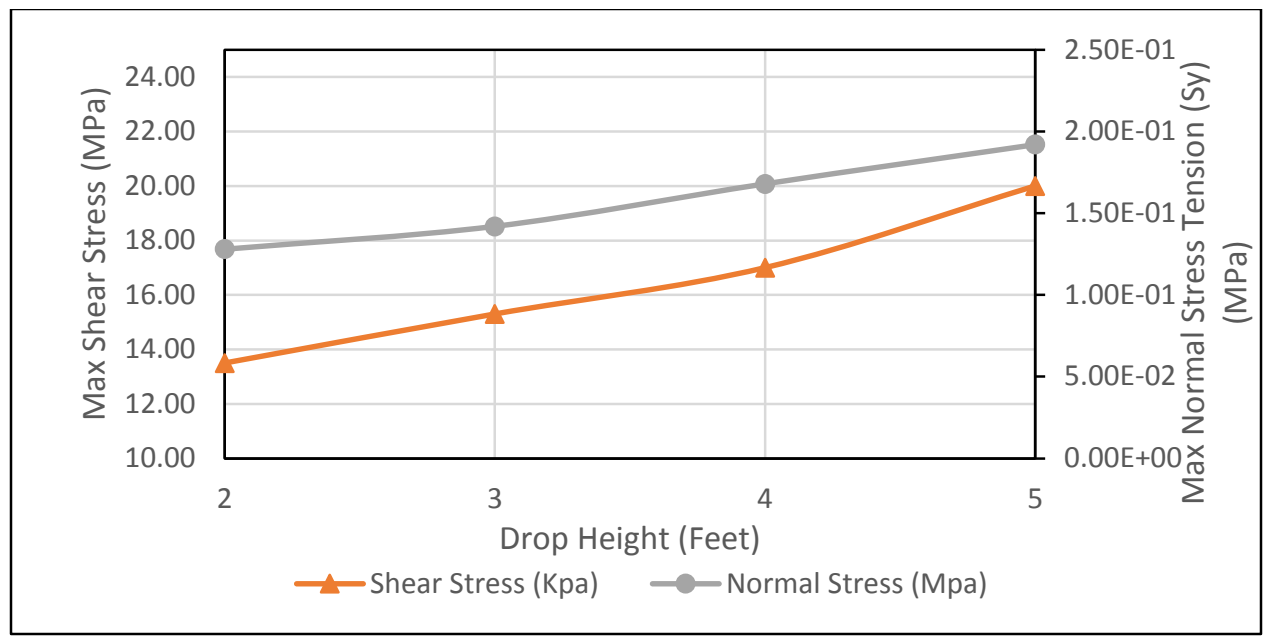

Figure 4.225 Stress Variation on Brain with height during impact on posterior region

Upon observing the results of the simulation the following information can be inferred.

- One can see that the pressure wave travels from the occipital lobe (site of impact) to parietal lobe and thus to frontal lobe and gets reflected back in the opposite direction as a pressure wave surfacing upon the occipital lobe (Refer to Fig B47 and B480 towards the site of impact explaining the concept of Coup and Contre Coup Injury. The maximum Pressure is observed around the peak acceleration of the impact curve specifying the travel of the pressure wave during the impact.

- The maximum shear stress values are obtained in the regions of parietal lobe (top of the head) and occipital lobe which are under tension, while the brain is in compression from both the opposite sides.

- The maximum von Mises stress values are obtained in the regions around the brain stem and on the parietal lobe.

- The moment of the brain is not so predominant in this region when compared to $45^{\circ}$ to frontal and lateral region implying the injury in this region is mainly due to linear acceleration 


\subsubsection{Overall Results Discussion}

An overall comparison of the outputs obtained from all the drops will be discussed in this section.

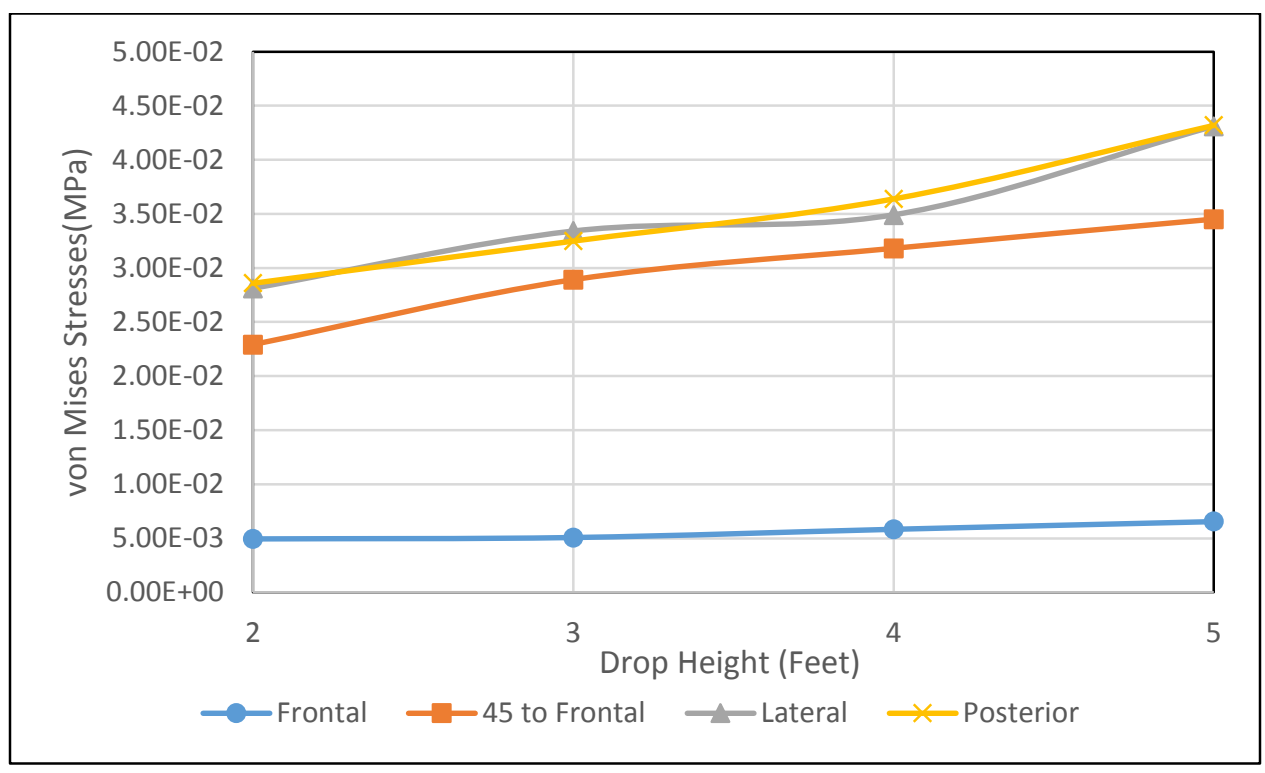

Figure 4.226 von Mises stress Vs Drop height for different regions of impact

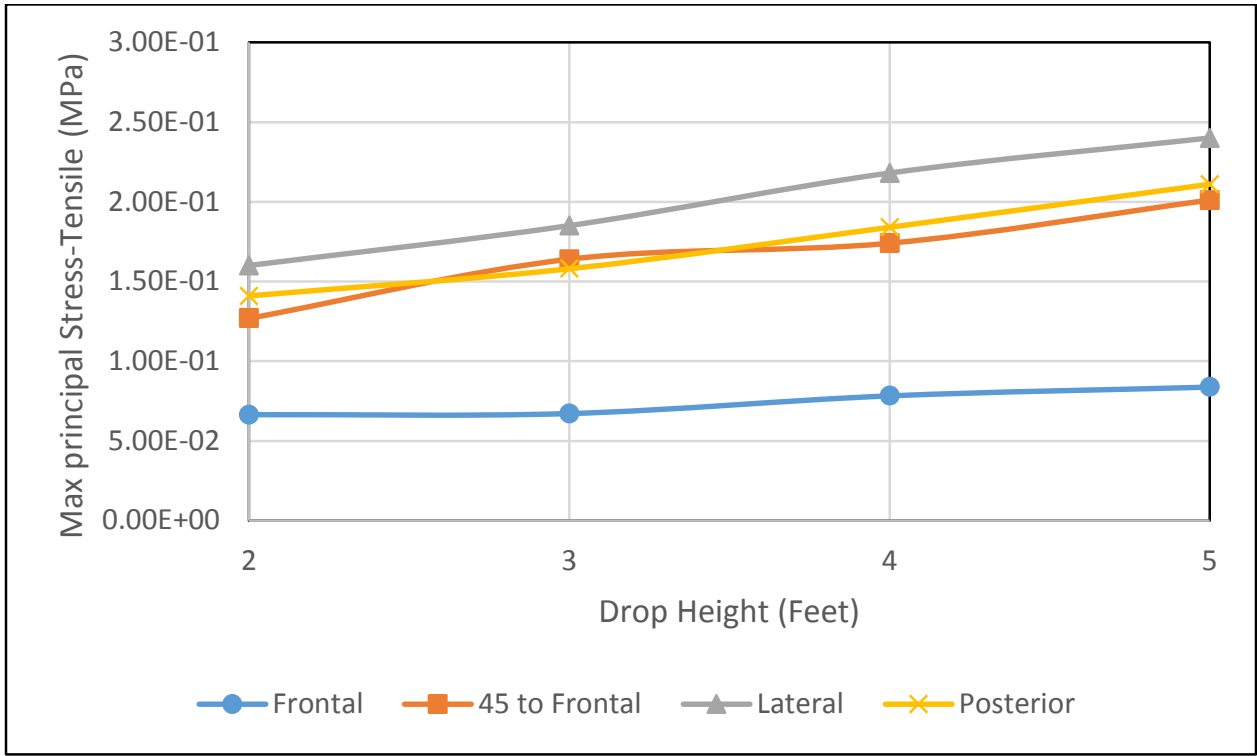

Figure 4.227 Maximum Principal Stress Vs Drop Height for different regions of Impact 
- We know that brain is strong in compression, and weak in tension, hence only tensile stresses are considered in the injury analysis.

- The peak value of pressure on the brain (0.2 MPa-Tension) is observed in the Lateral 5 feet drop while the peak values of the HICP are observed in the posterior region. The range of pressures (0.14-0.2 MPa Tension) developed in these region are higher when compared to similar drops in other region. The maximum values of pressures developed on the brain in $45^{\circ}$ to frontal impact $(0.175 \mathrm{MPa}$ Tension) and posterior region $(0.177$ MPa Tension) are lesser than the pressure on the brain at lateral 4 feet drop $(0.186 \mathrm{MPa}$ Tension). On the other hand the lowest range of pressures can be observed on the frontal region (0.06 - 0.08 MPa Tension).

- Although the Posterior regions have the highest values of HICP than the lateral region we can also observe that the lateral region has lowest impact times than the posterior region. Hence it can be understood that the injury in the lateral region is much more critical than the posterior region according to the Wayne state tolerance curve [13], which states that lower the time duration, higher the impact on brain for a given acceleration. - The Maximum principal stress (tension) values are almost similar to that of the pressure developed on the brain, but they are in opposite sense. All the principal stress discussed above in this chapter are in negative magnitude. The maximum principal stress is observed in the lateral 5 feet drop $(0.24 \mathrm{MPa})$ while the minimum is observed for frontal region $(0.065 \mathrm{MPa})$. Hence either pressure or principal stress can be used as determining factor measuring the extent of brain injuries.

- The Maximum values of von Mises stress (0.043 MPa) are also observed in the Lateral 5 feet Impact while the minimum is observed for the frontal 2 feet impact $(0.005 \mathrm{MPa})$. 
- The shear stress can cause concussion when the maximum von Mises stresses are observed at the brain stem.

- The von Mises stresses for lateral and posterior are in the same range while the posterior and 45 to frontal region have their principal stresses in the same range for a given height. - For any given height the lateral region has highest values of principal stresses and von Mises stresses, while the least are observed in the frontal region.

- Tensile stresses will be a deciding criteria for TBI only if there is an impact without rotation (only linear acceleration and no angular acceleration). But as we know all the impacts have rotation associated with it, hence von Mises stresses are also considered as a deciding criteria.

Hence it can be inferred that the lateral region is more susceptible to injury than other regions. This can be due to higher area of impacts, lesser thickness of skull and scalp in these regions and can be mainly due to the presence of Angular acceleration component as the line of injury is not passing through the center of mass of the head. While on the other hand the frontal region values are much low when compared to other regions making it much less susceptible to injuries. 


\section{Chapter 5 \\ Correlation between Head acceleration and Brain Stress Distributions}

\subsection{Introduction}

In earlier chapters the Kinematics of the Head during free fall are studied using the experimental methods and the results has been used as an input to study the brain kinetics.

In this chapter the tolerance levels for a TBI which are collected from the previous experiments will be used to determine the tolerance values of heights of drop after which the chances are higher for a TBI.

The shear stress tolerance value for a probable brain injury has been proposed by Kang [22] in his research work. The tolerance of the human brain in shear is defined as 16.5 $\mathrm{KPa}[23]$.

The tolerance drop heights for probable TBI from Chandrika's [25] work has been collected and the minimum of these two values will be used to determine a relation using which we can state the risk of a TBI for a given fall.

\subsection{Determination of TBI Tolerance drop height using Maximum Shear stress}

The Shear stress values for brain which are obtained from the Mohr's circle are plotted Y-axis for their corresponding heights for all the four region of drops namely Frontal, $45^{\circ}$ to frontal, lateral and posterior. Considering the shear stress tolerance for the TBI as 16.5 KPa, a straight line has been drawn across the plot to determine the tolerance drop heights for the TBI. The point of intersection of the TBI limit line with the plot has been 
traced down to X-axis to determine the TBI tolerance drop heights. The profile of the shear stress is approximated as a quadratic equation to minimize the human errors.

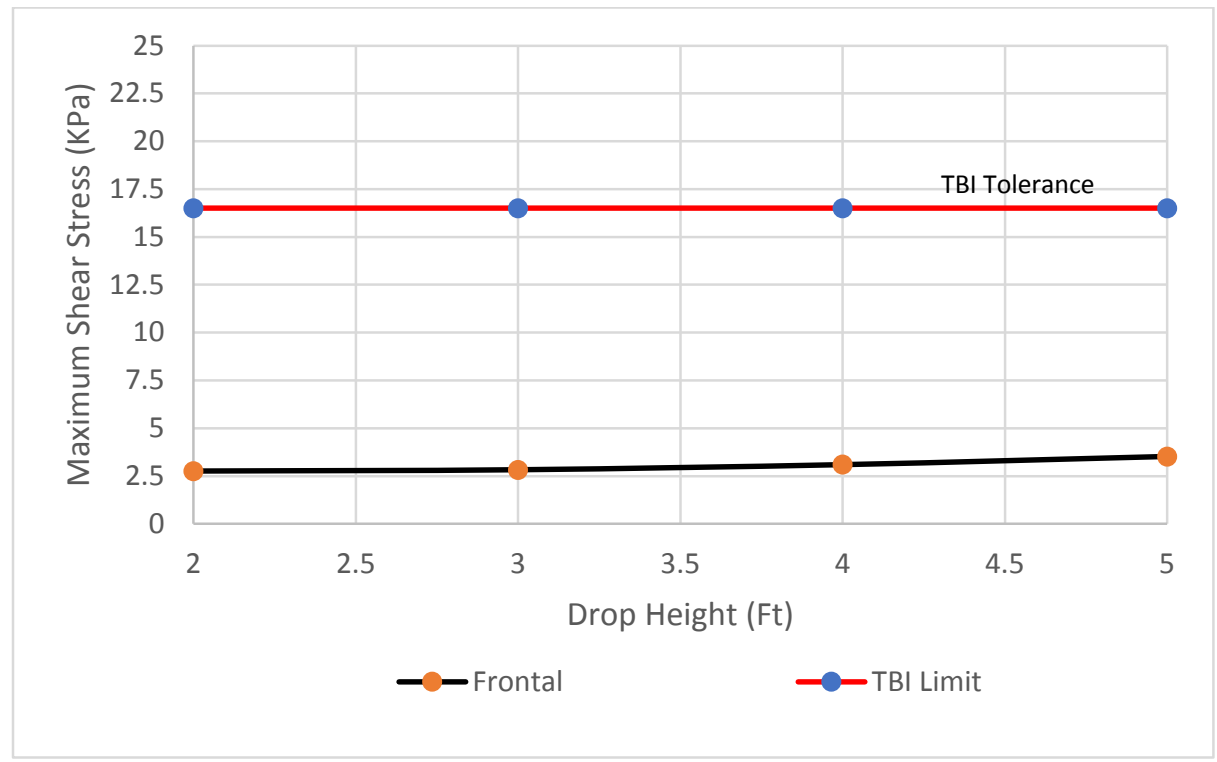

Figure 5.1 Maximum Shear Stress Vs Drop Height for the Frontal Region Impact

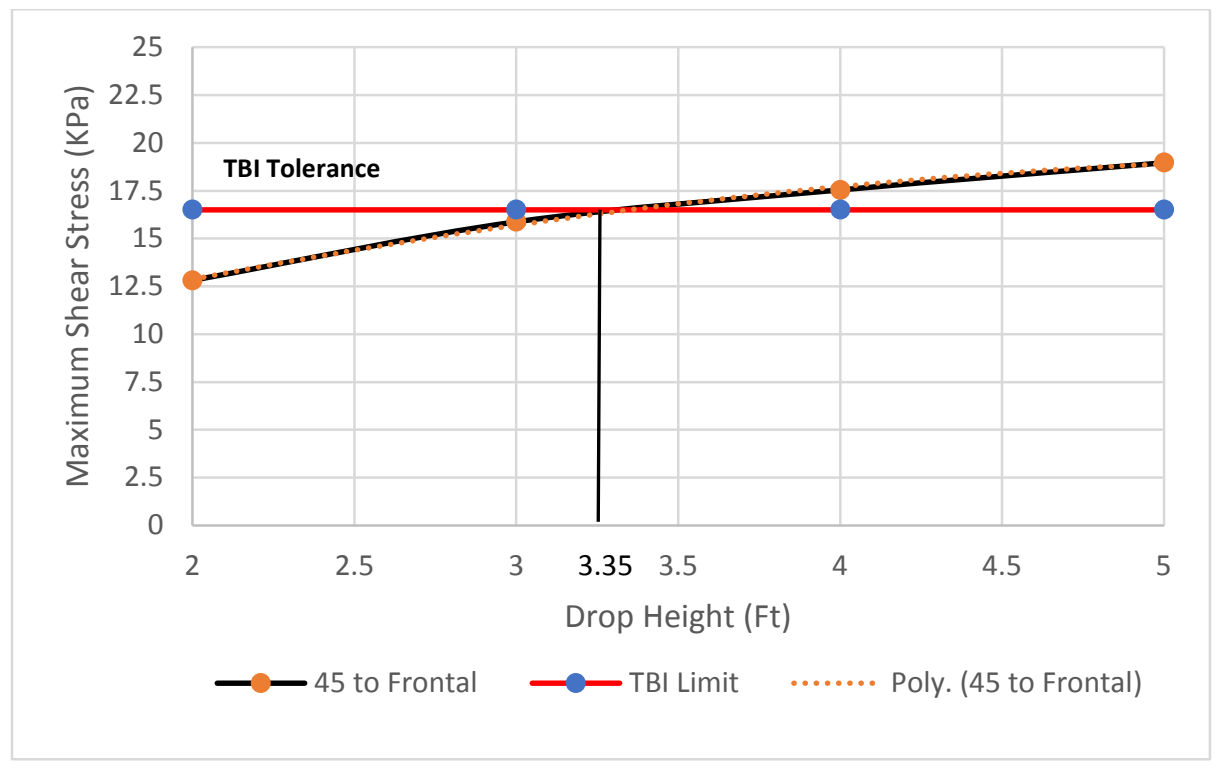

Figure 5.2 Maximum Shear Stress Vs Drop Height for the $45^{\circ}$ to Frontal Region Impact 


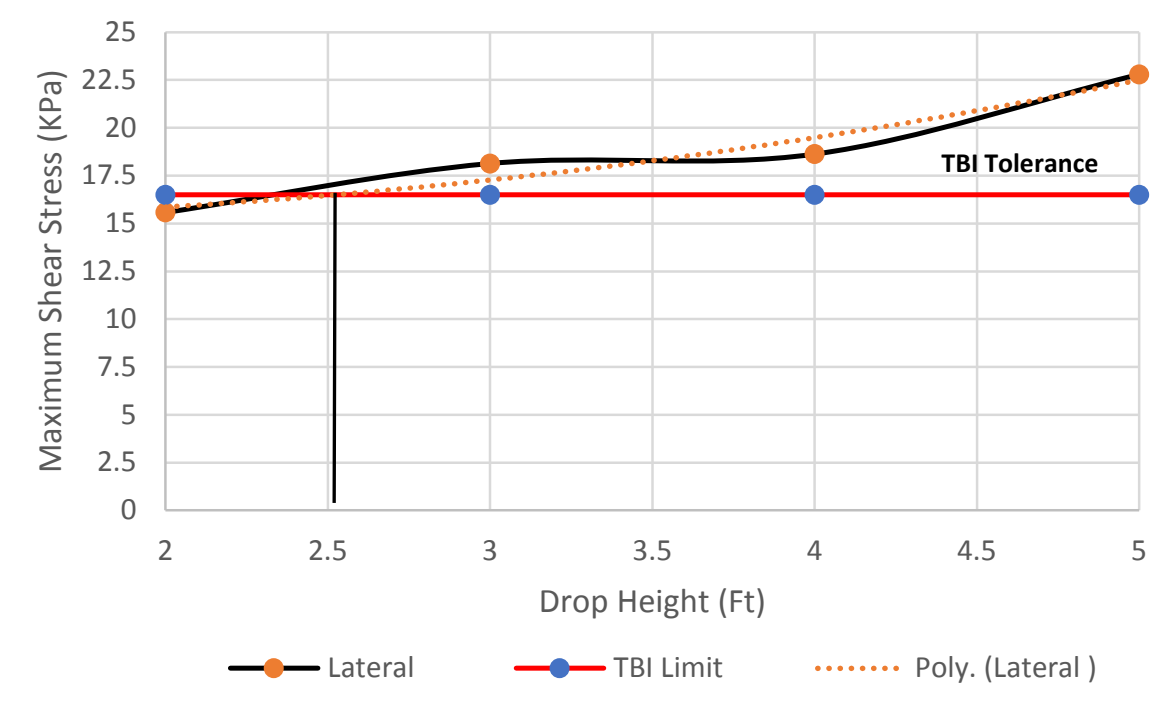

Figure 5.3 Maximum Shear Stress Vs Drop Height for the Lateral Region Impact

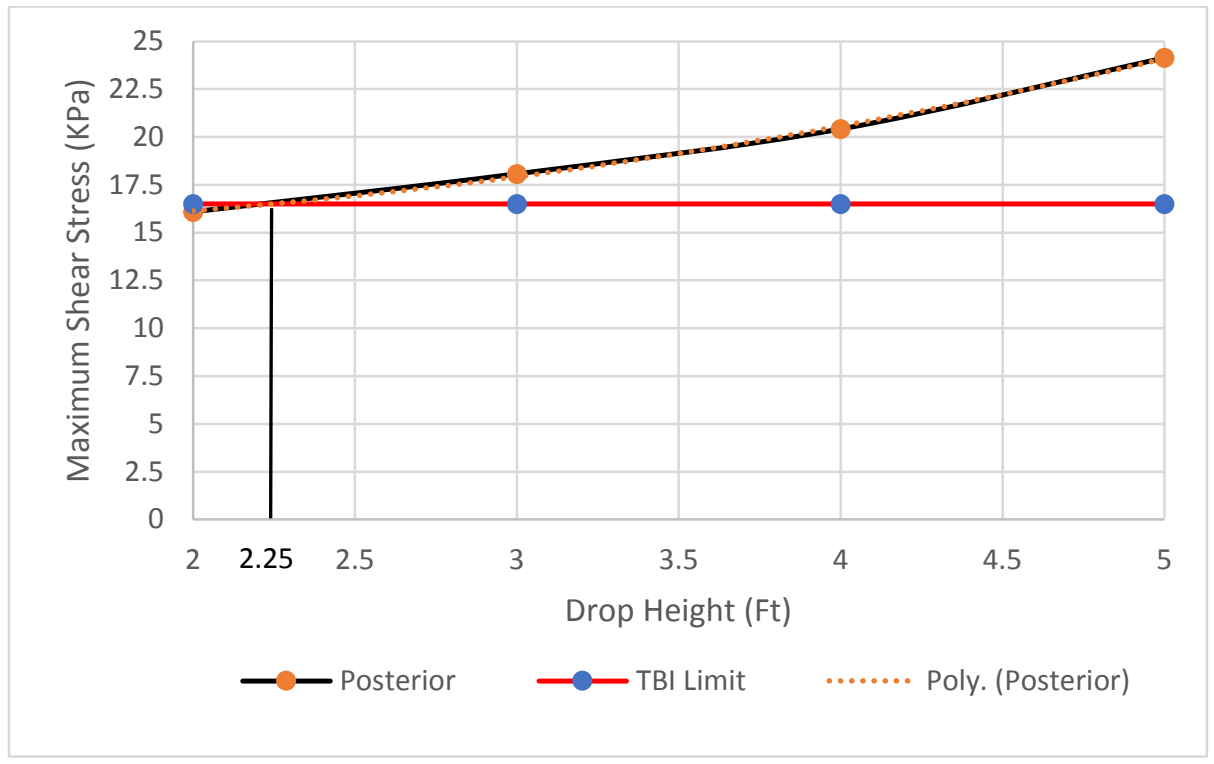

Figure 5.4 Maximum Shear Stress Vs Drop Height for the Posterior Region Impact

The TBI drop height tolerances for the four region of impacts calculated using the Shear stress tolerance for TBI have been tabulated below: 
Table 5.1 Maximum Shear Stress on Brain and TBI Tolerance Drop Heights for the respective regions of Impact

\begin{tabular}{|c|c|c|c|c|c|}
\hline & \multicolumn{4}{|c|}{ Region of Impact } & \\
\hline Height (feet) & Frontal & $\begin{array}{l}45 \text { to } \\
\text { Frontal }\end{array}$ & Lateral & Posterior & \\
\hline 2 & 2.759 & 12.808 & 15.574 & 16.089 & \multirow{4}{*}{ 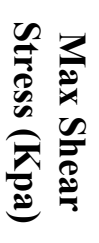 } \\
\hline 3 & 2.827 & 15.871 & 18.136 & 18.074 & \\
\hline 4 & 3.093 & 17.54 & 18.625 & 20.417 & \\
\hline 5 & 3.52 & 18.963 & 22.793 & 24.135 & \\
\hline $\begin{array}{c}\text { TBI Tolerance } \\
\text { Height }\end{array}$ & -- & 3.35 & 2.52 & 2.25 & \\
\hline $\begin{array}{c}\text { Linear } \\
\text { Acceleration (G) }\end{array}$ & -- & 125 & 138.67 & 129.14 & \\
\hline
\end{tabular}

The following observations can be made from the Table 5.1

It should be noted that the above Tolerance heights are for TBI due to shear stress which is majorly due to the rotation of head during the impact.

- In the Frontal region it can be noted that the shear stress values are much below the tolerance level. Hence the risk of a TBI due to shear stress is minimal in this region. It can also be inferred as the effect of angular acceleration is minimal in this region which has already been discussed in earlier chapters. The higher Area of impacts and lower HICP can also be the other reasons.

- In the $45^{\circ}$ to Frontal region the TBI tolerance for linear acceleration due to shear stress is the TBI tolerance drop height due to shear stress is 3.35 feet $(125 \mathrm{G})$. It is higher than that of the lateral and posterior regions. Although it has same Pressure range as the posterior region, smaller area of Impact and smaller range of linear accelerations can be a 
reason for an increase in the tolerance height. Hence it can be inferred that the angular acceleration has some role to play in causing TBI's in this region.

- In lateral region the tolerance for TBI due to shear stress is 2.52 feet $(138.67 \mathrm{G})$.

Although this region has higher range of pressures on the brain, the presence of higher area of impact can be a factor in higher tolerance limit than that of the posterior region as both the lateral and posterior regions have their linear accelerations distributed over the same range. Hence it can be deducted that the Area of Impact plays an important role in Height tolerance value for TBI due to shear stress. Higher the area lower the shear stress values and higher the tolerance limit. It can also be inferred that angular acceleration has an important role for TBI in this region.

- In Posterior region the tolerance for TBI due to shear stress is 2.25 feet $(129.14 \mathrm{G})$ which is lowest of all regions. It can be because of higher von Mises stresses, higher HICP and lower surface areas. It can also be observed that there is some discrepancies in the measurements in FE Analysis which also might have modified the results.

\subsection{Determination of TBI Tolerance drop height using Linear Accelerations}

The research in this area has been done by our research group following the criteria by Anna and group [23] and the following results have been generated by Chandrika S Abhang and have been documented in her work [24].

Table 5.2 Drop Height tolerance for TBI caused by Linear Acceleration [25]

\begin{tabular}{|c|c|}
\hline Region & $\begin{array}{c}\text { TBI Tolerance } \\
\text { Drop Height (feet) }\end{array}$ \\
\hline Front & 3.125 \\
\hline 45-to-Frontal & 4.25 \\
\hline Lateral & 2.625 \\
\hline Posterior & 2.825 \\
\hline
\end{tabular}


The above table shows the tolerance limit for the drop height for TBI caused by linear acceleration. It follows the similar profile as of the Principal stress. Higher the principal stress lower the TBI tolerance drop height limit.

\subsection{TBI Criteria}

Considering the drop height tolerances from Maximum Shear stress and Maximum Linear acceleration, the TBI can happen either because of the two cases or at least by any one of them. Hence the minimal of the two cases will be used to study injuries on the brain and to determine the tolerance limits for TBI. The Drop height tolerance level to cause TBI is tabulated below.

Table 5.3 Drop Height tolerance for TBI for respective regions of Impact

\begin{tabular}{|c|c|}
\hline Region & $\begin{array}{c}\text { TBI Tolerance } \\
\text { Drop Height (feet) }\end{array}$ \\
\hline Front & 3.125 \\
\hline 45-to-Frontal & 3.35 \\
\hline Lateral & 2.52 \\
\hline Posterior & $\mathbf{2 . 2 5}$ \\
\hline
\end{tabular}

It can be observed that unlike Frontal and 45 to Frontal, the TBI tolerance drop height is similar for Lateral and posterior regions which have major risk of TBI's.

The above values will be used to calculate the TBI Tolerance limits for von Mises, Maximum Principal Stress, from the plots drawn in earlier chapters. 


\subsubsection{Frontal region of Impact}

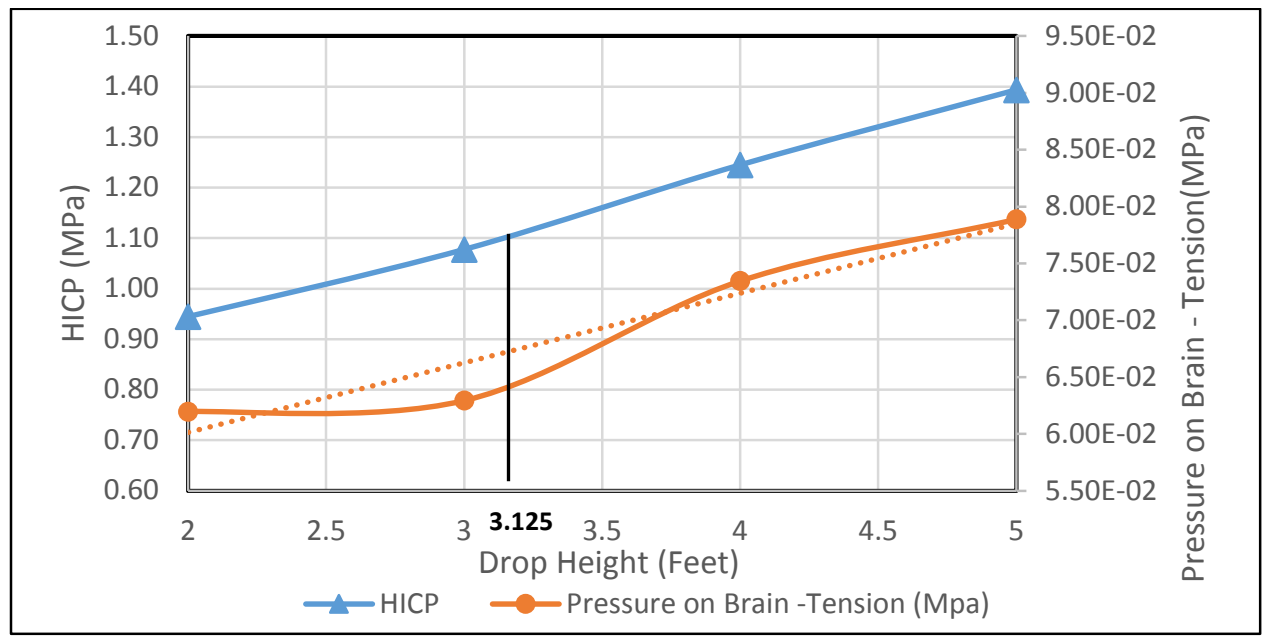

Figure 5.5 Linear TBI tolerance for HICP and Pressure on Brain Located on plot of Comparison of

Pressure on Brain and HICP during Frontal Impact.

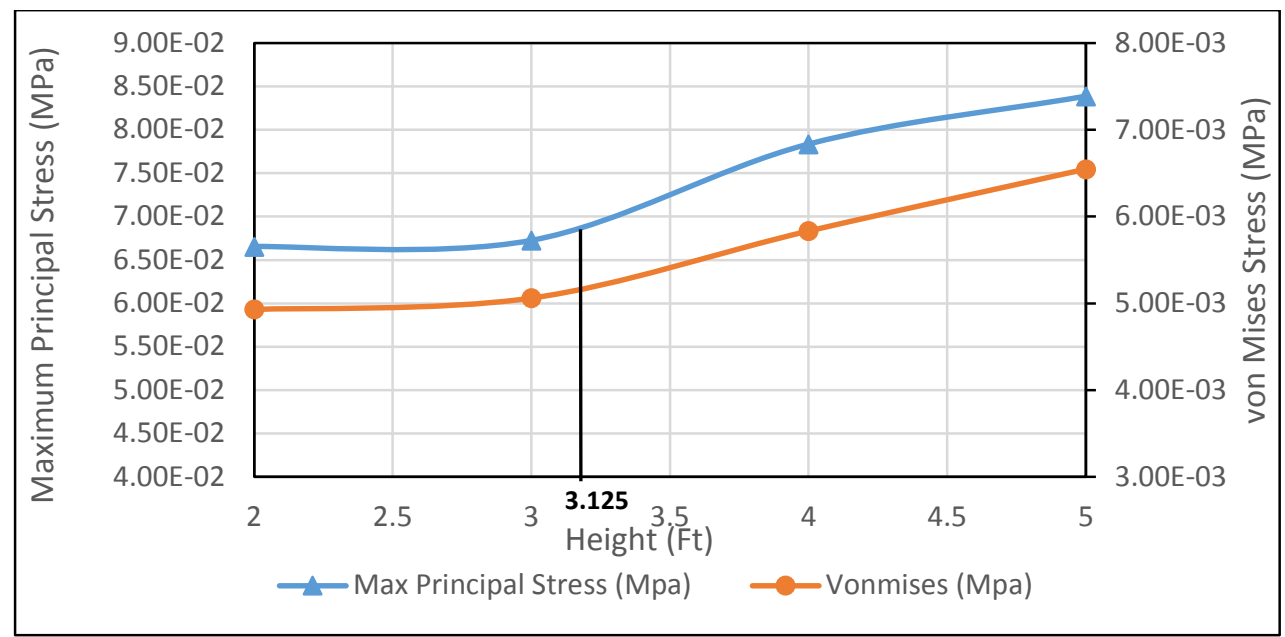

Figure 5.6 Linear TBI tolerance for Maximum Principal Stress and von Mises stress located on plot of Comparison of Maximum Principal stress and von Mises stress during Frontal Impact. 


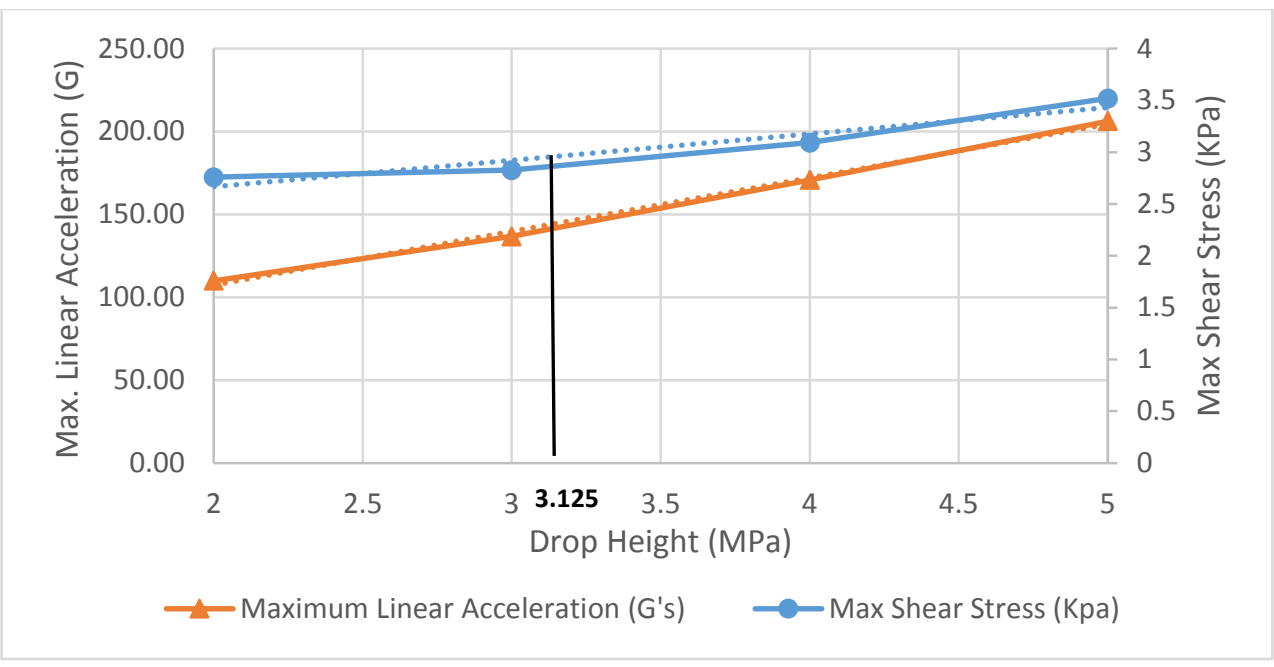

Figure 5.7 Plot for Variation of Max. Linear Acceleration \& Shear stress Vs height for frontal impact

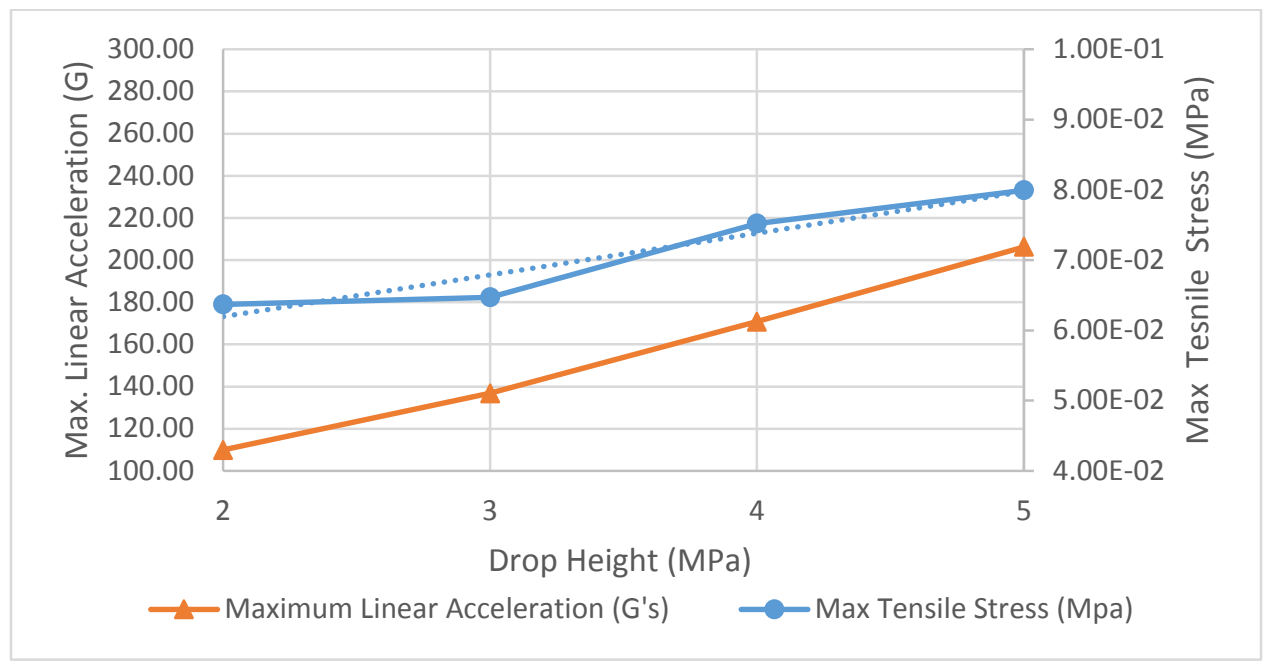

Figure 5.8 Plot for Variation of Max. Linear Acceleration \& Normal stress Vs height for frontal impact 


\subsection{2 $45^{\circ}$ to Frontal region of impact}

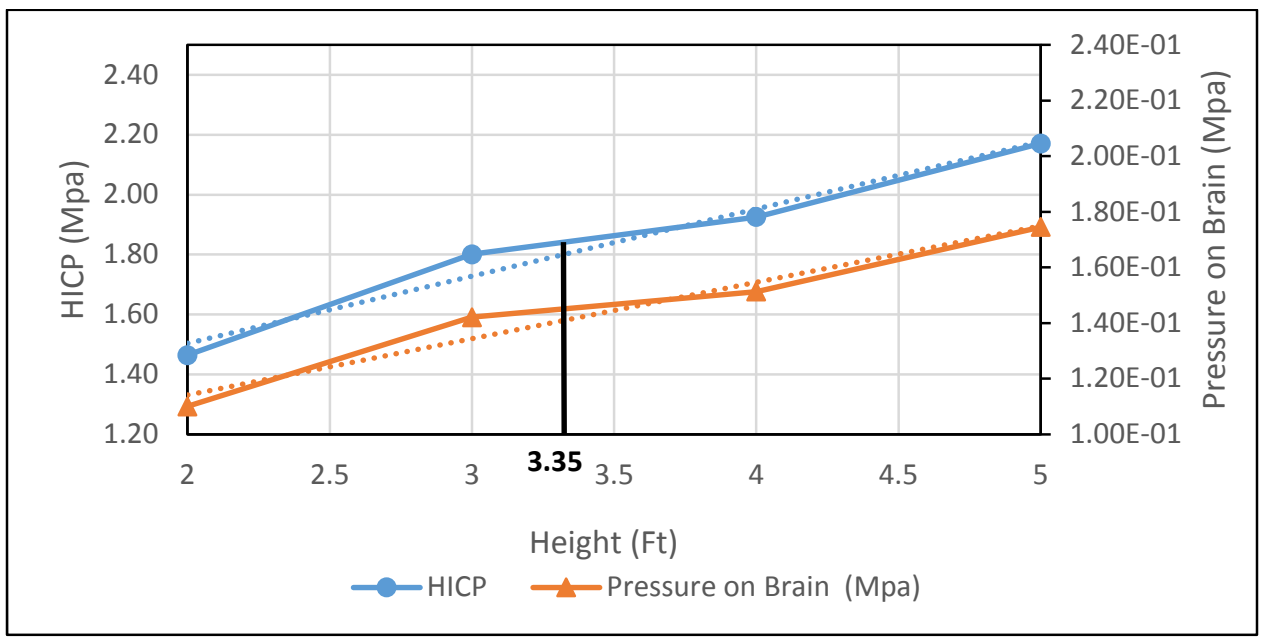

Figure 5.9 Linear TBI tolerance for HICP and Pressure on Brain Located on plot of Comparison of Pressure on Brain and HICP during 45 to Frontal Impact

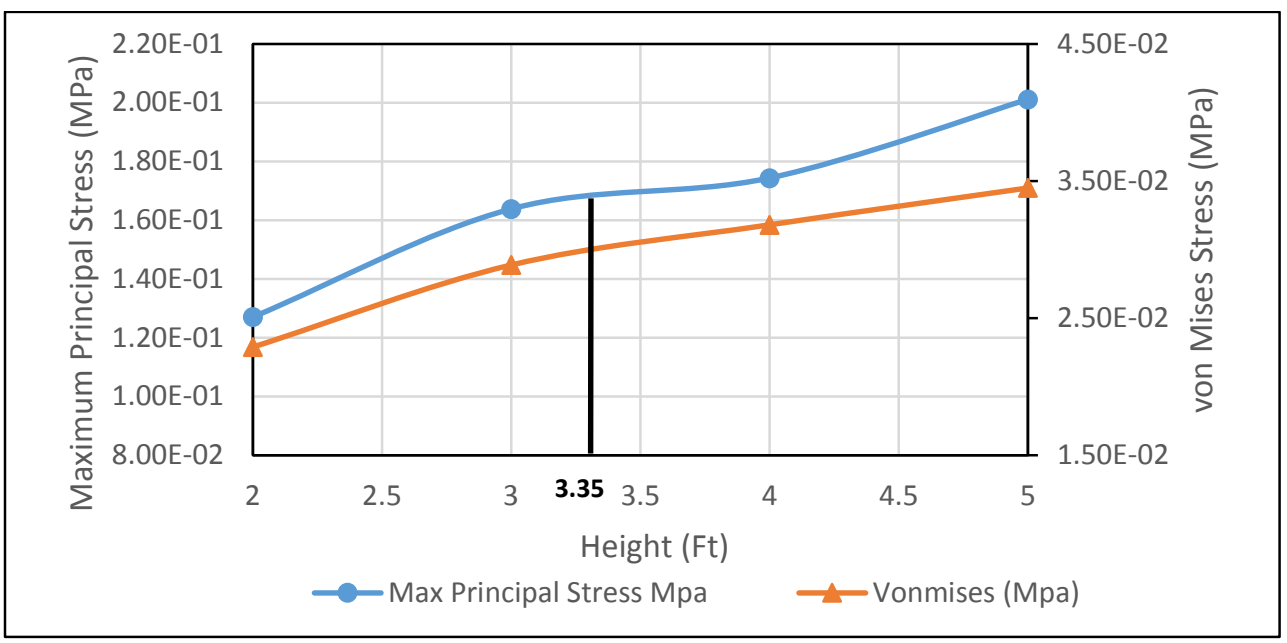

Figure 5.10 Linear TBI tolerance for Maximum Principal Stress and von Mises stress located on plot of Comparison of Maximum Principal stress and von Mises stress during 45 to Frontal Impact 


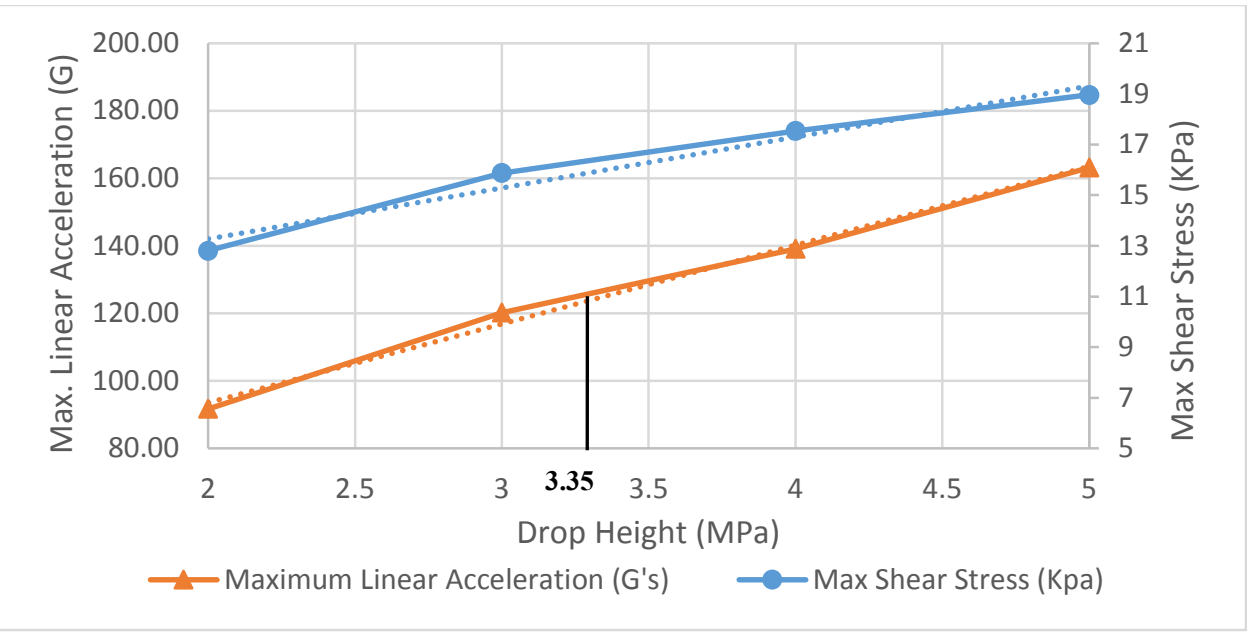

Figure 5.11 Plot for Variation of Max. Linear Acceleration \& Shear stress Vs height for 45 to frontal impact

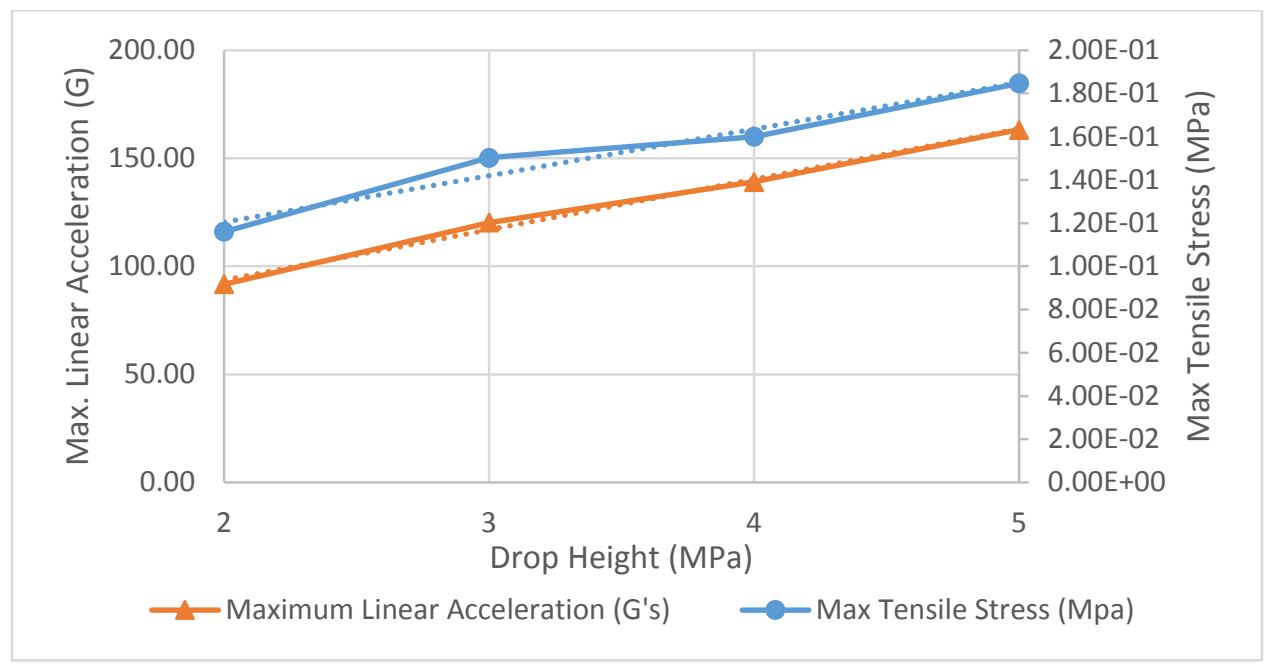

Figure 5.12 Plot for Variation of Max. Linear Acceleration \& Tensile stress Vs height for 45 to frontal impact. 


\subsubsection{Lateral region of impact}

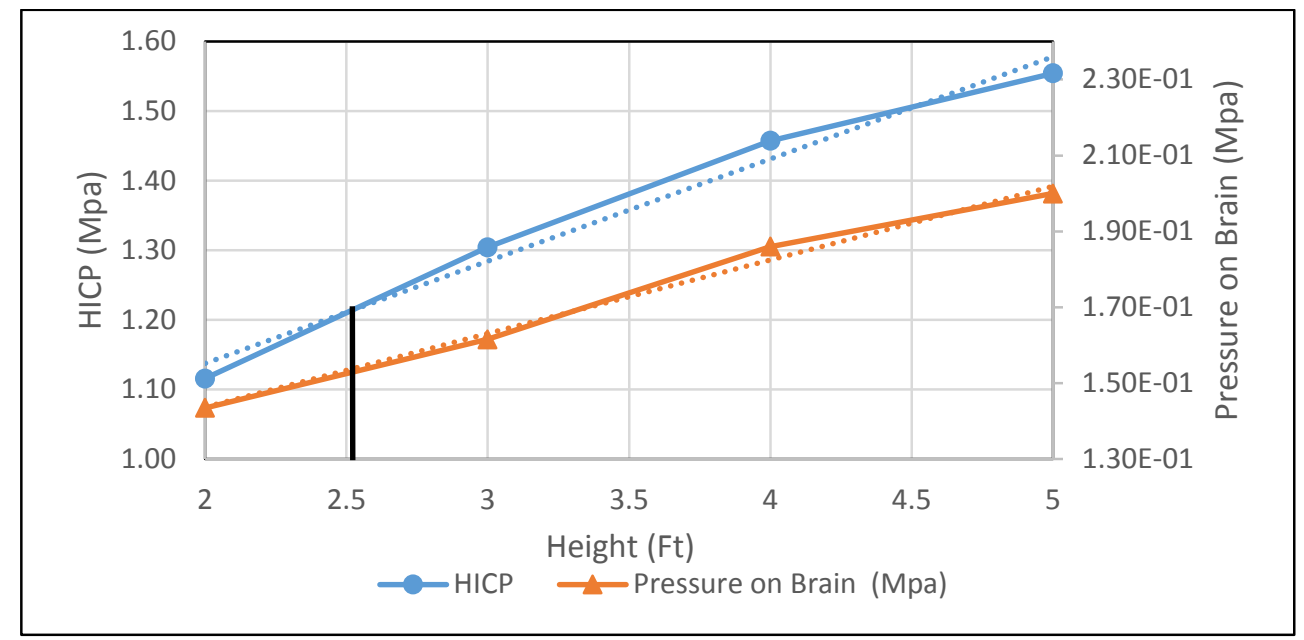

Figure 5.13 Linear TBI tolerance for HICP and Pressure on Brain Located on plot of Comparison of Pressure on Brain and HICP during Lateral Impact

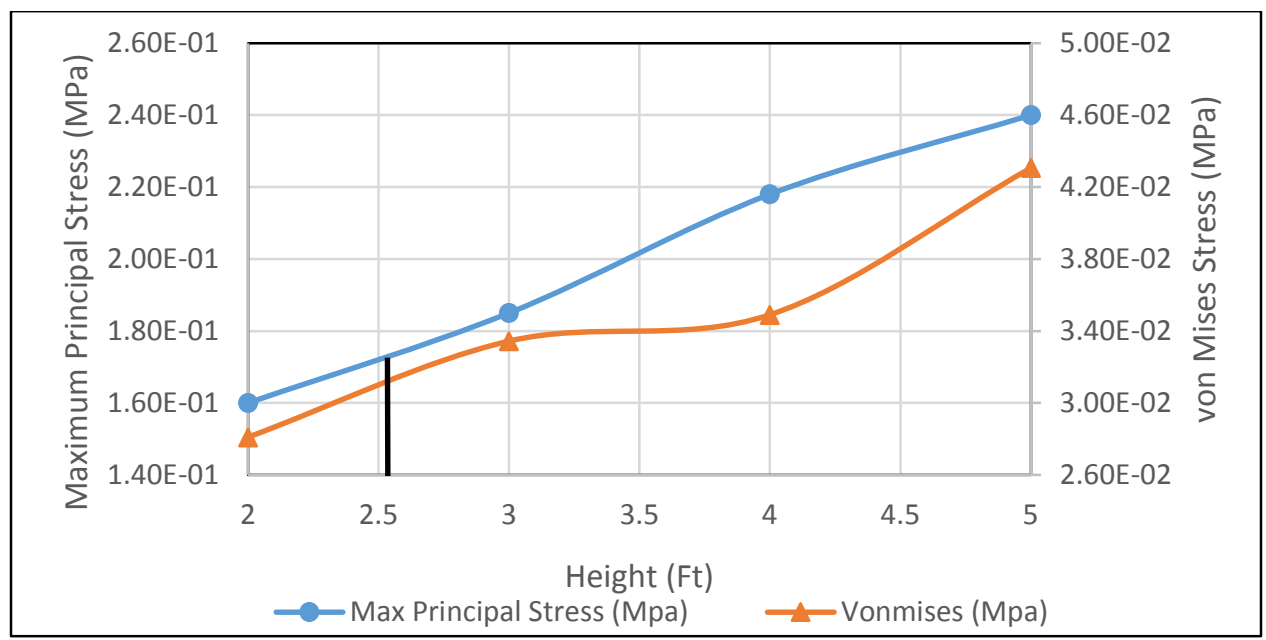

Figure 5.14 Linear TBI tolerance for Maximum Principal Stress and von Mises stress located on plot of Comparison of Maximum Principal stress and von Mises stress during Lateral Impact. 


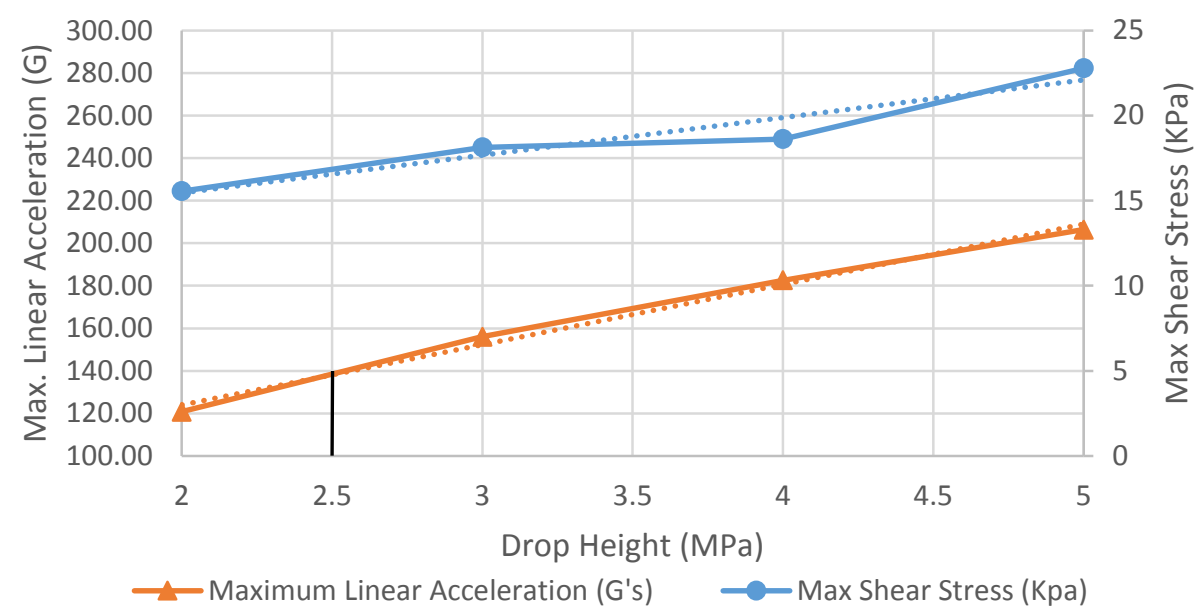

Figure 5.15 Plot for Variation of Max. Linear Acceleration \& Shear stress Vs height for lateral impact

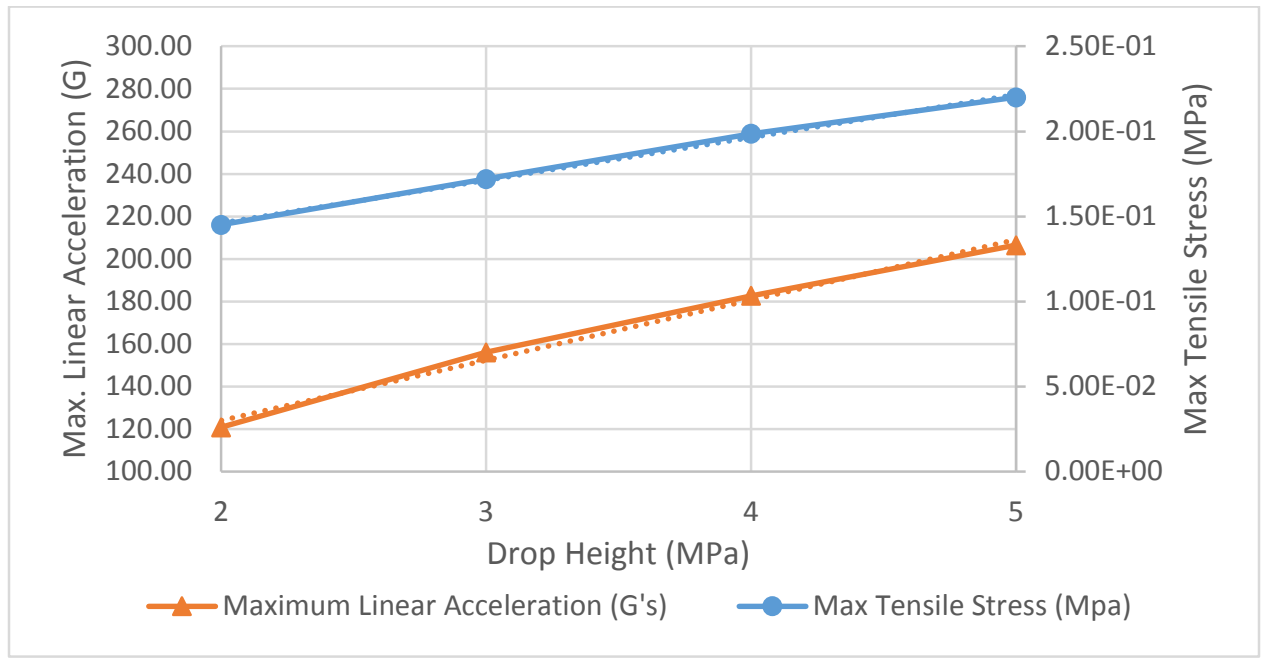

Figure 5.16 Plot for Variation of Max. Linear Acceleration \& Tensile stress Vs Height for Lateral impact 


\subsubsection{Posterior region of impact}

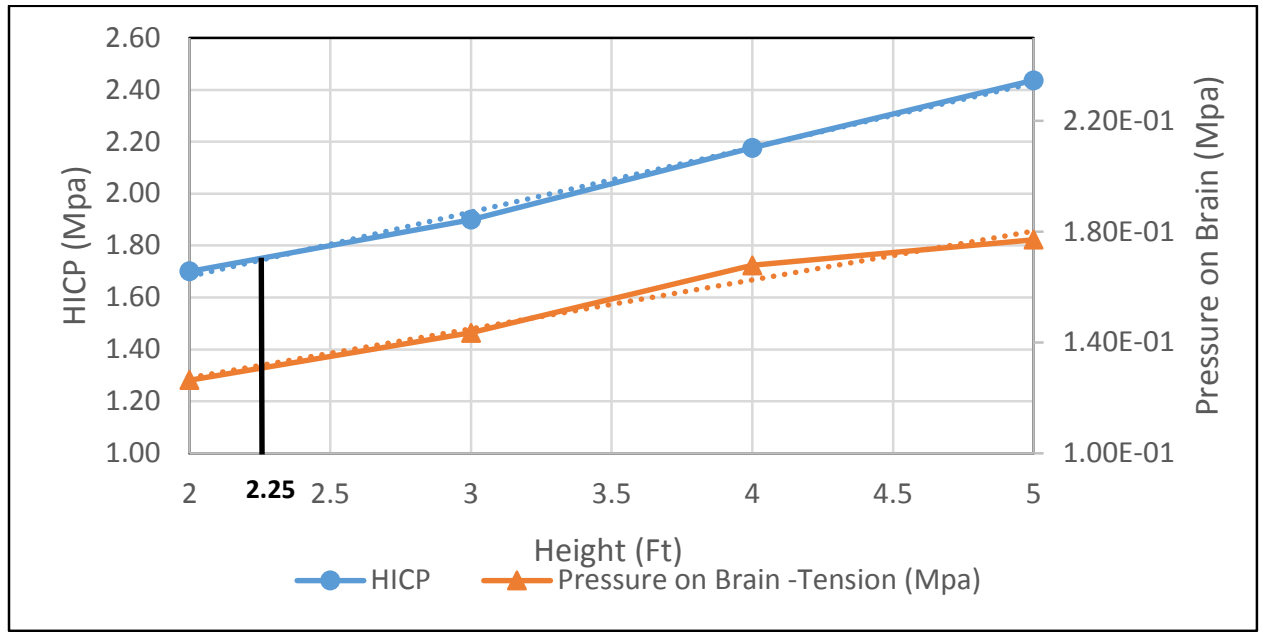

Figure 5. 17 Linear TBI tolerance for HICP and Pressure on Brain Located on plot of Comparison of Pressure on Brain and HICP during Posterior Impact

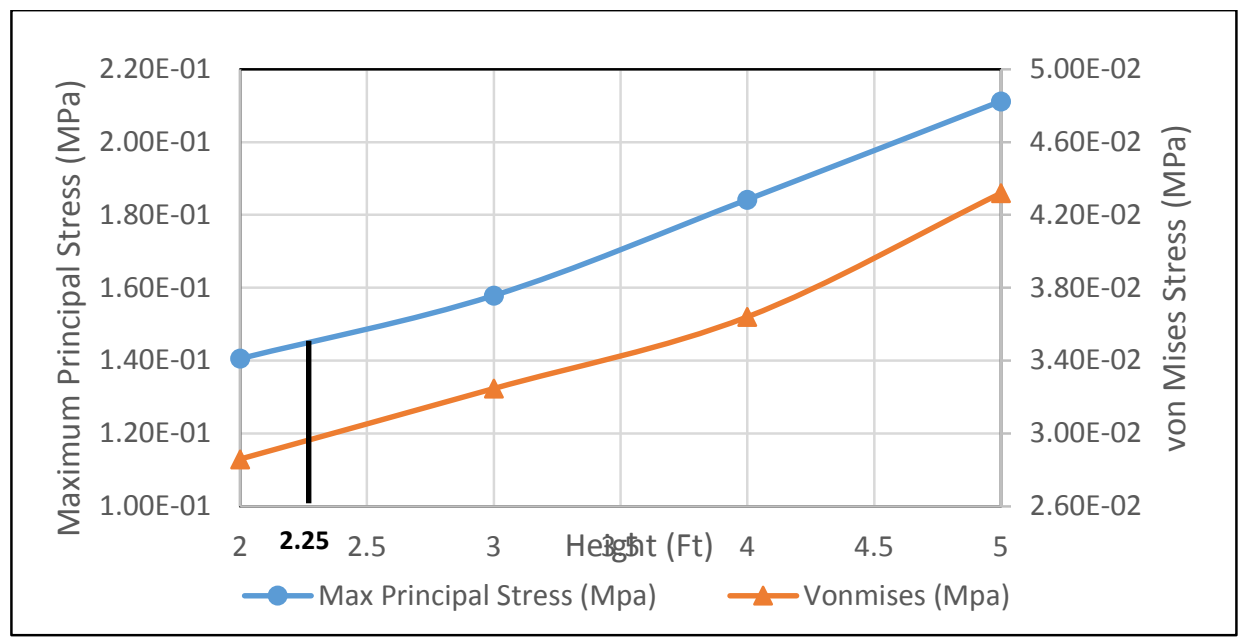

Figure 5.18 Linear TBI tolerance for Maximum Principal Stress and von Mises stress located on plot of Comparison of Maximum Principal stress and von Mises stress during Posterior Impact. 


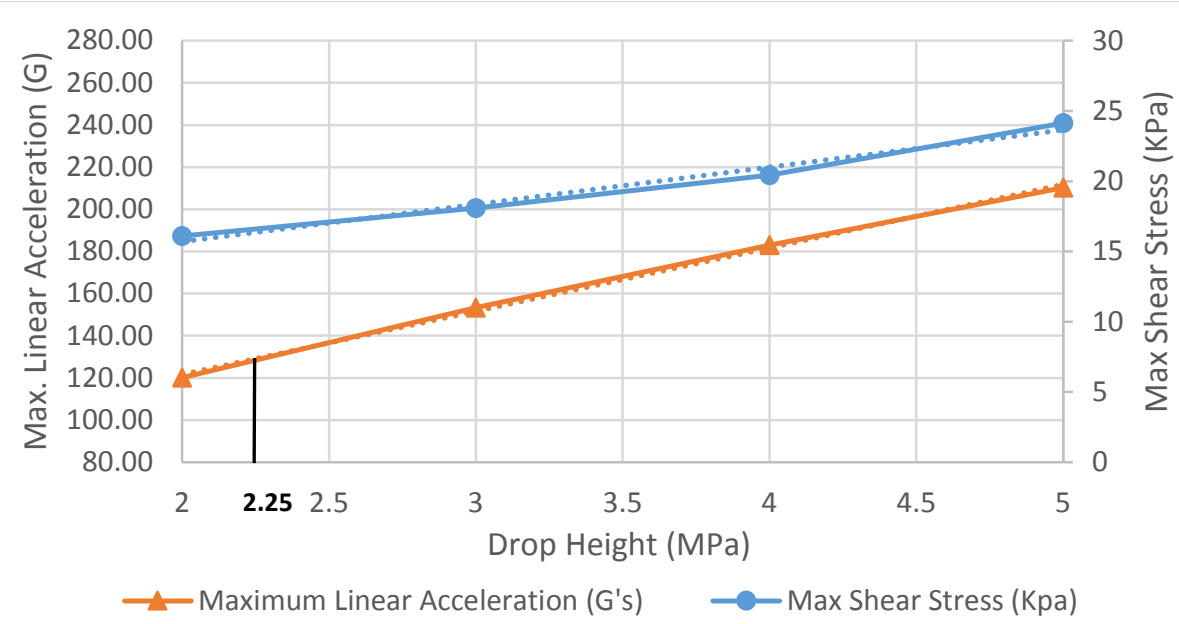

Figure 5.19 Plot for Variation of Max. Linear Acceleration \& Shear stress Vs height for Posterior impact

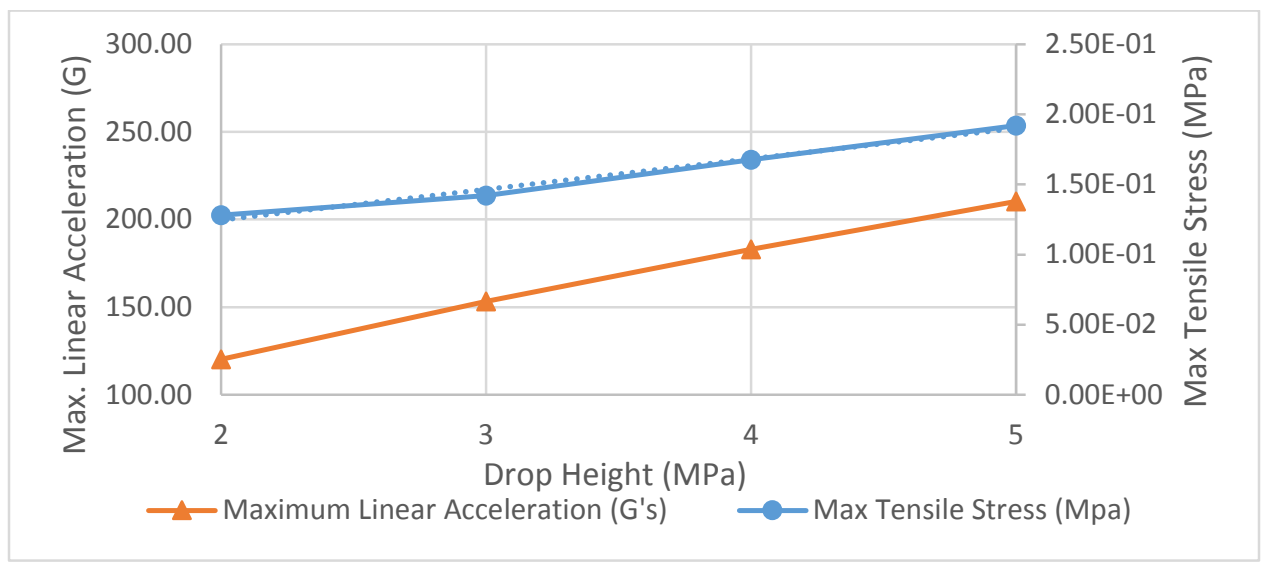

Figure 5.20 Plot for Variation of Max. Linear Acceleration \& Tensile stress Vs height for Posterior impact

Perpendiculars have been drawn from the TBI Tolerance heights from the X-axis on to the plots and the plots are approximated to be curves which are derived from the curve fittings and corresponding tolerance values for HICP, Pressure on Brain, Linear acceleration, Maximum principal stress and von Mises stress have been extracted and tabulated below. 
Table 5.4 TBI Tolerance Limits for different regions of Impact

\begin{tabular}{|c|c|c|c|c|c|c|}
\cline { 2 - 7 } \multicolumn{1}{c|}{} & \multicolumn{7}{c|}{ TBI Tolerance Limits (MPa) } \\
\hline Region & $\begin{array}{c}\text { Drop } \\
\text { Height } \\
\text { (feet) }\end{array}$ & $\begin{array}{c}\text { Max Linear } \\
\text { Acceleration } \\
(\mathbf{G})\end{array}$ & $\begin{array}{c}\text { HICP } \\
\mathbf{( M P a )}\end{array}$ & $\begin{array}{c}\text { Pressure on } \\
\text { Brain } \\
\mathbf{( M P a )}\end{array}$ & $\begin{array}{c}\text { Maximum } \\
\text { Principal } \\
\text { Stress } \\
\mathbf{( M P a}\end{array}$ & $\begin{array}{c}\text { von } \\
\text { Mises } \\
\text { Stress } \\
\text { (MPa) }\end{array}$ \\
\hline Frontal & 3.125 & 143.83 & 1.11 & $6.72 \mathrm{E}-02$ & $7.16 \mathrm{E}-02$ & $5.1 \mathrm{E}-03$ \\
\hline $\begin{array}{c}\mathbf{4 5} \text { to } \\
\text { Frontal }\end{array}$ & 3.35 & 125 & 1.80 & $1.42 \mathrm{E}-01$ & $1.63 \mathrm{E}-01$ & $3.04 \mathrm{E}-02$ \\
\hline Lateral & 2.52 & 138.67 & 1.21 & $1.54 \mathrm{E}-01$ & $1.74 \mathrm{E}-01$ & $3.01 \mathrm{E}-02$ \\
\hline Posterior & 2.25 & 129.14 & 1.74 & $1.32 \mathrm{E}-01$ & $1.44 \mathrm{E}-01$ & $2.94 \mathrm{E}-02$ \\
\hline
\end{tabular}

The following observations can be made from the table 5.4:

- As the HICP and the other corresponding values for a given height is lesser for the frontal region when compared to other regions, the tolerance limits for this region are pretty high when compared to other region. Hence higher drop heights but lower Pressures and stresses are capable of causing TBI in this region but it can be observed that most of the impact is not transferred to the brain in this region making this region safer when compared to other regions of impact. For example 3 feet drop generate a stress of $0.067 \mathrm{MPa}$ in this region while Lateral region generate a stress of $0.174 \mathrm{MPa}$ for just 2.5 feet. The drops below 3 feet are in the tolerance level while the drops higher than 3 feet might cause TBI's.

- For a given height, 45 to frontal have higher tolerance values for TBI's followed by frontal region of Impact. The drops below 3 feet are safe while 4 feet and 5 feet drops can cause TBI's. The 3.35 feet drop generates a stress of $0.164 \mathrm{MPa}$ on brain for 3.35 feet while similar amount of $0.174 \mathrm{MPa}$ can be generated for just 2.5 feet. Hence drops below 3 feet are safer in this region while the same might cause TBI's in other regions like Lateral and Posterior. 
- For a given height the tolerance levels for the Lateral region are pretty lower when compared to other 3 regions. The drops below 2 feet are safe while the drops above this height might cause TBI. The highest values of von Mises stresses (0.03 MPa) and Maximum Principal Stress (0.174 MPa) are observed in this region for a lower height of 2.52 feet drop making this region more susceptible to injuries than the other regions.

- For a given drop height the tolerance levels of principal stress for the posterior regions are lower after lateral region. A mere drop at 2.25 feet produces a stress of $0.144 \mathrm{MPa}$. The drops under 2 feet are safe while the drops above 2 feet might cause TBI's. The presence of cerebellum and spinal cord makes this region pretty sensitive to injury. - The highest value of TBI tolerance for the acceleration is observed for frontal region with $143.83 \mathrm{G}$ for a drop height of 3.125 feet, while the lowest tolerance is $125 \mathrm{G}$ for a drop height of 3.35 feet for 45 to frontal region. But when observed along with drop height the a higher TBI tolerance acceleration of $138.67 \mathrm{G}$ is observed for a mere height of 2.52 feet, making this region more susceptible to injury, while for 45 to frontal region the tolerance value is around $125 \mathrm{G}$ even for a height of 3.35 feet making this region less susceptible to TBI when compared to other regions.

The above observations can be consolidated as the following table.

Table 5.5 Safety criteria for drops in respective region using the TBI Tolerance values from table 5.4

\begin{tabular}{|c|c|c|c|c|}
\cline { 2 - 5 } \multicolumn{1}{c|}{} & \multicolumn{4}{c|}{ Drop Height (feet) } \\
\hline Region & $\mathbf{2}$ & $\mathbf{3}$ & $\mathbf{4}$ & $\mathbf{5}$ \\
\hline Frontal & Safe & Safe & Unsafe & Unsafe \\
\hline $\begin{array}{c}\mathbf{4 5} \text { to } \\
\text { Frontal }\end{array}$ & Safe & Safe & Unsafe & Unsafe \\
\hline Lateral & Safe & Unsafe & Unsafe & Unsafe \\
\hline Posterior & Safe & Unsafe & Unsafe & Unsafe \\
\hline
\end{tabular}




\subsection{Formula Proposition}

From the above observations it is evident that the tolerance values for TBI's is different for different regions. TBI's can be caused either by Maximum Principal Stresses ${ }^{4}$ and von Mises stresses or at least one of them. Hence our research team have proposed a new formula to study the role of von Mises and Principal stress in causing TBI.

$$
\frac{\sigma_{V M-\text { regional }}}{\sigma_{V M-T B I-\max }}+\frac{\sigma_{M P-\text { regional }}}{\sigma_{M P-T B I-\max }} \leq 1 \text { then no TBI }
$$

Where,

$\sigma_{V M-\text { regional }}=$ von Mises stress developed on the brain due to drop or Impact, $\sigma_{V M-T B I-\max }=$ Tolerance value for TBI caused to von Mises Stress for that region of Impact ... (refer Table 5.4)

$\sigma_{M P-\text { regional }}=$ Maximum Principal Stress developed on the brain due to drop or Impact, $\sigma_{M P-T B I-\max }=$ Tolerance value for TBI caused to Maximum Principal Stress for that region ... (refer Table 5.4)

The above formula when utilized in our case yields the following results which are tabulated below

\footnotetext{
${ }^{4}$ As mentioned earlier Maximum principal stress behave similar to the pressure developed on the brain, but more efficient that the later. Hence maximum principal stress are consider for the Formula Generation.
} 
Table 5.6 TBI Stress criterion for Frontal Impact using Eq. 5.1

\begin{tabular}{|c|c|c|c|c|c|c|c|}
\hline $\begin{array}{c}\text { Height } \\
\text { (feet) }\end{array}$ & $\begin{array}{c}\text { Max } \\
\text { Principal } \\
\text { Stress } \\
\text { (Mpa) }\end{array}$ & $\begin{array}{c}\text { TBI } \\
\text { tolerance } \\
\text { for } \\
\text { Principal } \\
\text { Stress } \\
\end{array}$ & $\begin{array}{c}\text { Principal } \\
\text { Stress } \\
\text { Ratio }\end{array}$ & $\begin{array}{l}\text { von } \\
\text { Mises } \\
\text { (Mpa) }\end{array}$ & $\begin{array}{c}\text { TBI } \\
\text { tolerance } \\
\text { for von } \\
\text { Mises } \\
\text { Stress } \\
\end{array}$ & $\begin{array}{c}\text { von } \\
\text { Mises } \\
\text { Stress } \\
\text { Ratio }\end{array}$ & $\begin{array}{c}\text { TBI } \\
\text { Condition } \\
\end{array}$ \\
\hline 2 & $6.65 \mathrm{E}-02$ & \multirow{4}{*}{ 7.16E-02 } & 0.93 & $\begin{array}{r}4.93 \mathrm{E}- \\
03 \\
\end{array}$ & \multirow{4}{*}{$5.10 \mathrm{E}-03$} & 0.97 & 1.90 \\
\hline 3 & $6.72 \mathrm{E}-02$ & & 0.94 & $\begin{array}{r}5.06 \mathrm{E}- \\
03\end{array}$ & & 0.99 & 1.93 \\
\hline 4 & 7.83E-02 & & 1.09 & $\begin{array}{r}5.83 \mathrm{E}- \\
03\end{array}$ & & 1.14 & 2.24 \\
\hline 5 & 8.38E-02 & & 1.17 & $\begin{array}{r}6.55 \mathrm{E}- \\
03\end{array}$ & & 1.28 & 2.45 \\
\hline
\end{tabular}

Table 5.7 TBI Stress criterion for 45 to Frontal Impact using Eq. 5.1

\begin{tabular}{|c|c|c|c|c|c|c|c|}
\hline $\begin{array}{c}\text { Height } \\
\text { (feet) }\end{array}$ & $\begin{array}{c}\text { Max } \\
\text { Principal } \\
\text { Stress } \\
\text { Mpa }\end{array}$ & $\begin{array}{c}\text { TBI } \\
\text { tolerance } \\
\text { for } \\
\text { Principal } \\
\text { Stress } \\
\end{array}$ & $\begin{array}{c}\text { Principal } \\
\text { Stress } \\
\text { Ratio }\end{array}$ & $\begin{array}{l}\text { von } \\
\text { Mises } \\
\text { (Mpa) }\end{array}$ & $\begin{array}{c}\text { TBI } \\
\text { tolerance } \\
\text { for von } \\
\text { Mises } \\
\text { Stress } \\
\end{array}$ & $\begin{array}{l}\text { von } \\
\text { Mises } \\
\text { Stress } \\
\text { Ratio }\end{array}$ & $\begin{array}{c}\text { TBI } \\
\text { Condition } \\
\end{array}$ \\
\hline 2 & $1.27 \mathrm{E}-01$ & \multirow{4}{*}{$1.63 \mathrm{E}-01$} & 0.78 & $2.29 \mathrm{E}-02$ & \multirow{4}{*}{$3.04 \mathrm{E}-02$} & 0.75 & 1.53 \\
\hline 3 & $1.64 \mathrm{E}-01$ & & 1.00 & $2.89 \mathrm{E}-02$ & & 0.95 & 1.95 \\
\hline 4 & $1.74 \mathrm{E}-01$ & & 1.07 & $3.18 \mathrm{E}-02$ & & 1.05 & 2.12 \\
\hline 5 & $2.01 \mathrm{E}-01$ & & 1.23 & $3.45 \mathrm{E}-02$ & & 1.14 & 2.37 \\
\hline
\end{tabular}

Table 5.8 TBI Stress criterion for Lateral Impact using Eq. 5.1

\begin{tabular}{|c|c|c|c|c|c|c|c|}
\hline $\begin{array}{c}\text { Height } \\
\text { (feet) }\end{array}$ & $\begin{array}{c}\text { Max } \\
\text { Principal } \\
\text { Stress } \\
\text { (Mpa) }\end{array}$ & $\begin{array}{c}\text { TBI } \\
\text { tolerance } \\
\text { for } \\
\text { Principal } \\
\text { Stress }\end{array}$ & $\begin{array}{c}\text { Principal } \\
\text { Stress } \\
\text { Ratio }\end{array}$ & $\begin{array}{l}\text { von } \\
\text { Mises } \\
\text { (Mpa) }\end{array}$ & $\begin{array}{c}\text { TBI } \\
\text { tolerance } \\
\text { for von } \\
\text { Mises } \\
\text { Stress }\end{array}$ & $\begin{array}{l}\text { von } \\
\text { Mises } \\
\text { Stress } \\
\text { Ratio }\end{array}$ & $\begin{array}{c}\text { TBI } \\
\text { Condition }\end{array}$ \\
\hline 2 & $1.60 \mathrm{E}-01$ & \multirow{4}{*}{$1.74 \mathrm{E}-01$} & 0.92 & $2.81 \mathrm{E}-02$ & \multirow{4}{*}{$3.01 \mathrm{E}-02$} & 0.93 & 1.85 \\
\hline 3 & $1.85 \mathrm{E}-01$ & & 1.06 & $3.34 \mathrm{E}-02$ & & 1.11 & 2.17 \\
\hline 4 & $2.18 \mathrm{E}-01$ & & 1.25 & $3.49 \mathrm{E}-02$ & & 1.16 & 2.41 \\
\hline 5 & $2.40 \mathrm{E}-01$ & & 1.38 & $4.31 \mathrm{E}-02$ & & 1.43 & 2.81 \\
\hline
\end{tabular}


Table 5.9 TBI Stress criterion for Posterior Impact using Eq. 5.1

\begin{tabular}{|c|c|c|c|c|c|c|c|}
\hline $\begin{array}{c}\text { Height } \\
\text { (feet) }\end{array}$ & $\begin{array}{c}\text { Max } \\
\text { Principal } \\
\text { Stress } \\
\text { (Mpa) }\end{array}$ & $\begin{array}{c}\text { TBI } \\
\text { tolerance } \\
\text { for } \\
\text { Principal } \\
\text { Stress } \\
\end{array}$ & $\begin{array}{c}\text { Principal } \\
\text { Stress } \\
\text { Ratio }\end{array}$ & $\begin{array}{l}\text { von } \\
\text { Mises } \\
\text { (Mpa) }\end{array}$ & $\begin{array}{c}\text { TBI } \\
\text { tolerance } \\
\text { for von } \\
\text { Mises } \\
\text { Stress } \\
\end{array}$ & $\begin{array}{c}\text { von } \\
\text { Mises } \\
\text { Stress } \\
\text { Ratio }\end{array}$ & $\begin{array}{c}\text { TBI } \\
\text { Condition } \\
\end{array}$ \\
\hline 2 & $1.41 \mathrm{E}-01$ & \multirow{4}{*}{$1.44 \mathrm{E}-01$} & 0.98 & $2.86 \mathrm{E}-02$ & \multirow{4}{*}{$2.94 \mathrm{E}-02$} & 0.97 & 1.95 \\
\hline 3 & $1.58 \mathrm{E}-01$ & & 1.10 & $3.25 \mathrm{E}-02$ & & 1.11 & 2.21 \\
\hline 4 & $1.84 \mathrm{E}-01$ & & 1.28 & $3.64 \mathrm{E}-02$ & & 1.24 & 2.52 \\
\hline 5 & $2.11 \mathrm{E}-01$ & & 1.47 & 4.32E-02 & & 1.47 & 2.94 \\
\hline
\end{tabular}

The above proposed formula should be considered only when either of $\frac{\sigma_{V M-r e g i o n a l}}{\sigma_{V M-T B I-\max }}$ or $\frac{\sigma_{M P-\text { regional }}}{\sigma_{M P-T B I-\max }}$ is less than 1. For example consider the Impact for a drop height of 2 feet at 45 to Frontal the TBI tolerance ratio for principal stress is 0.78 and the TBI tolerance ratio for the von Mises stress is 0.75 . Although it may seem that the von Mises and Principal stresses don't cause ant TBI individually, but when considered together its sum is greater than 1 implying that there is a sufficient chance of TBI in this region for 2 feet drop in 45 to frontal region.

Hence it is evident that although the individual effect Principal Stress or von Mises Stress might occur as if they won't cause any TBI, but in reality their effect as an entity together might cause TBI. 


\section{Chapter 6}

\section{Conclusions and Recommendations}

\subsection{Conclusions}

In this study Kinematics of the head were studied by conducting experiments using a Hybrid Dummy Head form and the HICP developed due to free fall from different heights has been used as an input to a 3-D FE model to study the kinetics of the brain and based upon the shear stress criteria by Ward [3], the TBI tolerances heights were obtained which were used in conjunction with the TBI drop heights obtained from the work of Chandrika Abhang[25] which used Anna[24] criteria, based on accelerations to obtain TBI tolerance drop heights. The above results were used to calculate the TBI tolerance values for linear acceleration, Principal stresses and von Mises stresses. The response of the brain to an input of HICP was also studied and the following observations were made:

- TBI's are highly dependent on the site of Impact. Criteria for Linear acceleration which cause TBI differ from region to region. A HICP which is safe in a particular region might cause serious injury when applied in another region.

- The rotation of head which implies presence of angular accelerations is observed more in Lateral and 45 to Frontal regions when compared to Frontal and Posterior regions.

- The Tensile stresses, pressure on the brain and maximum principal stresses were almost similar hence principal stress values were used in formula proposition for determining a TBI. The tensile stress and pressure travel in the similar manner while the principal stress travels in opposite direction of above two. 
- Shear stress plays a major role in causing TBI if von Mises stress is not dominant in that region.

- von Mises stresses gives a better idea about the angular acceleration of head during impact than shear stresses, hence they were also used in formula proposition for determining a risk of TBI.

- Area of Impact also plays an important role in determination of TBI tolerance limits due to shear stress. Higher the area, lower the shear stress values and higher the tolerance limit. -A new formula has been proposed to determine the risk of TBI in a particular region due to free fall

$$
\frac{\sigma_{V M-\text { regional }}}{\sigma_{V M-T B I-\max }}+\frac{\sigma_{M P-\text { regional }}}{\sigma_{M P-T B I-\max }} \leq 1 \text { then no TBI }
$$

Where,

$\sigma_{V M-\text { regional }}=$ von Mises stress developed on the brain due to drop or Impact,

$\sigma_{V M-T B I-\max }=$ Tolerance value for TBI caused to von Mises Stress for that region of Impact

$\sigma_{M P-\text { regional }}=$ Maximum Principal Stress developed on the brain due to drop or Impact, $\sigma_{M P-T B I-\max }=$ Tolerance value for TBI caused to Maximum Principal Stress for that region

Where $\frac{\sigma_{V M-\text { regional }}}{\sigma_{V M-T B I-\max }}$ accounts for the angular acceleration of head during impact and $\frac{\sigma_{M P-\text { regional }}}{\sigma_{M P-T B I-\max }}$ accounts for the linear component. Hence it can be inferred that angular acceleration component in additional to linear acceleration component plays an important role in causing a TBI. 
- Although when considered individually, Principal Stress or von Mises Stress might be below the tolerance level and can be mistaken for no risk of TBI, but in reality their effect as an entity together might increase the risk of TBI.

- The lateral region is much susceptible for a TBI followed by posterior, while the chances of injury for a given HICP is lesser for Frontal region.

- The TBI Tolerance limits have been tabulated below

Table 6.1 TBI Tolerance Limits for respective regions of Impact

\begin{tabular}{|c|c|c|c|c|c|c|}
\cline { 2 - 7 } \multicolumn{1}{c|}{} & \multicolumn{7}{c|}{ TBI Tolerance Limits } \\
\hline Region & $\begin{array}{c}\text { Drop } \\
\text { Height } \\
\text { (feet) }\end{array}$ & $\begin{array}{c}\text { Max Linear } \\
\text { Acceleration } \\
(\mathbf{G})\end{array}$ & $\begin{array}{c}\text { HICP } \\
\mathbf{( M P a )}\end{array}$ & $\begin{array}{c}\text { Pressure on } \\
\text { Brain } \\
\mathbf{( M P a )}\end{array}$ & $\begin{array}{c}\text { Maximum } \\
\text { Principal } \\
\text { Stress } \\
\mathbf{( M P a}\end{array}$ & $\begin{array}{c}\text { von } \\
\text { Mises } \\
\text { Stress } \\
\text { (MPa) }\end{array}$ \\
\hline Frontal & 3.125 & 143.83 & 1.11 & $6.72 \mathrm{E}-02$ & $7.16 \mathrm{E}-02$ & $5.1 \mathrm{E}-03$ \\
\hline $\begin{array}{c}\mathbf{4 5} \text { to } \\
\text { Frontal }\end{array}$ & 3.35 & 125 & 1.80 & $1.42 \mathrm{E}-01$ & $1.63 \mathrm{E}-01$ & $3.04 \mathrm{E}-02$ \\
\hline Lateral & 2.52 & 138.67 & 1.21 & $1.54 \mathrm{E}-01$ & $1.74 \mathrm{E}-01$ & $3.01 \mathrm{E}-02$ \\
\hline Posterior & 2.25 & 129.14 & 1.74 & $1.32 \mathrm{E}-01$ & $1.44 \mathrm{E}-01$ & $2.94 \mathrm{E}-02$ \\
\hline
\end{tabular}




\subsection{Recommendations}

There are several suggestions to improve the quality of study to obtain a detail response of brain under applied HICP on head. The following suggestions can be helpful for future research:

- Area of Impact- Proper methods to measure the 3 dimensional area of impact has to be used as it was evident from this study that it plays a major role in Impact pressure calculations and other tolerance values.

- Impact Pressure- The impact pressures which were calculated manually has been used in this study. A proper means to measure the impact pressure during the impact should be followed to validate the pressures for calculating precision tolerances. With more means available to measure the impact pressure being available, the same should be used to precision validation and pressure measurement.

- Pressure Films- New variety of Pressure films are available which are specifically designed for measuring Impact pressures, The drop tests can be repeated with these to get an accurate value of the HICP during Impact.

- Material properties for the head - Update the material properties of the model as new data would be available from latest research.

- Improvisation of Model - The model has some layers of the head missing in it, a developed model with Cerebro Spinal Fluid, separate hemispheres, cerebellum and other minute details such as foldings on the surface of the brain should be prepared, which would give much more precise results.

- Angular Acceleration: As it was evident that the angular accelerations caused due to the rotation of head plays a major role in the TBI, Proper experimental set up has 
to be developed to perform drop tests to record the angular acceleration during impact, and the same can be used as an input to recalculate the more appropriate tolerance value for TBI's.

- A new criteria for determination of TBI using accelerations can be developed.

$$
\frac{a_{\text {Max-regional }}}{a_{T B I}}+\frac{\alpha_{\text {Max-regional }}}{\alpha_{T B I}} \leq 1 \text { then no TBI }
$$

Where,

$a_{\text {Max-regional }}=$ Maximum Linear acceleration in a particular region during impact.

$a_{T B I}=$ Tolerance value of linear acceleration for TBI in that particular region.

$\alpha_{\text {Max-regional }}=$ Maximum angular acceleration in a particular region during impact.

$\alpha_{T B I}=$ Tolerance value of angular acceleration for TBI in that particular region.

- The velocity of fall during impact has been tabulated in earlier sections, proper validation has to be done to propose the TBI tolerance values for velocity.

- Instead of the peak acceleration curve the entire impact curve should be used in FE study to observe the response of brain under application of given pressure on head. 


\section{Appendix A}

The results obtained from the Topaq Analyzer have been shown below

\section{A1 Frontal}

\section{A1.1 Pressure film deformations}

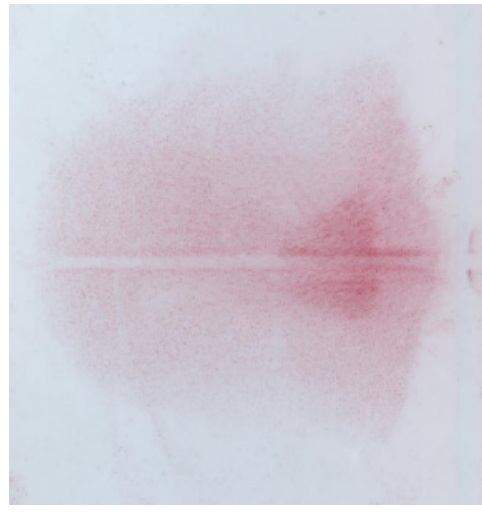

Fig. Al Frontal 3 feet

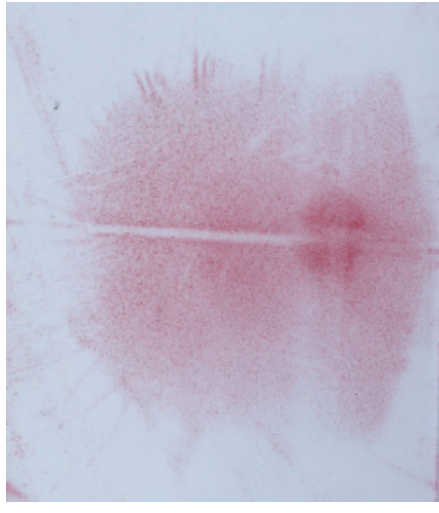

Fig. A3 Frontal 4 feet

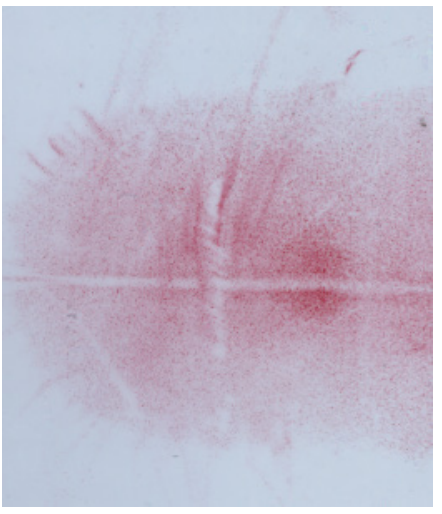

Fig. A2 Frontal 2 Feet

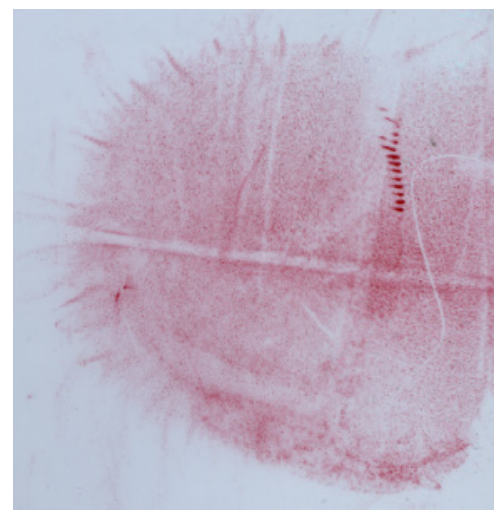

Fig. A4 Frontal 5 Feet 


\section{A1.2 Topaq analyzer Outputs}

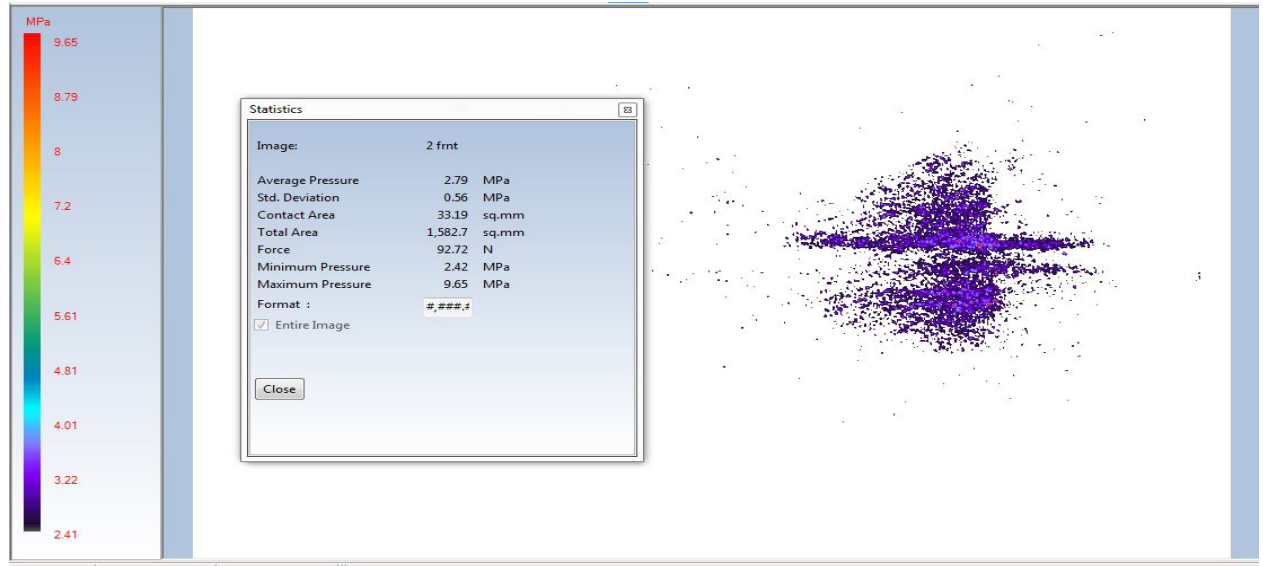

Fig. A5 Topaq Analyzer output for Frontal 2 feet Impact

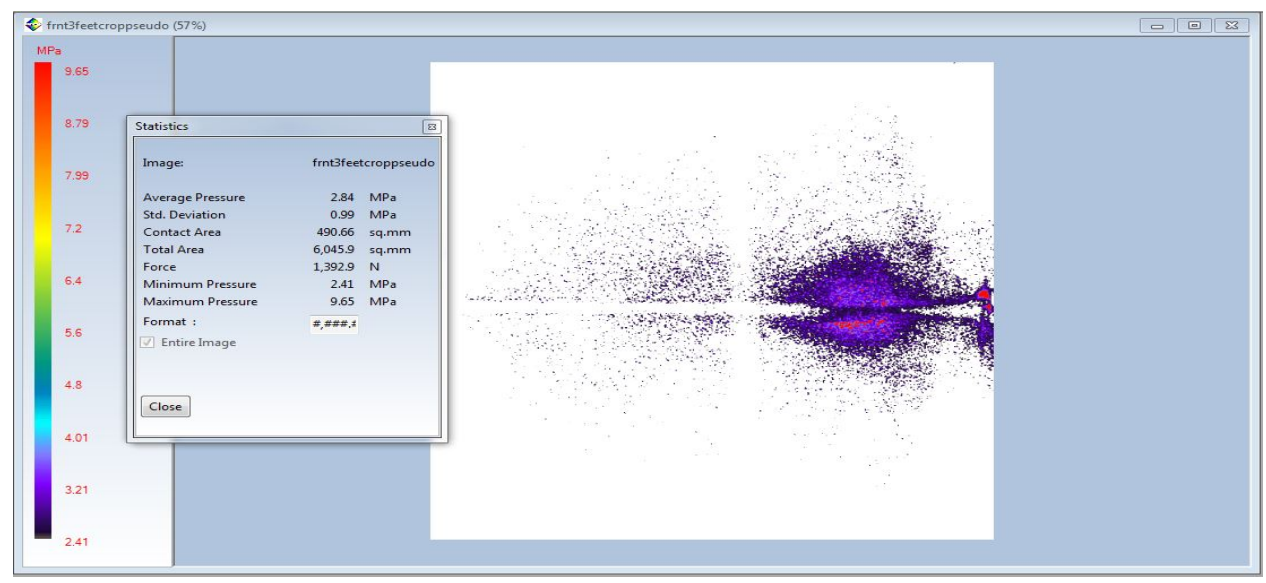

Fig. A6 Topaq Analyzer output for Frontal 3 feet Impact

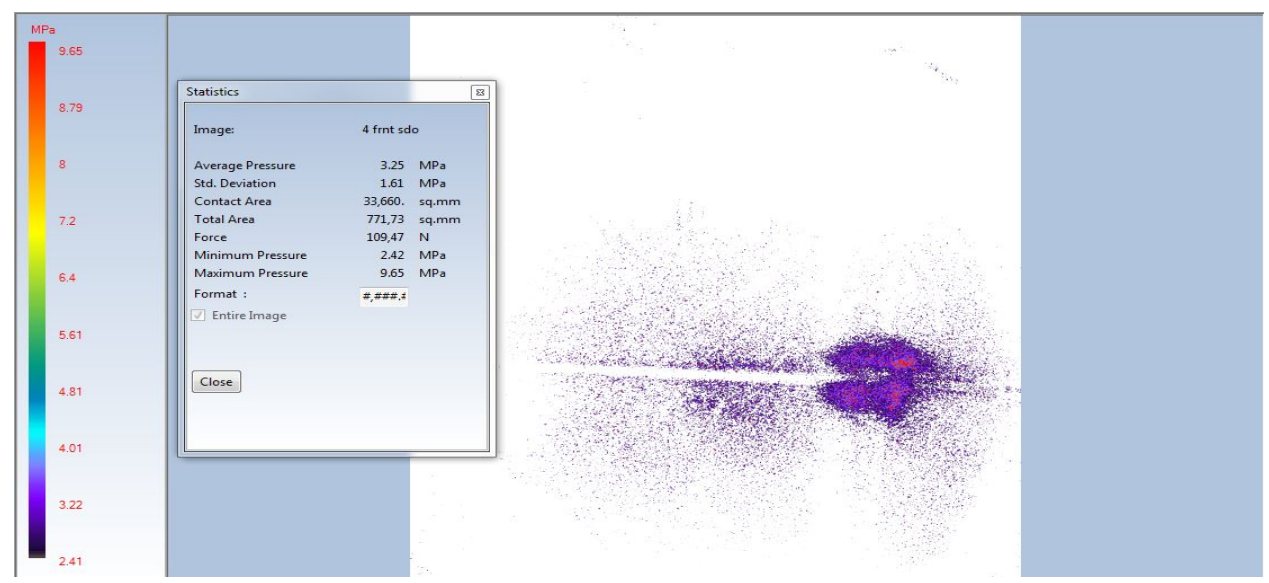

Fig. A7 Topaq Analyzer output for Frontal 4 feet Impact 


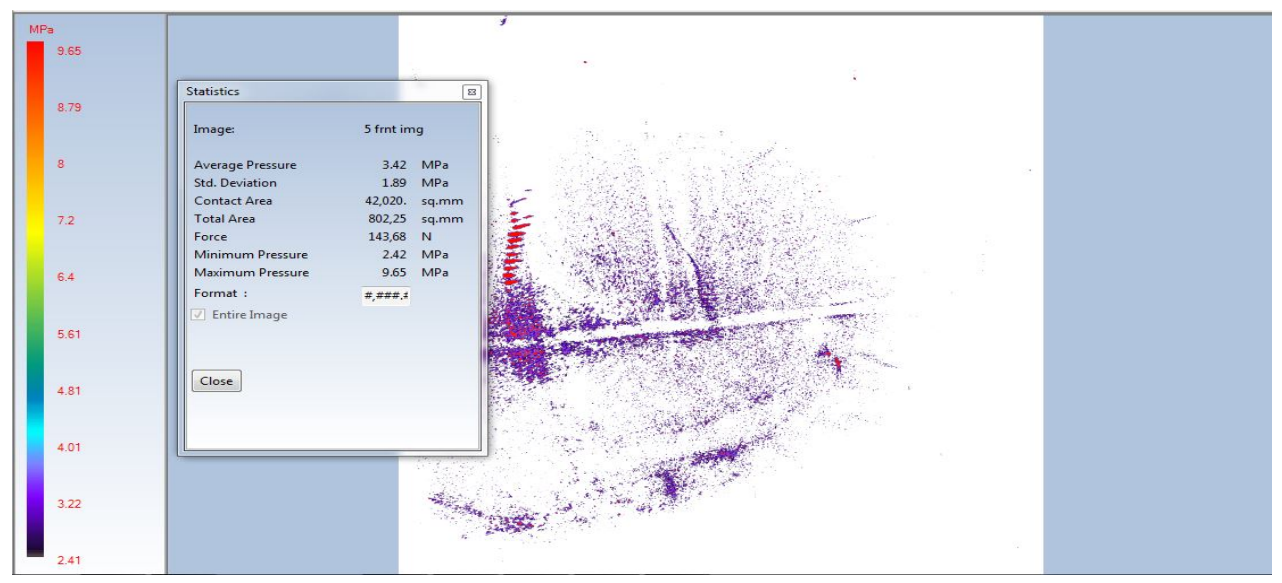

Fig. A8 Topaq Analyzer output for Frontal 5 feet Impact

\section{A2 $45^{\circ}$ to Frontal}

\section{A2.1 Pressure film deformations}

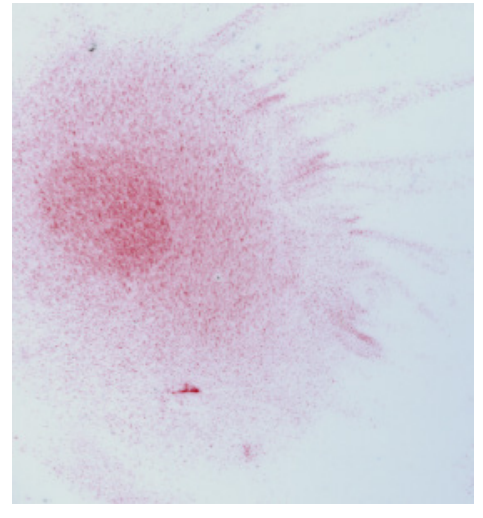

Fig. A9 2 feet $45^{\circ}$ to Frontal

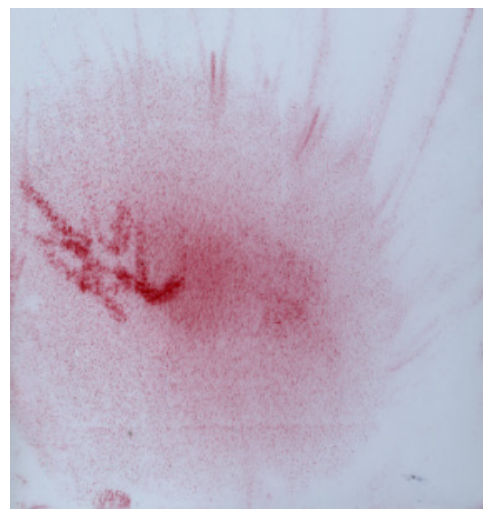

Fig. A11 4 feet $45^{\circ}$ to Frontal

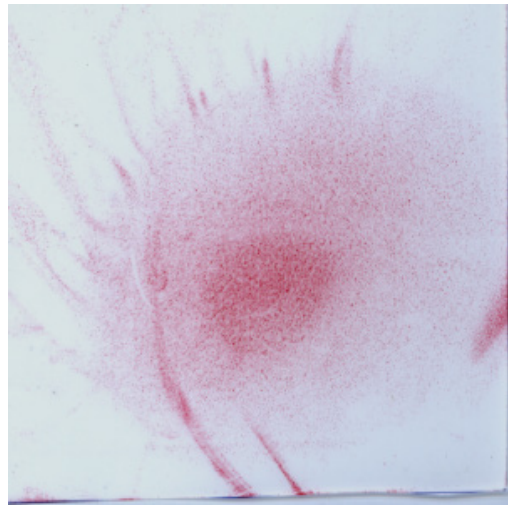

Fig. Al0 3 feet $45^{\circ}$ to Frontal

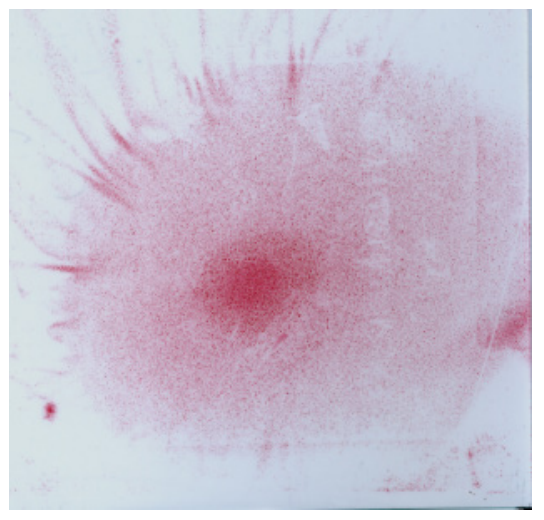

Fig. A12 5 feet $45^{\circ}$ to Frontal 


\section{A2.2 Topaq analyzer Outputs}

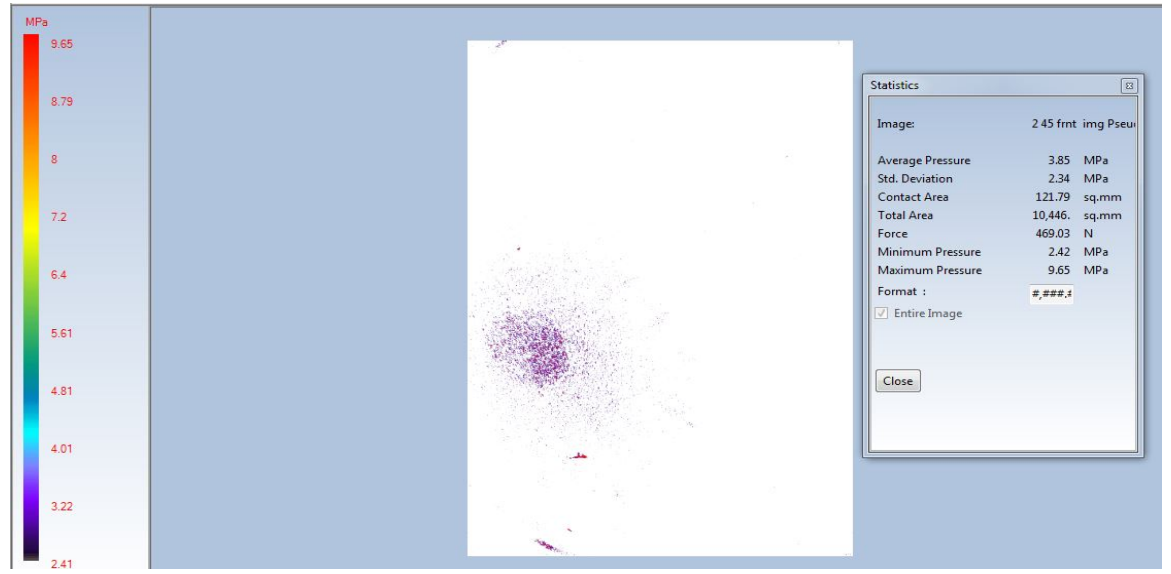

Fig. A13 Topaq Analyzer output for $45^{\circ}$ to Frontal 2 feet

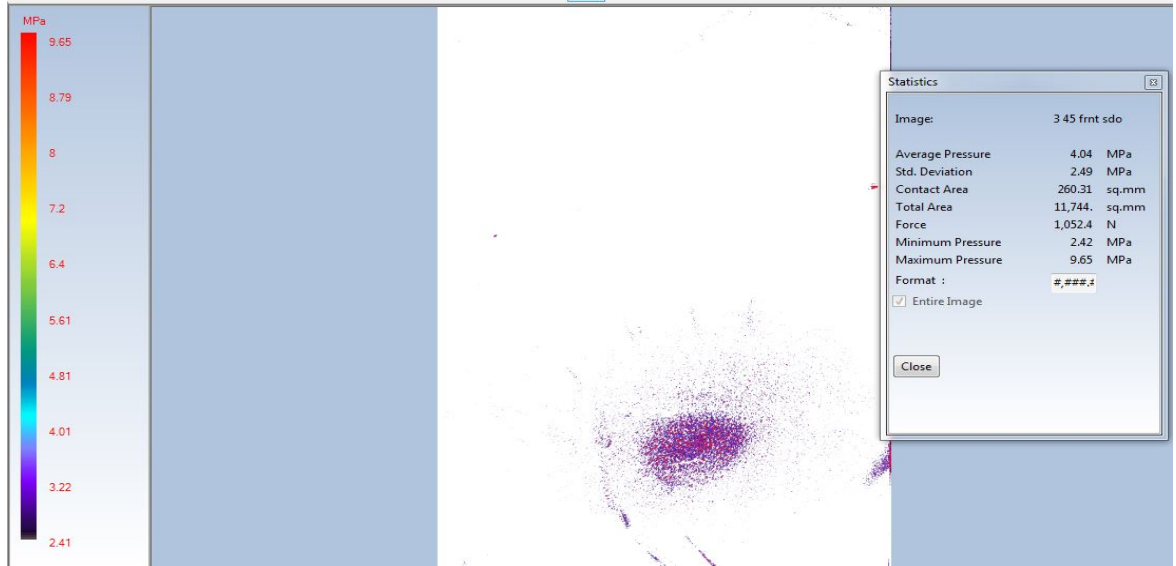

Fig. A14 Topaq Analyzer output for $45^{\circ}$ to Frontal 3 feet

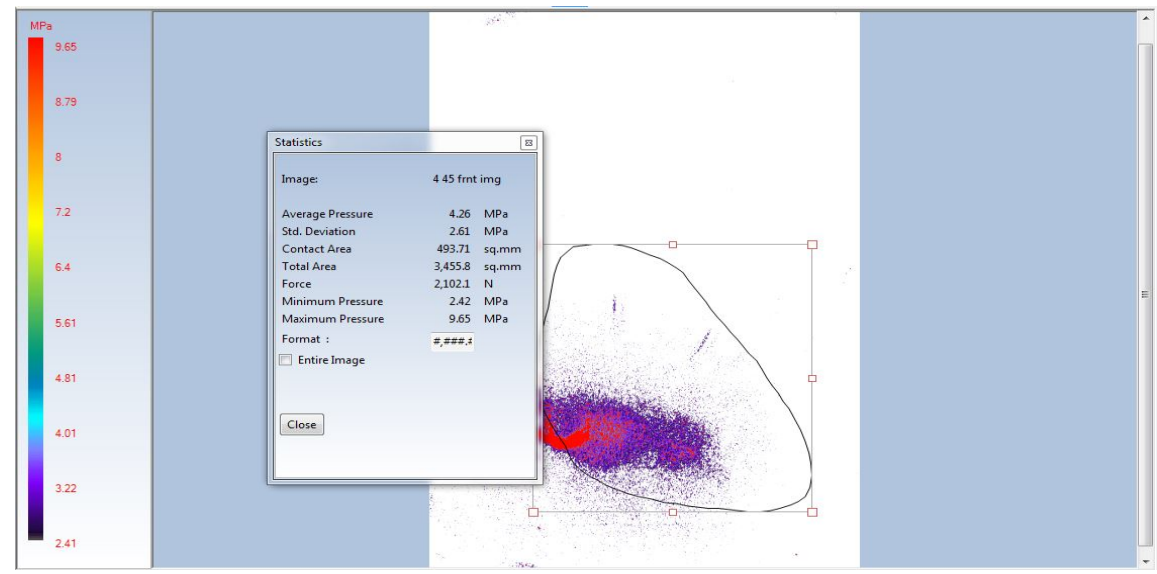

Fig. A15 Topaq Analyzer output for $45^{\circ}$ Frontal 4 feet Impact 


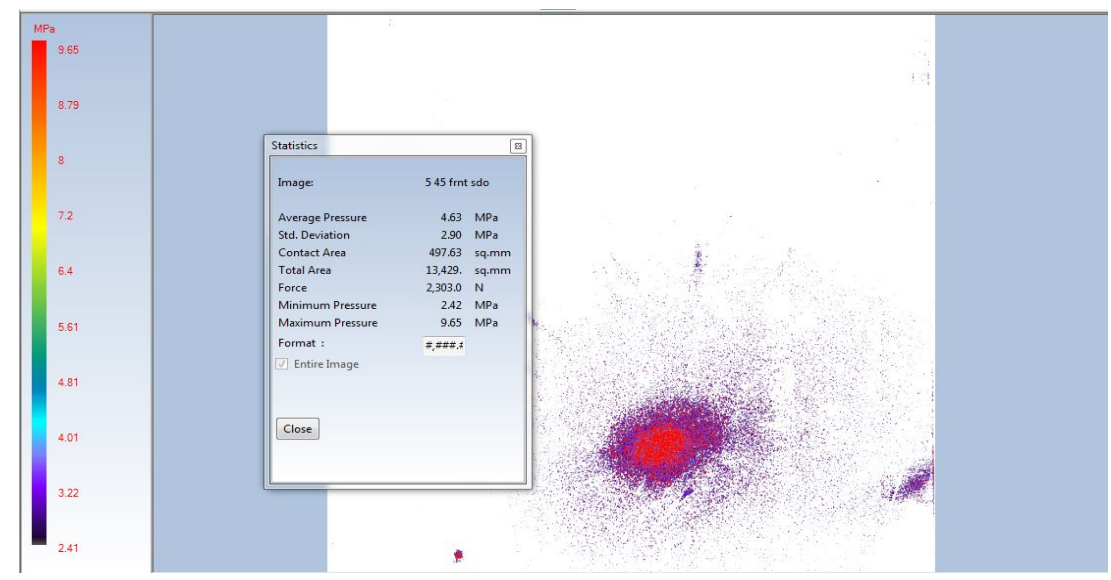

Fig. A16 Topaq Analyzer output for $45^{\circ}$ Frontal 5 feet Impact

\section{A3 Lateral}

\section{A3.1 Pressure film deformations}

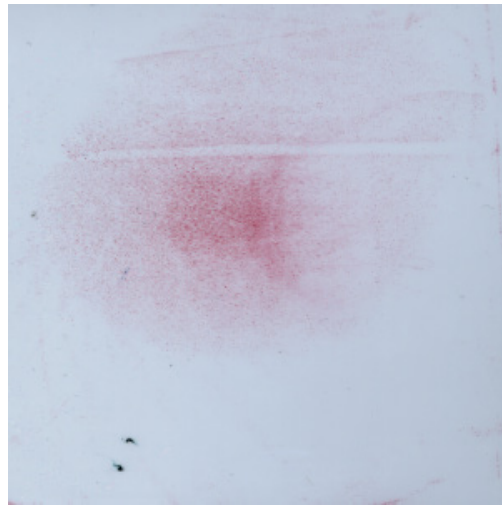

Fig. A17 2 feet Lateral

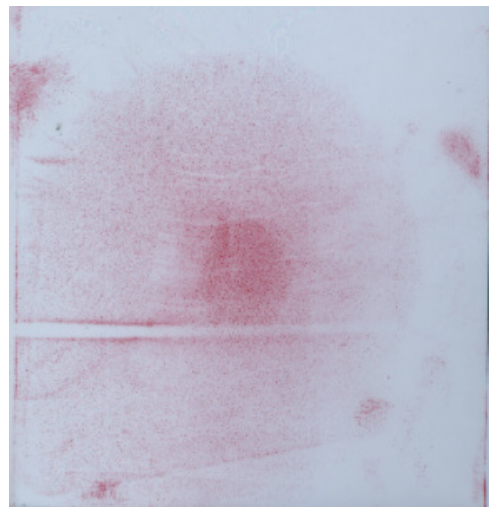

Fig. A19 4 feet Lateral

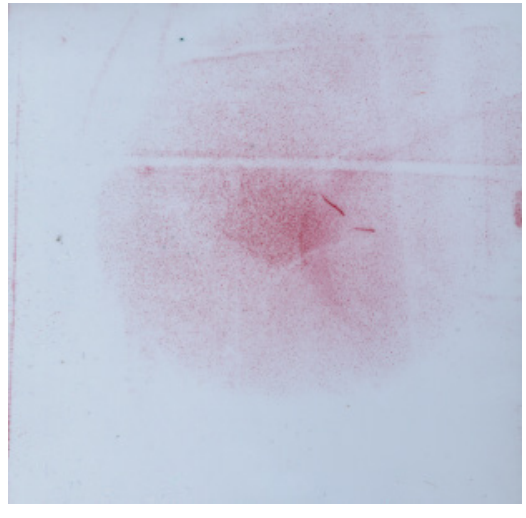

Fig. A18 3 feet Lateral

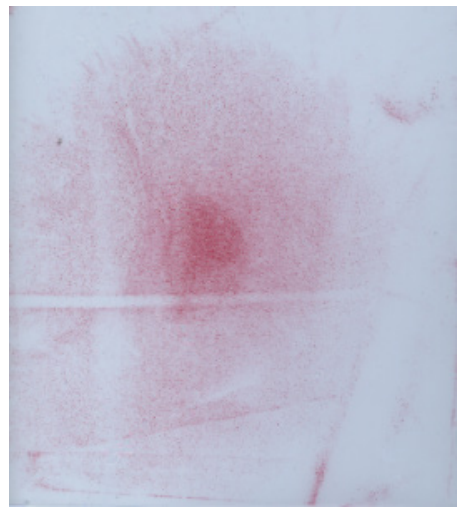

Fig.A20 5feet Lateral 


\section{A3.2 Topaq analyzer Outputs}

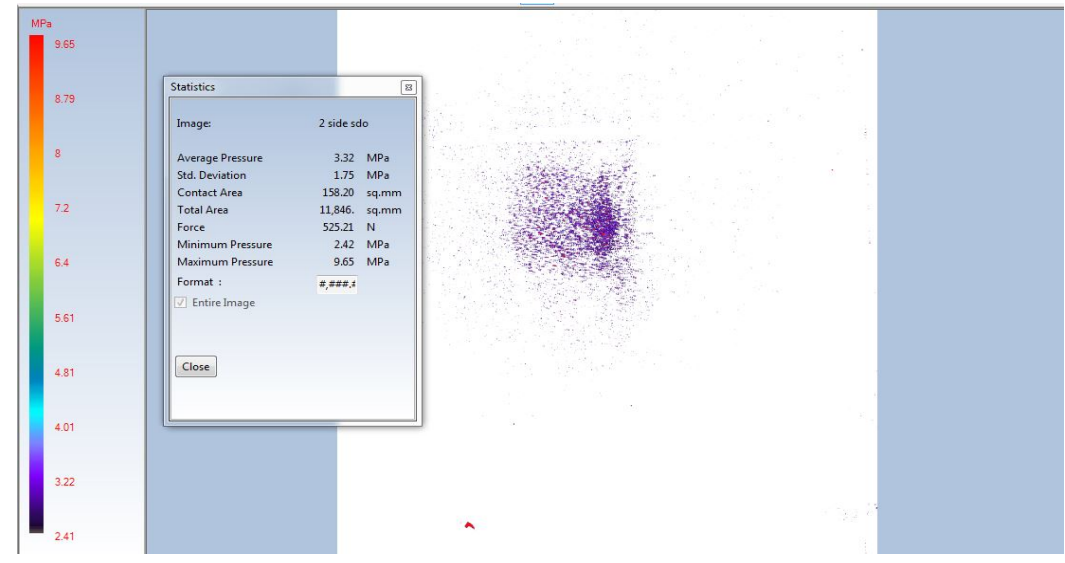

Fig. A21 Topaq Analyzer output for Lateral 2 feet Impact

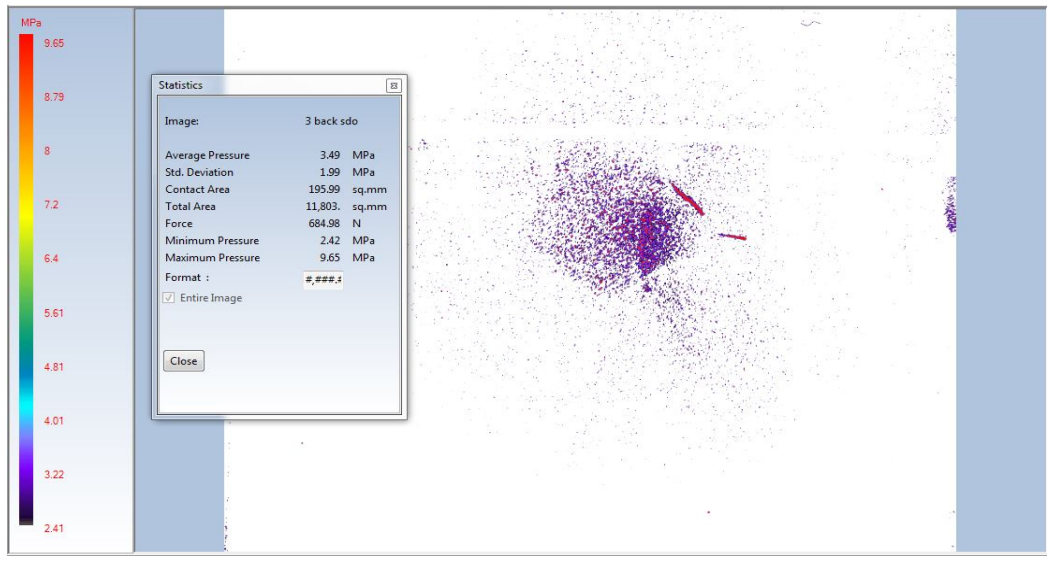

Fig. A22 Topaq Analyzer output for Lateral 3 feet Impact

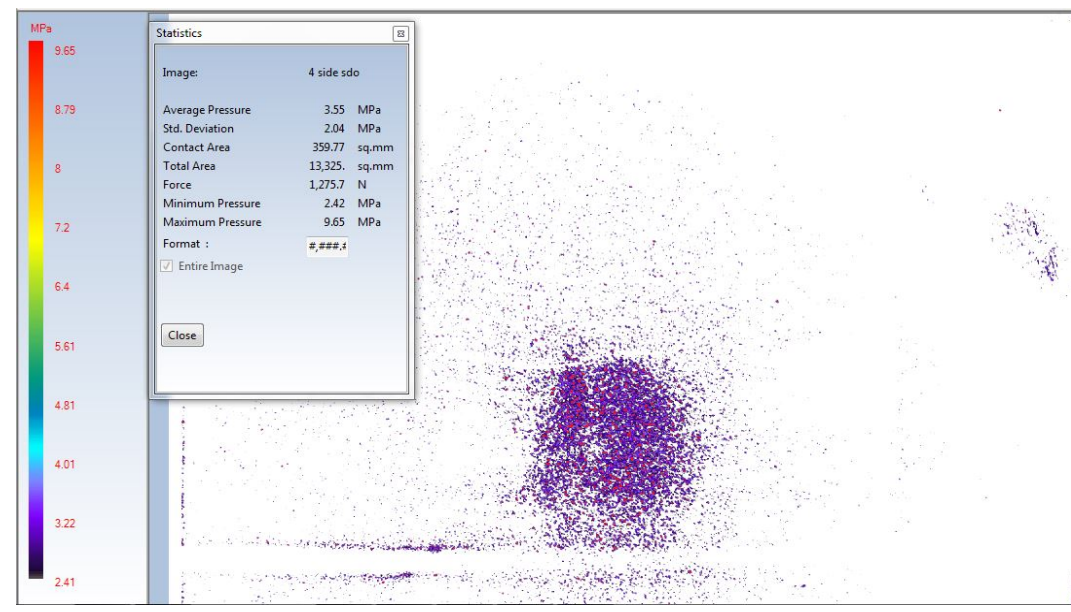

Fig. A23 Topaq Analyzer output for Lateral 4 feet Impact 


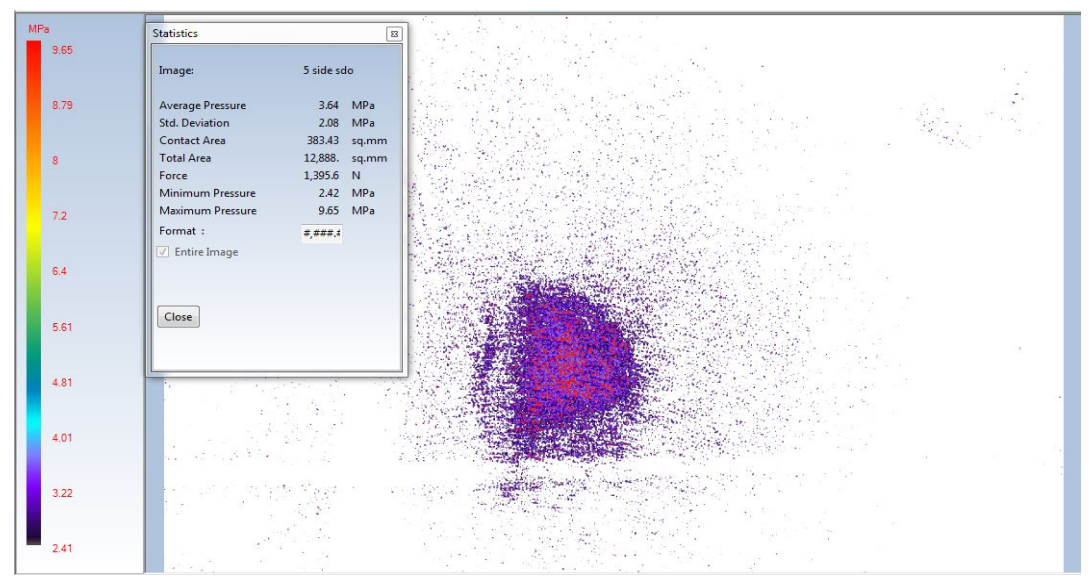

Fig. A24 Topaq Analyzer output for Lateral 5 feet Impact

\section{A4 Posterior}

\section{A4.1 Pressure film deformations}

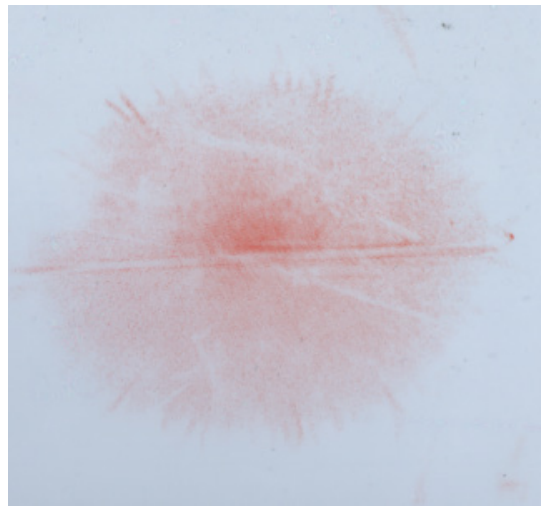

Fig. A25 2 feet Posterior

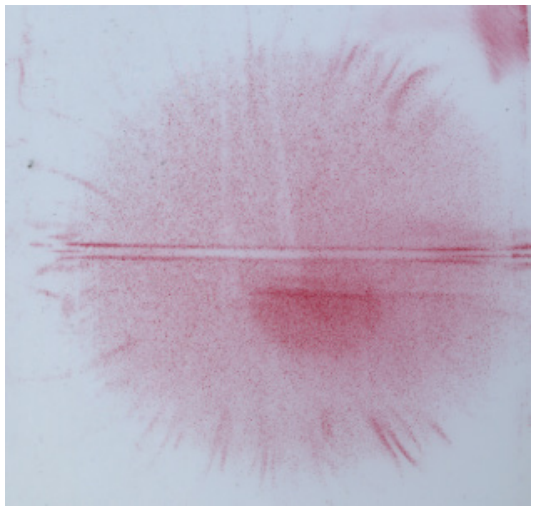

Fig. A27 4 feet Posterior

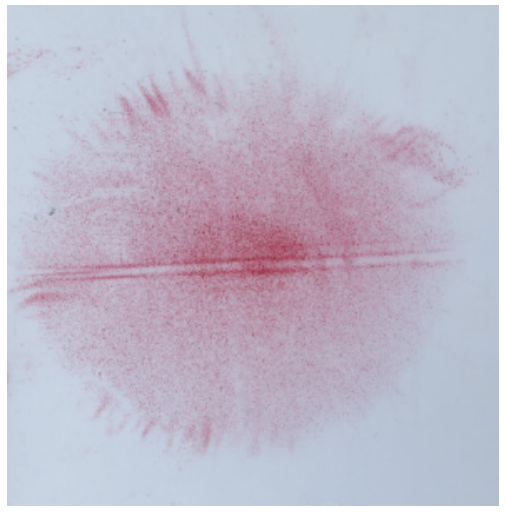

Fig. A26 3 feet Posterior

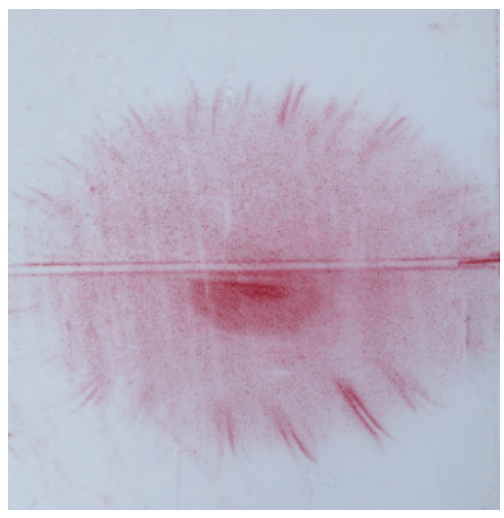

Fig. A28 5 feet Posterior 


\section{A4.2 Topaq analyzer Outputs}

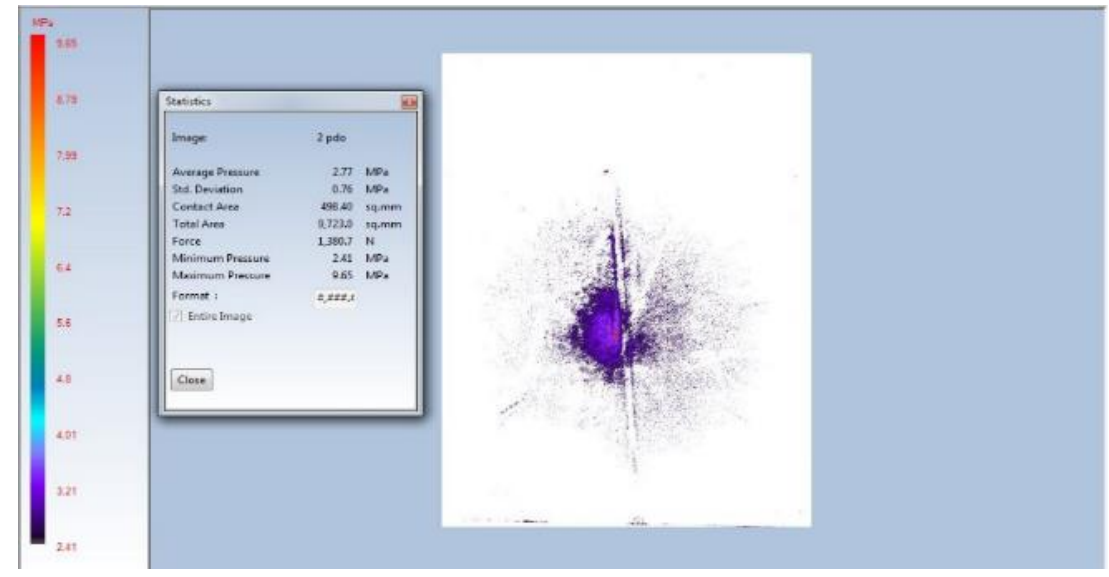

Fig. A29 Topaq Analyzer output for Posterior 2 feet Impact

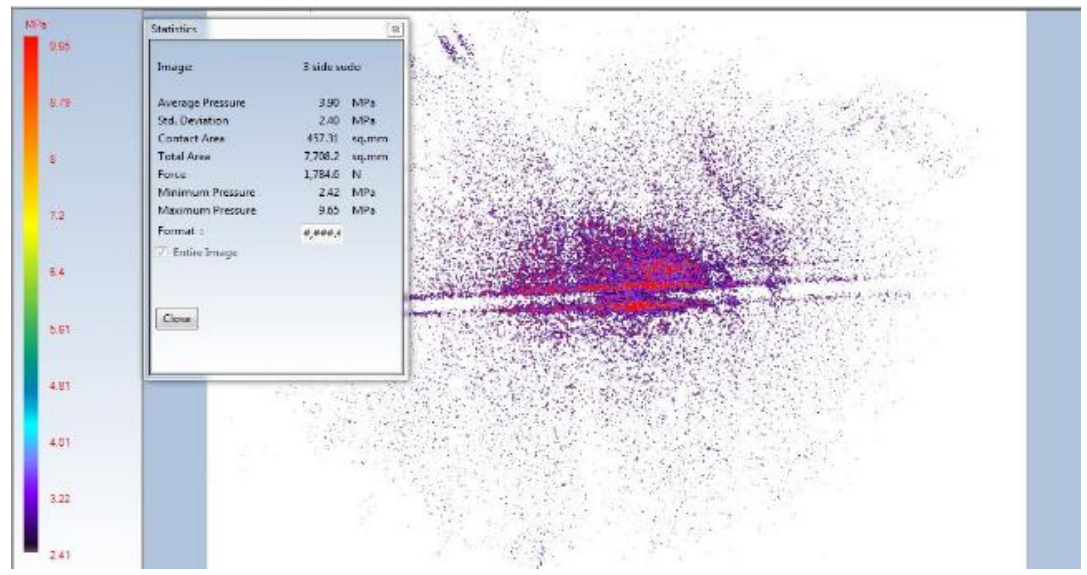

Fig. A30 Topaq Analyzer output for Posterior 3 feet Impact

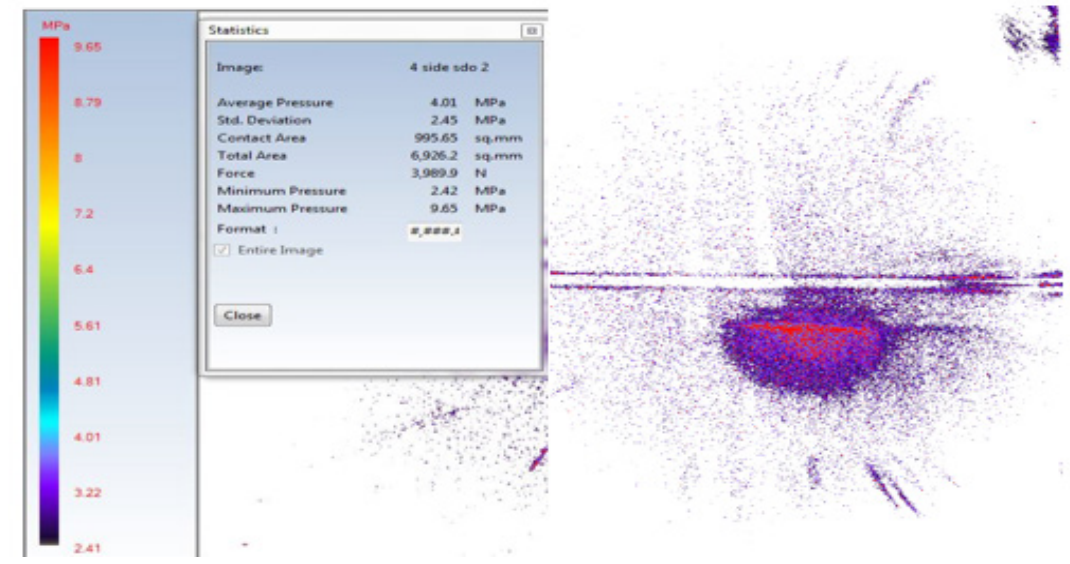

Fig. A31 Topaq Analyzer output for Posterior 4 feet Impact 


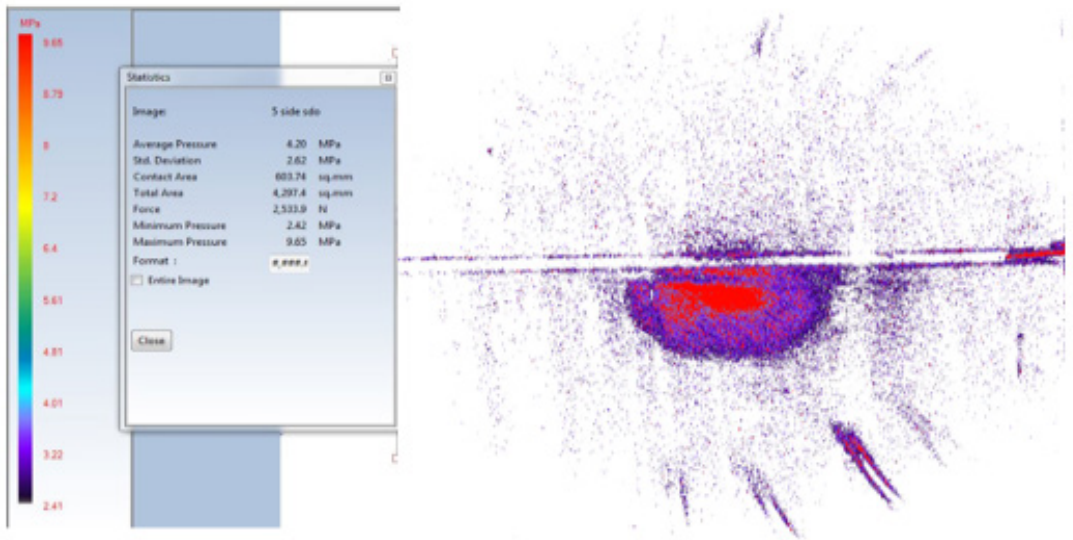

Fig. A32 Topaq Analyzer output for Posterior 5 feet Impact 


\section{Appendix B}

The results obtained from the FE Simulation are placed below.

\section{B1 Frontal}

\section{B1.1 Drop Height of 2 feet}
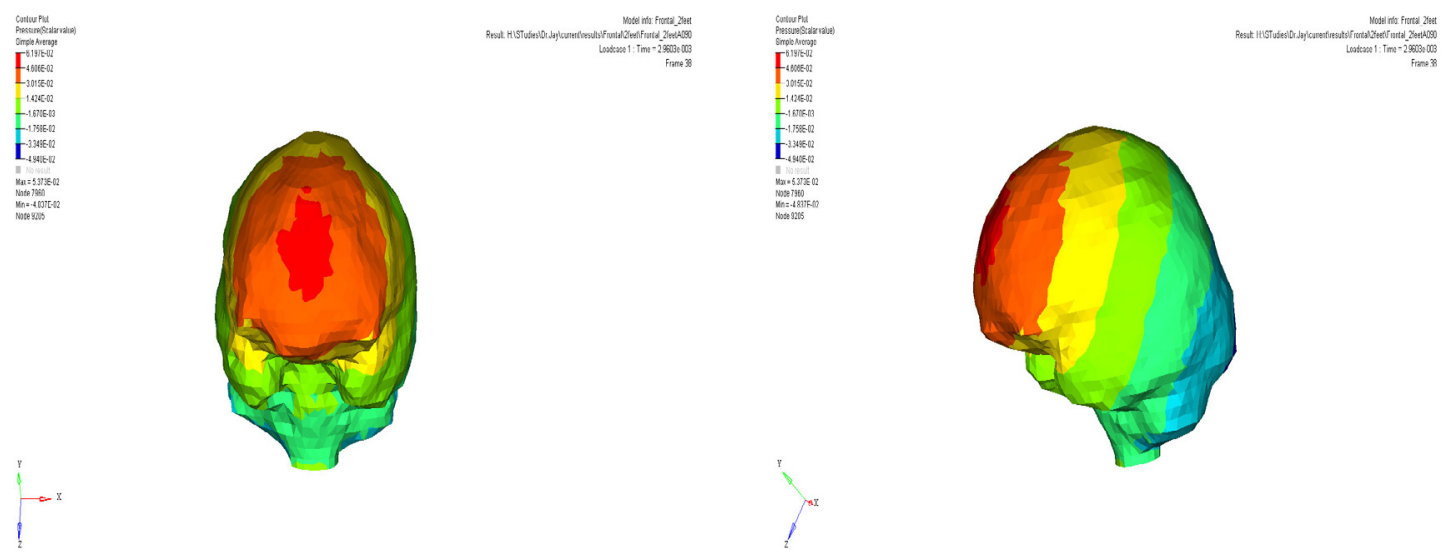

Figure B1 Pressure Frontal 2 feet

Figure B2 Pressure Frontal 2 feet

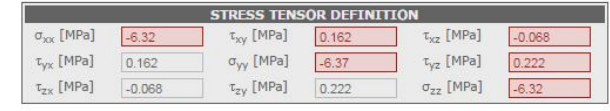

\begin{tabular}{|c|c|c|}
\hline \multicolumn{3}{|c|}{ MOHR CIRCLE SOLUTION } \\
\hline$\sigma 1[\mathrm{MPa}]$ & Principal stress I & -6.1011 \\
\hline ofl [MPa] & Principal stress II & -6.256 \\
\hline oIII [MPa] & Principal stress III & -6.6529 \\
\hline$\tau_{\max }[\mathrm{MPa}]$ & Guest - Tresca & 0.2759 \\
\hline$\sigma_{V M}[\mathrm{MPa}]$ & Huber - Hencky - Von Mises & 0.4929 \\
\hline
\end{tabular}

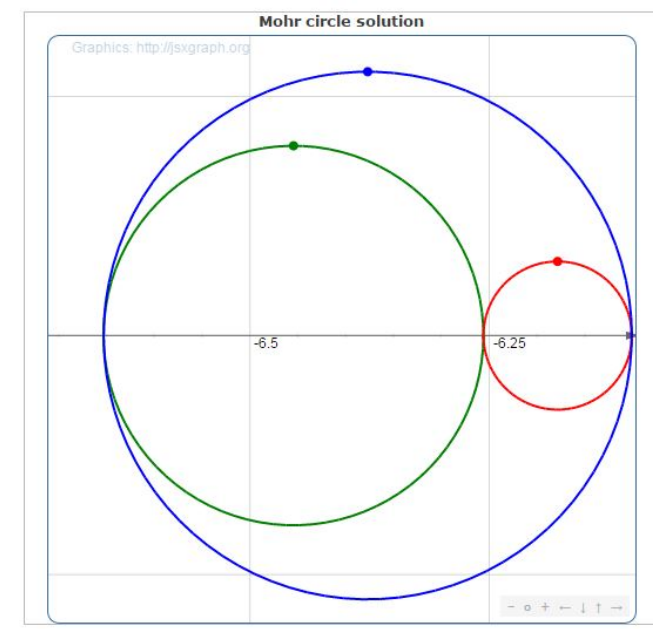

Figure B3 Mohr Circle for Frontal 2 Feet Impact 


\section{B1.2 Drop Height of 3 feet}

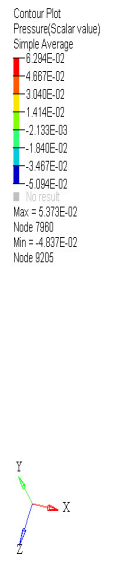

Figure B4 Pressure Frontal 3 feet
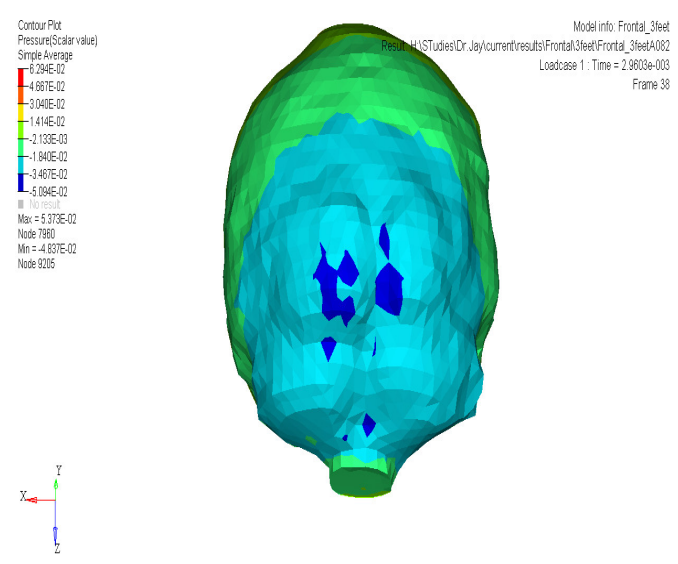

Figure B5 Pressure Frontal 3 feet

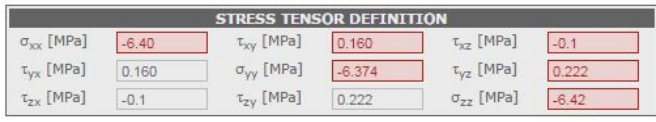

\begin{tabular}{|c|c|c|}
\hline \multicolumn{3}{|c|}{ MOHR CIRCLE SOLUTION } \\
\hline$\sigma \mathrm{I}[\mathrm{MPa}]$ & Principal stress I & -6.1581 \\
\hline oII [MPa] & Principal stress II & -6.3125 \\
\hline oIII [MPa] & Principal stress III & -6.7235 \\
\hline$\tau_{\max }[\mathrm{MPa}]$ & Guest - Tresca & 0.2827 \\
\hline$\sigma_{\mathrm{VM}}[\mathrm{MPa}]$ & Huber - Hencky - Von Mises & 0.5062 \\
\hline
\end{tabular}

Mohr circle solution

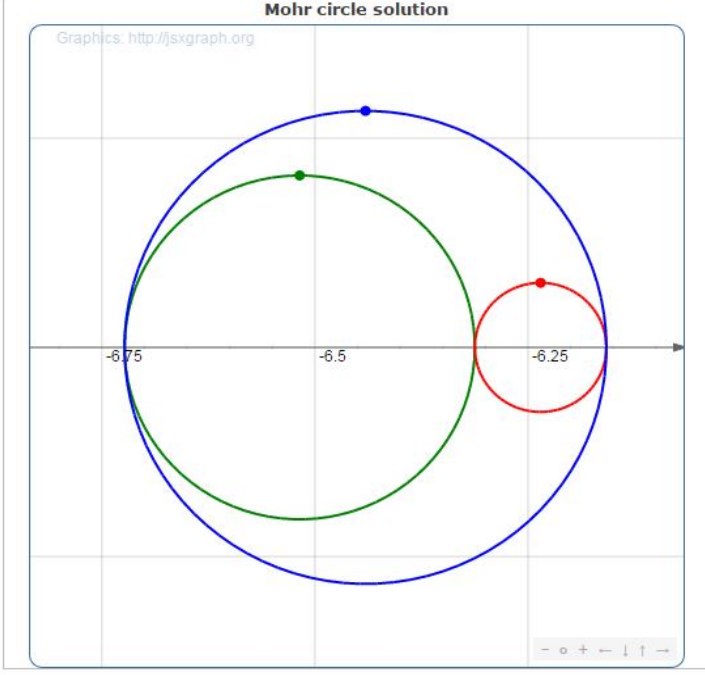

Figure B6 Mohr Circle for Frontal 3 Feet 


\section{B1.3 Drop Height of 4 feet}
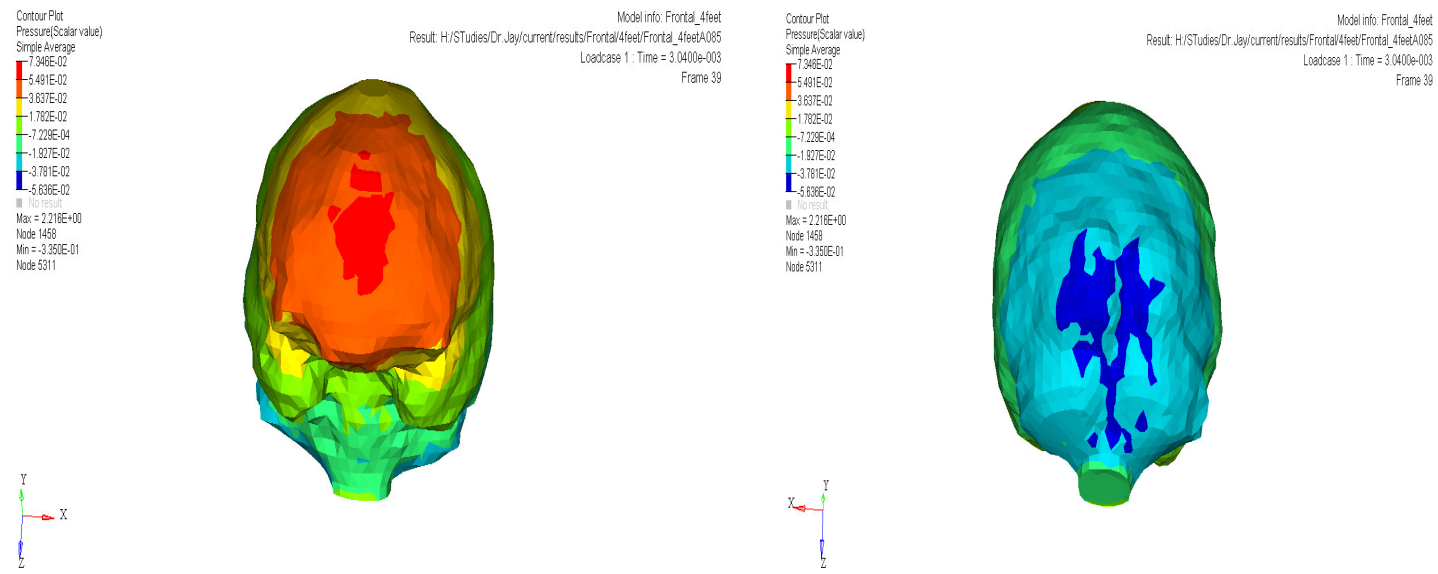

Figure B7 Pressure Frontal 4 feet

Figure B8 Pressure Frontal 4 feet

\begin{tabular}{|llllll|}
\hline \multicolumn{5}{|c|}{ STRESS IENSOR DEFINIIION } \\
\hline$\sigma_{x x}[\mathrm{MPa}]$ & -7.41 & $\tau_{x y}[\mathrm{MPa}]$ & 0.19 & $\tau_{x z}[\mathrm{MPa}]$ & -0.125 \\
$\tau_{y x}[\mathrm{MPa}]$ & 0.19 & $\sigma_{y y}[\mathrm{MPa}]$ & -7.52 & $\tau_{y z}[\mathrm{MPa}]$ & 0.24 \\
$\tau_{z x}[\mathrm{MPa}]$ & -0.125 & $\tau_{z y}[\mathrm{MPa}]$ & 0.24 & $\sigma_{z z}[\mathrm{MPa}]$ & -7.41 \\
\hline
\end{tabular}

\begin{tabular}{|c|c|c|}
\hline \multicolumn{3}{|c|}{ MOHR CIRCLE SOLUTION } \\
\hline oI [MPa] & Principal stress I & -7.2142 \\
\hline oII $[\mathrm{MPa}]$ & Principal stress II & -7.2931 \\
\hline oIII [MPa] & Principal stress III & -7.8328 \\
\hline$\tau_{\text {MAX }}[\mathrm{MPa}]$ & Guest - Tresca & 0.3093 \\
\hline$\sigma_{\mathrm{VM}}[\mathrm{MPa}]$ & Huber - Hencky - Von Mises & 0.5832 \\
\hline
\end{tabular}

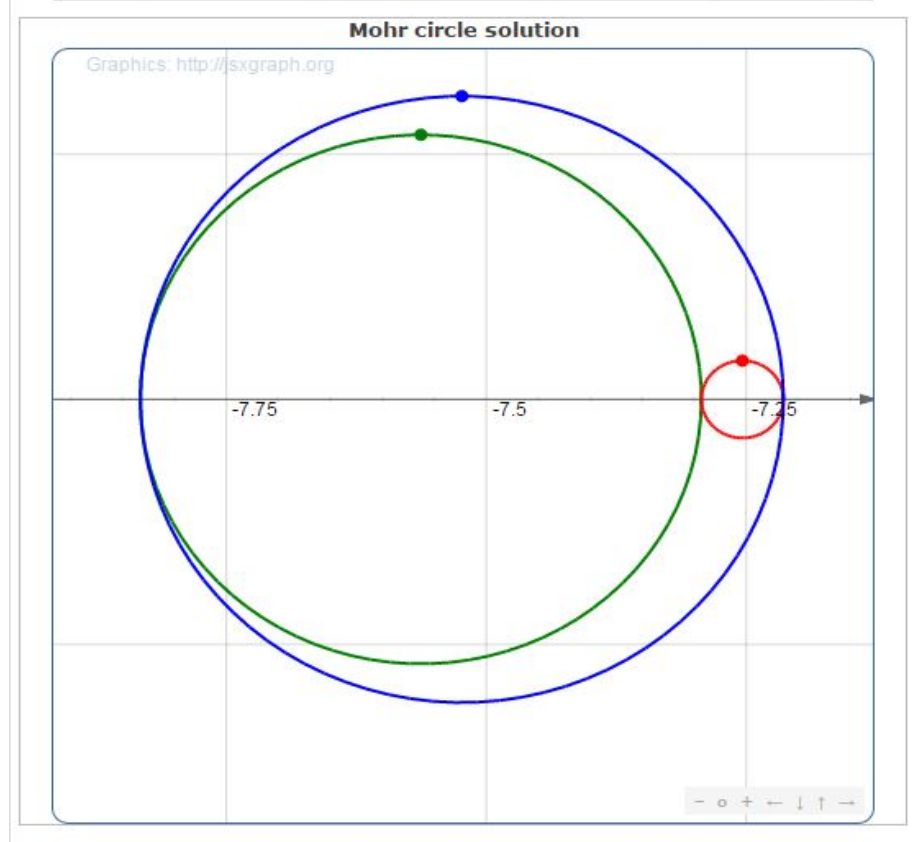

Figure B9 Mohr Circle for Frontal 4 Feet Impact 


\section{B1.4 Drop Height of 5 feet}
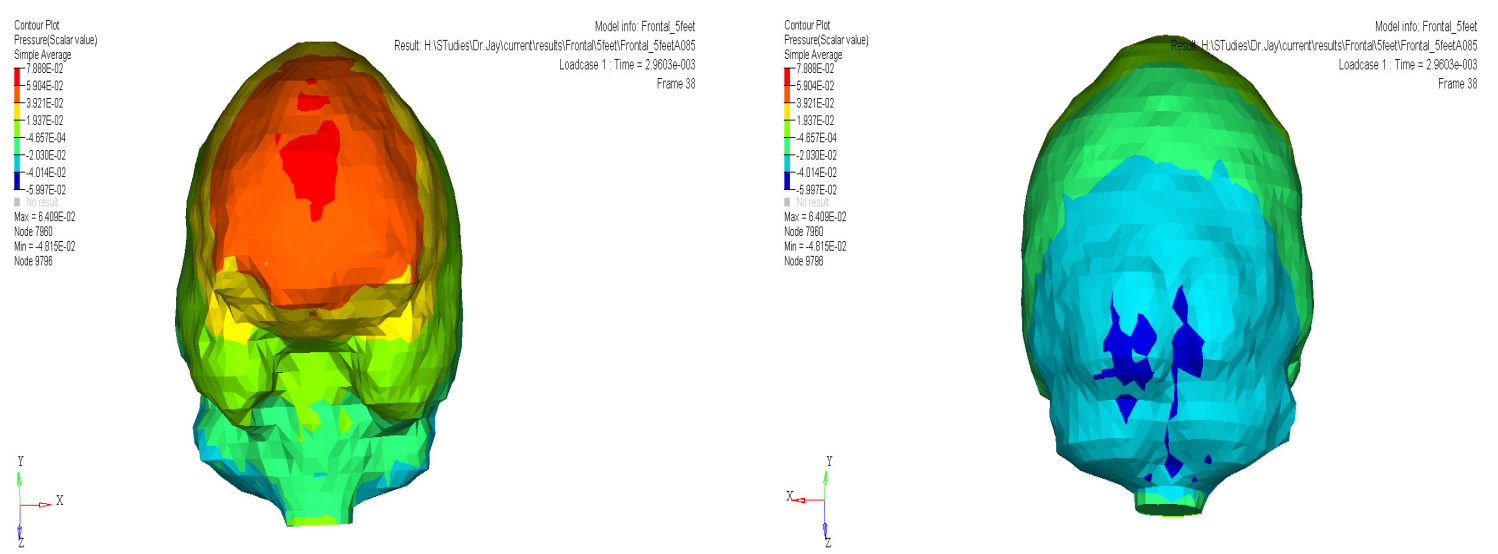

Figure B10 Pressure Frontal 5 feet

Figure B11 Pressure Frontal 5 feet

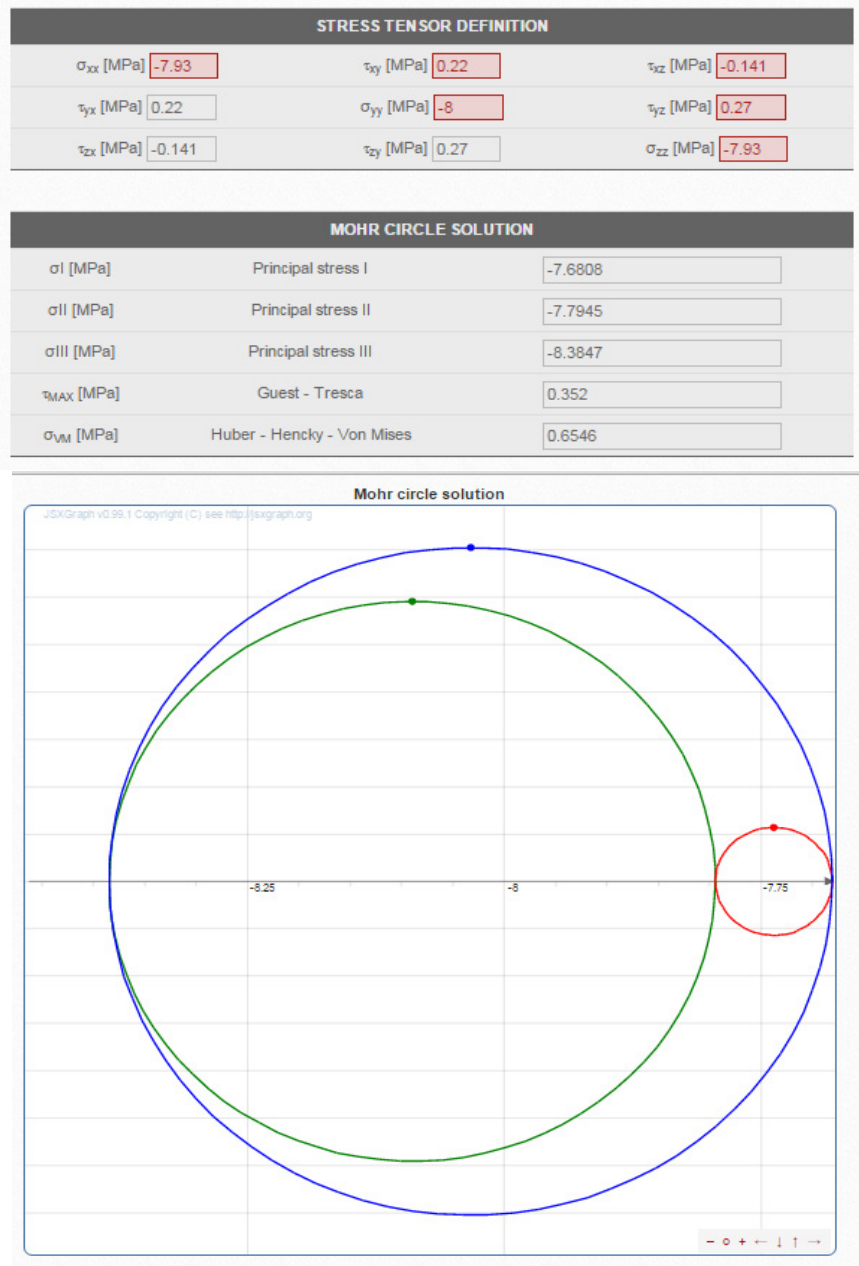

Figure B12 Mohr Circle for Frontal 5 Feet Impact 


\section{B2 $45^{\circ}$ to Frontal}

\section{B2.1 Drop Height of 2 feet}
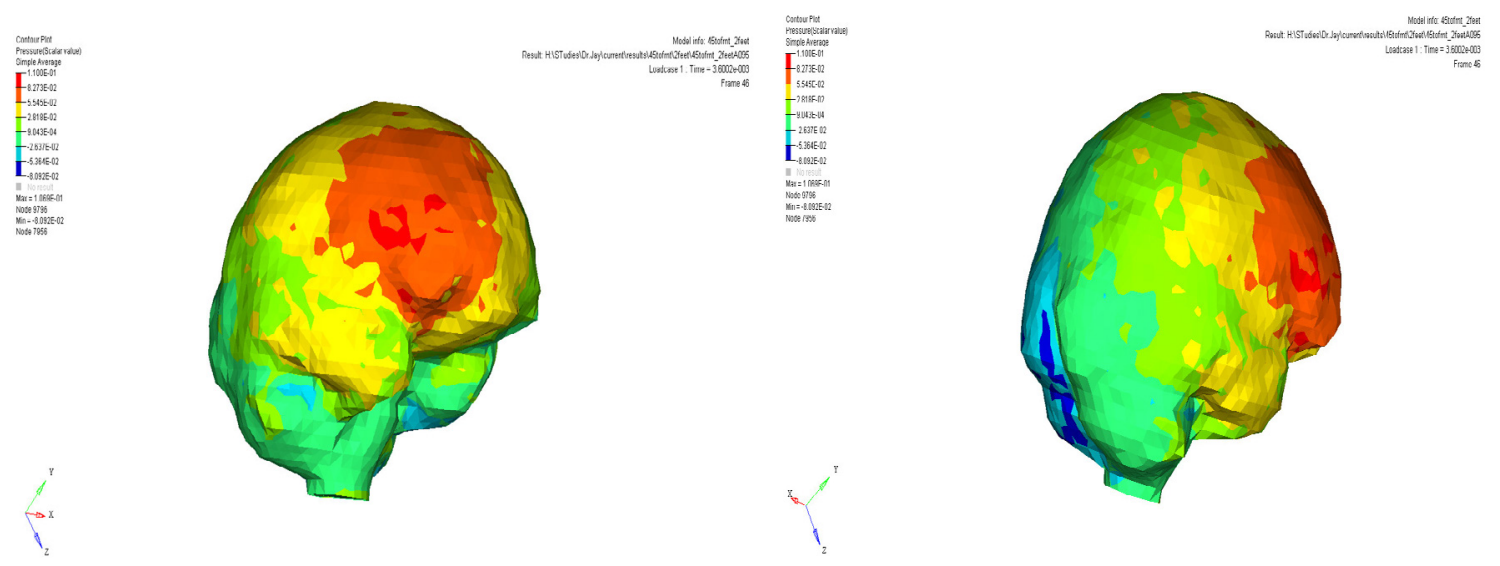

Figure B13 Pressure $45^{\circ}$ to Frontal 2 feet

Figure B14 Pressure $45^{\circ}$ to Frontal 2 feet

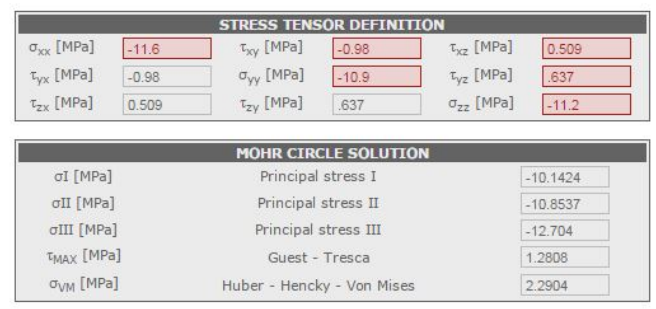

Mohr circle solutio

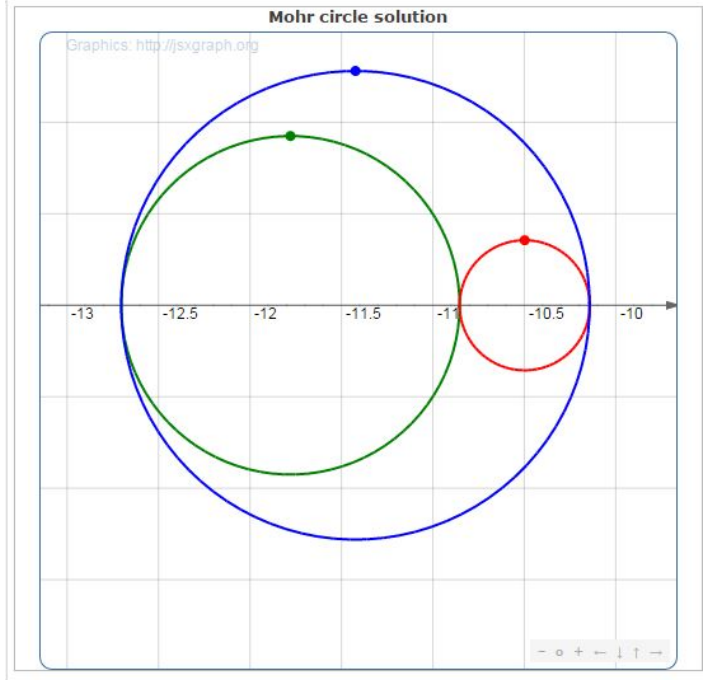

Figure B15 Mohr Circle for $45^{\circ}$ to Frontal 2 Feet Impact 


\section{B2.2 Drop Height of 3 feet}

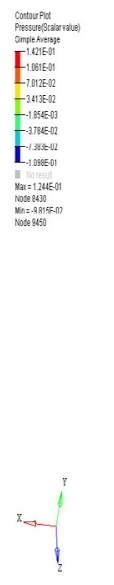

Figure B16 Pressure $45^{\circ}$ to Frontal 3 feet
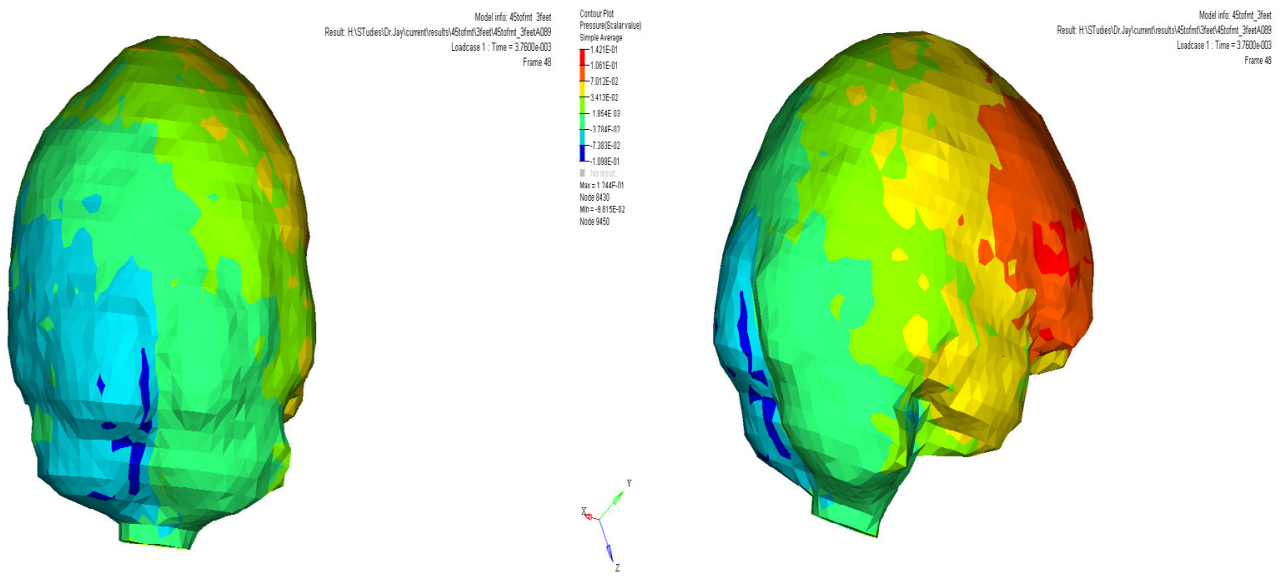

Figure B17 Pressure $45^{\circ}$ to Frontal 3 feet

\begin{tabular}{|llllll|}
\hline \multicolumn{5}{|c|}{ SIRESS IENSOR DEFINIIION } \\
\hline$\sigma_{\mathrm{xxx}}[\mathrm{MPa}]$ & -15.0 & $\tau_{x y}[\mathrm{MPa}]$ & -1.23 & $\tau_{x z}[\mathrm{MPa}]$ & .658 \\
$\tau_{y x}[\mathrm{MPa}]$ & -1.23 & $\sigma_{y y}[\mathrm{MPa}]$ & -14.2 & $\tau_{y z}[\mathrm{MPa}]$ & 0.804 \\
$\tau_{z x}[\mathrm{MPa}]$ & .658 & $\tau_{z y}[\mathrm{MPa}]$ & 0.804 & $\sigma_{z z}[\mathrm{MPa}]$ & -14.3 \\
\hline
\end{tabular}

\begin{tabular}{|c|c|c|}
\hline \multicolumn{3}{|c|}{ MOHR CIRCLE SOLUTION } \\
\hline ol [MPa] & Principal stress I & -13.2092 \\
\hline oII [MPa] & Principal stress II & -13.9074 \\
\hline oIII [MPa] & Principal stress III & -16.3834 \\
\hline$\tau_{\operatorname{Max}}[\mathrm{MPa}]$ & Guest - Tresca & 1.5871 \\
\hline$\sigma_{\mathrm{VM}}[\mathrm{MPa}]$ & Huber - Hencky - Von Mises & 2.8891 \\
\hline
\end{tabular}

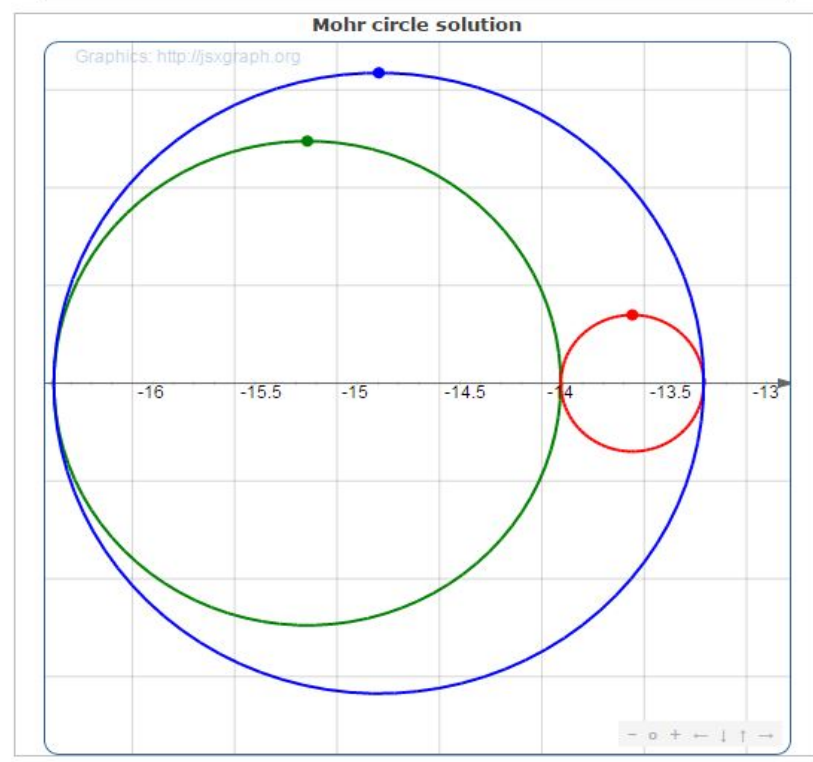

Figure B18 Mohr Circle for $45^{\circ}$ to Frontal 3 Feet Impact 


\section{B2.3 Drop Height of 4 feet}

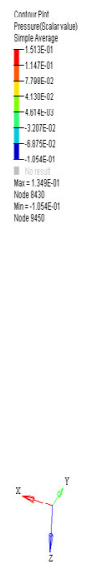

Figure B19 Pressure $45^{\circ}$ to Frontal 4 feet
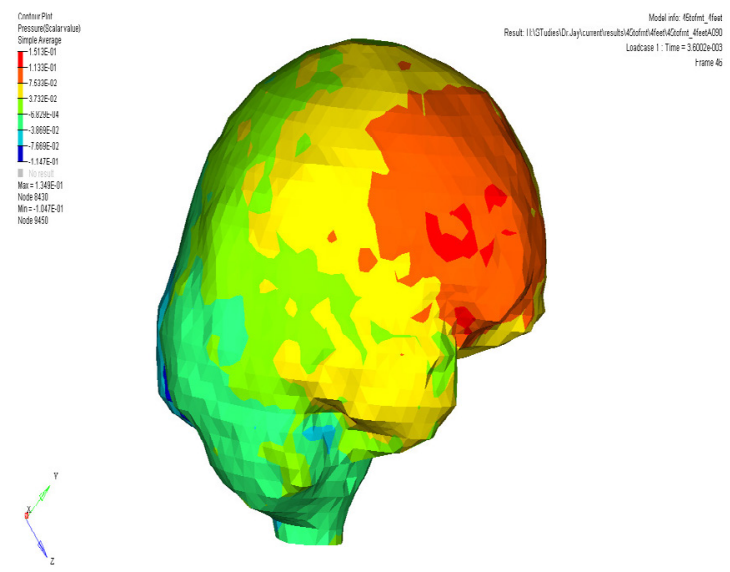

Figure B20 Pressure $45^{\circ}$ to Frontal 4 feet

\begin{tabular}{|c|c|c|}
\hline \multicolumn{3}{|c|}{ STRESS TENSOR DEFINITION } \\
\hline$\sigma_{\mathrm{xx}}[\mathrm{MPa}]-16$ & $\tau _ { x y } [ \mathrm { MPa } ] \longdiv { - 1 . 3 3 }$ & $t_{x z}[\mathrm{MPa}] \mathrm{701}$ \\
\hline $5_{x x}[\mathrm{MPa}]-1.33$ & $\sigma_{y y}[\mathrm{MPa}]-15$ & $x_{y z}[\mathrm{MPa}] .901$ \\
\hline$\tau_{z x}[\mathrm{MPa}] .701$ & $\tau_{z y}[\mathrm{MPa}] .901$ & $\sigma_{z z}[\mathrm{MPa}]-15.1$ \\
\hline \multicolumn{3}{|c|}{ MOHR CIRCLE SOLUTION } \\
\hline бl [MPa] & Principal stress I & -13.9285 \\
\hline oll [MPa] & Principal stress II & -14.7352 \\
\hline olll [MPa] & Principal stress III & -17.4364 \\
\hline $\max [\mathrm{MPa} a]$ & Guest - Tresca & 1.754 \\
\hline$\sigma_{M M}[\mathrm{MPa}]$ & Huber - Hencky - Von Mises & 3.1822 \\
\hline
\end{tabular}

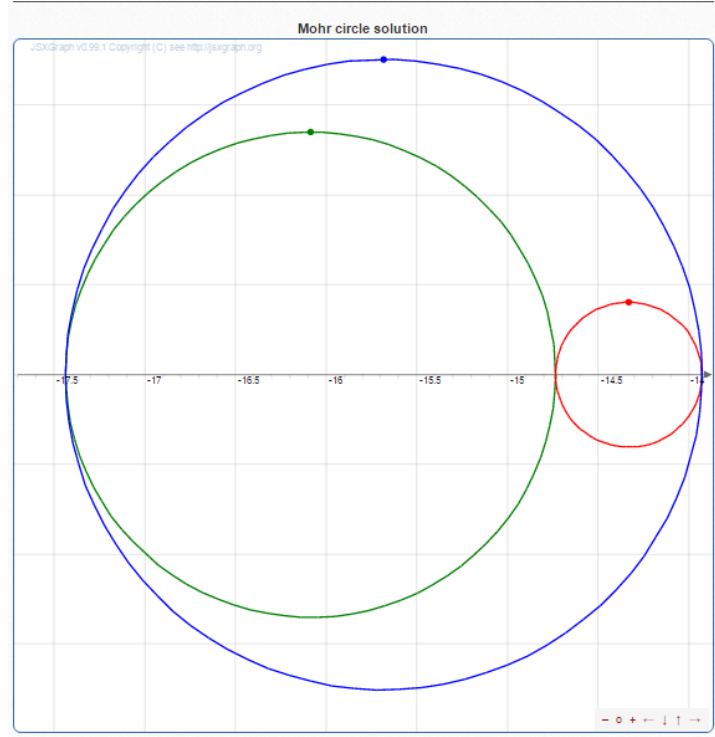

Figure B21 Mohr Circle for $45^{\circ}$ to Frontal 4 Feet Impact 


\section{B2.4 Drop Height of 5 feet}
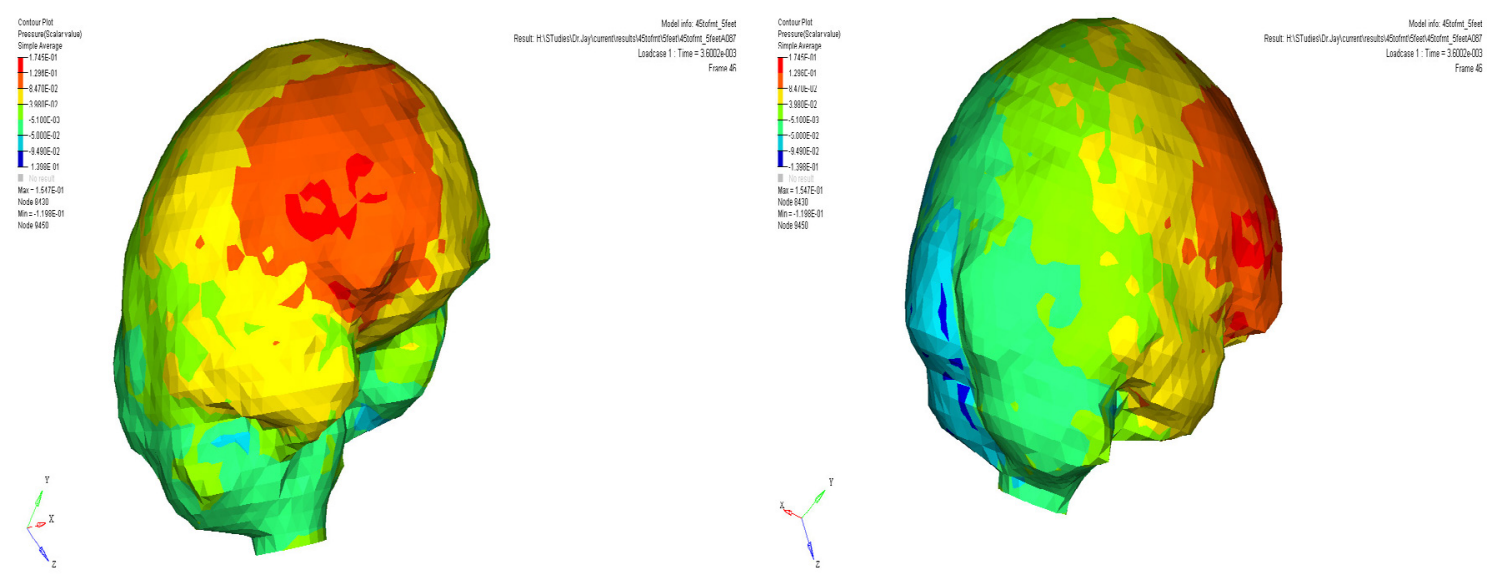

Figure B22 Pressure $45^{\circ}$ to Frontal 5 feet

Figure B23 Pressure $45^{\circ}$ to Frontal 5 feet

\begin{tabular}{|c|c|c|c|c|c|}
\hline \multicolumn{6}{|c|}{ SIRESS IENSOR DEFINIIION } \\
\hline$\sigma_{\mathrm{xx}}[\mathrm{MPa}]$ & -18.5 & $\tau_{x y}[\mathrm{MPa}]$ & -1.46 & $\tau_{x z}[\mathrm{MPa}]$ & 0.777 \\
\hline$\tau_{\mathrm{yx}}[\mathrm{MPa}]$ & -1.46 & $\sigma_{y y}[\mathrm{MPa}]$ & -17.5 & $\tau_{y z}[\mathrm{MPa}]$ & .965 \\
\hline$\tau_{2 x}[\mathrm{MPa}]$ & 0.777 & $\tau_{z y}[\mathrm{MPa}]$ & .965 & $\sigma_{\mathrm{zz}}[\mathrm{MPa}]$ & -17.6 \\
\hline \multicolumn{6}{|c|}{ MOHR CIRCLE SOLUTION } \\
\hline \multicolumn{2}{|c|}{$\sigma \mathrm{I}[\mathrm{MPa}]$} & \multicolumn{2}{|c|}{ Principal stress I } & & -16.3235 \\
\hline \multicolumn{2}{|c|}{ oII [MPa] } & \multicolumn{2}{|c|}{ Principal stress II } & & -17.1605 \\
\hline \multicolumn{2}{|c|}{ oIII [MPa] } & \multicolumn{2}{|c|}{ Principal stress III } & & -20.116 \\
\hline \multicolumn{2}{|c|}{$\tau_{\operatorname{MaX}}[\mathrm{MPa}]$} & \multicolumn{2}{|c|}{ Guest - Tresca } & & 1.8963 \\
\hline \multicolumn{2}{|c|}{$\sigma_{\mathrm{VM}}[\mathrm{MPa}]$} & \multicolumn{3}{|c|}{ Huber - Hencky - Von Mises } & 3.451 \\
\hline
\end{tabular}

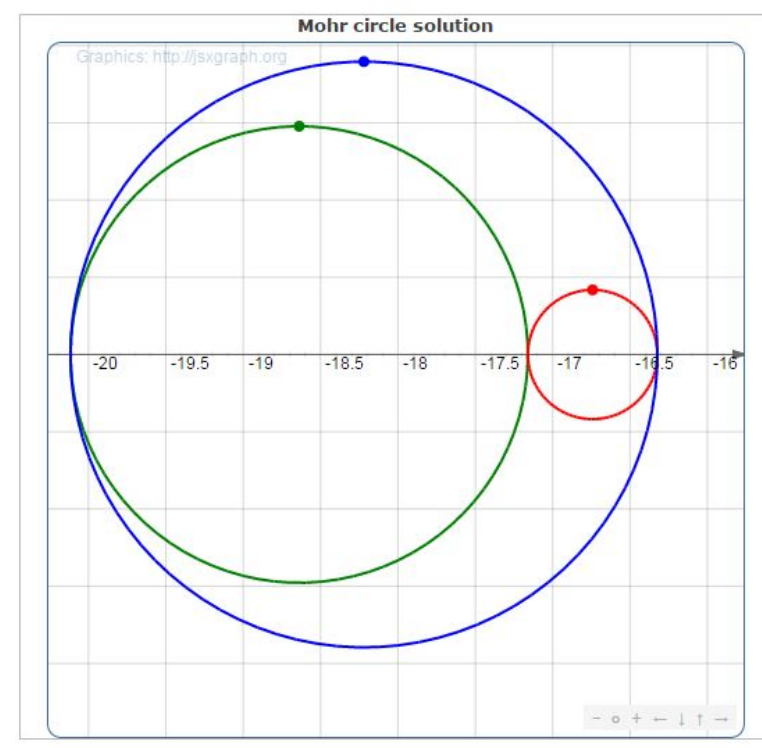

Figure B24 Mohr Circle for $45^{\circ}$ to Frontal 5 Feet Impact 


\section{B3 Lateral}

\section{B3.1 Drop Height of 2 feet}
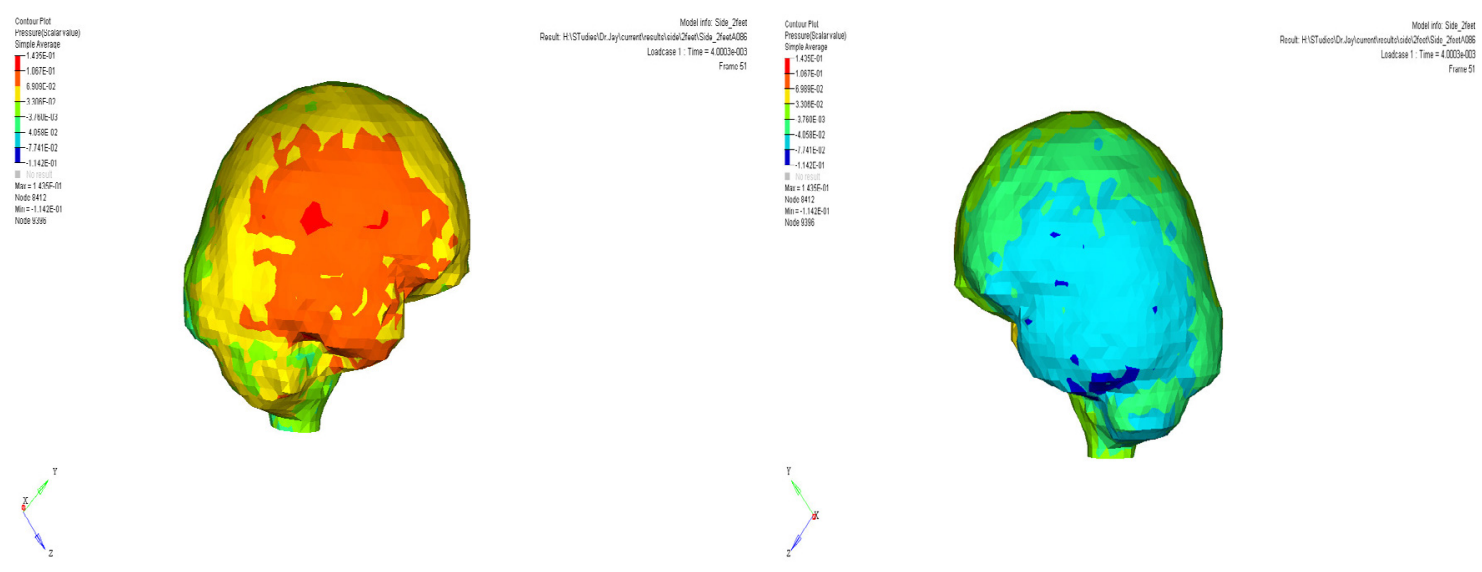

Figure B25 Pressure Lateral 2 feet

Figure B26 Pressure Lateral 2 feet

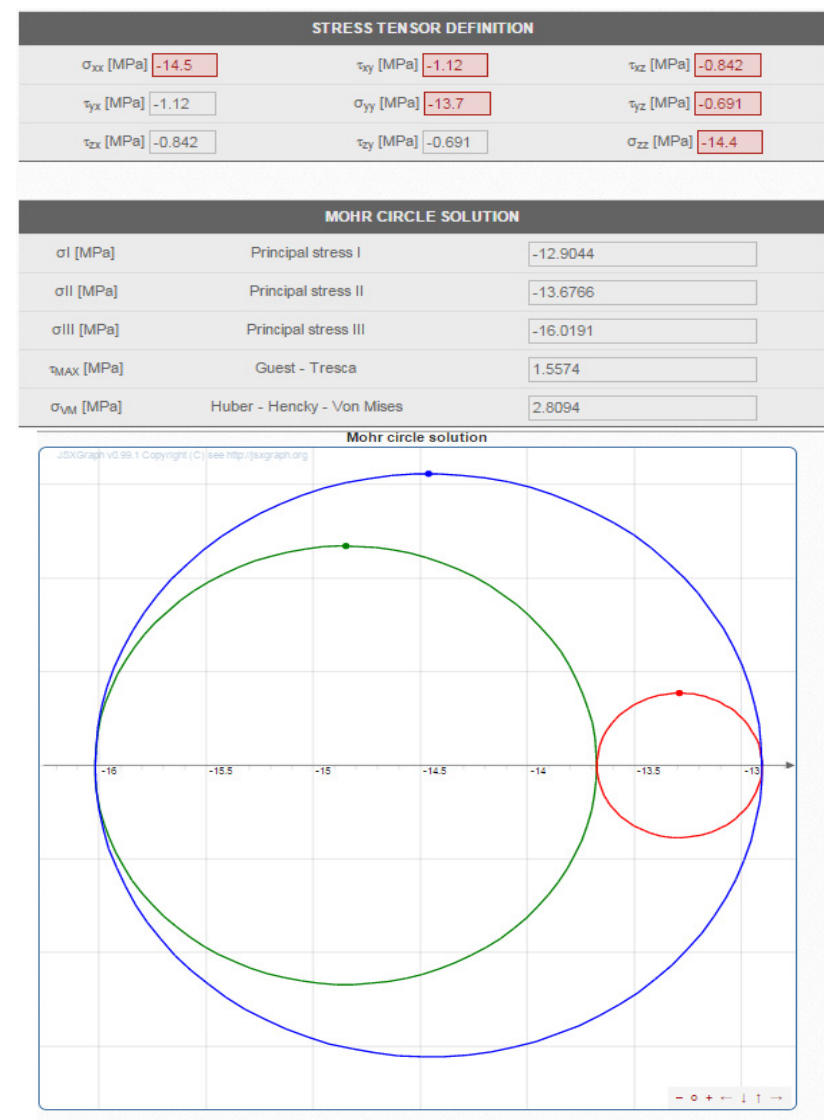

Figure B27 Mohr Circle for Lateral 2 Feet Impact 


\section{B3.2 Drop Height of 3 feet}

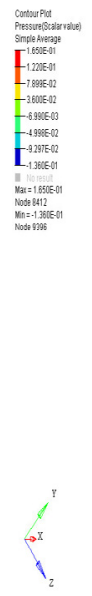

Figure B28 Pressure Lateral 3 feet
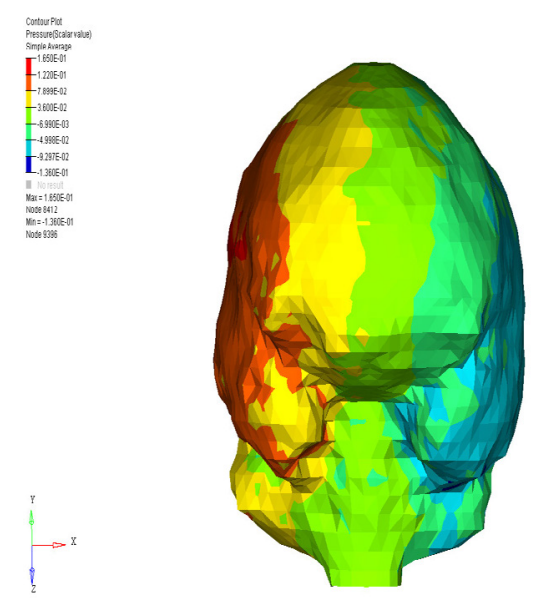

Figure B30 Pressure Lateral 3 feet
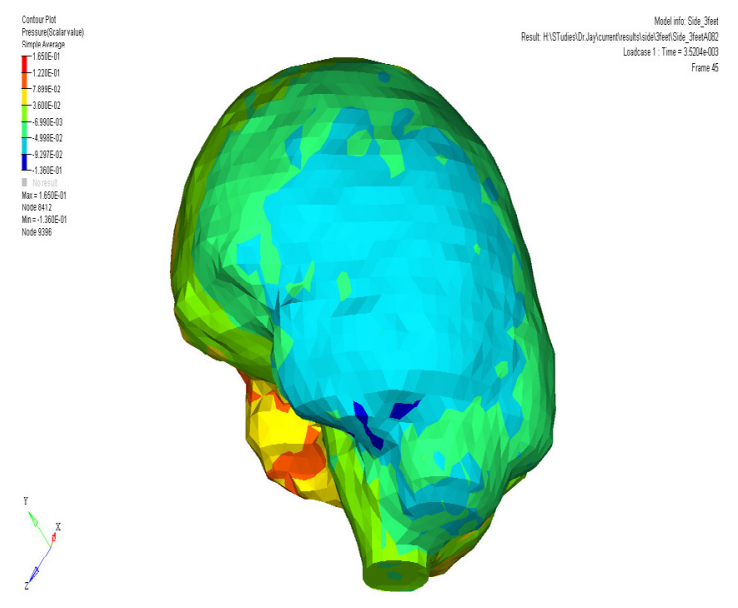

Figure B29 Pressure Lateral 3 feet
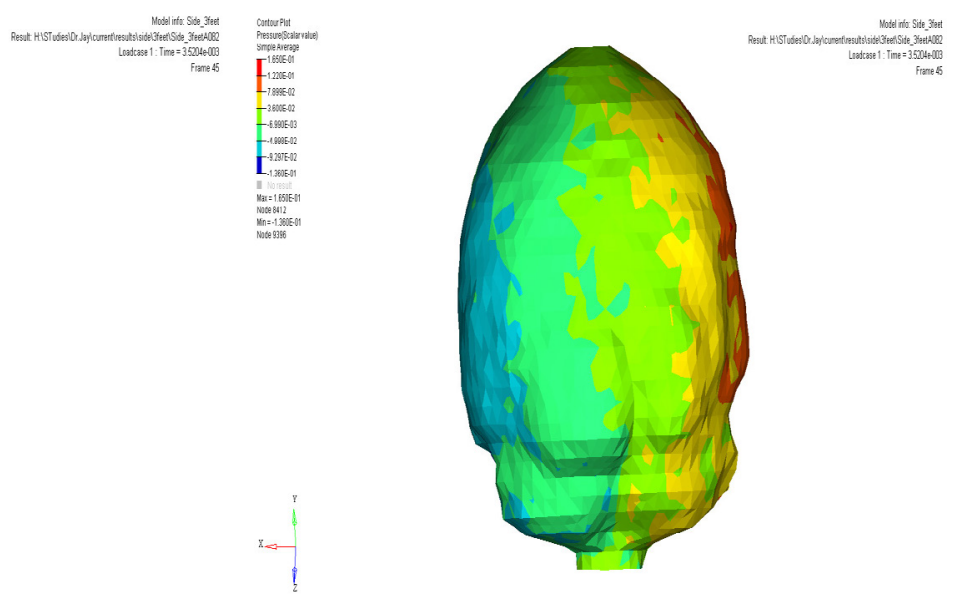

Figure B31 Pressure Lateral 3 feet 

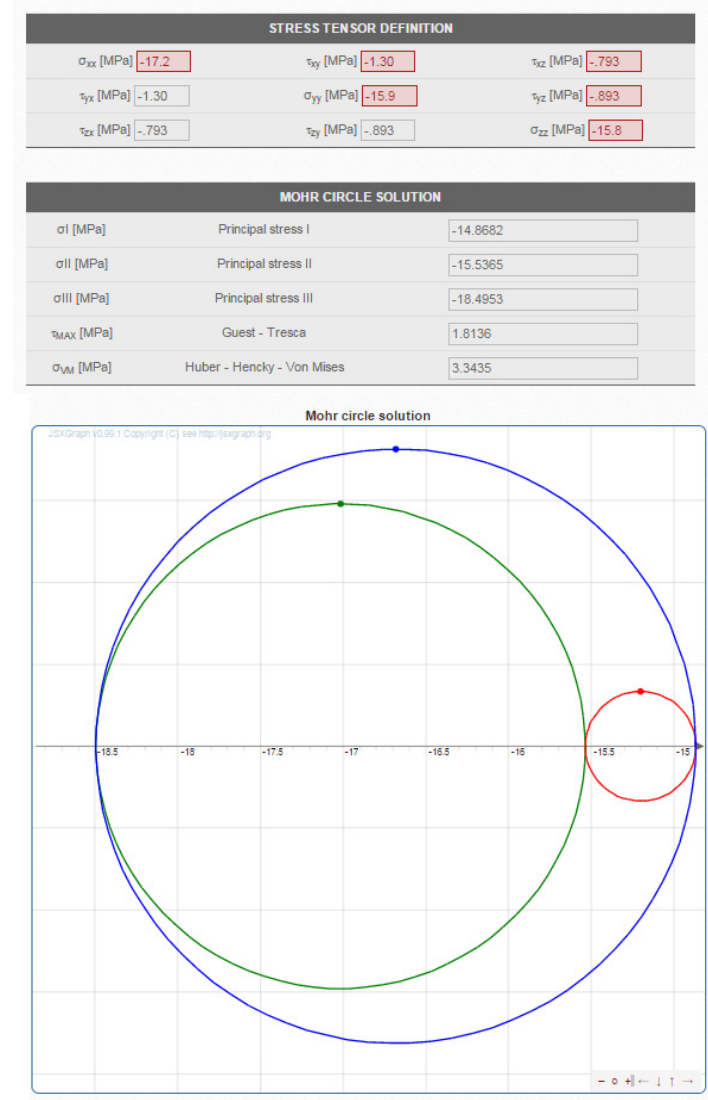

Figure B32 Mohr Circle for Lateral 3 Feet Impact

\section{B3.3 Drop Height of 4 feet}

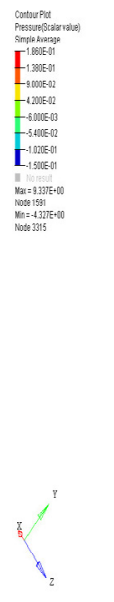

Figure B33 Pressure Lateral 4 feet
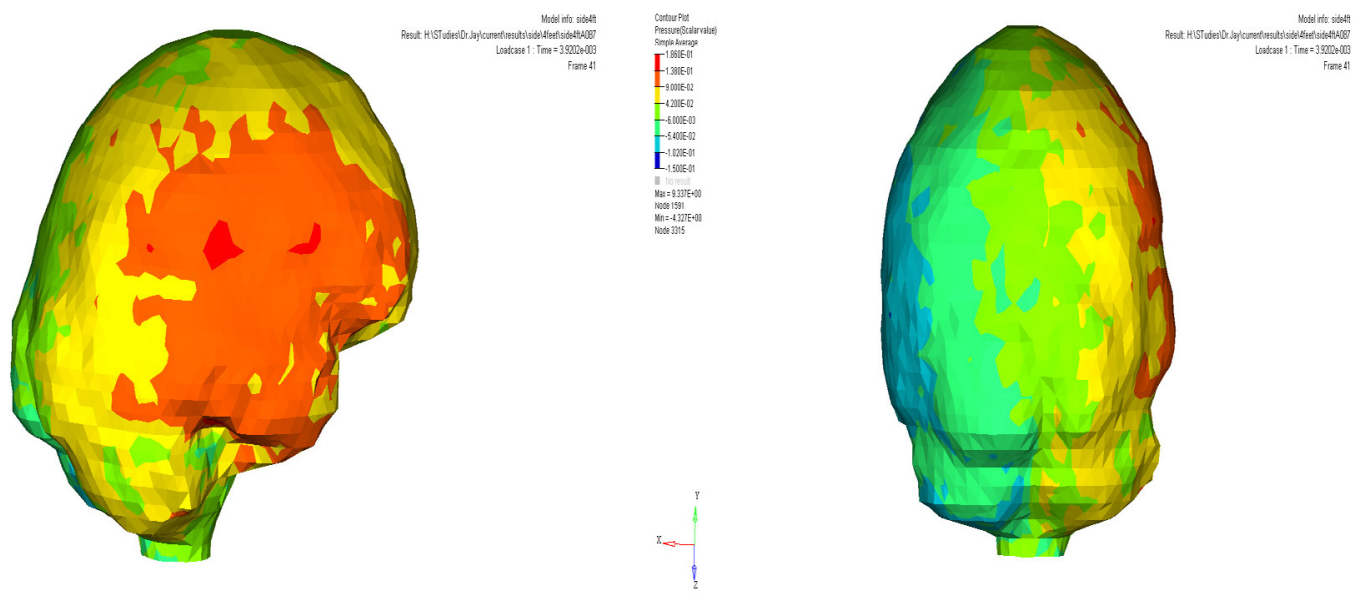

Figure B34 Pressure Lateral 4 feet 


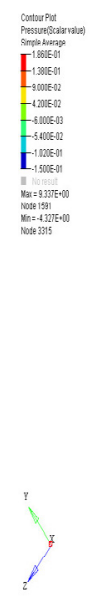

Figure B35 Pressure Lateral 4 feet
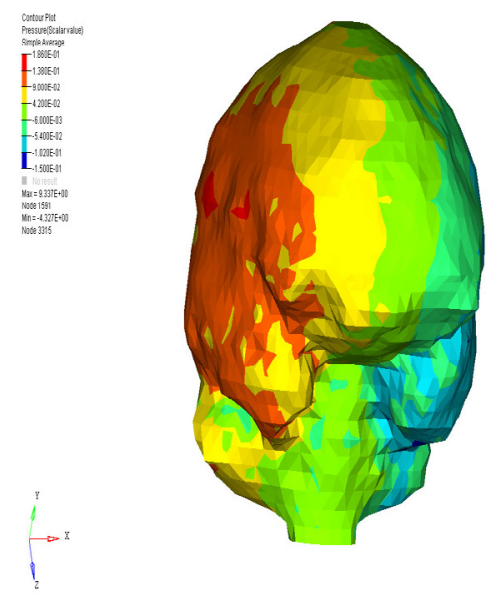

Figure B36 Pressure Lateral 4 feet

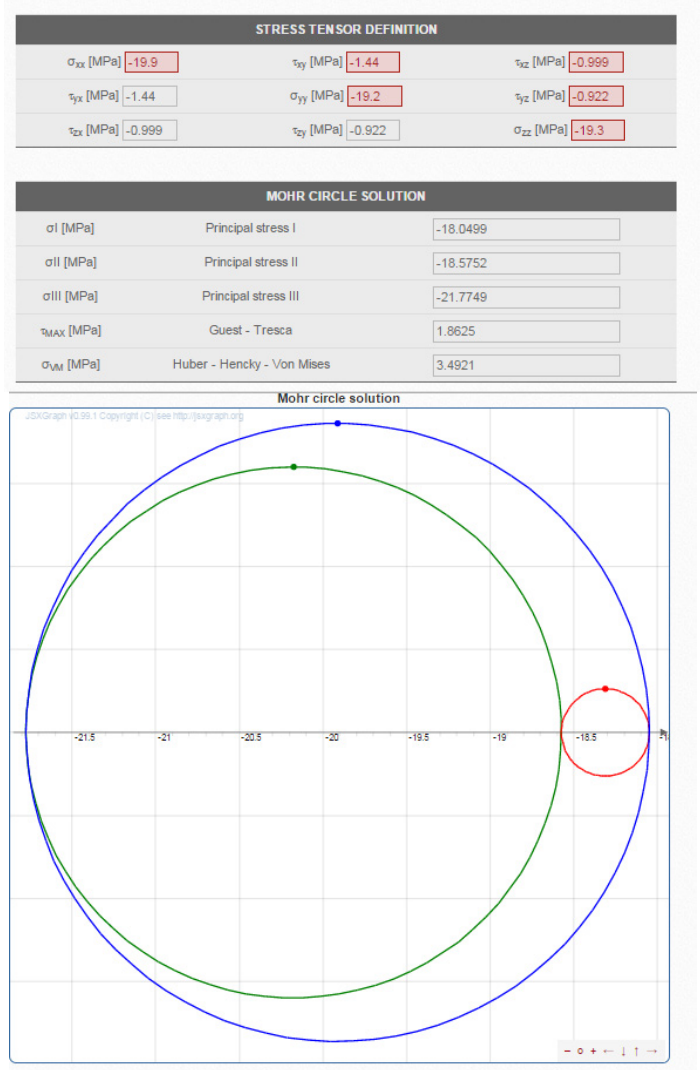

Figure B37 Mohr Circle for Lateral 4 Feet 


\section{B3.4 Drop Height of 5 feet}
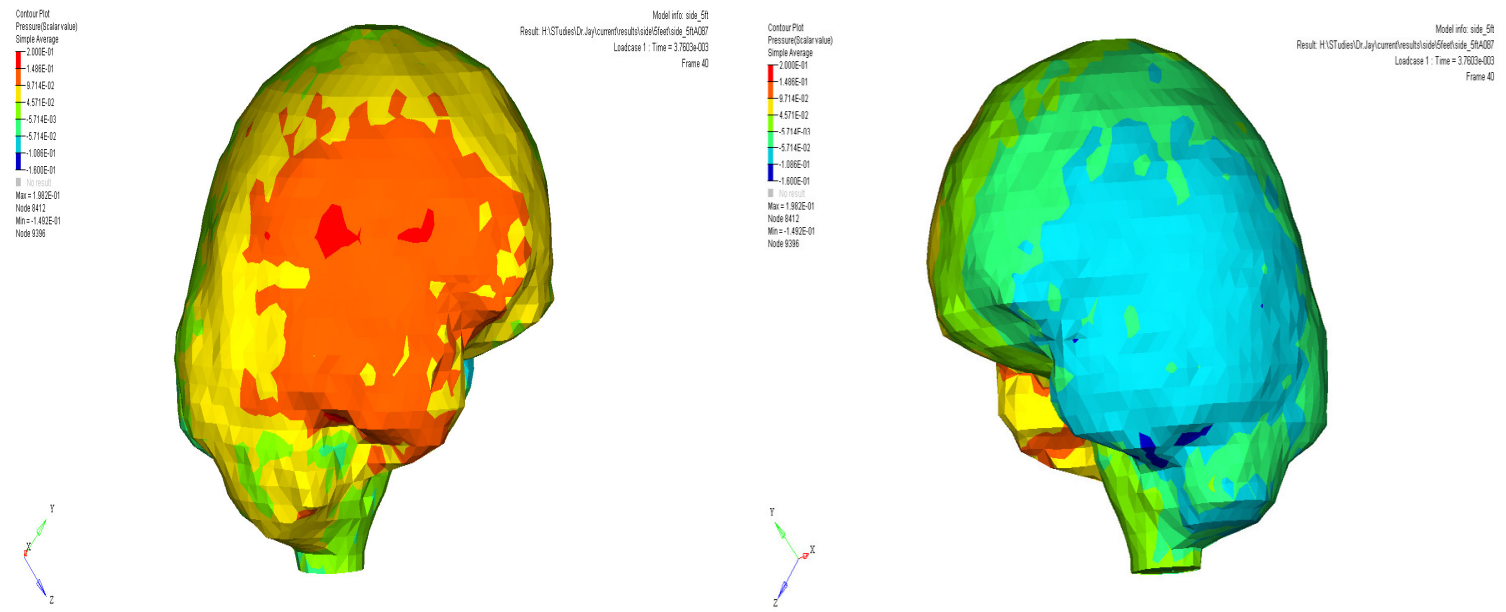

Figure B38 Pressure Lateral 5 feet

Figure B39 Pressure Lateral 5 feet
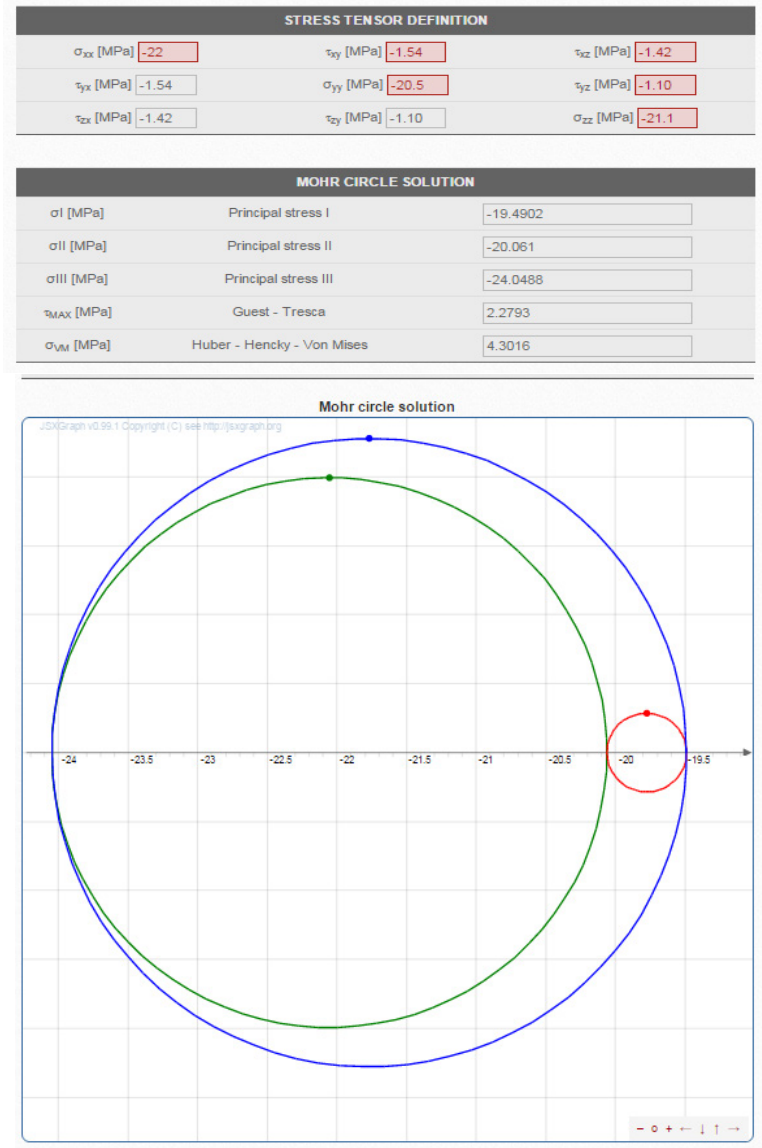

Figure B40 Mohr Circle for Lateral 5 Feet 


\section{B4 Posterior}

\section{B4.1 Drop Height of 2 feet}
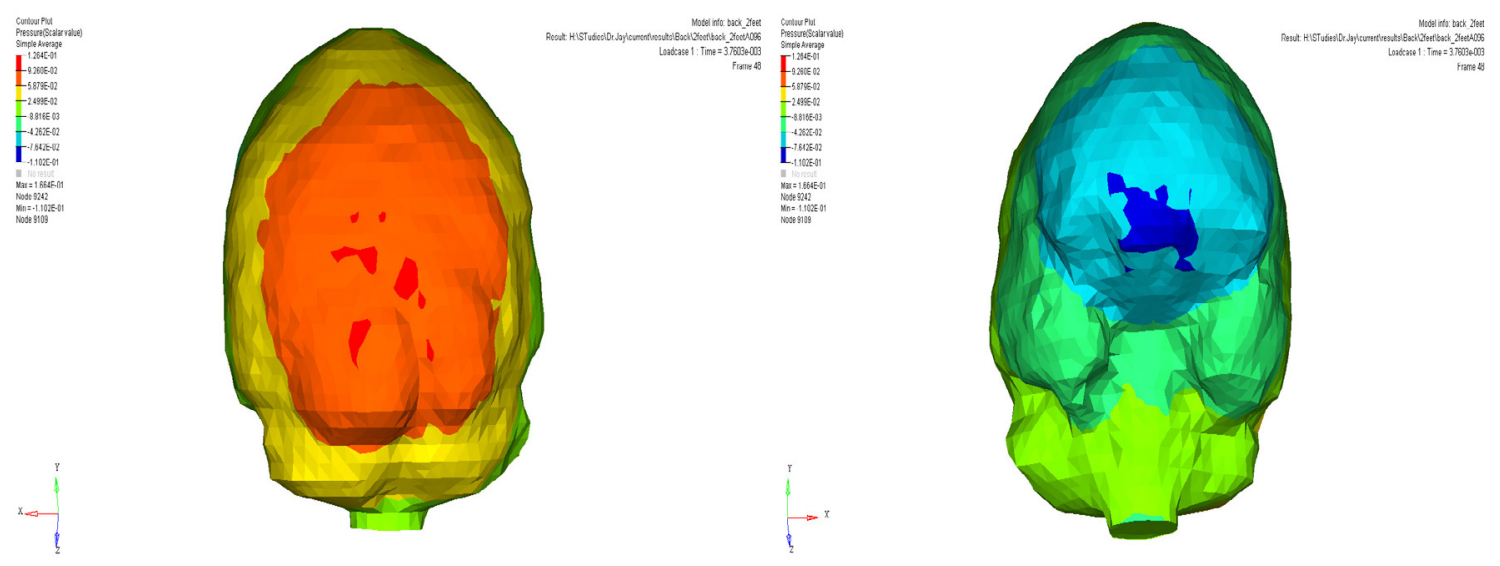

Figure B41 Pressure Posterior 2 feet

Figure B42 Pressure Posterior 2 feet

\begin{tabular}{|c|c|c|c|}
\hline \multicolumn{4}{|c|}{ STRESS TENSOR DEFINITION } \\
\hline$\sigma_{x x}[\mathrm{MPa}]-12.6$ & $\tau_{x y}[\mathrm{MPa}] \quad 0.714$ & & $\tau_{J_{2}}[\mathrm{MPal}]-0.615$ \\
\hline 5yx $[ \mathrm { MPa } ] \longdiv { 0 . 7 1 4 }$ & $\sigma_{y y}[\mathrm{MPa}]-12.80$ & & ${ }_{7 y z}[\mathrm{MPa}]-1.35$ \\
\hline $\mathrm{J}_{\mathrm{z} x}[\mathrm{MPa}]-0.615$ & $\mathrm{~T}_{\mathrm{z} y}[\mathrm{MPa}]-1.35$ & & $\sigma_{z z}[\mathrm{MPa}]-12.6$ \\
\hline \multicolumn{4}{|c|}{ MOHR CIRCLE SOLUTION } \\
\hline बI [MPa] & Principal stress I & -10.8454 & \\
\hline oll [MPa] & Principal stress II & -13.0912 & \\
\hline Glll [MPa] & Principal stress III & -14.0633 & \\
\hline тMax [MPa] & Guest - Tresca & 1.6089 & \\
\hline$\sigma_{\mathrm{m}}[\mathrm{MPa}]$ & Huber - Hencky - Von Mises & 2.8586 & \\
\hline
\end{tabular}

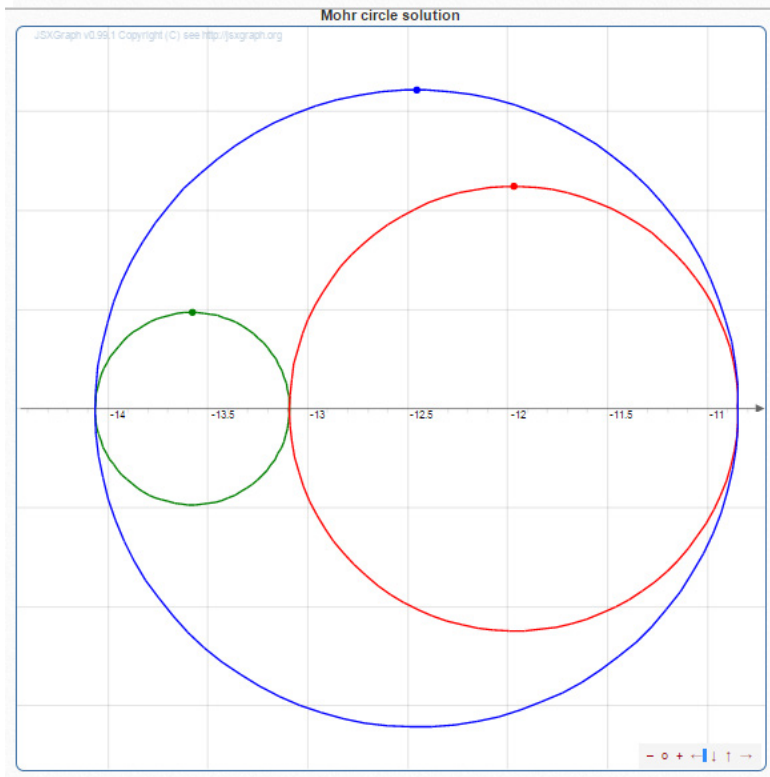

Figure B43 Mohr Circle for Posterior 2 Feet impact 


\section{B4.2 Drop Height of 3 feet}
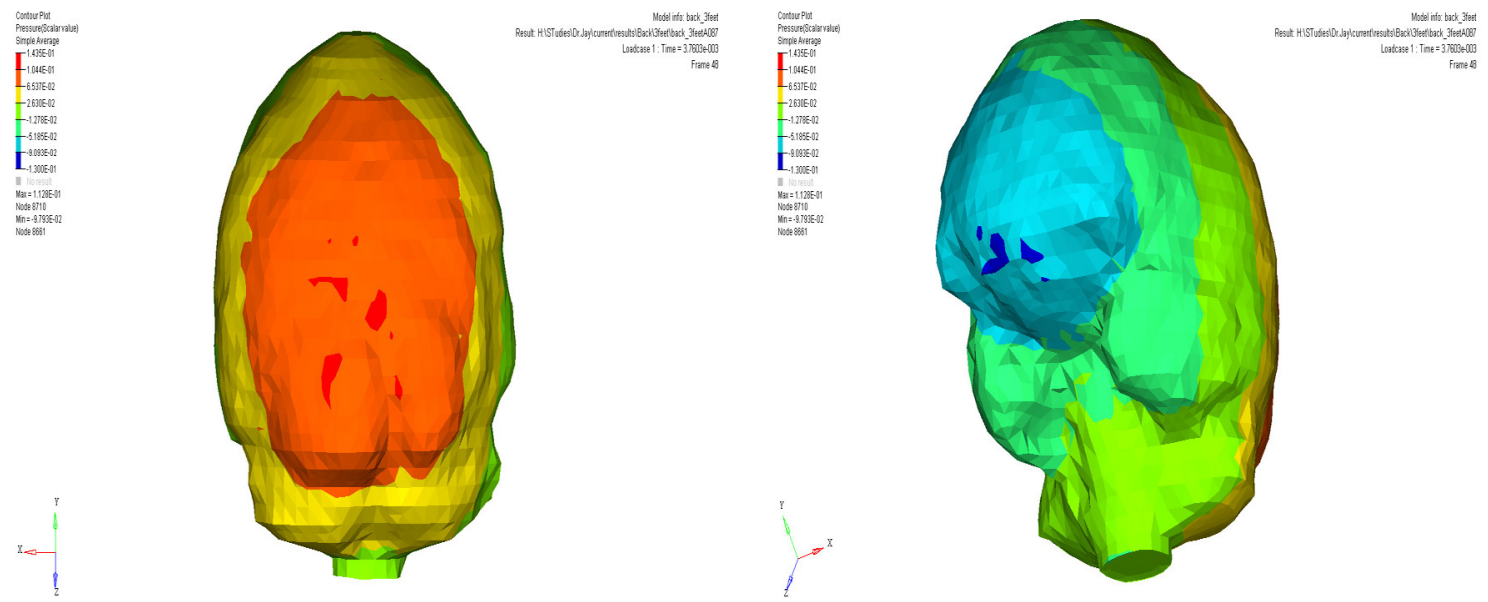

Figure B44 Pressure Posterior 3 feet

Figure B45 Pressure Posterior 3 feet

\begin{tabular}{|c|c|c|c|}
\hline \multicolumn{4}{|c|}{ STRESS TENSOR DEFINIIION } \\
\hline$\sigma_{\mathrm{xx}}[\mathrm{MPa}]-14.3$ & $\tau _ { y y } [ \mathrm { MPa } ] \longdiv { 0 . 8 3 6 }$ & & 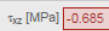 \\
\hline $5 \times[\mathrm{MPa}] 0.836$ & $\sigma_{y y}[\mathrm{MPa}]-14.2$ & & $x_{y z}[\mathrm{MPa}]-1.53$ \\
\hline $\operatorname{szx}_{[\mathrm{MPa}]}-0.685$ & sy $[\mathrm{MPa}]-1.53$ & & $\sigma_{z z}[\mathrm{MPa}]-14.3$ \\
\hline \multicolumn{4}{|c|}{ MOHR CIRCLE SOLUTION } \\
\hline ol [MPa] & Principal stress I & -12.1731 & \\
\hline oll [MPa] & Principal stress II & -14.8389 & \\
\hline olll [MPa] & Principal stress III & -15.788 & \\
\hline $\max [\mathrm{MPa}]$ & Guest - Tresca & 1.8074 & \\
\hline$\sigma_{\mathrm{M}}[\mathrm{MPa}]$ & Huber - Hencky - Von Mises & 3.2461 & \\
\hline
\end{tabular}

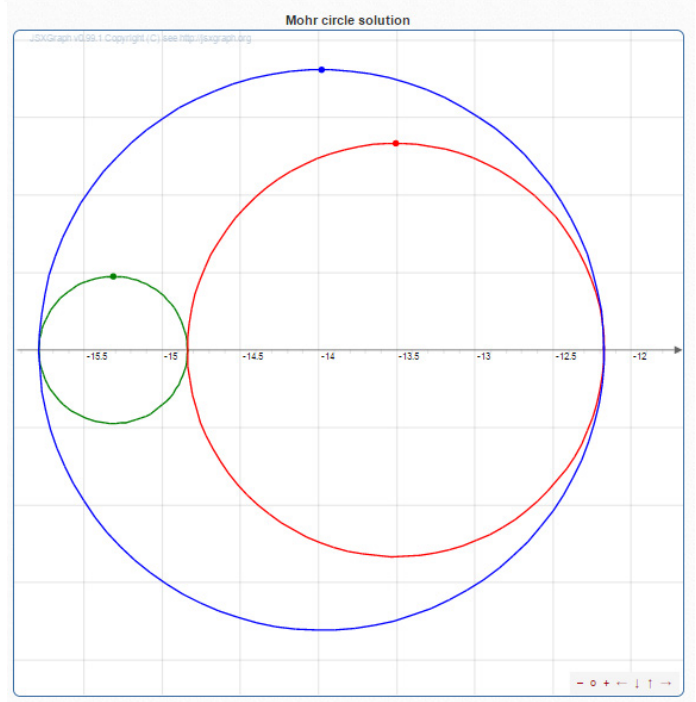

Figure B46 Mohr Circle for Posterior 3 Feet 


\section{B4.3 Drop Height of 4 feet}

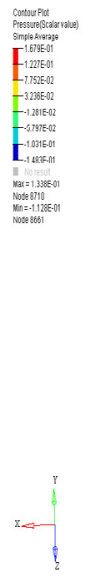

Figure B47 Pressure Posterior 4 feet
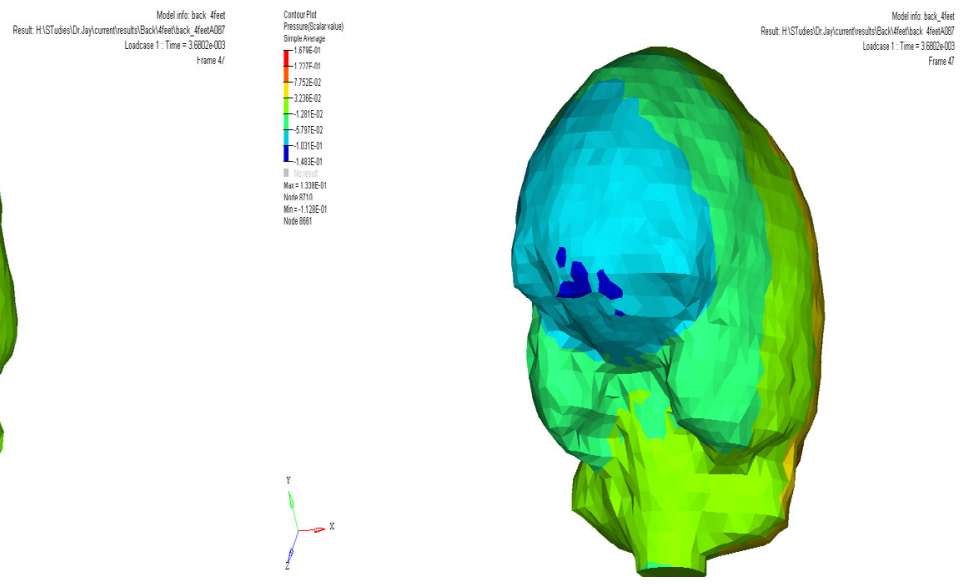

Figure B48 Pressure Posterior 4 feet
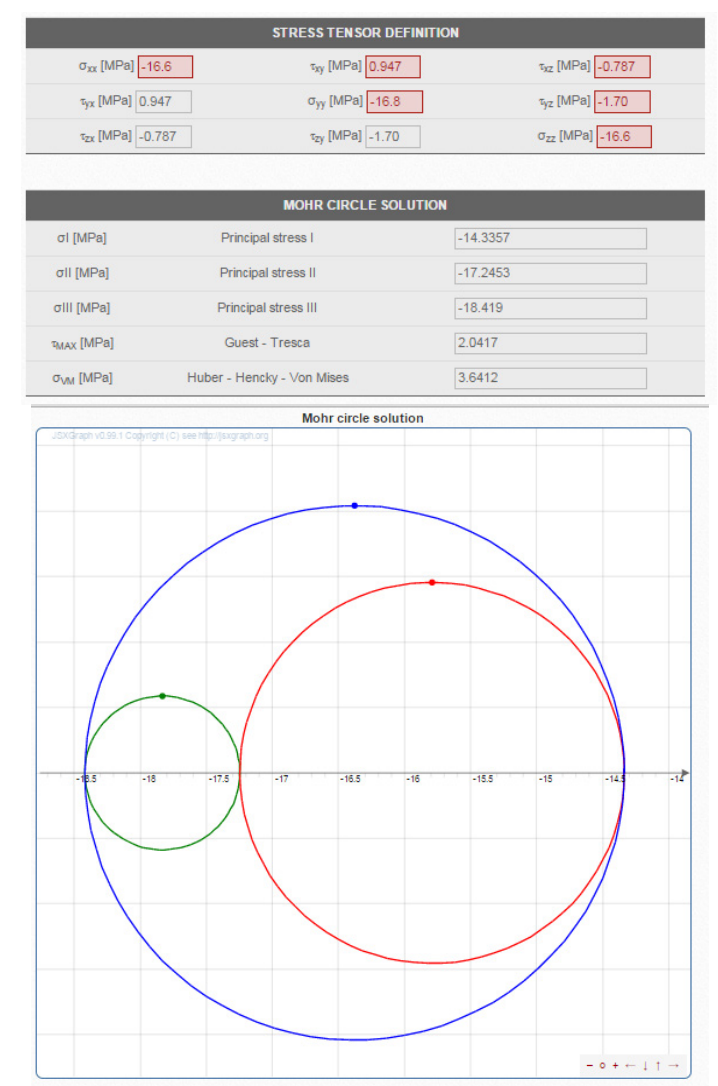

Figure B49 Mohr Circle for Posterior 4 Feet Impact 


\section{B4.4 Drop Height of 5 feet}
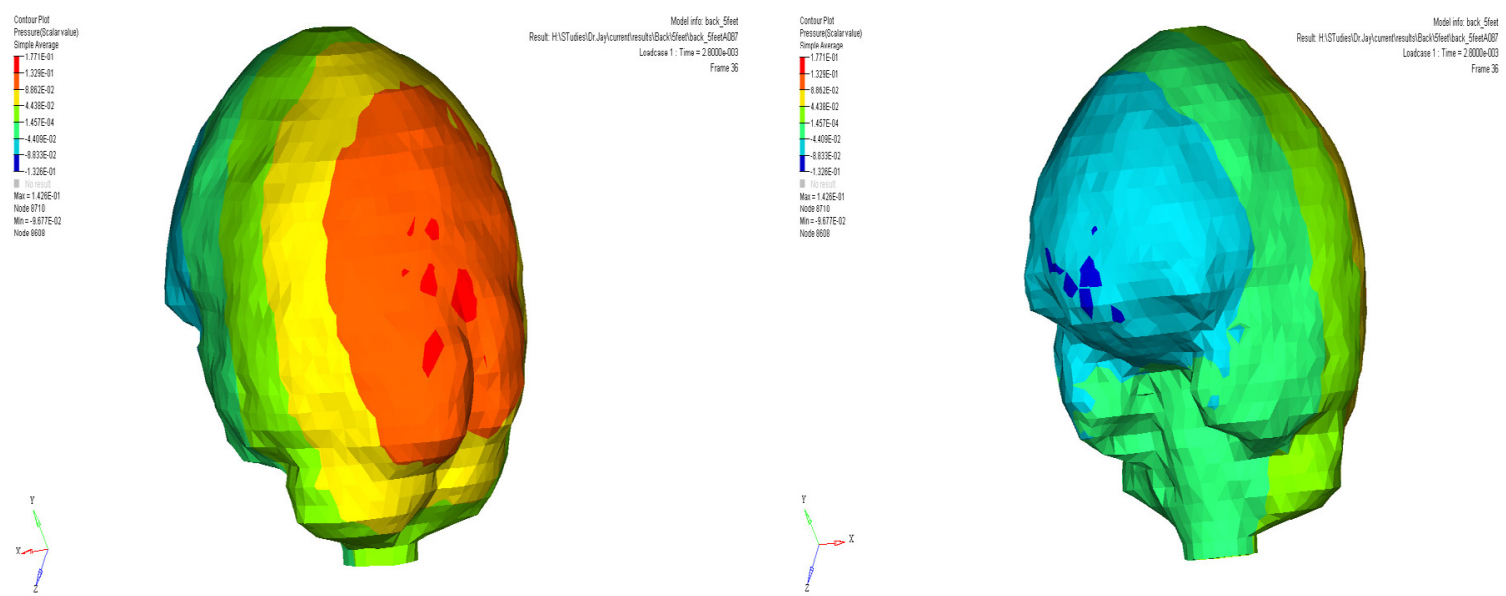

Figure B50 Pressure Posterior 5 feet

Figure B51 Pressure Posterior 5 feet

\begin{tabular}{|c|c|c|c|}
\hline \multicolumn{4}{|c|}{ STRESS TENSOR DEFINITION } \\
\hline$\sigma_{x x}[\mathrm{MPa}]-19$ & $\tau_{x y}[\mathrm{MPa}] 1.13$ & & ${ }^{5}[\mathrm{MPa}]-0.914$ \\
\hline$\tau_{y x}[\mathrm{MPa}] \quad 1.13$ & $\sigma_{y y}[\mathrm{MPa}]-19.2$ & & $x_{y z}[\mathrm{MPa}]-2$ \\
\hline$\tau_{z x}[\mathrm{MPa}]-0.914$ & $\tau_{z y}[\mathrm{MPa}]-2$ & & $\sigma_{z z}[\mathrm{MPa}]-19$ \\
\hline \multicolumn{4}{|c|}{ MOHR CIRCLE SOLUTION } \\
\hline ol [MPa] & Principal stress I & -16.3204 & \\
\hline Gll [MPa] & Principal stress II & -19.755 & \\
\hline olll [MPa] & Principal stress III & -21.1246 & \\
\hline $\operatorname{Max}[\mathrm{MPa}]$ & Guest - Tresca & 2.4021 & \\
\hline$\sigma_{\mathrm{MM}}[\mathrm{MPa}]$ & Huber - Hencky - Von Mises & 4.2868 & \\
\hline
\end{tabular}

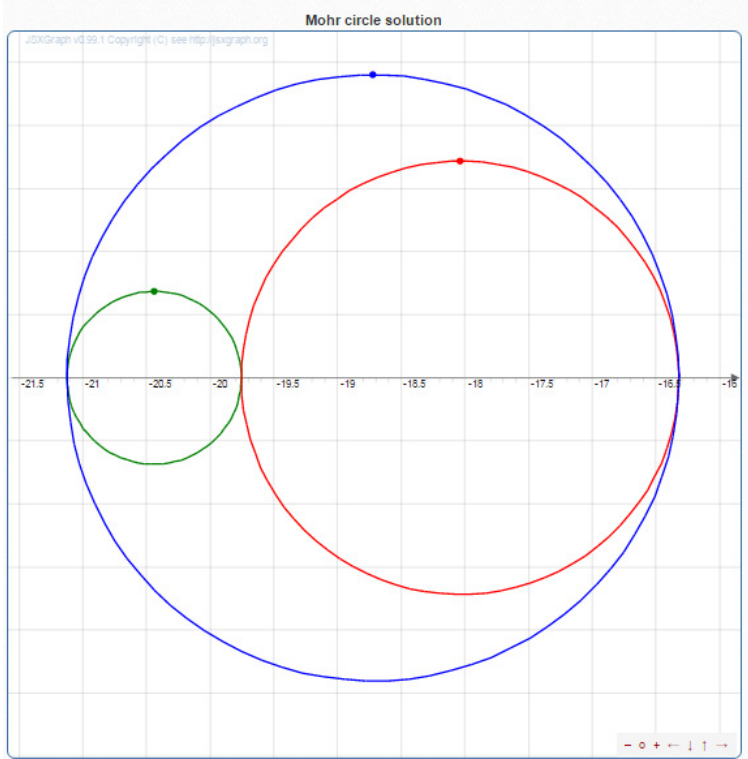

Figure B52 Mohr Circle for Posterior 5 Feet impact 


\section{Appendix C}

\section{Approach to Finite Element Analysis in Hypermesh.}

The detailed approach followed for the FE analysis in Altair Hypermesh ${ }^{5}$ has been explained below.

\section{Opening the Environment}

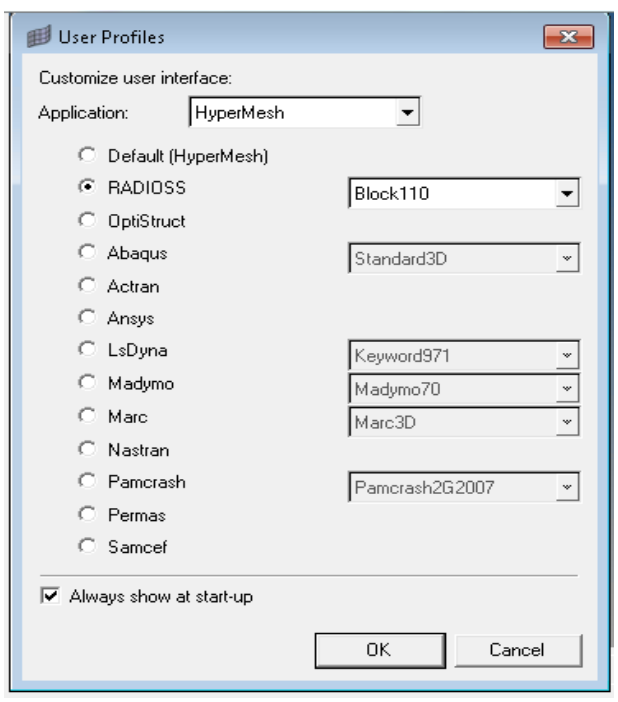

Figure C1 selecting the user profile in Hyperworks environment

Open the Hypermesh environment and select Altair ${ }^{\circledR}$ RADIOSS ${ }^{\circledR}$ and Block 110 module for the Impact analysis.

\section{Importing the Model.}

The 3D model of the head form has been imported into the Altair ${ }^{\circledR}$ RADIOSS ${ }^{\circledR}$ environment. This model has the properties imported along with the environments.

\footnotetext{
${ }^{5}$ All Images in this chapter are screen shots taken from Altair Hyperworks software and has been used as a representation for a step by step guide to FE Analysis work done in this work.

Image Courtesy: http://www.altairuniversity.com/category/united-states/ 


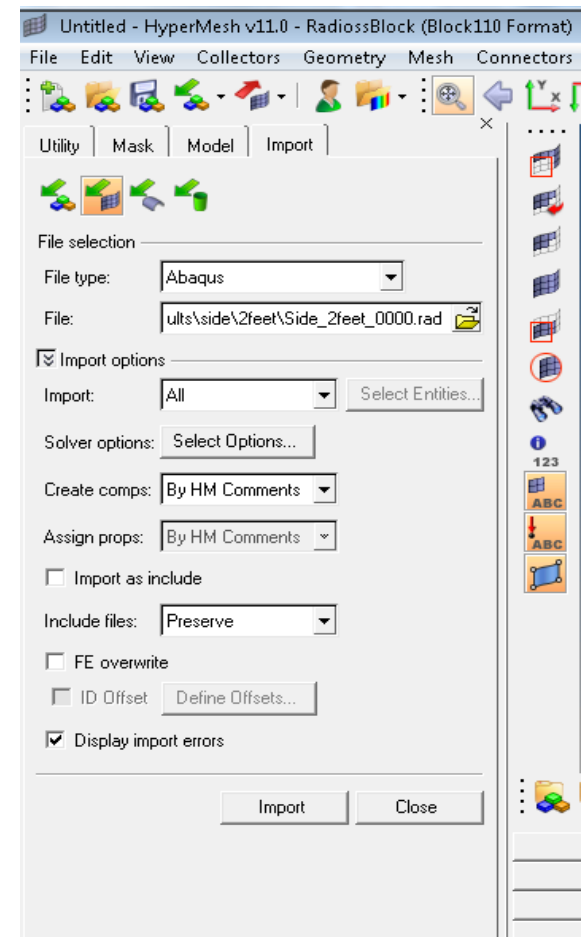

Figure C2 Importing FE Model from other environment

\section{Creating a Mesh.}

The mesh has been created by following the steps below and the properties of the mesh has also been shown.

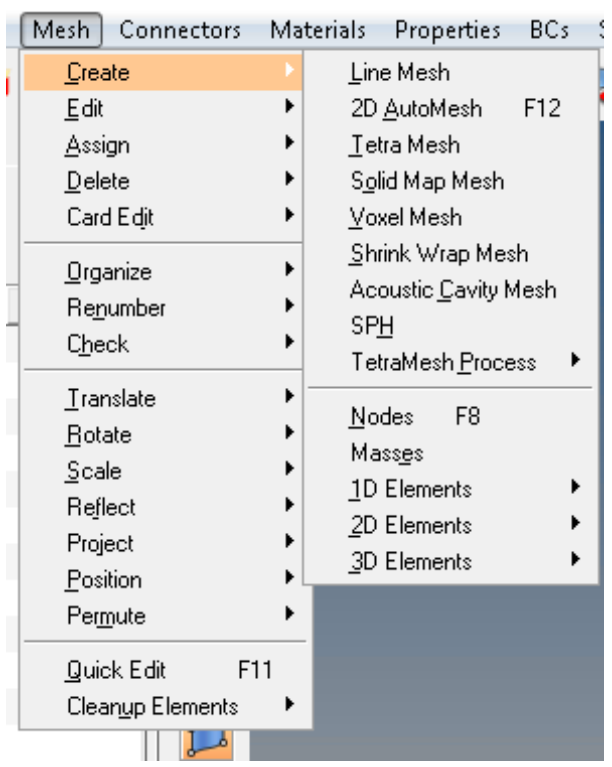

Figure C3 Creation of mesh 


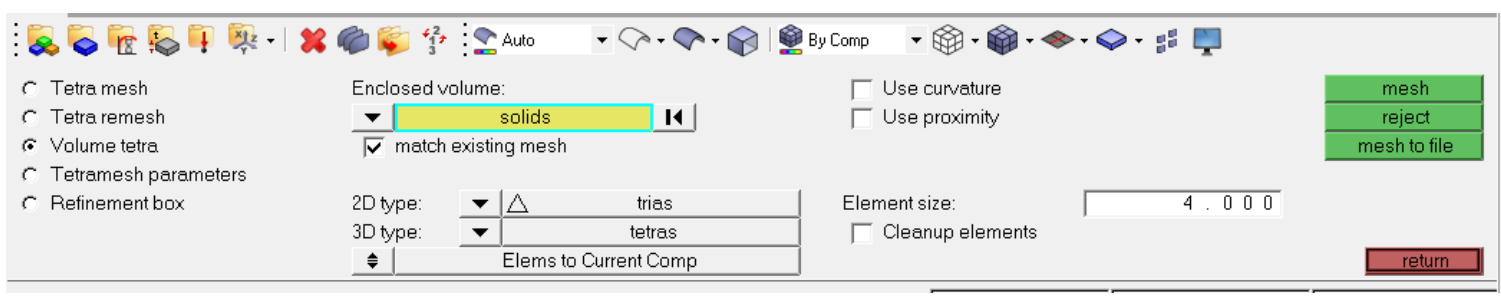

Figure C4 Mesh Properties

Tetra mesh was used for this purpose and care should be taken not to mesh all the layers at a time and keep the other layers hidden while meshing a particular layer. The element size should not be too big that there would be a chance for error while it should not be too small to increase the analysis time.

\section{Creating a material.}

Create a material and assign the cards accordingly. The material was considered elastic for our analysis.

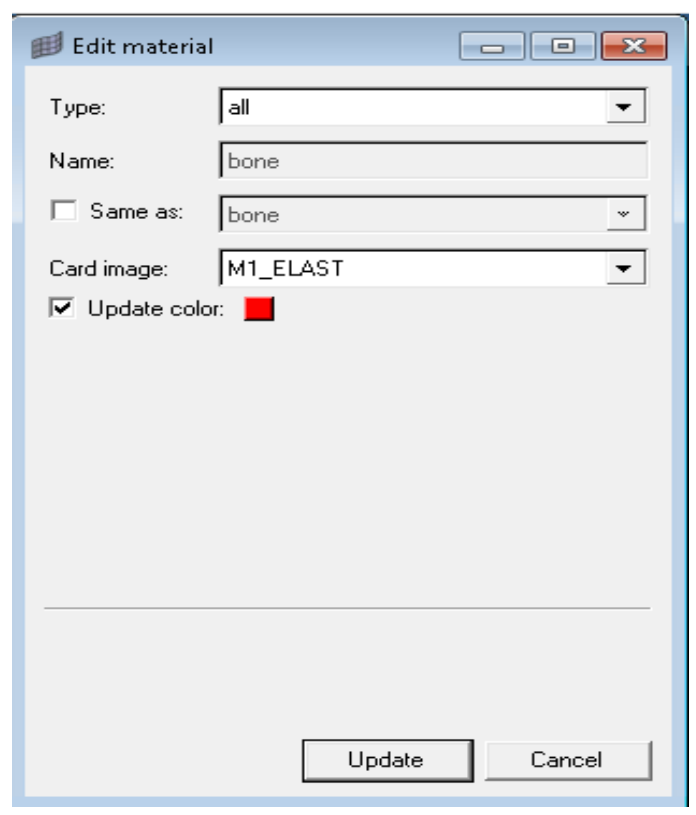

Figure C5 Material assignment Tab

\section{Creating a Component.}


Create a component for each and every layer. Assign the "part" card file for the same.

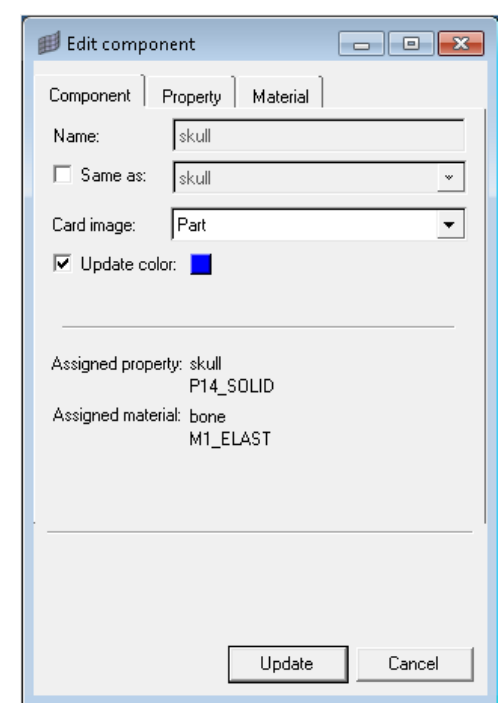

Figure C6 Component Assignment tab

\section{Assign a Property.}

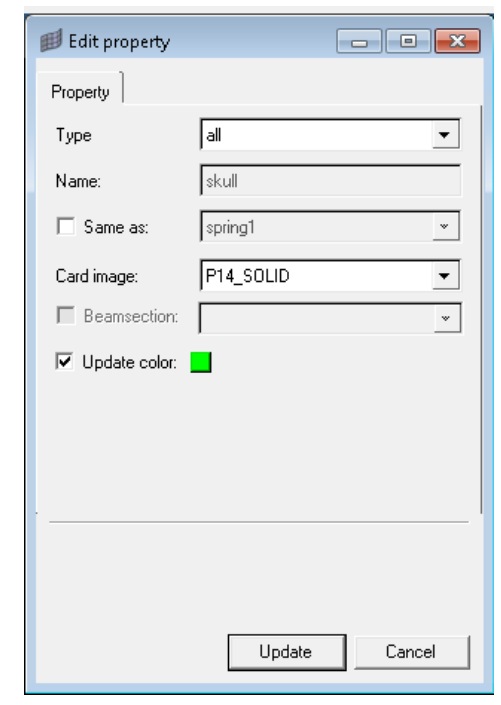

Figure C7 Property assignment tab

Create a property for every layer and Assign the "P14 Solid" card for every component.

Edit the card for that particular component to assign the properties which were shown in the table 4.1 


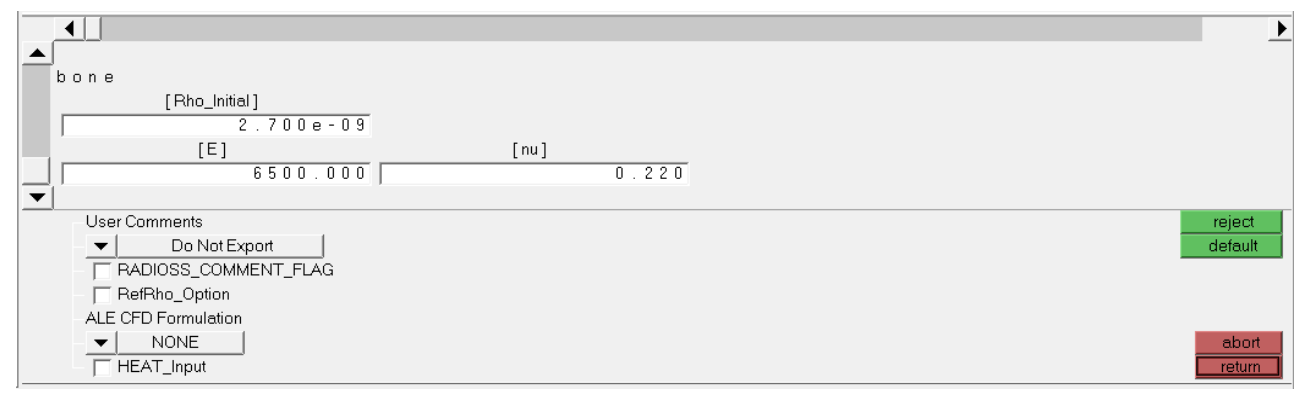

Figure C8 Mechanical Property assignment to the FE Model

\section{Spring element}

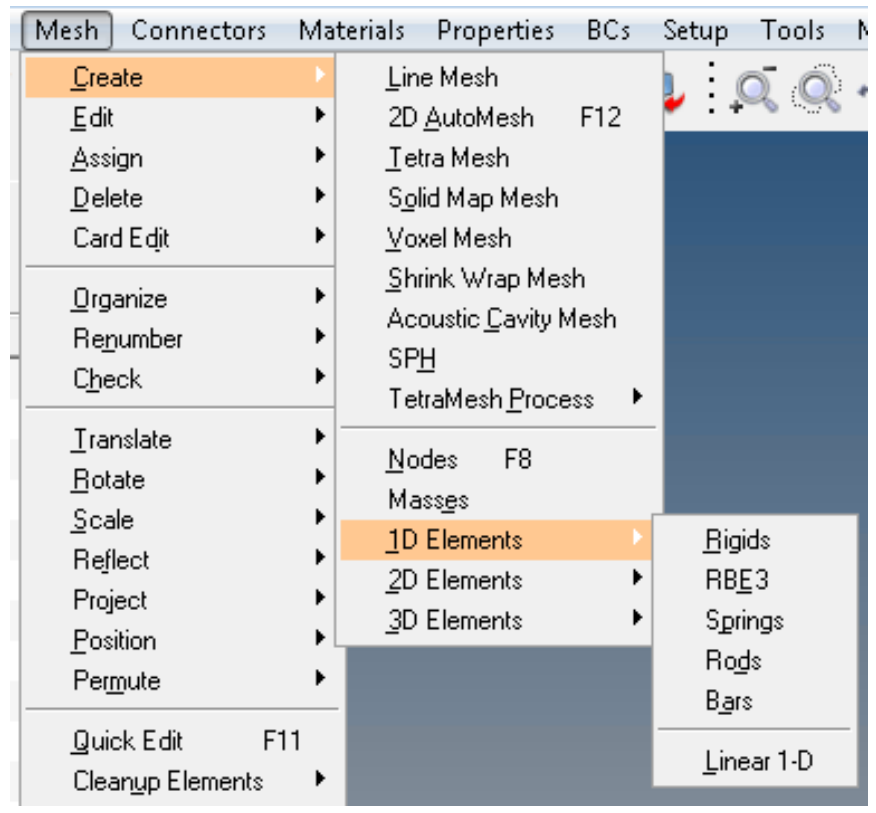

Figure C9 Creation of Spring element

Create a node at a unit distance from all the elements which need to be constrained.

Create a spring element to constrain the 6 degrees of freedom for all the nodes.

Create a corresponding property and material and assign the spring constant for the spring element.

\section{Contact surfaces}

The area of impacts are imposed on the model as contact surfaces. Create the contact surfaces for respective regions of impact by selecting the particular elements. 


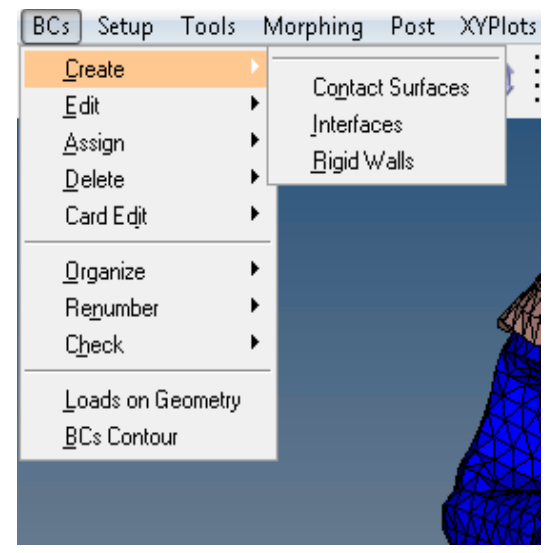

Figure C10 Creation of Contact Surfaces

\section{Curves}

The HICP has been applied to the FE model in terms of Impact curve. Create the curve for every Impact.

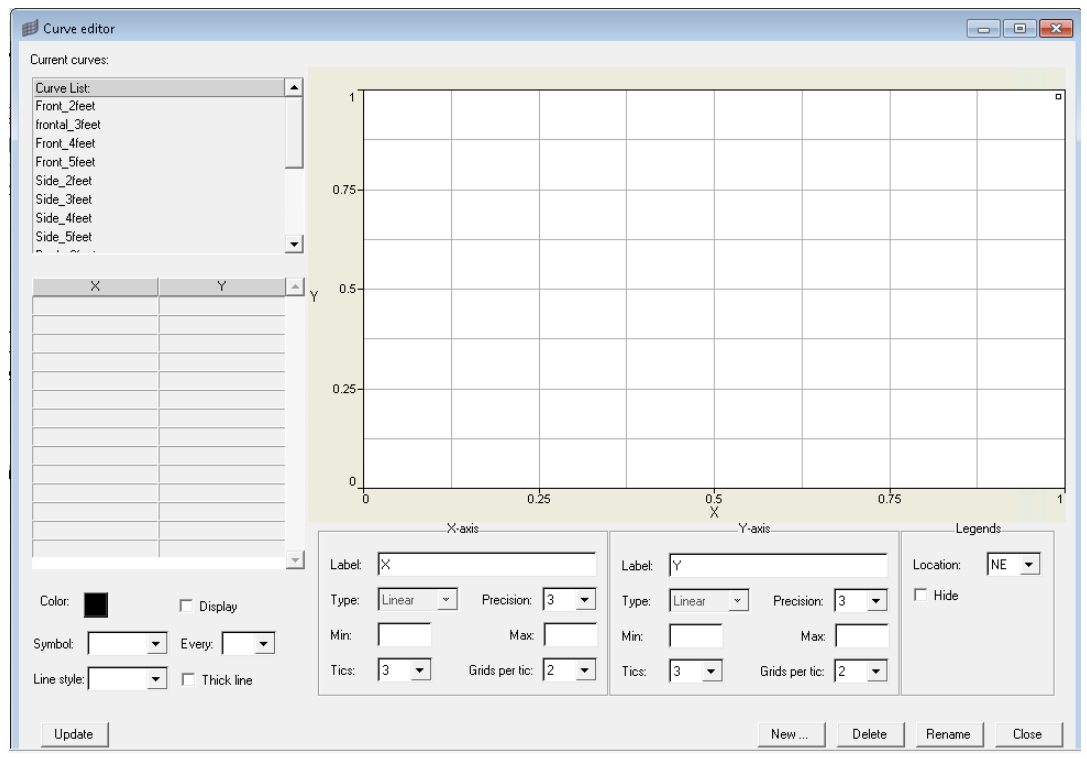

Figure C11 Creation of Input plots

\section{Load Collector}

Create a load collector for Boundary condition and the pressure input. Assign the corresponding card images for them. 


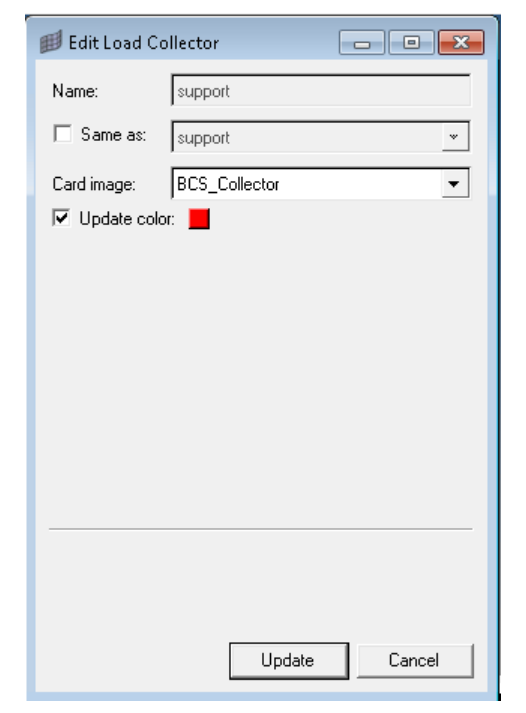

Figure C12 Creation of Load collector

\section{BC Manager}

It is the step in which we constrain the model and assign the HICP curves to the model.

Constrain the spring node in all directions (6 Degrees of Freedom).

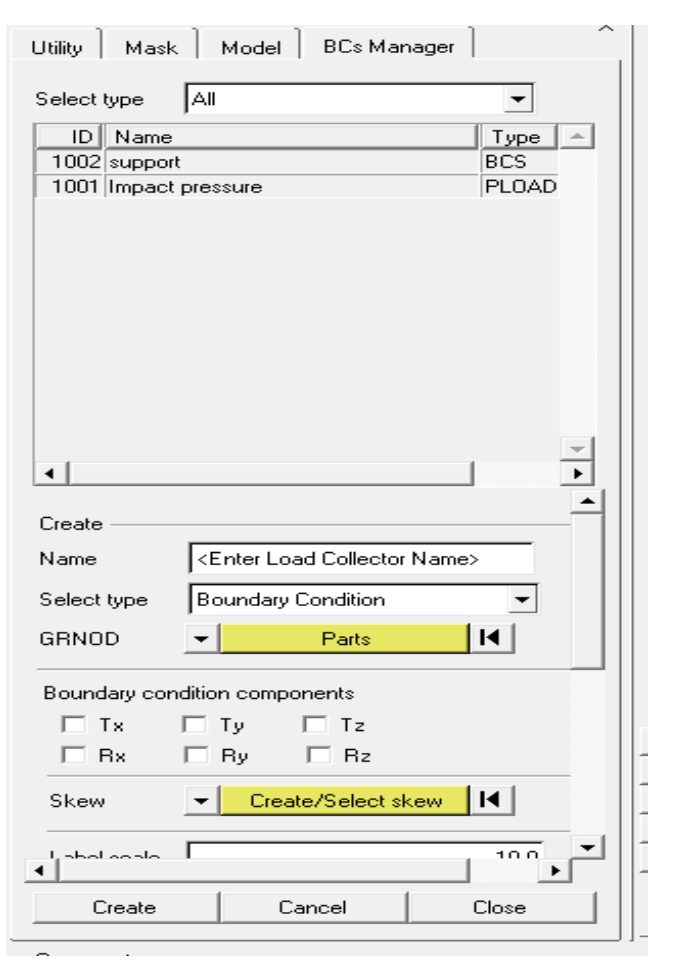

Figure C13 BC Manager 
Create a corresponding $\mathrm{BC}$ manager property for constraining the model, select the appropriate pressure curve and corresponding area as the input.

\section{Engine File}

It is an important step where we select the properties which we want in the output. It is an important step where we create the output time step.

In the Fig C14 TStop corresponds to the value in which we want the analysis to stop, while Time frequency refers to the point where we decide how many time steps we want for the analysis. We have considered a time step of 100 for this analysis.

ANIM Keyl corresponds to the selection of output parameters like stresses and pressures in the analysis.

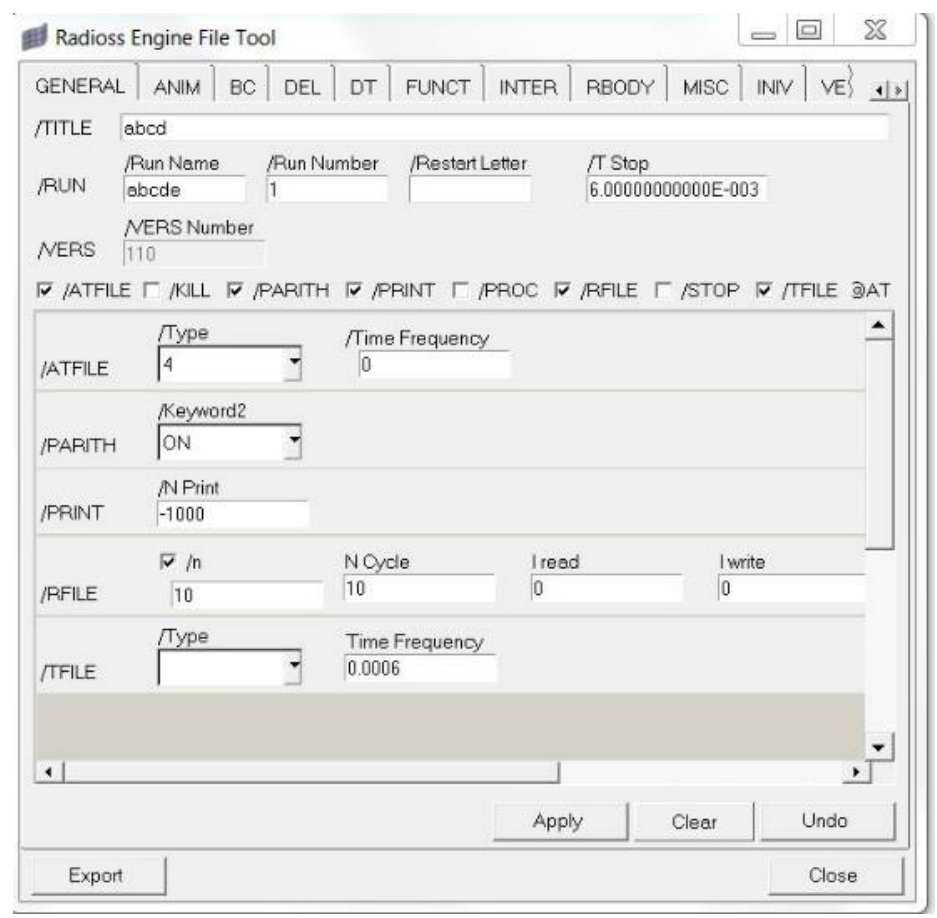

Figure C14 Engine File 1 showing output time step settings 


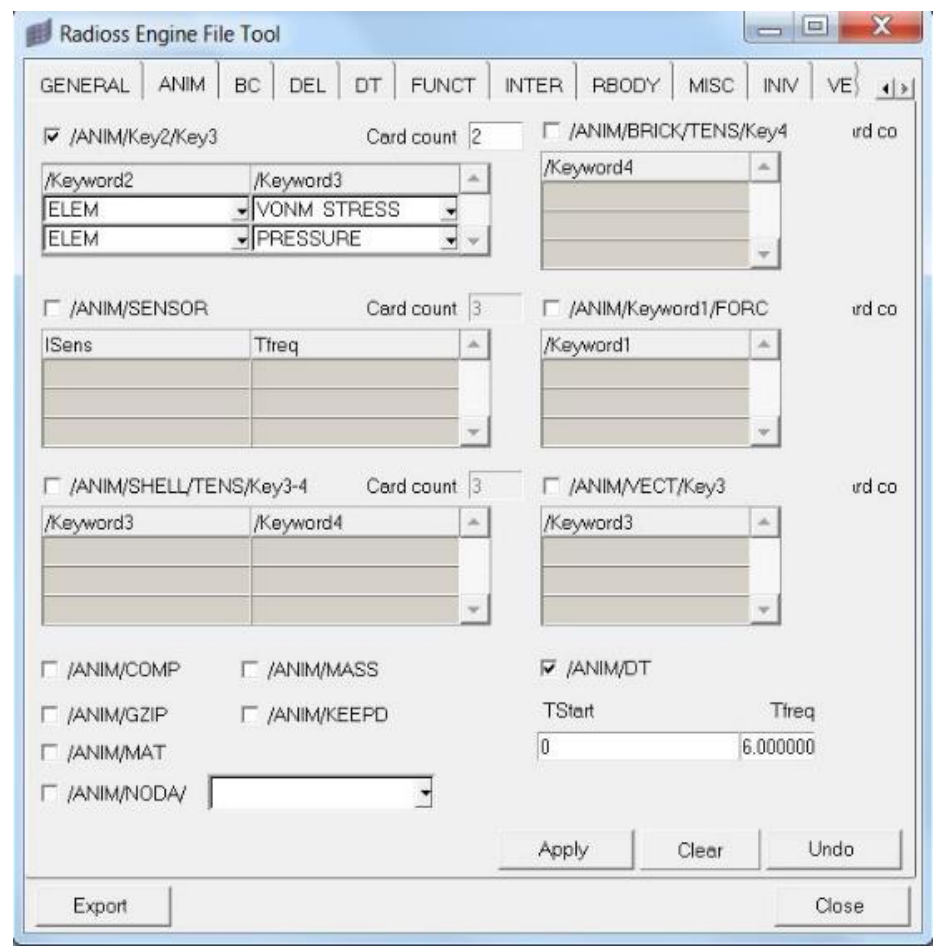

Figure C15 Engine File 2

\section{Exporting the Engine File toe Altair ${ }^{\circledR}$ RADIOSS ${ }^{\circledR}$ solver:}

The engine file needs to be exported and saved as Altair ${ }^{\circledR}$ RADIOSS $®$ solvable format (*.rad) in order to be in a valid format to be run by the Altair ${ }^{\circledR}$ RADIOSS $®$ solver. 


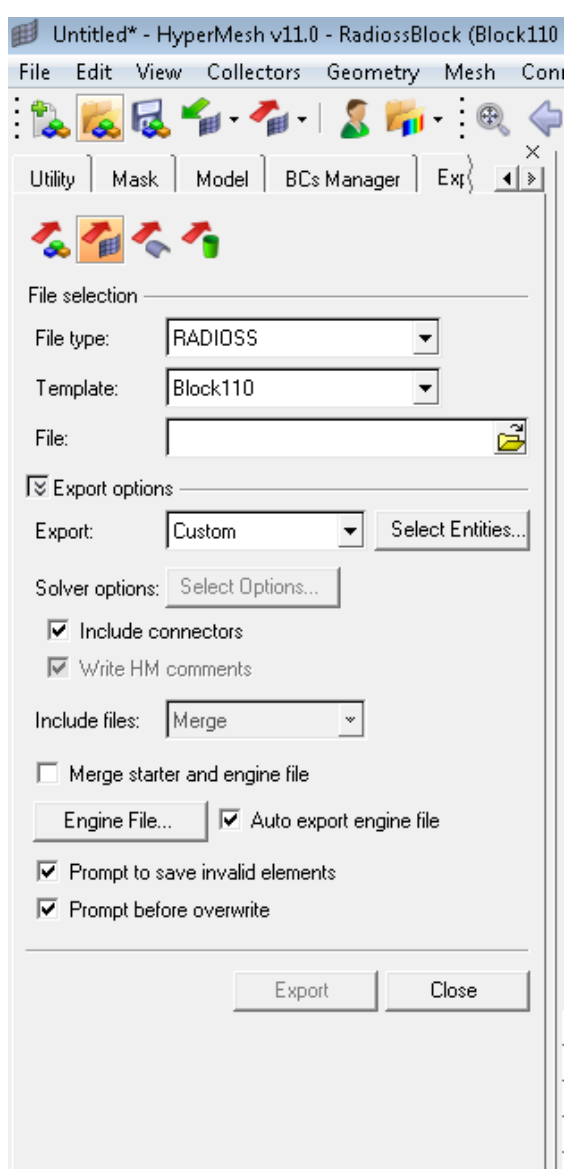

Figure C16 Creation of Altair ${ }^{\circledR}$ RADIOSS ${ }^{\circledR}$ File

The particular file can be run using the Altair ${ }^{\circledR}$ RADIOSS $($ solver.

\section{Post Processing.}

There would be a huge data which is obtained as an output and the animation files will be analyzed in Hyper View, which is a post processing tool.

The loaded animated file would be processed for obtaining the output. 


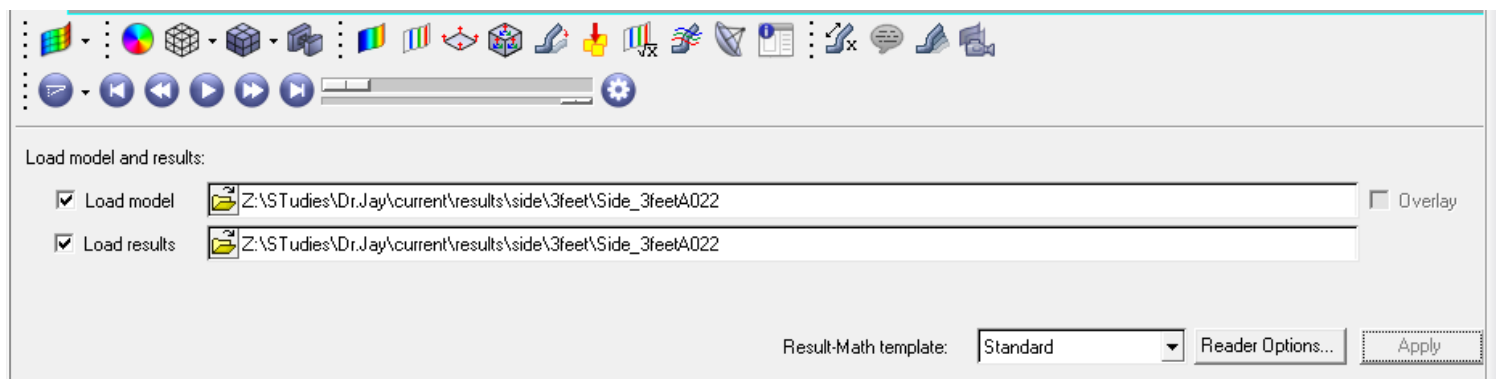

Figure C17 Importing results file into HyperView

\begin{tabular}{|c|c|c|c|c|c|c|c|c|c|}
\hline \multirow{2}{*}{$\begin{array}{l}\text { Result type: } \\
\text { Pressure (s) }\end{array}$} & \multirow{2}{*}{$\frac{\ddot{*}}{\nabla}$} & \multicolumn{2}{|c|}{ Selection: } & \multicolumn{2}{|r|}{ Averaging method: } & \multirow{6}{*}{$\begin{array}{l}\text { Display options: } \\
\square \text { Discrete color } \\
\Gamma \text { Interpolate colors }\end{array}$} & \multicolumn{2}{|c|}{ Legend threshold: } & \multirow{3}{*}{$\begin{array}{l}\text { Result display control: } \\
\Gamma \text { Overlay result display } \\
\text { Clear Contour } \\
\end{array}$} \\
\hline & & $\nabla$ & Components & | 14 & Simple & & $Г \operatorname{Max}:$ & 0 & \\
\hline Scalar value & $\nabla$ & \multicolumn{2}{|c|}{ Resolved in: } & & $\Gamma$ Variation< $\longdiv { 1 0 }$ (\%) & & $Г$ Min: & 0 & \\
\hline Entity with layers: & $\square$ & Analy & is System & $\nabla$ & Envelope trace plot: & & Multiplier: & $\overline{1}$ & 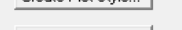 \\
\hline \multirow[t]{3}{*}{$\Gamma$ Use corner data } & & & System & 14 & |None & & Offset: & 0 & Show Iso Value \\
\hline & \multirow{2}{*}{\multicolumn{4}{|c|}{$\Gamma$ Use tracking system }} & & & \multirow{2}{*}{\multicolumn{2}{|c|}{ Edit Legend... }} & Projection Riule... \\
\hline & & & & & Apply & & & & Query Results... \\
\hline
\end{tabular}

Figure C18 Output Property manager in Hyperview

Select the colored format as the required output and select the result type which we want to analyze (Pressure in the above case) and select the averaging method to be simple and edit the legend in order to get the output in the range of values for the brain by trial and error method.

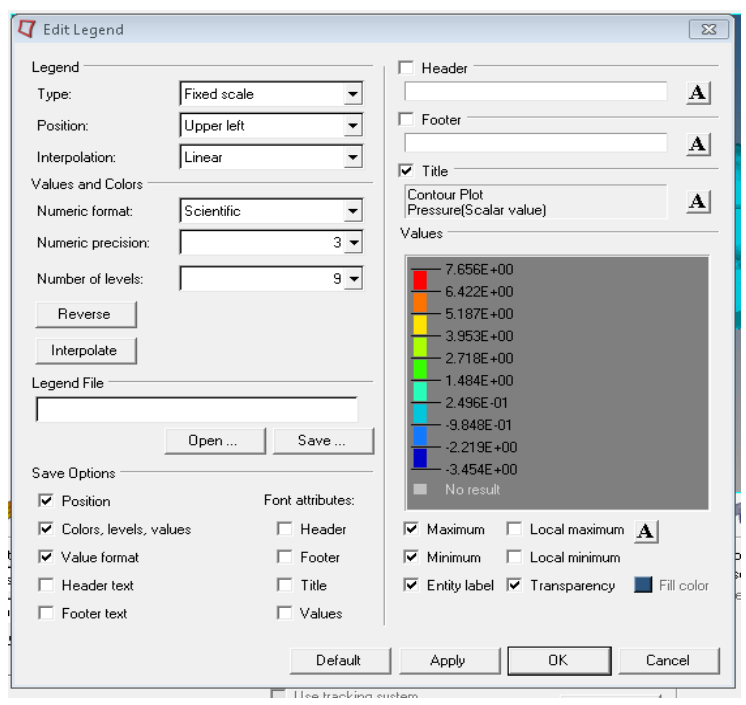

Figure C19 Editing the output scale in the analysis viewer 


\section{Appendix D}

\section{Anatomy of Human Head}

The basic anatomy of the human head is required in order to properly understand the terminology used in the above study. The human head consists of different layers which are explained in order below.

Scalp- It is a 5-7 mm thick outer covering and it consists of facial skin and hair. It starts above the eyebrows and extends all the way up to the jawline.

Skull - It is the strongest part of human head and made up of bones which encapsulates brain. It is like a natural helmet for the brain. The average thickness of the skull is around 4-7 mm.[15]

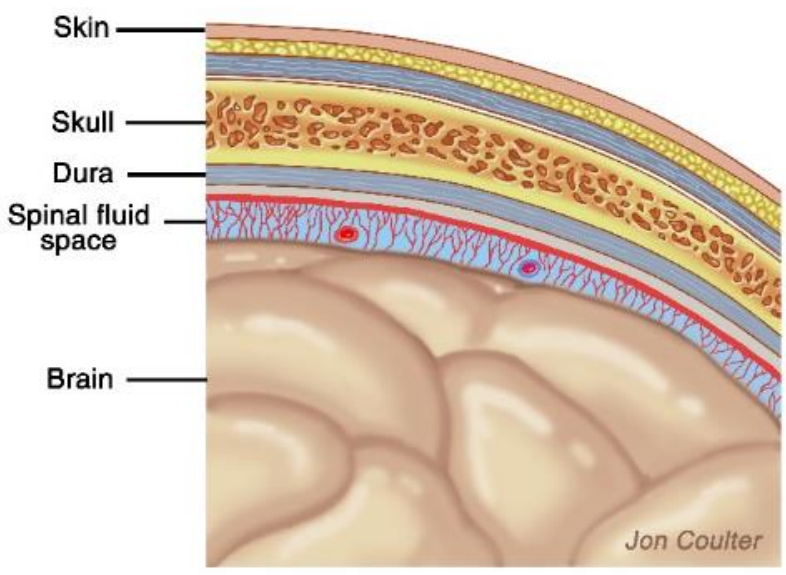

Figure D1 Different Layers of Human Head [25]

Meningeal covering - It's a 3 layered membrane which separates the brain and the skull. It is made up of duramatter, arachnoid and pia mater. Because of its role in injury only the dura mater is considered in the FE analysis. 
Cerebro Spinal Fluid - It serves as a protection layer saving injury by absorbing the vibrations and shocks. It is an incompressible fluid which is helpful in providing nutrients to brain. In order to reduce the complexity of the FE model this layer was not considered in the analysis.

Brain - It is one of the most important parts of the human body. It is generally made up of nerve cells and it's a gel like substance mostly consists of water. The brain is divided into lobes which are shown in Fig.D2

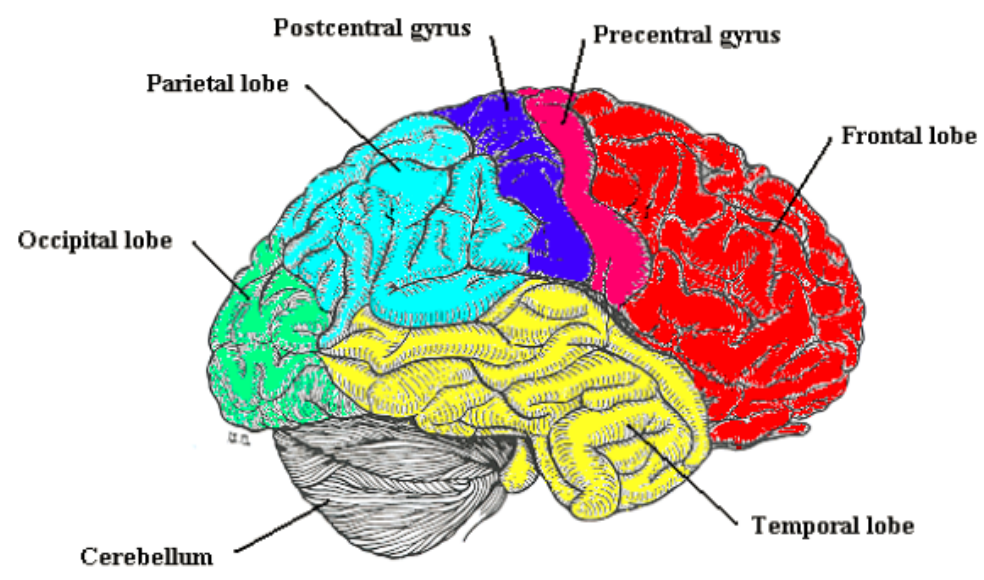

Figure D2 Cross section of brain showing different lobes [20]

The frontal lobe is located to the anterior side and is mainly responsible for the consciousness. Just below the frontal lobe is the temporal lobe which controls the audio system. The parietal lobe which is situated on the top is responsible for controlling body senses. The occipital lobe which lies on the posterior of the brain is responsible for vision[26]. The cerebellum lies beneath the parietal and occipital lobes and the brain stem co-ordinate the higher level functions of the body by connecting into spinal cord. The following figure depicts the regions of the brain and their respective functions. 


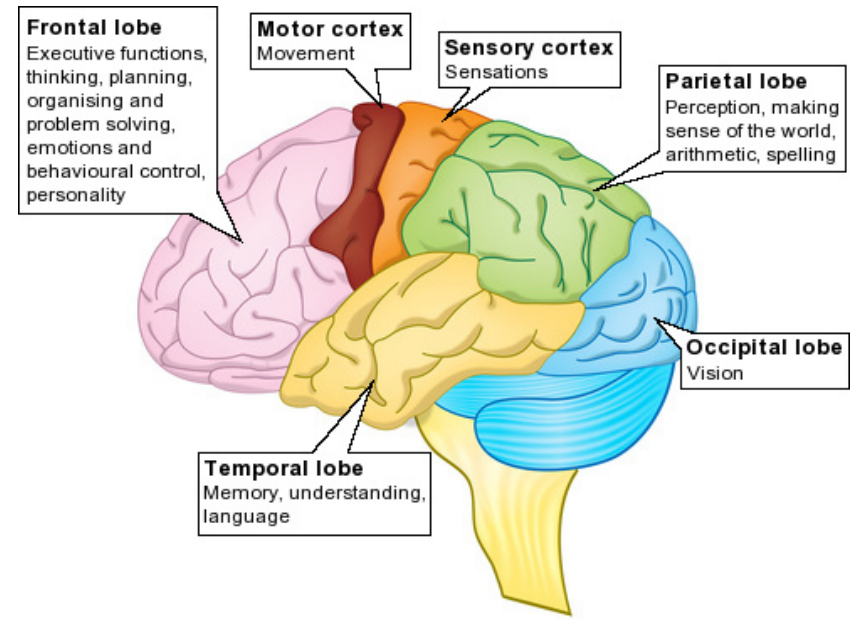

Figure D3 Different regions of brain and their respective functions [27]

Image taken from Headway - the brain injury association, U.K. 


\section{References}

[1] C.C Ward , P.E.Nikravesch and R.B.Thompson. "Biodynamic finite element models used in brain injury research", Journal of Aviation, Space and Environmental medicine, vol 49, no.1, 1978

[2] Centers for Disease Control and Prevention (CDC), 2003, "Traumatic Brain Injury in the United States: Fact Sheet” [Online]. Available http://www.cdc.gov/traumaticbraininjury/get the facts.html [Accessed 10 Oct,2015] [3] Ward, C., Chan, M., Nahum, A., "Intracranial Pressure - A Brain Injury Criterion." The Society of Automotive Engineers Paper \# 801304, pp 3867-3880, 1980.

[4] CNN, "Minor head injuries can turn serious rapidly, experts say" Wed Mar 18,2009, [Online] : Available [Accessed on 10 Sep,2015] http://www.cnn.com/2009/HEALTH/03/18/brain.injury/index.html?iref=24hours [5] Murray JA, Chen D, Velmahos GC, et al. Pediatric falls: Is height a predictor of injury and outcome? Am Surg. 2000;66(9):863-865.

[6] HSP Supply Inc,. National Safety Products Inc,. .[Online]:Available http://hspsupplyinc.com/stats.htm [Accessed on 1 Sep,2015] [7] American College of Surgeons, "Injuries Due to Falls from Heights", Oct 17, 2002.[Online]:Available https://www.facs.org/quality\%20programs/trauma/ipc/falls [Accessed on 1 Sep,2015]

[8] Centers for Disease Control and Prevention. Injury Research Agenda: Preventing Injuries at Home and in the Community. National Center for Injury Prevention and Control. [Online]. Available at 
http://www.cdc.gov/homeandrecreationalsafety/falls/adultfalls.html [Accessed on 21 Sep,2015]

[9] Hall JR, Reyes HM, Horvat M, et al. The mortality of childhood falls. J

Trauma. 1989;29(9):1273-1275.

[10] Lallier M, Bouchard S, St-Vil D, et al. Falls from heights among children: A retrospective review. J Pediatr. 1999;Surg 34(7):1060-1063.

[11] Alleyne B, Stuart P, Copes R. Occupational and other drug use in occupational fatalities. J Occup Med. 1991;33:496.

[12] Alexander BH, Rivara FP, Wolf ME. The cost and frequency of hospitalization for fall-related injuries in older adults. Am J Public Health. 1992;82(7):1020-1023.

[13] Fan, W.R.S., "Internal Head Injury Assessment." Proc. $15^{\text {th }}$ Stapp Car Crash Conf., The Society of Automotive Engineers Paper \# 710870, pp 645-665, 1971.

[14] Thurman, D. J., Branche, C. M., Sniezek, J. E., “The Epidemiology of SportsRelated Traumatic Brain Injuries in the United States: Recent Developments.” J. Head Trauma Rehabil, Vol. 13, No. 2, pp. 1-8, 1998.

[15] Melvin, J. W. and Lighthall, J. W., Accidental Injury Biomechanics and Prevention Second Edition. Nahum, A.M., Melvin, J.W., ed., Springer-Verlag, NY, pp.277-302, 2002.

[16] Bailes, J. E., Sports Neurology, Second Edition, Jordan, B. D., ed., Lippincott-Raven Publishers, PA, pp. 215-233, 1998.

[17] Shugar, T.A., “A Finite Element Head Injury Model.” Report No. DOT HS 289-3550-TA, Vol. 1, 1977. 
[18] Standard Linear Impactor Test Method And Equipment Used In Evaluating The Performance Characteristics Of Protective Headgear And Face Guards - NOCSAE Doc (Nd) 081- 04M04

[19] Sensor Products Inc,. "Fujifilm Prescale ${ }^{\circledR}$ Tactile Pressure Indicating Sensor Film” [Online], Available at http://www.sensorprod.com/fuji-prescale.php

[20] D. M. Labyak, "Interpretation of Head Injuries Due to Oblique Impact by Finite Element Modeling," Michigan Technological University, Houghton, 2003.

[21] Granit Engineering, “3-DvMohr Circle Generator \& Solver”. [Online]; Available at http://www.graniteng.com/mohr-3d?lang=en

[22] Kang, H., Willinger, R., Diaw, B. M., Chinn, B., "Validation of a 3D Anatomic Human Head Impact in Motorcycle Accident by Finite Element Modeling.” The Society of Automotive Engineers Paper \# 973339, 1997.

[23] O. Anna, K. Clara, P. Andrew, R. Philippe, H. Blaine, M. Shawn, B. Susan, S. Aynsley and C. Michael, "An Examination of Headform Dynamic Response for Concussive and Traumatic Brain Injury," in 1st International Conference on Helmet Performance and Design, London, UK, 2013.

[24] Abhang, Chandrika S., "MEASURING HEAD IMPACT CONTACT PRESSURE IN COLLEGIATE FOOTBALL GAMES TO CORRELATE HEAD KINEMATICS TO BRAIN KINETICS ELUCIDATING BRAIN INJURY DYNAMICS", Master's report, Michigan Technological University, 2014.

[25] Earsite.com, "Acoustic Neuroma," 2014. [Online]. Available: [Accessed on 08 Oct,2015] http://www.earsite.com/sites/default/files/userfiles/images/acousticneuroma/an4--head layers.jpg 
[26] Centre for Neuro Skills,” Brain Function”, Robert P. Lehr Jr., Ph.D.

Professor Emeritus, Department of Anatomy, School of Medicine,

Southern Illinois University,[online],Available [Accessed on 08 oct,2015]

http://www.neuroskills.com/brain-injury/brain-function.php

[27] Headway-The Brain Injury association "Executive dysfunction after brain

Injury”,[Online], Available:[Accessed on 12 Oct,2015]

https://www.headway.org.uk/executive-dysfunction-after-brain-injury.aspx 


\section{Permission to Use Figures from your work}

5 messages

R Krishna Tej Bhamidipati <rbhamidi@mtu.edu> Thu, Nov 12, 2015 at 5:45 PM

To: Chandrika Abhang <csabhang@mtu.edu>

Chandrika,

I would like to use the following Figures from your work "MEASURING HEAD

IMPACT CONTACT PRESSURE IN COLLEGIATE FOOTBALL GAMES TO

CORRELATE HEAD KINEMATICS TO BRAIN KINETICS ELUCIDATING BRAIN

INJURY DYNAMICS" in my thesis work.

2.6 - Cross section of a Fujifilm Prescale

D0.6 - Layers of human head

D0.7 - Structural differentiation of human brain.

Kindly respond inline with your approval.

Thank you

Regards,

R KrishnaTej Bhamidipati,

Graduate Student,

Mechanical Engineering Department

Michigan Technological University.

Ph.:- 906-281-8522

R Krishna Tej Bhamidipati <rbhamidi@mtu.edu>

Thu, Nov 12, 2015 at 5:48 PM

To: David Labyak <dmlabyak@mtu.edu>

David,

I would like to use the following Figures from your work "Interpretation of Head

Injuries Due to Oblique Impact by Finite Element Modeling" in my thesis work.

Figure 2.3 Wayne State Tolerance Curve

Figure 3.4 Side View of the Brain

Kindly respond inline with your approval.

Thank you

Regards,

R KrishnaTej Bhamidipati,

Graduate Student,

Mechanical Engineering Department

Michigan Technological University.

Ph.:- 906-281-8522 
David Labyak <dmlabyak@mtu.edu>

To: Krishna <rbhamidi@mtu.edu>

Krishna,

Yes you have my permission to use the figures from my thesis.

David Labyak

[Quoted text hidden]

R Krishna Tej Bhamidipati <rbhamidi@mtu.edu> To: Chandrika Abhang <csabhang@mtu.edu>

Fri, Nov 20, 2015 at 9:04 PM

Please find the attached screenshots of the images.

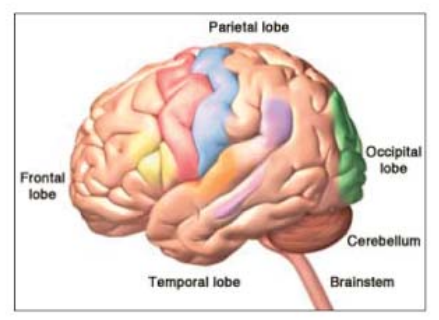

Figure D0.7 Structural differentiation of human brain [32]

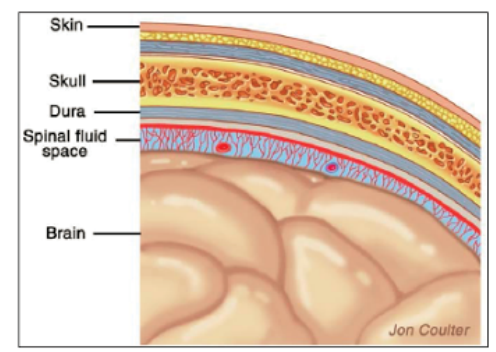

Figure D0.6 Layers of human head [31]

Kindly respond.

Thank you.

Regards,

R KrishnaTej Bhamidipati, Graduate Student, Mechanical Engineering Department Michigan Technological University.

Ph.:- 906-281-8522

[Quoted text hidden] 
Chandrika Abhang <csabhang@mtu.edu>

Sat, Nov 21, 2015 at 11:03 PM

To: R Krishna Tej Bhamidipati <rbhamidi@mtu.edu>

Hi Krishna,

Please go ahead and use images D0.6 and D0.7 from my report.

Thanks,

Chandrika

[Quoted text hidden]

The above correspondence refers to the permission for figures in Appendix-D 


\section{Qutherifgenters}

R Krishna Tej Bhamidipati <rbhamidi@mtu.edu>

\section{Fwd: Headway image}

1 message

Krishna Tej <brkrishnatej@gmail.com>

Thu, Nov 5, 2015 at 9:40 AM

To: R Krishna Tej Bhamidipati <rbhamidi@mtu.edu>

Forwarded message

From: Tamsin Ahmad <publications@headway.org.uk>

Date: 5 November 2015 at 08:54

Subject: Headway image

To: brkrishnatej@gmail.com

Hi Krishna,

Thank you for recently making contact with us regarding using the Headway image of the brain explaining its functions. You would be welcome to use this image, but please ensure that you use proper referencing, ie: image taken from Headway - the brain injury association, U.K.

Kind regards,

Tamsin

Tamsin Ahmad

Publications and Research Manager 


\section{Bradbury House}

\section{Bagnall Road}

Old Basford

Nottingham

NG6 8SF

Tel: 0115924 0800/Direct line no: 01159471915

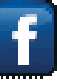

This is an email from Headway - the brain injury association. The contents of this email are confidential to the ordinary user of the email address to which it is addressed. No-one else may place any reliance on it, or copy or forward all or any of it in any form.

Headway - the brain injury association is a Registered Charity No 1025852 and a company limited by guarantee Registered in England No. 2346893

The above correspondence refers to the permission for figure D3 in Appendix-D 


\section{Problem with the Topaq Analyzer}

1 message

R Krishna Tej Bhamidipati <rbhamidi@mtu.edu> Wed, Jul 23, 2014 at 4:59 PM To: Gopal Jayaraman <gjayar@mtu.edu> Cc: Chandrika Abhang <csabhang@mtu.edu>, David Labyak<dmlabyak@mtu.edu>, achen@sensorprod.com, Vadim Shalyt <vshalyt@sensorprod.com>

Dear All,

I spoke to Mr.Andy Chen from Sensor prod, who's a technical contact person concerned with the Topaq Analyzer. The summary of the telephonic conversation regarding the problems we had with the analyzer are mentioned below.

1) The Analyzer is generally used for the static analysis and rarely used for the Impact testing.

2) The source of error can be due to the multiple impacts of Head form with the film. The Analyzer works perfect for the single Impact conditions. As we cant control the minor re-bouncing of the head form, we are prone to get some errors

3) Out of many outputs only the Pressure and Contact area are reliable as the Analyzer is not designed for the Impact force measurement.

4) The Pressure films are designed for the Flat surfaces, as our head form has a curved profile, the center region of the Impact area is prone to have more pressure concentration than the other regions, which in turn varies the average pressure.

5) The software is not suitable for multitasking, so we are supposed to analyze only one film at a time.

The above reasons are considered to cause discrepancies in the values measured from the analyzer.

Mr.Andy has advised to use the low films for 2-4 feet and medium film for 4-5 feet drops which have chances to reduce the error.

Thank you,

\section{Regards,}

R KrishnaTej Bhamidipati, Graduate Student, Mechanical Engineering Department Student Supervisor - Van Pelt and Opie Library Michigan Technological university.

Ph.:- 906-281-8522 


\section{Permission to Use the Prefilm Scale image in my Thesis Work}

4 messages

R Krishna Tej Bhamidipati <rbhamidi@mtu.edu>

Mon, Oct 26, 2015 at 5:26 PM

To: Vadim Shalyt <vshalyt@sensorprod.com>

Mr.Shalyt,

I hope you are doing good.I hope that you remember that I have used your pressure films and analyzer for our research work at Michigan Tech under the guidance of Dr.Jay. I would like to use one of the Image from your website showing the cross section of a pressure film. It would be great if you can extend me your permission to use the same in my report to document and provide information about the pressure films and the work I had done on them.

Would be waiting for your response.

Thank you

Regards,

R KrishnaTej Bhamidipati,

Graduate Student,

Mechanical Engineering Department

Michigan Technological University.

Ph.:- 906-281-8522

R Krishna Tej Bhamidipati <rbhamidi@mtu.edu>

Thu, Nov 12, 2015 at 6:09 PM

To: Vadim Shalyt <vshalyt@sensorprod.com>

Kindly respond as I need your permission to present the details of the pressure films in my Thesis work.

Thank you

Regards,

R KrishnaTej Bhamidipati,

Graduate Student,

Mechanical Engineering Department

Michigan Technological University.

Ph.:- 906-281-8522

[Quoted text hidden]

Vadim Shalyt <vshalyt@sensorprod.com>

Fri, Nov 13, 2015 at 7:10 AM

To: rbhamidi@mtu.edu 
sure.

but be sure he names it properly as prescale film and not prefilm scale.

Vadim Shalyt

Sr. Application Specialist

Sensor Products Inc. USA

300 Madison Ave.

Madison, NJ 07940

1.973.428.8985 (phone)

1.973.495.9800 (cell)

vadim@sensorprod.com

Please contact me DIRECTLY for BEST Prices, Delivery, Service \& Expert Advice.

The finest compliment I can ever receive from doing business is a referral from my clients.

From: R Krishna Tej Bhamidipati [ mailto:rbhamidi@mtu.edu]

Sent: Thursday, November 12, 2015 7:10 PM

To: Vadim Shalyt

Subject: Re: Permission to Use the Prefilm Scale image in my Thesis Work

[Quoted text hidden]

R Krishna Tej Bhamidipati <rbhamidi@mtu.edu>

Fri, Nov 13, 2015 at 8:16 AM

To: Vadim Shalyt <vshalyt@sensorprod.com>

Sure.... Definitely.

Thank you

Regards,

R KrishnaTej Bhamidipati,

Graduate Student,

Mechanical Engineering Department

Michigan Technological University.

Ph.:- 906-281-8522

The above correspondance refers to the permission for Figure 3.22 


\section{RE: A user sent a message via the contact form}

2 messages

Rahul Ponginan <rahul.ponginan@altair.com>

Tue, Dec 8, 2015 at 4:56 AM

To: Krishna Tej Bhamidipati <rbhamidi@mtu.edu>

Cc: "altairuniversity@altair.com" <altairuniversity@altair.com>

Hi Krishna,

Thanks for your email, please feel free to use snapshots and mention

HyperWorks products in your thesis, provided the thesis is not critical of the products themselves,

Please be careful about plagiarism and make sure you clearly reference any Altair document you are mentioning in your thesis,

You will have to make sure however that the products are mentioned correctly and that you mention registered trademarks, for instance when mentioning RADIOSS use

Altair ${ }^{R}$ RADIOSS $®$ and note that

Altair and RADIOSS are registered trademarks of Altair Engineering Inc.

Please do send us a copy of your thesis, we will review it and if found suitable we may publish its abstract for instance on our website etc

Regards

Rahul Ponginan | Team Leader | HW Support

rahul.ponginan@altair.com | www.altairhyperworks.com

Altair | Innovation Intelligence ${ }^{\circledR}$

Secure file dropbox https://ftam1.altair.com/dropbox/ 0simQA 


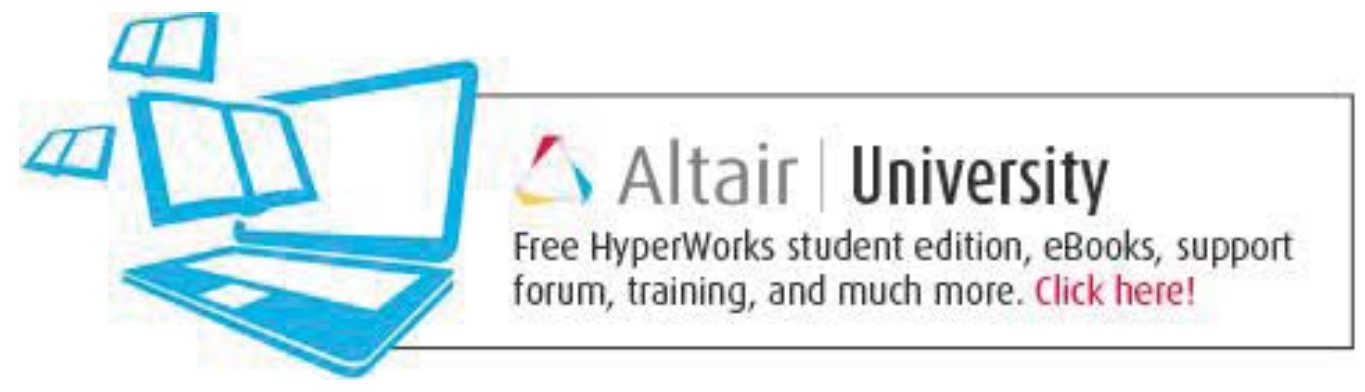

From: Altair HyperWorks Forum [mailto:altairuniversity@altair.com]

Sent: Tuesday, December 08, 2015 11:06 AM

To: altairuniversity@altair.com

Subject: A user sent a message via the contact form

\section{Altair HyperWorks Forum}

A user has sent a message using the Contact Us form.

Krishna Tej Bhamidipati said:

To the Concerned,

I have used the Radioss module for performing an Impact analysis in my thesis work and as a part of documentation,I have included the screen shots from the Hypermesh software with the properties i have used for my work. It would be really helpful if you can grant me a permission to use them in my thesis work. It would be really helpful if you can send me your response at your earliest, as the last date for the submission of the permissions to 
my school is $12 / 12 / 15 /$

Waiting for a response

Thank you

- Altair HyperWorks Forum

Altair HyperWorks Forum, 1820 E. Big Beaver, Troy, Michigan, 48083

R Krishna Tej Bhamidipati <rbhamidi@mtu.edu>

Tue, Dec 8, 2015 at 9:39 AM

To: Rahul Ponginan <rahul.ponginan@altair.com>

Cc: "altairuniversity@altair.com" <altairuniversity@altair.com>

Dear Mr.Ponginan,

Thank you very much for your kind response. I will forward my thesis document to you, once I get an approval from the Graduate School. I would like to inform you that I am just including the screen shots of the Properties and the Materials I have used in my work so that my research peers can continue their work.I will make sure that I include Altair $\AA$ RADIOSS $\AA$ in place of Radioss.

Thank you

\section{Regards,}

R KrishnaTej Bhamidipati, Graduate Student, Mechanical Engineering Department

Michigan Technological University.

Ph.:- 906-281-8522

[Quoted text hidden]

The above correspondace refers to the permission for figures in Appendix- $\mathrm{C}$ 